Marta Wójcicka

\title{
Collective Memory and Oral Text
}

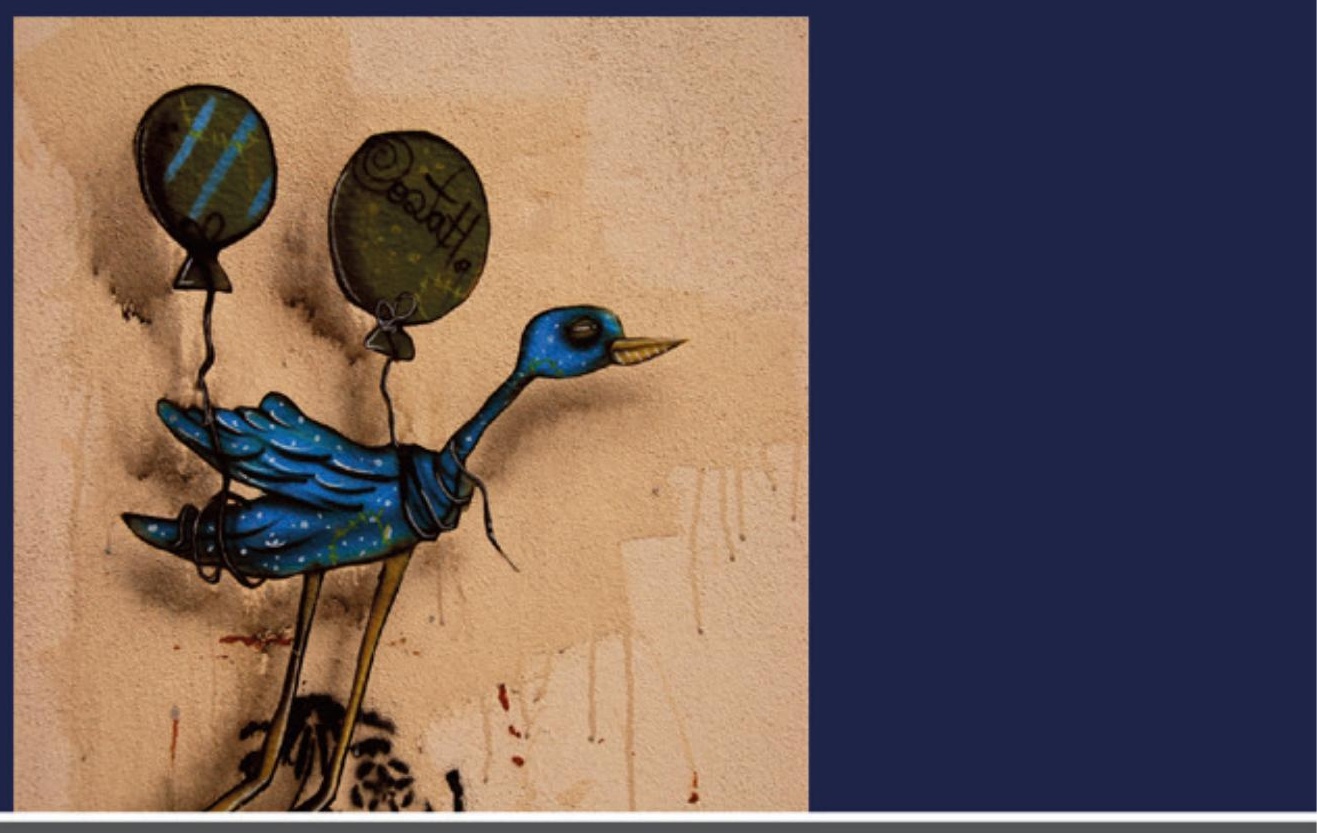




\section{Marta Wójcicka}

\section{Collective Memory and Oral Text}

The aim of this monograph is an attempt to examine the relationship between collective memory and oral texts. The material basis for this presentation consists of folklore oral texts, both prosaic and poetic, different as regards their genres (fairy tales, fables, recollections, traditions, legends, proverbs, and songs) as well as texts that are fragments of spontaneous interviews. The monograph consists of five main parts devoted to the following themes: theoretical considerations, the relation between memory and language, text memory, genre memory, and the relation between memory and the folk artistic style.

\section{The Author}

I have been working as a professor at the Maria Curie-Skłodowska University in Lublin. My research interests lie within Texts, Collective Memory, and Communication in Culture. 
Collective Memory and Oral Text 


\title{
SOUNDS - MEANING - COMMUNICATION \\ LANDMARKS IN PHONETICS, PHONOLOGY AND COGNITIVE LINGUISTICS
}

\author{
Edited by Jolanta Szpyra-Kozłowska
}

\author{
Editorial Board: \\ Eugeniusz Cyran (John Paul II Catholic University of Lublin) \\ Halina Chodkiewicz (Maria Curie-Skłodowska University, Lublin) \\ Adam Głaz (Maria Curie-Skłodowska University, Lublin) \\ Haike Jacobs (Radboud University (Nijmegen), The Netherlands) \\ Henryk Kardela (Maria Curie-Skłodowska University, Lublin) \\ Przemysław Łozowski (Maria Curie-Skłodowska University, Lublin) \\ Bert Peeters (Australian National University (Canberra) and Griffith University \\ (Brisbane), Australia)
}

\section{VOLUME 11}

Notes on the quality assurance and peer review of this publication

Prior to publication, the quality of the work published in this series is reviewed by an external referee appointed by the editorship. 
Marta Wójcicka

\section{Collective Memory and Oral Text}

Translated by Przemysław Łozowski

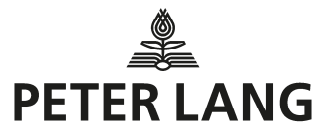




\section{Bibliographic Information published by the Deutsche Nationalbibliothek \\ The Deutsche Nationalbibliothek lists this publication in the Deutsche Nationalbibliografie; detailed bibliographic data is available online at http://dnb.d-nb.de.}

\section{Library of Congress Cataloging-in-Publication Data A CIP catalog record for this book has been applied for at the Library of Congress}

The Publication is funded by Ministry of Science and Higher Education of the Republic of Poland as a part of the National Programme for the Development of the Humanities. This publication reflects the views only of the author, and the Ministry cannot be held responsible for any use which may be made of the information contained therein.

Cover image courtesy of Professor Jerzy Durczak

Printed by CPI books GmbH, Leck

ISSN 2365-8150

ISBN 978-3-631-80800-9 (Print) · E-ISBN 978-3-631-81904-3 (E-PDF)

E-ISBN 978-3-631-81905-0 (EPUB) · E-ISBN 978-3-631-81906-7 (MOBI)

DOI $10.3726 / \mathrm{b} 16830$

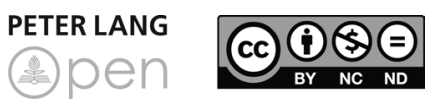

Open Access: This work is licensed under a Creative Commons Attribution Non Commercial No Derivatives 4.0 unported license. To view a copy of this license, visit https://creativecommons.org/licenses/by-nc-nd/4.0/

(C) Marta Wójcicka, 2019

Peter Lang - Berlin · Bern · Bruxelles · New York ·

Oxford $\cdot$ Warszawa $\cdot$ Wien

This publication has been peer reviewed.

www.peterlang.com 


\section{Preface}

As Magdalena Saryusz-Wolska (2009: 7) writes, 'Memory is one of these key concepts of modern scientific research that - in various senses - happen to be explored by representatives of numerous disciplines: from information technology (computer memory) via neurobiology, psychology, sociology, philosophy, history to culture and literary studies. However, despite the considerable extent that M. Saryusz-Wolska ascribes to memory research at large, one can hardly find in Polish any full-length language- and folklore-based studies on memory. This is surprising if one allows for the fact that texts of folklore do operate in memory, that is, they are, after all, recalled and reproduced from memory resources. Although memory has long been recognised as a shaping, moulding, and modifying factor of folklore texts, it has not as yet become a research focus in text and folklore studies. Instead, it is typically taken for granted as something that is self-evident and does not need defining, or explaining. Memory has so far been researched mainly by sociologists and historians, as well as by psychologists. More recently these have been joined by culture researchers, and that has come with the Polish scholars' discovery of Jan Assmann's and Aleida Assmann's analyses. Still, it is in linguistics that the category of memory attracts relatively smallest attention, even though it is well-established that memory happens to be externalised by language itself:

This abstraction is not arbitrary, but is constitutive of the linguistic moment of memory as it is promoted by the practice of ordinary language, as it permits naming and describing distinctly the "mental", mind, as such. (...) In its declarative phase, memory enters into the region of language; memories spoken of, pronounced are already a kind of discourse that the subject engages in with herself. What is pronounced in this discourse occurs in the common language, most often in the mother tongue, which, it must be said, is the language of others. (Ricoeur 2004: 127, 129; emphasis added)

The group of the Polish scholars dealing with the problem of memory includes just a few: Anna Pajdzińska, Wojciech Chlebda, and Renata Grzegorczykowa, with their analyses embracing the ways and mechanisms of how memory comes to be conceptualised in language. To mention A. Pajdzińska's conclusion to her phraseology-oriented research, 'the most numerous is the set of realisations of the ontological metaphor MEMORY IS CONTAINER' (Pajdzińska 2012: 101). Memory is, then, a vessel, or a receptacle, where texts of folklore are stored and from where - providing situational conditions are favouring at a specific time and space - they are recalled as complete wholes. At the same time memory 
moulds and transforms that which it contains, that is, texts. Memory can also be conceptualised as a means of movement in space: ktoś przebiega coś pamięciq 'something crosses one's mind; lit. somebody runs over something with one's memory', ktoś cofa się pamięcia do czegoś 'somebody casts one's mind back to something' or ktoś wraca pamięcia do czegoś 'lit. someone returns to something with one's memory'. What we have here in these expressions is a blend of two conceptual metaphors: TIME IS SPACE and THINKING/REMEMBERING IS MOVEMENT IN SPACE (Pajdzińska 2012: 101), which is likely to explain why memory researchers should be interested in the so-called memory figures among other things, they, indeed, do involve both time and space considerations (cf. J. Assmann 2011).

The major objective of this monograph is an attempt to approach the memory issue from a linguistic and folklorist perspectives. In this sense, the author believes the study deals with what will prove to be an essential account of how texts of folklore operate in a socio-cultural environment. For this reason, the subsequent parts of the book are meant to address the questions of, respectively, the memory-language interface (Chapters III and IV), the text, especially in relation to folklore texts (Chapters V, VI, and VII), the genre (Chapter VIII), and the style (Chapter IX).

More specifically, the research problems include here the following:

- the relationship between collective memory vis-à-vis tradition and cultural heritage. Jan Assmann emphasizes the incompatibility of tradition and memory culture, the latter having been scheduled, in his view, to play the role of "social obligation and [be] firmly linked to the group" (J. Assmann 2011: 26), and, thus, forming a community, which amounts to a global and universal phenomenon. It seems, then, that memory is linguistic in nature as it happens to be expressed in language and texts, and depends on everyday colloquial speech. In other words, language provides its users with suitable means for memory to be externalised in the form of narration. (Cf. Pomian 2006: 147.) This is how Krzysztof Pomian (also W. Chlebda) sees the point:

Language shapes the very content of memory. This is because language directs and channels perception and effects data retention, thus determining the way the obtained data is organised and providing novel [linguistic] data, the latter being subject to retention as well. In this way language supplies every single individual memory with the information that otherwise would not be acquired at all. Language makes it possible, then, for an individual to accumulate the ancestors' stories, no matter whether these stories are true or not, and keep them in memory, extending the memory zone so that it embraces now the remote past (...) as one identifies him/herself with his/her 
predecessors. Memory then puts on the same footing that which has been subjected to its resources by the past generations as well as that which it has perceived itself. In other words, memory takes over the recollections that have already been selected by the past generations and imprinted with their subjectivity, together with their points of view and hierarchy of values. (Pomian 2006: 146)

While memory is language-expressed on principle, tradition and heritage (in the sense of Jerzy Szacki) can be language-expressed as well, but they do not have to. Also, memory seems to be a broader term so as to include tradition and cultural heritage. (For tradition, esp. artistic tradition, as part of cultural heritage, see Szczęsna 2002: 314 and here Chapters II and III.)

- the relationship between collective memory and texts of culture, especially oral texts. In this respect, it is assumed that the basic function of memory is social and results in narrating a story (cf. Le Goff 1996), for which see Chapter II;

- the influence that orality exerts on the way collective memory operates and, further on, the impact that collective memory has on the way oral texts are constructed. Here it is assumed that memory is a constitutive factor of texts of folklore as well as a distinguishing feature of orality, orality being defined as

a conscious attempt at condensing knowledge in the form of easily recognisable (...) images and communicating memory in terms of theses representations. This explains why stored knowledge can be regained at any time, and also why - as an interpretation of symbolic characteristics, or attributes, it can be "developed" into its fully-fledged form. (Prejs 2009: 20)

Marek Prejs calls this technique 'iconographic memory patterning', which makes orality not only what it says, that is, an oral medium of communication, but also an indicator of the cherished system of values and of the picture of the world, as projected in/by, among other things, texts of folklore. Orality is also a shaping factor of collective memory, and it thus determines the way folklore texts circulate in a given population. We address these issues in Chapters II and V.

Finally, there is a question of the relationship between the three: collective memory, linguistic picture of the world, and common-sense knowledge. Throughout this monograph it is argued that collective memory is not identical to common-sense world knowledge because memory is how we depict the past, and not what we know about the past. To mention some of the characteristics K. Pomian identifies in memory,

memory is always somebody's memory and in this sense it depends on one's past experiences, chiefly internal and external sensory perception; it is event-like because 
it affects the usual monotony, deviates from the routine, breaks the continuity, takes by surprise; it is qualitative because quantities escape one's perception; it is selective; it is egocentric in the sense that whatever is subjected to it, it relates to "I" whose memory it constitutes - although memory has a number of rhetoric devices on its disposal, it always speaks in the 1st person and depends on colloquial speech. As event-like, qualitative, selective, judgemental, and egocentric, human memory is unavoidably partial and biased. (...) Memory does not provide with evidence because it itself is its own evidence. "I remember that this is what happened" is a convincing piece of evidence once we are prepared to assume that this is what actually happened. (...) Still, memory does attempt to give evidence, which is, on the one hand, material artefacts considered to be relics, and, on the other hand, places considered to be the locations of the events having been recalled. (Pomian 2006: 147)

As to the linguistic picture of the world (henceforth: LPW), it is 'a languageencoded interpretation of reality (...), which can be generalised in terms of a set of judgements about the world' (Bartmiński 2007: 12). As such, LPW is a carrier of collective memory because it appears to involve the worldview that is handed down from generation to generation in language and petrified texts. Memory is then conceptualised in terms of activity, as a process of communicating linguistic forms, each form containing elements of LPW. To use one of the memory metaphors, memory presents itself here as a container whose various linguistic forms store the corresponding pieces of LPW. On the other hand, however, memory can be given an objective slant, that is, it is an image of the past, which is that part of the world which is concerned with that which is already gone. These two readings of memory are brought, or bridged, together by the subject, or the bearer of both the image of the world and memory. This is why, be it an activity or an object, memory is unavoidably interpretative in nature.

As stated above, memory is not to be confused with knowledge. The latter may be one of the constituents of collective memory, yet it seems to be most promising to assume that knowledge is simply an interpretation of the past, or an image of the past, as encoded in and projected by texts of culture.

The material basis of the present monograph embraces various genres of folklore texts, including prose ones, such as (magical, animal, novelistic) fairy tales, tall tales, legends (urban legends included), (belief and historical) reconstructions, recollections, anecdotes, as well as verse ones: ballads, carols, wedding songs, beggars' songs, funeral songs and others. In terms of their form, some of these texts represent well-established and petrified genres, whereas others do not. That the texts (and genres) selected here are formally and internally divergent allows to detect and discuss numerous intricacies of the memory-oral text and the memory-text genre relationships. 
Generally, more than half of the texts quoted here have not as yet appeared in print. As a result of laborious field work, they were collected by the colleagues and students of the Department of Polish Culture, Maria Curie-Skłodowska University, Lublin.

This book is an abridged, changed, and updated version of the monograph published in 2014 by the Maria Curie-Skłodowska University Press. The alternations and modifications can be found in each of the parts of the book. To mention the most important ones, in Part I and II some of the Polish research on memory has been presented (e.g., Wojciech Chlebda, Waldemar Czachur). These insights seem to have been unavailable to the English-language readers so far. The selection includes the studies that have appeared in print since 2014 . The part on language-expressed nature of memory has been extended by further specific metaphoric conceptualisations of memory. The number of the illustrative examples is now smaller, yet those quoted are tailored to meet the English readers' (cultural, linguistic) expectations. To the same effect, whenever possible and desirable, the Polish cultural references are given their explanations and descriptions. For example, apart from its English descriptive translation ('characteristic of the Sitno region'), the expression po sitnieńsku can now be related to several notes on the area this dish is characteristic of (see Chapter IV, footnotes 6 and 10). Some of the original examples have been found redundant. Similarly, instead of lengthy descriptive footnotes, there are now, for short, references given to the corresponding literature. In Chapter VII, the subchapter on the genres of collective memory and non-memory is new, and it reflects the author's latest research interests. The subchapter on the style of collective memory (Chapter VIII) is also that which cannot be found in the original (Polish) edition.

Generally, each chapter has been updated on the basis of the latest relevant literature, that is, mainly Polish contributions that have appeared since the publication of the original monograph in 2014.

This publication has been financed with the Ministry of Science and Higher Education 2018-2020 grant No 21H 17026285 within 'The National Programme for the Development of Humanities'). 



\title{
Table of Contents
}

\author{
Abbreviations
}

\section{Part I: Theoretical issues}

I Collective memory: definitions, types, functions .................. 21

1 Memory: collective or social? ................................................................ 21

2 Collective memory: literal or metaphorical? ...................................... 23

3 Collective memory: a sum total of individual memories, or a supraindividual construct? ................................................................. 25

4 Memory $v s$. history: relational possibilities ....................................... 26

4.1 Memory versus history: disintegrating approaches ................... 27

4.2 Memory versus history: integrating approaches ....................... 32

5 Collective memory: definitions and attributes .................................. 35

6 Collective memory: typological attempts .......................................... 40

7 Collective memory: functions ........................................................ 54

II Cultural heritage - memory - texts of culture ....................... 57

1 Memory as a carrier $v s$. memory carriers: preliminary remarks ....... 57

2 UNESCO's Convention for the Safeguarding of the Intangible Cultural Heritage: definition and scope ............................................ 58

3 Cultural heritage as a building material of memory ......................... 59

4 Memory as a carrier of cultural heritage .............................................. 60

5 Text of culture as a manifestation of cultural heritage ..................... 63

5.1 Text of culture: what is it? .......................................................... 63

5.2 Text of culture: a survey of definitions ....................................... 64

5.3 Text of culture as a structure …………………………………....... 65

5.4 Text of culture as a process ............................................................ 66 
5.5 Linguistic (oral) text as a prototypical text of culture .............. 69

5.5.1 Texts of culture: an analogy to natural language ........ 72

5.5.2 Texts of culture as an amalgam of codes ...................... 72

5.5.3 Intersemiotic translation of texts of culture into natural language: selected issues .................................... 73

6 Cultural heritage - memory - texts of culture: research and analytical perspectives

\section{Part II: Memory in language - language-embedded}

III Memory depicted in linguistic metaphors .............................. 83

1 'Metaphor bridges reason and imagination' ………………............... 83

2 Memory in linguistic metaphors: a state of research ........................ 85

3 Memory as a structure and a process: specific elaborations ........... 86

4 Is memory a language-like entity? ................................................... 98

IV Proper names as carriers of collective memory ..................... 103

1 Cooking as language and memory ................................................. 104

2 Names of dishes as carriers of declarative memory ....................... 106

3 Functions of dish names ...................................................................... 113

\section{Part III: Memory and text - text memory}

V Oral text structure as a reflection of memory structure .... 119

1 Oral text vis-a-vis oral memory ……………................................. 119

2 Text as a memory aid: recalling a text from memory ..................... 123

3 Text as a memory mirror: textual ways of expressing memory ... 125

3.1 Text structure based on intertextual memory ......................... 127

3.1.1 Intertextual memory: procedural dimension ............ 127

3.1.2 Intertextual memory: the structural dimension ....... 130 
3.2 Text structure based on associative memory (keywords) ...... 131

3.3 Text structure based on intertextuality-cum-association memory

\section{Text variation as information about the collective memory functioning of a text}

1 The double nature of a folklore text as collective memory information

2 Folklore text variation: from structure of a text to picture of an object

3 Morphological analysis as an examination of an oral text circulation in collective memory

4 Text in a social group's memory: circulation of an oral text 155

5 Folklorism: from cultural to intercultural memory or dialogue with tradition and traditional ways of apprehending folklore

VII Memory figures versus memory aspects in oral texts 199

1 Memory figures in a research perspective 199

2 Memory in a functional perspective ............................................... 200

2.1 Time - narration - memory ................................................... 200

2.1.1 Time vis-a-vis order of discourse ................................ 202

2.1.2 Time vis-a-vis order of events ..................................... 205

2.1.2.1 Creating the world of a narrative ............... 211

2.1.2.2 Time in creating a protagonist .................... 213

2.2 Space - narrative - memory ...................................................... 216

2.2.1 Space $v i s-\grave{a}$-vis order of discourse .............................. 217

2.2.2 Space $v i s$ - $a$-vis order of events .................................... 218

3 Reconstructivism as an objective aspect of memory ...................... 231

3.1 Mythological reconstructivism ................................................ 232

3.2 Belief-oriented reconstructivism ........................................... 244

3.3 Apocryphal reconstructivism .................................................... 247 
3.4 Historical reconstructivism ……………………..................... 251

3.5 Family-personal reconstructivism ............................................ 259

3.6 Ritual reconstructivism ........................................................... 261

4 Subjective aspect of memory: reference to a social group ............ 270

4.1 The addresser of a text ................................................................ 270

4.2 The addressee ......................................................................... 294

$5 \quad$ Functions of memory figures ............................................................. 298

\section{Part IV: Memory and text genre - genre memory and genre non-memory}

\section{Memory types versus genre differentiation in folklore} texts

1 Genres of collective memory and non-memory 305

2 Folklore genre as a factor of collective memory and non-memory 306

3 Memory as a criterion of typologising folklore genres: mnemonic typology of texts of folklore 309

3.1 The Criteria of folklore genre differentiation ........................... 309

3.2 The memorates-fabulates distinction versus mnemonic typology of folklore genres

3.3 Features of memory figures versus genre differentiation of folklore texts

3.4 Traditional and modern folklore genres in a memory theory perspective

4. Transformations of folklore text genres: from communicative to cultural memories 


\section{Part V: Memory and linguistic style - style memory}

IX Memory as a distinguishing value of folk artistic style 331

1 Collective memory style 331

2 Folk artistic style in a folklorist perspective ...................................... 332

3 Memory as a worldview category ............................................... 333

3.1 Memory as a source of collectivity ........................................... 335

3.2 Memory as support of orality ................................................... 337

4 Formula as a main exponent of memory …………………………... 338

5 Memory as a treasure of folklore, folklore as a narrative about memory

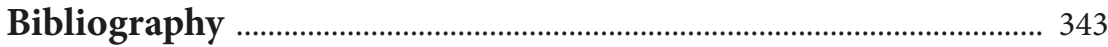

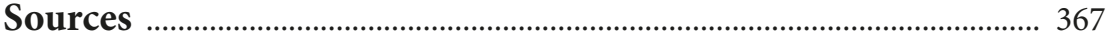

List of Diagrams ...................................................................................... 369

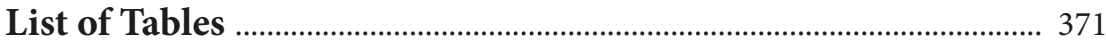





\section{Abbreviations}

ISJP Inny słownik języka polskiego PWN, edited by Mirosław Bańko, Warszawa 2000.

PSWP Praktyczny słownik współczesnej polszczyzny, edited by Halina Zgółkowa, vol. 28, Poznań 2000.

SJP Słownik języka polskiego, Wydawnictwo PWN, http://sjp.pwn.pl.

SJPDor Słownik Języka Polskiego, edited by Witold Doroszewski, Warszawa 1958-1969, www.doroszewski.pwn.pl.

SJP Szym Słownik języka polskiego, edited by Mirosław Szymczak, vol. III, Warszawa 1992.

WSJP Wielki słownik języka polskiego, edited by Piotr Żmigrodzki, http:// www.wsjp.pl. 

Theoretical issues 



\section{Collective memory: definitions, types, functions}

\section{Memory: collective or social?}

The terms collective memory (Pol. 'pamięć zbiorowa'), social memory ('pamięć społeczna'), group memory ('pamięć grupowa'), historical memory ('pamięć historyczna'), or cultural memory ('pamięć kulturowa') can all be found in literature on the subject. As noted by Stefan Bednarek (2010: 101), 'this terminological abundance may well underestimate the issue, but, on the other hand, it allows for a whole array of semantic distinctions. Although all these terms relate to one and the same area, they nevertheless differ in scope'.

The researchers that seem to favour the term collective memory include Maurice Halbwachs (1992), Krzysztof Pomian (2006), Paul Ricoeur (2004), Andrzej Szpociński (2006), Jan Assmann (2008, 2009), Jacek Nowak (2011), and Barbara Szacka $(2006,2012)$. The term social memory is used by Marian Golka (2009). For some (e.g. Kamilla Biskupska 2011 and Krzysztof Malicki 2012), these two terms happen to be used interchangeably. Yet, some others make deliberate attempts at keeping them apart (for example, the Polish scholars Marian Golka and Barbara Szacka). The divergence that Golka (2009:14) finds between one and the other has to do with the connotations of the corresponding adjectives, social ('społeczna') and collective ('zbiorowa'):

What the adjective social brings to mind is not only collective memory, but also individual memory, which is the one that relates to social issues and is conditioned by social factors. The adjective collective, or group, in turn, may denote a more real [Pol. reistyczny] understanding of memory, as some form of a collective entity.

That Szacka (2012: 16) has opted for the term collective memory comes with advances in social psychology:

Over the last quarter of a century psychology has confirmed Halbwachs' intuitions about social conditioning of individual memory. (...) It was the recognition of the influence which social factors exert upon individual memory that brought about the concept of 'social memory'. This is why I assumed that for me, as a sociologist, collective memory is a better general term.

Accordingly, in one of her other works, Szacka (2006: 38) suggests that the term collective memory should be superordinate in relation to social memory, the latter often being considered to be merely informal: 
Two kinds of collective memory can be distinguished within every social group. One used to be called institutional by virtue of its being formally recognised and disseminated by official mass media, while the other one operates outside official circulation and embraces the contents that at times drastically diverge from the contents of the former. Once we distinguish the two, we arrive at various terminological distinctions. (...) As I consider collective memory to be a general term, I tend to call the informal kind social, thus obliterating the alleged synonymy of these two terms.

It is worth looking both of these two adjectives up in dictionaries. Witold Doroszewski's Słownik języka polskiego identifies społeczny, or 'social', as having the following definitions:

(1) relating to human society; originating, emerging in society; implemented in society; bound with society;

(2) produced, accumulated by society in the production process, brought about by joint efforts, being a public property, belonging to the common good;

(3) obtained, meant to serve the society and their needs; contributing to the common good of society;

(4) implemented, realised by the general public; collective, general;

(5) shared (SJPDor, http://doroszewski.pwn.pl).

Edited by Mirosław Bańko, Inny słownik języka polskiego points to the following four definitions of społeczny:

relating to society, involving its character, ways of organisation, or functions its individual members perform in it;

(1) relating to the attitudes and behaviour of the majority of the members of a society;

(2) produced by society and constituting its common property;

(3) serving to satisfy the needs and improve the living conditions of society (ISJP, II, 654).

The meaning of the adjective społeczny seems to be extended in Praktyczny słownik współczesnej polszczyzny (edited by Halina Zgółkowa):

Bound with society, relating to society, belonging to society, as a product of society as a whole or of its part; collocations: social system, class, social group, social movement, social transformations, great/poor social awareness, reforms, social changes;

(1) meant to satisfy the needs of society as a whole or of its part; also: working towards the good of society, caring for society;

(2) common, general (PSWP, XL, 32). 


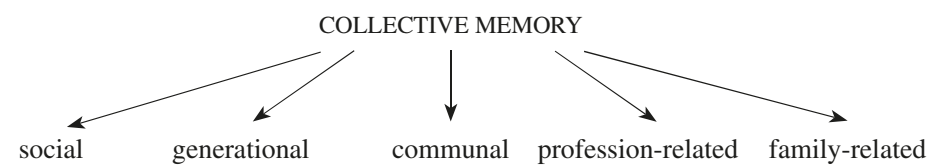

Diagram 1: Kinds of collective memory according to their scope of influence: own proposal.

Now, collective 'zbiorowy' is given the following definitions: 'relating to a certain group of people or to a set of things; characteristic of a given set; composed of many units, being a part of a given set; group-like [Pol. gromadny], communal [Pol. kolektywny]' (SJPDor, http://doroszewski.pwn.pl), 'relating to a group of people, or (seldom) to sets of things and phenomena' (ISJP, II, 1305), 'relating to a group of people or a set of things' (PSWP, XLIX, 84).

As evidenced in the above definitions, social is related to some general grouping, the whole of society and with social structures. This means that social memory could be understood as a subtype of collective memory, as the latter involves various social groupings, including society as a macrostructure as well as various bigger or smaller microstructures, such as social units of a generational, regional, or subcultural character. I would then opt for collective memory as a superordinate term, whereas social memory would be - next to generational memory, or group memory - one of the subtypes of collective memory. In other words, collective memory embraces various groupings, from society as the biggest to many smaller ones. However incomplete, the following scheme is meant to illustrate some of these distinctions:

\section{Collective memory: literal or metaphorical?}

There does not seem to be any general consensus as to whether social/collective memory should be taken literally or metaphorically. This echoes the question Paul Ricoeur (2004: 123) asks in relation to what it is that constitutes the actual object of memory processes: who it is that we can ascribe to both pathos (memory reception) and praxis (memory retrieval).

Let us note that even in reference to individual (personal) memory, that is how 'the inner man [is[remembering himself' (Ricoeur 2004: 98), Ricoeur uses several metaphorical expressions: 'spacious palace' of memory, the storehouse, or the sepulchre 'where the variety of memories (...) are "stored away"' (Ricoeur 2004: 98-99). Elżbieta Tarkowska (2012: 29) observes that identifying memory in terms of a store, a supermarket, a reservoir from which relevant themes, subjects 
and objects are derived, is what keeps on recurring in current reflections on memory. According to Astrid Erll, both concepts of, respectively, "cultural" and "collective" memory, have to do with one and the same conceptual metaphor:

The concept of "remembering" (a cognitive process which takes place in individual brains) is metaphorically transferred to the level of culture. In this metaphorical sense, scholars speak of a "nation's memory", a "religious community's memory", or even of "literature's memory" (which, according to Renate Lachmann, is its intertextuality). (Erll 2008: 4)

That memory is a metaphor is Marian Golka's position, too. He describes memory metaphorically as a conversation with the past, and states that in order to survive, every social group must continue this dialogue. In his understanding, memory is "a unique kind of trinity [Pol. trójca], an accumulation of past knowledge, past experiences, and present-day activity" (Golka 2009: 23).

Many memory researchers (e.g., Jan Assmann) follow Halbwachs' claim that although it can only be an individual that projects memory, a group has also their role to play:

This means that a person who has grown up in complete isolation - though Halbwachs never puts the argument in such a direct way - would have no memory, because memory can only be fashioned during the process of socialisation. Despite the fact that it is always the individual who "has" memory, it is created collectively. This is why the term collective memory should not be read as a metaphor, because while the group itself does not "have" a memory, it determines the memory of its members. Even the most personal recollections only come about through communication and social interaction. We recall not only what we have learned and heard from others but also how others respond to what we consider to be significant. All such experiences depend on intercourse, within the context of an existing social frame of reference and value. There is no memory without perception that is already conditioned by social frames of attention and interpretation. (J. Assmann 2011: 22)

No surprise then, that J. Assmann would strongly emphasise the communicative aspect of memory:

The subject of memory is and always was the individual who nevertheless depends on the "frame" to organise this memory. [...] Memory lives and survives through communication, and if this is broken off, or if the referential frames of the communicated reality disappear or change, then the consequence is forgetting. We only remember what we communicate and what we can locate in the frame of the collective memory. (J. Assmann 2011: 22-23)

A similar position is taken by Paul Connerton, who believes that Halbwachs' concept of collective memory is still plausible providing that we understand that much of what the term embraces is simply interpersonal, rather than collective or social, communication (cf. Connerton 1989: 38). 


\section{Collective memory: a sum total of individual memories, or a supraindividual construct?}

The question posed in the title of this section involves, in fact, a problem of a relationship between individual (personal) memory and collective memory. Since the publication of M. Halbwachs' now classic Cadres sociaux de la memoire (Pol. edition: Społeczne ramy pamięci), it has been assumed that individuals' memories are closely tied in with the social group these individuals belong to. Halbwachs argues that memory depends on its social environment (Halbwachs 1992: 4). It is in a society that an individual acquires memories, learns to identify and recognise them, and where his memories happen to be fostered by what others remember: 'no one ever remembers alone' (Ricoeur 2004: 122). A similar position is taken by S. Schmidt, whose argument is that memory and remembering acquire their social dimension not because they are located outside the responsible actors, but because they become dependent on reversible processes of expectation and ascription/attribution. This creates an impression that members of a community tend to think in a given way. In the context of collective memory, then, remembering amounts to a representation which is a derivative of memory understood as either a structure or a competence (cf. Schmidt 2008: 196).

What is, then, collective memory, if it is related to individual memory? Is collective memory merely a background referent for what individuals remember, or is it an independent and autonomous construct?

'[I]t must first be said that it is on the basis of a subtle analysis of the individual experience of belonging to a group, and through the instruction received from others, that individual memory takes possession of itself' (Ricoeur 2004: 120). If so, collective and individual memories seem to be closely related, conditioning and supplementing each other, with any attempt at telling them apart being a futile exercise. This is what stems also from Ricoeur's phenomenological conception of memory: '(...) it is this capacity to designate oneself as the possessor of one's own memories that leads to attributing to others the same mnemonic phenomena as to oneself' (Ricoeur 2004: 128).

Nevertheless, in Halbwachs' original insight, collective memory is not meant to be a sum total, or an accumulation, of individual memories, each projected by members of one and the same society. The social framework of memory includes 'the instruments used by the collective memory to reconstruct an image of the past which is in accord, in each epoch, with the predominant thoughts of the society' (Halbwachs 1992: 40). An individual remembers assuming the point of view of the group he/she belongs to, but, on the other hand, the memory of the group finds its reflection in what its individual members remember. What 
occurs, then, in-between these two kinds of memories is reciprocal relations, with collective memory being more than a mere sum of individual memories. One notable example of someone who regards collective memory as a sum of individual memories is Jacek Nowak (2011: 9), who states that 'Collective memory includes in its scope individual memories of the people that constitute societies'. Moreover, he also claims that collective memory is not exclusively a combination of individual memories, or a set of past-representing ideas, but is 'an act of communication, an activity that results in memory being handed down and recreated in rituals and symbols; the way we remember the past is constantly being adapted to the way we build our identity' (Nowak 2011: 54).

That collective memory is supraindividual can be found in Manier and Hirst (2008: 254). Though similar to individual memories, collective memories follow their own specific principles: 'Collective memories are not just gatherings of individual memories, and they cannot be reduced to the principles that relate to individual memories'. In other words, as Manier and Hirst argue, collective memory is not distributed in any simple way in a given society. It must perform a specific function for that society, and this function is mainly identification (Manier and Hirst 2008: 253).

Still, Elżbieta Hałas believes that the analogies and correspondences between collective memory and individual memory are all clear. This becomes particularly evident when one pays attention to the scope of the identification function that both kinds of memory perform:

The conception of collective memory as a property of a social group is built on an analogy to personal memory, which implies that the former is a kind of memory of a collective "person" that - quite like an individual - enjoys its own history that can be told. For a social group, memory - again quite like for an individual - is the basis for preserving identity in time, with looking backwards at one's own activity becoming a source of social emotions, such as pride or humiliation. (Hałas 2012: 156)

Finally, Krzysztof Pomian takes memory, as much as history, not to be an abstraction, or an idea, but a semiophysical phenomenon, that is a 'sign system (...) entrenched in material media. For him, memories are semiophores (Pol. semiofory), or two-sided objects, each being a unity of the semiotic dimension and the material dimension (Pomian 2006: 143).

\section{Memory $v s$. history: relational possibilities}

Whenever memory has been approached - in sociology, history, anthropology, or social psychology - some relationship between memory and history has been assumed. These postulated relations appear important in the present book for 
two main reasons. First of all, history is a reference point for memory and, thus provides its definitional basis. The other reason is that the texts we examine here (songs, tales, stories, legends) make references to both local and general history, and are then registers of what and how the country folk as much as the town dwellers remember in relation to history, be it national, communal, or individual. At the same time, memory (what we remember) and remembering (what we recollect) are the gist and parts of the names of some folk genres (e.g. the Polish generic name opowieści wspomnieniowe and its English counterpart recollections are clearly bound with, respectively, wspominać and to recall as two of the terms for 'to remember').

How and why memory and history can relate to each other has been a matter of many controversial proposals. These are categorised by Barbara Szacka into two major approaches:

- in traditional approaches, collective memory is denied any unique status of its own and happens to be understood exclusively as a defective (simplified, incomplete) subkind of historical knowledge,

- in postmodernistic approaches, history is denied any unique status of its own and happens to be understood as one of many forms of collective memory (Szacka 2006: 24).

However, yet another distinction seems to be plausible, which is one into:

- disintegrating approaches, where memory and history are considered to be antithetical, unrelated, and mutually independent;

- integrating approaches, where various mutual criss-crossing influences between memory and history are emphasised.

\subsection{Memory versus history: disintegrating approaches}

That collective memory and history are antithetical to each other goes back to Maurice Halbwachs' canonical insight that the direction history follows is precisely opposite to the direction that can be found in collective memory (cf. J. Assmann 2011: 28: "it [history] works in a reverse way from collective memory").

This calls for criteria that may serve the purpose of differentiating between memory and history. One proposal comes from Andrzej Szpociński, who distinguishes three sets of parameters, all complementary in some sense:

- functional criteria, where the focus is on the intent, or the motivation, behind one's interest in the past; 
- structural criteria, where the focus is on the differences between specific temporal categories;

- cognitive criteria, where the parameter of truth comes to the fore as the most important (Szpociński 2006: 19).

If so, the postulated divergences between history and collective memory ${ }^{1}$ can be presented in terms of binary oppositions. Nevertheless, it should be stressed that Szpocińki's parameters are, in fact, idealisations, whereas the divergences between memory and history are a matter of degree and measure. This is why in comparison to a historiographic text, a collective memory driven text will tend to be biased, simplified, temporally cyclic, emotionally-loaded, poetic, equivocal etc.

This binary oppositeness of, or antithetical relationship between, history and memory, should be understood in terms of complementary distribution: if a given feature appears in memory, it does not in history and vice versa. And so, in terms of:

- presence/absence of a social group grounding:

Whereas collective memory looks at the group from inside - and is at pains to present it with an image of its past in which it can recognise itself at every stage and so exclude any major changes - history leaves out any periods without change as empty interludes in the story in order that the only worthwhile historical facts are those that reveal an event or a process resulting in something new. (J. Assmann 2011: 28)

- presence/absence of a cultural text grounding (e.g., place, gesture, picture, object):

In contradistinction to memory,

What history is concerned with is a critical destruction of spontaneous memory. In history's eyes, the memory of a group appears always suspicious because it aims at the group being disintegrated or persecuted. History may well preserve and appreciate museums, souvenirs, memorabilia, statues, all as useful objects of historical research, but it anyway deprives them of what it is that makes them symbolically significant places of collective memory - lieux de memoire. (Nowak 2011: 35)

- presence/absence of axiological assessment;

- latency/robustness:

1 In the sources quoted here, history is understood as res gestae, or the past or historical developments in the past, and historia rerum gestarum, or accounts (reports, narrations) of the past, historiography included. Most of the distinguishing features that we ascribe to history in the main text relate to this latter reading of history. 
Collective memory is evolving, present in the dialectics of remembering and forgeting, assessed in different ways, capable of surviving after having been latent - even if not retrieved for a long time, it may suddenly wake up anew. On the other hand, history is a reconstruction that always appears problematic and incomplete. (Nowak 2011:35)

Similarly, it is also some other contrasts between memory and history that show binary oppositions:

- continuity versus discontinuity: memory focuses only on resemblance and continuity, whereas history emphasises difference and discontinuity;

- subjectivity versus universality: there are as many memories as there are social groups that preserve and hand down what they remember, but 'there is only one history, and this shuts out all connections with individual groups, identities, and reference points, reconstructing the past in a tableau without identity' (J. Assmann 2011: 29);

- partisanship versus impartiality:

History is aware of the complexity of phenomena, stays detached in relation to whatever it speaks about, knows that everything may be approached from different perspectives, comes to terms with the obscurity and multiplicity of motives and behaviours. Collective memory, in turn, is always biased, simplifies problems, and acknowledges only one point of view. Moreover, it does not tolerate any ambiguities as much as it reduces phenomena to the level of mythical archetypes. (Szacka 2012: 15)

- self-interest versus selflessness: History projects extreme selflessness, or an interest in the past for the sake of the past itself:

It is for practical reasons that collective memory addresses the past. This serves the purposes of making certain (cultural, political, social) orders legitimate, and provides the building material for structuring collective identity. (Szpociński 2006: 19)

- simplicity versus complexity;

- living versus fossilised: collective memory functions in an existing society;

- past versus present: collective memory is always an on-going phenomenon that relates directly to the present, whereas history depicts the past (Nowak 2011: 35); in Marcin Brocki's words (2013: 123), 'in narration, the past gets recreated in novel ways as a result of one's assumed point of view in the present', while history attempts to reproduce the past;

- cyclicity versus linearity: While in history time is linear, it is cyclic and/or mythical in memory. As B. Szacka (2006: 24) sees this difference, 'collective memory places the actors and the events in timeless remoteness and not as historians would do, which is as a linear chronology';

- text as a reflection of the past versus text as a reconstruction of the past;

- emotions versus intellect: 
As a derivative of emotions and magic, collective memory allows only for those facts that suit its purposes. It is then susceptible to transmission, portrayal, censorship, and various kinds of projections. History, in turn, consists in an intellectual activity and involves an analytical and critical discourse. (Nowak 2011: 35)

- current truth versus objective truth:

Historical narration aims at providing true knowledge of the past, whereas collective memory - just because it often expresses the particular interests and values of particular social groups - tends to be largely defective, falsified. (Szpociński 2006: 19)

The same criterion is highlighted by B. Szacka:

For history, the knowledge that is considered to be true has been obtained by means of rigorous research and proves scientifically falsifiable. In collective memory, in turn, knowledge is considered to be true if it complies with a given group's actual feelings, systems of values and the worldview. (Szacka 2006: 29)

- explicitness versus equivocality: As represented in history, the past is given many different equivocal readings, while in collective memory an event often happens to be phrased in simple and explicit terms of one slogan (cf. Szpociński 2006: 20);

- figurative (metaphorical) language versus analytical (descriptive) language (Szpociński 2006: 22). This opposition allows Szpociński to draw a parallel between memory and art:

If experienced as the past (which is when reality happens to be driven emotionally and anchored in values), memory may bring satisfaction, create aesthetic feelings (in the sense of the Kantian sublime), and give a feeling of grandeur, as it is in art. (Szpociński 2006: 24)

Because of its metaphorical import, current collective memory is much more opinion-forming than historians' history (Szpociński 2006: 25);

- single point of view versus multiplicity of points of view: History is then expected to be detached and represent many points of view, whereas collective memory sees the past from one selected angle and, thus contains simplifications. This is how Szacka understands Wetsch:

In history, interpretations are subject to change, which is of no concern because this changeability is understood to be a regular part of historical inquiry. Collective memory, on the other hand, does, in fact, undergo transformations, but it anyway believes that its truths reflect the invariable essence of the group, and, if so, these truths are determined once and for all and they never change. (Szacka 2006: 26)

History reflects a scientific point of view, which is what a researcher identifies in their pursuit of objectivism. This involves the following: multiplicity of 
interpretations, fuzziness, multiperspectival approaches. Memory follows a common-sense point of view, which is what an average member of a social and cultural group perceives, and this eventually leads to simplified and clear-cut judgments.

- sacrum versus profanum: 'collective memory operates in the sphere of sacrum, whereas history, in its ferreting out fashion, changes whatever it deals with into profanum' (Nowak 2011: 35);

- knowledge retrieval and application versus knowledge acquisition and storage: As Szacka (2006: 31) makes use of Hanakała's psychology-oriented tripartite theoretical division of human memory, 'history has to do with knowledge acquisition and storage, while collective memory has to do with knowledge retrieval and application.

There are then reasons to claim, after Maurice Halbwachs and Jan Assmann, that history is not memory. ${ }^{2}$ What tells the latter from the former apart is - among other distinctions - continuity, social group grounding, subjectivity, and multiplicity. History is universal, memory is not. Memory is collective by definition, which means that it is bound with a given social grouping and its identity (J. Assmann 2008: 59). According to Halbwachs, history and memory do not operate simultaneously or jointly, but, if at all, are related in terms of supersession: wherever the past is no longer an object of one's experience, or, simply, it is not remembered any more, memory is superseded with history (J. Assmann 2008: 60). A similar position is taken by Barbara Szacka and Jacek Nowak - history and collective memory are seen in terms of binary oppositions. Both history and collective memory Szacka presents as bipolar models of the past. What she places in-between one and the other is different representations of the past (Szacka 2006: 30). Similarly, Nowak realises that 'for many researchers history and memory are not mutually exclusive', yet he believes that 'memory can no longer be taken as a mere reflection or completion of history [because] nowadays memory is more and more often becoming history's antithesis and it replaces history' (Nowak 2011: 35).

Back to Szacka's argumentation, which states that the three most important divergences between history and collective memory stem from the triad: language - vantage point - worldview, the latter being defined generally

2 It is worth mentioning that a sharp distinction between history and collective memory is typically championed in sociology (Szacka, Szpociński) and culture studies (J. Assmann and A. Assmann). 
as the representation of the past. In her sociological perspective, '[history and collective memory] are two distinct kinds of knowledge of the past, each following divergent principles of construing representations of past things' (Szacka 2006: 19). In sum, what history communicates is a scientific worldview, whereas the worldview disseminated by collective memory is common-sense, which, in short, is how history is narrated by members of a given social group. ${ }^{3}$

\subsection{Memory versus history: integrating approaches}

The conceptual basis of integrating approaches is rooted in the conviction that history and collective memory cannot be seen in terms of binary oppositions. As Aleida Assmann (2009b: 152) understands this change of focus, all the bipolar (disintegrating) models of the history-memory interface assume that historical science consists in a supraindividual abstract research process which is autonomous from the constraints of any specific point of view, and, as such, contrasts rather heavily with living, subjective and emotionally-loaded memories. Although this does not imply that the history-memory distinction as such should be abandoned, there are interesting combinations of the two. History and memory are simply interrelated in a complex way, which echoes Paul Ricoeur's (2004: 58) conviction that the true partner of history is memory:

The historian undertakes to "do history" (faire de l'histoire) just as each of us attempts to "remember" (faire m'emoire). For the most part, the confrontation between memory and history will play itself out on the level of these two, inseparably cognitive and practical, operations.

Still, the point of departure for A. Assmann is some version of a classical disintegrating approach:

Memory belongs to living and robust bearers of a specific outlook. By contrast, history is everyone's property that is no one's property - it is objective, hence it involves indifferent identity. (A. Assmann 2009a: 127)

Aleida Assmann presents this distinction schematically in terms of inhabited memory vis-a-vis uninhabited memory (see Tab. 1).

According to A. Assmann, both positions, of, respectively, polarisation and identification of history and memory, are hardly satisfactory. That is why her

3 That this picture of the world is merely common-sense does not mean that it is anyhow inferior to the scientific worldview. It is, however, true that the so-called 'seven sins of memory' can be identified: transience, absent-mindedness, blocking, misattribution, suggestibility, bias, persistence (Rosińska 2012: 115). 
Tab. 1: Inhabited vis-a-vis uninhabited memory (after A. Assmann 2009a: 127)

\begin{tabular}{|c|c|}
\hline Inhabited memory... & Uninhabited memory... \\
\hline $\begin{array}{l}\text {...is bearer-bound; the bearer can be an } \\
\text { individual, a group, or an institution }\end{array}$ & ....is bearer-independent \\
\hline $\begin{array}{l}\text {...bridges the past, the present, and the } \\
\text { future }\end{array}$ & $\begin{array}{l}\text {...radically separates the past from the } \\
\text { present and the future }\end{array}$ \\
\hline $\begin{array}{l}\text {...acts selectively, remembering one and } \\
\text { forgetting another }\end{array}$ & $\begin{array}{l}\text {...embraces everything as every thing is } \\
\text { equally significant }\end{array}$ \\
\hline $\begin{array}{l}\text {...communicates values that have formed } \\
\text { identity and norms of behaviour }\end{array}$ & $\begin{array}{l}\text {...in its pursuit of the truth it overrides } \\
\text { values and norms }\end{array}$ \\
\hline
\end{tabular}

proposal of making a difference between inhabited and uninhabited memories is meant to be an attempt at getting around the frozen model of history and memory as two complementary modes of how the past can be remembered. Inhabited memory is functional as it is characterised with group reference, selectivity, normativity, and future orientation. As A. Assmann continues,

Historical science correlates with the other kind of memory, which, in fact, is a memory of other memories, the one that absorbs what has already lost any touch with reality. I suggest this kind of memory could be named "storing memory" [Pol. pamięć magazynująca]. (A. Assmann 2009a: 128)

Functional memory would account for legitimisation, delegitimisation, differentiation, and profiling. Storing memory, in turn, constitutes a reservoir of oncoming functional memories and, in this way, it conditions cultural transformations and becomes a source of restoration of cultural knowledge (A. Assmann 2009a: 136). However distinct, functional memory and storing memory are correlated to each other:

If detached from storing memory, functional memory becomes an illusion. On the other hand, if detached form functional memory, storing memory is a mere unordered potpourri of meaningless pieces of information. (A. Assmann 2009a: 139)

Moreover, storing memory may be verification, support, or correction for functional memory, whereas what functional memory can contribute to storing memory is orientation and motivation. Both belong to each other and to their differentiating culture (A. Assmann 2009a: 139).

Another scholar that questions a simple identification of history and memory is Astrid Erll. Not only does she call the identification approach 'a blind valley in memory research and one of Achilles' heels of that research' (Erll 2008: 6), but also opts for obliterating the useless opposition between memory and 
history for the sake of distinguishing various ways and modes of remembering in culture. The past is not given, but it must be continuously reconstructed and represented anew:

This embraces not only what is remembered (facts, data), but also how it is remembered, or what quality and what significance are given to the past. In effect, we obtain different ways of remembering otherwise identical past events. (Erll 2008: 7)

Still, Krzysztof Pomian and Marek Woźniak emphasize the similarities between history and memory. For the former, both are semiophysical phenomena that spread over a given territory and remain subject to change. The analogy that Marek Woźniak builds between the two is this:

Similarly to memory, history, in its nature, is all the same event-like. Also, like memory, history tends to be discriminatory. (...) Memory - and this is what we have already ascribed to history as well - depends on language because it is language that provides means of how memory [and history, too] can be externalised in narration. (Woźniak 2008: 54)

History and memory perform similar functions: legitimisation, valorisation, and socialisation (cf. Woźniak 2008: 56).

Next to the shared commonalities, collective memory and history appear in mutual, complex interrelations. As Jacques le Goff would say, memory, be it oral or written, contributes to history, which makes it a reservoir from which historians derive their data (Le Goff 1996: 22). In this context, P. Ricoeur remarks that history is more extensive than memory, memory being the matrix of history (cf. Woźniak 2008: 53).

This subtle interrelation has been noticed by other researchers as well. For Szacka (2006: 24), historical knowledge is a building material of collective memory. What she means by this is that social memory preys on historical knowledge 'discriminatively, employing the historical material to the task of portraying the past in its own way' (ibid.). For Marian Golka (2009: 45), history is one possible embodiment of social memory. In his metaphor, social memory feeds on history, thus extending its scope by, and supplementing its content with, historical knowledge. In all this, history remains 'a form of memory that facilitates understanding not only of one's own social group, but also other groups' (Golka 2009: 46). It seems to be worth mentioning at this point that while possible history-memory relations are most of the time worded in terms of the building metaphor, the orientation, or direction, of these relations is equally important. In other words, memory may well be presented as the building material of history in one context and for history to be seen as the foundation of memory in some contexts. Does that mean that the two are interrelated in terms of feedback? If it 
does, memory does not exist without history because it is history that memory is built upon, and history cannot do without memory because it is memory that history is stored in.

Another figurative way of presenting history-memory relations is based on the cooking metaphor, with the relations being unidirectional and the orientation going from history to memory. In this case, memory feeds on history, which means that history influences, molds, and creates memory.

The opposite orientation can be found in yet another metaphor, the container metaphor. In terms of influence, this time we move from memory to history, as it is history that mines the resources of collective memory.

Let us notice on the margin that Ricoeur himself preferred to see the two in terms of partnership, saying that memory is the partner of history. At face value, this statement could mean that history and memory enjoy equal status, and their relations are well balanced.

Finally, what probably illustrates the difficulty of relating history and memory to each other best is J. Assmann's proposal of coining a separate term, mnemohistory, which would grasp the difference between history proper that deals with the past as such, and history that deals with the past as it has come to be remembered (after Olick 2008: 151).

By means of relating to our material basis in this book, we need to say that most of the relational problems that we have discussed so far find their illustration in folklore texts, especially in historical reconstructions and in historical songs. What we find there is that while on the one hand, texts are erected upon a historical (universal, objective, global) basis, on the other hand, texts preserve (social, subjective, local) history.

\section{Collective memory: definitions and attributes}

It seems that there are as many definitions of collective memory as there are those that deal with it. The conception that collective memory is a picture/image of the past can be traced back to Maurice Halbwachs (cf. Halbwachs 1992: 167168). What may be striking is that Halbwachs places his conception in the context of the integrating function of memory, whereas he speaks of the image of the past that is subject to change - some of the characteristics happen to be foregrounded, others are backgrounded or completely forgotten. It is, then, difficult to think how memory should be of any integrating effect.

However, those that follow Halbwachs' position show several subtle differences. In the first place, some researchers present memory as a representation of the past (Manier and Hirst 2008), while others see it in terms of imagining the past 
(Confino 2008), or of creation and interpretation (Nowak 2011), or of reflecting the past reality (Brocki 2013).

More specifically, Manier and Hirst see collective memory as a representation of the past in the minds of the members of a given social group, which gives them a feeling that everything makes sense. Naturally, Manier and Hirst's definition relates closely to the concept of identity, but this identity does not have to be expressed verbally; it stems from the shared experience that may, but does not have to, be articulated in narration (Manier and Hirst 2008: 253). What proves important is that collective memory is grounded not only in stories, but also, if not first of all, in mentalities and historical experience.

The research object for Confino, in turn, is how people imagine the past, and not what the past actually looked like (Confino 2008: 80). This correlates with Barbara Szacka's definition of collective memory:

[Collective memory is] a set of a social group members' depictions of their past, which embraces ways of imagining past actors and events, as well as ways of remembering them and knowing about them, as it is expected of an average member of this social group. This includes all the images present in the social imagination that a given social group may share about their past and their deliberate references to these images. (Szacka 2006: 19)

Some variation of Szacka's position is present in this from J. Nowak:

Although memory happens to be recorded in the human mind as a replica, or documentation, of on-going events, it is their interpretation. This means that our memory is being created, with our identity depending on how the past, the present and the future are brought together to be constructed in narration. (J. Nowak 2011: 12)

If so, collective memory is, in the first place, built of common-sense knowledge, yet the two probably cannot be equated with each other in any simple way.

The narrative character of memory is emphasised also by Marcin Brocki, for whom it is 'a mechanism of experience (understood as uninherited information) being selected and ordered, or a mechanism of the semiosis of the past' (Brocki 2013: 122). For Brocki, then, memory is a process, or, rather, 'an element of on-going narration and of changing living conditions' (Brocki 2013: 122). That memory is as much processual as structural can be found in Paweł Ciołkiewicz (2012). In the sense of the latter dimension, collective memory is 'a set of images of the past that are cherished within the bounds of a given social group, which makes it antithetical in regard to, for example, the so-called historical consciousness' (Ciołkiewicz 2012: 17), whereas in its processual dimension, memory functions as 'a novel way of presenting the past, which makes it antithetical in regard to history' (Ciołkiewicz 2012: 17). 
Now, let us go back to the claim that most researchers seem to advance, i.e. that the primary function of memory has to do with identity. And, thus, as Jacek Nowak argues, collective memory is 'a set of images that a given social group shares of its past, images that are negotiated in acts of internal communication and disseminated in cross-generational transmission in order to maintain coherent identity narration' (Nowak 2011: 13). (On its face value, Nowak's conception resembles what Assmann names to be communicative memory.) In his detailed characterisation of social (here: collective) memory, Marian Golka mentions the following:

- communisation (Pol. uspołecznienie): individual memory tokens are subject to relative standardisation in various aspects and spheres of social life;

- levelling: the emerging picture of the extensive epochs and complex past events is simplified and synthetic;

- accumulation: divergent events of different temporal references are brought together into some kind of amorphous form that lacks any specific temporal grounding; if so, this characteristic seems to be dissonant with Halbwachs' and Assmann's original insights that one of the pillars of memory is time, and, thus, temporality, similar to locality, is an essential element of memory;

- fuzziness (Pol. mgławicowość): the remembered images are usually deprived of details that can thus be substituted with historical knowledge or its implants, such as mythopoetic suppositions and mystifications; however, contrary to Golka, many other researchers argue that collective memory does preserve the details that the subject considers important for their construing an image of the past;

- haphazardness (Pol. chaotyczność): the set of facts that are remembered is relatively random and arbitrary; this characteristic seems to be problematic because, as many psychologists suggest, memory is certainly ordered, structured, and logical. It may not follow any neat chronological progression, but, still, this does not mean that is must be regarded as chaotic;

- self-interest (Pol. interesowność): the choice of remembered content is not absolutely accidental, but it derives from the ideology of a group and its social interests; under the heading of self-interest, this characteristic has in Polish all the same negative connotations, which is why it should perhaps be better called "engaged memory";

- polymorphism: what is derived from typically flexible and capacious social memory resources is that which is actually required or useful to satisfy current needs and interests; I suggest this characteristic should be called selectivity, for polymorphism to embrace what it actually names, i.e. first of all, 
the notion of memory carriers as distinct forms that memory can assume to function. These forms are narrations, films, photos, etc. Otherwise, there seems to be a lack of correspondence between how memory is defined and what this specific feature of memory is called;

- uniqueness: the events that come to be remembered are usually extraordinary, special, or spectacular;

- heterogeneity: collective memory is not homogeneous in any social grouping; as much as polymorphism, this characteristic is meant to imply the internal differentiation of memory; again, what matters is not that there are many different memories, just because there are many different subjects, but because memory can be discriminated internally;

- forgetting and implantation: memory losses can be restored (Golka 2009: 24).

As already signalled, Golka's list of collective memory characteristics need to be supplemented and modified. In my view, the complete and final set of features that can be acribed to collective memory is this:

- social group grounding: memory happens to be employed to the benefit and for the sake of current issues of a social group, which amounts to making selective choices of the events to be remembered proportionately to a group's needs;

- cultural grounding: in this we follow B. Szacka who claims that collective images

are understood, selected, and modified according to the group's own cultural standards and ideological outlooks; these standards are social products and are thus shared by all of the members of the group, which facilitates the process of making images of the group's past uniform and legitimizes the notion of the group's collective memory of the past. (Szacka 2006: 45)

It is also Russian semioticians (mainly J. Łotman and B. Uspienski) who emphasise close correspondences between memory and culture; in Żyłko’s summary,

Culture is here understood as the society's uninherited memory that finds its expression in a specific system of dos and don'ts (...) Taken as a whole, culture is one of the forms of collective memory. Each of the systems of culture includes memory of the past states, or, in other words, its history. (Żyłko 2009: 104)

- dynamicity: Żyłko argues that the picture of the past is constantly changing: some elements come to be remembered, some other ones forgotten, yet nothing has to be definitive, or final' (Żyłko 2009: 105); this echoes Fortunati and Lamberti's position that cultural memory is complex, layered, and closely related to $(. .$.$) the way how one and the same history and experience happen$ 
to be interpreted in time, both individually and collectively. Memory is dynamic, or to use Fortunati and Lamberti's words, 'As a process (...), memory changes proportionately to the changes of the present' (Fortunati and Lamberti 2008: 128);

- mythologisation of the past: actors and events of the past happen to be transformed into 'timeless exemplars and personifications of virtues sanctioning the behaviours and the attitudes important to the community' (Szacka 2006: 24);

- event-orientation and emotionality: according to A. Szpociński,

Collective memory embraces what remains of the past in the experiences of members of a social group or what these members consider to be their past, that is a set of memories of past events (actual or imagined), experienced explicitly or handed down from generation to generation as oral tradition, written narration, or other means of information dissemination. (Szpociński 2006: 27).

- orality, or, more generally, verbality: that collective memory depends on oral transmission has been pointed out by, among others, Wojciech Chlebda (2012) and Krzysztof Pomian; the latter has got this to say:

Collective memory is dependent on oral tradition in varying degrees in different cases, but, generally, this dependence is extensive. Indeed, deprived of verbal assistance, what images communicate appears incomprehensible because it is this verbal background that establishes relations between actors and scenes vis-a-vis stories and beliefs. (Pomian 2006: 150)

- diversity of products and practices: this is to follow Olick's distinction between mnemonic 'products' and 'practices'; the former include stories, rituals, books, statues, presentations, speeches, images, pictures, records, historical studies, surveys, etc., whereas the latter involve reminiscence, recall, representation, commemoration, celebration, regret, renunciation, disavowal, denial, rationalisation, excuse, acknowledgement, etc. As Olick asserts, 'mnemonic practices (...) are always simultaneously individual and social', whereas 'no matter how concrete mnemonic products may be, they gain their reality only by being used, interpreted, reproduced or changed' (Olick 2008: 158);

- process-orientation: this characteristic relates to Olick's statement that 'collective remembering is a highly complex process, involving numerous different people, practices, materials, and themes', which is why 'collective memory is something - or rather many things - we do, not something - or rather many things - we have' (Olick 2008: 159); as Szacka would add, collective memory is not static, but dynamic and changeable. It is a meeting point of never-ending encounters, controversies, or a melting pot of different images 
of the past as they are construed from different perspectives and constructed of different elements' (Szacka 2006: 45);

- structural organisation: memory is structured according to a group's shared exemplars and cultural scripts, narrative ones included; part of this structural organisation is what Szacka specifies as constituting elements of memory: (i) the kind of memory that individuals recall of their own experiences, (ii) the kind of memory that stems from many individuals' personal or shared experiences as well as the symbolic language that has been agreed for communicating that memory, and (iii) formally transmitted images of the past and festivities commemorating past events (Szacka 2006: 45).

\section{Collective memory: typological attempts}

Collective memory has been typologised according to various sets of parameters. One of these is temporal considerations, as put forward by, among others, le Goff (1996). In his examination of historical memory, he points out the differences in how societies employ oral and written kinds of memory, as well as observes that the transition between, or the development of, the two is gradable. This brings him to distinguish the following kinds of memory:

- ethnic memory;

- the rise of memory: from orality to writing, from prehistory to antiquity; this development brought about two forms of memory: celebration inscription and the so-called document-monument.

- memory in the Middle Ages;

- the progress of written and figured memory from the Renaissance to the present and the contemporary revolutions in memory (the rise of electronic memory, growing importance of collective memory [le Goff 1996: $81 \mathrm{ff}$ ]).

The parameter that Maurice Halbwachs, another renowned memory researcher, takes into consideration is the source of memory. He thus makes use of two pairs of opposites: autobiographical memory versus historical memory and history versus collective memory:

The first opposition embraces the contradistinction between how past events are remembered in our own personal experience and how they are presented in some other sources. The other pair of opposites sets fossilised knowledge of the past against the "living history" of the past, the latter being saturated with emotions and circulated on a daily basis among members of a social group. (Szacka 2006: 37)

On a more critical level, Szacka believes that if it is historical memory that is supposed to be the research object, then both opposites of the latter contradistinction 
should be taken into consideration (that is, history as well as collective memory), and that leads to obliterating any differences between history and collective memory (Szacka 2006: 37).

Yet another proposal comes from Szpociński, who distinguishes three different kinds of remembering the past. His typology is based on the parameters of memory robustness and of memory functionality:

- antiquarian memory ('dead' and nonfunctional): remembering the past so that remote cultural products, events, and actors happen to be distorted to a very large extent (Szpociński 2006: 30);

- historical memory ('living' and nonfunctional): it involves 'disinterested' contemplation of what happened in the past (behaviours, values, ideas), with art being the main locus of historical memory (Szpociński 2006: 30); the difference between historical memory and monumental memory (as the third kind of memory; see below) is that historical memory does not make explicit references to the present day;

- monumental memory ('living' and functional): it functions as an opposite to historical memory:

[Monumental memory] serves the purposes of explaining reality, sanctioning or rejecting systems of values (...). It is precisely the past as experienced in terms of monumental memory that provides a social group with the building material for construing their own image. (Szpociński 2006: 30)

A truly elaborate typology of kinds of memory can be found in Golka:

- stable memory (knowledge that is handed down from generation to generation) and transient memory (knowledge of the past is not passed on, and its temporal robustness is limited to one generation only; this differentiation into stable and transient seems to be superordinate with regard to the other ones);

- verbally-communicated memory and artefacts-based memory, the latter being various cultural carriers (writing, pictures, physical objects);

- first-hand (witness-based) memory and second-hand (transmitted) memory;

- actual memory and potential memory;

- latent (passive, discreet, seldom recalled in people's awareness and in cultural artefacts) and active memory (that is the one that fans emotions and fuels debates and discussions);

- remembering the past (Pol. pamiętanie) and dwelling on the past (Pol. rozpamiętywanie); this distinction is based on the parameter of emotional involvement;

- neutral memory and stigma-like memory; 
- archival memory (i.e. the one that stores complete knowledge of the past of a given community) and topical memory (i.e. the one that singles out selective elements of the past);

What is controversial in this case is both the very definition of memory as knowledge of the past, as well as the alleged completeness of archival memory. Memory is not what we know of the past, but how we portray the past, with selectivity being one of the absolutely fundamental features of memory. That Golka insists on the archival/topical memory distinction is even more striking as he himself admits that 'the events that come to be remembered are usually extraordinary, special, or spectacular' (Golka 2009: 24; already quoted above), and acknowledges accumulation and fuzziness as being basic characteristics of memory.

- homogeneous memory and heterogeneous memory: similar to the archival/ topical memory distinction above, an objection can be made that the alleged difference between homogeneous and heterogeneous kinds of memory is forced, superfluous, and does not reflect the essential characteristics of memory, such as accumulation and fuzziness;

- universal memory (the one that involves the whole of society) and local memory;

- the masters's memory (Pol. pamięć dominujących) and the servants' memory (Pol. pamięć zdominowanych);

- sacrum memory and profanum memory;

- high-ranking events memory and low-ranking events memory;

This distinction does not follow the prevailing conviction that what memory embraces is, by definition, socially significant and relevant. That means that whatever the subject remembers is equally 'high-ranking, whereas Golka seems to assume an external and relative perspective that lacks subject-centered focus.

- instrumental memory and autonomous memory (the parameter employed is the way memory is actually used, or applied);

- power-guided (created, inspired, manipulated) memory and spontaneous memory;

- staged (imagined, implanted) memory and authentic (genuine) memory;

- institutional memory (i.e. the one that is championed by specially established organisations (museums, archives)) and cultural memory (the one that resides in specific products of culture, such as open public spaces, buildings, texts, pictures);

There is a problem with this distinction, too. After all, museums, archives and other similar institutions house nothing but cultural products. Now, if 
institutional memory is juxtaposed with cultural memory, that implies that institutional memory is not cultural, which is overtly untrue. After all, the institutions that meet Golka's standards of institutional memory are cultural by definition.

- official (state-guided) memory and private memory, the latter being sustained in family stories, photo albums, and interpretations of public (mass) events;

- registered memory (i.e. closed, sealed, not recalled on any regular basis) and celebrated memory (i.e. cherished and revered on various occasions and in various contexts);

- factual (fact-based) memory and axiological (value-centered and factrelated) memory; Golka's intention of making a difference between remembering facts as such and remembering the values that go together well with these facts again seems questionable. After all, memory is a way of evaluating, or assessing facts, a measure of ascribing values to facts. If so, facts and values are inseparable.

- favourable (positive; Pol. fortunna) memory (i.e. the one that remains loyal to the past and facilitates an adequate interpretation of the past) and unfavourable (negative; Pol. niefortunna) memory (Golka 2009: 30).

Another proponent of memory classification has been offered by J. Assmann. According to him, collective memory functions in a bimodal way: one mode involves the foundational memory, which is the one that goes back to prehistory, and the other mode is the biographical memory, which is the one that encounters and embraces individual experiences and their framing factors (cf. J. Assmann 2008: 67). To elaborate on the distinction, the former mode is based on those memory carriers that are permanent and objectified (in illiterate cultures as well), such as rituals, dances, myths, cloths, tattoos, trails, paintings, landscapes etc. J. Assmann describes them in terms of various sign systems that serve the mnemotechnic function (sustaining memory and identity) and can be grouped under the umbrella concept of memoria. The other mode is grounded in actual social interaction (in literate cultures as well).

Next to these two modes, J. Assmann also distinguishes four different memory zones:

- mimetic memory that stores patterns of behaviour for us to acquire by imitation;

- objective memory that is focused on remembering objects and their attributes; this facilitates one's sense of purpose, comfort, and beauty; in a way, then, the way we remember things reflects on us as creators of these things; as J. Assmann would argue, the material/objective reality is our time-machine in 
the sense that while it refers to the present, it actually sends us back to the past (J. Assmann 2008: 36);

- communicative memory that binds language and communication;

- cultural memory that is a unique transformation of all the other kinds of memory, which feeds both tradition and communication, but, at the same time, is not exhausted in either of them (J. Assmann 2008: 38);

J. Assmann offers a comprehensive explanation of how and why communicative and cultural memories differ. As a typical example of the former, he gives generational memory. That is, communicative memory embraces the recent past, or the past events that one can share with his/her generation. In other words, a social group acquires its communicative memory in a historical process. This kind of memory comes into being and then passes away at a given time. As this given time is generation-specific, communicative memory dies with the generation that ceases to function as its carrier. Once dead, one communicative memory is superceded with another communicative memory (J. Assmann 2008: 66).

Cultural memory, in turn, cannot store the past as such, so it is directed towards established and recognised points in the past. That means that in cultural memory, the past is transfigurated into symbols that come to be its foundation. The kind of transfiguration we have here has to do with changing factual history into remembered history, which ultimately leads to a mythological conviction of and belief in 'the founding history' (J. Assmann 2008: 68), a narration that happens to be retold in order to explain the present from the perspective of a prehistorical origin. In other words, it is due to cultural memory that history projects into a myth.

This is the reason why J. Assmann ascribes to cultural memory a certain amount of sacrum. Indeed, transfigurated into memory figures, history may often have a religious implication, with these figures, whenever being remembered, transforming into festivities. As Assmann remarks, among many other functions, festivities are meant to bring to life what he calls foundational (object-oriented) memory. Simply, by making references to the past, or, more generally, by remembering the past, a social group builds its own identity (J. Assmann 2008: 68).

That J. Assmann's conception has proved to be inspiring and influential can best be evidenced with a great number of references to, and modifications of, what he distinguishes as the two basic kinds of memory, communicative and cultural. In some of the proposals, cultural memory is redefined as a socioculturally contextualised interplay of the present and the past, and that is believed to range from individual/personal acts of memory via group memory (as found in the family, among friends, veterans etc.) and national memory (with 
its 'institutionalised' traditions) to numerous transnational lieux de memoire (e.g. The Holocaust, or 9/11; cf. Erll 2008: 2). In this redefinition, cultural memory amounts to, as Erll (2008: 4) calls it, "an umbrella term," which embraces the kinds of memory she is prepared to distinguish, that is social memory, material/ medial memory, and mental/cognitive memory.

An equally general conception of memory can be found in Paul Connerton. By cultural memory, he means not only cognitive memory (i.e. any acquired conceptual knowledge), but also 'habitual skills', table manners included (Connerton 1989: 77), which for many other researchers, as Hałas (2012: 162) remarks, is part of habitual memory, not cultural memory.

This brings us to Elżbieta Hałas' critical view of J. Assmann's ideas. What she emphasises in her criticism is the limited applicaton of Assmann's distinctions:

Assmann's idea of cultural memory, where it is contradistinguished with communicative memory, can at best have only a limited application. This is because cultural memory has been given - in Assmann's view - the identity-building function, and as such, it has not been told apart from either cultural heritage or cultural tradition. Memory, in fact, has a capacity of obliterating the enslaving power of tradition, and it consists in making reflexive references to the past. It should not, then, be identified with tradition, precisely because it can lead to a radical breach with tradition. (Hałas 2012: 169)

As Hałas continues, neither is it unproblematic to dissociate cultural memory from communicative memory,

the former being understood as the lasting and objectified remembering of past events and the latter envisaged as the vernacular memory on a daily basis. Instead, cultural memory is put forward here as a temporal dimension of meaning. In other words, memory consists in acts of communication, each disseminating reflexive knowledge of the past-driven experience as seen from the vantage point of the future present [Pol. $z$ punktu widzenia przyszłej teraźniejszości]. (Hałas 2012: 169)

No wonder, then, that unlike J. Assmann, Hałas sees cultural memory in terms of a number of 'subjective' attributes, such as communication, axionormativity, affectivity, future-oriented temporality, and, first of all, reflexivity of the pastdriven knowledge. Reflexive by nature, cultural memory, or, to put it more descriptively, the memory that happens to be externalised and symbolically objectified, appears in the last instance as people's experience (Hałas 2012: 171).

An interesting attempt at confronting J. Assmann's typology with Antonina Kłoskowska's conception of culture can be found in Kaja Kaźmierska’s research. Having accepted J. Assmann's distinction between communicative and cultural memories, Kaźmierska presents the former in terms of diachrony and the latter in terms of synchrony: 
Once we apply the communicative memory versus cultural memory distinction to Kłoskowska's three areas of culture, we can conclude that communicative memory functions in the first area [material culture] and belongs to the first category (Kłoskowska calls it the category of means of communication and characterises it with the directtransient attributes). (...) Cultural memory, in turn, would function in the second [societal culture] and the third [symbolic culture] areas and belongs to the category (...) of the indirect-transient characteristics and, in the first place, to the category (...) of the indirect-stable characteristics. (Kaźmierska 2012: 49-50)

A similar limitation in J. Assmann's cultural memory has been noticed also by Magdalena Saryusz-Wolska:

Assmann constructed his theory primarily in reference to ancient cultures, which is why he practically did not consider any medially mediated information which - already in their most primeval forms - constituted a part of cultural memory. (Saryusz-Wolska 2009: 31)

This kind of information is taken into consideration by Erll. The use she makes of it brings her to distinguish two aspects of how cultural memory functions and also two levels of the culture-memory relation. The first level is individualbased, cognition-oriented, and relates to biological memory. In effect, memory is here shaped by collective (socio-cultural) contexts in which people acquire schemata and patterns of remembering the past and of coding their experiences as adjectives. On this level, the noun memory is used in its literal sense, while the adjective cultural is used metonymically and means 'socio-cultural contexts and their influence on memory' (Erll 2008: 5). The other level is described by Erll as collective because it 'refers to the symbolic order, the media, institutions, and practices by which social groups construct a shared past' (ibid.), which gives the term memory a metaphorical flavour. As Erll hastens to add,

in practice the cognitive and the social/medial continuously interact. There is no such thing as pre-cultural individual memory; but neither is there a Collective or Cultural Memory (with capital letters) which is detached from individuals and embodied only in media and institutions. (Erll 2008: 5-6)

However comprehensive Erll's conception seems to be, it refers exclusively to cultural memory, and appears similar to J. Assmann's theory in some parts. Indeed, in both proposals the distinguished kinds of memory interpenetrate and supplement each other. Moreover, deprived of its communicative slant, Erll's medial level as well as cultural memory prove to be dead concepts. This has been emphasised by Welzer:

"Cultural" and "communicative memory" can only be strictly separated in a theoretical context; in the actual memory practice of individuals and social groups, their forms and methods are linked together. (Welzer 2008: 285) 
In J. Assmann's original insight, cultural and communicative memories are compared to, respectively, a festivity and a weekday, or sacrum and profanum, and are described as everyday memory and festival memory. J. Assmann finds this polarity on the sociological level as well, that is in terms of a relative participation structure. While a social group members' contribution to communicative memory is diffuse, their respective participation in cultural memory is always differentiated and hierarchically structured. Simply, in the latter case, cultural memory is transmitted by specialised carriers. As Assmann argues,

[C]ultural memory always has its specialists, both in oral and in literate societies. These include shamans, bards, and griots, as well as priests, teachers, artists, clerks, scholars, mandarins, rabbis, mullahs, and other names for specialized carriers of memory. In oral societies, the degree of specialization of these carriers depends on the magnitude of the demands that are made of their memory. (J. Assmann 2008b: 114)

This makes cultural memory based on stable, or even permanent, elements. To use Assmann's own metaphor, cultural memory does not function like an electric current which interpenetrates an individual from outside, but is a world of phenomena that people externalize from the inside (cf. J. Assmann 2008: 74). (See Tab. 2 for an overview of J. Assmann's specific understanding of both cultural and communicative kinds of memory with regard to selected parameters.)

Should we need to contrast cultural memory with communicative memory now, here we have Welzer's opinion:

Tab. 2: Communicative versus cultural memory according to Assmann (2011:41, similarly 2008b:117)

\begin{tabular}{|c|c|c|}
\hline & Communicative memory & Cultural memory \\
\hline Content & $\begin{array}{l}\text { Historical experiences in the } \\
\text { framework of individual biographies }\end{array}$ & $\begin{array}{l}\text { Mythical history of origins, events } \\
\text { in an absolute past }\end{array}$ \\
\hline Forms & $\begin{array}{l}\text { Informal, without much form, } \\
\text { natural growth, arising from } \\
\text { interaction, everyday }\end{array}$ & $\begin{array}{l}\text { Organized, extremely formal, } \\
\text { ceremonial communication, festival }\end{array}$ \\
\hline Media & $\begin{array}{l}\text { Living, organic memories, } \\
\text { experiences, hearsay }\end{array}$ & $\begin{array}{l}\text { Fixed objectifications, traditional } \\
\text { symbolic classification and staging } \\
\text { through words, pictures, dance, and } \\
\text { so forth }\end{array}$ \\
\hline $\begin{array}{l}\text { Time } \\
\text { structure }\end{array}$ & $\begin{array}{l}80-100 \text { years, with a progressive } \\
\text { present spanning three-four } \\
\text { generations }\end{array}$ & $\begin{array}{l}\text { Absolute past of a mythical, } \\
\text { primeval age }\end{array}$ \\
\hline Carriers & $\begin{array}{l}\text { Nonspecific, contemporary witnesses } \\
\text { within a memory community }\end{array}$ & Specialized tradition bearers \\
\hline
\end{tabular}


"Communicative memory," (...) is an interactive practice located within the tension between individuals' and groups' recall of the past. Compared to "cultural" memory, it can be seen as the short-term memory of a society (...). [Cultural memory] is supported by fixed points which do not move along with the present, but are instead perceived as fateful and meaningful and are marked by texts, rites, monuments, and commemorations. (Welzer 2008: 285)

Nevertheless, let us assume that - after J. Assmann - collective memory is a general term that embraces the notions of both cultural memory and communicative memory, and try to relate this distinction to levels of communication. What we find is that communicative memory correlates with interpersonal communication, whereas cultural memory functions in mass communication. Moreover, communicative memory relates to verbal communication, while cultural memory functions in cultural communication, that is, in texts of culture.

With these generalisations in mind, it is now apposite to present Aleida Assmann's modification of J. Assmann's original proposal. In Saryusz-Wolska's account,

[Aleida Assmann's] model embraces a hierarchical structure, where individual memories to be passed on to the next generations (i.e. communicative memory) are placed at the very bottom; collective memory can be found one level higher up, and the top level is occupied by cultural memory. (...) While for Jan Assmann [collective memory] is an all-embracing category that captures the social character of memory, for Alida Assmann, collective memory is just one kind of memory, the one that relates to a social group, be it of a national, local, political etc. dimension. (Saryusz-Wolska 2009: 34)

In A. Assmann's conception, communicative memory is, then, what an individual remembers in his/her verbal externalisations in communication, or, to use her own words, 'the memory that interpenetrates people from outside, with the language undoubtedly being the most important factor' (A. Assmann 2009b: 158). This kind of memory is time-limited, can be seen as a juncture of individual and collective memories, and be described as social, short-term, and generational.

Collective memory, in turn, appears to be a higher degree of generational memory:

Memory and a social group depend on each other: the group is a carrier of memory, while memory gives the group stability. (...) Collective memory is political in nature. Unlike diffuse communicative memory, which is the one that comes into being by itself and comes to its end by itself, collective memory is shaped from the outside and shows a relatively high degree of homogeneity. (A. Assmann 2009b: 164) 
If homogeneous, collective memory is typically characterised with conceptual minimalism and symbolic reductionism. The reason why this should be so, A. Assmann sees as follows:

It frequently happens that it is one single event that becomes the "icon" of historical experience and, as such, it exerts its impact on memory, this historical experience being, in fact, highly complex and differentiated. [...] Collective memory brings the past and the future to a symmetrical relation in which a given memory triggers a given expectation. (A. Assmann 2009b: 164)

In A. Assmann's hierarchy, the next level is occupied by cultural memory. It serves the purposes of transmitting experiences and knowledge in a transgenerational fashion, which ultimately leads to socially-motivated long-term memory. This kind of memory is grounded in external media and institutions:

The basis of cultural memory includes such artifacts as texts, paintings, sculptures, and other spatial compositions (statues, landscape architecture), as well as temporal orders (festivities, customs, rituals). They all code a certain set of messages that are subject to historical transfomations and, for that reason, need to be re-read, contemplated and restored for them to meet the demands and requirements of the ever oncoming present. (...) Collective memory fosters experience and shared will, whereas communicative memory facilitates communication in a long-term, historical, transgenerational perspective, which is why it makes it possible for people to check on their identity as identity acquires its shape in a transgenerational tradition and in a supraindividual historical experience. (A. Assmann 2009b: 171)

In short, in its character, communicative memory is both medial and material.

To round off my presentation so far in this book, I follow J. Assmann's proposal, his typology of memory kinds included, with collective memory being the general concept and falling into cultural memory and communicative memory. Yet, I also assume that both of these two kinds of collective memory are cultural by nature, even though they find their expression in different texts of culture. More specifically, the communicative memory carrier is typically a non-petrified oral text, but it can also be other texts of culture - iconic, verbal, non-verbal.

I also follow the distinction A. Assmann makes between the memory of the ars kind and the vis kind:

By ars, I understand the path that consists in storing memories, the concept involving any identity-structuring mechanical process of accumulating and recalling the data. (...) This storing process is also a unique faculty of the human memory capacity that facilitates knowledge acquisition by means of remembering information. (A. Assmann 2009a: 119)

The ars (information storing) procedure is juxtaposed with the vis (remembering 
information) process which, unlike ars, is not an intentional act, but it resides in making reconstructions: 'for the vis process, the reference point is invariably the present, which means that at the very moment of recalling the data a fair amount of deformation, distortion, malformation, reassessment, or updating should certainly be expected' (A. Assmann 2009a: 119). From this (vis) reading, memory is an immanent power that follows its own order.

Further on, A. Assmann allows for yet another distinction, between the cultural working (active) memory and the cultural reference (passive) memory, calling the two, respectively, the canon and the archive. Although, she argues, it is possible to envisage a culture without its archive, it is not quite plausible to have a culture without its canon. As she makes the point for the latter,

[Canonisation] means "sanctification"; to endow texts, persons, artifacts, and monuments with a sanctified status is to set them off from the rest as charged with the highest meaning and value. Elements of the canon are marked by three qualities: selection, value, and duration. Selection presupposes decisions and power struggles; ascription of value endows these objects with an aura and a sacrosanct status; duration in cultural memory is the central aim of the procedure. (A. Assmann 2008:100)

As the name suggests, the canon involves most stable elements of memory, and a canonized text itself becomes a stable point of reference. A. Assmann makes that clear when she says that 'A canon is not a hit-list; it is instead independent of historical change and immune to the ups and downs of social taste' (ibid.). Nevertheless, it should also be noted that however stable in general, 'the working memory stores and reproduces the cultural capital of a society that is continuously recycled and re-affirmed' (ibid.), which can only foster collective identity.

A. Assmann distinguishes three core areas of working cultural memory: religion, art, and history. This makes her speak of two separate functions of cultural memory:

the presentation of a narrow selection of sacred texts, artistic masterpieces, or historic key events in a timeless framework; and the storing of documents and artifacts of the past that do not at all meet these standards but are nevertheless deemed interesting or important enough to not let them vanish on the highway to total oblivion. (A. Assmann 2008: 101)

Next to the canon, the other dimension of cultural memory is the archive, or the cultural reference memory of a society. The role of the archive is to provide 'a kind of counterbalance against the necessarily reductive and restrictive drive of the working memory' (A. Assmann 2008: 106). In that sense, the archive can be regarded as 'a second-order memory that preserves what has been forgotten', and compared to a "lost-and-found office" for what is no longer needed or 
immediately understood' (ibid.). Yet, this does not mean that the archive cannot be selective. It may well be not all-inclusive, but it anyway has its 'own structural mechanisms of exclusion in terms of class, race, and gender' (ibid.).

To mention yet another typology of memory kinds, J. Olick's proposal includes the following two:

- collected memory: this kind of memory is a cultural phenomenon and includes all the knowledge and experience that people owe to their being participant members of a society or to their experiencing history;

- collective memory: This kind of memory includes symbols, carriers, institutions, social practices - all past-oriented and functioning as possible metaphors of memory.

As Olick admits, collected memory is 'the aggregation of socially framed individual memories', while collective memory involves 'collective phenomena sui generis' (Olick 2007: 333) that are understood to be a shared value of the whole group (cf. Saryusz-Wolska 2009: 35). It seems that Olick's classification corresponds rather closely to J. Assmann's proposal, with collected memory and collective memory being Olick's counterparts for, respectively, J. Assmann's communicative memory and cultural memory.

A psychologically- and individually-oriented conception of memory comes from David Manier and William Hirst (2008). As they themselves admit, they 'want to build a taxonomy based on the work by cognitive psychologists on individual memory systems' (ibid., p. 254). This lets them deny that collective memories should be merely aggregates of individual memories, and that principles of collective memories could be reduced to principles of individual memories. On the other hand, however, the principles of individual memory can in some ways limit the functioning of collective memory. As they argue,

if individuals are the ones who do the actual remembering, then how a group remembers and what the group remembers will be shaped, at least in part, by the nature of individual memory. (ibid., p. 254)

Their taxonomy includes, then,

- collective episodic memory: This is shared memories of a community's experience. The authors give the following example: 'when a group of friends go to a World Cup match and see their national team play beautifully, they may form a collective memory of the game that they will share with each other for years to come' (ibid., p. 257). In other words, each of the friends will relate the same event to the same spatial-temporal context, i.e. sitting in the stadium and watching the game, which will be the basis of their memories. Moreover, 
as the argument goes, 'the memory of the experience will not only be shared, but it will also contribute to their identity as a group of friends' (ibid.).

- collective semantic memory: This embraces what people remember from/ about the past without necessarily remembering where they learned it. As an example, Manier and Hirst give the authors' memories of the Vietnam War: 'Although we were not in Vietnam during the war, we did learn about it from the media, friends, books, teachers, and other sources while it was happening' (ibid., pp. 257-258). So, this kind of memory is not episodic because it typically lacks reference to any particular day or place in people's lives.

- collective Procedural or Implicit Memory: This kind of memory is meant to relate to community traditions, practices, and rituals. Although Manier and Hirst realise that rituals are not anything to be remembered in the first place, they give this convincing example: 'some Roman Catholic parishioners may follow the procedure of the Mass without any explicit memory of what each movement symbolizes or where they learned the ritual' (ibid., pp. 258-259). In other words, they remember the procedures (how to celebrate) of the Mass without having to remember the facts about the Mass, as, for instance, that the way 'it is celebrated today has its roots in the Council of Trent, beginning in $1545^{\prime}$ (ibid., p. 259). In this way, rituals and traditions, or, in Manier and Hirst's terminology, 'procedural memories', serve as 'mnemonic tools that shape the collective identity of their practitioners, collectively reminding them of declarative memories' (ibid.). In this particular example, though a ritual in the first place, the Mass 'is intended to remind parishioners of Jesus's crucifixion' (ibid.).

By means of taking issue with J. Assmann, Manier and Hirst believe that in order to understand properly the temporal horizon of collective memory, the communicative-versus-communicative distinction is not enough, but, rather, we should consider whether memory is episodic, semantic, or procedural. In this respect,

By definition, collective episodic memories can only last a generation. Collective semantic memories can be transmitted across generations, but are still relatively fragile. Unless they are externalized, in texts or cultural artifacts, collective semantic memories will tend to decrease from one generation to the next and may eventually be completely forgotten. However, collective procedural memory is more likely to be accessible (and available) over the long term, less likely to be distorted, and more likely to be transmitted intact from one generation to the next. Collective procedural memories (such as skills at using instruments and tools) are more likely to form the basis of a community's "actual" cultural memory than are collective semantic memories. (Manier and Hirst 2008: 261) 
On this reading, a community's cultural memory and its identity are grounded in and based on collective procedural memories, rather than on any other kinds of memories.

It proves essential at this point to mention so-called countermemory and postmemory. The former notion was introduced by Foucault as counterevidence of official versions of historical continuity (Nowak 2011: 44), whereas the other term was put forward by Marianna Hirsch and is defined as 'the memory of the past that shapes one's identity on the basis of someone else's experience of the past' (Nowak 2011: 51), so in postmemory the connection to the past is mediated, yet 'not by recall, but by imagination, projection, and creation' (Hirsch 2008: 107). Specifically,

Postmemory describes the relationship that the generation after those who witnessed cultural or collective trauma bears to the experiences of those who came before, experiences that they "remember" only by means of the stories, images, and behaviors among which they grew up. (Hirsch 2008: 106)

In other words, Hirsch' postmemory has to do with inter- and trans-generational transmission of (traumatic) knowledge and experience. As she admits, it is a consequence of traumatic recall but (...) at a generational remove' (ibid.), hence its inherited and reconstructed nature.

This is how postmemory is presented by other researchers as well. Joanna Tokarska-Bakir describes postmemory as surrogate memory, or appropriated memory, or displaced memory (Tokarska-Bakir 2004: 171). Zofia Rosińska reports on Avisha and Margalit's attempts at seeing postmemory in terms of shared memory: 'Shared memory is a shared commonality, even though it is not based on shared experience. The term postmemory implies a kind of memory that is weakened, and belated' (Rosińska 2012: 120).

One specific psychologically delimited type of memory is autobiographical memory. Its function is typically described in terms of individual memory storage (Maruszewski 2005: 18). The reason why I find it important to mention it here, i.e. in the context of collective memory, is that although autobiographical memory is strictly limited to an individual's life, the individual cannot really stay separated either from the community he/she lives in or history as such. A typical expression of autobiographical memory can be found in what the folklorist would describe as recollection stories. Maruszewski mentions several distinctive features of autobiographical memory, as evidenced in this kind of text: internal organisation that consists in structuring memories by means of social interaction rules, participation of both semantic and episodic elements, correlation of the remembered material and its context (ibid., p. 20). As he concludes, 
'autobiographical memory is declarative memory that relates to one's own past' (ibid., p. 31). As it may embrace semantic data as much as episodic information, 'the former involve one's individual life facts, and the latter sequences of events in which an individual took part either as an actor, or as an observer' (ibid., p. 32).

As to the forms that autobiographical memory can be given, it primarily finds its expression in narration, yet it can also manifest itself in facts, such as the information on first names and surnames, or on personal traits identified with one's past life (ibid.). This makes recollection stories just one of the constituents of autobiographical memory, its specific subtype. Apart from them, autobiographical memory can be encoded in pictures, oral expressions, and abstractions, with several different functions to be performed: informative, communicative ${ }^{4}$, interpersonal, motivational/emotive, and organisational (ibid., p. 78). To quote Maruszewski's generalization, 'to some extent, autobiographical memory is composed of cognitive schemata that in their nature are generalised, or abstracted' (ibid., p. 88).

\section{Collective memory: functions}

As signalled already in the previous sections, one of the major topics in collective memory research has been its functions. On the whole, the functionality of collective memory seems to embrace ten basic tasks:

- cognitive function: Paraphrasing L. Wittgenstein's thesis that the limits of my language mean the limits of my world, Golka offers a similar statement in reference to memory: 'The limits of our memory mean the limits of our history, or at least of our awareness of history' (Golka 2009: 7). This brings us to the cognitive function of memory. Like language, 'memory communicates information about both an individual and a social group' (ibid., p. 17). In practice, then, memory serves the purpose of ordering the world of an individual and of his/her community (Biskupska 2011: 25). Marek Ziółkowski distinguishes two specific subtypes of this function:

- cognitive-idiographic function: memory serves as a tool of learning the past, and

4 Maruszewski makes an interesting attempt at distinguishing the informative and the communicative functions of autobiographical memory. As he sees the difference, the former includes those aspects of individual past history that facilitate the on-going relations of an individual with the surrounding community, whereas the latter serves to communicate one's individual experiences to others (Maruszewski 2005: 78-81). 
- cognitive-reflexive function: memory facilitates reflection of the past and of its conditioning factors (Ziółkowski, after Ciołkiewicz 2012: 25).

- subjective function: As Prejs argues,

Memory seems to be an eternal and invariable trait of homo sapiens. What appears most significant in an existential perspective is not what has been written, printed, videoed or recorded on $\mathrm{CD}$, but what we carry in our selves. It is the latter that shapes our subjectivity and gives sense to our lives, the former being merely a communicative record of our being. (Prejs 2009: 11)

- identificational function: Most of the memory researchers find it important to emphasise correspondences between collective/social/cultural memory and collective identity. In this context, memory is said:

- to bring unrelated past events together into a more or less coherent whole;

- to remind the group of their significant values;

- to facilitate the friend-foe identification (Golka 2009: 53)

- to give a sense of transgenerational continuity, of shared destiny, identity and responsibility for the past and the future (Golka 2009: 8).

Indeed, it is also Szacka who presents the functionality of social memory in terms of its role in collaborating collective identity, this identity being based on shared awareness of the common origin, destiny, ancestors, and symbols (Biskupska 2011: 24). In short, 'the past is one of the mechanisms of self-identification' (Dziekanowska 2012: 27).

- self-presentational function (Pol. funkcja autoprezentacyjna): No matter whether memory functions in its individual or collective dimensions, it contributes to generating public images (cf. Leary 1996).

- socio-cultural function: Memory brings us into social structures and cultural scripts. This has to do with the supposition that, in Jurgen Straub's words, 'even the presumably most intimate and personal things are constituents of social and cultural memory' (Straub 2008: 226). What our memory provides us with is not any objective reality or a mirror reflection of the natural world. As Straub continues, "[memory] encodes and stores things which have already been perceived and received beforehand in the light of available representational modi (terms and concepts, schemata and scripts) as well as symbolic forms" (ibid.). Indeed, memory needs its representation, but these modi, be it on the level of decoding or rendition, are, again, social and cultural constructs. J. Straub makes his point very clear:

To visualize the past and history, one employs images and a language which is never completely one's own. (...) Without [culturally-driven] symbolic forms and means one 
would search in vain for a specifically human memory. Without them, all those memories and narratives which help us vividly visualize and communicate the past and history of humankind, or even of one single individual, would disappear. (Straub 2008: 227)

- communicative function: Memory facilitates intercultural communication as it transmits patterns of behaviour that prove to be important for a group's being and values (Golka 2009: 17). This function corresponds partly to Ziółkowski’s emotional-evaluative function, which is meant to grasp the aspect of memory that allows for making assessments of the past and the present (Ziółkowski, after Ciołkiewicz 2012: 25). In Rosińska’s words, memory 'makes us coherent in our selves, which means that it is identification-formative, yet, at the same time, it leads us away from our selves towards another man, towards culture' (Rosińska 2012: 115).

- legitimizing function: What this function grasps is that memory is a way of legitimising power and authority (Golka 2009: 17), or that collective memory is not only an achievement of power, but also its instrument and objective (le Goff 1996: 155). In Ziółkowski’s taxonomy, this would be an instrumentallegitimizing function, by which Ziółkowski understands that memory constitutes the basis for making claims with regard to a given social order (Ziółkowski, after Ciołkiewicz 2012: 25).

- consolidation function: Golka verbalises this function as straightforwardly as this: 'That social memory thrives is simply a manifestation of that a group and its culture do thrive as well' (Golka 2009: 7).

- group-forming (structuring) function: As collective memory creates a social order, it happens to be both a cause and an effect of group-formation processes - if robust, it triggers the process of forming newer and newer social groups. This, naturally, includes the information on the genesis and the structure of these groups (cf. Golka 2009: 8, 17).

- text-forming function: This is not a function that could be typically found in memory research, yet I find it absolutely necessary to distinguish it. Be it individual or collective, memory constructs texts by structuring narration, or adjusting a story to a group's accepted pattern of text format and cultural script. 


\section{Cultural heritage - memory - texts of culture}

\section{Memory as a carrier $v s$. memory carriers: preliminary remarks}

First of all, let us clarify the very ' memory as a carrier. This, indeed, needs explaining because the term that seems to be used most frequently is memory carriers, and not memory as a carrier. What the researchers mean by memory carriers are those cultural artefacts (means and media) by which and through which memory happens to be transmitted, such as writing, photographs, various objects (cf. Kula 2002, Golka 2009: 30). In Wielki stownik języka polskiego, the lexeme carrier (Pol. nośnik) is given four definitions:

(1) a means of transportation;

(2) something that serves to transmit and disseminate information (cf. a similar definition in Stownik jezyka polskiego PWN: 'something that expresses and propagates [emphasis added, M.W.] significant contents and values [emphasis added, M.W.] that are vital for and characteristic of something else');

(3) material that can be used, or has already been used, for recording sounds, pictures, and data of other kinds;

(4) something that can provide certain substances or facilitate their movement or flow ('something on which or in which objects can be transmitted or transferred; also: something on which something else can deposit' [Pol. coś się osadza, empahsis added, M.W.]).

In the light of these 4 meanings, it is definitions 2 and 4 that justify the claim that memory can be presented as a carrier of cultural heritage. What I mean, then, is not the meaning of carrier as in memory carriers, that is a carrier in the sense of a data storage device, or a physical artefact, that is used to store, transport, and transmit information, such as memories. On my reading here, a carrier is a phenomenon, a value that serves the purposes of accumulating, depositing, and propagating some other phenomena or values. As a carrier, memory expresses and disseminates those values that are typical, characteristic, or distinctive of/ for a given social group. It is in memory that values find their place, and it is by memory that values are handed down from generation to generation. More about this will be discussed in what follows below. 


\section{UNESCO's Convention for the Safeguarding of the Intangible Cultural Heritage: definition and scope}

According to Article 2 Paragraph 1 of UNESCO's 'Convention for the Safeguarding of the Intangible Cultural Heritage', of 17 October 2003,

The "intangible cultural heritage" means the practices, representations, expressions, knowledge, skills - as well as the instruments, objects, artefacts and cultural spaces associated therewith - that communities, groups and, in some cases, individuals recogniSe as part of their cultural heritage. This intangible cultural heritage, transmitted from generation to generation, is constantly recreated by communities and groups in response to their environment, their interaction with nature and their history, and provides them with a sense of identity and continuity, thus promoting respect for cultural diversity and human creativity.

If seen in the light of Jerzy Szacki's insight on tradition, UNESCO's notion of the $\mathrm{ICH}$, as defined above, can, in fact, be given 3 dimensions ${ }^{5}$ :

(1) processual dimension: the object of the intangible cultural heritage is a process of transmitting, from generation to generation, specific goods of a given group that are mostly spiritual in nature;

(2) objective dimension: a researcher's attention is shifted from how these goods are transmitted to what goods are transmitted, or to what it is that is being transmitted; in terms of the Convention, the intangible cultural heritage which embraces practices, images, messages, knowledge and skills as well their corresponding instruments of transmission (objects, artefacts, and cultural spaces);

(3) subjective dimension: still, what comes to the fore is not the transmission process or an object being transmitted, but a generation's attitude to the past (i.e. what groups, communities, and - in some cases - individuals consider to constitute their own cultural heritage) and their acceptance or rejection of that past as part of their heritage (cf. Szacki 1971: 98).

As marked already in Footnote 1, these three dimensions have been recognised by Szacki in his attempts at defining the phenomenon of tradition. Yet, mnemonically, Szacki would also call them, respectively, social transmission (1), cultural heritage (2), and tradition (3), as if they were not different dimensions of the same phenomenon, but different phenomena themselves. If we still insist on matching Szacki's proposal with UNESCO's Convention, we need to notice that

5 Indeed, these three dimensions are delimited by Jerzy Szacki in his approach to tradition (1971). 
UNESCO's concept of the intangible cultural heritage does, in fact, embrace all three (i.e. transmission, heritage, and tradition). Therefore, this is how I intend to understand the scope of the intangible cultural heritage, as a unity of the three categories distinguished by Szacki. ${ }^{6}$

\section{Cultural heritage as a building material of memory}

Let us focus on the relation between intangible cultural heritage and memory, and assume that it is the former that builds the latter. In the first quote from

6 What also seems worth mentioning is the relation between tradition and memory. According to J. Assmann, cultural memory can in some parts be described as tradition or message, "but this leaves out the aspect of reception, the bridging of the gap, and also the negative factors of oblivion and suppression. (...) These are the elements that characterize cultural memory and take it far beyond the reaches of tradition' (J. Assmann 2011: 20). For that reason, he questions Halbwachs's memory-tradition distinction: 'Halbwachs distinguishes between memory and tradition in a manner similar to our own distinction between biographical and foundational, or communicative and cultural memory' (J. Assmann 2011: 48). To mention yet another researcher, Golka believes that tradition has much to do with the continuity of behavioural patterns. If so, 'social memory is close to tradition, and, in some sense, it can even be a derivative of tradition because it involves the elements of the past that are conventionalised and recreated. On the other hand, it can also be said that tradition is a derivative of memory because tradition is continued to a large extent due to memory. Yet, tradition embraces such elements as habits and behaviours, and these two, because of their automatic and unreflexive nature, cannot be said to be part of social memory. This means that these two concepts criss-cross each other semantically in a significant, though not a straightforward, way' (Golka 2009: 36). Here are some of the analogies that Golka finds between tradition and social memory: both have a consensus status in time, which involves understanding and agreement; neither continuity of time nor continuity of society is possible without either of the two; both are marked with the past, yet the past does not have a bearing on their content, but it simply witnesses it; people are subject (if not subjected) to tradition as much as they are manipulated with/by social memory; although tradition and memory stem from the past, they are unique, never-exhausted life resources of a group; both can function in a secret or tacit way, imposing social behaviors out of their hiding; both can be justified by/in actual past events, but they can also be borrowed from other social groups or crop up as imagined and implanted; both witness to a constant 'self-regulating [Pol. homeostatyczny] process of remembering and transforming', indispensable for a group's existence; interpreting both is multidimensional and dynamic; within the bounds of the same groups, slightly divergent traditions and forms of social memory can coexist; both are inherent components of a social group's culture, and, thus, prove to serve as mechanisms of a group's symbolic communication; they cannot exist without each other (Golka 2009: 36-37). 
UNESCO's "Convention" (see above), the two are presented in terms of a building metaphor: heritage is a material of memory, while memory is a product of heritage. This metaphor implies a question of the builder/creator, the agent/ subject of the building process. If the heritage is what collective memory is built of, the subject is a social group that is actually erecting - out of the elements of cultural heritage - their identity and memory.

In short, then, memory is constructed of heritage. Heritage is a material, and memory is a statute, or - to put the same in different words - heritage is an inherent component of the memory-container.

However, if we assume that heritage and memory are related to each other, as advanced above, this poses a question that seems to be especially pending in the light of how UNESCO's "Convention" defines the intangible cultural heritage ('the practices, representations, expressions, knowledge, skills - as well as the instruments, objects, artefacts and cultural spaces associated therewith that communities, groups and, in some cases, individuals recognise as part of their cultural heritage'): how can we possibly determine whether or not a group recognises a given phenomenon as part of their own cultural heritage, if what is meant by the term heritage is an object of academic pursuit, and not any everyday (common, vernacular) picture of the world? In other words, how can we arrive at a set of 'practices, representations, expressions, knowledge, skills' and be sure that we have actually arrived at a group's cultural heritage?

\section{Memory as a carrier of cultural heritage}

The answer to the questions above seems to do with a novel reading of memoryheritage relations. Namely, memory may well be a container, but it is not so much composed/build of cultural heritage elements as it stores the elements that a group considers to be absolutely essential for their heritage. As J. Assmann observes, 'collective memory looks at the group from inside - and is at pains to present it with an image of its past in which it can recognise itself at every stage and so exclude any major changes' (J. Assmann 2011: 28). If, indeed, 'collective memory looks at the group from inside, that includes the group's heritage as well. In other words, as seen through the lenses of the group's memory, cultural heritage presents itself as the group's internal and subjective projection, that is, without its having to be imposed or inflicted on the group by external subjects (institutions, authorities, researchers).

In this way, memory proves to be a key to a subjective reading of cultural heritage. Whatever can be found in a group's collective memory, i.e. what is being derived from their memory and what is being transmitted, witnesses 
to the identification function of heritage - the group decides what it is that constitutes its cultural heritage, and in doing so, the group projects its identity. As Szacka would say, memory consists in extracting knowledge (on cultural heritage, one could add) and in using that knowledge (as stated in UNESCO's "Convention") (cf. Szacka 2006: 31). One should remember, however, that 'collective memory changes proportionately to the changes in a group's system of values' (Nora, after Szpociński 2006: 28). What ultimately comes to be regarded as cultural heritage must be intriguing and thought provoking. Collective memory 'constitutes one of the basic constituents of a social group's identification and it legitimises value orders recognised by the group's members' (Szpociński 2006: 28).

Further on, our discussion of the memory-heritage relation would be incomplete if we did not mention the problem of transmission, or, as Szacki calls it, the processual dimension of cultural heritage:

What comes to be remembered and preserved in oral communities is only that which has been experienced by the community and has a direct bearing on its present situation. For this reason, preliterate societies have no history. What takes place in them instead is a never-ending "self-regulating [Pol. homeostatyczny] process of remembering and transforming", which makes that survive only what is actually and currently needed. (Szacki 1971: 108)

In other words, what is being transmitted, remembered or, generally, can be derived from memory, all qualifies to be regarded as cultural heritage. However, orality should not be understood narrowly as a mere way of transmission, but should be given a much wider meaning, that is, of a way of inter- and intracultural communication as well as a way of categorising and perceiving the world. Let us notice that it is still the case in modern societies that whatever is considered most important, what is passed on from generation to generation, and what appears relatively stable, are all transmitted orally. It seems that orality is indeed the only way of communicating a group's intangible cultural heritage as encoded in collective memory. Yet, we are living in communicative noise, and are being attacked with media-generated information of the oral, written, and pictorial kind. In this communicative melting pot, cultural heritage is actually losing its one-dimensional aspect of transmission, which so far has been orality:

The multiplicity of transmitted messages results in situations where these messages prove to be contradictory to one another. This makes one have to choose from among available messages, yet their reliability is far from obvious. As the amount of cultural tradition is increasing, the picture of the past is no longer coherent, with an individual becoming a kind of palimpsest composed of layers of beliefs and attitudes deriving from different periods of historical time. The same can be said of a society as a whole, 
because each of its social groups is exceptionally vulnerable to systems of ideas projecting from different stages of a nation's history. Needless to say, for an individual as much as for social groups a given society is built of, the past may mean many divergent things. (...) This situation fosters scepticism with regard to social heritage as such. (Szacki 1971: 109-110)

It seems that having considered the nature of transmission and selected types of society, we have to go back now to the subjective dimension of cultural heritage, which is the question of how a group relates to its heritage. And this has to do with language, or metalanguage, a significant part of cultural heritage on the one hand, and, on the other, a means of communicating this heritage. How a group relates to its heritage will, then, in the first place come with an analysis of the modality the whole cultural heritage discourse is phrased in.

In literate societies, the palimpsest nature of both an individual and a social group is one of the challenges of how an intangible cultural heritage can be documented, examined, and safeguarded. Let us not forget that there are as many memories as there are social groups, each group storing and transmitting its memory from generation to generation in a specific way.

The third aspect of the intangible cultural heritage, as defined by UNESCO's "Convention", can be identified with Szacki's objective dimension. Article 2 Paragraph 2 enumerates several different categories of objects, called "domains", in which the intangible cultural heritage can be manifested:

(a) oral traditions and expressions, including language as a vehicle of the intangible cultural heritage;

(b) performing arts;

(c) social practices, rituals and festive events;

(d) knowledge and practices concerning nature and the universe;

(e) traditional craftsmanship.

Still, one should remember that what makes heritage durable is its being prone to change. In order to guarantee this (changeability) effect, memory stores what is actual, or on-going. "Every cultural fact endures through time only as far as it keeps on changing. Transmission consists, in fact, in transformation [Pol. metamorfoza]' (Szacki 1971: 118). Cultural heritage is not, then, anything permanent and unchangeable. If so, which of its forms should be singled out to be documented and safeguarded? The most original one? The one that is remembered or restored from memory, but already updated?

This all makes me claim that memory is, first, a carrier and, second, a storage container of cultural heritage, and, third, that there is hardly any other way of exploring memory resources than by examining texts of culture. 


\section{Text of culture as a manifestation of cultural heritage}

\subsection{Text of culture: what is it?}

The term text of culture [Pol. tekst kultury] has recently attracted considerable academic attention. It can be found not only in the works of semioticians, linguists, or, especially, of text and culture specialists, but also in formal and general education-related documents, such as the latest 'Core Curriculum for the Polish Language' [Pol. Podstawa programowa dla języka polskiego], for which see Jerzy Bartmiński and Stanisława Niebrzegowska-Bartmińska (2009: 72)7.

The very concept of a text of culture can be traced back to the Tartu-Moscow Semiotic School (Władimir Toporow, Jurij Łotman, Borys Uspienski). Stefan Źółkiewski is believed to have transplanted the idea into Polish in his 1988 work (Źółkiewski 1988). In recent years, the concept has been subject to two specialised lexicographic definitions (J. Sławiński’s Słownik terminów literackich and E. Szczęsna’s Słownik pojęć i tekstów kultury), several conferences and their published proceedings (e.g., Mazur and Rzeszutko-Iwan (eds.) 2006 and Nowożenowa (ed.) 2011). In these and other publications, many different objects are meant by texts of culture, such as an anthropological photograph, a film, dictionaries of so-called spatio-visual languages, pieces of hip-hop music, a student's oral examination performance, a musical, the body, the cognitive definition ${ }^{8}$, historical sources ${ }^{9}$, etc.

Interestingly enough, neither Mazur and Rzeszutko-Iwan (eds.), 2006, nor Nowożenowa (ed.), 2011, the two conference volumes mentioned above, offer any formally attempted definition of the term text of culture. So, on one hand, while the term, and its notion, seems to be prolific and analytically capacious, as evidenced with a relatively great number of phenomena examined under this rubric, on the other hand, there seems to be a basic difficulty, the probable cause being its popularity and universality, of defining its scope and delimiting its methodological procedures.

7 Cf. Gorczyca (ed.) 2010.

8 I refer here to Bartmiński's paper Definicja kognitywna jako tekst kultury (Eng. 'The cognitive definition as a text of culture') delivered at the conference „Językowy obraz świata czy językowe obrazy światów? Wokół koncepcji JOS w rozumieniu lubelskiej szkoły etnolingwistycznej" (Eng. 'The linguistic picture of the world [JOS], or the linguistic pictures of the worlds. On the JOS concept in the Lublin Ethnolinguistic School'), Maria Curie-Skłodowska University, 17-18 October 2011. Cf. Bartmiński 2013.

9 Cf. Źródło historyczne jako tekst kultury (Eng. 'An historical source as a text of culture'), edited by Bożena Płonka-Syroka and Mateusz Dąsal, Warszawa, 2014. 


\subsection{Text of culture: a survey of definitions}

Even a cursory survey of what a text of culture is taken to stand for shows that the term has been given a very wide application. In specific, it may mean the following:

- a human semiotic product; in this sense, texts of culture involve not only verbal expressions, but also nonverbal works of art, working tools and other similar artefacts, religious and non-religious rituals, 'lifestyles', 'important attitudes and behaviours' (Żyłko 2009: 94);

- a (finite and autonomous) code structure implementing one or more sign systems characteristic of and functioning in a given culture (Żółkiewski 1988: 23);

- cultural phenomenon understood as a realization of a cultural model of the world in which rules, principles and worldviews, as characteristic of a given culture, are focused and reflected (Źółkiewski 1988: 65 ff.); according to Lew Wygotski, a text of a work of art should be understood as a behaviour program that imposes a certain model of the world in which this program is meant to be implemented; similarly, Jurij Łotman believes that text is a program from the addresser's perspective and a culture from the addressee's perspective;

- a model of 'the represented world' in a specific relation to extra-textual reality; this is a 'reduced model', to use Claude Lévi-Strauss' term, as it reflects reality, no matter how it is actually understood, in its own peculiar ways, profiles several things at one and the same time (the world as a whole, the author's personality, the author's worldview), and projects its audience (this element of a text could be called, after Charles Morris, 'semantic aspect' (Żyłko 2009: 145));

- a product of culture, or a phenomenon that is given a high sense of understanding and is ranked together with such superordinate categories as time, space, and matter (cf. Tołstaja 2007: 29);

- a product of human cultural activity in the sense of 'texts of substantial importance, or at least of some cultural value' (Bartmiński and NiebrzegowskaBartmińska 2009: 72);

- the collective (common) good that is stored, transmitted and enriched by subsequent generations (Szczęsna (ed.), 2002: 307); this corresponds to Jurij Łotman and Borys Uspienski's definition of culture as the community's memory that finds its expression in a specific system of signs (Łotman and Uspienski 1977: 150); if so, culture is both a set of texts, as well as a mechanism projecting this set of texts, whereas texts themselves are products of culture (Lotman and Uspienski 1977: 156);

- a carrier of ideas; a text of culture "has the capacity to influence imagination and emotions, and has been recognised by the community as important, 'iconic'” (Bartmiński and Niebrzegowska-Bartmińska 2009: 72); 
- a research tool (Gomóła and Rygielska 2014), with attempts at reading a given text of culture being the starting point for examining any cultural phenomena (Żółkiewski 1988).

\subsection{Text of culture as a structure}

What all the definitions presented in the preceding section share is some structural slant that presents a text of culture in static terms of a cultural product. In other words, a text of culture is 'a ready-made outcome/effect whose constituent elements are ascribed to specific communicative functions' (Duszak 1998: 18). On this reading, a text of culture can be given the following attributes:

- it can be subjected to a holistic semantic interpretation;

- it is structurally coherent;

- it is semantically cohesive;

- it has "a spatial dimension (i.e. it can be placed in 'real' space, this being a characteristic of most of the messages that constitute human cultural heritage, whereas space has a textual dimension, i.e. space can be perceived as a message, or what is being communicated)" (Tołstaja 2007: 29);

- it is composed according to a set of well-defined structuring rules and principles, such as spatial oppositions ${ }^{10}$, a numerical concept (i.e. how numbers are represented in language), a temporal sequence of events etc. (cf. Niebrzegowska-Bartmińska 2007);

- it has a clear-cut user-aimed textual frame, such as a picture frame, a cemetery enclosure, a church enclosure wall, opening and closing phrases in a magic tale etc.; this is how Lotman puts it:

Being spatially limited, a work of art is a model of an infinite universe. The frame of a painting, the footlights in theatre, the beginning and end of a literary or musical work, the surfaces which mark the borders between a sculpture or an architectural edifice and the space artistically excluded from it - all these are various forms of a law that applies to all art: a work of art is a finite model of an infinite universe. (Łotman 1977: 210)

Indeed, the frame of a text of culture, similarly to the frame of an oral text, constitutes an integral part of the whole text, and it identifies the genre/type of the text. For example, the expressions Żył król i miat trzech synów 'there lived a king and he had three sons' and $\dot{Z} y l i, \dot{z} y l i, \dot{z} y l i$ a $\dot{z}$ pomarli $i$ pognili 'they lived on and on till they died and liquified' function as the signal of, respectively, the

10 Cf. Wójcicka 2013b. 
beginning and the end of the text itself as well as the signal for the addressee as to how the represented world is actually structured in the text ${ }^{11}$ (cf. Wójcicka 2010). The frame is often constructed of the same fabric as the text itself and likewise is addressed by its author/addresser ${ }^{12}$;

- it can be composed of/in many codes, such as verbal code and some nonverbal code (somatic, iconic, musical);

- it most often is construed in terms of space, as a finite/bounded entity, for example an enclosed graveyard/cemetery (Kolbuszewski 1995: 17-40).

Finally, let us notice that as long as we examine a text of culture in structural terms, we follow a synchronic approach and take the text to be a static and finite product, that is a reflection of a group's culture at given point in time.

\subsection{Text of culture as a process}

Nevertheless, a text of culture can be approached in terms of functional and communicative parameters as well, which is as a dynamic and cultural process that contains stable and reiterated elements next to those that the subsequent generations modernise proportionately to the changing historical, economical, political and cultural conditions. This approach owes much to Teun Adrianus van Dijk who considers the text to be a holistic communicative event (Duszak 1998: 173), a result of specifically human activity (Duszak 1998: 31). On this reading, a text of culture could be defined as culture users' socio-cultural activities which the users employ for communication purposes within the bounds of a given society and culture. As van Dijk (2001b: 23) argues, text is not just a product, but is a process that takes place in a dynamic way and is monitored by the communication act participants.

To give an example, what counts to be an object of research scrutiny from a functional perspective now is not merely a wayside shrine, but human activities related to the shrine. The shrine will still be one of the elements of the

11 Similar functions can be identified in the cross of the cemetery gate - see for example the Grudziądz cemetery gate at http://pl.wikipedia.org/w/ index.php?title=Plik:Grudzi\%C4\%85dz,_Brama_cmentarna.jpg\&filetimest $a m p=20070924222745$ (accessed 12 November 2011).

12 The title of a poetic work 'is constructed of the same material (i.e. signs of the same kind) as the work itself is. Moreover, communicated by the author, the title is, naturally, part of the work' (Wallis 1974: 26). Great masters of the Renaissance, such as Micheangelo, to give one example, were very particular about the frames they used and they very often designed them themselves. 
communication act, but only one of many signs used in the communication process (apart from songs, gestures and other nonverbal acts of communication). As Duszak says, what comes to the fore in functionally oriented research is the function a text of culture performs. In the case of our shrine, this function can be described in terms of delimitation, commemoration, socialisation, religion (cult-related), information, etc. (cf. Adamowski and Wójcicka (eds.) 2008). 'What text research aims at is, then, human communication activities and their linguistic, cognitive, situational, and cultural constraints' (Duszak 1998: 13). Understood this way, texts of culture would also include rituals (funerals, weddings) as well as the cemetery and the Christmas tree. They all have some processual dimension - these are messages that take part in the process of social and cultural communication.

'Text is not only a communicative phenomenon because textuality comes into being as a result of the participants' assessment' of the communication act (Duszak 1998: 13), this assessment being subject to changing moral standards and civilization- and culture-related transformations.

By means of illustration, selling and eating candy floss and sausages at the cemetery gate on All Saints' Day ${ }^{13}$ can be analysed in terms of textuality and, thus, regarded as activities that more or less satisfy the expectations of the participants of a certain type of socio-cultural communication. 'This communication is always a projection of an individual's state of the mind [a social group's awareness? M.W.], which is not to say that the act of communication is totally and exclusively personal in nature. What kind of communication act it is will, then, depend largely on what types of representations and what cultural and social patterns condition a given system of communication' (Duszak 1998: 19).

Understood as a process, a text of culture amounts to a sum effect of the choices forced by changing conditions. In this way, 'text witnesses decisions taken and is a consequence of the choices and estimations that the communication act participants must successively make proportionately to the available and constantly changing data' (Duszak 1998: 32).

In specific, as a process, a text of culture:

- is extended in time;

- is historically changeable; for example, the cemetery may be as much of a sacrum site (for funeral purposes) as of a profanum location (when some form of carnivalisation takes place);

13 See for example https://superbiz.se.pl/wiadomosci/wszystkich-swietych-swietokielbasy-z-grilla-czy-zadumy-zdjecia-aa-w1qH-Tct5-wtbc.html (accessed on 12 November 2018). 
- the frame of a text of culture is marked with the activities that, respectively, begin and terminate the text as a process;

Take the decorating of the Christmas tree as an example; at the beginning of the process the tree is topped with a $\operatorname{star}^{14}$, and at the end of it, chains are placed all around, the former reflecting from-the-most-important-to-the-less-important structure, and the latter the-inside-outside pattern. While placing the star marks the vertical direction of the process, the chains delimit the tree from the rest of the space in a horizontal dimension. At the same time 'the chains are meant to safeguard the whole space against misfortune. The reason why it is placed on the tree at all is precisely for happiness, not to run away from the household' (Smyk 2009: 166).

- the structuring principles involve, first of all, chronological arrangement, cause-and-effect relation, and sacrum-profanum opposition;

- textuality makes a text of culture dynamic, changeable, temporally- or chronotopically-determined;

In that sense, a text of culture remains open to further transformations. For example, while the cemetery may still serve funeral purposes, it may as well be acquiring new applications in novel acts of communication. The same can be seen in the city understood as a text of culture:

Saint Petersburg used to be a kind of message that Peter the Great, as the demiurge of the city, communicated to his contemporaries. The Tsar's "communicative intentions" came to be encoded in the name of the city, city arms, town layout, many characteristic buildings. As a kind of "open work" that endured and developed through time, the city could later absorb various influences, reaching the status of an important phenomenon of (not only Russian) culture. (Żyłko 2009: 159)

This all amounts to the claim that one and the same semiotic object may be

14 The top of the Christmas tree may also be called the edge/end of the Christmas tree (Pol. koniec choinki). This term „connotes (...) the attribute of 'something ending/ finishing at its top' (...). The top is the most honoured location, and this is where the most important toppers are placed, the star and the angel. This gives us an image of the Christmas tree as a triangle whose topping vertex has a culturally-motivated symbolic meaning of 'the source of light or the radiating point (...)', or of the point 'at which everything else begins' (Smyk 2009: 124). (The translator's note: naturally, placing the topper(s) at the beginning of the decoration process is culture-specific, or, at least, is a matter of taste; no surprise, then, that the actual frame may be just opposite to the one described here, as it is at https://www.bhg.com>BHG.COM > Christmas > Trees (accessed on 15 August 2018).) 
perceived as a finite structure as well as an on-going process. For example, the Lublin cemetery in Lipowa Street is both - structurally, it is closed and complete because no new graves can be added, yet processually, it is open and transforming, as it is changed and redecorated by subsequent generations of visitors and users.

- embraces many codes, such as verbal, iconic, musical, gestural ones;

This can be illustrated with various ceremonies and rituals, such as the wedding and the funeral, but also with oral texts.

The nature of a text of culture is determined by 'the actual communication act's participants' dynamic and subjective assessment. While the conception of text as a product invites a search of text generating mechanisms, the conception of text as a process highlights the complexity and mutual dependence of the communication act integration factors' (Duszak 1998: 29).

In the light of the characteristics presented above, especially dynamicity and changeability in time, it is only natural to conclude that the prevailing temporal perspective for researching a text of culture as a process is diachronic analysis.

By means of confronting the two conceptions of a text of culture discussed so far, it must be said that both appear complementary to each other: 'an act of communication has a processual as well as a resultative dimensions, is dynamic as well as static' (Bartmiński and Niebrzegowska-Bartmińska 2009: 34), as evidenced above with the oral text, the Christmas tree, the cemetery, ceremonies, or rituals.

\subsection{Linguistic (oral) text as a prototypical text of culture ${ }^{15}$}

It may be clear now that the two conceptions of a text of culture (see Sections 5.3 and 5.4 above), especially attempts at reconstructing its characteristic attributes, owe much to, if not simply project from, a general definition of a linguistic (verbal) text. If so, one could argue for the prototype theory ${ }^{16}$ now and claim that the linguistic text, especially in its oral format, constitutes a prototypical exemplar of a text of culture. Indeed, oral texts can easily be defined in terms of both

15 I thereby wish to thank Professor Jerzy Bartmiński for his inspiring talks that resulted in this part of the monograph.

16 "There are two ways in which to understand the term "prototype". We can apply the term to the central member, or perhaps the cluster of central members, of a category. Thus, one can refer to a particular artefact as the prototype of CUP. Alternatively, the prototype can be understood as a schematic representation of the conceptual core of the category. On this approach, we would say, not that a particular entity is the prototype, but that it instantiates the prototype' (Taylor 1995: 59; emphasis original). 
a process and a semiotic structure. Niebrzegowska-Bartmińska argues that the oral text is processual because it develops in a synchronic and linear fashion, is extensive in time because of its linguistic (mainly phonetic) nature and has an attribute of that which is happening. However, it is a product as well because it is stored in collective memory, which allows for its multiple reproductions (cf. Niebrzegowska-Bartmińska 2007: 48).

Here is the set of characteristics that Bartmiński and NiebrzegowskaBartmińska ascribe to oral texts:

- sonicity:

As a "living" fabric generated by the human body, the sound substance communicates an exceptionally high load of information. It can transmit the speaker's attitudes, hesitations, doubts, as well as various emotions: anger, anxiety, need of acceptance, complaints, threats. (Bartmiński and Niebrzegowska-Bartmińska 2009: 100)

- gesturality:

[While] speaking is a human somatic behaviour, an oral text is a constituent element of this "behaviour-text". That the speaker maintains (face-to-face) eye contact with the hearer activates the most basic gestural, kinetic code and facilitates a kind of "theatrealisation" of communication. Behavioural (somatic, gestural) elements collaborate with words in order to create a holistic (syncretic) oral message. (Bartmiński and Niebrzegowska-Bartmińska 2009: 101)

An oral text not only consists of a linguistic code, but also involves body language (facial expressions, gesticulation, body postures).

- situatedness: this includes such basic parameters of an oral act of communication as 'I', 'here', and 'now'.

The relevant environment of an oral text embraces the physical dimension (time and place, a tool of communication, accompanying activities, participants), the social dimension (interpersonal relations, participants' age, social and regional background, profession, education), the descriptive dimension (autobiography, home, work, education, entertainment, culture, services, ideology), the speech act structure (pragmatic function, degree of intentionality, formality, or intimacy) (Bartmiński and Niebrzegowska-Bartmińska 2009: 102) ${ }^{17}$, the psychological dimension (the addresser's attitude to what is being communicated), and the existential dimension (the role of the text in the overall activity) (ibid.). Of these, Hall (2009) would emphasize the place of an act of speech and the interpersonal relations (between the interlocutors; proxemic).

17 Cf. Ożóg 2001: 93; Nieckula 2001: 102. 
- simultaneousness of speaking (coding) and hearing (decoding);

- dialogue structure (or, rather: participant-orientation) ${ }^{18}$.

Moreover, typical oral texts can be characterised in terms of sequentiality (i.e. the linear, unidirectional succession of elements), mnemonic devices, and axiological perspective determined by the community's collectively created message (Niebrzegowska-Bartmińska 2007: 41). Apart from the linguistic, kinetic, and proxemic codes, oral communication employs an iconic one as well (costumes/ garments, jewellery, accessories). The latter plays an active role in both the process of information coding and decoding.

From the argumentation so far, it seems natural to conclude that the oral format of a linguistic text occupies the central position in the whole theory of texts of culture. Indeed, this can only be strengthened with a further observation that oral texts make use of the maximal number of signs and codes of both verbal and nonverbal nature, which makes them communicatively most complex. The inspiration behind this language-cantered understanding of a text of culture can most directly be traced back to the Tartu-Moscow Semiotic School:

The centre of culture is natural language. (...) [It is language] that provides the primary modelling system embracing a certain global and "common sense" picture of the world. That the role language plays makes it privileged has to do with the fact that language is the most advanced of all the semiotic systems ("system of systems") and the most universal of all means of communication. Natural (ethnic) language presents itself as a model of systemicity for the remaining systems of culture, such as mythology, religion, art., science. These all are only "secondary modelling systems", in the sense that they are built upon natural language or mimic its structure and functionality. (Żyłko 2002: 6)

Naturally, this reflects the privileged and primary position that Ferdinand de Saussure ascribed to language:

De Saussure was primarily concerned with the linguistic sign and its phonetic format (phonocentrism). (...) For him, written language was a comparable format, yet separate, secondary and dependent. (...) In other words, the relation that Saussure envisages between speech and writing corresponds to how he understands the relation between the signifying and the signified. To use Derrida's words, for Saussure writing is "a sign of signs". (Chandler 2011: 32)

It is, then, in both structural-semiotic and processual dimensions that the oral text must be recognised as prototypical, that is central, typical, and the most

18 The interactional nature of an oral text, even if the other (decoding) party remains silent, has been emphasized by Janina Labocha (1996: 56). 
salient, text of culture. If we now apply this generalisation to the examples of texts of culture quoted at the beginning of this chapter, we need to say that they are, indeed, but only as far as they more or less approximate and match the characteristics of the prototypical text of culture, which is the oral one.

\subsubsection{Texts of culture: an analogy to natural language}

As implied above, a literary, musical, theatrical work of art is compared in the TartuMoscow tradition to language, the latter falling into Saussure's langue (abstract, social, potential system) and parole (actual and individual realisation). In this sense, music is regarded as a kind of language, with musical compositions being concrete instantiations. A similar analogy is suggested between language and film:

Making a comparison between the language of the film and natural language (...), Lotman argues that a frame in the film corresponds to a word in the language, while film editing corresponds to syntax. (...) As a result of the film editing process, a single frame of relatively complex internal structure loses its autonomy and becomes a part of a bigger meaningful whole, with the sequence of the frames amounting to not the sum total of their individual meanings but meaningful entities of a higher rank. (Żyłko 2011: 38)

On the whole, analogies between texts of culture and linguistic texts (oral ones in the first place, that is) must be attempted within how texts are structured and how they function.

\subsubsection{Texts of culture as an amalgam of codes}

An oral text, to be remembered, is both a structure and a process at one and the same time. It is, then, situationally determined and, as such, it absorbs many different codes. The same combination of codes can also be found in films, theatre performances etc.

The language of film includes a specific combination of various codes, such as images, speech, music, non-linguistic noises, captions. It is these codes that organise the heterogeneous physical material [into a coherent whole]. This multiplicity of codes determines the synthetic, or polyphonic (syncretic), character of the film. (Żyłko 2011: 38)

In a similar fashion, theatre is described as 'an encyclopedia of semiotics, semiotic ensemble, harmonious whole that is composed of heterogeneous elements' (Żyłko 2011: 45). In Lotman’s words,

The uniformed text of a theatre performance consists of at least three sufficiently independent subtexts: verbal text, acting, and musical-pictorial text (as well as lighting). That on a higher level these subtexts project into a whole does not mean that the coding process follows the same pattern in all of them. (Lotman 2002: 115) 
However, natural language is here not only a model exemplar of a text of culture, but also, especially in the case of literature, theatre, and film, the substance of a text. As any other work of art, a literary work can be defined as

(...) a semantic structure that contains a certain picture of the world and a behaviour programme for the addressee. The structure has its boundaries (beginning and end), internal organisation, and is moulded of the substance that in the case of a literary work is natural language. This linguistic substance is marked with structural complexity even in its "pre-aesthetic" hypostasis. (Żyłko 2011: 11)

The multi-code characteristic of an oral text specifically and of a text of culture in general determine their reception. An oral text triggers all of the senses, basically because it is so deeply grounded in an on-going situation. For that reason, it can be labelled not only as a situational text, but also as a sensory text. Of the other kinds of texts of culture, the closest to the prototypical (linguistic) text is the theatre performance, the most distant being painting and music. 'Painting is set in space, music in time, the former activates the sense of sight, the latter the sense of hearing' (Żyłko 2011: 60).

\subsubsection{Intersemiotic translation of texts of culture into natural language: selected issues}

As said above, language and oral text constitute models and fabric of cultural texts, but they also facilitate intersemiotic translation. We find it only natural to attempt to verbalise various texts of culture (films, theatre performances, even sculptures and paintings) in natural language.

The semiotic space is, on the one hand, filled with "languages" of a relatively limited application and of simple semantics (facial expressions, gestures, omens, auguries, horoscopes, dreams etc.). This kind of "systems of signs" are easy to be translated into natural language. Equally unchallenging is to verbalise the semiotic dimension of objects such as clothes, jewelry, ornaments, wreaths [Pol. wianek], garlands etc. On the other hand, however, a text may include independent sign systems that do not project from natural language and cannot be reduced [to verbal representations], their translation into language posing considerable problems. This includes painting, sculpture, drawing, architecture, music, applied art, singing, dance, choreography. (Żyłko 2011: 25)

If we then take a linguistic (oral) text to be the prototypical text of culture, which implies that it is both a model exemplar for and substance of other kinds of cultural texts ${ }^{19}$ as well as that it creates an opportunity of intersemiotic translation,

19 This substantive role of language in the case of, for example, a painting or a photograph is performed by the titles and captions paintings/photographs may be accompanied with. 


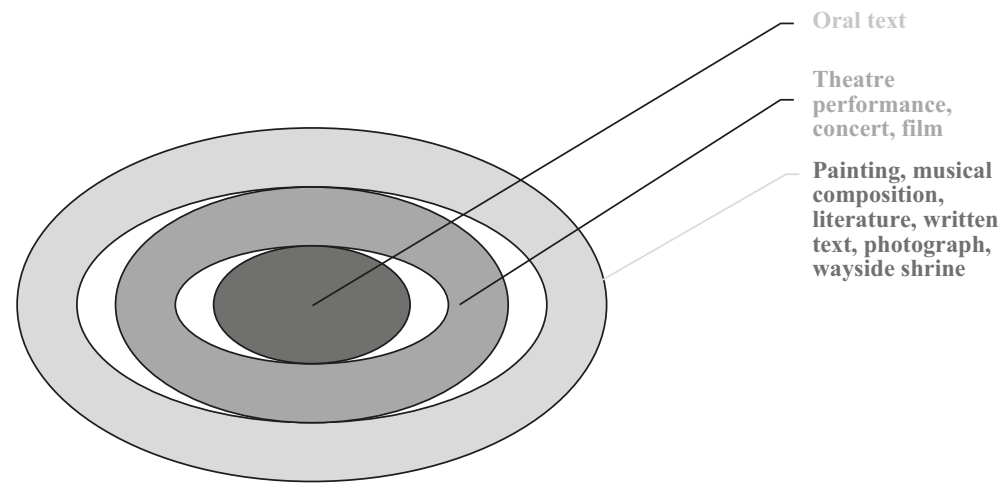

Diagram 2: Prototypical versus peripheral texts of culture (source: own representation).

there appears a question of the relation that obtains between an oral text and other kinds of texts of culture. Diagram 2 is an attempt at grasping possible correspondences between, on the one hand, the oral text as basic and prototypical and, on the other, the remaining (more or less) peripheral texts (e.g., a photograph). The major guiding criterion behind the distinctions represented in the diagram has been the multi-code and multisign dimensions of texts of culture and their resulting sensory characteristics. Simply, the kinds of texts that seem to be most akin to the (linguistic, oral) prototype can be found relatively close to the centre, whereas the periphery is occupied with those texts-products that are composed of only one code and, for that reason, happen to be decoded only with one sense, their translation into natural language representations posing smaller or bigger problems.

That the oral text is to occupy the central position in the overall text-ofculture considerations projects directly the Tartu-Moscow School inspiration. For the School members, oral texts are the clearest possible manifestations of natural language, with the latter being the absolute primary system of culture. In other words, language

(1) is an epitome of systemicity in culture,

(2) can perform the role of an organising matrix for other cultural phenomena, and

(3) can serve as a universal metalanguage for any other domain (Żyłko 2009: 109).

The reason why an oral text should be regarded as a primary means of transmission and a superior realisation of natural language has to do with the fact 
that it originated prior to other forms of culture and is now a basic way of communication.

As can be seen, what the Russian semioticians of the Tartu-Moscow School understood by language was its everyday and oral form:

An oral text not only facilitates symbolic representations of reality, each serving, in the terminology used by the School, as a secondary modelling system (...), but it also enables understanding of the texts that come into being within these representations. In this case, we can say that high culture products are "translated" into the language of everyday. (Żyłko 2009: 115)

In fact, an oral text is, then, a primary realisation of the vernacular style (Pol. styl potoczny) of natural language, and, as such, is 'the first variety of language to be acquired (...), the simplest, the most concrete, the closest' (Bartmiński 2001: 115), the centre of the stylistic system of language (ibid., p. 116), the basis for other language styles to be derived and, more specifically, 'the reference [Pol. tło] for specialised styles to function and to relate to in order to show their specific characteristics' (ibid., p. 117).

In Diagram 2, those texts that are placed closest to the oral category are most complex and bear the greatest resemblance to natural language, orality often constituting their element. Naturally, this proposal does not accord with a commonsense understanding of a text. In common-sense terms, the prototypical text of culture should be a written one. Yet, realised as their formal, academic, or artistic formats, written texts can hardly be regarded as examples of the primary system of culture, or a model and exemplar for secondary modelling systems. 'Written texts, be it formal, academic, or artistic, one way or another ultimately stem from the vernacular oral text' (ibid.).

\section{Cultural heritage - memory - texts of culture: research and analytical perspectives}

To sum up, a text of culture, its prototypical linguistic (oral) format included, is, then, a manifestation and an expression of broadly understood cultural heritage of both tangible and intangible nature. So, for example, a text that constitutes a part of the tangible cultural heritage, say, a work of architecture or a painting, can be described as a semantic structure, one-code product decoded with, basically, only the sense of sight.

Despite possible correspondences, the tangible and the intangible forms of cultural heritage differ considerably, the major difference constituting the nature of a carrier. In material texts of culture, the carrier is physically-real, space-delimited, sensory-perceivable, whereas in intangible texts, the carrier 
is immaterial, both time- and space-delimited, multi-code, and situational. No carrier of cultural heritage can exist or be handed down from generation to generation without collective memory, communicative and cultural. Deprived, or void, of memory, (tangible and intangible) cultural heritage loses its semantic motivation and becomes a mere relict, if not just an empty, meaningless artefact.

The relations postulated above, i.e. (tangible and intangible) cultural heritage vis-a-vis memory vis-a-vis texts of culture, are attempted to be represented in Diagram 3 (source: own representation).

In a nutshell, then, we arrive at the following two generalisations: the carrier of (tangible and intangible) cultural heritage is memory, whereas the carrier of memory itself is a text of culture. One could posit a question at this stage of whether or not the opposite is possible, that is whether or not a text of culture is always a carrier of collective memory, and if not, perhaps it can also create collective memory. Following the Russian semioticians rather closely, we need to conclude that even a most original text of culture is merely a carrier of memory because, as Lotman and Uspienski would argue, "culture is a society's uninherited memory that finds its manifestation in a given system of dos and don'ts" (after Żyłko 2009: 104). Cultural behaviours must, then, be learned and the whole learning process consists here in 'acquiring the previous generations' cultural heritage that has been stored in symbols and signs' (ibid., p. 102). So, even an

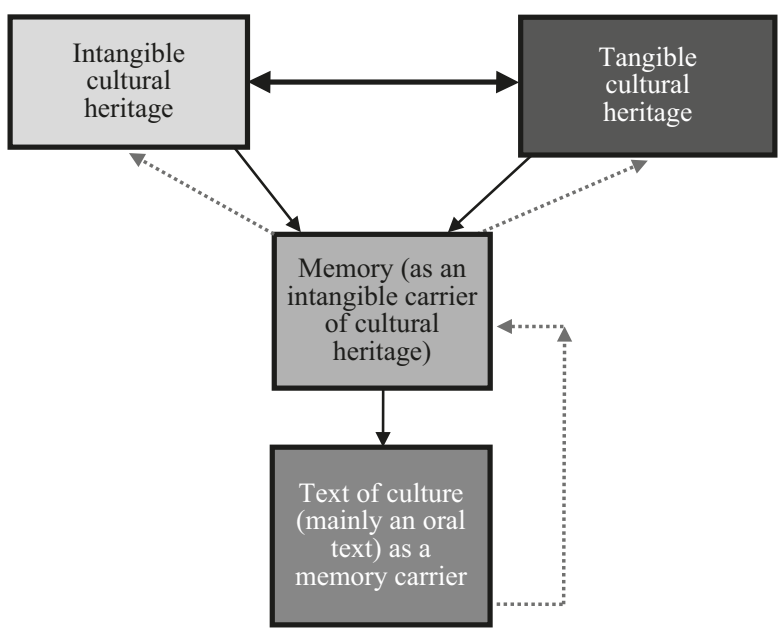

Diagram 3: (Tangible and intangible) cultural heritage vis-a-vis memory vis-a-vis texts of culture (source: own representation). 
exceptionally innovative text of culture will all the same be submerged in culture, that is, in genetically uninherited collective memory. Lotman would go further, claiming that 'any functioning of any communicative system presupposes that [the corresponding] common collective memory does exist' (ibid., p. 104) because every authorial text is necessarily based on knowing symbols and means of artistic expression that are transmitted through collective memory.

Independently from this, every text of culture is built upon collective memory, it is also a carrier of the culture it functions in. For that reason, despite its authorial and individual nature, a text of culture can surface, in parts or as a whole, in the domain of collective memory and in this way enrich the tangible or intangible (this depends on the form of realisation) cultural heritage. This process is symbolised in the diagram with dashed arrows. What is represented with the dashed lines is relations that obtain between tangible and intangible cultural heritage, which is what the preamble to UNESCO's "Convention" makes absolutely clear: 'Considering the deep-seated interdependence between the intangible cultural heritage and the tangible cultural and natural heritage (...)'. This "interdependence" can be described in terms of bidirectional relations:

- in relation to the tangible cultural heritage (henceforth: $\mathrm{TCH}$ ), the intangible cultural heritage (henceforth: $\mathrm{ICH}$ ) can serve as a metalanguage, which involves the capacity of explaining, revealing, unlocking meanings and functions of TCH elements;

- TCH can be an essential element of ICH (for example, as a prop in a theatre performance, ritual, or ceremony);

- TCH can be a physical carrier of ICH (when, for example, it recalls a description of interior designs from the remote past).

Diagram 3 shows that neither ICH nor TCH can exist without memory. Outside collective memory, they either stop being in circulation and fall into oblivion (typical of ICH), or, if they somehow linger on, they lose their semantic functions (typical of TCH).

Research possibilities behind the text - memory - cultural heritage perspective are shown in Diagram 4. To be remembered, a text is a physical carrier of memory, with memory, in turn, functioning as a carrier of the ICH. What this amounts to in research practice is that one cannot hope to arrive at cultural heritage without a prior reflection on collective memory, as much as one cannot hope to reach for collective memory without examining texts of culture.

As shown in Diagram 4, cultural heritage, be it tangible or intangible, is stored in collective memory, whose manifestation, in turn, is a text of culture, especially a linguistic text. However, there is no direct link between cultural heritage and a 


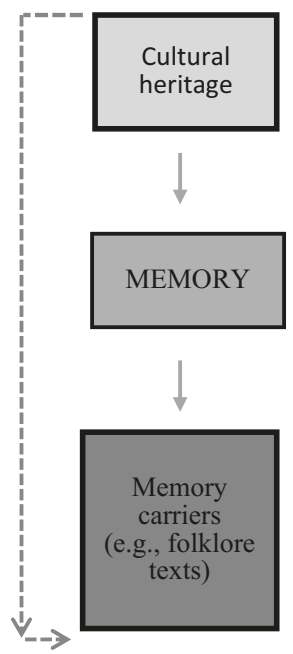

Diagram 4: Cultural heritage vis-à-vis memory vis-à-vis texts of culture relations in a research perspective (source: own representation).

text, hence a dashed line in the diagram. Theoretically, cultural heritage is stored in texts, yet the relation between the two is always facilitated by memory, and it is memory that guarantees the continuity and robustness of heritage. What is not being remembered proves simply to be unimportant for a social group and it does not have its carrier, or even if it does have a carrier, the carrier is merely a physical relict of what has already been forgotten (even if it constituted part of the basis of a group's cultural identity). Whenever names of objects do not appear transparent any more, or there is no perceived correspondence between an artefact and a system of beliefs, or there is a lack of information on how this artefact could/should be used, this all certifies to memory losses and, at the same time, cultural heritage suppression. Research on the so-called material culture (working tools, utensils, national heroes' monuments etc.), in both its regional and nation-wide dimensions, results, in fact, in examining tangible culture memory only, and should not be confused with examining culture per se. If so, the data collected in questionnaires and interviews on, for example, what an old traditional costume used to look like, or on a wooden hut's interior designs, or on eating habits of the past etc., are simply evidence of that part of collective memory that is triggered with specific physical/material objects. If not accompanied with the corresponding discourse, stories, oral recollections, they all appear to be merely scraps of memory providing very limited knowledge. To put 


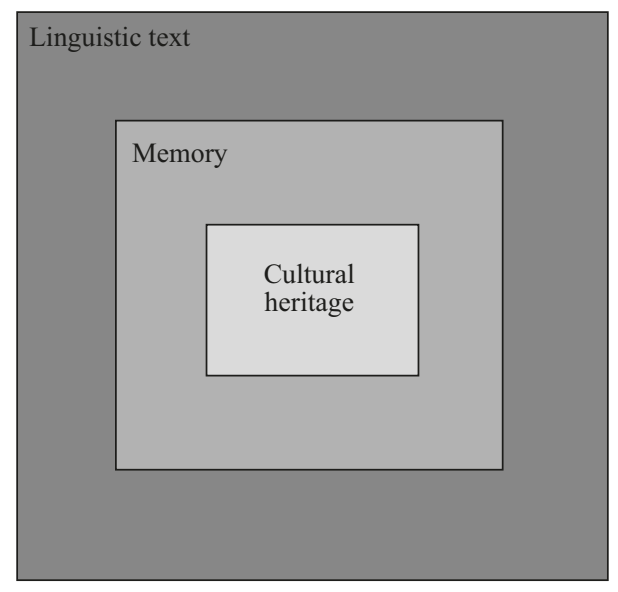

Diagram 5: Cultural heritage vis-à-vis memory vis-à-vis texts of culture relations in a metaphorical perspective (source: own representation).

it frankly, the research object in culture studies and ethnology is now the TCH memory communicated by means of oral transmission.

The object itself, as a carrier, transmits information, that is, recollections, as it is stored in collective memory and recalled in linguistic texts. The very artefact, then, serves to code and decode memory data.

Finally, it seems worth going back to the conceptual metaphors mentioned at the beginning of this chapter. Indeed, a metaphor-based approach to some of the cultural heritage vis-à-vis memory vis-à-vis texts of culture relations is represented in Diagram 5.

As visualised in Diagram 5, memory is a CONTAINER used for storing (tangible and intangible) cultural heritage. At the same time, memory is a construction material, if not just the cornerstone, of a text-BUILDING. ${ }^{20}$ The kind of texts that this schematic metaphorical representation of the heritage-memorytext relation can be exemplified with in the first place is folklore texts, as they frequently are precisely wholes built of ready-made building blocks (cf. Maćkiewicz 1999: 98).

20 I refer here to the conceptual metaphor TEXT IS BUILDING, as discussed by J. Maćkiewicz (1999) and Niebrzegowska-Bartmińska (2007: 29). See also Bartmiński and Niebrzegowska-Bartmińska (2009: 30). 

Memory in language - language-embedded 



\title{
III Memory depicted in linguistic metaphors
}

\author{
"We think of our memory in terms of metaphors \\ we just cannot otherwise"
}

(2012: 8).

As mentioned already, the nature of memory has been intriguing issue for a very long time now, with numerous approaches having been offered in philosophy, psychology, sociology, history, linguistics, or culture studies. However, the fact that memory poses basic definitional problems has not been emphasised by everyone, with some openly questioning the reality of memory and claiming that memory, especially in its social/collective format, should perhaps be approached merely as a metaphorical entity, Others have championed the alternative extreme and presented memory as a materially concrete entity.

The truth is that even individual/personal memory, where the inner man [is] remembering himself' (Ricoeur 2004: 98), depicts several metaphorical expressions being used: 'spacious palace' of memory, the storehouse, or the sepulchre ${ }^{21}$ 'where the variety of memories (...) are "stored away", "entrusted for safekeeping"' (ibid., pp. 98-99; in reference to Augustine; Ricoeur 2004: 98-99).

The objective in this chapter is to scrutinise selected linguistically-entrenched vernacular metaphors of memory. What follows then, is a systemic (lexicographic) data analysis that is aimed at giving a comprehensive answer to the question of how memory is conceptualised in the linguistic picture of the world in Polish.

\section{1 'Metaphor bridges reason and imagination'22}

As Dorota Piekarczyk writes, conceptual metaphor can be treated as a specific kind of knowledge organisation (Piekarczyk 2013: 9). So, the vernacular lexicographically-attested metaphorical expressions I plan to examine below ${ }^{23}$

21 For more on spatial metaphors of memory in Russian, see Natalia Bragina (2007).

22 Cf. Krzeszowski 2010: 9.

23 This involves only those metaphorical expressions that are specified in Polish dictionaries under the rubric of 'memory' (Pol. pamięć). Although it is not that each of the mentioned memory metaphors can be exemplified with a representative number of linguistic expressions, even those poorly attested, as Draaisma has shown in his 
represent the common-sense knowledge of a certain sample of reality in general and in this case, of memory specifically. The cognitively-oriented conception of metaphor, as understood in cognitive linguistics and developed in the classicalby-now works of Lakoff and Johnson, 'shows that linguistically-entrenched metaphorical expressions are not exclusively, nor even mainly, a result of individual ad hoc associations, or resemblance-guided illuminations bringing together objects that are otherwise dissimilar as belonging to divergent spheres of reality, but that, instead, they are projections of conceptual structures metaphorical in nature and deeply-rooted in our thinking' (Piekarczyk 2013: 44).

Conceptual metaphor is firstly presented in terms of its functionality, and in this sense, it is seen as 'a central component of our everyday use of language' (Krzeszowski 2010: 7), the component that 'structure[s] how we perceive, how we think, and what we do' (Lakoff and Johnson 1980: 4). It shows us a cognitive capacity of overriding, or neutralising opposites. 'The essence of metaphor is understanding and experiencing one kind of thing in terms of another' (ibid., p. 5).

As Draaisma puts it, 'An intriguing quality of metaphors is that they are a union of opposites: they combine concrete and abstract, visual and verbal, graphic and conceptual' (Draaisma 2000: 14), so that materially concrete images facilitate the understanding of abstract relations. As he concludes (in reference to Beck's research), 'the metaphor is the intermediary between [the sensory and perceptual level of thought and the verbal and semantic one]' (ibid.). In short, metaphors unite reason and imagination (Krzeszowski 2010: 9), or, as Draaisma would say, topic and vehicle:

According to Richards's analysis a metaphor is the formulation of a relationship between two terms. One is the 'topic term', the term about which the metaphor is asserting something, the other is the 'vehicle term', the term that transfers that meaning from another context, Aristotle's 'strange name'. (Draaisma 2000: 11)

This union of the topic term and the vehicle term can be described in terms of two kinds of relations:

- structural relations: in Draaisma's words, 'the entities to which the topic and the vehicle term refer have a similar structure' (ibid., p. 16), as in, for example, a cell is like a room, with a floor, a ceiling and walls;

historical study, prove to be worth considering. This is because a linguistic expression/ representation is not only a carrier of a given conceptual metaphor, but also a carrier of the history of memory, or, in other words, a carrier of subsequent generations' reflection on memory, in both individual and collective dimensions. 
- functional relations: 'the two terms of the metaphor have their operation in common' (ibid.), as in feedback operates like a thermostat.

There is, then, much of both systematicity and regularity in metaphors. No wonder that Lakoff and Johnson claim that 'because the metaphorical concept is systematic, the language we use to talk about that aspect of the concept is systematic [as well]' (Lakoff and Johnson 1980: 7). Yet, they also notice a kind of asymmetry:

The very systematicity that allows us to comprehend one aspect of a concept in terms of another (...) will necessarily hide other aspects of the concept. In allowing us to focus on one aspect of a concept (...), a metaphorical concept can keep us from focusing on other aspects of the concept that are inconsistent with that metaphor. (Lakoff and Johnson 1980: 10)

This corresponds with Draaisma's observation that 'it is only from a combination of [different] metaphors that the most complete image of reality can be expected' (Draaisma 2000: 20).

\section{Memory in linguistic metaphors: a state of research}

Which categories is memory typically presented in? A partial answer to this question comes with Anna Pajdzińska’s analyses:

The most numerous is the set of realisations of the ontological metaphor MEMORY IS CONTAINER. What belongs to this set includes such obvious expressions as pojemna pamięć 'voluminous/capacious memory' and pojemność pamięci 'memory capacity', as well as prepositional phrases $w$ pamięci 'in memory' and $z$ pamięci 'from memory' whose metaphorical background is not anything we are usually aware of. The same 'container' metaphor can also be found behind many idiomatic expressions: ktoś szuka czegoś w pamięci 'someone searches their memory for something', ktoś grzebie w pamięci 'someone digs into someone's memory for something', ktoś a. coś staje komuś w pamięci '(appr.) somebody or something jogs someone's memory', coś wyleciało // uleciało // wypadło // uciekło komuśz pamięci 'something slips//keeps slipping someone’s memory'. (Pajdzińska 2012: 101)

What is emphasised in the 'container' metaphor is that memory is objectified, that it, it is ascribed to characteristics such as dimensions, that typically are attributes of physical objects/things:

Non-objective [Pol. nieprzedmiotowa] in its nature, memory is thus culturallylinguistically conceptualised in terms characteristic of a box-object. In the first place, memory is given some external space [usunąc coś z pamięci 'to erase memory; (lit.) to erase something from memory'] as well as some internal space [szukać czegoś w pamięci 'to search your memory; (lit.) to look for something in memory'], the latter being 
limited by the actual dimensions of memory [przestrzenie pamięci 'memory spaces'].

(Nowak and Siwiec 2008: 68)

This metaphor has two dimensions, global and specific ${ }^{24}$. Globally, memory is a container, but in addition, as Paweł Nowak and Adam Siwiec argue, 'a place, a delimited space, a building, a safe, that serve as something on which or in which a society's and/or an individual's important recollections, information, feelings can be stored (miejsca pamięci 'memorial/remembrance sites')' (Nowak and Siwiec 2008: 68). A further characterisation of memory as a space filled with objects or as a surface of an object (a sheet of paper, wax, stone, wood) can be found in Bragina (2007: 112).

However, there are many other metaphors of memory:

- a living creature/organism/human being

Although memory is an integral part of a human being, it is also an independent entity, as in pamięć żywi się wspomnieniami 'memory lives on recollections', or chłonna pamięć 'good (absorptive, receptive) memory'.

- a precious, valuable object that is narrated in terms of "war or excavation imagery", as in pamięć wydobyta $z$ ziemi '(lit.) memory extracted from the ground; memory excavated' (Nowak and Siwiec 2008: 68). In this case, 'memory is perceived as something technological and technistic' (ibid., p. 69).

The aforementioned survey can be completed with further memory metaphors. Generally, in the Polish language, memory is conceptualised in a dozen or so ways, and detailed below are specific elaborations of the 'container' metaphor.

\section{Memory as a structure and a process: specific elaborations}

The primary metaphor, that is, the 'container' imagery, can be given several specific dimensions. Memory can be conceptualised as a natural object, or, more generally, as an element of the Universe:

\section{- MEMORY IS EARTH}

Memory is conceptualised as earth in the sense that it conceals/hides recollections-objects, which is why they need to be unearthed (as in odkopywac $z$ pamięci 'to unearth (from) memory'), or it fixes plants-objects, which is why they are rooted (as in zakorzenić w pamięci 'to be rooted/grounded in memory').

24 The same two dimensions can be identified in conceptualizations of a text (Maćkiewicz 1999: 93). 
In both of these two cases, a processual character of memory is foregrounded, be it in the sense of 'remember = commit to memory' (zakorzenić $w$ pamięci) or 'remember $=$ recollect' (odkopywać $z$ pamięci). Interestingly enough, conceptualised in terms of open-pit (surface) mining/excavating and gardening, remembering and recollecting are given a teleological characteristic - extended in time, both require making efforts and attempts (as in zakorzenić 'to root/ plant'). More specifically, committing to memory connotes a centripetal (inward) movement (driving towards the centre-earth; zakorzenić), whereas recollecting memories connotes a centrifugal (outward) movement (driving away from the centre-earth; odkopywać). Memories are, then, plants rooted in memory-earth or objects deposited deep down in memory-earth. In both conceptualisations, memory is unavailable to naked-eye inspection. After all, the root is an underground part of a plant, yet it is the plant's most solid element that facilitates growth and regeneration. Similarly, recollection-objects reside deep down in memory and it is only in favourable conditions that a whole recollection can be unearthed on the basis of memory traces (as in the case of the so-called deep memory). Still, the doer/agent of both processes, that is, committing to memory as well as recollecting memories, is a human agent. It is him/her who 'roots/ plants' something in memory and 'unearth/excavate' something from memory.

\section{- MEMORY IS CELESTIAL BODY}

One representative linguistic expression of this conceptualisation can be evidenced with zaćmienie pamięci 'dim memory' (lit. 'memory eclipse' by analogy to zaćmienie słońca/księżyca 'Solar/Lunar Eclipse'). The metaphor seems to embrace memory slips, the kind of memory losses that are temporary, transient, and recoverable. If forgetting, in this case, results in an absence of light and darkness, remembering by contrast implies brightness and illumination, which, metaphorically, extends to knowledge as well. The 'celestial' imagery here is akin to the metaphor distinguished by Robert Fludd of the human mind conceptualised as a microcosm (Draaisma 2000: 42) Memory (mental) processes are then apprehended metaphorically, with forgetting specifically compared to a solar or lunar eclipse.

\section{- MEMORY IS BODY OF WATER}

The Polish expressions include zmącona pamięć 'murky memory' and wyłowić coś $z$ pamięci 'to fish something out of memory'. According to Bragina (2007: 113), this metaphor includes conceptualisations of memory that make use of images of such bodies of water as sea, ocean, and deep lake. Within this, a further characteristic of memory can be found - memories/recollections are fluid and the process of remembering/recalling is indiscriminate. In other words, what one 
actually remembers/recalls is haphazard and random - as memories keep on deforming and flowing (as if they were liquids), it is rather accidental that we are able to remember what we actually do (as in fishing). Simply, we cannot anticipate what it is going to be, that we will remember and recall. Additionally we cannot know, control, or be aware of the mechanisms of memory retrieval. Recalling is like fishing, and it consists in an outward movement. What triggers recollections may be an association, a key-word, an image etc. - they all function as 'baits' that the recaller-fisherman uses to catch a memory-fish.

- MEMORY IS MATERIAL (e.g. rock, wood, iron, stone etc. $)^{25}$

In Polish, we can find, wyryć się $w$ czyjejś pamięci 'to be engraved in (one's) memory; to be etched on (one's) memory', wykućlkuć na pamięć 'to learn something by rote; (lit.) to forge something into memory', wbić się w pamięć '(lit.) to be driven into (one's) memory (as nails can be driven into the wall'). This metaphor presents remembering/recalling as a permanent and stable process, with a human agent in the background conceptualised as a blacksmith, a stonemason, or a sculptor. However, the reflexive verb wbić się 'to be driven' in wbić się w pamięć '(lit.) to be driven into (one's) memory' does not show any doer of action, which implies that we are not in control of what we can remember/memorise. Simply, recollections are 'driven' into our memory by themselves and this happens without our participation. Again, what we learn from this metaphor is that memory processes are not anything we can claim we know and understand. Unlike in the previous conceptualisation, remembering involves a centripetal (inward) movement, as in wbić się w pamięć.

Yet another metaphor that makes use of a natural element, is fire. That MEMORY IS FIRE is projected for example from pamięć ludzka nie wygasła '(lit.) human memory has not been extinguished/put out yet' This conceptualisation involves both remembering and forgetting, and presents memory as if it were a natural fire, as something that can be extinguished but may well still be burning/smouldering. If memory has not yet been 'put out' (that is, it is alive and robust), it means that recollections keep fanning the memory-fire/flame and, in this way, do not let it blow out. In the light of this imagery, memory is a temporary phenomenon.

In the next set of metaphors, memory is animalised and personified as in:

- MEMORY IS LIVING CREATURE

Polish provides the following expressions: żywa pamięć 'living/abiding memory', wierna pamięć 'faithful memory', serdeczna pamięć 'loving/affectionate memory', 
tkliwa 'tender memory' wdzięczna pamięć 'grateful memory'. Memory is, then, ascribed to positive human attributes, such as tenderness, faithfulness, cordiality, gratitude, that happen to be externalised only in interpersonal contacts. If so, memory is perceived as another person, as somebody different from us, yet closely related to ourselves, so that memory is conceptualised generally positively, with its remembering aspect being emphasised. However, there are also isolated expressions that uncover the negative aspect of memory, that is, forgetting. This is the case of pamięć zawodzi 'memory fails; (lit.) memory lets someone down', as if memory was an unreliable, or untrustworthy, person. There are also expressions, e.g. ćwiczyć pamięć 'to exercise to boost/improve memory', or wytężýc pamięć '(lit.) to tone memory' that present memory in terms of a variable capacity whose robustness, as liable to change, depends directly on one's efforts.

This brings us to a related set of expressions which evidence memory as a body part or a tool:

\section{- MEMORY IS BODY PART or TOOL}

The reason for this claim is that, in Polish, memory can be conceptualised as a body part or a tool and an analogy can be observed between such corresponding expressions as siegać pamięcia '(lit.) to reach something with memory; as far as one remembers' vis-à-vis sięgać ręka 'to reach something with a stretch of the arm', siegać kijem 'to reach something with a stick', sięgać wzrokiem 'as far as the eye can see'. In all of these, memory, as an abstract human attribute, is metonymically pictured in terms of a visible body part (arm, hand, eye) or a tool (stick). What matters here is the ability to recall, which in sięgać pamięciq is identified with an outward movement, as much as it is when we stretch out our arms, hold out our hand, reach something with a stick, or see something in the distance. It can also be said that zanik pamięci 'memory loss' and wytężyc pamięć 'to strain/ tone one's memory; to put strain on one's memory' are concerned with bodypart imagery: straining/toning one's memory is like flexing one's muscles, and memory loss is like (muscle) atrophy. One way or another, the message here is that for recalling to be successful, we need to take great pains and make an effort.

Memory can also be conceptualised in terms of a living space (of humans, animals, and birds). Accordingly,

\section{- MEMORY IS PLACE/ROOM/SPACE}

In Polish, something literally may come/go out of one's memory, as in wyjść $z$ pamiecci, as if memory was a room that one can leave. In this context, recollections are intelligent creatures, completely sovereign in making their decisions, i.e. to stay or to leave the memory-space. If they decide to go out, forgetting can be comprehended as an outward movement. 


\section{- MEMORY IS STORAGE AREA}

This is a variant of the previous metaphor, with space now being specifically identified with a storage area. So, memory serves as a locker, a shed, or a cubbyhole where memories and recollections can actually be stored and stockpiled, as in zachować $w$ pamięci 'to preserve something in memory', przechowywać coś $w$ pamięci 'to store something in memory', zakamarki pamięci 'every nook and cranny (of memory)'. Memory has a structure of certain dimensions, but it is both spatially and temporarily limited. As Draaisma notes, this metaphor has been commonly known since Saint Augustine's Book X of his Confessions, where there is a passage on buildings, granaries, caverns, and treasure houses (cf. Draaisma 2000: 41). This storage area does not have to be a solid construction, such as those just mentioned, but it also may be mobile. Then, we have nosić coś $w$ pamięci 'to bear=carry something in memory', and pamięć przenośna 'portable memory'. Generally, if conceptualised in terms of a storage area, memory evokes its positive dimension, i.e. remembering. This is reflected in bagaż wspomnien 'burden of memory, emotional memory; (lit.) a baggage of memory'. Memory is here conceived as a suitcase used for carrying memories, with life being associated with travelling, man as a wanderer, and recollections as objects packed in a suitcase. No matter what kind of storage area memory is actually conceptualised as, it is given a well-defined structure even if, by itself, it is unstructured.

There are, nevertheless, expressions in Polish that connote the (negative) forgetful aspect of memory. Memory is still a specific place, or area, but it serves not so much to store memories as to recollect memories, or bring memories back. This is the case in wskrzeszać w pamięci '(lit.) to resurrect something in memory', and odżyc $w$ pamięci 'to be brought back to life in memory' Remembering then results in making memories return to life, with forgetting being only allegedly an irreversible process.

One further elaboration of the MEMORY IS PLACE/ROOM/SPACE metaphor can be found among animals-related expressions:

\section{- MEMORY IS NEST}

In Polish, coś ulatuje//wylatuje//wypada z pamięci 'something flies away from// falls out of memory'). Memory is filled with fleeting ('flying') recollections. Forgetting is not a purposeful process. It connotes an outward movement, away from memory. This metaphor has been marked out by Draaisma in his reference to Socrates's image of memory as a dovecot, or an aviary. In Draaisma's reading of Socrates, remembering results in recalling behaviour that was earlier experienced in a confined space (of memory). Metaphorically, then, whoever wants to 
recall anything must enter this memory-space again in order to try and find what has been stored there (cf. Draaisma 2009: 41).

Another substantial group of memory metaphors make use of the category of human products, creations, artefacts:

\section{- MEMORY IS THING}

More generally, memory is an object that can be lost (tracić/stracić pamięć and odjać komuś pamięć 'to lose memory'), can be left (behind, over) (zostawić po sobie dobra/zła pamięć 'to leave/make a (good/bad) impression on someone'), can be retained/kept (zachować o kimś dobra pamięć 'to keep someone in good memory'), can be appreciated (chłonna pamięć 'absorptive memory'). In this context, forgetting amounts to losing a precious object (a gift or present) for which one is expected to give thanks (dziękować za pamięć 'to thank someone for remembering something; (lit.) to thank for memory'), and keep in mind (zachować o kimś dobra pamięć 'to keep someone in good memory'). In other related expressions, specific attributes of the memory-thing are conceptualised, such as its dimensions (mieć krótką/długa pamięć ' to have a short/long memory'). So, memory can be better or worse, but cannot really be controlled, which finds one of its manifestations in dziurawa pamięć 'patchy/spotty memory'. However valuable, the memory-thing gets dirty, old, needs fixing, tidying up etc. (odświeżyć pamięć 'to refresh (one's) memory'). As to the directionality of forgetting, it involves an outward movement within memory, to be remembered, seen as container in general and as a box culvert specifically. In Polish metaphorical expressions, memory can also be conceptualised as an object of worship (święcić//szanować//czcić czyjąś pamięć 'to worship//respect//celebrate one's memory'), which turns memory into a thing of utmost value and significance.

The MEMORY IS THING metaphor can further be elaborated into:

\section{- MEMORY IS DEVICE/APPLIANCE}

Expressions like szwankuje pamięć 'memory is acting up', or odtworzyć coś $w$ pamięci 'to restore something in memory', serve to conceptualise memory operations, forgetting being a malfunction of the memory-appliance and recalling being an activity of recovering/retrieving prior encoded memories. This activity is, in fact, a movement that the user is in full control of - the user is here a human agent in charge of restoring something in memory. This metaphor is also recognised by Draaisma who explains it in terms of human memory being an utterly mechanical device, equipped with springs and cogs, set to make appropriate movements at the right time or place (cf. Draaisma 2000: 94). 


\section{- MEMORY IS BOOK}

There are many expressions in Polish that illustrate the MEMORY IS BOOK metaphor: zapisać $w$ pamięci 'to write something in memory', notować // odnotować // zanotować coś w pamięci 'to take note of something in memory', coś zapisało się // utrwaliło się w pamięci 'something has got written into // preserved in memory', wykreślić kogoś//coś z pamięci 'to erase (lit. 'to cross out') something // somebody from memory'. As written in the memory-book, experiences become recollections that can be compared to a written text. This memory-book assumes the role of a macro-sign, an open text that is being constantly enriched and completed with novel texts. In short, memory is a text, understood both as a structure and a process (notować w pamięci to take // to be taking notes in memory'). Although it is the memorisation aspect of memory that is highlighted in the first place, we also have the remembering aspect (coś utrwaliło się $w$ pamięci 'something has been preserved in memory') and the forgetting aspect (wykreślić//wymazaćl/wytrzeć coś z pamięci 'to cross out // erase // wipe something from memory'). Let it be noted that in this latter case the effect of forgetting may be complete, that is, no trace of an earlier memory is left (wytrzeć 'to wipe out; '), or incomplete, that is, some trace of an earlier memory can be identified (wykreślić 'to cross out'). To paraphrase Draaisma's claim, "memory has ultimately become a book of metaphors and is constantly being extended page by page" (Draaisma 2000: 47).

Finally, Polish gives expression to yet another metaphorical rendition of memory:

\section{- MEMORY IS MOVEMENT}

Although the related linguistic manifestations will present memory as a movement in general terms (przebiec coś pamięcia 'to trace (lit. 'to run across') something with memory' and przebiec coś w pamięci 'to track down (lit. 'to run across') something in memory), most often this movement is directionless and involves moving backwards (wracać // powracać pamięcia do czegoś // do kogoś 'to go back (lit. 'to return') to somebody // something in memory; cofać się pamięcia 'to go back in time in memory'). Let it be noted that this does not correspond with the Polish-entrenched imagery of 'forward is good' and 'backward is bad'. Still, memory facilitates transference in time, which invites the MEMORY IS ROAD metaphor. This is how Pajdzińska understands the road metaphor here: 'in some of the idiomatic expressions of conceptualising memory are a combination of the TIME IS SPACE and THINKING/RECALLING IS MOVEMENT IN SPACE metaphors' (Pajdzińska 2012: 102; emphasis added). Recalling is then, an 
expedition that consists of making a quick delve inside memory and that takes place along the memory-road (as in przebiec coś $w$ pamięci 'track down (lit. 'to run across') something in memory). In this context, the 'recaller' can be said to be homo viator 'the travelling/moving man'.

As argued above, metaphors serve to facilitate the understanding of a selected aspect of a concept, backgrounding simultaneously some other aspects of the same concept. 'Metaphors and metonymies are not random but instead form coherent systems of which we conceptualize our experience' (Lakoff and Johnson 1980: 41). Indeed, what we learn from a variety of specific memory metaphors includes the following:

(1) in relation to the abstract and difficult-to-define concept of memory, human cognitive capacity proves to be both complex and limited;

(2) there is a multiplicity of attempts at foregrounding and backgrounding different aspects of memory (see Tab. 3);

(3) in container-based metaphors, memory is conceptualised in significantly divergent ways, from memory being pictured as a container of well-delimited dimensions (as in body-parts metaphors) to memory being presented as a container of no boundaries at all (as in body-of-water metaphors), which implies that memory can be a closed container (a room, a safe) as much as an open one (an ocean, a nest);

(4) the smallest group of memory metaphors refers to memorizing (i.e.committing to memory), which may mean that of all the memory processes, memorizing is the one that humans are in control of most; this connects with the observation that we have at our disposal a number of different memorisation techniques, or mnemonic tools: rhythm, rhymes, sayings, keywords; by contrast, the most capacious set of metaphors refers to the ability to remember, as if we did not yet know or understand that aspect of memory that makes us retrieve what we once stored in our memory; as to forgetting and recollecting/recalling (Pol. przypominanie (sobie)), both are represented in comparatively similar numbers, and both, like retrieval, seem to remain a mystery;

(5) in memory metaphors, humans are conceptualised in terms of agency, that is, as doer of action (a fisherman, a stone mason, a blacksmith), memorising being specifically identified with those manual jobs that require physical effort and strength (a gardener, a stone mason, a blacksmith); memorising then, is again, a human-controlled and -monitored process developing in time. 


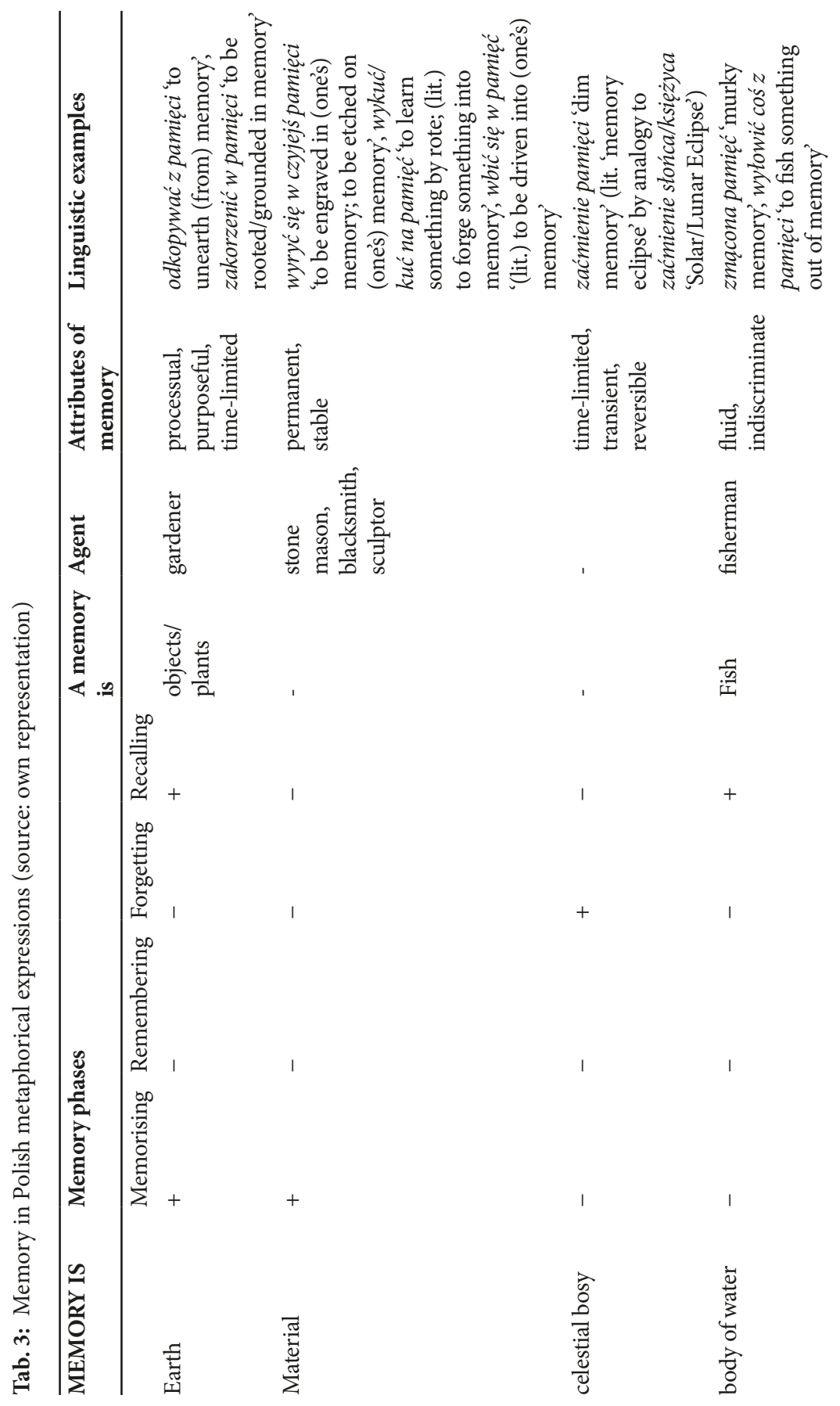




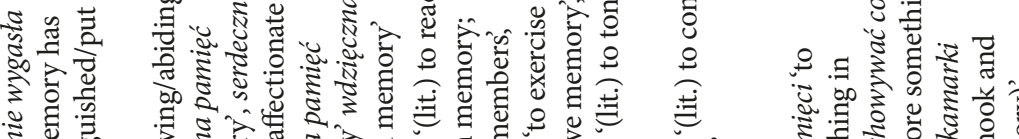

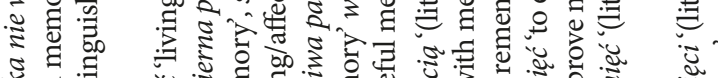
년.

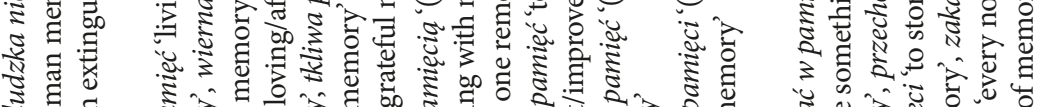

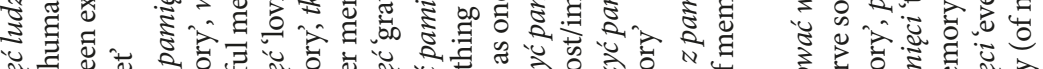

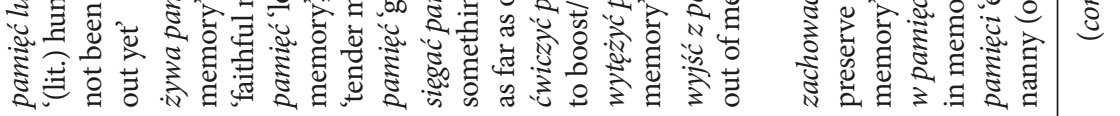

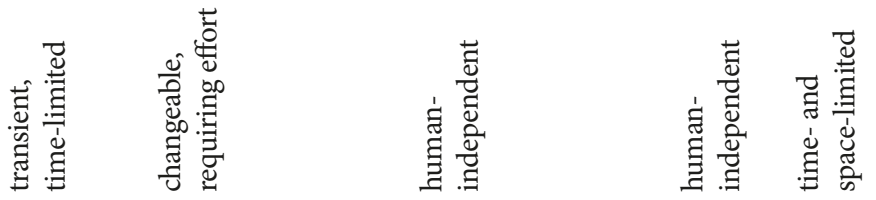

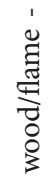

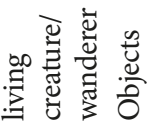

. 


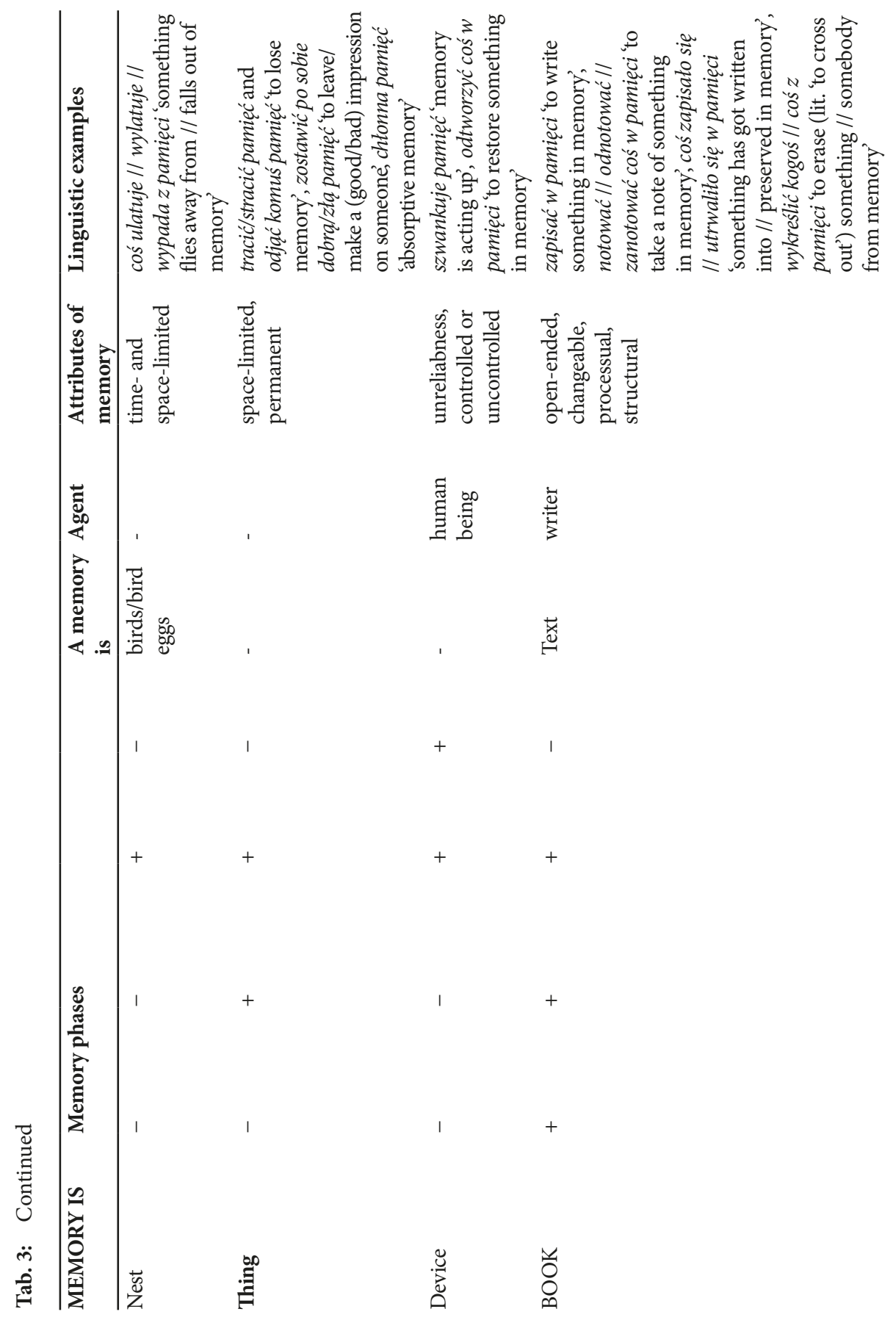




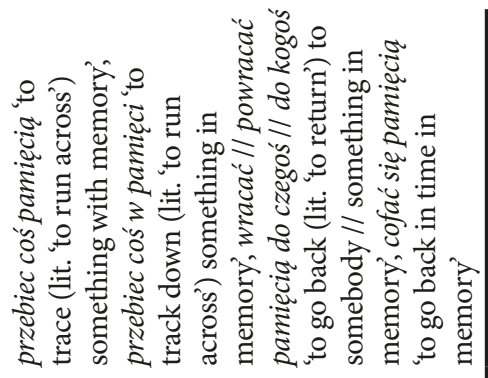

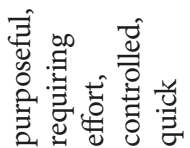

步

I

I

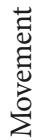


To sum up, in Polish, memory is conceptualised as both a structure and a process. The former conceptualisation projects specifically from MEMORY-ISCONTAINER metaphors, whereas the latter conceptualisation can be identified in those metaphorical expressions that highlight aspects of memory broadly understood as specific stages/types of the remembering process (memorising, remembering, recollecting/recalling, or forgetting).

\section{Is memory a language-like entity?}

The four memory-related processes that can be discovered in Polish metaphorical expressions of memory, i.e. memorising, remembering, recollecting/ recalling, or forgetting, can be presented graphically in the following diagram:

In truth, in the light of the examined metaphors, memory is a process that falls into four stages, or phases. The first of these has to do with encoding, or memorising, or committing data to memory which is conceptualised as a movement into/inside a body part, a book, or some material. Memorising is then an individual-based process, as much as speaking is an individually-executed part of using language, that consists in 'putting' into the memory-structure novel elements, experiences, and therefore complementing what has already been 'put' in there (in the diagram, this is represented with the arrow pointing towards the inside of the memory-circle

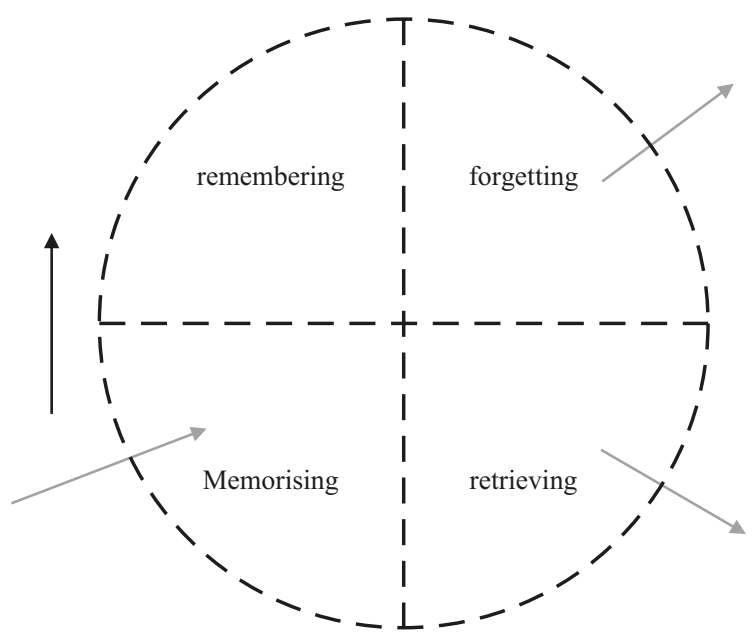

Diagram 6: Four stages of memory (source: own representation). 
The second stage involves storing, or remembering what has been committed to memory. This is conceptualised as a continuing state, or a constans (coś komuś stoi w pamięci '(lit.) something stands in one's memory', mieć $w$ pamięci '(lit.) to have something in memory'), or an enduring life ( $\dot{z} y c ́$ w czyjejś pamięci 'to live in one's memory'). Though static and structural by nature, remembering constitutes an element of memory as a process. If we were to look for any analogies in language, we could say that remembering resembles the capacity to understand spoken words on the one hand, but, on the other hand, it functions more globally like language as a social phenomenon. Namely, it grasps the fact that we cherish what we have committed to our memory as something important only for ourselves, but simultaneously we also add this contribution of ours to the existing memory-container that embraces not only the individual and personal, but also the collective and social handed down from generation to generation (for example, traditions, customs, rituals etc.). In effect, remembering amounts to a social process that incorporates individual memories into the collective structure of what has been inherited and acquired by a group.

The third stage of memory is forgetting, and this, in Polish, is conceptualised in terms of putting things in order, tidying up, or organising things (wyrzucic kogoś/coś z pamięci 'to throw somebody/something out of one's memory', by analogy to wyrzucać smieci 'to take the rubbish out'). What happens to be forgotten is no longer useful, needed, necessary, or coherent with the present memory structure. As an act of 'tidying up', forgetting can be deliberate and conscious as much as accidental and unintended (wywietrzeć $z$ pamięci '(lit.) to air memory' by analogy to wywietrzyć pokój 'to air the room', wylecieć $z$ pamięci 'to escape (from) memory; (lit.) to fly away from one's memory', coś umknęto (czyjejś) pamięci) 'to go unnoticed by one's memory'. In the diagram, forgetting as a process of deleting/erasing memories - is depicted with the arrow pointing outside the memory-circle.

Finally, recalling/recollecting is conceptualised as an effort (wysilać pamięć 'to strain/tone memory', ktoś stara sobie coś przypomnieć 'one tries hard to remember somebody/something', szukać $w$ pamięci 'to search memory'), as, for example, in effortful calling out (przywodzićlprzywoływać na pamięć 'to call out somebody/something in memory', by analogy to przywoływać kogoś 'to call/ shout in an attempt for one to come over'). This time, the process is centrifugal, directed from the inside to the outside of the memory-circle (see the arrow in the diagram).

In order to make the memory-language analogy clearer, the following quote by Tadeusz Milewski characterises the speaking process: 
The four phases of speaking project from each other and are grounded in each other. As an abstract system of social norms, language constitutes the basis for the whole speaking process that enables the expressing of individual and concrete thoughts and experiences. However personal, these thoughts and experiences are phrased according to social standards of language use, by which one's individual utterance facilitates the process of social communication. The conventionalised product of this communication becomes a text out of which linguistic norms are abstracted, with these norms becoming, in turn, the basis of a novel utterance. These four stages of speaking, succeeding each other, form a closed circuit and interpenetrate each other so closely that the task of delimiting the role of language [as an underlying abstract system] in the whole process of speaking, is possible only if various kinds of signs are identified and examined. (Milewski 2004: 7)

A similar view can be found in the Tartu-Moscow School of Semiotics, especially in Lotman's and Uspienski's claims that

(1) culture is a disinherited memory of a society,

(2) culture is 'language-like' (after: Żyłko 2009: 109).

It seems safe to conclude, then, that collective memory is also 'language-like, which, in fact is what we have seen in the metaphors examined above.

Again, the four stages of memory, as found in Polish metaphorical expressions, can be seen as stemming from and mutually influencing and conditioning each other. Of these four, the social category is remembering, the basis for the whole memory process. That remembering is a socially-driven process was already noted by Halbwachs. In J. Assmann's assessment of Halbwachs' argumentation,

Even the most personal recollections only come about through communication and social interaction. We recall not only what we have learned and heard from others but also how others respond to what we consider to be significant. All such experiences depend on intercourse, within the context of an existing social frame of reference and value. There is no memory without the perception that is already conditioned by social frames of attention and interpretation. (J. Assmann 2011: 22)

In other words, an individual committing information to memory results in incorporating this information (e.g., through speaking, telling stories, everyday communication) to the overall process of social remembering. The product of this incorporation process may in time be forgotten, if its content is no longer compatible with the content of social memory. Yet, the forgotten may again be incorporated into a group's memory, and become the basis of the remembering process, that is, of committing to memory. The four stages or memory may not go full circle, but if they do, they form a closed circuit: whatever has been forgotten may be recalled anew, and if a group's collective memory has changed so that a recollected individual memory proves to be important, vital, or worth 
retrieving, it will now be given a social dimension. We can see this in those memory metaphors that conceptualise memories as objects.

To conclude this chapter, memory can be seen as a structure that unites, or brings together, the social and the individual, and the abstract and the concrete. Remembering (committing to memory) involves incorporating, on a short-term or long-term basis, experiences into the memory structure. Forgetting consists of deleting the elements that have been found superfluous, useless, unimportant, incompatible with the present (social and individual memories), uneasy, or traumatic. Finally, whatever is recalled or recollected, is incorporated anew into the structure of what is taken to be individually and socially significant, topical (even if traumatic), or otherwise worthy. For these reasons, recalling/recollecting involves a centrifugal (inside-outside) movement, which is very closely bound with communication because 'memory lives and survives through communication' (J. Assmann 2011: 23).

Memory is then, 'language-like' because

- it is an ordered system of signs, or is 'languagised' (Pol. ujęzykowiona, Chlebda 2012), or, still in other words, is a structure of its own organisation (as indicated by psychologists, for which see Herzyk 1980);

- it corresponds to Saussure's dichotomy between langue and parole;

- in its social dimension (here: collective memory, or social frames of memory), it finds its counterpart in langue, that is, a socially-sanctioned system of signs;

- in its individual dimension, it finds its counterpart in parole, that is an individually-executed realisation of memory, always grounded in collective memory (i.e. social frames of memory);

- it shows some of the language properties ${ }^{26}$, such as those enumerated by John Lyons: interchangeability (memory results in exchanges between the addresser and the addressee), displacement (Pol. zdalność; communicating things that are not immediately (spatially or temporally) present), or cultural transmission (language is learned/acquired, not endowed genetically) (after: Grzegorczykowa 2007: 22).

26 For more on memory-language analogies, see Wójcicka 2015b. 



\section{Proper names as carriers of collective memory}

In this chapter, I plan to make use of psychologically- and psycholinguisticallydelimited distinctions between declarative (or explicit) and procedural (or implicit) kinds of memory. Though this typology refers essentially to two different kinds of long-term memory, my intention here is to extend and apply it specifically to collective memory. In this, I follow Manier and Hirst's (2008) observation that the principles governing individual memory may in some ways influence collective memory. That is, if remembering is indeed an in individual's capacity, then what and how a whole group remembers is, at least in part, shaped by individual memories. Manier and Hirst's hypothesis is then, that specific structures of individual memory may be reflected in corresponding collective memories. As they argue, 'collective memories (...) are representations of the past in the minds of members of a community that contribute to the community's sense of identity' (Manier and Hirst 2008: 253).

In general terms, from a psychological point of view, the following kinds of memory can be distinguished:

- semantic memory: the general world knowledge (facts, concepts, judgments) that a community has accumulated throughout its history; this knowledge is independent of the contexts in which it once happened to be acquired;

- episodic memory: the collection of past personal (autobiographical) experiences, events, or stimuli and their corresponding contexts (times, places, emotions);

- declarative (explicit) memory: the conscious, intentional recollection of factual information, previous experiences and concepts that can be communicated verbally; it falls into two specific subtypes, episodic memory and semantic memory (see above);

- procedural (implicit) memory - the unconscious knowledge that facilitates performing specific tasks (e.g., skiing, riding a bike, or speaking Polish) without the conscious awareness of previous experience in performing these tasks; it functions on the subconscious (automatic) level and is hard to verbalise (Jagodzińska 2008: 131).

This is how the latter two are distinctively characterised by Ida Kurcz:

Declarative knowledge (and memory) amounts to the "that" [Pol. $\dot{z} e$ ] kind of knowing [i.e. that something is known], or to storing in memory various kinds of information on 
facts, events etc., that are typically easy to be verbalised, whereas [procedural knowledge (and memory)] embraces the "how" [Pol. jak] kind of knowing, that is, performing various skills, that is, mentally-encoded procedures, strategies of how given kinetic or mental activities, otherwise difficult to be verbalised, should be executed. (Kurcz 1992: 57)

As mentioned above, psychologists (e.g., Endel Tulving) subdivide declarative memory into two further kinds, semantic memory and episodic memory:

Originally, this subdistinction used to refer to two kinds of long-term memory. A substantial part of our memory includes our generalised world-knowledge that has no direct bearing on personal experiences and, for that reason, is not bound up with any specific context. (Jagodzińska 2008: 203)

This subtype of declarative memory corresponds to what Tulving calls 'semantic memory'. Episodic memory, in turn, involves 'individually-experienced events that can be referred to specific temporal and spatial contexts' (Jagodzińska 2008: 203).

The psychologically delimited distinction between declarative and nondeclarative (or procedural) kinds of memory will constitute the framework of my analysis of the names of food dishes, as seen in the context of theory of memory. More specifically, here are the questions I attempt to answer in what follows:

- can the names of dishes (or names in general) be regarded as carriers of collective memory? ${ }^{27}$

- what kind of memory can be identified in the names of specific dishes?

- what does the memory hidden behind the names refer to?

- what kinds of information happen to be hidden in the names of dishes?

- which dish attributes happen to be reflected in their corresponding names?

\section{Cooking as language and memory}

As Claude Lévi-Strauss (1972: 80; after Łeńska-Bąk 2010: 18) sees it, 'Cooking is a language ${ }^{28}$ through which society unconsciously reveals its structure and which

27 According to Artur Rejter, a proper name is an element of cultural memory: 'The kind of cultural memory that happens to recorded in [proper] names is so unique that names constitute components of tropes and stylistic figures, and frequently play a role of title-naming in which they reveal their extra semantic-cultural potential. That they are charged with memory load explains why -onyms exemplify well-defined characteristics which often transgress their individual referents and transform them into names-symbols' (Rejter 2016: 38).

28 Inspired with Lévi-Stauss' research, I have attempted to analyse the 'culinary language' of the South Podlachia (Pol. Podlasie) community, with special emphasis on their 
may prove informative as to its sociological, economic, aesthetic or religious differentiation'. Lévi-Strauss thus compares food and cooking to language, putting forwards the theory of 'the culinary triangle' with the basic binary oppositions of changed-vs-unchanged and culture-vs-nature. Each of the triangle apexes corresponds to, respectively, the raw, the cooked, and the rotten.

Similarly to Lévi-Stauss, Barthes would also build an analogy between food/ cooking and language: as much as in language, 'what gets reflected in every act of cooking is the cultural system of a given nation; ${ }^{29}$ cooking, like language and religion, has an identification capacity and, therefore, out of necessity, it differentiates [people]' (Katarzyna Łeńska-Bąk 2010: 20).

At this point, it now seems worth asking a question regarding the possible relationship between language and memory. ${ }^{30}$ As Gerald Echterhoff (2008: 263) remarks,

Given the abundance of (...) examples [of the possibility that the language by which one captures experience also shapes one's memory and knowledge] (...) one may suspect that the linguistic format can have profound effects on memory in its individual, collective, and cultural manifestations.

Indeed, as he continues (p. 264), there are at least two ways of examining these relationships. One is concerned with the task of seeing how language shapes memory. What comes to the fore in this approach, is memory and its dependence or reliance on language. If so, language can be said to be a model for

vocabulary and the collective memory that can be identified in selected culinary expressions. The present chapter aims then at reconstructing the subjective picture of cooking that the South Podlachia inhabitants reveal in their names of the dishes they cook. In other words, the research objective here is not to describe the Podlachian cuisine from an external, objective, or scientific point of view, but to present it as it is naively understood by the South Podlachians themselves when they are taken to be carriers of folk culture. The reconstructed picture is then meant to be linguistic and cultural in its nature in the sense that it reflects a collective image of cooking, food, or, more specifically, selected dishes.

29 For more on the role of food and cooking in culture, see Historie kuchenne. Rola $i$ znaczenie pożywienia $w$ kulturze, ['Culinary stories. On the role and importance of food in culture'], ed. by Rastislava Stolična and Anna Drożdż, Cieszyn-Katowice-Brno, 2010, and Katarzyna Łeńska-Bąk (2010).

30 For more on language as a building material of memory, see Pamięć w ujęciu lingwistycznym. Zagadnienia teoretyczne i metodyczne ['Memory in a linguistic perspective. Theoretical and methodological issues'], ed. by Waldemar Czachur, Warszawa, 2018. 
the entire memory system (that is, language model memory) in that it moulds and expresses memory (that is, memory as linguistic in nature ${ }^{31}$ ) as well as it interprets memory (Wójcicka 2018: 70-71). In other words, language is a memory medium in the sense that it is a building material and a carrier of collective memory (Czachur 2018: 21).

In the other approach, it is memory that is expected to influence language, with language and its dependence on memory functions and processes being the central objects of examination. Echterhoff argues that if these two approaches were set in the context of experimental methodology, the first approach would assume that memory is a dependent variable and language one of the potentially significant independent variables, whereas in the other approach, this would be reversed. Consequently, for one to have anything to say on memory and thinking, one has first to examine language (Echterhoff 2008: 264).

Two different approaches to the language-memory relationship are also distinguished by Wojciech Chlebda:

The moulding force of language is bidirectional and it works in two mutually conflicting directions: centripetally, which is when it shapes the substance (content) of memory as such, and centrifugally, which is when it shapes the relations of this substance that have already emerged. (Chlebda 2018: 60)

In this analysis, I follow Echterhoff's second research possibility, which is how memory shapes language, especially its lexical resources. In doing so, I will also rely on the analogy between cooking and language and assume that both are two-dimensional as they consist of a collective system (langue) and an individual realisation (parole). Moreover, what I consider to be the shared commonality of a given social group (langue) as far as the names of the dishes are concerned, is a carrier of one specific type of collective memory - declarative memory.

\section{Names of dishes as carriers of declarative memory}

As previously mentioned, declarative memory is of the 'I know that...' kind. If we now write the names of food dishes into this scheme of memory, ${ }^{32}$ we can

31 Cf. Chlebda 2012.

32 Again, I mean the dishes characteristic of South Podlachia as prepared/cooked by its inhabitants for culinary competition purposes, which means that apart from their typical consumption and ritualistic designations, the dishes may also serve some identification function. Indeed, the very context of a competition brings the latter function to the fore and invites the question of what dishes the South Podhalachians consider to be specifically characteristic of their region. The material includes 110 dish names that the 
discover which type of knowledge has been recorded in a given name, what is the object of the declarative collective memory exemplified in specific names, which dish attributes happen to be reflected in their names, and what referents of declarative memory are recorded in the names, etc. As the objects of my examination mainly include ingredients, which vary from dish to dish, I have created the following classification of dish names:

- single-ingredient dish names; although these names are most often nominal, they do not reveal any information as to what ingredients are used, or even if they seem to, it is impossible to have any straightforward indication, as in mazurek, włuczegi ${ }^{33}$, drygieliny, sołuducha, kaski, kulebiak, osuch, kołduny, kućmok, halimane; alternatively, the ingredient information may be limited only to the main component, as in kartoflaki ( potatoes), orzechowiec ( nuts), sernik ( (cottage) cheese), kaszanka ( kasha), gryczaniak ( buckwheat), jagielniaki ( millet);

- two-ingredient dish names, with the first element of the name referring to the primary ingredient (most often potatoes or flour), and the other element revealing the extra ingredient (cheese, meat, cabbage, (blue)berries, kasha), as in kartoflaki z serem ('potato cutlets with cheese'), kartoflaki z mięsem ('potato cutlets with meat'), kapusta $z$ grzybami ('cabbage with mushrooms') ${ }^{34}$, śledź $w$ oliwie ('herring in olive oil'), ryba zapiekana $w$ warzywach ('fish roasted in vegetables');

- three-ingredient dish names: smalczyk z boczkiem i ogórkami kiszonymi ('bacon fat and pickled cucumbers'), pierogi z kapusta i grzybami ('dumplings with cabbage and mushrooms), paczki parowane $z$ soczewica i serem ('steamed

Borki-borough inhabitants identify as typically South Podhalachian. The dishes were especially cooked for the competitions and other events organized by the Borki borough cultural center (Pol. gminny ośrodek kultury) in Wola Osowińska, such as Spotkania z Pieśnią i Tradycją Wielkopostną (Eng. 'Easter songs and traditions festival'), Teatr w Opłotkach (Eng. 'theatre in the hedges'), Spotkania z Pieśnią i Tradycją Weselną (Eng. 'wedding songs and traditions festival') etc. The Borki-borough inhabitants would take part in such-like events, presenting the meals that they considered typical of their region (South Podlachia in specific and Lublin voivodship in general). The data was collected in the years 2006-2011.

33 The spelling is original.

34 In most contexts here, the term mushrooms is referred not to the cultivated white button mushrooms characteristic of grasslands and known technically as Agaricus bisporus, but the varieties of edible fungi which are found in the woods and are given specific names, such as bolete, bay bolete (imleria badia), chanterelle, morel, russula etc. 
doughnuts with lentils and cheese'), ziemniaki faszerowane zapiekane ze śledziem i pieczarkami ('roast potatoes stuffed with herring and mushrooms'), chleb gryczany $z$ masłem i twarogiem ('buckwheat bread with butter and cottage cheese').

The number of ingredients specified in the name of the dish correspond to the number of ingredients actually used in the dish. When this occurs, the names differ regarding the amount of information they provide. In addition, the syntagmatic distance between the primary ingredient and a given extra ingredient bears witness to the relative importance of the latter providing an idea of how many of the specific ingredients may be necessary to prepare a given dish. How many ingredients to be expected is indicated in the word order of a given name. Grammatically, culinary vocabulary can be divided into several categories:

- nominals (nouns), as in kartoflaki, mazurek, drygieliny; which may reveal their ingredient(s), e.g. kartoflaki kartofle 'potatoes'; single-ingredient dish names are nominals of this kind;

- prepositional or adjectival phrases that reveal some characteristic(s) of a given dish, as in paczki parowane $z$ soczewica $i$ serem ('steamed doughnuts with lentils and cheese'), ziemniaki faszerowane zapiekane ze śledziem i pieczarkami ('roast potatoes stuffed with herring and mushrooms'):

In the extra-linguistic world, these characteristics do not exist independently, but always function as attributes of somebody or something. The kinds of attributes that are signified with adjectives can most often be identified on the basis of the nouns that these adjectives describe. The signified noun points to an object, and this object, in turn, is characterised with the attribute described with the adjective. (Smółkowa 2001: 401)

Accordingly, there are several different patterns of how the declarative memory of the 'I know that...' kind happens to be understood in prepositional and adjectival phrases used in the names of dishes:

$\checkmark$ I know that... the dish corresponds to a given type of a situational context

This equates with Tokarski's (2001: 344) conviction that 'language, especially in its lexical dimension, remains in a defined relation $v i s-\grave{a}$-vis the extra-linguistic reality'. In other words, the relationship between the name of a dish and the corresponding situational context of cooking and serving the dish, allows to situate, or not situate the very meal. This situatedness can be considered in two ways:

- through an analysis of the lexical (dictionary, objective) meaning, and/or

- through a reconstruction of the contextual (pragmatic, subjective) meaning of a given dish name, that is, through the actual meaning of the name. It is in 
the actual context that 'names lose their original (dictionary) meaning and acquire the contextual one' (Rzetelska-Feleszko 2001: 408). ${ }^{35}$

Of these two possibilities, I find the former to be more relevant as far as the name-memory relationship is concerned. The reason for this, is that this objective approach is precisely the one that makes us examine the vey situatedness that has been written into the name, and this, in practice, amounts to analysing the dictionary meaning behind the name.

And, thus, what can be identified in the adjectives used in dish names, are various categories of situations ${ }^{36}$ :

- wedding (Pol. wesele): korowaj weselny and placek weselny ('wedding bread')

- lent (Pol. post): kapusta postna ('Christmas Eve cabbage with mushrooms')

- Easter (Pol. Wielkanoc): baba wielkanocna or babka wielkanocna ('Easter yeast cake'), ciasto Pasja (lit. 'Passion cake'), mazurek wielkanocny ('shortcrust tart')

As we can see in these and other similar names, the correspondence between the attributes as expressed with the adjectives (weselny, postna, wielkanocna) and the objects (dishes) themselves are quite specific and straightforward.

$\checkmark$ I know that... the dish consists of the following ingredients

- the dish is made of sth, as in kotlety z czerstwego chleba (lit. 'chops/cutlets (made) of stale bread'), klops z mięsa wieprzowego (lit. 'a chop (made) of pork meat '), kaczuszki z jajek (lit. 'ducklings (made) from eggs'), piwo $z$ podpiwka własnego wyrobu (lit. 'beer (produced) from self-made leaven'), pasztet podlaski z kaczki (lit. 'Podhalacian pate (made) from duck'), zupa z dyni ('pumpkin soup'; lit. 'soup (made) from pumpkin');

35 What I mean by contextual meaning here is the one triggered by the title, or the subject matter, of a culinary competition for which, to be remembered, the South Podhalachians have prepared their dishes. However interesting, the contextual meanings of Podhalachian dish names are not examined in this chapter. If they were, we would arrive at a subjective approach to food, cooking, and specific dishes/meals.

36 Naturally, this survey is neither complete nor finished. It includes only these categories of situations that could be found in the examined culinary competitions. For that reason, they all refer to some ritual, be it family-related (wedding) or Church-related (lent, Easter). The choice of dishes was then conditioned by the subject matters of the available competitions. Any other categories of situations (funeral and funeral meal/ reception/luncheon, baptism and christening) are not mentioned here because the Borki borough cultural center did not organize relevant competitions. Neither can we generalize anything about the daily cuisine of the Borki inhabitants. 
- the dish is of the something-with-something type, as in kartoflaki $z$ soczewica (lit. 'potato cutlets with lentils'), pierogi $z$ kartoflami (lit. 'dumplings with potatoes'), chleb $z$ ziarnem słonecznika (lit. 'bread with sunflower seeds');

- the dish does not have/include something, as in dyniowy placek bez jaj (lit. 'pumpkin (cake) without eggs').

$\checkmark$ I know that... the dish looks similar to something else, for example a duckling, a mouse, a wanderer, a fish (as in the rhyming expression grzyby jak ryby 'lit. mushrooms (that look) like fishes).

What we have here are names that originally were names of common objects, but then went through a process of animisation - and shifted to the lexical category of proper names:

- names derived from the human world: włóczeggi ('wanderers/vagabonds'), podlasiak gryczany (lit. 'a buckwheat Podhalachian'), babka gryczana ('a buckwheat cake'), baba wielkanocna ('an Easter cake');

- names derived from the natural world (of fauna and flora): kaczuszki z jajek (lit. 'ducklings (made) from eggs'), jajka myszy (lit. 'mouse eggs'), grzyby jak ryby (lit. 'mushrooms (that look) like fish'), gołabki z farszem ziemniaczanym ('potato stuffed cabbage leaves'; lit. 'doves/pigeons with potato stuffing').

$\checkmark$ I know that... the dish 'belongs' to somebody/something else, as if it was somebody's/something's 'property', as in jajka myszy (lit. 'mouse eggs'), chleb ułański (lit. 'uhlan bread'), swojska wędlina (lit. 'folksy cold cuts/meats'):

In this I follow Tokarski's (2001: 345) observation that 'the meaning of a word is not a faithful mirror reflection of the attributes of the corresponding object, but a deliberate foregrounding of some of the attributes and backgrounding, or even a complete neutralising, of some other attributes'. In this particular group of dish names, what happens to be foregrounded is related to the appearance of the object (jajka myszy 'lit. mouse eggs') or the origin of the cooking recipe (swojska wedlina 'lit. folksy cold cuts/meats', chleb własnego wypieku ze stoning 'lit. home-baked bread with lard').

$\checkmark$ I know that... the dish is 'ours', it is cooked in 'our' way, and functions as an element of 'our' local/regional religious or cultural identity, as in pasztet podlaski $z$ kaczki (lit. 'Podhalacian duck pate'), karp smażony w occie po sitnieńsku (lit. 'Sitnian carp fried in vinegar'), baba podlaska $z$ sosem grzybowym (lit. 'Podhalachian cake with mushroom sauce'), podlasiak gryczany (lit. ' buckwheat Podhalachian pastry'), przysmak bialski (lit. 'Bialskian delight'), paszenkowskie butki (lit. 'Pashenkian rolls/buns'), śledź po wiejsku (lit. 'country 
(folksy) herring'), pierogi z kasza po lubelsku (lit. 'Lublinian dumplings with groats'). ${ }^{37}$

On a more general level, as Rzetelska-Feleszko (2001: 406) writes, 'one of the basic functions of proper names results in individuation', or discriminating the individual from the whole group. As she continues, 'proper names are created from the same linguistic substance as common names are' (ibid.), yet, used as the name of a dish, a common noun is subjected to semantic derivation, so its function is precisely to discriminate a specific dish from all the similar, or even the same objects of the category. This individuation can be maintained through indicating the highly specific (say, uniquely 'our') way the dish is cooked, as in, for example po sitnieńsku ('prepared according to ta cooking recipe characteristic of the Sitno region', or 'à la Sitnian'). Proper names of this kind are often results of shifting a proper name from one category to another (transonimisation), as in when a given place-name is used either in its adjectival form as a toponymical expression (Sitno sitnieński, Bielsk bialski, Paszki paszenkowski), or in a form identical to the name of the inhabitants of the area, as in podlasiak gryczany, where podlasiak is the generic reference name of the Podlasie (Eng. Podlahia) people.

$\checkmark$ I know that... the dish is prepared/cooked in a given specific way, as in biata kietbasa pieczona (lit. ' roasted white sausage'), karp smażony $w$ occie po sitnieńsku (lit. 'Sitnian carp fried in vinegar'), kapusta zapiekana $w$ chlebie (lit. 'cabbage roasted in bread'), kluski krojone ('(hand) chopped noodles').

As noted above, all the examined dish names which are coined as adjectival and/ or prepositional expressions can be regarded as carriers of declarative memory. Yet, they also contain elements of procedural memory which embraces abilities, capacities, skills, habits, and most generally procedures, making it difficult to verbalise. This is how Jagodzińska (2008) describes the inventory of procedural memory:

It involves both simple acts as well as complex activities, with the latter being of sensorial, kinetic, cognitive, social, and emotional natures. At its simplest, they all can be described as the "how" kind of memory, which means that what we remember is how

37 Sitnian, Podhalacian, Pashenkian etc. are adjectival forms based on the place-names of, respectively, Sitno, Podlasie, Paszki. All these adjectival expressions are meant to suggest that a given meal is cooked in the way characteristic of the indicated place, or region, which is according a local recipe. 
a given act should be done or a complex activity performed. (...) In the first place, this kind of memory shows up in doing things, rather than in talking about things. Indeed, it may be difficult to verbalise procedural memory because many activities we perform automatically, unconsciously, without even realising what we are doing and how we are performing acts. In this sense, procedural memory is usually contrasted with declarative memory as the latter embraces facts and events, which is when memories are explicit, conscious and, thus, can be verbalised. Generally, the declarative-procedural opposition relates to Ryle's proposition that memory may have to do with "knowing" [things] and "knowing how" [to do things]. (Jagodzińska 2008: 194)

It should be emphasised at this point that the acquisition of habits, skills and procedures is to a large extent, collective in nature because it is forced and facilitated by the community one grows up in through socialisation and imitation. This fully justifies placing procedural memory under the rubric of collective phenomena, and we can clearly observe this in the names of the dishes examined here. Namely, regarding dish names, when we come across information about the way in which a dish is to be prepared (e.g., kluski krojone ('(hand) chopped noodles') or about its thermal processing (pieczone 'roasted/baked', gotowane 'boiled', gotowane na parze 'steamed', smażone 'fried' etc.), the kind of memory implied is procedural. When, on the other hand, the focus is on the ingredients (buckwheat, potatoes), appearance, seasonal serving time (Easter, Christmas), originality and locality of the recipe (self-made, home-baked) as well as identitybuilding (e.g., paszenkowskie butki lit. 'Pashenkian rolls/buns', or 'rolls à la Pashenkian'), dish names are carriers of declarative memory.

Now, once we examine the relationship between dish names and signified dishes/meals themselves, we can conclude that names are motivated with qualitative and relational attributes of the corresponding dishes-objects. So, we can speak of the semantic function (in the sense of Kosyl 2001a: 451) that dish names perform either directly or indirectly (i.e. as metaphors, metonymies, allusions etc.). Specifically, the declarative memory ('I know that...') recorded in the examined dish names can embrace the following qualities and relationships:

- recipe and flavour: sołoducha (rel. to słodki 'sweet'), jagielniaki (app. 'sweet rolls');

- colour: biała kiełbasa pieczona ('roasted white sausage'), szary barszcz ('grey beetroot soup'), żur czerwony ('red sour rye soup');

- size: podpłomyki ('flatbreads'), pierożki z kasza gryczana ('small dumplings with buckwheat');

- shape: grzyby jak ryby (lit. 'mushrooms (that look) like fish'), kaczuszki z jajek (lit. 'ducklings (made) from eggs'), zawijaniec kartoflany ('a potato wrap'), oponki ziemniaczane (lit. 'small potato tyres'); 
- stuffing: gryczaniak (containing buckwheat), amoniaczki (containing ammonia), tort chlebowy (lit. 'bread layer cake');

- texture: drygieliny (app. 'vegetables in jelly'), pampuchy (related to puch 'fluff'),

- methods of cooking: parowańce ('steamed yeast rolls'), biała kiełbasa pieczona ('roasted white sausage'), zupa $z$ dyni z lanymi kluskami ('pumpkin soup with (lit.) poured noodles'), kluski krojone ('(hand) chopped noodles').

\section{Functions of dish names}

Dish names can also be approached from a grammatical-functional perspective and given the two following functions:

- pragmatic function: information about the number of ingredients used, colour, appearance, ways of cooking and serving;

- persuasive (advertising) function; Dish names may be of little informative value, yet intriguing enough for the dishes themselves to be found attractive and desirable as meals to be consumed. For this reason, dish-based meals may have an enigmatic form (as in the rhyming comparison grzyby jak ryby 'mushrooms (that look) like fish'), or the metaphorical wluczegi ${ }^{38}$ 'wanderers, vagabonds') which makes a would-be consumer ask himself/herself what it is or what it is made from. Names of this kind are meant to initialise an interplay between the sender and the receiver, as in typical advertising slogans, with the name identifying the meal, fostering its image, and inviting us to consume it.

As memory carriers, dish names can also perform some other functions which have been recognised specifically in collective memory research (see Chapter I):

- cognitive function: both memory and language, dish names included, provide information about our past and therefore ourselves;

- identificational function:

It is their own identity that carriers of tradition and collective memory express in dish names (e.g. podlaskie 'Podhalacian', po sitnieńsku 'as in the Sitno region, $\dot{a}$ la Sitnian'). This highlights the we/our-they/their opposition because it fosters a sense of belonging and local pride.

- self-representational function: dish names contribute to the process of the image creation of a social group;

- socio-cultural function: as memory happens to be expressed chiefly through

38 The spelling is original, an alternative of the standard włóczegi. 
language, dish names are social in the sense that they are shared by the whole of a given group, as in po sitnieńsku 'as it is done in the Sitno region';

- consolidation function (i.e. sustaining a social group in time and space): handed down from generation to generation and conventionalised in actual use, dish names bear witness to the continuity of the group.

Here are some of the main conclusions:

1. Most of the South Podhalachian 'language' expressed in dish names refer to potatoes (Pol. ziemniaki/kartofle), as in zawijaniec kartoflany, pierogi $z$ kartoflami, kartoflaki $z$ soczewica, kiszka ziemniaczana, buckwheat (gryczaniak, kisiel gryczany, podlasiak gryczany, pierożki z kasza gryczana, kulebiak $z$ kartoflami i kasza gryczana) and millet (jagielniaki). (Naturally, there are many flour-based dishes but this is not represented by their names.) The examined names correspond to the dishes that have been recognised by the Borki inhabitants as typical and distinctive of their borough. Indeed, it was potato-, buckwheat-, and lentil-based dishes that happened to be cooked for the culinary competitions within the 'Our culinary heritage' format (Pol. Nasze dziedzictwo kulinarne).

2. Some of the examined dish names disclose their regionality, as podlaskie 'Podhalacian' or sitnieńskie 'Sitnian' do when they are used in Podlasiak gryczany, pasztet podlaski $z$ kaczki, karp smażony w occie po sitnieńsku, baba podlaska $z$ sosem grzybowym. On the one hand, these names refer to the dishes that can be described as traditional (e.g. podlasiak gryczany, where the personified place of habitation - podlasiak 'an inhabitant of Podhalachia', completely identifies the product-meal with people-carriers of a given culinary tradition), whereas on the other hand they embrace modern dishes (pasztet podlaski $z$ kaczki, karp smażony $w$ occie po sitnieńsku). If a name contains a toponymical adjective as well, then the name indicates yet another distinguishing way of cooking the dish, as in smażony po sitnieńsku ('fried in the way that is characteristic of the Sitno region').

3. It is not so much modern dishes, but culturally-alien (foreign) dishes that traditional ones clash with, overtly stated in the names of the former ones: ryba po japońsku (lit. 'fish à la Japanese'), sałatka grecka ('Greek salad'), zapiekanka szwedzka ('Swedish casserole'), sałatka żydowska ze śledziem ('Jewish (tomato) herring salad').

4. While the names of modern dishes are merely informative in nature (that is, they typically inform us about the content/ingredients of a given dish), the names of traditional dishes are less informative and consequently, more intriguing. 
5. Most of the dishes in the traditional set appear in numerous variants, as in the case of kartoflaki 'potato cutlets' that can be kartoflaki $z$ serem (with cheese), kartoflaki $z$ kasza (with groats), kartoflaki $z$ mięsem (with meat), kartoflaki $z$ soczewica (with lentils), etc. The variability stated in the name conveys the variability in the content and cooking recipe of the dish.

6. Names can have an informative function, typically in common nouns, persuasive (or, advertising) function, as in those proper names which consist of metaphors and comparisons and are aimed at the receiver as part of a certain language game, and an informational-persuasive function.

7. The meals that can be described as traditional seem to have highly unique names, both in form and function, as in jagielniaki and kartoflaki, the former having to do with millet and the latter with potatoes, yet neither signalling their content in any explicit or obvious way. Apart from their informative load (as to the primary component, for example), both perform a persuasive (advertising) function as well, in that they attract one's attention.

8. The dishes/meals that have come to be labelled as "South Podhalachian" in my analysis correspond to the Lévi-Strauss' category of that which is changed and culture-specific.

9. However, the examination invites some further distinctions to be made, such as traditional-vs.-modern and local-vs.-foreign. The latter opposition (that is, more descriptively, between what is one's own and what is somebody else's) can be seen in, for example, swojska kiełbasa ('folksy (homemade) sausage', lit. 'one's own sausage'), swojski chleb vs. ryba po japońsku (lit. 'folksy bread' vs. 'Japanese fish'), or sałatka grecka ('Greek salad'). The former (traditional-vs.-modern) opposition relates to meaning contextualisation.

10. The examined dishes/meals can also be grouped according to other criteria, such as the number of ingredients, the way ingredients are presented (listed and/or described), the type of situation, and ways of cooking. 

Memory and text - text memory 



\section{Oral text structure as a reflection of memory structure}

\section{Oral text $v i s-a-v i s$ oral memory}

For a long time now possible relationships between memory and oral culture have been examined on the grounds of culture studies, linguistics and ethnology. What has usually been emphasised is the communicative character of both orality and memory. It has been claimed that in oral communication, thoughts come into being and linger as long as they are communicated. Yet, this communication does not consist of merely repeating memorised texts. Rather, orality should be understood in terms of the original (etymological) meaning of communication and communicating - the Latin communicare means 'to share, to participate, to unite, to bring into common use' (after https://www.wordsense.eu/communicare/). As Pisarek understands it, the very notion of communication goes back to the Latin verb communico, communicare - 'to make common, to associate' and the noun communio - 'association, fellowship, sense of community' (Pisarek 2008: 13).

Oral communication brings people together. David Riesman (2004: 400) argues that while written communication projects a zone of personal space around people and even imposes a certain amount of isolation, oral discourse makes people feel closer to one another. Jack Goody (2010) sees the difference between writing/ reading and speaking, as the former isolating people from one another and the latter bringing them together and making them one:

[In writing] one begins at the top of the page and continues to the foot, then goes on to the next. One is (relatively) uninterrupted in the writing as well as in the reading. Oral discourse does not work like that; a speaker is constantly being interrupted because except in authoritarian situations it is dialogic, interactive. From one point of view there is no real division between speaker and audience. All are speakers, all are listeners (of a kind) and the conversation proceeds in starts and stops, often in incomplete sentences and nearly always in unfinished narratives. (Goody 2010: 142)

In other words, oral communication is collective, dialogic, ${ }^{39}$ and interactive, whereas written discourse - to use Riesman's (2004: 398) metaphor - leaves the

39 In order to appreciate the role of the speaker in the process of forming an oral text, oral discourse happens to be described as 'dialogic', or, more precisely, 'directed' towards somebody. Niecuła writes that 'the most typical oral (spoken) text is simply a dialogue, whereas written (printed) texts are typically monologues' (Niecuła 2001: 108). For 
inside door ajar but shuts the outside door, thus inviting alienation and isolation. The speaker enters into a direct relationship with the audience who, in a way, become spontaneous co-authors of the speaker's narration because their responses and reactions contribute to the ultimate shape of the speaker's message. 'Performing delivers a text' (Zumthor 2010: 127). That collectivity and sense of community, next to sequentiality and mnemonics, are typical characteristics of oral texts is also emphasised by S. Niebrzegowska-Bartmińska (2007: 41).

Oral memory ${ }^{40}$ abides in communication. Remembering fleeting and elusive messages of oral culture requires a specific kind of memory, something different from mere learning by heart because there is, in fact, nothing ready-made to memorise and recite in orality. Walter Ong (2002) makes it clear that 'oral memorisation is subject to variation from direct social pressures. Narrators narrate what audiences call for or will tolerate' (p. 65), which is why 'skilled oral narrators deliberately vary their traditional narratives because part of their skill is their ability to adjust to new audiences and new situations or simply to be coquettish' (p. 48). Thought is intertwined with memory systems. In oral culture, for a novel thought, worthwhile solution, or interesting idea not to fall into oblivion (that is, without it priorly being recorded in writing), it is not sufficient that it is clearly evidenced in a form that is easy to memorise. Thought, and thinking in general, must also follow defined mnemonic patterns meant, or designed, to be reiterated:

Your thought must come into being in heavily rhythmic, balanced patterns, in repetitions or antitheses, in alliterations and assonances, in epithetic and other formulary expressions, in standard thematic settings (...), in proverbs which are constantly heard by everyone so that they come to mind readily and which themselves are patterned for retention and ready recall, or in other mnemonic form. (Ong 2002: 34)

As J. Goody summarises the case, although 'in purely oral cultures, re-creation usually takes the place of a concern with exact recall' (Goody 2010: 54), yet this is done by means of formulaic expressions that are not void of meaning. To the contrary, however repetitive, they play an important role in composing and transmitting a story (Lord 2010: 94). This makes oral formulae indispensable in any oral culture:

this reason, Janina Labocha assumes that the essence of oral text consists in interactivity: 'the silent interlocutor and the speaking interlocutor are both equally "interactive"' (Labocha 1996: 56).

40 In using the terms oral memory and oral memorisation, I follow W. Ong (2002, esp. 56-66) and mean memory as it functions in oral culture. 
In an oral culture, to think through something in non-formulaic, non-patterned, nonmnemonic terms, even if it were possible, would be a waste of time, for such thought, once worked through, could never be recovered with any effectiveness, as it could be with the aid of writing. (Ong 2002: 35)

For this reason Paul Zumthor and Jean McGarry make a distinction between 'archival storage' and 'memorisation' (Zumthor and Garry 1984: 26). The former has to do with 'fixing all or part of the elements of the work [through writing or electronic recording]', whereas the latter, be it direct or indirect, 'necessitates an interiorisation of the text' (ibid.). This gives us twofold function of oral texts: for the group, that which people express/remember in oral texts is their source of knowledge, while for an individual member of the group oral texts provide an opportunity of enriching and extending that which is expressed/remembered. To quote Zumthor and Garry's example,

Having read a song in a score or heard it on a record, I can sing it myself or have it sung by another, and change it at will. The play of competition will lead me, perhaps, to remake an edition of this work or record a new interpretation (...). (Zumthor and Garry 1984: 27)

One way or another, although orality encourages further modifications and novel developments of texts, these will be of an interpretative nature. In Ong's words, 'the more sophisticated orally patterned thought is, the more it is likely to be marked by set expressions skilfully used' (Ong 2002: 35).

In summary, oral memorisation ${ }^{41}$ consists of repeating a vast inventory of set expressions:

$[\mathrm{O}] \mathrm{ral}$ societies must invest great energy in saying over and over again what has been learned arduously over the ages. This need establishes a highly traditionalist or conservative set of mind that with good reason inhibits intellectual experimentation. Knowledge is hard to come by and precious, and society regards highly those wise old men and women who specialise in conserving it, who know and can tell the stories of the days of old. By storing knowledge outside the mind, writing and, even more, print downgrade the figures of the wise old man and the wise old woman, repeaters of the past, in favour of younger discoverers of something new. (Ong 2002: 40-41)

41 W. Ong (2002: 36-56) enumerates and discusses a number of characteristics of orally based thought and expression. For him, oral culture is (i) additive (rather than subordinate), (ii) aggregative (rather than analytic), (iii) redundant or 'copious', (iv) conservative or traditionalist, (v) close to the human lifeworld, (vi) agonistically toned, (vii) empathetic and participatory (rather than objectively distanced), (viii) homeostatic, and (ix) situational (rather than abstract). 
Nevertheless, orality is not simply how an oral text functions or how it is communicated, but how it also embraces an axiological, or moral-ethic dimension, which makes it an interpretation of the worldview characteristic of a given culture, its aesthetic and axiological norms and standards. Orality is then, marked with (i) subjectivity entrenched in collectivity, (ii) spontaneity, (iii) situatedness, (iv) ethology (Sulima 1995b: 65; cf. Ożóg 2001). To quote P. Zumthor and J. Garry again,

Within a single text - as it is transmitted - and from text to text, one observes admixtures, reprises and repetitions which are probably elusive in nature. These are all "exchange phenomena" which give the impression of a circulation of wandering textual elements melding at each instance with others to form provisional compositions. (Zumthor and Garry 1984: 27)

No wonder, then, that because of its elusive nature oral texts are given numerous technical names, such as spoken, oral, verbal, or, as in Polish, potoczny 'colloquial, conversational' and ustny 'oral'.

However oral and synchronic in nature, folklore texts share some of the characteristics of written texts, such as the multiplicity and indeterminacy of addressees, the repetitiveness of the sending-receiving exchange and the exploitation of certain linguistic structures (Tołstaja 1989: 15). Similarly, J. Bartmiński assumes the lack of a clear-cut boundary between orality and literacy and as a consequence, between oral and written texts:

The oral/written opposition is binary only on the all-embracing level of culture. On the linguistic level, however, which is in the sense of performance and implementation, there seems to be a cline of orality-vis-à-vis-literacy, extending between the two extremes. (Bartmiński 2004: 433)

Yet, as J. Bartmiński claims, folklore texts are still different as they escape this simple orality-literacy opposition:

A popular opinion that oral texts are dynamic, variable, and imperfect because of their spontaneous character stems from an utterly unjustified generalisation about the whole category of folklore texts from the characteristics of merely one type of folklore texts. A close scrutiny of folklore texts in their whole does not legitimise such-like generalisation. (Bartmiński 1990: 132)

As can be seen in the preceding cursory survey of selected positions on orality and the possible relationship between memory and oral culture, the memory-oral text interface can be given two different readings, here phrased metaphorically:

- text as a memory aid (Pol. podpora pamięci),

- text as a memory mirror (Pol. lustro pamięci). 


\section{Text as a memory aid: recalling a text from memory}

That the structure of a text can strengthen a narrator's or a teller's memory, has been common knowledge since ancient times. One of the most successful aids in facilitating recalling has proved to be stylistic means, such as opening and closing formulae (see Wójcicka 2010), or the patterns of written texts described in detail by S. Niebrzegowską-Bartmińską (2007). Yet, the objective behind this part of the book is not an analysis of the text structure as a mnemonic device which would make it easier to memorise and remember a text, but a study of the text as evidence and a resource of collective memory. This means that whenever they are found in their memory-aiding function, stylistic devices will only be signalled and exemplified. Generally, a set of stylistic means can include the following: a formulaic, complex, set of objects organised on the basis of some commonality, opposition, mirror (that is, picture reflection and doubling), digital concept (a given digit signals and anticipates the rest of a text), sequence of events, equivalence and semantic loop.

A good example of a text built on an implied digital concept can be the following legend:

Text 1

[I] Proszę pań. Jak Pan Bóg stwarzał świat i stworzył człowieka, osła, psa i małpe $i$ wszystkim dał równo po trzydzieści lat. [II] Więc człowiek przeżywszy te trzydzieści lat, to sa najpiękniejsze lata. Popatrzyt, że świat jest taki piękny, a on już będzie musiał umierać, poszedł do Pana Boga z prośbą, żeby mu przedłużyt:

- Panie Boże, tak pięknie i tylko trzydzieści lat.

Przeszedł osioł z prośbą, żeby mu skrócit Pan Bóg:

- Bo te ciężary dźwigać i czekać na tą wiązkę tego siana, jak mi gospodarz przyniesie, to dla mnie za długo, Panie Boże.
[I] Dear Ladies. When God was creating the world, He created the man, the donkey, the dog and the monkey and He gave each of them 30 years of life. [II] So, the man would live these 30 years, and these were the most beautiful years. And the man would look around to see that the world was so beautiful, but he would soon have to die, and he went to God to ask God to do him a favour and let him live longer:

- Dear God, it is so beautiful all around me and I can only live for 30 years.

Then the donkey came to see God and asked Him to shorten his life:

- Because I must carry all these burdens and wait for the landlord to bring me a little bundle of hay and this all takes too long for me. 
Pan Bóg to wszystko wystuchał. Przyszedt później pies, że też za długo na tym łańcuchu stać $i$ czekać na miskę strawy, i szczekać, $i$ obszczekiwać:

- Trzydzieści lat, Panie Boże, skróć mi to.

No i Pan Bóg skrócił. Przyszła małpa: - Jestem brzydka, paskudna, ludzie pluja. Przecież przez trzydzieści lat tej śliny będzie więcej na mnie niż tej wełny, która posiadam. Panie Boże, zrób coś ze mną.

No i Pan Bóg odjąt te lata. No i siedzi, duma, jak tu przedłużyć. No i w kolejności przedłużył człowiekowi. [III] To przez te swoje trzydzieści lat, co żyje pełnym życiem, czy zatańczy, czy zaśpiewa i nawet jak popije i się przewróci, to nie bardzo jest się z czego śmiać. A następne piętnaście lat psie. To co już $z$ dobyt, co zapracowat psie. To co już zdobyt, co zapracowat, broni, ogarnia, ochrania, żeby mu kto tego nie zabrat. Strzeże, pilnuje ściśle. A następne małpie włosy siwieja, zęby wypadna. Ludzie patrza, no rzeczywiście się śmieja.

[IV] I to jest morał, ale $i$ bardzo prawda, $i$ ostatnie lata ma małpie. A to tylko zokazji tej, ze się wszyscy zrzekli, bo inaczej żyłby tylko te trzydzieści lat [WójPod, 66].
And God did as He was asked to do. Then the dog came and said it was too long for him, too, to be chained and wait for a bowl of food, and keep on barking: - Please, God, shorten my life.

And God did shorten the donkey's life. Then the monkey came:

- I'm ugly, hideous and people spit at me. So in the next 30 years there will be more saliva on me than the fur I possess. God, do something about this.

And God shortened the monkey's life. Then He sat and wondered how to make man's life longer. And He did. [III] There was nothing really to be happy about over the 30 years when the man lived a full life, no matter whether the man danced, or sung, or even drunk a bit and fell over. The next 15 years were truly dog-like. What the man has already got, what he has earned, is just a dog's life. For what he has now earned, he must watch over and guard so that nobody robs him. And guards what he has got quite attentively. And next the monkey is goes grey and starts losing his teeth. People look at the monkey and they laugh at him.

[IV] And this is the moral, and the very truth, that the last years are like the monkey's life. But were it not for the others to ask God to shorten their lives, the man would live only these 30 years. [WójPod, 66]

Text 1 is built of 4 segments, with Segments I and IV constituting the frame of the whole text. The text opens with the formulaic expression that is typical of religious texts - Jak Pan Bóg stwarzat świat... 'lit. When God was creating the world...., which introduces all the four protagonists of the story (the man, the donkey, the dog, the monkey). As found in magical fairy tales, this kind of formula is often labelled as the mother-formula because it gives rise to the rest 
of the narration. The next two segments (II and III) exemplify a parallel organisation of their texts in this sense that in each of the two, the order of the constituting elements stems from the order of the protagonists signalled in the opening formula (man - donkey - dog - monkey). Segment II can be described as an exemplification of what can be recalled from (mythological) collective memory that refers to the origin of the world and the man. Segment III constitutes a kind of summary, or generalisation of what has been the subject matter of Segment II, which is why the way the text is organised in Segment II is, in fact repeated in Segment III. There is however, one notable difference - the donkey part is not reproduced in Segment III.

Generally, Text 1 illustrates several of the mnemonics that can possibly be used as memory aids: text-structure generating formula, enumeration (of God's creatures), an implicit numerical concept that projects from the opening formula and man-animals opposition.

\section{Text as a memory mirror: textual ways of expressing memory}

As previously mentioned in Chapter I, one of the vital questions in relation to memory concerns the object of memory processes (Ricoeur 2004) - who it is that memory belongs to: an individual or a community and If it is the latter, how can collective memory possibly be researched. ${ }^{42}$

While studying individuals' memory, psychologists can rely on a number of tests (e.g. reproduction tests, which is repeating a text or selected words 10 minutes and then 24 hours after they have been read to a group of subjects). There seems to be no other way of arriving at collective memory than by examining texts. This corresponds with the psychologically-based threefold division of memory phases: (1) encoding, (2) storage, and (3) retrieval. 'The storage phase is implicit and we can know of it only on the basis of the next phase' (Kurcz 1992: 8), which means that we can infer about memory structure from what is retrieved and what is retrieved is the structure of a text. It is unimportant what the answer to the question of the true, or real, subject of memory processes is, there is no better way to it than through a text. Although this is well recognised in psychology, psychologists examine the memory-text relationship, whereas what matters in textual studies is the opposite orientation, that is, text-memory correspondences. In other words, a textologist examines a text structure order to infer about memory structures. More specifically, the important research

42 The term memory here means both 'memory operations' and 'that which is remembered'. 
question in text studies is not how people happen to remember a text, or how much of a text they may actually remember, but how what those people verbalise bears witness to what individuals and societies remember. This embraces the following problems: what kind(s) of memory is/are coded in a text, how the text develops or is being 'woven' by the narrator ${ }^{43}$, how the pieces of information included in the text happen to be recalled/remembered and communicated by the narrator, what the structure of an oral text tells us about the structure of memory (understood as 'that which is (being) remembered') and about the way memory is organised. As noticed by Atkinson i Hilgard (1975; after Herzyk 1980: 25), memory 'is not merely a loose and unordered set of facts and events. An information reservoir must have some organisation because if it did not, our [human] capacity of information retrieval would be a matter of sheer chance'. How can we then, discover this organisation if all that we can do is examine the way oral texts are organised? What do memory processes consist of if 'that which is remembered' is what can be found in a text, and what can be found in a text is a reflection of memory operations ${ }^{44}$ or, more specifically, the ways we encode information and predominantly, the ways we retrieve information.

Now, having examined non-petrified texts, we arrive at the threefold division of memory-reflecting structures: ${ }^{45}$

43 I mean here the metaphor in which a text is conceptualized as a fabric, or a cloth (cf. Niebrzegowska-Bartmińska 2007: 29).

44 Naturally, there are also other factors that determine structure of texts, such as situational parameters which include, for example, the explorer's question meant to direct, or distract in fact, the informant's attention towards something different. Nevertheless, this does mean that the structure of a text does not reflect memory. In fact, the structure of a text does show whether or not the speaker's memory is shaped by the recalled memories, and if it is, it reveals how much these memories influence (change) the whole process of memory retrieval. In Text 1 above, the informant (narrator) gives short answers to the asked questions only to be soon back to his/her way of thinking and narrating. So, these questions may well appear to be a kind of noise, or distraction, in the process of telling the story, but, in fact, they only reveal and confirm the true essence of oral collective memory, which is communication - oral collective memory lives in and through communication.

45 The texts analyzed here were collected by the members of the Department of Polish Culture, Institute of Culture Studies, Maria Curie-Skłodowska University, Lublin, during their field research in the format of free and loose interviews. The starting point of my examination is a theme-and-rheme analysis of the structure of the texts and an attempt at formulating models of text structures, each believed to reflect some memory structure. 
- intertextuality-based structure,

- association-based structure,

- intertextuality-cum-association structure (mixed type).

\subsection{Text structure based on intertextual memory}

The first of the three types of text organisation which reflect memory structure is based on the relationship between a verbal text and a text of culture, with the latter being referred to by the former. The obtained intertextuality is then understood here as the relationship between texts as such, not only linguistic ones but also cultural ones. In other words, we can speak, after Ryszard Nycz (2000: 84), about a kind of attribution, that is, a verbal text is a realisation/manifestation of the characteristics of the corresponding text of culture (e.g. chronological arrangement of events). In this sense, verbal texts are attributed with traits typical of texts of culture. In Gerard Genette's (1992) typology of transtextuality, this is the case of hypertextuality which captures the relationship between hypotext (an already existing text which here corresponds to a text of culture, such as a ceremony or a ritual) and hypertext (a resulting (verbal) text). In Genette's own words, hypertextuality is 'any relationship uniting a text $\mathrm{B}(\ldots)$ to an earlier text A (...), upon which it is grafted in a manner that is not that of commentary' (Genette 1997: 5). So, as Genette continues, in relation to the original hypotext, the resulting hypertext is, in fact a transformation, modification, elaboration or extension, which is why it may be a 'parody, spoof, sequel, translation' (ibid.).

From a textological perspective, we can speak of two kinds of intertextuality, that is, of two possible kinds of relationships between a verbal text and a text of culture:

- the procedural kind, as in Text 2 , and

- the structural kind, as in Texts 3 and 4.

\subsubsection{Intertextual memory: procedural dimension}

Text 2

[E:] A jak się odbywały swaty?

[I:] No mężczyzna przychodził najpierw do panny młodej, do tej, która miała być ta pannq młoda. No bo tam taka, no chco jo wydać, a on chce się Wojtek nas chce się uożenić. No i byśta prziszli tam. No to jak pośli, no to tom:
[E] And what did the matchmaking look like? [I:] Well, first the man would come and visit the bride, that is the girl that was to become this bride. This was all because people [her family] wanted her to get married, and he, Wojtek, wanted to get married, too. So, when they went to the bride, they said, as always: 


- Niech będzie pokwalony Jezus
Chrystus - jak zwykle.
- A po coście tu kumie przyszły?
Stołki się wycierało, żeby se, no bo
jak było dzieci, to mogły tam piasku
nasypać cy co.
- Nu, ja przyszedłem tu w takiej sprawie,
bo tom tom nas Wojtek, nasych tom
Jośków cy Bartków chciałby się uózenić.
Wy mocie Marynę taka to może by się,
byśta wydali za niego. To dobry chłopak.
No tak chwalili. No i jeżeli się zawołali
tej Marysi czy tam Zosi, jeżeli się ona
zgodziła, no to tam szykowali już wesele.
Ten poszedł, powiedział, że tak i że zgoda,
zrękowiny były. Za tydzień zaprosiły do
panny młodej rodziców i tego kawalera.
No młodzi siedzieli na odległość od
siebie i zerkali tylko oczyma, a starzy
dobijali targu. Jakie wiano dostanie, ile
czego. Czy krowę, czy świnię, czy to. No
bo to przecież było wszystko ważne. No
i później dochodziło do wesela po tych
zaręczynach. [INF 1]

- Praise be to Jesus Christ.

- And what did you come for?

The stools would be cleaned because if there were children around the seats, they might all be covered in sand or something. - I have come because our Wojtek, the one of the Jośkis or Bartkis, would like to get married. And you have got this Maryna and you could possibly let her marry him. He is a good boy.

And now the boy would be complemented. And if it happened that this Marysia or Zosia agreed, then they would start getting the wedding ready straightaway.. And the boy would go home and tell his people that everything was fine, and the engagement would follow. A week later this bachelor and his parents would be invited to the bride's home. But the boy and the girl would sit at a distance and would only look at each other, while their parents would do business, that is what the dowry is and how much of what. Whether it is a cow, or a pig, or what. Because all of this was naturally important. And later, after the engagement the wedding would take place. [INF 1]

The general subject matter (topic) of Text 2 is matchmaking (Pol. swaty, rel. to swat 'a matchmaker'), and this is introduced with the explorer's question $A$ jak sie odbywały swaty? (Eng. 'And what did the matchmaking look like?'). Let us note that the teller/narrator does not state the topic explicitly. The topic is concealed in the explorer's question, only to be later developed linearly.

Text 2 is structured chronologically, and its internal chronology is marked and signalled with the adverbs of time najpierw 'first', jak pośli 'when they went to..., za tydzień 'a week later', później 'later'. All of the sentences narrate something about matchmaking, even if this cannot be overtly identified in the text as such. Next to the general (global) topic, there are specific (local) ones - the visit at the would-be bride's place, agreement/deal, engagement, wedding preparation - arranged chronologically so that their progression can reflect the sequence of the actual events. This kind of scheme can be called, after Daneš (after Bartmiński 
and Niebrzegowska-Bartmińska 2009: 281), a 'thematic derivation'. 'On the suprasentential level of narration, [thematic derivation] happens to be used for the purposes of giving descriptions (...) when only one superordinate theme is assumed and distributed into a few subordinate, or local themes, each of which can be developed on its own' (ibid.).

Similarly, the text itself can be both a structure as well as a process developing in time; that is, it has its beginning and an end, matchmaking extends in time and has its marked beginning (No mężczyzna przychodził najpierw do panny młodej 'Well, first the man would come and visit the bride') and ending (No i później dochodziło do wesela po tych zaręczynach 'And later after this engagement the wedding would take place'). While the starting point of the matchmaking ritual is the visit at the bride's place, the end point is the wedding.

The text (Text 2) can also be seen as a reconstruction of the matchmaking ritual which, falls into the following stages:

(1) the matchmaker's visit to the bride's place (here: the exchange about the purpose of the visit),

(2) the girls' agreement/approval,

(3) wedding preparations,

(4) engagement - here: zrękowiny 'lit. handfasting', rel. to ręka 'a hand' (in Text 2 , engagement involves closing the deal),

(5) wedding.

Again, the structure of a matchmaking-related oral text, such as Text 2, reflects rather closely the structure of the matchmaking ritual itself. An important role in both structuring the text as well structuring memory is performed by keywords. In Text 2, the keywords (their choice and sequence) are motivated exclusively by the structure of the ritual that these words describe, hence the text follows, as Bartmiński and Niebrzegowska-Bartmińska (2009: 267) name it, the principle of partition - the whole of the matchmaking ritual happens to be distributed/ partitioned into the chronologically-sequenced parts of the ritual. So, the way the structure of both memory and text is organised is linear and partitive.

To sum up, the topic of Text 2 is a ritual having a well-defined structure and it is the structure of the ritual that organises the structure of the corresponding oral text. The two, the ritual and the text, are related to each other by means of intertextual correspondences, with the memory reflected in the text being collective memory of the procedural kind. More generally, while on the one hand we deal with a ceremony/ritual (wedding, funeral, carol singing, matchmaking) that can be described as a text of culture, on the other hand we have a verbal text that gives us an account of this text of culture. The structure of a given text of culture (here: matchmaking) shapes, imposes, governs and organises the structure of 
the corresponding verbal text. As much as in the lyrics of ritual songs there is specified the whole scenario of a given ritual' (Bartmiński and NiebrzegowskaBartmińska 2009: 230), the procedural outline of a piece of oral narration is given in the very ritual the piece discusses.

\subsubsection{Intertextual memory: the structural dimension}

Like the procedural kind of intertextual memory, the structurally-oriented intertextual memory embraces the relationship between oral texts and texts of culture, yet the latter comprises the narrator's description of space. According to Vladimir Toporov:

Text is spatial (i.e. it has its space, it is situated in "real" space, which is a characteristic of most human messages constituting the fundamental corpus of human culture), and space is a text (i.e. space can be understood as a message). (Toporow 2003: 15)

As the name suggests, structural intertextual memory favours the structural aspects of a text. Simply, a verbal text is a structure, and as a structure, it reflects the structure of the space being described and, at the same time, it mirrors collective memory. Take Texts 3 and 4.

Text 3

[E:] Jak wyglądały najstarsze domy, jakie pani pamięta?

[I:] Najstarsze domy pamiętam, i nawet sa po dzisiaj. Wysoka podmurówka $z$ kamienia. Z kamieniam. Było bardzo mało cementu $w$ nij. No jak to kiedyś... więcej wapna dawali. Ji był murowany bardzo wysoko. Bo pod tymi domami były obory. Czyli były krowy. Pod domem. Pod domem byty, tak chlew. A nad, dopiero nad chlewem byly mieszkania. To ważne. [Nie obok, tak?] Nie obok, pod. To jest bardzo ważne dla pani? [Tak, tak, tak] Czyli: podmurówka, podmurówka wysoka była z kamienia. Mało cementu. Wapna więcej sie dawało. Przeważnie to wapno było gorace, czyli na szybko, na goraco topione, żeby to chwytało ładnie. Ji byly obory. Po jednej stronie i po drugiej stronie. A na górze, u góry były mieszkania. [INF 2]
[E] What did the oldest houses that you remember look like?

[I:] I do remember the oldest houses, and they are even there still. High underpinning made from stone. Made from stone. There was not much cement in them. As often happened in the past, they would add more lime. And the house was very high because the cows were kept under the house. Below the house. They were below the house, yes, the pigsty. And it was only above the pigsty that there were rooms. This is important. [So, the rooms were not next to the pigsty, right?] No, not next to, but under, below. Is this very important for you? [Yes, it is.] So, the underpinning, high underpinning made from stone. Little cement. They would add more lime instead. This lime was usually hot, that is, they would melt it quickly so that it could bind fine. And there were cowsheds. On one side and on the other side. And at the top, on the top, there were rooms. 
The structure of Text 3 reflects the structure of the house being described, with the structuring principle being the bottom-up organisation. In Text 4, we have another structuring principle exemplified, this being a centre-periphery type of text and memory organisation (which is what reflects axiological assessment: from the most important to the less important).

Text 4

[E:] Co było w dużej izbie?

[I:] W tej dużej izbie to mieliśmy w rogu stół stał, jak to mówili, święty stół. Ji tam były kwiatuszki. Matka Boska była ulepiona, to byly takie z gliny, takie gliniane były ji świeczki stały. [Ten stół stał w rogu?] W rogu, tak, $w$ rogu. Ji jeszcze pod sufitem to było takie pająki, to taka, w jednym miejscu, kilka sie... szerokości pięć centymetry - to ja tak podejrzewam - pięć centymetry, była jak szeroka bibuła, tak pięć centymetry, to za dwa paski sie sklepiło ji tak sie kręciło. Ji to był taki pająk. Bo ji kierce byty. Kierce te z grochu. Ale te pajątki tak były. Ji to były jeszcze, u góry to takie były drewniane [...], takie belki, belki ji do tej belki na środku ji wtedy sie tak po rogach porozkręcały i sie kręcity. To takie ładne było, właśnie te pająki takie były. [INF 3]
[E:] And what was there in the big room?

[I:] In this big room we had a table in the corner, as they used to say - a holy table. And plants were there. And the Mother of God, made out of clay was there. This was made of clay and the candles were there. [This table was in the corner, right?] In the corner, yes, in the corner. And also, under the ceiling there were these spiders. At one place under the ceiling. Something like 5 centimetres wide this is at least what I think - 5 centimetres, like a wide piece of crepe paper. Yes, 5 centimetres, so we would glue two strips together and this all would go round and round. This was this spider. And also under the ceiling there were spiders made of wood. (...) They were beams, beams, attached to this beam in the middle, and then this all was wound up and would keep on spinning. This was so beautiful, these spiders were beautiful.

Texts 3 and 4 are meant to illustrate the relation where an oral text reflects the structure of the described space, implicitly pointing to the most important element of this space - the table. Naturally, a given space can also be described in other ways, for example, from the perspective of someone coming into the space (e.g. a house) and describing the space according to the assumed order: from the most conspicuous objects to the most indistinct objects, or from the left to the right, etc.). One way or another, the text is determined by the space that is described/narrated in the text. In this case, all that comes to the fore is the structural dimension of an oral text, and not its procedural dimension.

\subsection{Text structure based on associative memory (keywords)}

Associative memory is a kind of declarative and episodic memory that facilitates the relating of unrelated item by bringing them together in one whole and 
identifying the relationship between them. The phenomenon was previously recognised by Plato and Aristotle It was the latter who formulated his laws of association, which is that items can happen to be associated

- through contiguity in time (what is associated is objects that are next to each other in time);

- through contiguity in space (what is associated is objects that are close to each other in space)

- through similarity (concept A entails concept B due to the objective resemblance between the objects being conceptualised/imagined);

- through contrast (concept A entails concept B when the substance of, respectively, A and B, is antithetical to each other) (See Jagodzińska 2008: 32).

The texts I give below are, thus, meant to illustrate the possibility that text structure can be based on associations, which I hope to show through the following theme-and-rheme analysis. More specifically, as I claim, the transition between the subsequent local topics is facilitated through the keywords that invite/recall corresponding themes-memories.

Text 5 illustrates two kinds of associations: (i) through contiguity in time (war time and German occupation) as well as (ii) through the then-now (pastpresent) contrast (in the final part of the text).

\section{Text 5}

[E:] Jak już Niemcy odeszli, to ludzie inaczej zaczęli się ubierać? Coś się zmieniło w stroju?

[I:] Jak skończyła sie wojna? No troche inaczej. Traktory o te nastały. Zmieniło sie. A wpierw to kosa jeszcze była. Sierp tylko, kosy jeszcze nie było. Sierp kragły. Żnęli wszystko zboże.

[E:] A w tym ubiorze co się zmieniło? Cały czas te koszule lniane nosili?

[I:] E, późni to przestały. Kupowali. Takie handlarze sie narobili. Zwoziły skądś, bo to. Nie wiem, czy to nie stać było ludzi. To lniane wszystko było takie. I tak łatali te koszule. A dzieci na przykład co przed
[E:] And when the Germans were gone, did the people start dressing differently? What was different?

[I:] When the war was over? Well, there was little difference. Tractors appeared. Much of a change. First we would use the scythe. Or the sickle, in fact, as there was no scythe yet. A round sickle only. It was with the sickle that all the crops were harvested.

[E:] What changed in the way people would dress? Did they still wear those linen shirts?

[I:] Later on, they did not. They would buy them. So the hucksters were really busy bringing the shirts from I don't know where. I'm not sure whether people could really afford them. This all was 
wojno i potem już za uxokupacji jeszcze, to kto tam miat jakie meble dla dzieci. $O$, kotyska taka była, drzewiana, na biegunach. I tyle było zabawki dla dzieci. Spał tam dziecko to i tak, kolebka się nazywała. $\mathrm{Na}$ biegunach, na dwóch. I sie kołysało to dziecko. A w pole znów było na cztery nogi kołyska zrobiona i na ramie brał chłop, mąż, unojciec ten do roboty. Matka dziecko niesła. A uon kolyske na jednem ramieniu, na drugiem kose. Z temi dziećmi sie chodziło kosić przed wojna.

[E:] I ta kołyska taka w pole jak wyglądała?

[I:] Na cztery nogi. Cztery nogi miało, takie kije o tu dwa i drażek i płachte przywiazali, na dwa pęsty przywiązali lniano płachte. Jak koc. A to płachta była. I ona sie zrobiła tako kołyska. Nie widzieliście kołyski, nie? I to w pole było. Bo w polu cem dziecko uuśpił? Ji kołyska musiała być w pole. Jak daleko to sie jechało furmanką. Bo i pięć kilometrów było. A jak blisko, to po ramie, uo. A ona dziecko. Dziecko sie uśpiło, uona odbierała te. Kosiarz kosit na ściane sie nazywało. A ona podbierała to sie nazywało. Potem się wiązało i na dziesiątek sie składało. Gdzie indzij tam mendle sie nazywały, u nos dziesiątek sie nazywało, kopa zboża. I czapke sie potem zakładało na to zboże. I ono schło dwa tygodnie. I tak było. A potem juz jak ja przejął po uojou na przykład, to linen. And people would simply make do and mend those shirts. And take children, for example, before the war and then during the occupation who could possibly afford furniture for children? There might have been a wooden cradle, with rockers [Pol. here: kotyska 'lit. rocking cot']. And that was it. No other joy for children. The baby would sleep in it, and it was called a cradle [Pol. here: kolebka, 'lit. cradle']. With the rockers, two rockers. And people would cradle the baby. And when they worked in the field, they would take a four-legged cradle along. The man, the husband, father, that is the one to work, would carry it. The mother would carry the baby, and the man would carry the cradle under one arm and the scythe under the other. Before the war people would go harvesting with their babies.

[E:] And this cradle taken to the field, what did it look like?

[I:] It had four legs, four sticks, with the bar and the sheet tied. The linen sheet would be tied to two beams. Like a blanket. But this was a sheet. And in this way a kind of cradle was made. Have you never seen a cradle? No? And that one was meant for the field. How would you otherwise put the baby to sleep? There had to be a cradle. And people would go on a horse-driven wagon because at times it was even five kilometres. The baby would sleep. The reaper could carry on mowing by the wall, as it was called, and she would, as we say, land what he cut down. This all was later bundled and piled in tens. Somewhere else these tens, or stacks, were called mendels. And someone's cap would be placed on the top of these tens. And they would be left 


\begin{tabular}{|ll|} 
snopowiazałka była. Tera już bizon jest. & to dry for two weeks. Later on, we \\
Kombaj. Już syn co teraz, ale to wszystko & used a binder. Now we have a combine \\
upada u nos. Mój syn teroz mo gospodarke. & harvester. My son uses it, but this all is \\
Siedem kotów, trzy psy i tyle. A za mnie & going to the dogs. My son now runs \\
było cztery krowy, dwa jałówki, dwa konie & the farm. Seven cats, three dogs, and \\
było. A uxon tera mówi, że sie nie uxopłaci. & nothing else. Whereas in the past I had \\
Wszystko upada. Łąki nie kuszone. O taki & four cows, two heifers, two horses. And \\
las już uróst na takach, nie kuszone wcale. & now he tells me that all of this does not \\
A pierw taki co nie miat, taki gospodarz & pay. Everything is going down. The \\
biedniejszy, to sie nazywoł z wyrobku. Że nie & meadows are not mowed, not cut at all. \\
mioł konia, najmował, troche mioł ziemie & And in the past the husbandman was \\
tej. Co do skipki było wszędzie zorane, & poorer and did not have much but a little \\
zawsze wykoszone. A tera unugory uo leżo. & land was called [app.] an aspiring one \\
Nie wiem, do czego to dojdzie. [INF 4] & [Pol. zwyrobku]. And as he did not have \\
& any horse, he would hire one and would \\
& plough every single patch of his land. He \\
& would also cut the grass. And all that you \\
& see around is fallow fields. I honestly do \\
& not where this all is going. [INF 4] \\
\hline
\end{tabular}

The starting point in Text 5 is to question the way people used to dress before the (second-world) war. The subsequent local topics include the following: cradle, field cradle, working in the field: mowing, landing (Pol. podbieranie), the tens, farming today, aspiring husbandmen (Pol. $z$ wyrobku). All these topics share one and the same reference - the pre-war period, so no matter which topic is actually being developed, the elements of the text - dresses, cradle, stages of working in the field - are associated in the teller's mind through contiguity in time. Enumerated in one text, they jointly depict a picture of living in the country before the second-world war, with the narrator seamlessly passing from one topic to another. These topics (themes) are organised in a chain fashion in the first part of the text and in terms of a contrast in the final part. And so, the text opens with an account of what it was like before the war and ends with a reflection on what is it like now, in the present. This transition from 'then' (in the past) to 'now' (in the present), here in the context of farming conditions and prospects, seems to be characteristic of all folklore prose texts, especially recollections. That which happens to be retrieved in a recollection from storage memory, must be brought up-to-date, seen in the light of the present/current and as such, sided with functional memory.

Text 6, in turn, illustrates Aristoteles' law of contiguity through space. 


\section{Text 6}

No mój tatuś opowiadał, że ta chałupa jak była, bo ta cośmy mieszkali późnij, to była taka duża jedna, że późnij z tego domu, z tej, z tego pomieszczenia zrobili cztery. Stryjowie mieli kuchnie i pokoik, i myśmy mieli kuchnie i pokoik. I jeszcze sionke, sionka była u nas nieduża. Tak. To tego, to tam mówił tatuś, że jak tam dzieci było tych kilkoro, to jak były mrozy, to jak pierwszy mróz zaszedt na okna, to nie zszedł aż późni go słońce zagrzało. Ale dzieci byly małe, to jak babcia ugotowała, tam wytego, to postane tam coś było na kuchni, tam gdzie to palenisko było i jakiś tam worek czy coś rzucone i dzieci tam sie grzały na tem. Żeby jim ciepło było. To tatuś tak mój opowiadał, to juz nie pamiętam tego, to on opowiadat. Ale te piece to byty chlebowe. I ja jak nas było tyle ludzi, siedmioro, to Walduś był jeszcze w domu, nieżonaty byt, ji teściowie i rodzice i my, to co sobota piekłam chleb. Siało sie żyto i mielito sie na mąke i co sobota piekłam chleb. To tam było, sześć blaszki mi wchodziło do tego. Raz na tydzień sie piekło $i$ zawsze tam albo taki ryczany pieróg piekłam dwie blaszki, albo piekłam mielono bułke. No bo siedmioro ludzi, to było komu zjeść. I to co tydzień piekłam. Pieczony chleb, no bo to po prostu różnie ludzie piekli. A u nas sie na zakwasie piekło. Ale jaki ten chleb był pyszny, to aż mi sie nieraz śni w nocy, że ah... no mówie państwu, że no teroz nie ma takiego chleba. Nie dodawałam drożdzy nigdy, tylko na zakwasie. To sie zakwas robiło jednego dnia, troszke ciasta, on sie ruszyt. Późni sie rano sie, rano... wieczór sie rozczyniło. Rano sie zakwas robiło, na wieczór sie rozczyniło. Lało sie troszke wody i mąki i więcej sie robiło tego rozczynu. A późni rano sie wstało, dosypywało sie mąke, sól, wode, ile tam
Well, my daddy used to tell us what this house had been like because that was the one we lived in later and it had been such a big chamber that later four rooms were made out of it. My father's brother's family had a kitchen and a small room. So did we. And also a little hallway. Right. As my daddy used to tell us, when the frost came, when the first frostwork could be seen on a windowpane, it would stay on there till the sun melted it away. And there were quite a few children around, and they were small, so as the grandma was cooking, there was a kind of bedding, a bag or something, on top of the stove and the children would try to keep warm up there. So that they could feel warm. But what my daddy used to tell us I do not remember now. Still, these ovens were bread ovens. And as there were quite a few of us, seven altogether, with Walduś still living with us, unmarried, and the parents-in-law, and the parents, I would bake bread every Saturday. You would plant rye, then mill it into flour, and every Saturday I would bake bread, as many as six bread pans I could put into the oven. Once a week I used to do the baking, also two pans of buckwheat pierog, or bread crumbs. Seven people, so there was always somebody to feed. So I would do the baking every week. Different people would bake bread in different ways. I did the sourdough bread. How delicious this bread was! So good that sometimes I dream about it at night. Let me tell you this, what a pity that this bread is no longer available. I never added any yeast. Only sourdough. I would do the sourdough one day, a bit of dough to raise. (...) The sourdough would be prepared in the morning, and in the evening it would raise. 
trzeba było, ile była potrzebna i wymiesito sie i to rosto. Dzieża była taka specjalna, drewniana, zrobiona $z$ klepek $i$ to rosło. Jak petna dzieża była, to sie kładto w blaszki i rosto $w$ blaszki i w piec. Fajnie. I caly tydzień i nie byt czerstwy. Naprawde. Ten chleb taki byt pyszny. Jeszcze dzisiaj bym zjadła, ale żyta już nie siejemy $i$ kto by tam piekł na dwoje ludzi. Ile by to trzeba było. [INF 5]
You would pour some water on the flour and in this way you get more sourdough. And later in the morning you would wake up and add flour, salt, water, as much as necessary, and this all would be pugged and left to raise in a special bowl [Pol. dzieża], made of wooden staves. Once the bowl was full, the dough was put into the pans for it to raise further, and then into the oven. Good! And this bread did not get stale for the whole of the week. Really! This bread was so delicious. Even today I would like to have it straightaway, but we no longer plant rye, and who would bother to bake bread just for two people. This would be so much of an effort. [INF 5]

This example (Text 6) is a recollection which opens with a description of a country house. Unlike in Text 2 then, this narration does not make use of a situation extending in time which would follow its own order, but it is set in space. It is safe to assume that - according to what the informant communicates implicitly - the focal point of the room was the stove and it is the stove that becomes the next local theme (topic). The stove, in turn, triggers the informant's associations with bread and with baking bread, and this is precisely the third local topic in a row. The structure of both the text and the corresponding recollection is organised through their contiguity in space, in the sense that the subsequent local themes (oven, bread, baking) are associated with the space of the house. That the recollection opens with testimonial formulaic expressions - No mój tatuś opowiadat, że ta chałupa jak była, bo ta cośmy mieszkali późnij, to była taka duża jedna, że późnij z tego domu, $z$ tej, z tego pomieszczenia zrobili cztery (Eng. 'Well, my daddy used to tell us what this house had been like because that was the one we lived in later and it had been such a big chamber that later four rooms were made out of it') indicates that the text was meant for cross-generational oral circulation and played its communicative function of social memory. 'Social memory is possible only when interpersonal communication occurs' (Saryusz-Wolska 2011: 100).

The recollection ends with the transition to the present-time and present-day reality. So, structurally, the text develops from 'then' till 'now'. Moreover, in its structure, the text follows a Chinese-box organisation, that is, the local topics are projected like a set of boxes of graduated size, each fitting inside the next larger one on the from-the-general-to-the-specific basis: the house $>$ the oven $>$ the bread $>$ the sourdough. In practice, this is an association- or keywords-based text, where the flow of themes is determined with the most relevant notions. To 
use Daneš (1970) terminology, what we have in Text 6 is a simple linear progression where each rheme becomes the theme of the next part of a text, or a chain model (cf. Bartmiński 1990).

Now, Text 7 is an illustration of Aristoteles' law of association through similarity.

Text 7

[E:] A czy imieniny obchodzi się u pani w domu?

[I:] Imieniny [I], a to tak dzieci to i chodzo na imieniny i obchodzo imieniny, a mnie to tak przyjado, życzenia złożo i wnuki albo przyjado [II] no i babci, babci, bo na tego Władysława to już tam ni. Na święta to też, na święta [III] zawsze przyjeżḋajo. A w tym roku, w zeszłym roku [III A] zabrali mnie dzieci do Tarnobrzegu na święta na Boże Narodzenie, a $w$ tym roku to juz drugie znowu: „A jak mama tam była, to musi tu". I pojechałam do Lublina, a tak to. A tak święta to też takie, ale ono święta to już z dawna [IIIB]. Przeważnie święta Bożonarodzeniowe to dajo tak dużo uroku. Choinke [IIIB 1] to już się robiło czy lepszo czy gorszo. Pani, jak kiedyś jeszcze mało, młodeśmy byli małe, tośmy same robili aniołeczki [A] te. Robiło sie mu tako ładno sukieneczkę, tu paseczek miat, a główke przylepiało sie, takie były same główki. Tak o razem to sie urywało to tak $w$ jednym takiem na jednym papierku i te główke się przylepiło do tego $i$ to był aniołek już. A i wieszało się i jabłka, i ciasteczka się takie piekło [B]. Łańcuchy [C] się takie robiło $z$ tego takie się robiło łańcuszki, czasami słomka i takie cięte ładnie, to się umiało wyciać. Takie się cięte robiło i dołożyło sie do tej słomki i później drugi taki takie uo wyciete takie były z bibułki. I bibiłke sie kupiło i znowu słomka i takie ze słomki i z tej bibułki takie ładne były łańcuszki. A jak nie, to takie
[E:] Do you celebrate name days in your family?

[I:] Name days [I], well the children do celebrate name days, and when they come to visit me, they themselves, and the grandchildren, express their good wishes [II] to their grandma only as Władysław is no longer with us. For Christmas as well [III], they also come. And this year and last year [III A] one of my children took me to Tarnobrzeg for Christmas, and this year another one says this: 'Because Mum was there last year, you have to come to us this year'. So I went to Lublin. But Christmas now is not what it used be in the past [III B]. Christmas was usually full of charm. We used to dress the Christmas tree [III B1], and it was better or worse looking. When we all were young, we would do the angels ourselves [A]. They would be given their dresses in stripes, and the heads were glued, so there were only these heads. (...) And apples were placed on the Christmas tree, and cookies were baked [B]. And chains [C] were made, sometimes from straw, you would cut it nicely if you knew how to do that. One after another, all cut from the crepe paper. One would buy the crepe paper and add a stalk, and that would be chains. So we did these things ourselves, and the trees were not expensive. My Mum would buy some sweets [D]. But this all was cultivated, which is why all the children knew how to do this. Also, pictures 

\begin{tabular}{|l} 
jak prawdziwy łańcuch, o takie. I to tak z \\
takiego kolorowego papieru. To się robiło \\
i te choinki to nie były kosztowne, no \\
cukierków [D] coś tam się kupiło mama. \\
Ale to wszystko było i dlatego dzieci \\
umiały. Czy obrazy na te święta[IIIB 2] \\
to się przybijało, no już mieszkanie było \\
drewniane, było dobrze przybić. To tak \\
przybijało się, tak się wiązało gałazkki \\
i później tak się ładnie przybierało, a \\
firanki do obrazów to się umiało wycią́. \\
Ja umiałam, siostra umiała, ona jeszcze \\
lepij ode mnie takie gwiazdki takie różne. \\
Tak umiała złożyć jakoś, że te firanki takie \\
się do obrazu i później o tu się środek taki \\
był, a tu były dokoła te firanki takie do \\
obrazu. To tak już na święta to już było to \\
przystrajane, a takie starsze dziewczyny \\
jeszcze to umiały zrobić taki pająk [IIIB 3]. \\
To się nazywało pająk, to było przy powale, \\
było ze słomy, to było takie zrobione jak \\
pół tego stołu jedno największe. Słomki \\
na nitkach i to było powiązane i uxono się \\
trzymało tak jakby taki kwadrat ze słomy.
\end{tabular}

I jeden do drugiego byt przyczepiony $i$ to wyszło jakby pót tego stołu. Taka ze słomy jakby dech. A później do tego to znowu takie były kwiatuszki porobione i na nitce i tutaj, to było tak $z$ tyle takie długie i do tych słomek znowu były takie małe, mniejsze słomki takie, o tyle takie troche większe. Takie słomki i do nich byty dowiazane te nitki i jak się dmuchnęto. Wisiał o tak przy powale na środku, jak sie dmuchnęto albo ktoś drzwiami tam zapart, to się te pajaki poruszały. Bo to było wszystko na nitce i z bibułki. To było takie ładne, ale to trzeba było się długo tak dtubać, to trzeba, to kosztowało pracy, ale to było bardzo ładne. A jak nie myśmy takiego żeśmy nie robili, bośmy nie umieli jeszcze. Tośmy robili
[III B2] would be hung on the walls. The walls were wooden, so it was easy to drive the nails in. And this is how you did it. And the twigs would be bound into bundles, and they were later decorated. And one knew well how to do the curtains all around the pictures. I knew how to do them, and my sister did, and in fact she was better at doing the stars than me. She somehow knew how to fold the curtains that they fitted the pictures very well. And this all was ready well before Christmas, and the older girls knew also how to do the spider [IIIB 3]. It was called a spider because it would be hung at the very ceiling. It was made of straw and it could be as big as half of this table. Individual stalks would be bound with the thread and this all looked like a square made of straw. And these squares were attached to each other so that the whole thing might have been as big as half of this table. And little flowers were added to this, all hanging, attached with a thread. And as they were long, some shorted stalks were attached to the long ones. And when someone blew at it, or someone slammed the door, all the spiders would move. Because this all was hanging from the ceiling and was made of the crepe paper. It was all so beautiful, but it took a lot of time and it took a lot of work. And when we did not know how to do it all, we would simply cut a long piece of crepe paper and this was our spider. And we would attach it to the ceiling with a nail, and we would coil it and glue the rest to the ceiling. The whole thing would be coiled or skewed, and if blown at, it would move. So these were our decorations. Today one cannot possibly see that any more. It can't be found anywhere, and people no longer do anything like that because they have other [different] decorations. [INF 6] 
takie pająki, odcieło się tako dtugo bibułe i się wszystkie przybiło gwoździkiem, przybito do powaty, a później się one gdzieś poskręcało i przylepiło do powaty koniec. To byty takie skręcone, to też był pająk, też się go dmuchneło, to też się ruszat. I to takie byly te przystroje. Dziś tego to sie już nigdzie nie widzi, nigdzie nie ma i nawet ludzie tego już nie robia, bo to majo już inaksze stroje. [INF 6]

However difficult it is at times to follow Text 7 in terms of logic and relative chronology, the narration is well structured. The starting point in this recollection is stated in the explorer's question about name days. Yet, this is not the global theme of the whole text, but one of its local ones. The subsequent local themes are projected on the chain-association basis (i.e. rhemes become new themes) till Theme [III] appears - Christmas - and this proves to be the global topic of the whole. This theme develops through series-wound associations, which makes it possible for the local themes III A and III B to appear and be projected similarly, that is, as a one-after-another sequence. So, the first part of the text is structured by means of evoking associations and then the association-theme appears that is most interesting for the narrator. To sum up then, the kind of memory structure that we see behind/in the structure of Text 7 can be described as associative, partitive, and paradigmatic. Again, we need to conclude that the structure of this oral (verbal) text is determined by the structure of the corresponding text of culture, which resembles a (Christmas?) tree structure in the sense that the recollection proceeds from the higher to the lower levels of the text organisation.

\subsection{Text structure based on intertextuality-cum-association memory}

Next to clear-cut examples of either intertextuality- or association-based texts, one can also find the mixed type of text structure, which is a combination of both intertextuality memory nod association memory.

Text 8

[E:] Jak się dziecko rodzi czy jest jakiś taki zwyczaj?

[E:] And when the baby is born, is there any ritual? 
[I:] Urodziło się nas pięcioro dzieci [1], ale wszyscy, panie rodziliśmy się $w$ domu $[\mathbf{A}=\mathbf{T}]$. Nie było szpitala $[\mathrm{B}]$, no choćby, Boże, tu był taki mały szpital, tu gdzieś w Janowie. No teraz już jest duży [C]. Taki był mały szpital

[D], ale to nikt rodzić dziecka do szpitala nie jechat. Tylko była taka babcia [E], to się babcia nazywała [E1] i ona to uomiała odjąć to dziecko [E2]. Dzieci [2] wszystkie rodziliśmy się $w$ domu [A]. I już jak była starsza ode mnie [B], ja byłam młodsza [C] i jeszcze mój brat [D], to już jego chrzciny [D1], to już dobrze pamiętam [D1']. Dwa i pót roku ode mnie byt młodszy [D2], to dobrze pamiętam jego chrzciny [D3]. [3] A do śpiewania od mału miałam takie, gdzie taki jakiś pociag [A], że już zapamiętałam, jak jego chrzestna mama zaśpiewała na tych chrzcinach, to [A1]. A ja sobie stałam $z$ takim sasiedzkim dzieckiem, dzieckiem na skrzyni [B]. To byly jeszcze skrzynie [B1]. I stałam sobie na tej skrzyni [C], a tam śpiewali [D=4]. Już ci kumowie tamci goście to śpiewali [A], to ja już postyszałam. [E] To już umiałam zaśpiewać to, co już chrzestna zaśpiewała [F]. No i te dzieci wszystkie, to jeszcze powiedzieć o tym rodzeniu $[\mathbf{A}=\mathbf{T}]$. No to ta babcia [A1] przyszła, że to jakoś to było, że to bez lekarza, bez doktora. Ona tam już umiała [A1'] i to dziecko odjęła [A1"] i okąpała [A1"'] i jakoś ten pępuszek zawiązała [A1'"'=5]. To się zawiązywało pępuszek [5] dziecku lnem, co go przędło kadziele [A]. To jakoś to było najczyściejsze chyba najlepsze, tasiemeczek żadnych to nie było [B]. No i później te dzieci [A=T]. I jeszcze, jak sie później te dzieci były małe, to pamiętam, jak jeszcze mama te młodsze dzieci i jeszcze jak się ich później ich powijało [A1].
[I:] There were five of us children born [1], but we were all delivered at home $[\mathrm{A}=\mathrm{T}]$. There was no hospital [B], though, to be honest, there was something like a little hospital, somewhere here, in Janów. This hospital is a big one, now [C]. So, there was a little hospital [D], but no one would go to the hospital to give birth to a baby. All we had was a kind of grandma [E], she was called a grandma [E1] [Pol. babcia 'lit. a grandma'] and it was her who knew how to deliver a baby [E2]. We, the children, were all born at home $[\mathrm{A}]$. And I had an older sister [B], and I was younger [C], and I also had a brother [D], and his christening ceremony [D1], yes, I remember his christening very well [D1']. He was two years and a half years younger than me [D2], so I do remember his christening very well [D3]. [3] And from my early childhood I had a strong inclination to sing $[\mathrm{A}]$. So, I committed to my memory what his godmother sang at his christening [A1]. Together with the neighbour's child I was standing on a chest $[B]$. There were these chests still there in use [B1]. And I was standing on this chest $[C]$, and people were singing $[A]$, and I heard it all [E]. And I picked it up and was able to sing what his godmother was singing $[\mathbf{F}]$. And all these children, let me tell you more about how they were born $[\mathbf{A}=\mathbf{T}]$. So, when that grandma [A1] came, everything went fine without a physician, without a doctor. She knew somehow how to do it [A1'] and she would deliver a baby [A1"] and bathe it [A1"'] and tie off the belly button $\left[\mathrm{Al} 1^{\prime \prime \prime}=5\right]$. And you would tie the belly button [5] with a linen thread [A]. This was purest and, perhaps, best, and no ribbons were available as yet [B]. And later these children $[\mathbf{A}=\mathbf{T}]$. 
To im się tak rączki pieluszkq wzieno o tak sie uno [A1'] i tak sie prościutko do niego przyłożyło te ręce [A1"] i krajka taka była $i$ to sie jego okręciło [A1"'], ono było taki snopeczek [A1'"']. Takie sztywne [A1'”'"] i to chyba ono tak żeby sie. No mówili to tak trzeba zrobić, bo żeby się nie schylneło, żeby się tam nie skręciło [A1"'”']. Tak nie tak się chowało dzieci jak dzisiaj [A2]. To, to było takie, aż jak pomyśle dzisiaj, to dziwne. No i te dzieci $[\mathrm{A}=\mathrm{T}]$, no $i$ później nawet jak to było, że tak jak, jak już to dziecko, już ta mama tam tego była już zdrowsza. No, bo tam przecież każdy wie, musiała ozdrowić. No to, to dziecko szykowało się zaraz do chrztu [A1=5]. A chrzciło się dziecko [A1'=5], becika to nigdzie nie było [A1"=6]. Dlatego to dziecko owijało się ta krajka, żeby ono było takie sztywne. Bo teraz becikiem zwiąże sie i już go można wziąć. A w ten czas to było takie sztywne, taka kraje długo sie tak się go okręciło, te raczki miało przy sobie i tak leżało. Ono się tak nauczyło i też mogło se dobrze [śmiech]. A później jak do chrztu to robiło się to każde dziecko tak $w$ poduszce. Byle by taki stroik byt, to takie było uszyte takie długie, że tak ażo tak o tutaj z nóżek jeszcze spadło i tu takie falbanki. To się mu tam podsadziło pod niego tu rękaweczki mu nasadziło tu jakieś tam jakąś szlareczka może była. Ale to tak wszystkie dzieci sie w jednym ochrzciły. To tam było we wsi stroik taki. I później jak to dziecko do chrztu, poduszke się położyło na róg, się tak jakoś o tak ręko sie go wciungneło, o tak o się wcisnęło ten róg od poduszki i o tak miało tak troszke wyżej. Za to, że ten róg te pióra tam były. I to mu się zwiazało te poduszke i $w$ tej poduszcze go się tak wiozło. No, a tam już chrzestni ci chrzestni [7],
And also, when these children were still young, they were swaddled [A1]. Their arms would be bound with a nappy [A1'] so that the arms were placed straight along the body [A1"] and the baby would be swaddled in a kind of sheet [A1"'] so that the whole baby was like a little sheaf [A1'"']. This was pretty stiff [A1"'”] so that, as they used to say, the baby should not get bowed or curvy [A1"'"')]. So the baby were taken care of in a different way than today [A2]. As I think about this all now, this was sort of strange. And these children $[\mathrm{A}=\mathrm{T}]$, once their mum got stronger, and everybody knows that sooner or later [after the delivery] the mother must get healthier, were prepared for their christening ceremony $[\mathrm{A} 1=5]$. And the baby was christened [A1'=5]. And there was no such thing as a baby's sleeping bag [A1"=6], which is why the baby would be swaddled in this kind of sheet so that it would be stiff. Now one can put the baby into a sleeping bag and carry it along. But in the past this all was stiff, and the baby would be wrapped with this sheet several times, and its arms would be placed along the body, and the baby would be lying like that. It got used to that and was fine [laughter]. And at the christening the baby would be put on a pillow in a special and long frilled skirt. And all the babies were christened in this skirt. There was one for the whole village. And one of the corners of the pillow would be squeezed inside with the hand somehow so that the baby could have a kind of neckroll. This was possible because there were feathers in this corner of the pillow and the baby would be placed a bit higher. And this is how the baby would be taken to the church for the godparents to take care of it [7]. 
no to przychodziła chrzestna. No to która była tam bogatsza, to już coś tam przyniosła dla tego dziecka coś. Bo poduszka to już była domowa. To już zawsze z tego domu była poduszka. Już tam od dziecka. I tak sie ochrzciło to dziecko [A1"=5]. To wiezło się furo do kościoła, ale zaraz o teraz to sie ochrzci dziecko i tak jak u nas nawet w kościele i wszędzie no to mama później bierze, ksiadz błogosławi. To mama bierze dziecko, później tata bierze dziecko i chrzestna. Chrzestny już nie. I tak ksiądz błogosławi. A w ten czas to trzeba było do domu wrócić choć i mama była. Ale pamiętom, jak to było jeszcze już większa byłam, chodziło sie do kościoła, to wracali do domu, a później jechało się z tym dzieckiem, nazywało się do wywodu [8]. Mama jedzie [A]. Może to było czterdzieści dni może ile, nie pamiętam, ile tych dni było [B], ale później się jechało jeszcze raz ta fura [C]. Jeszcze, a to do wywodu pojechała $z$ dzieckiem [D]. Kobieta, matka, no tak już pojechała, już ci chrześni nie musieli jechać [E]. No i tak. A tych chrzestnych to się wybierało [E'], żeby tak więcej tak, tak $i$ teraz tak więcej, żeby to pobożni byli ludzie, zeby tam [E1]. No i to dziecko jak już było ochrzczone i po wywodzie, a do wywodu [8'] to matce nie było wolno chodzić, żeby za miedze gdzieś tam, bo jakby na sąsiedy, jakby gdzieś do rodziny, to nie. Matka dokad dziecko nie było $z$ nim, nie była do wywodu tego co się nazywało, to nie wolno jej było tak za miedze iść. No, a później to już chodziła, gdzie tam trzeba było czy gdzie tam o. [INF 6]
The pillow itself would come from the baby's home, but the godmother, if she could only afford it, would bring other things for the baby. And the baby would be christened [A1"=5]. Today everyone can go to the church for the christening ceremony. Mom holds the baby, and the priest blesses it. First Mom holds it, then Dad does, then the godmother does. But the godfather does not. And the priest does the blessing. But in the past you would need to come back home because this is where Mom had been left. I remember this as I was a bit older. First we would go to the church, then come back home, and then to the church again for Mom to be cleansed and blessed [8]. So, this time Mom would go [A]. It might have been forty days later, I don't remember how many days later this all took place [B], but we would certainly go by a horse cart again [C]. Again to the church, Mom and the baby [D]. As the woman, that is the mother, would go this time, the godparents did not need to $[\mathrm{E}]$. And these godparents were well chosen [E'] as they should be pious [E']. This mattered. So, when the baby was christened and then the mother cleansed [forty days later], and, mind you, till the cleansing day the mother would not be allowed to leave her place, not even to visit the neighbours or the family. For as long as the baby was not with her, which is till her cleansing day, the mother was not allowed to cross the balk. But later she could go wherever she needed. [INF 6]

In general, Text 8 is a brief enumeration of some of the rituals accompanying a baby's birth. In order to identify and analyse rather exhaustively how memory works in and throughout this text, let us first look for the mechanism of bringing 
its elements together in one whole on the local level, which is between the subsequent sentence-components. As can be seen, the global theme - again, signalled in the explorer's opening question - is childbirth. The explorer's general and impersonal question (Pol. jak się rodzity dzieci; specifically, it is a reflexive verb rodzić się 'to be born' used in an impersonal construction) happens to be transformed - in the informant's recollection - into a personal story concerned with her experiences and memories, as signalled already in Urodziło się nas pięcioro (Eng. 'There were five of us children born'). This shows the first fundamental characteristic of the memory hidden in the text: it is not an impersonal or timeless kind of memory. Instead, this memory is both time- and space-specific and relates to specific realia to reach the general and global only at the end of the story. So, the structure of this particular text can be given in terms of a development from autobiographical details to social generalities, or, to put it differently, from individual memory to collective memory, which is characteristic of and relevant to the teller alone to what is typical of and shared by the whole community. In other words, for the informant to answer the general question about the childbirth-related rituals cultivated in a given community, she begins with what she finds familiar, close, and known to herself, or what is relevant only for herself and that embraces her own memories of her own experiences. Naturally, this gives an egocentric slant to collective memory, which relates to Halbwachs' observation that collective memory manifests itself in individual memories but, in his/her recollections, the individual assumes a collective point of view (cf. Halbwachs 1992: 8).

As can be seen, any attempt at making clear-cut distinctions between individual memory and collective memory can be only of theoretical relevance. In practice, both of these two kinds of memory interpenetrate and foster each other. The reason seems to do with the fact that an oral text is, on principle, grounded in the colloquial and the conversational mode of speaking, which is why it is both concrete and anthropocentric. So is the departure point for analysing collective memory.

Now, having examined the structure of Text 8 , we can disclose the memory organisation behind it. Let us repeat that the global theme here is giving birth to a child. The narrator/informant introduces several local themes: Urodziło się nas pięcioro dzieci (Eng. 'There were five of us children born'), children, [I], śpiewali ('the people were singing'), jak się rodzity dzieci (lit. 'as the children were being born'), baptism/christening, a baby's sleeping bag, godparents, the mother's cleansing (Pol. wywód). At first glance, it seems that the informant departs notoriously from the global theme, at least several times. Let us notice that right at the beginning of the text, she does not answer the explorer's question in any explicit 
way, but begins with sketching something that might be considered to be a general background to her younger brother's baptism and christening. Yet, this does not mean that the order of subsequent local themes is accidental. On a closer reading, the text falls into two halves that can be entitled, respectively, as follows:

I. 'There were five of us children born': autobiographical recollections, and

II. 'As the children were being born': general recollections.

Once we allow for this division, we can clearly see the change in the narrative style: from an accumulation of verb forms used in the 1st person singular in Part I towards 3rd person singular verb forms in Part II. That this is so, projects from the narrator's own metatextual expressions: such as, half way through the text, No i te dzieci wszystkie to jeszcze powiedzieć o tym rodzeniu ('And all these children, let me tell you more about how they were born'), which is the narrator's metatextual reference to her global theme and to her opening Urodziło sie nas pięcioro ('There were five of us children born').

All the changes in the structure of Text 8 as well as in transitions in-between individual and collective memories are marked with the informant's specific sentences, some reflecting her own (autobiographical) memories and some reflecting her collective memory. It is worth noting that one of the local themes developing implicitly in a substantial part of the text is memory itself. This can be deciphered from the informant's autobiographical parts as well as from the metatextual formulae she uses: pamiętam 'I remember', nie pamiętam 'I do not remember'. The opening autobiographical part serves the purposes of a departure point for a long recollection about what the christening ritual used to look like in a given community. In other words, in order to recall old times and give evidence to one's recollections, one has to start with what is known, close, and individual. There are then three patterns of text organisation, all assuming a personal starting point:

- from the specific to the general,

- from the individual to the collective, and

- from the first thing remembered/recollected to the custom.

Memory (i.e. memory processes in general) is, then, a constitutive factor of Text 8. This framing role of memory is referred to in the text explicitly as many as five times, with the expressions pamiętam 'I remember', zapamiętałam 'I commited (sth) to my memory', nie pamiętam 'I don't remember'. Parallel to that, we have the narrator's metatextual expressions by which she signals that she is in control of the subject matter as well as seeming to discipline herself, or, rather, her memory. Another textual device that reflects memory processes is repetition. 
Specifically, it is through repetitions that a given rheme can become a new theme. In this way, the informant proceeds smoothly from one local theme to another without losing control over the global one, and successfully reconstructing the structure of the christening ritual (preparations, a baby's sleeping bag, choosing godparents, the mother's cleansing) as it is narrated in Part II of the text.

This all is a combination of association-based memory (as in Part I) and intertextuality-based memory (as in Part II), with the text proceeding from an individual recollection to a text of culture, here: the christening ritual. In its development, Text 8 is given a linear structure in the first part, and a paradigmatic one in the other part ${ }^{46}$ (cf. Bartmiński and Niebrzegowska-Bartmińska 2009: 267). Moreover, a closer look at the theme-and-rheme construction of the text reveals that once a given local theme (that is, a prior rheme, to be remembered) has been exhausted, the global one comes back.

A different scheme of text organisation can be seen in Text 9 below. This time, the text develops from collective memory through individual memory back to collective memory, or, in other words, from the general through the specific to the general again.

Text 9

[E:] Jak ubierali nieboszczyka do trumny?

[I:] No do trumny ubierali, no normalnie no. Jak starszy jak tam tego, to młodszy. Bo to zdarzało sie, różne umieraty. Różaniec dawały w ręke. uO tak ręce składały nieboszczykowi. uObrazek. No i trumna była u majstra.

[E:] A jaki obrazek?

[I:] Obrazek święty. Bo to wszystko katoliki u nas byty. Ludzie tego. Obrazek i tego. Bo to byty, na caly dzień. [II] Wyprowadzenie sie nazywało nieboszczyka do obiady. Jak mój dziadek zmar przed wojna, to ja
[E:] How would they dress the corpse for a funeral?

[I:] For a funeral the dead would be dressed in a typical way. Depending on whether the dead person was someone older or younger. People from all walks of life would die after all. A rosary would be placed in their hands crossed on the chest. And a picture. And the coffin was at the coffin maker's.

[E:] And what was this picture like?

[I:] This was a holy picture. We were all Catholics. That is why the picture was holy. [II] This all lasted the whole day. Until dinner time this was called seeing off the dead person. When my grandpa

46 As an example of this kind of structuring themes Bartmiński and NiebrzegowskaBartmińska give the chapter entitled Drzewa klimatu umiarkowanego (Eng. 'Trees of the moderate climate') in Ilustrowana encyklopedia. Drzewa świata, Kraków 2008, which is where the specific species are presented one after another: cypresses, junipers, firs, spruces, larches etc. 


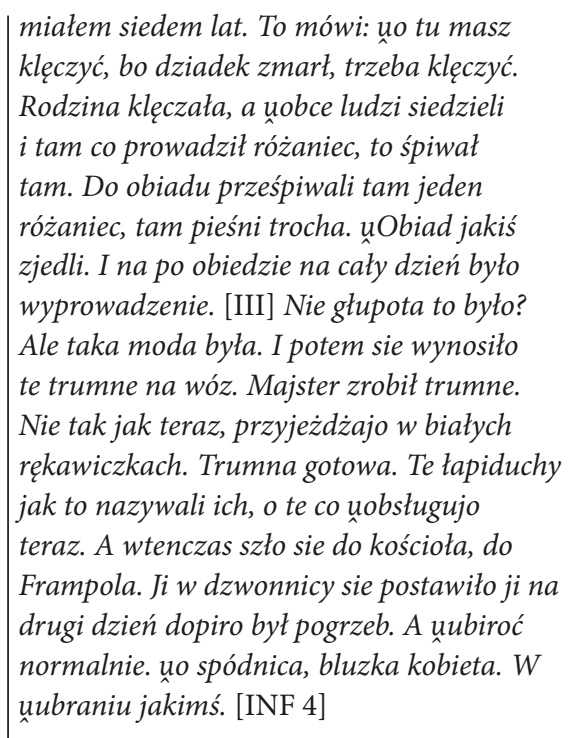

we need to be on our knees'. The whole family would be kneeling, and other people would be sitting around, and the one that would lead the rosery, he would also be singing. Until dinner they would pray one rosery and sing a couple of songs. Then they would have dinner. And then, after dinner, the rest of this seeing off the dead would follow. [III] This was no stupidity. It was a kind of fashion. And then the coffin was 'seen off' and placed on a cart. The coffin had been made by the coffin maker. Quite different from what it is now when they arrive wearing white gloves. And they bring the coffin along. This is all done by these sawbones, as those that do the service are called. But in the past you would need to drive the coffin to the church in Frampol. And the coffin would be left there in the belfry. And the funeral would take place only a day later. And the corpse would be dressed in a normal way. Some skirt, some blouse, if it was a woman. Dressed somehow, one way or another. [INF 4]

As the explorer's question about dressing the corpse opens the narrator's recollection, the role it plays is that of a key to the informant's memory storage. Once this information reservoir has been opened, an enumeration of things that are typically put into a coffin follows: the rosary and a holy picture. Contrary to what the explorer's question imposes and suggests, the global theme of the text is not dressing the corpse for a funeral, but a coffin. The second part of Text 9 is based on intertextual memory and, as such, it reflects the structure of the corresponding ceremony. The third (final) part is based on a now-then comparison (contrast), which is why it is both summary-like as well judgmental.

Now, it seems to be plausible to ask the question of how collective memory works in most general terms. In other words, having examined text patterns, can we posit any generalised models of collective memory? Could collective memory be regarded as a transition stage in-between communicative and cultural kinds 
of memory, or, perhaps, it should be seen as superordinate with regard to the other two?

In a psychological perspective, one can distinguish two kinds of semantic memory models: net models and semantic features models. The former presents memory in terms of a vast net of related concepts, whereas in the latter, concepts happen to be delimited by specified features, a semantic category being a set of features characteristic of the concepts belonging to a given category. As to the features themselves, there are two kinds of them: defining ones (essential for a given concept) and descriptive (relevant, yet not essential) (cf. Herzyk 1980). If we assume that the only chance to identify the structure of memory is through examining texts, we need to agree that both kinds of memory models are crisscrossing and complementary to each other.

Still, having analysed a text, one can also attempt a different typology of memory structures, which is when memory is taken to be the building material of texts. From this account, we obtain:

- intertextuality-based memory - a verbal text follows the structure of the corresponding culture text extending in space and/or in time.

Time here, is an organising principle for the subsequent rhemes to be recalled. The chronology of a text of culture (which, if we recall, provides the global theme for a verbal text) structures the linear layout of an oral text. As much as the text built on it, memory itself shows a chronologically organised structure, too. In this case, the theme embraces activities, customs, rituals (procedural memory) or space (structural memory), the dominant principle of organising themes being partition (i.e. the whole is partitioned into its parts which are organised chronologically).

- association-based structure, where the subsequent associations become theme-turned rhemes of a text.

Both memory and text have a chain-like structure, so subsequent local themes are recalled by means of associating different themes. Each of the local themes can be turned into a topic (theme) of an independent text, the structuring principle being paradigmatic and metonymical relations. What determines the structure of an oral text is either time or space.

Next to these two, some other models of memory may certainly be derived from a close analysis of how a text is structured, yet our proposal is an attempt at sketching a model which could directly correspond to the theme-rheme structure of oral texts. In this context, the following major patterns of memory organisation can be proposed: 
- ritual-based linear organisation $[2,7]$,

- now-and-then comparison parallel organisation [3],

- contrast-based organisation [5],

- from-center-to-periphery [4], or from-specific-to-general [6], or fromindividually-experienced-to-typical [8], or from general-to-specific [8], organisation.

Our analysis seems to favour Jan Assmann's proposal to consider collective memory as superordinate in relation to communicative and cultural memories. As evidenced in our examples, communicative memory and cultural memory interpenetrate each other within the bounds of one and the same text. In their reporting on past customs and rituals, our narrators begin with what is known to them either from their own experience or from what their families have told them. The Assmanns take rituals as such to be carriers of cultural memory, so ritual-related stories, no matter whether they are based on one's own participation or mere observation, could be examples of communicative memory. Text [2] is a clear-cut instance of a text where both kinds of memory interpenetrate each other, the starting point involving recollections based on communicative memory (autobiographical memories of the family place) and the end point concluding with a ritual-related story of the cultural memory kind. In short, our text-oriented examination seems to confirm J. Assmann's claim that communicative and cultural memories are components of the superordinate collective memory. 


\section{Text variation as information about the collective memory functioning of a text}

The present chapter aims at presenting specific ways of researching and examining memory-folklore text relationships. It also attempts to identify a means of investigating collective memory through text analysis.

\section{The double nature of a folklore text as collective memory information}

Initially, the aim is to tackle the question of why texts of folklore specifically provide an important insight into collective memory research and mirror the memory of a social group. A text of folklore, according to J. Bartmiński, is a superlinguistic unit, a macro-sign which is marked as both a given genre and a given style, can be subject to a holistic semantic interpretation, is coherent in its structure and its semantic import, can be analysed in terms of its internal semantic distinctions and delimitations, and - in the case of longer texts - can also be examined with regard to its logical and compositional structure. As J. Barmiński makes the point,

[texts of folklore] have a unique structure and function in a potentially unique way. On the one hand, they present a temporal and procedural succession of individual sentences, yet, on the other hand, they constitute a whole which has been organised and integrated according to a paradigm of its own. In folklore, this whole happens to be recognised in the process of reproduction correlated necessarily with the context of adaptation to specific coding-encoding situations. (Bartmiński 1992: 251)

This extended temporal procedural dimension is connected to the fact that texts of folklore are typically handed down from generation to generation,

stands for their double nature: as an abstract, potentially existing matrix and as a realisation of that matrix in a concrete situation, this implementation being, say, a working variant, or an adaptation of a socially accepted message that relates to the specific "here and now" of the speaker and its listeners. (Ługowska 2002: 13)

The double nature that Ługowska ascribes to texts of folklore cannot be found to any significant degree in other kinds of texts. However, individual 'working variants', texts of folklore can then, be examined in the context of collective memory. To repeat, a folklore text can be seen as a relatively stable crossgenerational pattern (matrix), but if seen historically, its respective variants serve to be reference points for charting transformations which have taken place in 
collective memory. In other words, despite the variability, multiplicity, and bias of its textual implementations, collective memory remains a continuum.

To mention some other attributes, texts of folklore are reiterative, dialoguelike, oral, syncretic, multi-textured, and referential, the latter involving all the aspects of a given situation (such as the speaker, the listener, the place, the time, and the perceived objects). Folklore texts can then, be given 'a systemic as much as a performative aspect because they belong to the competence of culture as well as the competence of implementation' (Bartmiński 1992: 253).

That texts of folklore have double nature can be a source of information on collective memory. More specifically, the matrix a text is built upon, points to a kind of continuous memory, that is, the stable elements of collective memory that happen to be recalled through generations. The various realisations of the matrix, in turn, disclose the multiplicity of collective memories, with a close reading of respective variants facilitating the answering of the question, what it is in collective memory that is recalled and explored and therefore, still proves relevant.

If that is the case, a text of folklore does not only evidence, record and transmit memory, but it is also - through its many variants - a witness to the selectivity and polymorphism (in the sense of M. Golka 2009: 24) of memory. Texts of folklore reveal transformations of memory, unveil changes in the value system of a social group which assumes the role of a depository of memory, and show what is forgotten and what is implanted. ${ }^{47}$ As Elżbieta Hałas (2017) understands B. Uspienski (1998: 28), in this respect,

Perception of the past influences the future course of history (...). The movement of history as a course of events (...) is oriented towards the future. However, although the course of history is determined in the present, the past is constantly being reconstructed and reinterpreted anew from the perspective of that very same present. (Hałas 2017: 377)

\section{Folklore text variation: from structure of a text to picture of an object}

As mentioned above, one of the characteristics of a text of folklore is that it can be implemented in many variants. Synchronic and diachronic analyses of this variation provide answers to the following questions:

47 Implanting (Pol. implantowanie) is defined by M. Golka as 'a supplementation of memory deficits, in the form of faithful copying, stylization, or even - at times - sheer mistification, the latter often being accepted after some time as true and only available memory' (Golka 2009: 24). 
- How does one? text of folklore function in a group's memory, or how extensive is the social circulation of a text?

One answer comes with an analysis of gossip, or urban myth, especially when the buzz projecting from a local community (micro-gossip), only refers to people that we know (relatives, acquaintances, friends), but unfolds over time and begins to involve further social circles to become macro-gossip.

- How do medially- and Internet-communicated texts affect collective memory?

An answer comes with a comparative analysis of current urban myths (as examples of folklore texts, that is) and the corresponding formally-disseminated coverage, as in the press, television, or Internet. Such examination is based on oral-versuswritten kinds of memory, which is a contrast that reveals the correspondences between collective memory and respectively, orality and literacy.

- How do the processes of folklorism and folklorisation affect collective memory?

The latter term, folklorisation, was introduced by Hermann Bausinger, popularised in Poland by Józef Burszta in 1965, and is now referred to

(...) a socio-cultural trend that aims at introducing folklore traditions to many aspects of the present-day life, as second-handed in import, transformed and stylised in form, and triggered by propaganda, commercial and other reasons which promote the use of a tradition outside the cultural context in which it was created. (Krawczyk-Wasilewska 1986: 50)

This term was later replaced with folklorism, which has been used ever since and is defined as

a phenomenon of a deliberate, intended, and purposeful translocation (...) of selected elements of folklore culture from their original and natural environment, be it historical or actual, to a different one which is larger in extent and involves the whole of a society and culture. This translocation is always accompanied with a positive reinforcement of the elements being translocated, and may be given different forms, from a mere „interpolation” (no formal modifications) (...) to a reflection of „the folklore reality” in terms of a given artistic convention of a given cultural elite. (Burszta 1974: 308)

The 'interpolation' case of folklorism corresponds to what Roch Sulima recognises as 'a popular and mass culture styling' (Sulima 1995a: 392) which consists of 'quoting' selected elements of folklore culture (Sulima 1992: 183).

Folklorism has been ascribed to three main characteristics: (1) extracting those elements of traditional folk culture which appear attractive in some sense, because of their artistic form or emotional import; (2) presenting these elements to an audience in a form which is either more or less authentic or processed, or 
even combining them with foreign elements, for the sake of satisfying individual and/or collective needs, for example aesthetic ones; (3) employing these elements outside the contexts in which they were originally used (Burszta 1974: 311). It is unsurprising, then, that folklorism can be further characterised by derivative nature in relation to folklore, institutionalisation, commonality (in the sense that it features widely in different spheres of culture: music, literature, dance, fine arts, applied art), and selectivity (i.e. only selected elements happen to be singled out for revival) (cf. Rokosz 2009: 60).

As can be seen, in Polish folklore research, folklorism and folklorisation are used interchangeably. Nevertheless, Vilmos Voigt's attempt at making a distinction between the two has also been recognised, as far as he 'opted for a bidirectional relationship between folklore and non-folklore phenomena; folklorism begins with folklore only to shade into non-folklore, whereas folklorisation starts with non-folklore and gravitates towards folklore' (Krawczyk-Wasilewska 1986: 52). This is presented in diagram:

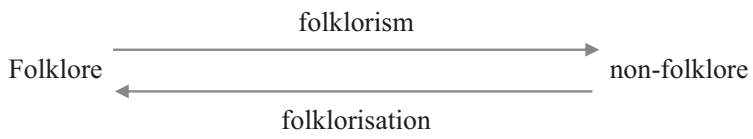

The process of transforming a traditional (anonymous) text into a present-day (authorial) one shows why folklore still deserves social recognition and how this recognition serves as a key to understanding how collective memory functions. Inspired by traditional folklore, current authorial texts must be described as discriminating, in the sense that their authors opt only for those traditional elements which appear timeless and stand for the essence of a given genre (e.g. fairy tales). Owing to its selectivity and social grounding, folklorism is, in fact, a memory-aiding phenomenon on the one hand, and on the other hand, a dialogue with many different traditions, a play of genre conventions.

- How can collective memory be affected by the transformations of a text's genre conventions?

One example of this problem can be observed in transforming a recollection story into a folk ballad, which, in fact, consists of turning a contemporary folklore genre, fluid and non-petrified, into a traditional folklore genre, well-established, if not fossilised, both in form and substance. If so, transformations of genre conventions can be seen to go? against Jan Assmann's conception of collective memory, be it in its communicative or cultural dimensions (see Chapter I). 
Namely, what we have here on one side, is a recollection story which is typically transmitted by non-specialised carriers of memory, such as nonspecific, contemporary witnesses within a given memory community, who tell the story in an underdeveloped and natural form acquiring its actual shape in everyday interactions. This story is transformed, on the other hand into a ballad which needs to be recognised as a fully petrified genre of a sophisticated form communicated by specialised carriers of tradition. The net effect of the transformation process is evidence of the past having been mythologised and of communicative memory having been converted into cultural memory.

As a result of folklore texts appearing in many variants, a multi-aspectual perspective on collective memory is permitted:

(1) as an activity, collective memory embraces the processes of remembering and forgetting, or, in other words, what (i.e. which folklore texts, which segments and motifs of texts) happens to be handed down from generation to generation;

(2) as an object, collective memory depicts a picture of the events which are narrated in a text, or, a general picture of what comes to be handed down in different folklore genres;

(3) as a subject, collective memory is neither a process of communication nor an object being communicated, but, firstly an attempt at recording the values cherished by a given social group understood as a collaborative carrier, or a depositary of collective memory. In this sense, residing in and deriving from collective memory, a text of folklore constitutes a source of information about the very social group and allows a pictorial reconstruction of that group as a memory carrier/bearer This reconstruction is an ethnolinguistic analysis as it answers the question of what it is that the remembered and/ or recalled folklore text tells us about those who remember and recall it (cf. Szacki 1971: 98).

As presented, this threefold approach paves the way for interdisciplinary research on collective memory: from historiography (which examines the relationship between textual memory and facts) through textual linguistics (where text structure is taken to be a reflection of memory structure and, thus, provides a textual picture of what (has) happened) to ethnolinguistics (which deals with the subject of memory). This account seems to comply with Halbwachs' and Assmann's notions of memory figures, that is, space and time (which corresponds to collective memory as an activity), reconstructivity (collective memory as an object), and social-group grounding (collective memory as a subject). 


\section{Morphological analysis as an examination of an oral text circulation in collective memory}

One way of examining text variants which - as argued above - provide information about how the text circulates in collective memory is W. Propp's morphologically-oriented textual analysis. This method can be considered the crowning achievement of structuralist narratology, its research objective being delimiting narration schemas, or, in other words, 'general patterns of structuring a story that is not a speech event or any concrete utterance, but a sequence of events which come to unfold in a specific situation and remain related to a more or less clearly designated subject' (Głowiński 2004: 8). In his analysis of one hundred fairy tales, Propp intended to identify the characteristics of a text structure, to delimit the stable and variable elements of texts from identical genres and, thereby, to arrive at a set of the text-type attributes.

A similar research objective can be found in a modified version of Propp's methodology which J. Bartmiński and S. Niebrzegowska-Bartmińska applied to Christmas carols, fairy tales and witch doctors' charms. As Niebrzegowska-Bartmińska admits, she 'employ[s] morphological analysis (...) in order to attempt to delimit a text matrix on various levels of description' (Niebrzegowska-Bartmińska 2007: 17). Her material includes rhyming texts (charms), songs (carols), and prose (fairy tales). As these three are petrified genres which have a relatively stable structure, what the morphological analysis reveals in this case is mainly how texts are constructed. This is because all that a comparison of different variants of the same text shows is that a text can be divided into respective components which may appear in various combinations, preserving the same form' (Bartmiński 1998: 151). A text resembles, then, a Lego-block construction, or a whole, built out of ready-made blocks, whereas tradition appears to be a warehouse where these blocks are stored. 'Tradition is an open-ended set of readily available structures (segments), each of which can be used over and over again' (Niebrzegowska-Bartmińska 2007: 109).

Naturally, non-petrified texts, that is, texts that have not yet been given any stable form, such as urban legends (gossip), historical tales, myths etc., can only partially be grasped in terms of the Lego-blocks metaphor. The tradition warehouse is also explored here, but there is a reasonable amount of casing the genrespecific segments with elements of other genres, which shows how collective memory not only accumulates and stores but also enriches its textual resources.

To sum up, in the case of non-petrified oral texts, the so-called morphological analysis proves to be key to the understanding of how these texts are being disseminated and circulated. In short, it reveals how a given text functions in the public domain. More specifically, the morphological analysis of variants of nonpetrified folklore texts consists of the following: 
(1) collating and comparing traditional and current variants of a text, revealing changes in collective memory, showing its relevance to a group and which memory resources are explored and why;

(2) presenting a text both as a memory carrier and a model of the world; as social transformations find their reflection in memory resources, nonpetrified folkloric texts such as fairy tales and record changes in the picture of the world and in collective memory;

(3) attempting to explicate general patterns of memory selectivity;

(4) identifying the subject of memory, which is the very value that determines what it is that happens to be committed to memory, remembered, recalled, and forgotten;

(5) examining one and the same motif in different text genres, which facilitates the use of operational concepts of genre memory and genre non-memory or, more descriptively, what it is that comes to be, independently remembered and forgotten in respective folkloric genres (i.e. which narrations of what has happened, e.g., historical events, are and are not recalled);

(6) text-type analysis of folklore texts, which brings together folklore genres and corresponding kinds of memory;

(7) evidencing that modifications in text genres bear witness to transformations in collective memory.

\section{Text in a social group's memory: circulation of an oral text}

In this section, variants of one non-petrified and highly communicative kind of folklore text will be scrutinised - the urban legend which is regarded as a modern folklore genre, typically subject to oral dissemination. Although the methodology used here is that of a morphological analysis (see above), the main purpose is not to advocate it as an analytical tool, but first of all, as a way of identifying how selected examples of the urban legend function, or circulate, in collective memory. To put it differently, the methodological position here is that the morphological analysis does, indeed, disclose ways in which an oral text functions among a social group. For this reason, the genre to be scrutinised has been chosen deliberately. In Polish, there are several terms that can be used interchangeably: plotka ${ }^{48}$ 'gossip', pogłoska 'rumour', legenda miejska 'urban legend/ myth' As can be observe, there remain serious definitional problems in defining

48 For more on that, see Thiele-Dohrmann 1980, Rosnov 1976, Uniłowski and Kędra (ed.) 1994, Kopczyńska and Kopczyński 2008, Baran-Łaszkiewicz, NiebrzegowskaBartmińska, and Wasiuta (ed.) 2010, Błachowicz 2010. 
plotka 'gossip' itself, especially in contrast to the related dowcip 'joke', pogtoska ${ }^{49}$ 'rumour', or pomówienie 'slander/allegation'. Nor is it easy to delimit the English term gossip from hearsay, tittle-tattle, or rumour. Evidently, however universal and basic gossip is as an oral folklore genre and as a type of verbal communication, some further research is required to clarify this notion.

For our purposes, it is assumed that, in terms of text-type considerations, gossip is most closely related to urban legend. In this we follow Brunvand's observation that there is a tendency now to extend the scope of gossip (i.e. brief and incomplete messages) into fully-fledged legends-stories (i.e. extended and/ or punch-lined versions of the same substance as in gossip) (cf. Błachowicz 2010: 29). For this reason, the terms gossip (Pol. plotka) and urban legend (Pol. legenda miejska) will be used interchangeably in what follows. In other words, there will be an attempt not only to show how in the process of its being transmitted, a piece of gossip may actually be transformed into a urban legend, but also to assume that gossip embraces the themes and motifs that are typical of urban legends. ${ }^{50}$ To make a working distinction between the two, Dionizjusz Czubala calls the latter macro-gossip and distinguishes them from micro-gossip, that is, gossip about one's relatives, friends, acquaintances, colleagues etc. In the context of this distinction, the text to be analysed below is a borderline case, as it concerns both macro- and micro-gossip. Namely, it originated in a local community, so by origin it is a piece of micro-gossip, but its actual range and prospect development point to macro-gossip as well.

The examination of the selected text variants about a missing student ${ }^{51}$ falls into two stages: an external (comparative) analysis of the text variants $\mathrm{s}^{52}$ and an internal (immanent) analysis of the text variants with the intention of identifying the so-called textual morphemes (Pol. tekstowe morfemy, after NiebrzegowskaBartmińska 2007: 113).

49 A distinction between plotka 'gossip' and pogłoska 'rumour' is attempted in, among others, K. Thiele-Dohrmann (1980:65). Accordingly, gossip is said to be aimed at one's personal affairs, whereas rumor deals with more general issues, of a greater importance. Still, in the Polish gossip research, both plotka and pogłoska are interchangeably used for the sense 'urban legend', as by Dionizjusz Czubala and Ewy Błachowicz.

50 This claim seems to be confirmed with the colloquial meaning of plotka 'gossip'.

51 The material basis of the analysis constitutes variants of the text about Marek W., a student that went missing in April 2009. The variants were collected by students of Culture Studies, Maria Curie-Skłodowska University, Lublin, in May 2009.

52 Texts 1-4 were collected and transcribed by Przemysław Lorenz, the remaining ones (Texts 5-8) by Magdalena Szymczyk. 


\section{Text 1}

Historie, z tego co mi tata opowiadal, który pracuje $w$ szkole u nas na wsi. Jednym $z$ nauczycieli jest geograf, pan Wojciechowski, który jest wujkiem Marka no i dlatego pewnego dnia jak zadzwoniłam do domu i powiedziałam, że zaginał chłopak $z$ drugiego roku, bodajże prawa, chyba prawo studiowat, to tato od razu wpadł, znaczy wpadt, dziwnie się zapytat, czy chodzi o Marka Wojciechowskiego, bo właśnie dzisiaj geograf dziwnie wyglądał $w$ szkole. No $i$ tak się okazało od słowa do słowa, że to ten sam, który kiedyś przyjeżdzał dzieciaki uczyć w szkole karate, no bo był chłopak wysportowany i prawdopodobnie to... no chodziły plotki, że gdy go znal..., że go znaleźli, zanim go znaleźli, że miał wycięte yyyy narządy wewnętrzne, do przeszczepu bodajże na czarny rynek, nie wiadomo. Jednak gdy go znaleźli w... w tym stawie $w$ zasadzie ja nie wierzyłam $w$ to, $\dot{z} e$ on dziesięć kilometrów przeszedł po pijaku i po prostu tak sobie przeszedt, wpadt $i$ utopit się $w$ stawie. Więc ... w każdym bądź razie yyy [...] plotka była, że właśnie wycieli mu te narzady. Kiedy $\boldsymbol{w}$ gazetach, $\boldsymbol{w}$ Internecie wyszło, że nie, że to jednak, że nie znaleziono na nim śladów żadnej przemocy, bo tak określiła policja. No mimo wszystko jakoś $w$ to nie wierzyłam, zwłaszcza że kilka lat wcześniej odnaleziono tutaj dziewczyne z naszych okolic, która była pozbawiona narządów, a znaleziono ja dopiero po dwóch latach ... po zaginięciu. Dlatego myślę, że Marek sam nie doszedł tam nad staw, ktoś mu musiał pomóc. A poza tym wyszło, wyciekło, ktoś mi ostatnio mówił, że wyciekło z prokuratury, że jednak miat te narzady wycięte i że to jest po prostu, chca złapać sprawców i to uciszaja, żeby media się nie dowiedziały czy coś w tym stylu.
I know the story from what my Dad told me, and he works at our village school. One of the staff is a geography teacher, Mr Wojciechowski, and he is Marek's uncle, which is why one day, when I phoned my parents and told them that some 2 nd year student was missing, a law student probably, it dawned on my Dad immediately, I mean, he asked me a strange question; if it could be Marek Wojciechowski, because his geography colleague from school did not look good that day. So, we understood that this must have been Marek because he used to come to school to teach the kids karate, as he was a sporty type, although he had been good at karate, he would not have... I mean when they found him he had had his internal organs cut out to be sold on the black market, or something. Anyway, when he was found in that pond, I did not really believe that he had made as much as 10 kilometres drunk and then simply fell into the pond and drowned. Anyway (...) there was a rumour that his vitals had been cut out. When it was later stated in the press and on the Internet that they had not, because, as the police said, there were no signs of violence, I still found it difficult to believe that because a few years earlier a girl was found, here in our area, without organs, and she was found two years after she went missing. That's why I think that Marek did not make it to the pond on his own and someone must have helped him. Moreover, there was this leak from the prosecutor's office that he in fact had had his organs cut out, but they keep silent on it because they wanted to catch the murderers without the media knowing anything about it. 
[E] ...czyli kłamią, oszukują nas...
[I] Nie kłamia, nie oszukują, chca nas
chronić.
[E] chcą nas chronić? żeby nie było paniki?

[I] No bo jeżeli, stuchaj, gdyby (żeby nie było paniki)... jeżeli się ludzie dowiedza, że młodemu chtopakowi, który ma dwadzieścia jeden lat wycięli narzaddy, rzuci ... pozostawili go w stawie, w którym przeleżał dwa czy trzy, miesiac czasu, no to nikt nie wyjdzie na ulice, bo wszyscy będa się bać, no bo grasuje ten, a poza tym oni się szybko zmyja, bo o to chodzi, jeżeli chca kogośzłapać, to musza utrzymać ich w pewności, że nikt się o tym nie dowiedziat. W zasadzie tyle. Osobiście go nie znałam. Mój tata zna jego wujka. Ale przestroga dla innych, nie włóczcie się w nocy sami. Przestroga dla drugiego wujka, nie zostawiaj bratanka samego.
$[\mathrm{E}]$... which is to say that they are telling lies...

[I] They are not telling lies, or cheating us, but they simply want to protect us.

[E] Protect us? So there won't be any panic, right?

[I] If people got to know that a 21 year old student had his vitals cut out, and the corpse was thrown into a pond only to be found 2-3 months later, no one would go out, scared that a killer? is still prowling the neighbourhood. If they really want to catch anyone, they have to make them insecure, that no one actually knows anything. That's it, really. I did not know him personally. My Dad knows his uncle. But let that be a warning to others: stop hanging around on your own at night. And a piece of advice for the other uncle: do not let your nephew go out alone.

\section{Text 2}

[I1] Ja tylko z Internetu znam historie, bo ja mieszkam $w$ Krakowie.

[I2] Ja styszałam tysiąc plotek o tym. Pierwsza historia, że go porwali na organy. Druga historia, że go znaleźli w parku akademickim i ...o Jezu, Jezu.. a najlepsze jest to, że nasi profesorowie nam sprzedawali takie kity. No prowadzacy przerywa wykład i ooo słyszeliście, że coś tam, coś tam, że porwali tego studenta na organy.

[I1] Znalazł się w rzeczce.
[I1] I only know the story from what I have read on the Internet, as I live in Cracow.

[I2] I have heard thousands of pieces of gossip about it. One that he was kidnapped for organ harvesting. Second that he was found in the University park, and... Jesus, the best one was that our professors would feed us that bullshit. They would stop the lecture and ask 'have you heard this.... that... some student was kidnapped to have his vitals removed?'

[I1] Well, he was found in some small river. 


\section{Text 3}

To znaczy tak, na pewno yyy słyszałem, na pewno widziałem w ogóle cały artykut w „Dzienniku Wschodnim”, nie, na Internecie, że było coś takiego, że w Lublinie krążyły plotki, że w ogóle gina ludzie i potem ich znajduja, nie wiem nawet bez źrenic, coś tam mówili, że to tak. To była wersja, że psychopata, nie, że wypruwa im flaki i oni się bez źrenic odnajduja. Teraz było tak, słyszałem, że złapali go na narządy, że znaleźli go gdzieś zakopanego pod akademikiem, nie. Generalnie po ulicach w ogóle grasuja te pogłoski, nie. I tak napisali w ogóle $w$ tym artykule, że to jest bzdura, że znalazł się gdzieś tam w Dąbrowicy w jakimś stawie rybnym. Znalazł go właściciel, no i tam nic nie wskazywało na to, żeby tych wnętrzności nie miał, aczkolwiek to jest plotka, jakieś ziarno prawdy musi być. Ginie chłopak, który, nie wiem, ani byt... jego rodzina nie była zamożna przecież, ...yyy...w ogóle po prostu znika i nagle znajduje się gdziekolwiek $w$ ogóle daleko tego miejsca, gdzie zniknąt, bo ostatnio widziano go gdzieś tam $w$ parku akademickim, nie, tam gdzie szedt styszałem, że w ogóle Wileńska. No i ta plotka pojawiła się w ogóle wcześniej, że on już się znalazł, już wcześniej, nie. Że to nie jest prawda, że on znalazł się, kiedy policja to mówi, że w stawie rybnym, bo to jak by się znalazł się po prostu tydzień albo pare dni wcześniej. Styszałem, że znalazł się dużo wcześniej i właśnie bez narządów, a policja ogłosiła, że znalazła go przypuśćmy tydzień później i nieprawda, bo w stawie rybnym. No i tyle właściwie co styszałem. Mało tego moi znajomi z Poznania, to kiedyś mi w ogóle napisali na
Well, I mean, I have certainly heard about it, I'm sure I saw the whole article in 'Dziennik Wschodni', no, it was on the Internet, that there was gossip circulating all around Lublin that people were missing, and then their corpses are found, with their eyes gouged out, or something like that. There was a version that it was some psychopath lurking in the background that ripped the vitals out and the corpses were found with their eyes plucked out. More recently I have heard that this student was caught for his vitals to be cut out, and the corpse was found buried nearby the dorm. And what was written was that this all is rubbish because he was actually found in Dąbrowica in some fish pond. The owner did find him and there was no indication that his vitals might have been cut out. But this is a piece of gossip, so there must be some grain of truth in all this. A boy is missing, and his family is not affluent. He simply disappears, and his corpse is suddenly identified miles away from the place where he went missing, as he was recently seen in the University park, and not, as I have heard, in Wileńska street. Moreover, this gossip had been heard much earlier, that is, before he was found. So, it is not true at all that been found, as the police say, in a fish pond, because if he has, that means that he was found a week earlier than when they say he was. I have heard that he was indeed found much earlier, and yes, with his vitals cut out. That much I have heard. More than that, in fact, because my Poznań friends once sent me a mail, asking what is going on in Lublin? Common! Well, they are not quite from Poznań, they live nearby Poznań. One way or another, they kept on asking what was going on in Lublin. 


Internecie: co się w was w Lublinie
dzieje... Bez kitu. No nie całkiem z
Poznania, tylko spod Poznania. W
każdym bądź razie pytali się, co się u
nas dzieje. Ja mówię: ale o co chodzi. No
podobno u was ludzie gina no nie i tam
narządy wypruwają. Skąd ty to wiesz? No,
mówi, plotka się roznosi, nie. Autentycznie
już to prawdopodobnie szerzej niż tylko w
lubelskim się dzieje. No to by było na tyle.
W sumie to co styszałem.

And I asked them, what was the matter? And they wrote that people are disappearing in Lublin, and their vitals are cut out. How do you know all that? That's what the gossip is all about. So, the whole thing got outside Lublin. And that was it. That's more or less what I have heard.

\section{Text 4}

[I1] To ja styszałam i mój kolega spytał się jakiegoś policjanta jeszcze wcześniej, więc jest to sprawdzona na pewno historia hahaha, że znaleziono tego studenta niedaleko Parku Ludowego i oczywiście czego mu brakowało? Brakowało mu nerek, serca $i$ wattroby i jeszcze tego no woreczka $\dot{z}$ yciowego? Żutowego? Żutowatego? Nie wiem, jak to się nazywa, jak się nazywa? O tak tego też mu brakowało, ogólnie miał ucięta głowę i ogólnie widziano oczywiście niedaleko tego zdarzenia porzucony wóz do transplantologii organów, koloru bordowego, był to taki miniwan bez rejestracji.

[I2] Ale w którym miejscu?

[I1] Pod Lublinem. Nie wiem dokładnie w którym miejscu. No w Parku Ludowym go znaleziono i co tam jeszcze, no $i$ ogólnie teraz się boję chodzić w nocy, bo nie wiadomo, ponoć grasuje tam jeszcze ten wóz. Styszałam, że wiele osób tak zginęło na Lubelszczyźnie. Jest wiele niewyjaśnionych wypadków, kiedy ktoś zaginat i do tego niektóre te osoby znaleziono właśnie bez tych narządów.
[I1] I have heard about it as my friend asked some policeman, so the story has been confirmed for sure, ha ha, that they found this student nearby in Park Ludowy, and, guess, what was missing from his body? The kidneys, the heart, the liver, and also this wall bladder? Ball bladder? Mall bladder? I don't know what the thing is called. Anyway, this was also missing. Generally, his head was cut off, and a transplantation ambulance was seen nearby, claret in colour, a minivan without number plates.

[I2] And where was that?

[I1] Close to Lublin. I don't know where exactly, but his body was found in Park Ludowy, and now I'm scared of going out at night, because, you never know, this car is said to still be prowling around there. I have heard that many people disappeared in this way in the Lublin area. There are many mysterious cases, when somebody was missing and in addition to that, some of these people were found without their 
Chociaż styszałam, że to niemożliwe, żeby wyciąc tyle narządów, jak się pobiera organy, hahaha, bo jak się na przykład pobiera nerki, to już nie można serca. Ale widać ten student był bardzo przydatny, hahaha, nie wiem, co jeszcze mam powiedzieć o tym studencie. Bardzo go lubiłam, chociaż go nie znałam, hahaha. organs. But I have also heard that it is impossible to cut out so many organs at once ha ha, because when you are cutting out the liver, for example, you cannot cut the heart out. But, evidently, this student was very useful, ha ha, I don't know what else I can tell you about him. I liked him very much even though I didn't know him, ha ha.

\section{Text 5}

Wiesz, że poznałem ta rzecz... no ta materię dopiero po jakimś czasie, po paru tygodniach, po trzech od tego jak zaginat, nie. No nie wiem, byłem u jakichś znajomych na stancji. Oni czasem zagląają na stronę „Dziennika Wschodniego”, by znaleźć jakieś aktualności. Tak z Internetu się dowiedziałem... coś $w$ tym stylu, nie. Wiesz no... piliśmy jakieś piwko, czy coś.... No [...] ten materiał źródłowy. Była informacja, wiesz o tym, że rektor płaci dziesięć tysięcy złotych za informacje o tym chłopaku. Obejrzałem ten materiał. Trwat, no nie wiem, jakiś czas, no. Nie wiem, czy... jak to odebrałem, czy byłem $w$ szoku, czy nie. No chyba nie, chociaż trochę, trochę może zaniepokojony, wiesz. Chodzi dużo plotek ostatnio, wiesz, po całej Lubelszczyźnie o łowcach organów, nie. Ale to raczej takie mity, wiesz. Co dokładnie ludzie mówili? Przytaczali na przykład inne historie, na temat tego, jak ktoś zaginą $i$ znaleźli jego ciało gdzieś, wiesz, w okolicznych krzakach, albo na jakiejś wiosce. Bez organów oczywiście. Ale oczywiście okazywało się to wszystko nieprawda ostatecznie. Teraz... teraz, no drugi kontakt $z$ ta sprawa. Już dowiedziałem się, że go znaleźli po prostu.
You know, I only got familiar with this case after some time, a few weeks later, three weeks after he had been missing. I was at my friend's lodgings. They occasionally take a look at 'Dziennik Wschodni' to stay in touch with what's going on. And I learned about that from the Internet... something like that. You know, we were drinking beer, and $[. .$.$] then this coverage. There$ was something about a Rector who is ready to pay ten thousand złoty for any information about this boy. So, I saw this material. It took; I don't know how long. I don't remember whether or not I was shocked. Probably I wasn't, just a bit concerned. There is a lot of gossip, you know, now circulating in the Lublin area about organ hunters. But it is all myth. What did the people exactly say? That for example, someone disappeared and his body was found among bushes, or in some village. With the vitals cut out, of course. But, in the end, it all proved to be false. Then there was the next stage of the case. That they simply found him. And I heard that on television. I don't know when it was exactly, but recently. The body was found some 10 kilometres from Lublin. 
Tylko to już z telewizji. Iiii nie wiem, kiedy to było dokładnie, jakiś... dosyć niedawno temu.... Znaleźli go dziesięć kilometrów od... od Lublina, nie. Poprzez ten materiał dowodowy mówił o tym, że nie wiem, któraś ostatnia z kamer, nie pamiętam, na którq ulicę skierowana, na Miasteczku Akademickim go rejestrowała, nie. I zginą, nie. Co znajomi mówili, nie wiem. Byłem u tej samej dwójki znajomych zresztą, no i oni... oni mówili na przykład, ze jest to zastanawiajace bynajmniej. Ale wiesz, raport policji mówi, że ten, że nie ma $\dot{z} a d n y c h$ obrażeń na ciele i tak dalej. Czyli $\dot{z}$ e musiat samoistnie... nie wiem... ulec wypadkowi chyba jakiemuś. Co ja mam do powiedzenia na ten temat...
In the news report there was something about that he was seen on one of the cameras, somewhere on the campus. And this was it - he just disappeared. What my friends said to this, I don't remember, really. I revisited the next stage of the case at the same couple's place, and they said, for example, that this all was puzzling. But, you know, the police report says that there were no injuries and so on, which means that he must have done it by itself, driving himself into the accident, or something.

\section{Text 6}

[I1] Styszałam, ze kolega, który zaginą na Głębokiej, o którym krążą różnorakie pogłoski, został znaleziony $w$ jeziorze $z$ powyrzyna... powyrzynanymi dwoma nerkami. Pogłoski sa... yyy... ugaszane u źródła, ponieważ policja boi się, że te informacje wprowadza zamęt wśród studentów. W tym momencie takie bezbronne kobiety jak ja boja się wkraczać na tereny Głębokiej. Głęboka wzbudza yyy ogólne przerażenie i przestrach.

[I2] Ale to na pewno było na Głębokiej, bo ja słyszałem, ze to była inna ulica.

[I1] To znaczy jaka?

[I2] Że to było gdzieś w parku Saskim.

[I1] Może to już jest ten drugi chłopiec, który podobno również zaginąt. Mafia, która... yyy handluje nerkami i innymi narzadami jest $z$ decydowanie niebezpieczna $i$ istnieje. Każdy powinien mieć się na baczności. Nie znasz dnia ani godziny.
[I1] I have heard that the fellow that went missing on Głęboka Street - there are various pieces of gossip about that and was eventually found with both kidneys carved out. The gossip has been, you know, silenced immediately because the police don't want this information to cause any panic among the students. Right now, defenceless women like myself are scared of entering the Głeboka area. Generally, Głęboka Street causes much terror and horror.

[I2] But was it really on Głęboka Street? I’ve heard another name.

[I1] Which is what?

[I2] That it happened in Saski Park.

[I1] Well, it may be this other boy that is also said to have disappeared. That means that the mafia that is trafficking in human organs is really dangerous, and it does exist. Everyone should be on their guard. Here today, gone tomorrow. 


\section{Text 7}

Z tego co czytatem oficjalna... oficjalna sprawa policji jest taka, że gościa zna... znaleźli po trzech tygodniach około, ale nie leżat trzy tygodnie w tym stawie, tylko mniej. Z Internetu czytałem, $z$ kroniki policyjnej. To jest ile ludzi, tyle legend. Moim zdaniem to sq bzdury.
From what I have read about it... the official police version is that they know the chap... they found him after a three week search, but it was not that he was all that time in the pond, much less. I got this from the Internet, from the police report there. There are as many legends as there are people. In my opinion, it's all rubbish.

\section{Text 8}

Styszałem, że został znaleziony $w$ lesie yyyy $z$ rozciętym ciałem $i$ wypatroszony na organy. Co wiem, że jest bezsensem, ale tak styszałem od mojej mamy własnej rodzicielki. Ale... nie, to nie, niemożliwe, bo to jest za dużo badań, żeby kogoś generalnie dopasować ciałem i organami, nie. No, ale to tak moja mama powiedziała, że został znaleziony w lesie, rozcięty na pót, wypatroszonyz wszystkich poważnych organów. YYY... pod Lublinem $w$ lesie. Ale styszałem te $\dot{z}$ druga wersję, od kolegi z kolei, parę dni temu, że zostal znaleziony nad zalewem $w$ wodzie i to samo... że mial zaszyte oczy...nie autentycznie, że miał zaszyte oczy i rozcięte od klatki piersiowej przez brzuch i bez organów też. Nad zalewem, tak. Ale zaszyte oczy mnie zdziwity. Po co zaszywać oczy? Komuś by się chciało zaszywać oczy? To jest bez sensu. Ja przyjechałem tak samo pare, wiesz, tygodni... dwa... tydzień... dwa? I tak samo moja mama... ja jak mam prawie trzydzieści lat, to moja mama zaatakowała mnie, że ona po mnie przyjedzie, bo był znaleziony ten chłopak bez organów. O! Ja styszałem też, że jego... od następnej osoby, że podobno byt wystawiony przez wujka, który miat
I have heard that his body was found in the woods, eviscerated and disembowelled, for his vitals. I know it makes no sense, but this is what I have heard, straight from my Mum. But..., no, no impossible, there is too much research that generally you can't just simply match someone's body with somebody else's organs. Still, this is what my Mum said, that he was found in the woods, his body cut in half, disembowelled of all the important organs... Near Lublin, in the woods. To be honest, I have heard another story, too. From my friend, a couple of days ago. That he was found by the artificial lake, in the water, and the same thing, that he had had eyes stitched up. Yes, that he actually had had his eyes stitched up, and his body cut in half, from the stomach to the chest, no organs inside. By the lake, yes. But I find these eyes puzzling. Why should you stitch up anybody's eyes? Who would bother? Makes no sense. Take this. It was two, three weeks ago, and my Mum, look, I'm 30 years old, my Mum insisted that she would pick me up because this boy 


\begin{tabular}{|ll|} 
dtugi, i ten wujek wziął go na impreze, & had been found with no organs. Wait, \\
i po imprezie okazało się, że jakiś van & there's also another story. I have heard \\
przyjechał i go zabrał i tak dalej, i tak dalej. & from someone that he was set up by his \\
Taki wujek włánie. Autentycznie, trzy & uncle who was in debt. This uncle took \\
różne osoby, trzy różne historie. Ludzie & him to a party, and when it was over, \\
potrzebują sensacji, tak... Prawda jest taka, & some van arrived and they took the boy \\
że prokuratura tam nic nie stwierdziła & away. Actually, three different stories \\
osób trzecich, ale jeżeli oglądasz „CSI Nowy & from three different people. People need \\
Jork” albo Majami to wiesz, że albo mówia & sensation. The truth is that the police have \\
wszystko, albo dają mylne informacje po to, & not identified any third party in all this. But \\
by pozyskać to... te informacje, które ich & when you watch 'CSI' or 'Miami Vice', you \\
tak naprawdę interesują. I w tym wypadku & know that they tell you everything or they \\
tutaj trzeba się [...] jak on się znalazt, & give false information in order to get the \\
wiesz, pijany chłopak, który wychodzi z & one that they truly need. (...) And this case, \\
klubu i nagle się znajduje osiem kilometrów & you know, how on earth could the drunken \\
od Lublina, utopiony w stawie, który ma & boy leave the club only to be found 8 kms \\
tam pół metra głébokości. Wiesz... no... & away from Lublin, drowned in a pond \\
nie, ale najważniejsze jest to, że ludzie & that is maybe half a metre deep? But what \\
mają o czym rozmawiać... i to powoduje, & matters is that people have got something \\
$\dot{z} e$ przez dwa tygodnie nic innego się nie & to talk about, and nothing else is important \\
dzieje, tylko oni żyją tym. & for 2 weeks or so but the missing boy. \\
\hline
\end{tabular}

The external part of the morphological analysis here shows that the compositional scheme of the missing student text is built of 10 segments:

I. plausible introduction: the narrator discloses the source of information and the circumstances of being informed about Marek W. s story

II. information about the missing student: the narrators' reaction to having learned that Marek W. is missing

III. hypotheses (conspiracy theories) about what has happened to Marek W.

IV. information about the circumstances of Marek W.s body having been found (place, time, finder)

V. information about the condition of Marek W.s body

VI. information about formal statements made by the prosecutor's office and interpretation of progress in the prosecutor's investigation

VII. information about similar cases

VIII. plausible vs. humorous ending

IX. warnings and admonitions

$\mathrm{X}$. the narrator's stand on the circulating pieces of gossip.

Segments I, III, IV and V are central, but their order in respective accounts is neither stable nor the same. The remaining segments (II, VI, VII, VIII, IX, X) are merely facultative. 
Another classification is also possible: with regard to the text, segments I, VI, VII, VIII, IX, X are external in the sense that they oscillate closely around the missing student and the plot, whereas segments II, III, IV, V are internal. The text-external segments provide information about the missing student, ways the gossip circulated, an assessment of the police investigation and the related conspiracy theories, attempts at setting the story in a broader context of similar cases and ate estimation of the plausibility of the circulating gossip. Let us have a closer look at each of these.

(1) ways of information dissemination

The specified text variants show a number of testimonial formulaic expressions which disclose the source of information. These sources include:

- the family - tata mi opowiadat 'my Dad has told me'/tak styszałem od mojej mamy własnej, rodzicielki 'that is what I have heard straight from my Mum',

- the media, mainly local media ('Dziennik Wschodni'), often in their online editions - ja tylko $z$ Internetu znam historie 'all I know about that is what I have read on the Internet'/widziatem $w$ ogóle caly artykut $w$ „Dzienniku Wschodnim", nie, $w$ Internecie 'I have seen the whole article in 'Dziennik Wschodni', no, it was on the Internet'/bytem u jakichś znajomych na stancji. Oni czasem zagladaja na strone „Dziennika Wschodniego" 'I was at my friend's lodgings. They occasionally take a look at the 'Dziennik Wschodni' web page',

- unspecified sources - styszałam tysiac plotek o tym 'I have heard thousands of pieces of gossip about that'.

What we have in the variants then, is a mixture of formal, official, medial, and hearsay pieces of information.

(2) assessment of the police investigation

Some of the segments present an interpretation of the investigation run by the prosecutor's office, for example: wyciekło z prokuratury, że jednak miat narzady wycięte $i \dot{z}$ e to jest po prostu, chca złapać sprawców i to uciszaja, żeby media się nie dowiedziały czy coś w tym stylu [...] bo o to chodzi, jeżeli chca kogoś złapać, to musza utrzymać ich w pewności, że nikt się o tym nie dowiedziat 'there is this leak from the prosecutor's office that he in fact had had his organs cut out, but they keep silent about that because they want to catch the murderers without the media knowing anything about it'. The expressions used (uciszaja 'they keep silent', policja ogłosiła 'the police say', mówia wszystko albo daja mylne informacje 'they tell you everything or they give false information') indicate that the police and the prosecutor's office are used interchangeably and referred to in general, if not impersonal terms. The informants are inclined to believe that there are hidden intentions in what is being done in this matter. So, they expect that the 
available information is either concealed or purposefully misguided, which they explain in a twofold way: for reasons of social safety (żeby nie byto paniki 'they want to protect us') and for the sake of the investigation (by pozyskać informacje, które ich tak naprawde interesuja 'in order to get the one that they truly need'). It is from films and TV series that the informants derive their knowledge about how to interpret the investigation: Prawda jest taka, że prokuratura tam nic nie stwierdziła osób trzecich, ale jeżeli ogladasz „CSI Nowy Jork” albo Majami to wiesz, że albo mówia wszystko, albo daja mylne informacje po to, by pozyskać to... te informacje, które ich tak naprawdę interesuja 'The truth is that the police have not identified any third party in all this. But when you watch 'CSI' or 'Miami Vice', you know that they tell you everything or they provide false information in order to get the one that they truly need'.

(3) similar cases

For the informants, Marek W's story triggers the recollection of similar cases, either individual (kilka lat wcześniej odnaleziono tutaj dziewczynę $z$ naszych okolic, która była pozbawiona narządów, a znaleziono ja dopiero po dwóch latach... po zaginięciu 'a few years earlier a girl was found, here in our area, without organs, and she was found only two years after she went missing) collective (było coś takiego, że w Lublinie krążyly plotki, że w ogóle gina ludzie i potem ich znajduja nie wiem nawet bez źrenic 'there was this gossip circulating around Lublin that people were missing and then their corpses are found with their eyes gouged out, or something like that'). This means that one specific story is used to recall other stories in a broader comparative context, which shows that gossip functions as a mixture of the present and the past.

(4) the narrator's position is signalled both directly and indirectly

The 'implicit' kind of narrator shows up in a text by offering a text-type characteristic (mainly plotka 'gossip' or pogłoska 'rumour') and corresponding expressions which disclose the narrator's understanding of how the text functions: plotka była 'there was this gossip'/tysiac plotek 'thousands of pieces of gossip'/to jest plotka, jakieś ziarno prawdy musi być 'this is a piece of gossip, so there must be some grain of truth in all this', pogłoski sq ugaszane u źródła 'the gossip has been silenced.'/ile ludzi, tyle legend 'there are as many legends as there are people'. The genre label plotka 'gossip' is usually accompanied by a verb of motion (chodzity plotki, krążyły plotki, plotka się roznosi/chodzi dużo plotek/krążą różne pogłoski, all oscillating around the meaning 'circulate') to emphasise the robustness of gossip and the ease of its dissemination. In this context, the reflexive verb roznosic sie 'to spread (by itself)' bears witnesse to some self-agency of gossip, as if gossip did 
not need any encoder, but was capable of circulating by itself. Gossip is generally considered to be a made-up story, but for some narrators, it nevertheless does contain a grain of truth. At the same time the expression ile ludzi, tyle legend 'there are as many legends as there are people' seems to indicate that gossip has some reference point, or starting point (the information about the missing student), only to be extended and elaborated into one's personal account enriched with novel elements and hypotheses. The latter can be traced to some resource of cultural memory (cinema films and TV series), storage collective memory, or experience-based individual memory.

The other type of narrator shows up in an explicit way. This time, the narrator's stance on a given piece of gossip is signalled through modal expressions (możliwe/niemożliwe 'possible/impossible') or signs of hesitation and uncertainty (wiem/nie wiem/wierzyłam 'I know/I don't know/I believed'). The prevailing modality is of the assertive kind, that is, the narrator asserts his convivtion that the events are not true: Jednak jak go znaleźli w tym stawie w zasadzie ja nie wierzyłam $w$ to, że on dziesięć kilometrów przeszedt po pijaku i po prostu tak sobie przeszedt, wpadt $i$ utopit się $w$ stawie; kiedy w gazetach, $w$ Internecie wyszło, $\dot{z} e$ to jednak, że nie znaleziono na nim śladów żadnej przemocy, bo tak określiła policja... no mimo wszystko jakoś $w$ to nie wierzyłam ('when he was found in that pond, I did not really believe that he had made as much as 10 kilometres drunk and then simply fell into the pond and drowned. (...) When it was later stated in the press and on the Internet that [he] had not, because, as the police said, there were no signs of violence, I still found it difficult to believe'). Modal expressions are mainly given their 1st person declarative forms: wierze 'I believe', wiem 'I know', myślę 'I think' etc.

The following excerpt shows two more characteristics: Styszałem, że zostat znaleziony $w$ lesie yyyy $z$ rozciętym ciałem $i$ wypatroszony na organy. Co wiem, $\dot{z} e$ jest bezsensem, ale tak slyszałem od mojej mamy własnej rodzicielki. Ale... nie to nie, niemożliwe, bo to jest za dużo badań, żeby kogoś generalnie dopasować ciałem i organami, nie... Ale zaszyte oczy mnie zdziwity. Po co zaszywać oczy? Komuś by się chciało zaszywać oczy? To jest bez sensu. ('I know this makes no sense, but that is what I have heard straight from my Mum. But..., no, no impossible, there is too much research that generally you can't just simply match someone's body with somebody else's organs. (...) But I find these eyes puzzling. Why should you stitch up anybody's eyes? Who would bother? Makes no sense.) On the one hand, the missing student gossip causes doubts (which is why the narrator asks questions), but, on the other hand, it ignites emotion, especially in the humorous ending. Humour proves to be a peculiar way of softening, or coming to terms with, a difficult situation. Allegedly incompatible with the story, it serves to communicate the 
narrator's attitude to the circulating gossip: Chociaż styszałam, że to niemożliwe, żeby wyciąc tyle narzadów jak się pobiera organy, hahaha, bo jak się na przykład pobiera nerki, to już nie można serca. Ale widać ten student był bardzo przydatny, hahaha, nie wiem, co jeszcze mam powiedzieć o tym studencie. Bardzo go lubiłam, chociaż go nie znałam, hahaha. ('But I have also heard that it is impossible to cut out so many organs at once, ha ha, because when you are cutting out the liver, for example, you cannot cut out the heart. But, evidently, this student was very useful, ha ha, I don't know what else I can say about him. I liked him very much even though I didn't know him, ha ha.) As to doubts, it is the course of events that seems to be most doubtful: ja nie wierzyłam $w$ to, że on dziesięć kilometrów przeszed t po pijaku i po prostu tak sobie przeszedt, wpadt i utopit się w stawie ('I did not really believe that he had made as much as 10 kilometres drunk and then simply fell into the pond and drowned) as well as the alleged condition of the body (wypatroszony na organs 'disembowelled of all the important organs'). However, in some other reports, the gossip triggers other emotions, such as fear which brings about admonitions and warnings: Ale przestroga dla innych, nie włóczcie się w nocy sami. Przestroga dla drugiego wujka, nie zostawiaj bratanka samego ('But let that be a warning to others: stop hanging around on your own at night. And a piece of warning for the other uncle: do not let your nephew go out alone.') / Każdy powinien mieć się na baczności. Nie znasz dnia ani godziny ('Everyone should be on their guard. Here today, gone tomorrow.).

On the whole, the external analysis leads to the following generalisations:

- what triggers gossip is usually some true and baffling event as well as a lack of reliable information of what has happened;

- macro-gossip preys on a mismatch, or a clash, between officially-stated mediadisseminated information and informal orally-transmitted circulating conjectures; in terms of genre characterisation, macro-gossip is a memory melting pot where elements of both communicative and cultural memories can be found;

- the way official organs and institutions run the respective investigation is attempted by the public in terms of analogies to films and series; what is going on in the real world is then identified with the corresponding carriers of cultural memory; it is these carriers that provide and transmit patterns of behaviour, for example what is expected of the police or the prosecutor's office;

- the opening and the ending of the story are constitutive elements of macrogossip; testimonial and formulaic in character, both inform us about the way the story is circulated, its source and transmission;

- the multiplicity of text-external segments shows that a given piece of gossip reveals as much about the course of focal events themselves as of the narrators and their memory. 
The internal part of this morphological analysis begins with the observation that the missing student text can be presented as a sequence of motifs-sentences:

A: Marek Wojciechowski, a student of law, went missing in Lublin on his way back from meeting his uncle;

B: Marek W. was kidnapped/was kidnapped for organ harvesting/(was) drowned/was framed by his uncle.

C: Marek W.s body was found in a pond/a lake/a fish pond in Dąbrowica/was buried by the dorm/was found in Park Ludowy.

D: When found, Marek W. had his kidneys cut out/had his vitals cut out/had his heart cut out/was beheaded/did not have any signs of violence or abuse on his body.

If all the text variants are included to form a synthetic picture, the following options can be obtained:

A: Zaginą chłopak $z$ drugiego roku, bodajże prawa ('some 2nd year student went missing, a law student, probably')/Pijany chłopak, który wychodzi z klubu ('the drunken boy who left the club');

B: Marek W. was kidnapped for organ harvesting (porwali na organy)/was caught for organ harvesting (złapali go na narzaddy)/was framed by his uncle who was in debt ('był wystawiony przez wujka, który miał dtugi).

C: 'he was found in that pond' (znaleźli go w tym stawie)/'he was found in the University park' (znaleźli go w parku akademickim)/'he was found in some small river' (znalazł się $w$ rzeczce)/'they found him buried near the dorm' (znaleźli go gdzieś zakopanego pod akademikiem)/'he was actually found in Dąbrowica in some fish pond' (znalazł się gdzieś tam w Dąbrowicy w jakimś stawie rybnym)/'the owner found him' (znalazł go właściciel)/'his corpse is suddenly identified miles away from the place where he went missing' (znajduje się gdziekolwiek w ogóle daleko tego miejsca, gdzie znikną)/'he was indeed found much earlier' (znalazł się dużo wcześniej)/'they found this student near Park Ludowy' (znaleziono tego studenta niedaleko Parku Ludowego)/'neraby Lublin' (pod Lublinem)/'they found him $10 \mathrm{kms}$ away from Lublin' (znaleźli go dziesięć kilometrów od Lublina)/'he was found in the lake/in the woods/near Lublin/by the artificial lake, in the water' (zostat znaleziony $w$ jeziorze/zostat znaleziony $w$ lesie, pod Lublinem $w$ lesie, nad zalewem $w$ wodzie).

D: Marek 'had his internal organs cut out to be sold on the black market'/'he was found without any organs'/'[what was missing was] the kidneys, the heart, the liver, and also this [searching for the name, the intended target being 'gallbladder'] wall bladder? ball bladder? mall bladder?'/'generally, his head was cut 
off'/'[he] was eventually found with both kidneys carved out'/'[he] was found in the woods, eviscerated and disembowelled, for his vitals'/'he actually had had his eyes stitched up, and the body cut in half, from the stomach to the chest, no organs inside' (miał wycięte narzady wewnętrzne do przeszczepu na czarny rynek/znalazł się bez narządów/brakowało mu nerek, serca $i$ wątroby $i$ jeszcze tego no woreczka życiowego (żutowego, żutowatego), ogólnie miał ucięta głowęl znaleziony z powyrzynanymi dwoma nerkami/z rozciętym ciałem i wypatroszony na organy, rozcięty na pót, wypatroszony $z$ wszystkich poważnych organów, miał zaszyte oczy i ciało rozcięte od klatki piersiowej przez brzuch i bez organów).

The picture of the world in the missing student urban legend.

Protagonists. There seems to be two types of protagonists in urban legends:

- a concrete, yet typified, individual

The hero of the urban legend can most frequently be identified with some individual label, be it the name (e.g., Marek W.) or some other reference term (student 'student', chłopak $z$ drugiego roku bodajże prawa '2nd year law student, probably'). In our legend, it is at times emphasised that he was drunk on that critical day. Out of the eight examined variants, only one offers more of a protagonist characterisation. All the remaining variants contain merely one- or two-element descriptions: social position (a student) and physical condition (drunken). If this is set in a broader comparative context, we see that our protagonist, Marek W., is, in fact deprived of personal characteristics, which makes him subject to folklorisation and stores, as an element of collective memory, where he - as the missing individual human being, that is - is further stripped of any distinctive features or particular traits.

- an auxiliary (additional) protagonist of some hampering (negative) function

In our variants, this auxiliary protagonist is the missing student's uncle. Mysterious and murky, the uncle is even implied, in one of the variants, to be an accomplice, his debts being the motivation to commit the crime. This figure serves also to explain that which is unknown in the story or soften its baffling effect, which is to give some rational account of the crime - it was committed because someone was short of money, or more generally, 'someone close is betrayed for money'.

Still, it is safe to assume that the most important protagonist of our texts is probably the narrator. It is his/her vision, inferences an observations that prove as important as the course of the events themselves. After all, Marek W and his story are not unique because, as we learn from the narrators, 'things like that happen', so, under the circumstances, the missing student legend under scrutiny 
here is just a trigger or a pretext, to reflect on, ask questions, and to disclose one's position on this and other similar cases and stories.

Time and space. As to time and space in our text variants, we can distinguish two perspectives: ${ }^{33}$

- a text-internal perspective, which is time and space in relation to the focal event.

- a text-external perspective, which is time and space in relation to the act of narration or to emphasise its dynamic nature, narrating.

Time and space develop - in both perspectives - by leaps. In the text-external perspective, space is expressed with place-names, which provides an idea of how gossip is being circulated and how its range is being expanded, e.g., znajomi $z$ Poznania 'my Poznan friends'. Time, in turn, amounts to the moment of becoming familiar with the gossip, as in po paru tygodniach, po trzech od tego jak zaginat ' a few weeks later, three weeks after he had been missing. This category of time is attempted in reference to the text-internal dimension of time.

In the text-external perspective, both time and space concern, respectively, the moment and location of the student going missing (ul. Głęboka 'Głęboka Street', park Saski 'Saski Park') and the moment and location of the student's body being found (las 'woods', jezioro 'lake/pond', rzeka 'river').

Another temporal source are the verbal forms used by the narrators in their respective text variants. On the one hand, present-time references present the course of events as a kind of continuum (gina ludzie, znajduja się 'people are disappearing, and then their corpses are found'), and, on the other hand, a concrete, individual story is set against this continuum of unspecified events and narrated in the past tense (złapali go, znaleźli zakopanego 'he was caught (...) and was found buried').

Text-internally, the space category involves three locations:

- water: $w$ jeziorze 'in the lake', $w$ Dąbrowicy w stawie rybnym 'in Dąbrowica, in a fish pond', $w$ rzeczce 'in a small river',

- park: odnaleziony w Parku Ludowym 'found in Park Ludowy',

- underground: zakopany pod akademikiem 'buried by the dorm'.

53 A similar account can be found in Irena Bogocz' analysis of space and time in fairy tales: 'Both categories have to do with motion. Generally speaking, there are two basic kinds of motion in fairy tales: 1) the protagonist-generated motion (i.e. internal with regard to the course of events in a tale), and 2) the narrator-generated motion (i.e. external with regard to the fairy tale)' (Bogocz 1996: 25-33). 
All three specify the space where the student's body was found. In more general terms, in folklore, these three space-locations are identified by something alienating, threatening, formidable, and mysterious, which shows that our missing student legend proves, in fact, to be vulnerable to folklorisation. All three spaces are also closed in the sense that they clearly-bounded, the boundary marking off 'a different world, the world where anything can possibly happen' (NiebrzegowskaBartmińska 2007: 95). Two of the three (the park and the underground) can only be found in oral (informal) transmission and as such, they belong to collective memory.

Message. The multiplicity of the text-external segments indicate that what an urban legend, as a genre reveals initially, is the narrators, their worldview, system of values, and how they understand the world and apprehend information about what is going on in it. If a specific, individual case is referred to (here: Marek $\mathrm{W}$. and his disappearance), it merely serves as a trigger of further reflections, judgements and inferences about current reality, especially the world of media and politics. On a most general level, the ultimate protagonist of urban legends is a man lost amongst the information noise, or infoglut much of which is mutually conflicting or contradictory and causes one to see the world as intimidating and hostile. It is unsurprising then, that Thiele-Dohrmann (1980:10) calls gossip 'a safety valve' that eases various kinds of tensions (inhibitions, reservations, socially-conditioned emotions).

The gist of gossip resides in motion - pieces of gossip are 'on the beat', and it is their usage that provides newer and newer interpretations. In terms of genre considerations, gossip emerges online, from pieces of information which are currently being circulated among speakers. This gives gossip a highly communicative character and distinguishes it from the genres discussed so far. Namely, text composition and theme modifications are only secondary with respect to the parameters of circulation and transmission - simply, morphological analysis allows one to reconstruct how a given piece of gossip happens to be disseminated.

The kind of memory that can be seen at work behind the missing student story (and its variants) is clearly communicative in character. As J. Assmann argues, what makes it communicative is that it comes into being and then expands during the oral transmission process of individual experiences to upcoming generations (cf. Saryusz-Wolska 2011: 82). This kind of transmission is not without its gaps and blanks, whereas collective memory tends to be complete in order to offer a well-rounded message. So, gossip needs to be supplemented with media coverage (Saryusz-Wolska 2011: 83). In the case of the missing student gossip, we find this in the form of clusters of various pieces of information, be it cross-generational (co wiem, że jest bezsensem, ale tak styszałem od mojej mamy własnej rodzicielki 
'I know this makes no sense, but that is what I have heard straight form my Mum'), intra-generational (Ale styszałem też druga wersje, od kolegi z kolei 'I have heard another story, too, from my friend'), or medial in character and origin (widziałem $w$ ogóle cały artykut $w$ „Dzienniku Wschodnim”, nie, na Internecie 'I have seen the whole article in 'Dziennik Wschodni', no, it was on the Internet'). As there are quite a few variants the same text/story, once a given baffling event has started being circulated, it functions in living memory. Its transmission at any point then is up-to-date and relevant because, as A. Assmann sees it, it is part of functional memory:

- it has a social-group reference

In the case of the examined variants, the social group is identified with localising the student's disappearance in the Lublin area (Mało tego moi znajomi z Poznania, to kiedyś mi w ogóle napisali na Internecie: co się u was w Lublinie dzieje... [...] No, mówi, plotka się roznosi, nie. Autentycznie już to prawdopodobnie szerzej niż tylko $w$ lubelskim się dzieje 'my Poznań friends once sent me an e- mail, asking what is going on in Lublin (...). So, the thing has moved outside the Lublin area') as well as with attempts at identifying the missing student (Jednym z nauczycieli jest geograf, pan Wojciechowski, który jest wujkiem Marka no i dlatego pewnego dnia jak zadzwoniłam do domu i powiedziałam, że zaginat chłopak $z$ drugiego roku, bodajże prawa, chyba prawo studiowat, to tato od razu wpadt, znaczy wpadt, dziwnie się zapytał, czy chodzi o Marka Wojciechowskiego, bo właśnie dzisiaj geograf dziwnie wygladat $w$ szkole 'One of the staff is a geography teacher, $\mathrm{Mr}$ Wojciechowski and he is Marek's uncle which is why one day, when I phoned my parents and told them that some 2 nd year student was missing, a law student probably, it dawned on my Dad immediately. I mean, he asked me a strange question; what if was Marek Wojciechowski because his geography colleague from school did not look good on that day').

- modality-expressed selectivity: Jednak gdy go znaleźli $w \ldots w$ tym stawie $w$ zasadzie ja nie wierzyłam $w$ to, że on dziesięć kilometrów przeszedł po pijaku $i$ po prostu tak sobie przeszedł, wpadt $i$ utopił się $w$ stawie ('Anyway, when he was found in that pond, I did not really believe that he had made as much as 10 kilometres drunk and then simply fell into the pond and drowned')

- explicitly-stated normativity (in the moral-like endings to some of the variants): Ale przestroga dla innych, nie włóczcie się w nocy sami. Przestroga dla drugiego wujka, nie zostawiaj bratanka samego ('But let that be a warning to others: stop hanging around on your own at night.... And a piece of advice for the other uncle: do not let your nephew go out alone')

- future orientation combined with normativity: Każdy powinien mieć się na 
baczności. Nie znasz dnia ani godziny ('Everyone should be on their guard. Here today, gone tomorrow')

The missing student individual piece of narration activates and elicits similar stories. In this context, we could say that that which is living and actual in functional memory triggers that which is similar in storage memory (zwłaszcza, że kilka lat wcześniej odnaleziono tutaj dziewczynę z naszych okolic, która była pozbawiona narzadów, a znaleziono ja dopiero po dwóch latach ... po zaginięciu 'a few years earlier a girl was found, here in our area, without organs, and she was found only two years after she went missing') and that which is known from the media, for example, from iconic TV series (ale jeżeli ogladasz „CSI Nowy Jork” albo Majami to wiesz, że albo mówia wszystko, albo daja mylne informacje po to, by pozyskać to... te informacje, które ich tak naprawdę interesuja 'when you watch "CSI" or "Miami Vice", you know that they tell you everything or they give you false information in order to get the one that they truly need'). Gossip indeed appears to be a memory melting pot.

\section{Folklorism: from cultural to intercultural memory or dialogue with tradition and traditional ways of apprehending folklore}

Collective memory is a phenomenon that finds its expression in texts of culture, including folklore texts. Texts of folklore are then, carriers of various kinds of collective memory. If folklore undergoes changes, these changes can be assumed to be forms of collective memory. In other words, changes in folklore or rather the effects of these changes all come to serve as memory carriers. By means of clarifying all the prior correspondence, it is necessary to start with the observation that what makes folklore an integral part of collective memory are the characteristics and the functions the two share.

First of all, both folklorism and collective memory work by selectivity. In addition, what also brings folklorism and collective memory together is that they are socially-grounded, interesting and polymorphic. In the context of the four characteristics enumerated above, folklorism could be argued to constitute forms of collective memory because transformations in folklore foreground those elements of collective memory which are considered to be useful or necessary from the perspective of current needs and interests (Golka 2009: 24). Folklorism constitutes the part of collective memory that A. Assmann calls 
inhabited memory (i.e. the one that is bearer-bound, bridges the past, present, and future, acts selectively and communicates values or, in short, builds identity and shapes patterns of behaviour; for more, see Chapter I).

Folklorism performs numerous functions (cultural, aesthetic, social, political), one of which is concerned with 'a national remedy for the unification processes fostered by mass culture and for the process of cosmopolitanism of the world culture' (Krawczyk-Wasilewska 1986: 51). It is in this latter sense that folklorism relates closely to collective memory, preserves that which makes us distinct from others, and presents itself as a constitutive element of cultural heritage and collective identity. In other words, similarly to memory, folklorism is an expression of collective identity and as such, is conditioned by the need of 'abiding in tradition' (Krawczyk-Wasilewska 1986: 55). In its psycho-social and cultural aspects, this 'abiding in tradition' can mainly be found in those ethnic groups which manifest their identity symbolically; either unconsciously (through folklore) or deliberately (through folklorism, among other things) (cf. Krawczyk-Wasilewska 1986: 56).

As already emphasised, folklore and collective memory are social in nature and thus, can build a group's identity. Though both serve the function of identity-building, 'in the modern world, it seems that folklorism is only secondary in importance as a way of manifesting ethnic distinctiveness, its function reduced to sustaining and fostering tradition' (Krawczyk-Wasilewska 1986: 56).

What follows is a comparative analysis of two versions of the Roszpunka (Rapunzel, lit. 'corn salad') fairy tale, which is meant to exemplify the process of exploiting selected patterns of traditional folklore for the sake of giving them present-day relevance. ${ }^{54}$

54 Text 9 is traditional and anonymous, whereas Text 10 was written by a contemporary folk writer, for which she was given the 2nd degree award at Ogólnopolskim Konkursie Literackim im. Jana Pocka in 2006. Both texts will be subject to a comparative morphological analysis. As the morphological analysis of, specifically, fairy tales has a long standing tradition now (Propp 1976, Niebrzegowska-Bartmińska 2002, 2003, 2007), it will be shortened here only to the most important aspects, with the earlier research findings merely referred to. 


\section{Text 9}

\section{Raponcka}

Razu pewnego żyli sobie szczęśliwie małżonkowie, ale nie mieli dzieci [1. Brak czegoś]. Szukali różnych lekarstw, lecz wszystko było daremne. Żonie się śniło, że u czarownicy w ogrodzie rośnie roślina, co się nazywa raponcka. Kto tę roślinę zje, dostanie dziecko. Żona prosi męża:

- Idź mi po te zioła. Jak nie pójdziesz, to umrę ze starości.

Mąż wiedział, gdzie czarownica mieszka, $i$ w nocy wlazt przez murowany ptot do ogrodu. [odejście] Narwał ziót, które przy murze rosty. Patrzy, a tu stoi tabliczka, a na niej bialy napis: „nie tykać raponcków”. [2. zakaz] Mąż idzie z powrotem [3. naruszenie zakazu], a tu na murze stoi czarownica i mówi:

- Czego tu chcesz, złodzieju? Chcesz się w kamień obrócić?

Mąż zaczą prosić i błagać, żona jest ciężko chora i pragnie tych roślin.

Czarownica powiada:

- Idź, skąd przyszedteś, ale to dziecko, co za rok otrzymacie, musicie mi dać. [4. podstęp]

Mą̇ przyszedł z ziołami do domu, ale był smutny. Żona się bardzo cieszyła, gdy zioła ujrzała. Nawarzyła, wypita i była zdrowa. Za rok porodziła córkę, a nazwali ją Raponcka. [5. Likwidacj a braku czegoś] W pewnej nocy, gdy mąż pracowat, przyszła czarownica i potajemnie ukradła dziecko. [6.szkodzenie] Wzięła i schowała je w jednej leśnej wieży. I tak minęło szesnaście lat. Czarownica była szczęśliwa, bo

Raponcka musiała na nia pracować. Raponcka była bardzo piękna, miała czarne oczy, a włosy na parę metrów długie.

\section{Rapunzel}

Once upon a time, there lived a happily married couple, but they did not have children. [1. a lack of something] In vain they tried various remedies. The wife once dreamed about a plant in a witch's garden, called 'rapunzel'. And the one who ate it got a baby. So the wife asks her husband:

- Fetch this herb for me! If you don't, I'll die of old age.

The husband knew where the witch lived, and one night he jumped over her stone wall and made it to the garden. [departure] He picked up the herbs that grew close to the wall before noticing a board with the sign: 'Do not touch the rapunzel.' [2. ban] He was just about to go home in [3. violation of the ban], when he saw the witch standing on the wall:

- What are you doing here you thief? Do you want to be turned into stone? The man started begging, saying that his wife was seriously ill, which is why she needed these herbs.

- Go well then, back where you have come from; but this baby that you have in a year's time, you must give to me. [4. deceit]

The husband came home with the herbs, looking sad. The wife instead was happy. She cooked the herbs and drank them, and recovering from her malady. A year later she gave birth to a baby girl. They gave her the name Rapunzel. [5. a lack of something neutralised] One night, when the husband was working hard, the witch arrived, stole the baby. [6. detriment] and hid it in one of the towers in the woods. Sixteen years passed. The witch was happy because

Rapunzel worked for her. The girl was very beautiful; she had black eyes, and her hair was a few meters long. 


\section{Raponcka}

Razu pewnego król jechał ze swymi sługami na gon. [7. wyprawa] Kiedy król jechał koło leśnej wieży, jego koń nie chciat iść dalej. Król usłyszał jakiś piękny śpiew. Patrzy na wieże, a tu nie ma żadnych drzwi. Już się ćmiło, lecz król stoi w lesie i z daleka przygląda się. Naraz widzi, że w powietrzu leci czarownica. Stanęła pod wieża, pod okienkiem i woła:

- Raponcko, spuść twoje włosy!

Włosy sięgały aż do ziemi. Czarownica chwyciła się za włosy, a Raponcka wciągnęła ja do okienka. Za jakaśs chwile czarownica spuściła się na włosach $i$ poleciała. Król sobie te słowa dobrze zapamiętał. Za chwile staną pod okienkiem $i$ wota:

Raponcko, spuść twoje włosy!

Ona spuszcza, bo myśli, że czarownica wróciła. Król chwyta się za włosy, ona ciągnie, a tu stoi przed nia król. Zlękła się Raponcka, bo jeszcze $w$ swoim życiu króla nie widziała. Król zaczą mówić:

- Styszałem twój piękny śpiew. Koń mój nie chciał iść dalej i chciałem przekonać się, kto się tu znajduje. Nie bój się, dziewczyno, nic ci się nie stanie. Ja cię chcę wybawić powiada. - Dlaczego tu jesteś sama?

- Ja się nazywam Raponcka, nie znam nikogo, świata nie znam i nie mam nic. Moja uciecha to mój śpiew. Nie znam rodziców, tylko tę staruchę, która mnie prześladuje. Król powiada:

- Pójdź ze mną, będziesz szczęśliwa! O północy przyleciała czarownica, a tu widzi króla. Powiada.

- Czego tu chcesz, grzeszniku. Wynoś się! Chcesz się w kamień obrócić? [8. walka]

\section{Rapunzel}

One day the king was riding by with his servants. [7. excursion] When he was passing the tower, his horse suddenly refused to go on. The king heard some beautiful singing, but when he look at the tower, he did not see any doors. It was getting dark but the king remained in the woods, looking around. Suddenly, he noticed the witch flying in the air. She landed by the tower and cried out: - Rapunzel, let down your hair, [so that I may climb thy golden stair]!

The witch grabbed the hair and Rapunzel pulled her up. Soon enough, she came down by the hair and flew away. The king remembered her words well. Now it was his turn him to stand by the window and cry out:

- Rapunzel, let down your hair!

So did as she was bid as she thought it was the witch. The king grabbed her hair and she pulled him up, and there he was standing in front of her. Rapunzel was quite frightened because it was the first time she had seen the king. The king said: - I heard your beautiful singing. My horse did not want to go any further, and I was curious as to who lives here. Do not be afraid, girl, I want to save you. Why are you here alone? - My name is Rapunzel, I don't know anybody, and my only joy is this singing. I only know this old witch who torments me.

- Come with me, I will make you happy! The witch returned at midnight. She saw the kind king and said:

- What do you want, sinner? Get out! Do want to be turned into stone? [8. fight] 


\section{Raponcka}

Ona go chwyciła i z okienka wyrzuciła, on wybit sobie oczy [9. Naznaczenie bohatera znamieniem]. Potem chwyciła Raponcke $i$ te $\dot{z}$ ja wyrzuciła, lecz onej się nic nie stało. Król błaga:

- Ratuj mnie, będziesz moja żona.

Raponcka wzięła go za rękę i szli, aż przyszli koło jednej studni. Raponcka wyjęła swoją chusteczkę, na która zawsze patrzyła, bo starucha jej powiedziała, że to chusteczka od jej matki. Złożyła tę chusteczkę do wody. Potem umyła oczy $i$ zaraz król widział. [10. użycie magicznego środka] Szli przez góry i lasy, aż wreszcie przyszli na zamek, za pare dni się poślubili. [11. wesele] $\mathrm{Na}$ wesele przyszła też czarownica. Król kazał ja powiazać $i$ wrzucić do piwnicy. Tam musiała siedzieć aż do śmierci. [12. ukaranie] Król zaś kazał szukać rodziców swojej żony. Rodzice się zgłosili i królowi powiedzieli, jak im czarownica ukradła córkę. Potem żyli wszyscy szczęśliwie (SimKum, 37).

\section{Rapunzel}

The witch shoved him from the tower, sending him down where he got his eyes plucked out. [9. the protagonist stigmatised] She shoved Rapunzel as well, but the girl did not get hurt. The king begs the girl:

- Save me, and you'll be my wife!

Rapunzel took his hand and they came to some well. Rapunzel had a handkerchief that the witch told her belonged to the girl's Mom. She put the handkerchief into the water, washed the king's eyes with it, which restored his sight. [10. magical substance used] Then they carried on through the mountains and the woods, and arrived at the castle where they got married a few days later. [11. wedding] The witch came to the reception as well. The king ordered the witch to be bound and thrown into the cellar, where she was to be kept till her death. [12. punishment] Next the king ordered his servants to find his wife's parents. When they were found, they told the king how his daughter had been stolen by the witch. And then they all lived happily ever after.

\section{Text 10}

Dagmara Minda

Nowa historia Roszpunki

Widze ja, jak biegnie przez las. Dlaczego tak biegnie? Jedynym sposobem poznania jest wplecenie tej wizji w opowiadanie. A chce znać ciąg dalszy. Włączam więc komputer i zaczynam opisywać to, co ujrzałam przed chwila oczyma duszy.

\section{Rapunzel: a new story \\ by Dagmara Minda}

I can see her running through the woods. Why is she running like that? The only way to know is to tell a story. I do want to know how it is to be continued.

Then I turn my computer on and start describing what I have just seen in my mind's eye. 
Biegła przez las. [1. odejście] Biegła tak szybko, jak tylko pozwalały jej na to wiotkie i słabe nogi. Wokół furkotały liście, usuwające się pośpiesznie z jej drogi. Czuła, jak oplatają ją zerwane w biegu pajęcze sieci. Szła jak burza. Po twarzy smagały ją powyginane gałązki. Po policzkach spływały łzy. Biegła tak już dosyć długo. Myśli huczały w głowie. Słyszała wyraźnie każde uderzenie swojego serca, które pracowało teraz jak oszalałe. Dyszała ciężko. Pomału zwalniała. Dalej tak nie mogła. To zabójcze tempo. Była wycieńczona. Każdy kolejny krok kosztował ją sporo wysiłku i odbijał się echem w głowie. W skroniach czuła pulsujący ból. Z każdym przebytym odcinkiem drogi opadała $\mathrm{z}$ sił. Czemu więc wciąż biegła? Drzewa w lesie nagle zawirowały wokół niej. Przed oczyma pociemniało. I nagle padła nieprzytomna na ziemię.

Teraz na pewno się nie dowiem. Obudź się! Obudziła się w jakiejś grocie. Nad sobą miała niski, ciemny strop jaskini. Zwisały z niego cieniutkie niczym patyczki kamienne sopelki. Kiedyś pamiętała, jak się nazywają. A le teraz nie będzie się nad tym zastanawiała. Wciąż kręciło się jej w głowie. Wszystko ją bolało. Nie czuła rąk i nóg. Serce co prawda już się uspokoiło, ale była bardzo zmęczona. Jak nigdy przedtem. No, ale nigdy przedtem przecież nie biegała. Teraz nagle stanęły jej przed oczyma ostatnie wydarzenia.

Może teraz nareszcie się dowiem, czemu tak biegła. Ale gdzie ona teraz jest?

Babcia od tygodnia nie przychodziła do niej. Zwykle odwiedzała jej wieżę co dwa, trzy dni. I przynosiła świeże jedzenie. Szóstego dnia nieobecności babulki Roszpunka zjadła ostatnie zapasy pożywienia. Była bardzo głodna i strasznie niepokoiła się o swoją opiekunkę. Co
She was running through the woods [1. departure], running as fast as her legs could carry her.. The leaves were whispering all around her, rustling out of her way. (...) She had been running for quite some time now. Thoughts were buzzing around her mind. She could hear every single pounding of her heart (...). She was slowing down. She could not go fast any longer. (...) She was simply exhausted. (...) Why would she be running like that? The trees suddenly started swirling around her. Her mind went blank, and she fell on the ground, losing consciousness. (...)

I will certainly not get to know anything now. Wake up!

She woke up in some cave. (...) Her mind still kept on spinning. (...) She was very tired. As never before. After all, she had never run that much before.. Now she could recall what had happened.

Will I get to know at last why she had kept on running like that? But, where is she now?

Her Granny had not visited her for a week. She used to come and see her every two, three days, and bring some fresh food. On the sixth day Rapunzel had eaten all the food that was left. She was very hungry, and concerned about her caregiver. What has happened to her? 
się jej stało? Czemu tak długo jej nie ma? W końcu dziewczyna usiadła na parapecie swojego jedynego okna i zaczęła wzywać pomocy. Oczywiście w okolicy przechodził jakiś syn wieśniaka i zainteresował się nią. Samotna dama zamknięta w wieży, to musiało podziałać. I podziałało. Namówiła chłopaka, żeby przyniósł jej coś do jedzenia. I linę przy okazji. Będzie mogła wreszcie zjeść porządny posiłek, a potem zejść, by odszukać babcię. Młody wieśniak dobrze się spisał. Po kwadransie wrócił z dzbankiem pełnym zupy, bochenkiem chleba i długą, mocną liną. Zaproponował jej, że wejdzie na górę z tym wszystkim, a potem oboje zejdą na dół.

Nie ze mną te numery - pomyślała Roszpunka i spuściła do chłopaka koszyk, przywiązany do jej długich włosów. To właśnie po nich wchodziła na górę babulka. Wieśniak jednak o tym nie wiedział i dlatego nie wpadł na pomysł, by wejść po nich do wieży. Zrezygnowany, włożył posłusznie wszystko do koszyka. Dziewczyna wciągnęła go do siebie i zjadła przyniesiony obiad, patrząc $z$ góry na chłopaka. Ten pokręcił się jakiś czas na dole, ale w końcu odszedł. Wreszcie Roszpunka mogła spróbować ucieczki. Ubrała się w swoją najlepszą sukienkę, spakowała najważniejsze rzeczy do uszytej przez siebie torby, przywiązała linę do ramy okiennej i zaczęła po niej schodzić.

Robi sa ciekawie. Więc to Roszpunka, no prosze.

Nie przewidziała tego. L ina przyniesiona przez wieśniaka nie była wystarczająco mocna, w połowie drogi na dół nie wytrzymała jej ciężaru i przerwała się. Przerażona dziewczyna z piskiem spadła na ziemię z wysokości trzech metrów.
(...) In the end she sat on the window sill and started crying out for help. Naturally, some peasant's son was passing by (...). She talked the boy into bringing her something to eat. (...) He did a good job (...) and even suggested that he could climb the tower (...) for both of them to get down.

-Nuh-uh, not on my watch, Rapunzel said to herself, and let down the basket with her long hair. (...) The boy felt disappointed but he obediently put the things he had brought into the basket and let the girl pull it up. He hung around a bit longer, but went away in the end. Rapunzel could now try to escape. (...)

It's getting quite interesting. So, this is Rapunzel. Well...

She could not possibly predict that. The robe that the peasant had brought was not strong enough. So half way downwards, it broke and the girl fell flat from three meters. [2. excursion] (...) Only had she get hold of herself, she saw the peasant 
[2. wyprawa] Chyba nie był to jej dobry dzień. Ledwie się pozbierała $\mathrm{z}$ upadku, gdy zobaczyła nadchodzącego wieśniaka. Babulka przestrzegała ją, by nigdy nie kontaktowała się z nieznajomymi. A ponieważ znała tylko babcię, nigdy $\mathrm{z}$ nikim tak naprawdę się nie widziała. Sama poprzednia rozmowa $\mathrm{z}$ chłopakiem wymagała od niej sporej śmiałości. A le wtedy kierował nią głód. Teraz nie była bardzo głodna, a i tak nie miała ochoty zadawać się z tym pryszczatym wyrostkiem, który paskudnie się do niej uśmiechał z oddali. Czym prędzej wstała i pobiegła przed siebie.

Gdy obejrzała się za siebie, zobaczyła, że chłopak ją goni. Przeraziła się nie na żarty. Nie miała kontaktu ze światem zewnętrznym od urodzenia, nie znała się na ludziach. Skręciła w prawo, bo zobaczyła tam małą ścieżynkę, prowadzącą prosto na zachód, równiutko wydeptaną. Ponownie odwróciła się i ku swemu zdumieniu ujrzała, że zaraz za nią ścieżka nagle znika i wyrastają gęste, kolczaste krzaki. To pewnie jakaś sztuczka babuleńki. Ona umiała robić różne niezwykłe rzeczy. Możliwe, że specjalnie wyczarowała tę drogę, by nikt nie mógł jej wytropić. Skoro tak, to może ta ścieżka prowadzi do jej chatki!? Roszpunka bardzo się ucieszyła tą myślą. Przestała biec, była już mocno zdyszana. Jak już wiadomo, nigdy wcześniej nie wychodziła $z$ wieży i dlatego nie była przyzwyczajona do spacerów. Tym bardziej do długich biegów. Ku wielkiej uciesze Roszpunki wkrótce ścieżynka doprowadziła ją do maleńkiej chatki, należącej niewątpliwie do babci. Opiekunka dużo opowiadała jej o tym miejscu.

Dziewczyna rozpoznała widziane wcześniej oczyma wyobraźni malwy, przykrywające stare belki ściany domku i czerwoną ławeczkę przy ganku. approaching. Her granny would always warn her against talking to strangers. (...) So, she promptly got back on her feet and started running straight ahead.

When she turned round, she saw the boy chase her. She was now seriously terrified. (...) When she turned right, she noticed a little path (...). Maybe this path would lead her to her Granny's cottage? (...) Indeed, to Rapunzel's joy, the path brought her to a little hut, no doubt, as she believed, her Granny's one. (...) 

\begin{tabular}{|l} 
Ładnie tu było. Weszła do chatki i nie \\
mogła się napatrzeć na te wszystkie \\
sprzęty, znane jedynie z opowieści. Gdy \\
wreszcie oderwała wzrok od nieznanych \\
jej przedmiotów, takich jak flakoniki \\
z miksturami, szklane kule i czaszka \\
szympansa, ujrzała widok straszliwy: w \\
kącie izdebki leżała na łóżku babuleńka. \\
Nieżywa. Umarła ze starości. \\
Ale Roszpunka o tym nie wiedziała, \\
przecież nigdy nie miała do czynienia \\
ze śmiercią. Dlatego, gdy podbiegła do \\
babulki, zawołała: \\
- Babciu, wstawaj! Strasznie długo spałaś! \\
Ale nieboszczka oczywiście nie była w \\
stanie jej odpowiedzieć. \\
No, tak ale dlaczego ona tak biegła? Czy \\
kiedyś są dowiem? Dokończę pisanie jutro. \\
Jest już bardzo późno. Dobranoc Roszpunko, \\
jutro opowiesz mi resztę. Roszpunka nie \\
dokończyła swojej opowieści ani „jutro”, ani \\
„pojutrze”, ale dopiero kilka dni później. Z \\
powodu mojego lenistwa, oczywiście. Znów \\
zasiadłam do klawiatury jedynie po to, by \\
dowiedzieć się, co się przydarzyło tej biednej \\
osóbce.
\end{tabular}

Roszpunka przeraziła się, gdy dotknęła ręki swojej babulki. Była zimna, bardzo zimna. Do tego staruszka nie reagowała w ogóle na jej wołanie. Tchnięta złą myślą sprawdziła puls. Dopiero wtedy zrozumiała, że serce jej babulki już nie pracuje. Odsunęła się trwożnie od łóżka. W oczach zabłysły jej łzy. Opadła bezsilnie na podłogę i zaczęła płakać.
The place was cosy. She entered the hut and she just could not stop looking around (...).

But, then, she saw something gruesome: in the corner of the hut, her Granny was lying in bed. Dead. She had died of old age. But Rapunzel did not know anything about that as she had never seen any dead people. So, she ran up to the bed, and cried out: - Get up, Granny! You have been sleeping for so long! But, naturally, the deceased could not possibly answer anyhow.

Right, but why should she run like that? Will I ever get to know that? I will finish writing tomorrow. It is too late now. Goodnight, Rapunzel. Tomorrow you will tell me the rest. Rapunzel did not finish her story either 'tomorrow' or 'a day after tomorrow', but only several days later. For my laziness, of course. So, I got down to writing again only to get to know what had happened to this little girl. 
Obudził ją promień słońca, wpadający do ciasnej izdebki przez duże okno z pożółkłymi firankami. Wstała z podłogi i rozprostowała zdrętwiałe ciało. Po raz pierwszy spała poza wieżą i szczerze mówiąc wolała swoje wygodne łoże z baldachimem od twardej i zimnej podłogi. Rozejrzała się po chatce. $\mathrm{W}$ kącie dojrzała drewniany kredens. Otworzyła pierwszą szafkę. Była w niej duża miska, nóż, widelec i łyżka. Oprócz tego dojrzała w głębi kilka garnków i gliniany, brzydki kubek. A więc była blisko, gdzieś tutaj z pewnością znajdzie coś do zjedzenia. Miała szczęście, odkryła mocno zeschnięty bochenek chleba, zawinięty w bawełnianą szmatkę, i biały ser $\mathrm{w}$ miseczce. Ser pokryty był pleśnią i śmierdział, więc wyjęła tylko chleb i zatopiła w nim zęby. Przez chwilę mocowała się ze stwardniałą skorupą, aż w końcu udało się jej oderwać mały kawałek. Trzymała go przez chwilę w ustach, a gdy trochę zmiękł, pogryzła i połknęła pierwszy kęs. Jedzenie zeschniętego chleba i szukanie jeszcze jakiegoś pokarmu zajęło Roszpunce dwie godziny. Wreszcie uznała, że już chyba nic więcej tu nie znajdzie i wyszła przed chatkę. Pod ścianą domu zobaczyła beczkę wypełnioną deszczówką. Dopiero wtedy poczuła, jak bardzo chce jej się pić. Rzuciła się do beczki i zaczęła łapczywie chłeptać wodę. [3. pierwsza funkcja donatora] Akurat wtedy przechodził tamtędy ów wyrostek, który wcześniej dał Roszpunce pożywienie. Zgubił się w lesie, goniąc za długowłosą pięknością, a teraz, gdy szedł zrezygnowany wśród drzew i szukał znajomej ścieżki prowadzącej do jego wsi, oto ujrzał ją nachyloną nad beczką i pijącą wodę. Zakrzyknął triumfalnie, po czym zaczął ku niej biec.
Rapunzel was really terrified when she touched the her Granny's hand. It was cold as stone. When she checked the pulse, she understood that the granny's heart stopped beating for good. (...) She sank on the floor and started crying. She was lucky to find a loaf of stale bread (...) and some cottage cheese in a small bowl. (...)

Rapunzel ate whatever she could find, and this took her two hours. Then she realised that there was nothing else she could find to eat, so she walked out of the hut. At the wall of the hut she noticed an open barrel filled with rainwater. It was only now that she realised how thirsty she was. She brought herself to the barrel and started lapping the water. [3. the donator's first function] Just at this moment, this lad who had given the food to Rapunzel was passing by. He got lost in the woods, having chased the beauty, and now he was walking with a resigned look on his face, looking for the path to his village. When he saw the girl bent over the barrel and lapping the water, he shouted triumphantly, and started to run towards her: 
Co to za idiota, żeby krzyczeć! Przecież mógł do niej się podkraść po cichu! Założę się, że Roszpunka mu ucieknie.

Gdy dziewczyna usłyszała ochrypły wrzask, wyjęła głowę z beczki i również krzyknęła. Tyle, że z przerażenia. Zostawiła beczkę i znów zaczęła uciekać. Chłopak był jednak tuż za nią. Słyszała jego głośny, chrapliwy oddech. Przyśpieszyła.

Wieśniak był już bardzo zmęczony, głodny i zły, a dziewczyna wypoczęta i po śniadaniu. Dlatego już po minucie pościgu chłopak dał za wygraną i zostawił w spokoju cudowne zjawisko. Cudowne zjawisko jednak tego nie zauważyło i biegło dalej, coraz szybciej i szybciej, dysząc ciężko. Po zaczerwienionych policzkach spływały jej łzy. Bała się, tak bardzo się bała. Nagle jakaś gałązka uderzyła ją mocno w twarz, zostawiając po sobie różową pręgę. L iście szeleściły, gdy przedzierała się przez krzaki. Teraz ona coraz bardziej słabła, serce jej biło jak oszalałe. Ze skłębionych myśli jedna wybiła się na pierwszy plan, że dalej tak już nie może. Zwolniła nieco, ale nie oglądała się za siebie. I wtedy nagle pociemniało jej w głowie i padła wyczerpana na ziemię. Zemdlała.

To wszystko. Dalej już nie pamiętała nic, prócz ciemności i pustki. W końcu straciła świadomość. A le gdzie teraz jest? No, wreszcie się wszystko wyjaśniło! Ale właśnie teraz nie wiadomo, gdzie ta Roszpunka jest. Nie zostawię jej tak samej w tej jaskini. Pisze dalej. Zawsze dotrzymuje słowa... Tak, jasne... Już nie mam do siebie siły! Znów zostawiłam biedna dziewczynę na pastwe losu. Tym razem jednak zasiadam do klawiatury, bo wstydzę się mojego lenistwa $i$ mam
What an idiot to yell like that! He could have skulked among the trees quietly! I bet she will run away again.

When the girl heard the yelling (...), she indeed started running away. Yet, the boy was just behind her, (...) so she sped up. The peasant was already very tired, hungry, and angry $(. .$.$) , so a minute later$ he simply gave up (...).

She was scared, very scared. Some twig hit her across the face, leaving a pinkish scar. (...) She was now fading, with the heart pounding like mad. (...) She slowed down, but did not look back. And, then, suddenly she fell down on the ground, exhausted. She fainted.

That is all. She did not remember anything now, anything but darkness and emptiness. In the end she lost consciousness. But where is she now? Right, everything is clear now! But, wait, I don't know where she is, actually. I cannot leave her just like that, in this cave. Let me write on. I always keep my word... Yes, sure... I'm just impossible. I left the poor girl alone in the cave again, high and dry. But this time I'm getting down to writing because I'm ashamed of 
$\mid \begin{aligned} & \text { dziwne poczucie obowiązku, i przeczucie } \\ & \text { oczekiwania. W końcu jeszcze nie } \\ & \text { skończyłam opowiadania. I wciąż nie wiem, } \\ & \text { gdzie ta Roszpunka leży. Co to za jaskinia? }\end{aligned}$

Dziewczyna podniosła się na łokciach i rozejrzała. Rzeczywiście leżała w ciemnej jaskini. Obok siebie zobaczyła ślady po ognisku i rozrzucone wokół białe kości. Poczuła dziwny lęk na widok tych szczątków. Coś jej to przypominało, tylko że sama nie wiedziała co... Poruszyła się. Chciała wstać, ale coś krępowało jej ruchy. Przyjrzała się sobie. Była związana. Teraz dziwny lęk nagle gdzieś wyparował i zastąpiła go panika. Jak mogła zapomnieć, przecież czytała kiedyś bestiarium pożyczone od babulki! Dowiedziała się tam, że tylko jedne stworzenia mieszkają w ciemnych, ponurych jaskiniach, rozpalają w nocy ogniska, a w dzień wychodzą na polowania...

I jedzą ludzkie mięso... To były trolle... [4. szkodzenie] Gdy oglądała rysunek trolla umieszczony w bestiarium, wzdrygnęła się z obrzydzenia i zamknęła książkę z silnym przekonaniem, że nigdy nie wyjdzie z wieży. Możecie więc sobie wyobrazić, co czuła, gdy zobaczyła śpiącego kilkanaście metrów od niej trolla - trolla w całej swojej olbrzymiej okazałości, śmierdzącego, lepiącego się od brudu, z wystającą z półprzymkniętej paszczy zakrwawioną łapą niedźwiedzia. Oczywiście wrzasnęła. Całe szczęście, że troll był na tyle syty i śpiący, że nie obudził się na wołanie swojej ofiary, którą zostawił sobie na kolację. I całe szczęście, że usłyszał je przejeżdżający koło wejścia do jaskini książę (jakże w bajce mogłoby zabraknąć księcia!). my laziness, and I feel a strange sense of responsibility (...). I haven't finished the story, after all. And I still don't know where it is that this Rapunzel is lying. What kind of cave is this?

The girl picked herself up and looked around. Indeed, she was lying in a dark cave. (...)

She wanted to get up, but (...) she was bound. The strange fear had worn away and was now substituted with panic. (...) She knew that there is only kind of creatures that live in dark gloomy caves, light the fire at night, and go on hunting during the day...

And they prey on human flesh... It was the trolls... [4. detriment] (...)

You can imagine how she felt when she saw a troll sleeping just a dozen or so meters away (...).

Naturally, she screamed. Luckily, the troll was so replete and sound asleep that he did not wake up (...). And, luckily, a prince that was just passing by the entrance to the cave heard the scream (of course, how there could possibly be no prince in a fairy tale!)

The young man drew the sword from the sheath, just in case, and silently dismounted the horse. (...)

Rapunzel was crying with bitter tears, and she kept moaning:

- I don't want to die... I don't want to die! I'm still so young! (...) 
Młodzieniec wyjął na wszelki wypadek miecz z pochwy i zeskoczył bezszelestnie z konia. Podkradł się, jak mógł najciszej, do jaskini i zaczął nasłuchiwać. Histeryzującej Roszpunce łzy ciekły z oczu, jęczała:

- Ja nie chcę umierać... Ja nie chcę jeszcze umierać! Jestem jeszcze młoda!...

Wiła się po podłodze, nie zważając na to, że poturlała się prosto w popioły po ognisku i teraz jej suknia zrobiła się tak czarna jak jej włosy i twarz.

Książę wyłowił cichutkie jęki i uznał wreszcie, że czas działać. Zebrał się w sobie. Wzniósł miecz i wkroczył do jaskini. Gdy jego oczy przyzwyczaiły się do panującego mroku, dojrzał pogrążonego w głębokim śnie trolla oraz szamoczącą się na ziemi dziewczynę. Chwycił ją czym prędzej w ramiona $\mathrm{i}$ - ściskając kurczowo $\mathrm{w}$ ręce miecz - wybiegł jak oparzony z groty. Wskoczył na konia, a raczej wpełzł na niego z Roszpunką w objęciach, i ruszył cwałem do zamku. [5. walka]

No, to już wiem, że jednak był w to wszystko zamieszany książe... Ale też jest mi smutno, bo oznacza to, że bajeczka już się kończy.

Ciekawe, czy znajdzie się miejsce na formułkę ze Shreka: Żyli długo i szczęśliwie i było im zielono-...

W połowie drogi książę wstrzymał gwałtownie konia, bo zobaczył, że uratował nie powabną dziewicę, jakiej się spodziewał, ale płaczącą histerycznie, ubabraną w popiele potworę. Wystraszył się, czy aby nie zagalopował się w żądzy ratowania, i wrzucił Roszpunkę do najbliższej rzeczki. Dziewczyna pisnęła ze strachu, wpadając do wody. Książę zsiadł z konia i przyjrzał się jej. Woda była tutaj do kolan, więc Roszpunka nie utopiła się, tylko bardzo potłukła. Rzuciła nienawistne
The prince identified some quiet moans and decided in the end that it was high time to act. He lifted his sword up and walked into the cave. (...)

He saw a sleeping troll and a struggling girl lying on the ground. He took her in his arms and - with his sword in his hand - he swiftly ran out of the cave. He got on the horse, or, rather, crawled onto the horse, with Rapunzel still in his arms, and galloped to the castle. [5. fight] So, I now know that the prince was involved in all this... I'm also sad because this little fairy tale is about to end. I'm curious if there is still any room for the Shrek slogan: And they lived happily ever after and they all felt greenish...

Half way to the castle, the prince suddenly reined his horse to a halt because he realised that the girl that he had just saved was no beauty but a hysterical and ash-covered monsteress. He was frightened that he had gone too far in his desire to save the girl, so he threw Rapunzel to a nearby river. The prince got off his horse and had a good look at her. The waters were shallow, so Rapunzel did not drown, but was merely a little bruised. (...) She washed her face and made her look more like a human being. She walked out of the water with dignity and said to the prince: 
spojrzenie młodzieńcowi. Zimna woda uspokoiła ją, ale gdy przejrzała się w niej, znowu wrzasnęła. Zanurzyła twarz w wodzie i zaczęła się myć. Po chwili wynurzyła się, nieco już podobna do istoty ludzkiego rodzaju. Wyszła z rzeczki z godnością i odezwała się do księcia:

\section{- Co to miało znaczyć?}

Książę patrzył na nią przez chwilę zbaraniałym wzrokiem. Nikt nigdy nie odezwał się do niego takim tonem i do tego bez tytułów.

- Byłaś brudna... - wyjąkał.

- I tylko dlatego? - prychnęła

niezadowolona, wyżymając włosy.

- Och, przestań. Jestem księciem oznajmił stanowczo. - Pamiętaj, że cię uratowałem.

- No i co z tego? - spytała nie rozumiejąc Roszpunka.

- Powinnaś mi być wdzięczna na wieki wyjaśnił książę - tak przynajmniej mówią zwykle uratowane dziewice. Nigdy o tym nie słyszałaś? Nie czytałaś bajek?

- Szczerze mówiąc, to nie - powiedziała rozgniewana dziewczyna.

Skąd miałaby o tym wszystkim wiedzieć? Przecież siedziała tyle czasu w wieży. Bajki jednak czytała.

- Ale bajki znam - oznajmiła po krótkim namyśle.

- No więc przyjmij do wiadomości, że jestem księciem, że cię uratowałem i że winna mi jesteś wdzięczność na wieki warknął zdenerwowany młodzieniec.

- Co jest z tobą, dziewczyno? Nie mówi ci to nic?

- Nie - wypaliła Roszpunka niemal obrażona.

- Będziesz moją żoną! - wrzasnął doprowadzony do furii książę. - A kto tak powiedział?
- What was this all supposed to mean? The prince went speechless because never before had anyone addressed him like that (...).

- You were sort of ... dirty.

- Is that all?

- Oh, stop it. I'm the prince, after all. And remember that it was me who saved you.

- So what?

- You should be grateful to me forever, or this is at least what the saved virgins typically say. You've never heard about that? You don't read fairy tales, or what? - Honestly, I don't.

How could she possibly know all about that? After all, she had been kept in the tower for so long. But, she did read fairy tales.

- In fact, I do know fairy tales - she had second thoughts.

- If you do, let me tell that I am the prince, I have saved your life and you should be grateful to me for that forever. - What's wrong with you, lady? This doesn't mean anything to you? - No, it doesn't.

- You'll be my wife - he screamed, driven to the verge of fury.

- And who says so?

- This is what always happens! Tradition!

- Suppose I don't feel like that?

- I will force you to marry me, then! the young man shouted, embraced the girl, threw her over his shoulders as if she was a sandbag, and mounted his horse.

- Yes, I will force you! 


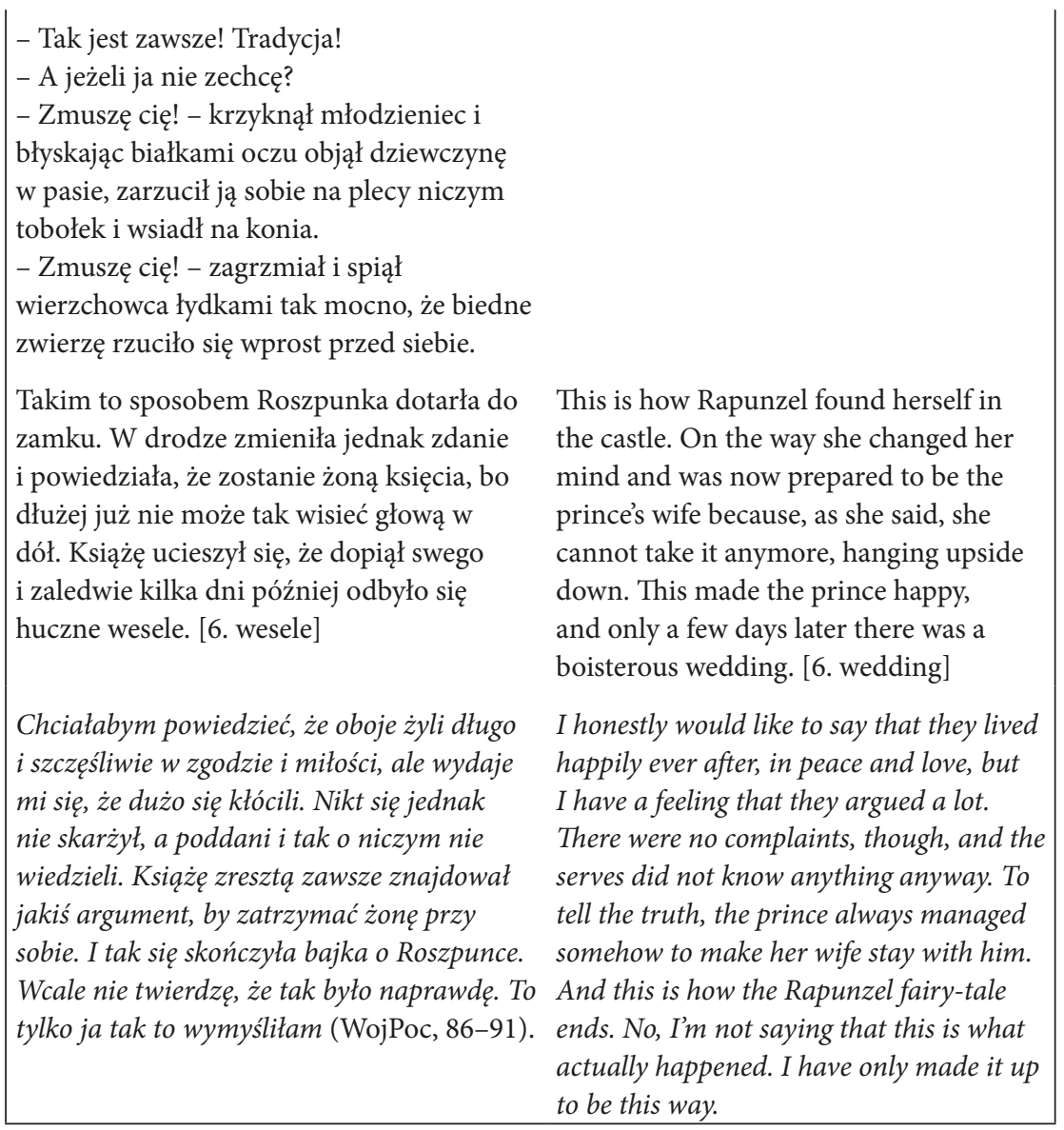

Compositional scheme. Of Propp's thirty one characteristic functions of fairy tales, Text 9 (Raponcka) exemplifies as many as twelve:

(1) lack of something (here: no child),

(2) ban (of touching the plants),

(3) ban violation (picking the forbidden plants),

(4) deceit (ultimatum: baby for plants),

(5) neutralisation of the lack (baby's birth),

(6) detriment (kidnapping of the child),

(7) excursion (the prince to the woods),

(8) struggle (between the witch and the prince), 
(9) stigmatising the protagonist (making the prince blind),

(10) magical substance (sight restored with a handkerchief and water),

(11) wedding

(12) punishment (the witch sentenced).

The compositional scheme of Text 9 is then typical of a fairy tale. The scheme is signalled with characteristic opening and closing existential formulaic expressions $^{55}$ (Razu pewnego żyli sobie szczęśliwie małżonkowie, ale nie mieli dzieci 'Once upon a time, there lived a happily married couple, but they did not have children' versus Potem żyli wszyscy szczęśliwie 'They lived happily ever after'). 'The basic structuring principle of the text (...) is a sequence of events, each event being presented as a part of the textual sequence' (NiebrzegowskaBartmińska 2007: 254).

In Text 10 (Rapunzel: a new story), the traditional compositional scheme of fairy tales is reflected in the following elements:

(1) departure,

(2) excursion,

(3) the donator's first (posthumously performed) function (food supply),

(4) detriment (trolls),

(5) fight (here: escape),

(6) wedding.

As can be seen, in comparison to the traditional Rapunzel fairy tale, Text 10 begins halfway through. Dagmara Minda's story does not explain the girl's mysterious birth. Yet, what her narration shares with the traditional variants is in no doubt; the excursion motif which proves to be determining the events to follow. Still, Rapunzel: a new story begins with the girl already imprisoned in the tower and not with her would-be father's departure to the witch's garden, or her birth.

Nor is there any fairy-tale-like opening formula in text ten.. The story begins with a in medias res kind of introduction: Biegła przez las 'She was running through the woods. Technically speaking, this sentence is rhematic not thematic, as the theme (topic) is for the time being unknown and only becomes revealed later in the text. In a typical fairy tale, the very first sentence serves to introduce the protagonist.

As to the closing of the story, the ending corresponds to a traditional fairy tale as long as the existential formulaic expression is used: Chciałabym powiedzieć, $\dot{z} e$ oboje żyli dtugo i szczęśliwie w zgodzie i miłości, ale wydaje mi, że dużo się kłócili

55 For more, see Wójcicka 2010. 
i operacyjną: I tak się skończyła bajka o Roszpunce. Wcale nie twierdzę, że tak byto naprawdę. To tylko ja tak to wymyśliłam. ('I honestly would like to say that they lived happily ever after, in peace and love, but I have the feeling that they argued a lot. (...) And this is how the Rapunzel fairy-tale ends. No, I'm not saying that this is what actually happened. I have only made it up to be this way.'). Yet, the author's commentaries at the end of the story mark her distancing from the expected convention of the fairy tale as a genre.

It is not only in the ending of the story that we see the author's interpolations. In fact, the text is frequently interrupted with her commentaries which directly relate and refer to various kinds of traditional resources: folklore, cartoons, fairy tales etc. To some extent they all are auto-thematic in nature, that is, they are focused on the writing process itself. In other words, the author unveils the backdrop of her writing, and this creates an impression that, in her creative process, she is guided by what is going on in the story: No, tak ale dlaczego ona tak biegła? Czy kiedyś sa dowiem? Dokończe pisanie jutro. Jest już bardzo późno. Dobranoc Roszpunko, jutro opowiesz mi resztę. ('Right, but why should she run like that? Will I ever get to know that? I will finish writing tomorrow. It is too late now. Goodnight, Rapunzel! You'll tell me the rest tomorrow'). All in all, the Rapunzel story does not seem to be told either by Rapunzel or the author, but it is, say, 'narrated' by the genre itself, its various conventions, and the transformations it is undergoing in modern culture.

\section{The picture of the world in traditional and modern fairy tales}

Protagonists. The heroes of fairy tales (cf. Nedo 1965, Krzyżanowski (ed.) 1965, Simonides 1969) represent types - they do not have names or any personal characteristics, but simply stand for good or evil. Indeed, in Raponcka (Text 9) the protagonists are pictured as indicated by W. Propp, in well-defined and stable relationships: the heroine - Rapunzel versus the adversary - the witch. Next to family-related (internal) protagonists, there are two external characters, i.e. the prince and the witch, which gives us a relatively small set of characters. They represent types not only in what they are, but also in what they do. It is only Rapunzel whose characterisation is more explicit and elaborate: Raponcka była bardzo piękna, miała czarne oczy, a włosy na parę metrów długie 'Rapunzel was very beautiful, she had black eyes, and her hair was a few metres long. She is gorgeous and good-hearted, the latter being the reason why she restores the prince's sight. Rapunzel's adversary is the witch. The witch first kidnaps her and then locks her up in the tower, forcing the girl to work for her.

Text ten can be read as a dialogue with tradition. Of the long-established Rapunzel fairy-tale convention, the author only adopts three characterstypes: Rapunzel, the prince and the granny, all three having been given novel 
functions and new authorial interpretations. On the one hand, they represent characters-types, which is why most of them are not given personal names, yet on the other hand, Rapunzel and the prince can hardly be reduced to typified protagonists. In D. Minda's revision, the protagonists are not naive, but rebellious, cunning and know what they want: Nie ze mna te numery - pomyślała Roszpunka 'Not on my watch, Rapunzel said to herself'. Generally, Rapunzel is not a passive poor girl. She is depicted as sassy, decisive and high-spirited, which can perhaps best be seen in the final dialogue with the prince. The prince, in turn, seems to be most traditional of all the protagonists of this fairy tale. His 'conservatism' may stem from the sustaining (social) function he is scheduled to play: Książe wyłowit cichutkie jęki i uznał wreszcie, że czas działać ('The prince identified some quiet moans and decided in the end that it was high time to act'), or Wystraszył się, czy aby nie zagalopowat się w żadzy ratowania i wrzucit Roszpunkę do najbliższej rzeczki ('He was frightened that he had gone too far in his desire to save the girl, so he threw Rapunzel into a nearby river').

The witch is different as well. In D. Minda's story, she is not a witch, really, but a very old woman that appears to be agreeable even after her death, that is, when she serves as a donor who posthumously provides Rapunzel with food (instead of some traditionally-expected magical substance, that is). In fact, there is no mention of any magical substances in D. Minda's version, but there are fantasy characters instead (trolls).

Minda's characters are genre-conscious in the sense that they are well aware that they are fairy-tale protagonists and as such, they have to comply with their assigned conventions. Minda may have the Shrek cartoon in mind here, which is what she reveals at some point in one of her metatextual interpolations: Ciekawe, czy znajdzie się miejsce na formułkę ze Shreka: Żyli długo i szcześliwie i było im zielono-... 'I'm curious if there is still any room for the Shrek slogan: And they lived happily ever after and they all felt greenish.... Minda also allows for new characters. The peasant appears in a twofold function, which is not possible in traditional fairy tales: as a food provider, he is a donor. But as a chaser, he is a mild adversary. The true enemy is the troll. Even though the cast is limited, the protagonists are not attempted in terms of family relationships. Two further missing elements in the compositional scheme of Rapunzel are: a new story involving the lack of punishment and the prince's defeat of the troll.

Space. As indicated by S. Niebrzegowska-Bartmińska:

What makes space significant in fairy tales is its role in structuring the overall compositional scheme. Namely, space records the protagonist's shifts from place to place, be it in the home-world or home-world-home perspectives. The point of departure and at the same time, the first element of the space as structured in a fairy tale is the protagonist's 
native place. It is at his/her home that the plot is initiated, and it is what he/she departs from and comes back to. (Niebrzegowska-Bartmińska 2007: 279)

In our traditional version of the Rapunzel story, space is dichotomous; as something firstly between her family place and the witch's garden. The latter is walled off from the rest of the world, which symbolically points to the boundary between the real, known and close and the unknown and dangerous. The other opposition is between Rapunzel's home and the woods; the woods/forest usually identified as 'the most typical object of alien [external] space, present in virtually all fairy tales' (Niebrzegowska-Bartmińska 2007: 280). It is where the witch imprisons Rapunzel and it is what the prince's horse senses as a threat. In their long and exhausting wayfaring through woods and mountains, the protagonists go past the well which symbolises their passage to a kind of inside-world (cf. Niebrzegowska-Bartmińska 2007: 281). The destination point for Rapunzel and the prince is his castle, which stands for the happy-end conclusion of the whole fairy tale.

In Text 10, the space which is known and domesticated is the tower, the only place that Rapunzel would be familiar with. All the other spaces - the woods, the cave - are presented in contrast to the tower, and it is in them that the author places fantasy monsters and other dangerous things. What brings hope to Rapunzel in her wandering through the woods is the old woman's hut. The girl finds a potion vial, crystal balls, and a chimp's skull there, which indicates that the deceased woman was a witch, after all. On the way to the prince's castle, there is a river which can be interpreted as a boundary or a transition zone, between the tower and the world of humans and as a passage to being married. In both versions, the castle epitomises a happy ending.

Time in the traditional variant is linear, unidirectional, chronologically sequenced. It is also segmented into respective events, which is how it marks the significant points in the story. For this reason, the narrative part of the story is told in the past tense, the space of this past tense time being clearly divided by the oncoming motifs and themes. The narrative part starts with the first event, i.e., typically, either the element of detriment or lack of something, which leads to the main protagonist's departure and closes with a focal event, which again, typically involves winning the queen's favour, overcoming the last obstacle and coming back home. This kind of time is confined and develops by leaps from one event to the next (Niebrzegowska-Bartmińska 2007: 276), so it is marked in the text with references to the time of the day/night, or of the year: $W$ pewnej nocy, gdy mąz pracował, przyszła czarownica i potajemnie ukradła dziecko ('One night, when the husband was working hard, the witch arrived and stole the baby') / O pótnocy przyleciała czarownica ('The witch was back at midnight')/ 
Za rok porodziła córkę ('A year later she gave birth to a baby girl') / I tak minęto szesnaście lat ('Sixteen years passed').

In Text nine, the most important events take place at night: Już się ćmiło, lecz król stoi $w$ lesie ('It was getting dark, but the king was still there, in the woods')/O pólnocy przyleciała czarownica ('The witch was back at midnight'). Indeed, the night constitutes the setting for 'powers of darkness, magic, witchcraft' (Niebrzegowska-Bartmińska 2007: 148).

In Text ten, the narration is of the retrospective kind, which is unheard of in traditional fairy tales. Apart from that, time does not seem to play any significant role in Text ten. All we have is the information that the whole story takes two days and that the night Rapunzel spends at the old woman's hut is her first night outside the tower.

Message. 'The name of the genre, bajka [Eng. fairy tale] comes from the verb bajac ['to fable, to make up'] and relates the genre's intention with concepts of telling lies, making things up, falsehoods and trumping things up' (NiebrzegowskaBartmińska 2007: 282). Traditional fairy tales do not expose this intention, so if we are aware the story is made-up, this comes with the very text frame where the reader's attention is, on principle, directed towards a different world, a world which is neither real nor true. However, the fabled intention comes to the fore in modern fairy tales where we find formulaic truth-assertions (absent in traditional ones), as in Chciałabym powiedzieć, że oboje żyli dtugo i szczęśliwie w zgodzie i miłości, ale wydaje mi się, że dużo się kłócili. [...] Wcale nie twierdzę, ze tak było naprawdę. To tylko ja tak to wymyślitam. ('I honestly would like to say that they lived happily ever after, in peace and love, but I have a feeling that they argued a lot. (...) No, I'm not saying that this is what actually happened. I have only made it up to be this way').

All kinds of fairy tales (animal-, aetiology-, or magic-related) store and incisively embody elements of the folk worldview, especially anthropomorphic visions of the world, ideas of harmonious natural living, conceptions of righteous behaviour and of virtuous social bonds. (...) Structured according to the chronological sequence of events, the world presented in fairy tales is merely imaginary, yet it is depicted with the intention to resemble the real one. The focal point of this world is the house/ home and its residents, and not the space where the protagonist is actually placed. The protagonist's wayfaring and adventures present themselves as a metaphor of human fate, never-ending search, choices to be made and tasks to be performed. Fairy tales allow the assessment of both their protagonists and their events, they confirm the choices and positive values, communicate - directly or indirectly - the world of values, which is that the true merit of humans is not their birth or riches, but spiritual assets, that disinterested kindness happens to be requited, and that truth and justice always win. (Niebrzegowska-Bartmińska 2007: 284) 
As to values, the most cherished are the family and life (cf. NiebrzegowskaBartmińska 2007: 149). Let us remember that it is for the sake of his family and the expected baby that the father leaves his place to run the risk of finding herbs. Equally important is freedom - the reason why the prince stands up to the witch is precisely to liberate Rapunzel from the tower.

As an oral text, which is to be remembered, a prototypical text of culture, a fairy tale is 'an embodiment of a culture-specific model of the world where rules, principles and patterns which are characteristic of a given culture all happen to be focused and reflected' (Źółkiewski 1988: 65 ff). In fact, any text of culture qualifies as an embodiment of some given model of the world, as encoded in a specific culture. The model of the world that is reflected in fairy tales then is traditional, (in the sense of S. Niebrzegowska-Bartmińska 2002). In this context, Rapunzel: a new story (Text $10)$ is where the traditional worldview meets a modern model of the world. The net effect is that the story departs from the traditional account in several respects. For example, Text ten does not embody the idea of peaceful life in the world of nature; once Rapunzel has left the tower and wanders through the woods, everything and everybody she meets appears threatening to her, which is why she either runs away or rebels. Nor can we find here any embodiment of righteous behaviour. Although the ending of the story is relatively happy, evil behaviour escapes punishment, and justice does not win. The picture of the world contained in the closing paragraphs tells the truth about the modern world - the wedding does not mark the end of troubles and is not a passage to a long and happy life ever after. The wedding is simply one of many stages in human life. The married people live a normal and typical life, which is why they may argue a lot, for example. Text 10 does not present 'the protagonist's wayfaring and adventures (...) as a metaphor of human fate, a never-ending search, choices to be made and tasks to be performed' (NiebrzegowskaBartmińska 2007: 283). It is striking that instead of a typical wayfaring, there is in fact, a never-ending bolting in Text ten: Rapunzel runs away from the peasant, the troll and even tries getting away from the prince. If the opening of a fairy tale has indeed an encoding function (cf. Łotman 1984: 309), then the first lines of Text ten present a very non-traditional message (as for a fairy tale, that is): Widze ja, jak biegnie przez las. Dlaczego tak biegnie? [...] Biegła przez las ('I can see her running through the woods. Why is she running like that? (...) She was running through the woods'). Human fate is here metaphorically depicted as running and more specifically, as running away and/or chasing something. Interpreted against the times it represents, it reflects the modern man's way of thinking about life and place in the world. Still, the primary value that is cherished in Rapunzel: a new story is life, or staying alive. Rapunzel is prepared to overcome her own inhibitions twice in the story and break the old woman's ban not to talk strangers only to get some 
food and satisfy her hunger. Moreover, we see her prepared not only to run away from what she needs to survive, but also to achieve comfort and stability: $W$ drodze zmieniła jednak zdanie i powiedziała, że zostanie żoną księcia, bo dłużej już nie może tak wisieć głowa $w$ dót ('On the way she changed her mind and was now prepared to be the prince's wife because, as she said, she could not take it anymore, hanging upside down'). Neither the values she shares nor her motivation are of the moral kind, which is what we expect of a traditional fairy tale. In Text 10, Rapunzel is after convenience, robustness, physical ease.

Dagmara Minda's fairy tale is highly selective. The author pulls out of the folklore bag only that which is universal, if not timeless and stands for the fairy tale as a text-type. In this sense, her choice of the fairy tale genre is far from accidental. Fairy tales are characterised to be texts which have 'a capacity of being transformed in actual variants into unique exemplars of intentionally-driven human situations' (Ługowska 1981: 23). 'These stereotyped themes, situations and protagonists make fairy tales expressions of human dreams and desires' (ibid., p. 16). In other words, as J. Ługowska understands W. Propp's analyses, in terms of genre distinctions, 'the superordinate semiotic principle of theme organisation [in fairy tales] consists of constructing intentional reality that corresponds to a man's dreams and satisfies in an absolute and exemplar-like way, the naïve sense of justice and moral order of the world' (Eugowska 1981:21). In practical terms, what is extracted from the collective memory resources over and over again, what appears to be reiterative in nature, may be regarded as an expression of intentional reality. In Texts nine and ten this includes the girlprince scheme, with Text ten giving this scheme some feminist flavour.

As to the protagonists in Text ten, the way they are depicted must be considered novel in comparison to the traditional version (Text 9). Rapunzel is an active, assertive and independent woman. The prince is fully aware of the role he is scheduled to play in the fairy tale and the granny (old woman) is not a witch or an adversary, but a supportive donor. Again, in her Rapunzel: a new story, Minda elaborates only on that which happens to be associated most closely with the traditional version of the story and this is both the adversary function and the happy-end function. Text ten is presented as an attempt at modernising and refreshing the text-type which is otherwise nothing but a petrified genre. This hold true for both its form (no traditionally-expected opening formula, but authorial interpolations and retrospections instead) as well as its substance (new protagonists performing traditional fairy-tale-like roles: the one that provides Rapunzel with the rope is the peasant and this makes him a donor, whereas the 
adversary is the troll). On the whole, because they are most numerous, the formal modifications seem to be meant to redefine the traditional message and to give it a novel and attractive shape. The constituents which appear most stable, if at all likely to change, in the Rapunzel fairy tale include the good-evil opposition and the happy-end. Naturally, in Text ten, both are taken with a pinch of salt.

Generally, Rapunzel: a new story does implement the genre conventions of fairy tales, but the author is selective in her choice of what she finds socially relevant and desirable, which is conviction of a dichotomous structure of the world and a belief in the happy ending. In this context, it is an example of how a traditional text of folklore can be transformed for specific reasons. It also shows that folklorism can be presented, on the one hand, as a memory-aiding phenomenon based on selectivity and grounded in a social group and on the other hand, as a dialogue with various kinds of traditions or a play of genre conventions. This leads us to the following generalisations:

(1) changes in collective memory become revealed in a contrastive analysis of traditional and modern versions of an identical text-type; the comparison shows what deserves current recognition, what memory resources are explored and why;

(2) the text is not only a memory carrier but also a model of the world; social changes and transformations are followed by bringing memory resources up to date; the fairy tale, a highly petrified genre of folklore is a notable record of changes in the picture of the world as much as of modifications in the corresponding collective memory;

(3) a comparative analysis of text variants allow the identification of mechanisms of memory selection; the analysis shows that what is singled out of the whole fairy tale tradition in the end only includes the girl-prince scheme, the happy-end motif, and the good-evil distinction; the elements which happen to be modified are more numerous:

- moral values are superseded with utilitarian and conformist considerations;

- the protagonists are made to be aware of the fairy tale conventions, yet at the same time they are transformed into rebellious and independent individuals which escape their traditional naïve counterparts;

- instead of symbolising human life in terms of wayfaring, life is depicted as escaping from the dangers of the world, be it human or non-human threats and perils;

- as the text is overloaded with information, its structure is made to appear eye-catching, unpredictable and intriguing, which is achieved by means of metatextual interpolations, intertextual correspondences and authorial retrospections; 
Tab. 4: Memory: communicative, cultural, and intercultural (source: J. Assmann and own representation)

\begin{tabular}{|c|c|c|c|}
\hline & $\begin{array}{l}\text { Communicative } \\
\text { memory }\end{array}$ & Cultural memory & Intercultural memory \\
\hline Substance & $\begin{array}{l}\text { Historical } \\
\text { experience within an } \\
\text { individual's lifetime }\end{array}$ & $\begin{array}{l}\text { Mythical prehistory, } \\
\text { events from absolute } \\
\text { history }\end{array}$ & $\begin{array}{l}\text { Absolute past events } \\
\text { reinterpreted in the light } \\
\text { of the present and related } \\
\text { to current events }\end{array}$ \\
\hline Form & $\begin{array}{l}\text { Informal, natural, } \\
\text { undeveloped, } \\
\text { resulting from } \\
\text { everyday interactions }\end{array}$ & $\begin{array}{l}\text { Organised, refined, } \\
\text { ceremonial } \\
\text { communication, } \\
\text { festivity }\end{array}$ & $\begin{array}{l}\text { Petrified, yet also } \\
\text { deliberately transformed/ } \\
\text { intertextual }\end{array}$ \\
\hline Media & $\begin{array}{l}\text { Living recollections } \\
\text { in an individual's } \\
\text { memory, experience, } \\
\text { and transmission }\end{array}$ & $\begin{array}{l}\text { Objectivised/traditional } \\
\text { and symbolic coding/ } \\
\text { staged performances } \\
\text { (literature, visual art, } \\
\text { dance etc.) }\end{array}$ & $\begin{array}{l}\text { Deliberately } \\
\text { subjectivised/traditional } \\
\text { and modern coding }\end{array}$ \\
\hline $\begin{array}{l}\text { Temporal } \\
\text { structure }\end{array}$ & $\begin{array}{l}80-100 \text { years, } 3-4 \\
\text { generation span, } \\
\text { evolving together } \\
\text { with the sense of the } \\
\text { present }\end{array}$ & $\begin{array}{l}\text { Absolute past of a } \\
\text { mythical, primeval age }\end{array}$ & $\begin{array}{l}\text { Absolute past of the } \\
\text { mythical foretime } \\
\text { subjected to current } \\
\text { interpretation }\end{array}$ \\
\hline Bearers & $\begin{array}{l}\text { Unspecialised } \\
\text { witnesses of memory } \\
\text { community }\end{array}$ & $\begin{array}{l}\text { Specialised bearers of } \\
\text { tradition }\end{array}$ & $\begin{array}{l}\text { Specialised bearers } \\
\text { of tradition (e.g., folk } \\
\text { writers) }\end{array}$ \\
\hline
\end{tabular}

(4) collective memory resources serve as the point of departure for formulating judgements about the modern world;

(5) as a petrified genre of folklore, the traditional fairy tale is a cultural memory text (in the sense of J. Assmann's distinctions), that is (i) it narrates events of some absolute past time (i.e. this past is indeterminate so the temporal setting resembles timelessness and expresses some mythic foretime), (ii) it is given elaborate (petrified) forms, (iii) is encoded with traditional and symbolic signs, (iv) its temporal structure is borne out of specialised tradition bearers (story tellers, folk writers);

(6) a modern transformation of traditional fairy-tale motifs is a dialogue with tradition.

On this last point, although a transformed variant is a text that relies on a given genre convention, it includes novel interpretations anyway. If that is the case, it can also be seen as an intercultural memory text, a combination of 
communicative and cultural memories or a superstructure erected upon cultural memory. Intercultural memory can be characterised as a specific kind of translation, where elements of traditional (source) culture are rendered as elements of modern (target) culture, the whole process being perhaps more of an assimilation, i.e. old cultural meanings and forms are adapted or assimilated, to modern culture expectations (cf. Golka 2010: 195). This also means that a transformed variant is intertextual in character, which can be understood as communication among members of different social groups of the same national culture (cf. Mikułowski-Pomorski 2003: 11). J. Assmann's table can then be supplemented with the notion of intercultural memory (Tab. 4): 


\section{Memory figures versus memory aspects in oral texts}

\section{Memory figures in a research perspective}

This chapter begins with Maurice Halbwachs' and Jan Assmann's insights into the nature of memory. More specifically, Halbwachs' conception of memory frames is echoed; that is memory constructs which are shared by members of the same social group. The basis for the notion of memory as a shared commonality derives from Halbwach's observation that what people do remember depends on the groups they belong to and on the ideas these groups find most significant (cf. Halbwachs 1992). This is Halbwachs' way of bringing together individual and collective memories and claiming that an individual's memory is moulded by the group this individual identifies with.

Moreover, Halbwachs emphasises a close relationship between memories and current on-going events. As he would argue, people remember past events because these events contract various relationships with present-day beliefs and convictions. One of the correspondences that build these close relationships and recall memories is localisation because it is localisation that not only anticipates memories and their recollection, but first of all determines their content. In this way, localisation embraces part of the building material of a given memory (cf. Halbwachs 1992: 179). The other element of memory frames is time. Similarly to localisation, time determines memory recollection and constitutes a specific point of reference for memories. However, a given event can indeed become a point of reference only as far it is found to be related with the times and places that are reference points for the whole group (cf. Halbwachs 1992: 189).

Inspired by Halbwachs' research, J. Assmann puts forward the notion of memory figures which he understands as culture-determined and sociallysanctioned memory accounts, the term figure being identified with narratives. Following Halbwachs, J. Assmann assumes that memory figures include 'models, examples, and elements of teaching[, so] they express the general attitude of the group; they not only reproduce its history but also define its nature and its qualities and weaknesses' (J. Assmann 2011: 25-26). Memory figures, as J. Assmann sees them globally, 'emerge out of th[e] interplay between concepts and experiences' (ibid. p. 24), which makes remembering concrete and actual. That is why J. Assmann ascribes 'three special features' to memory figures: a concrete relationship to time and place, a concrete relationship to a group, 
and an independent capacity for reconstruction, or reconstructivism (cf. ibid., pp. 24-26).

More specifically, 'memory figures need to be given substance through a particular setting and to be realised at a particular time. In other words, they are always definitively related to time and place, even if this is not necessarily in an historical or geographical sense' (ibid., p. 24). Another feature of memory figures consists of making references to a group, which entails the claim that collective memory cannot be passed on arbitrarily, that is without its bearers being involved. 'The social group (...) preserves its past mainly through two factors: its peculiarity and its durability' (p. 26). What J. Assmann means by this is that 'through the image that [the group] creates for itself, it emphasises externally the difference that it plays down internally' (ibid.). This explains references to the group's peculiarity. At the same time, the group builds its durability, that is, it 'forms a consciousness of its identity over time in order that remembered facts are always selected and proportioned according to parallels, similarities, and continuities' (ibid.). Finally, assuming that memory works through reconstruction, J. Assmann believes that 'collective memory operates simultaneously in two directions: backward and forward. It not only reconstructs the past but it also organises the experience of the present and the future' (p. 28).

The notion of memory figures, as discussed by Halbwachs and J. Assmann, respectively, can be seen in terms of the three following aspects of memory functioning: functional, objective, and subjective. As its name suggests, the functional aspect takes memory to be a function, or more descriptively, a purposeful activity, of handing down a given group's heritage from generation to generation. In this dimension, memory figures are supportive in regard to memory transmission, they trigger memory recall and frame time and space for memories to be recalled. The objective aspect involves that which is (being) handed down, that is, reconstructed pictures of the past. The subjective aspect, in turn, embraces the attitude a given generation shows in relation to the past, with collective memory being supported by the corresponding social group, or, to use J. Assmann's words, by 'reference to a social group'.

\section{Memory in a functional perspective}

\subsection{Time - narration - memory}

In his way of examining time and space, J. Assmann seems to follow M. Bachtin's idea of a chronotope. Although chronotope embraces some unity of time 
and space, in what proceeds, time and space independently are examined independently.

As T. Todorov asserts, time can be examined in terms of two opposing orders, as an order of events and an order of discourse (Todorov 1981: 30). In terms of mutual correspondences between these two orders, time references can be given two orientations:

- retrospections (backward looks) which report on what happened and what picture of the past emerges from texts;

- prospections (forward looks) or anticipations, in which something that will occur later is, announced in advance (Todorov 1981: 30).

Of these two, retrospections can typically be found in the opening elements of folklore texts.; best evidenced by the formulaic expression dawno dawno temu 'a long long time ago'. This expression makes it possible for the teller/narrator to put the clock back many years, if not centuries. Retrospective stories include legends, historical narratives, myths, and belief reconstructions. On the whole, they are concerned with very remote times, such as the origin of the world, the beginnings of a state(hood), or the genesis of a social group. In terms of narration, they can relate to the sequence of events (storyline), as in

Za dawnych czasów nie było ani kapeczki wody, ani strumyka, ani stawu, ani jeziora, w których nie żyłby utopiec (SimLud, 44), A było to tak: Pewnego razu, dawno, dawno temu, żył taki ważny jaśnie pan na dworze. A miał on stangreta... (SimLud, 55; 'And this is what happened: once upon a time, a long long time ago, there lived an old lord in the manor house. And he had a coachman...'),

as well as to the sequence of speaking, as in

Wedlug legendy miasto Cieszyn zostało założone przez trzech synów Leszka III w 810 roku. Nam to w szkole opowiadano tak. (SimLud, 126; 'According to the legend, Cieszyn was founded by Leszek III's three sons in 810. This is what we were told at school'), Nasi starka $z$ Wójtowej Wsi opowiadali jeszcze w okresie przed pierwsza wojna światowa o wojsku śpiącym świętej Jadwigi (SimLud, 136; 'Our old ones (...) used to tell a story, even before World War I, about Saint Jadwiga’s sleeping army').

The overwhelming majority of the retrospections that are found in opening formulaic expressions are concerned with the sequence of events, rather than the sequence of speaking. In these cases, the time continuum is foregrounded in the sense that what happened dawno, dawno temu ('a long long time ago') is basically that which is now.

As one of J. Assmann's 'special features' of memory figures, time will now be examined in terms of the two temporal orders/sequences mentioned above. 


\subsubsection{Time vis-a-vis order of discourse}

In order to grasp the relationship between the time of discourse and the time of events, T. Todorov employs the parameter of frequency. This gives him the following threefold classification of retrospections:

- singulative narratives: a unique discourse evokes a unique event;

- repetitive narratives: several discourses evoke an indistinguishable event;

- iterative narratives: an indistinguishable event evokes several (similar) discourses (cf. Todorov 1981: 31).

Naturally, Todorov bases his classification narratives on what he can potentially find within one literary text. However his typology can be extended towards a whole set of texts functioning in a group's collective memory.

More specifically, individual texts represent singulative narratives, are concerned with one unique event, and develop one storyline (except the fairy tale which typically is structured of two, or even three storylines). The plot is introduced with the so-called master formula, i.e. an existential formulaic expression that fosters memory and generates the oncoming parts of a text, for example Byt ojciec $i$ miat trzech synów ('there lived a father who had three sons').

In practice, repetitive narratives embrace variants of one story, each enriching and/or filling the gaps in individual memory and thus, introducing novel elements (motifs) into collective memory. If repetitive narratives are in fact text variants, then the way they function in collective memory can be shown by means of morphological analysis (see the preceding chapter).

The iterative kind of narrative can be found in the plot of a folk fairy talewhich is constructed on a mirror-reflection basis, for example two sisters make the same journey, meet the same protagonists and have the same adventures. But fairy tales of this kind are a highly petrified genre, so it is recalled as a whole. An example that would meet Todorov's characterisation of iterative narratives more closely would have to be less fossilised; in the sense that it would recall not one event, but several similar events and present them not in an objective way, but in a subjective one. This could be the following part of an interview (Text 11):

Text 1

[E:] A słyszał pan, żeby kiedyś jakieś uroki odprawiali? Coś takiego?

[I:] Takich uroków to nie. No raz mi tako babcia opowiadała. Taki leśniczy byt, koło nas, tamok. I uona, to za jij pamiecci było. Bezdzietne było dwoje, starszych ludzi.
[E:] Have you heard of any witchcraft? Spell casting, for example?

[I:] Not really. My grandma once told me about a forester and his wife. They were an old couple, who did not have children. The forester fell ill so his wife called a 
I on coś zachorował. I wezwała księdza $z$ Frampola, bo to parafia była, do spowiedzi. uny tak pod lasem mieszkały. Mieli, leśnik sie nazywoł. Gajowy, bo to państwowe jeszcze lasy byty, o tu teroz podzielune, teroz ludzi maja. Państwowe lasy były. I ksiundz wyspowiadoł go. I powiedzioł tyj żone, że jakby umort, jakby tego wieczora, bo to było $w$ dzień, to żeby nie nocowała. Czegoś tak jij powiedzioł po swojemu. Ale ona pomyślała. I zmart on potem. Po obiedzie już zmart, leży sobie. Ale mówi, co bede tutaj, nie bede nocować, w zgodzieśmy żyli. Nie bała go sie ni tygo, wpuściła sobie psa do mieszkania. Ji obnocowała sie. Dwunasta godzina. Pies do dźwi, z zębami, zawarczał coś. Una poderwała sie, to nieboszczyk już siedział, mąż. Siedziat na siedzaco, a pierw leżat zmarly. To ona wtencza koło tego psa $i$ we dźwi, nic nie widziała więcyj. We dźwi i tam na wioske, na morgi policiała. Przenocowała sie. Uciekła, bo ze strachu, bo pies zawarczał tak do dźwi. No i potam rano poszły, zobaczyły. To un przekręcony byt, na twarzy leżoł. Ten nieboszczyk. Pies rozdarty koło dźwi, na pół. I więcyj nic nie widać było. A co tam było na tyj spowiedzi, ze ksiadz tak nie kazol jej tam nocować jakby $w$ razie jakby umorł. Takie zdarzenie było. Opowiadała.

[E:] To ciekawe. Zna Pan więcej takich historii ciekawych?

[I:] O, takie o. Kolege takiego pochowali my o trzy dni temu. Takie zdarzenie miałem. W czterdziestem czwartem roku Niemiec do Wisty doszedt, a tu Ruskie napierały, wojsko. I tam pół roku stał front, bo aż Warszawe trza było zbić. Tak prawdopodobnie było. No i ja jade w pole sobie po unowies. Pojechali my, ugrabili furę owsa. I jedź, mówi, zrzuć. Ja miałem priest from Frampol for her husband to confess his sins. (...) The priest heard his confession and he told the woman not to spend the night at home once her husband passed away. (...) the man died just after lunch. But she thought that they were an agreeable couple and she stayed the night at home. She was not afraid, or anything. She only let their dog in, and went to bed. At midnight she heard the dog growling at the door so she got up immediately only to see her deceased husband sitting right in front of her and the dog dead on the floor. So, without hesitation she ran for her life to the village and spent the night there. In the morning people came over to see what had happened. They found the deceased man lying on his belly and the dog cut in half, at the door. They did not see anything else. So, there must have been something in this confession that made the priest tell the woman not to stay the night at home. This is what happened.

[E:] That is interesting. Do you know any other interesting stories?

[I:] Well, we buried a friend three days ago. But let me first tell you this. In 1944 the Germans got as far as the Vistula river, but the Russians were also pushing forwards. I mean the army. The battle raged for half a year because Warsaw was at stake. This is what probably happened. One day we went out to the field to harvest the oats and came back with a 
wtenczas szesnaście lat. Zrzuć owies sam, tam stodoła pusta, a my dograbiemy reszte ji, bo to koso było koszone. I przywieziemy. Zawiozłem, zrzuciłem ten owies. Jade, $w$ droge, tam pod Goraj aż, bo tam pole było daleko. Leci samolot $z$ frontu $z$ Wisty, dziura o taka $w$ skrzydle, widze przestrzelone. Jade sobie furo, patrze, na pare koni. Światełka świci. uO tako pogoda była jak tego. Jade prosto, a on leci tak uo i takie cztery watki wypuścił. Tak sie świeciały, u o takie jak moja ręka. Takie cztery bomby to było. Ji uo tak beze mnie te bomby policiały. Jakie piętnaście metry ode mnie pasł krowy o ten, cośmy go pochowali. Urwało noge. Konie moje nawrócity zaroz, zepsuła sie fura, cało rozwronowało. Piasek mi przywalił. Szum taki sie zrobił. Potem ucichło, słysze: jęk tamok. Poszedłem do niego zobaczyć. Un leży nad tem dołem, cztery metry,o takie wybiło dót. Dwie krowy poszło do dumu, jedna szczęka urwana, krowa, a druga krowa, nic jej nie było. Jeno szczęke jednej urwało. A un leży, widze, noga taka zmaltretowana. Przyleciał tam jeden sąsiad tam, mówi, wracaj, wóz i zawieziemy go do dumu. Ja mowie, no jak, zepsuty wóz całkiem, nie pojedzie, bo złamane wszystko, nawróciły konie całkiem.

Potem drugigo poleciałem, zawołałem. Włożyliśmy go na wóz, powiózł go i Popasek, taki dyrektor był $w$ Biłgoraju, ucią mu te noge. Tako zmarnowana była noga. Ji u o dożył osiemdziesiąt dwa lata. uO cztery dni, jak jego pochowali my. Takie było zdarzenie w czterdziestem czwartem roku. Jak jeszcze wojna nie była skończona, bo w czterdziestem piątem sie skończyła. [INF 4] full cart of them. I was told to unload the cart. I was 16 then. Unload the cart they said, because the barn is empty and we will carry on harvesting the oats with the scythe. (...) So, I was on my way, near Goraj, and I saw a plane in the sky, approaching from the Vistula frontline, with a huge hole in the wing. I carried on driving the cart with a pair of horses and I saw the plane drop four bombs. (...) They whizzed over my head and landed some 15 metres away where this man, that we buried the other day, was tending to his grazing cattle. The blast shattered his leg and he lost it. My horses ran away, the car was damaged and all I had in my eyes was dust. When it was all over, I heard some moans so I walked up to see the man. He was lying by the bomb crater. Four metres wide. Two cows went home, one was intact but the other one had no jaw. (...) One of the neighbours ran up to us. Let us take him home on your cart, he said to me. No way, I said, as the cart was broken, everything was in pieces and the horses had run away. Then I called another neighbour. We put the man on the cart and took him to Biłgoraj. The leg was so shattered that Popasek, a director, cut this leg off, Look, this man lived up to 82 years. We buried him just four days ago. This is what happened in 1944. The war was not then over because it came to an end in 1945. 
Text 1 develops two separate themes, the husband's death and the friend's accident, respectively. Despite the fact that the former is mythical and the latter is personal, these two narratives share elements of eeriness and weirdness.

Both narratives involve memory in their own unique way and rely on unique collectively-driven memory patterns. These patterns enable a story to be derived from one's individual memory, therefore facilitating substantial modifications of memory resources to a certain extent. It is only to a limited extent that iterative narratives make room for alterations. The reason is that the motif that follows is fully dependent on the motif that precedes it, so it must be narrated in a parallel way and if it is at all different, it involves the protagonists' attitudes and behaviour, which happens to be reflected in the ending of the whole story. Repetitive narratives in turn, allow for numerous modifications of collective memory, depending on a group's actual interests, problems and outlooks. It is the group that stores and reproduces folklore texts.

With regard to oral texts, all the aforementioned types of narratives are mutually complementary, depending on what or whose point of view is assumed or whether a single text or a number of variants are examined.

\subsubsection{Time vis-a-vis order of events}

As a feature of memory figures, the category of time can be typologised in such a way that different functions of time are revealed in folklore texts.

(1) Time of the beginning versus time of the ending. As already mentioned, in folklore texts, time can refer to the beginning of a text as well as its ending.

Time of the beginning is signalled in the initial formula of a text. This formula features mainly in legends where the temporal reference usually points back to the origin of the world, as in Kiedy już Pan Bóg stworzył ludzi i aniołów, to pomyślał, że dobrze by Mu było, gdyby nie musiał się cały czas przypatrywać temu, co ludzie wyprawiaja na świecie (SimLud, 16; 'when God created humans and angels, he thought that he would not like to see what people do in the world all the time'). Naturally, this is an account of the origin of the world according to a certain social group, tone which broadly assumes, Christian values and recognises God as the source of everything (the world, the Universe, plants, animals, humans, natural phenomena).

In prose texts, time of the beginning can include the following:

$\mathrm{x}$ the origin of the world, the origin of Adam and Eve: Kiedy Adam i Ewa zjedli jabłko $z$ drzewa rajskiego, ukryli się i nie chcieli się pokazać nawet samemu Panu Bogu (SimLud, 21; 'when Adam and Eve ate the apple of the 
Paradise tree, they hid themselves and did not want to be seen even by God himself');

$\mathrm{x}$ Jesus's birth, as in for example, this Christmas carol:

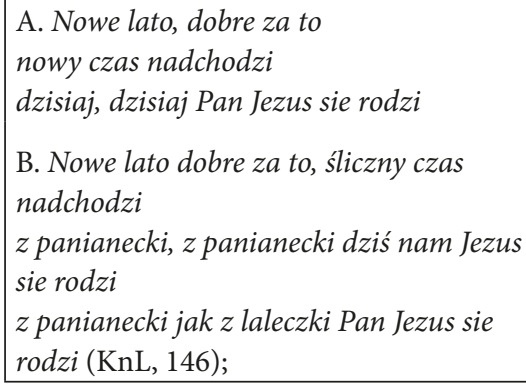
A. A new summer, good summer, A new dawn is coming today, today the Lord Jesus is being born
B. A new summer, good summer, a lovely time is coming
From the Lady, from the Lady Jesus is being born
From the Lady like a baby the Lord Jesus is being born

x Jesus Christ's activity in the world: W owym czasie, kiedy nasz Zbawiciel jeszcze był dziecina, zesłał ojciec jego niebieski aniołów na ziemię, dając im postać pacholat, ażeby $z$ matym Jezusem i innymi pobożnymi dziatkami w Jerozolimie igrali (SimLud, 26; 'when our Saviour was a little child, his heavenly father sent angels down to the earth, shaping them as children so that they could play with little Jesus and other pious children in Jerusalem'). The indicative pronoun nasz 'our' points to a very close relationship between Christ and the time implied with the name of Christ on the one hand and on the other hand, the memory and identity of the very social group that happens to recall the carol.

$x$ origin of a town, village, river, mountain:

- towns: Według legendy miasto Cieszyn zostało założone przez trzech synów Leszka III w 810 roku. (SimLud, 126; 'according to the legedn, Cieszyn was founded by Leszek III's three sons in 810'); ... tak się cieszyli, że z tej radości postanowili w tym miejscu zbudować miasto, któremu nadali nazwę Cieszyn. W mieście jest baszta i studnia Trzech Braci, to na tę pamiątke (SimLud, 127; 'they were so happy that they decided to build a town in this place they called Cieszyn; there is a well and a tower named after these three brothers in the town, and this is a kind of relic');

- mountains: To jest ten ród hrabiowski, co w Rudach Raciborskich mieszkat $i$ Górę św. Anny wybudowat (SimLud, 145; 'these people are of a noble kin, they used to live in Rudy Raciborskie and erected Saint Ann's Mountain'); 
$\mathrm{y}$ origin of the heaven, the sun, plants and animals, humans, demons etc.:

- rainbow: O tęczy opowiadali tak. Było to bardzo dawno temu, jak jeszcze anieli $z$ nieba schodzili $i$ dalej świat naprawiali (SimLud, 29; 'this is what they used to say about the rainbow: a long long time ago, when angels would still step down from heaven to make the world better...);

- the earth: Na poczatku, kiedy nie było ani zoom, ani wody, a tylko wszystko było pomieszane jak rozczyn chleba, zły duch stracony z wysokości niebieskiej nie miat oparcia na tym świecie i prosił Boga, żeby była ziemia, po której mógłby chodzić (SimLud, 34; 'in the beginning, where there were neither the heavens nor the earth and everything was mixed up like sourdough, an evil spirit was cast out of the heavens only to find no support in this world, so he asked God for a piece of land that he could walk on');

- woman: kiedy Pan Bóg stworzył Adama, ten mu codziennie w niebie smutny chodzit i ciagle prosit, coby mu i jaka zabaweczkę Pan stworzyt, aby mu się nie cniło (SimLud, 54; 'when God created Adam, Adam would be sad day in and day out, constantly asking God to give him [(lit.) a little toy] so that he would not suffer that much').

Selected randomly, the above examples show that in folklore culture, the time of the beginning has to do with the creation of the natural world and of both animate and inanimate elements of this world. The animate part of the world is dealt with in legends, with the creator being God and/or the Devil. This points to a Christian-oriented dualistic vision of the creation of the world. As Simonides writes, 'In a folk-mythical world-view, there is a widely-accepted dualism which involves oppositions, such as good-evil and God-Satan' (Simonides 2010: 14). Inanimate objects in turn, are a subject matter of historical narratives where the origin of mountains, villages, castles, towns etc. are ascribed to outstanding individuals, such as kings or monarchs.

The time of the beginning also embraces the origin of a social group's worldview, typically identified with the figure of Jesus Christ. His numerous activities are given as reasons why the world was created at all:

- God wanted to help people, as in the following legend: [Bóg] potrzebuje takie wielgachne sklepienie niebieskie, ale takie kiere się na noc będzie zawierać, a na dzień otwierać, bo wiecie, On se spomniał, że w dzień ludziom musi być jasno (SimLud, 17; 'God needs such a huge vault of heaven - so that it could close for the night and open for the day - because he knew that people would need light during the day'); similarly in a New Year's carol for a husbandman: 
A wyjdźże, wyjdźże, panie gospodarzu, Bóg się szerzy w twym podwórzu:

Krówki ci sie pocielily, Trzysta byczków popłodzity [...] (KnL, 85)
Go out, go out, husbandman,

God is doing wonders in your yard:

Cows have just calved

Three hundred bulls (...).

- God wanted to ease people’s anxieties: Jak świat światem, ludzie się zawsze lękali, aby niebo na nich nie spadło. Ale Pan Bóg widzac trwogę ludzkiego rodzaju, rzekł do swych aniołów... (SimLud, 17; it is as old as the hills that people worry that the heavens may fall, so seeing the anxiety of humankind, God said to his angels (...)');

- God himself wanted to feel comfortable: rozmyślat, jak by to zrobić, żeby mieć trochę wygody, spokoju i nie patrzeć cały czas na stworzony świat (SimLud, 16; '[God] was contemplating what to do in order to have a bit of comfort and rest and not to look at the world he had created, all the time.').

There are also texts where the God-Creator punishes people for their evil behaviour, which explains, for example, what the sky looks like today: już wy ludzie nieba ręka nie dosięgniecie. Nie umiecie uszanować firmamentu, to go i blisko mieć nie możecie (SimLud, 17; 'you, people, will never touch the sky with your hands; you do not respect it and that is why it cannot be found within your reach').

The origin-related texts, no matter whether they deal with the origin of man, earth, plants, animals, or birds, bear witness to folk beliefs, mostly forgotten today, yet still stored in collective memory. In this sense, they also contain answers to the questions of the origin of the surrounding world, questions that projected from people's observation of nature.

The time of the beginning then, can be marked implicitly, that is by making reference to the origin of things as understood and believed by a social group, or explicitly, that is by means of surface structural devices, as in Na poczatku oblewała kule ziemska woda; duch tylko Boży unosił się nad nia (SimLud, 33; 'in the beginning the globe was doused in waters, and God's spirit moved upon them'). However, no matter whether the time of the beginning is signalled directly or indirectly, it anyway pertains to the origin of the world according to a social group's beliefs, be it Christian and/or non-Christian.

A particularly expressive example of this can be found in the following formulaic expression: Było to tak dawno, że ludzie nie moga tego pamiętać. $\mathrm{Na}$ samym początku stworzenia świata nasza ziemia była przezroczysta i Pan Bóg mógł widzieć, co się na niej dzieje (SimLud, 36; 'it was so long ago that people just cannot remember it at all; at the beginning of the creation of the world, the earth was transparent and the Lord God could see what was happening on it'). What is interesting here is the fact that although deposited in collective memory and 
recalled as part of collective memory, the text begins with the assertion that it is unlikely that people may at all remember it. This paradox shows how resourceful memory is and at the same time reveals the limitations it exhibits if seen as a collective property. This is to say that according to folklore, the remote events of culture bearers cannot be preserved or retained in memory, but instead, it is texts of folklore, remembered and handed down from generation to generation, that take over the function of memory carriers. The time of the beginning is then closely connected with the origin of a given vision of the world. It relates to the beginnings of a social group, its values and its worldview. In other words, as depicted in a folklore text, the picture of the time of the beginning also often becomes a prospection (anticipation) of the end times (not to be confused with the end of time). In this way, the time of the beginning, such as Jesus's birth anticipates the fate of a Christian believer (Text 2):

Text 2

Ach, zła Ewa cóż zrobiła, kłopotu nam nabawiła.

$Z$ wężem sama rózmawiała,

ji jabłuszka skósztuwała, nas zgubiła.

Adam z raju wypędzony, zostawił płód zarażony, alie go z kłopotu tego matka Syna przedwiecznego, wybawiła.

Zwiód wąz chytry Ewe-matke, $z a$ tę wine sam wpad $w$ klatke, bo mu głowe podeptała, która od wieków przyjść miała, białogłowa.

Czemu dawno pożądali cni ojcowie ogladali, już dziś sa wypetnione od proroków ogłoszone (objawione) święte słowa

Dziś we żłobie odpoczywa, $z$ nieba zszedszy prawda żywa, która nie będzie zawarta, owszem na wieki otwarta Bóg Zbawiciel.
What she did, evil Eve,

Is only trouble.

She conversed with the serpent alone,

Tasted the apple,

And she made us forlorn.

Driven out of Paradise

Adam left his seed stained,

But he was saved from this problem

By the mother of the eternal Son.

The subtle Serpent seduced Eve, the Mother,

But himself could not go any farther, 'Cause the lady that was to come Bruised his head at once.

That which our fathers

Craved for

Can be seen today

Foretold (revealed) by the prophets'

Sacred words

Today he is resting in the manger Having come down from heaven The living truth that will never be sealed But for ever revealed, God the Saviour. 
$\mid \begin{aligned} & \text { Od aniołów ogłoszony, } \\ & \text { z Panny w stajni narodzony, } \\ & \text { skąd weselie nam przynosi, } \\ & \text { miły pokój ludziom głosi, }\end{aligned}$

Odkupiciel (KnL, 136).
Proclaimed by the angels

Born of the Virgin in the stable

He brings us joy

And peace to all people,

The Redeemer.

The time of the ending can then, refer to the end of the world, as in this beggar's song:

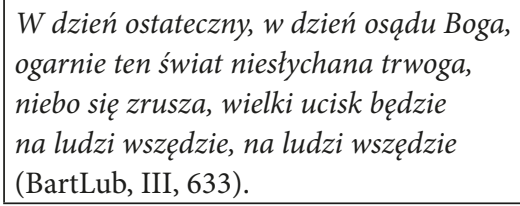

$W$ dzień ostateczny, w dzień osq̨du Boga, ogarnie ten świat niesłychana trwoga, niebo się zrusza, wielki ucisk będzie na ludzi wszędzie, na ludzi wszędzie (BartLub, III, 633).

\author{
When doomsday comes, judgment day \\ arrives, \\ The world will hardly thrive, \\ The sky will fall, people squeezed \\ Will hardly be able to breathe
}

This song depicts a truly apocalyptic vision of the end of the world. Yet, the way the time reference is made here does not foster collective memory as such, but rather, it induces a social group reference, 'a concrete relationship to a group' (J. Assmann 2011:24) which is yet another feature of memory figures.

In folk ballads, the time of the ending may explicitly be concerned with giving up lying (e.g., Lecz wszystko ma swój koniec i wszystko do czasu,/pewnego dnia leśniczy pojechat do lasu (BartLub, IV, 74); 'everything must end, everything is up to a point,/one day, a forester went to the woods'), and it can be identified with the end of one's life (W jimie Ojca, Syna i Ducha świętego,/koniec mnie, ach, koniec będzie życia mego (BartLub, IV, 77); 'in the name of the Father, and of the Son, and of the Holy Spirit, this must be the end of my life'). It is worth noting that in many texts of folklore, the ballad included, the end of the beginning and the end of the ending constantly interweave and interact with each other.

It seems that it is only the time of the beginning and the time of the ending that directly relate to the category of memory because they can be referred to a collective memory bearer, that is a social group.

(2) The remaining elements of time serve to depict the world of a narrative, or more specifically, the reality of a text itself and of its protagonists. Still, there is a room for a social group reference, however indirect and for the values a group cherishes. This is to say that these remaining elements of time (apart from the time of the beginning and of the ending, respectively) can also be regarded as features of memory figures. After all, whatever is important and worthwhile for a given social group happens to be stored and transmitted by its members and this includes the way the world is depicted in a narrative. 


\subsubsection{Creating the world of a narrative}

A. The time of the world depicted in a text can be described as physical, in the sense that 'it can be measured out' (Głażewska and Kusio 2012: 158) with, for example, seasons of the year, as in Dwaj aniołowie zestapili na poczatku wiosny na ziemię, chcąc się nad pilnościa ludzi uweselić (SimLud, 112; 'two angels descended to the earth in early spring (...)'). This excerpt comes from a text about God's creation of flowers, so - in terms of common-sense considerations, which is a characteristic feature of folklore texts in general - the time of the narrative closely reflects an experiential inference about the blooming time of the first flowers despite the fact that, objectively speaking, it is God at work behind the scenes who could do the creation even in the middle of a frosty winter. What we have in this example is that the worldview reflected in folklore texts is exceptionally and deeply grounded in everyday reality, which is material, actual and readily-available to perception. For this reason, the time of a narrative cannot really escape the time of the real world humans live in and experience. Time does not merely aid a group's memory, it also characterises the very group that is a bearer of this memory.

The physical time of many Lublin-area ballads are frequently connected with spring as a time of flowering as well as a time of their protagonists' blossoming in some way, giving us an interesting thematic parallelism: Rozkwitały kwiaty i róże w ogrodzie,/kochał Janek Zosie, bo była w urodzie (BartLub, IV, 66; 'The roses and [other] plants were blooming in the garden/when Janek fell in love with Zosia for her beauty').

Spring can also mark the end or the death of protagonists: Tak nadeszła wiosna każdymu mita,/a ich przykryła ciemna mogła (BartLub, IV, 69; 'while the spring came to everybody's delight/they were buried into the ground'). The parallelism here turns the thematic contrast into a tragedy: the natural world springs into new life, whereas the protagonists' lives come to an end.

B. The dimension of time that is described above as physical or real, happens to be contrasted with the kind of time that marks a departure or a deliberate escape from physicality which is metaphysical in nature: Ale ta brzoza pochyła była/i do jawora sie pochylita./Ach, czy wy wiecie, czy wy nie wiecie,/że jest kochanie na tamtym świecie (BartLub, IV, 86; 'and that birch was leaning forward/to be closer to one sycamore maple;/whether you want to know it, or not,/there is love in this world').

Metaphysical time not only goes beyond any concrete temporal reference, but also surpasses spatial (objective) reality. In the ballad quoted above, the message is that there are things that happen (people falling for one another) and values that people share (love) of some universal and timeless significance. Again, time 
does not serve to be a memory support but instead, it can be seen as a mirror which reflects the values cherished by a group, a collective bearer of memory. C. Micro-time is another temporal dimension which serves to create the world in a foklore text. It refers to subconsciousness and relegates the world description to an almost primal level of culture. For example, in folk ballads micro-time includes the day-night opposition which entails at least the following two: lightdarkness and sacrum-profanum: $O j$, dobrze im sie siedziało,/dopóki słonce świecito (BartLub, IV, 57; 'They were doing fine/till the sun could shine'), or Ale niedobrze jim było, bo im słoneczko świeciło (BartLub, IV, 58; 'they were not quite well/'cause the sun made them swell').

The sun shines on good love, but it also lays bare a love relationship that is sinful. In this latter sense, the sun or the sunlight is a threat to bad love, hence this plea: Moja Zosieńko, chodź dalej,/niech nas słoneczko nie pali (BartLub, IV, 59; 'My dear Zosia, let us move a bit from here/so that the sun could not burn us to ashes'). So, the daytime and the sunlight mark the time of revealing the truth, as in Gdy sie rozwidniało, juz trupa zdybali (BartLub, IV, 77; 'when it was just about to dawn, a corpse was found'), and are at times mentioned in the context of admonitions, as in Nie zabijaj ty mnie w nocy,/bo me serce w ciężkiej mocy [...] zabijże mnie $w$ ten dzień biały,/wszystkim pannom na dowiady (BartLub, IV, 43; 'do not kill me at night/'cause my heart is sinking (...),/kill me in the daylight/ for the other girls to see ").

Night is 'one of the elements of a dichotomous organisation of the world' (Kowalski 2007: 351). In this sense, nighttime is a metonymy of death and sometimes of chaos as well because it is in the darkness that a ballad's protagonist loses any sense of moral integrity and is driven to commit a crime (e.g., murdering his loved one): Wnocy o pólnocy, opierszy godzinie,/wstawaj, Walentyno, odprowadzisz ty mnie (BartLub, IV, 60; 'at midnight,/get up Walentyna, you will walk with me'). Night and darkness then, are meant 'to conceptualise the nether world which is where no communication is possible' (Kowalski 2007: 351): Ciemno było, dyszczyk rosit, ja nie stuchał, jak sie prosit (BartLub, IV, 14; 'it was dark, it was drizzling, I did not hear who was whispering'). 'Night makes people realise how severely limited their ways of experiencing and conceptualising the world can actually be' (Kowalski 2007:351):Zapłacza, zapłacza twojeczarne oczy,/gdy mnie odprowadzisz do pociagu w nocy (BartLub, IV, 55; 'your black eyes will cry/when you see me off at night'). Nighttime foregrounds the mood of horror: Kiedy juz nadciagnąt wieczór umówiony,/wyły psy nieznośnie, krakały wrony (BartLub, IV, 89; 'when the night was approaching/dogs started barking and crows were cawing). Night is also when the living meet the dead, as in A gdy nadejdzie wieczorna pora,/kroć gwiazdek na niebie wschodzi,/jakiś mężczyzna $z$ młoda kobietąna brzeg jeziora 
wychodzi (BartLub, IV, 93; 'when the night comes,/the stars appear in the sky,/and a man and a young woman/come out of the lake to the shore'), or humans meet extra-terrestrial beings, as in Utopce zawsze wracaly do dwunastej. Jak nie wrócit, to dycki się zgubit, to już go potem nie było (SimKum, 124; 'drowned people would always be back at midnight; if they did not, that meant that hey had disappeared for good'). Associated with alien, dangerous and unknown spaces, darkness belies protagonists' evil deeds, and epitomises a human soul. This can be found in ballads $(\mathrm{O} j$, dobrze im sie siedziało,/dopóki słońce świeciło [...] A gdy słoneczko już zaszło,/chodź, pójdziem, Zosiu, za miasto (BartLub, IV, 57; 'they were sitting next to each other/as long as the sun was shining (...)/but when it set down,/ come Zosia come, we will go out of town'), and in fairy tales, e.g., the Rapunzel story: Kiedy król jechał koło leśnej wieży, jego koń nie chciał iść dalej. Król ustyszał jakiś piękny śpiew (SimKum, 37); '[it was getting dark] when the king was riding past the tower and his horse refused to go on; the king heard beautiful singing.

The day-night dichotomy can also help assess a protagonist's behaviour, as in the following heroic song where it stands for a hero's untimely death:

Już dwunasta, już czas mija

Czego wy dłużej czekacie.

Pragnę tego abym zginat

A wy do mnie nie strzelacie.

Tylko te wymówił słowa

Dano ognia padty strzaty.

Głowa zawisła na ramieniu

Usta jęku nie wydały. (BartLub, III, 413).
It is twelve already, time is flying fast, Why should you wait any longer?

While I desire to die

You are not shooting at me.

Once he had uttered these words,

The guns were fired,

His head drooped

And his lips did not moan

In this and similar cases, micro-time is symbolic and archetypal in nature. It relates to a group's system of values and is rooted in a group's beliefs.

\subsubsection{Time in creating a protagonist}

A. The process of crafting a protagonist is in harmony with biological time. It is a specific realisation of the time of the beginning, yet it does not have to be correlated with any opening element of a text. It may be later signalled in a subsequent segment. Nor does it have to relate exclusively to the events being narrated because it frequently pertains to the protagonists, for example, their age. More specifically, in its biological dimension, time is measured against an individual's growth, his/her dreams, some form of hibernation or human reproduction. What is communicated in a text are social norms; the text when it is expected to have a family or when it is appropriate to dispose of one's wreath (a symbol of 
virginity). Concomitantly, the text presents a vision of what it means to be young or what privileges and perils youth connotes. This is a typical scenario of fairy tales, be they magical, animal-based, novel-like or folk ballad.

As to the latter genre, the time of the beginning of a story may also be the time of a heroine's growing maturity and readiness for love: Przysiegam ci, mój Janeczku, ja dla ciebie rosła (BartLub, IV, 70; 'I swear, Janeczku, my love, I have been growing up for you'), or Przyszed do niej podoleniec,/podolanko, daj mi wieniec (BartLub, IV, 21; 'here he is, a Podole man, and he says:/my Podole girl, give me your wreath'), or Piękna Alfreda poszła do lasu/na ślubny wianek nazbierać ró $\dot{z}$ (BartLub, IV, 49; 'One beautiful Afreda went to the forest/to pick roses for her wreath').

Coming of age can be found in relation to male protagonists as well, but there it refers to one's being prepared to get married and/or start a family: Trzeba to by było Jasieluńska żenić,/tylko ta synowe Kasiuleńkie zmienić (BartLub, IV, 67; 'it seems good for Jaś to get married/but this Kasia is too different'). Sometimes a ballad explicitly informs us how old its protagonists are: $I d w u d z i e s t o p i e ̨ c i u l e t n i$ Michał Tylus/kochat sie w pięknej dziewczynie (BartLub, IV, 68; I, Michał Tylus, twenty five,/was in love with a beautiful girl'), Osiemnaście latek miał młodziutki Janek/i już uplótł Jance swej miłości wianek (BartLub, IV, 88; 'Janek was only 18/ when he gave Janka his wreath of love').

It may well happen that the time of the beginning of a ballad projects itself imperceptibly into the time of the end (death): Jakżeś mała była, wtedy sie modliła,/a teraz się będziesz tu w Wiśle topiła (BartLub, IV, 55; 'when you were small, you did pray,/and now you will drown in the Vistula river').

Unlike the ballad, the fairy tale does not signal the biological dimension of time in any explicit way. The reason is that fairy tales do not directly characterise their heroes and heroines. Still, in fairy tales, like in ballads, protagonists are middle-aged, which is important insofar as they are capable of procreation: $W$ dawnych czasach żył sobie król z królową. Królowa, czując się w błogosławionym stanie, kazała, by cały naród składał jej życzenia (SimKum, 52; 'once upon a time there lived a king and a queen; once the queen felt she was having a baby, she ordered the whole nation to wish her all the best'). If protagonists happen to be wayfaring, their subsequent adventures represent the metaphor of becoming mature and ready to make the most important life decisions.

In the remaining epic kinds of folklore texts (that is, apart from fairy tales and ballads), biological time is used very infrequently: Pewien złoczyńca poszedł pod koniec żywota do kościoła, wyspowiadał się i postanowit pokutować (SimLud, 80; 'towards the end of his life, some criminal went to church to confess his sins and atone for his evil deeds'). This character of the criminal is totally fictitious here 
and is meant to be an exemplum for the sake of teaching some moral or didactic truth. Even if not stated explicitly, biological time refers to some highly significant, critical and liminal moment in peoples' lives (death, wedding): Wedtug podania ludu brat i siostra, nie wiedzac o swoim pokrewieństwie, pobrali się (SimLud, 112; 'without knowing that they are related, a sister and a brother married each other'). Biological time then is connected to rites of passage, its consequence being that people learn what is possible and what is not (e.g., it may turn out that pansies are not likely to grow again, as in SimLud, 112). On the whole, folklore texts depict their protagonists as relatively young people in the process of becoming mature and/or coming of age, which is when they are vulnerable to changes and in a position of shaping their own worldview. This naturally explains why these texts are mainly didactic in character.

Also, it reveals that biological time, as it is - implicitly or explicitly - signalled in a given text may perform an identity function, as in the following quotation from an epic song about Kazimierz Bogdanowicz: Bogdanowicz sie nazywat,/ liczył lat dwadzieścia pare,/w młodym wieku pokazywał,/jak czcić ojczyzne i wiarã (BartLub, III, 413; 'His name was Bogdanowicz,/twenty something years of age,/already in his youth he showed/what it means to love the fatherland and respect the faith').

Again, one can conclude that texts of folklore are not only memory carriers, but they also disseminate values which, handed down from generation to generation, aid and foster collective memory.

B. Yet another kind of time dimension that can be identified in folklore texts is personal time. It is seldom explicitly-stated in texts and when it is, it embraces variations of emotional states. In ballads, for example, personal time may have to do with a girl's reluctance to dispose of her (maidenhood) wreath (Nie chciałam wianka utracić,/musiałam życiem zapłacić (BartLub, IV, 57; 'I did not want to lose my wreath,/I had to pay for that with my life'), or with love and courtship (Lecz niedługo było tego całowania,/cieszył sie zabójca tylko do śniadania (BartLub, IV, 75; 'there was not much of this kissing/as the murderer only enjoyed it until breakfast'). If epic protagonists' emotional states are expressed directly at all, they almost exclusively happen when either the emotions in question are negative, or negative effects of emotions are anticipated. But on the whole, folklore texts, especially petrified ones, do not expose one's feelings. That we can learn about what and how protagonists can feel, comes through thematic parallelisms: Zerwała sie fala, $w$ morzu brzegi rwała,/Oj, ładna dziewczyna namówić się dała (BartLub, IV, 53; 'the wave started foaming, washing the sea shore away,/a pretty girl surrendered in the end'). It is especially in ballads, as well as in other epic texts meant for 
singing, that personal time is correlated with physical time. The same holds true for fairy tales where we get to know protagonists in and through what they do. C. Finally, sacral time can also be distinguished as a means of crafting protagonists and their worldview. This temporal dimension is marked with history-independent myths and rituals. In this sense, sacral time 'appears to be a complete opposite of linear time, that is, of a progression of subsequent events developing towards the future. [Sacral time] is reversible, circular' (Głażewska and Kusio 2012: 162), reiterated and for this reason, invariant. Like other temporal dimensions, sacral time helps to identify and characterise a group, its values and rituals. In ballads, for example, this may involve the following:

- an offer of marriage (proposal): Więc Michał Tylus poszeł do Bieńka/i próbowat prosić o Frani ręke (BartLub, IV, 69; '(...) o Michał Tylus went to meet Bieniek/ and tried asking for Frania's hand'),

- a girl's swearing an oath as her loved one goes to war: Stoi $w$ polu krzyż, zbliz sie, luba, zbliż,/bo ja jade na wojenke, przysiege mi złożysz (BartLub, IV, 70; 'there is a cross in the field, get closer, my love,/'cause I'm going to war, you will swear an oath'),

- getting married: Luby już z wojska listy przysyła,/koledzy mu odpisuja, że za mą̇ं juz wyszła (BartLub, IV, 70; 'he sends letters from the trenches,/his friends write back that she is now married'),

- Sunday mass as a time of disclosing a crime: W niedziele rano dzwonili,/żeby sie ludzie schodzili (BartLub, IV, 82; 'the bells kept ringing on a Sunday morning,/ so that people should gather at the church').

Liminal in nature, sacral time is closely connected with rites of passage, marking the beginning of a protagonist's time of trial; mainly fidelity and loyalty.

\subsection{Space - narrative - memory}

Similar to time, space serves the purposes of memory support in the sense that it recalls that which is stored in collective memory. In terms of ontology, space forms a chronotope with time, which means that it can be examined in a way which is analogous to the way time has just been discussed in the preceding section. In Władimir Toporow's words:

First of all, in an archaic model of the world, space and time are not polarised, external and internal forms of contemplation are not disunited. In general, with regard to most sacral situations, which are to be remembered, exclusive building material of a higherrank of reality, space and time, to be precise, are inseparable and constitute a time-space continuum (...). They can also be regarded as transition forms combining the physicality of the space-time structure with life (...). (Toporow 2003: 21) 


\subsubsection{Space vis-à-vis order of discourse}

By analogy to the analysis of time in Section 2.1 above, we can distinguish two orders of space organisation: space as an order of the presented world and space as an order of the narrative this world is presented in. This corresponds to Todorov's distinction between the order of events and the order of discourse (Todorov 1981: 30).

The following urban legend (Text 3) illustrates both of these orders:

Text 3

Chłopak mojej siostry ciotecznej opowiadat mi taka legendę, że ... w ogóle to ustyszat gdzieś w jakimś klubie motocyklowym, bo on jeździ na motocyklu. No w Rajdersie na Trzeciego Maja. Że tam chyba jakieś, no tam mu opowiadał taki kolega, że grupa znajomych jechała sobie motocyklami no $i$ ten główny bohater tej opowieści jechał sobie junakiem, gdzieś tam z przodu... i jechat sobie i oni jechali bardzo szybko i on ich wszystkich wyprzedził i on... ci, którzy jechali tak $z$ tyłu, nagle tak patrza, a on zjeżḋa sobie tak do rowu i się przewrócił. Oni się zatrzymali, a on leżał już tam martwy. I okazało się, że jak tak jechał z ta prędkościa, to jaskótka tak leciała $i$ wbiła mu się w mózg i właśnie zmarł na miejscu. [INF 7].
My cousin's boyfriend once told me this legend. Well, to be true, this is what he himself had heard at some motorbike club, as he is a biker. Yes, it was the Rajders Club, in Trzeciego Maja street. So, a group of friends were riding their bikes and the main hero of this story was riding a junk bike, well ahead of all the others. They all were riding really fast but he managed to overtake them all, one after another. Suddenly those that were following him could see that he had turned the bike right into a ditch and flipped over. When they pulled up, they saw that he was dead. It turned out that while cruising along, a swallow had smacked into his skull and killed him on the spot.

As we can see in Text 3, the space of discourse involves the very place (the club) where the story was heard and from where it was further communicated on. Confined yet cosy, this space has the social function of unifying and bringing the club members together as adherents of the same hobby (motorbiking). Both the name of the space (The Rajders Club) as well as its function are meant to authenticate the story. As are the narrator's testimonial formulaic expressions. Now, the space of events (a road/street) is different - open, unlimited, dangerous. As the two spaces/orders compact multiple mutual relationships, space can be considered in terms of the following:

- recalling the space of events, which aims at reporting on what once happened and what picture of the past has been stored in a text: Dawno, bardzo dawno 
temu Zdzieszowice byly mała wioska na brzegu Odry. Woda w rzece była czysta, więc rozwijało się w niej życie. Najważniejszymi mieszkańcami rzeki byty utopce (SimKum, 131; 'A Long, long time ago Zdzieszowice was a little village on the Oder banks. The water in the river was crystal clear, so life in it flourished. The most important inhabitants of the river were utopce [lit. 'drowning demons']).

This text takes us back in time and space to the place that is named and described (Zdzieszowice). So, shifting in time is marked by means of spatial expressions, the two - time and space - forming a chronotope, a unity which serves as a background or a starting point, for the whole story.

- exiting the space only to anticipate what is going to happen later in that space: [...] Wszyscy wiedza, że Bucze może jeszcze ktoś wybawić, ale czy się taki kto sprawiedliwy a mocny znajdzie? (SimKum, 141; 'everyone knows that Bucze can still be saved, but can any righteous and strong be found man to do this?'). The theme of the story is the village Bucze, and the story ends precisely when we exit the space of the village in order to anticipate its future.

\subsubsection{Space vis-a-vis order of events}

In this section, space is assumed to be part of the time-space chronotope and described analogously to the category of time (see Section 1 above).

The space of the beginning and of the ending. What is meant here is the kind of space that makes a direct reference to a social group, how this group understands its origin and how it anticipates its end. More specifically, by the space of the beginning, the following is intended:

(1) the space of the origin of the world and its objects;

This does not have to necessarily involve the space of Paradise or the Holy Land. To the contrary, the space of the beginning is often subject to polonisation: Raz Chrystus z Najświętsza Panienką zawędrowali aże pod Górę Św. Anny. Panienkajak to kobiety - chciała poogladać odpustowe budy, a Chrystus siadt na górę $i$ spoglądał z niej na dót (SimKum, 120; 'once Christ and the Virgin Mary climbed Saint Ann's Mount and they looked down from its summit, the Virgin Mary, as it is expected of women, wanted to take a good look at the fair's booths, while Christ reposed there and was looking down'). That biblical events and protagonists are often localised in the space that is familiar, close and known (e.g. Saint Ann's Mount) is characteristic of apocryphal texts. Space shifts of this kind help to assess given places and when that assessment is desirable, to ennoble the groups residing in these places, especially if a group considers themselves to be chosen 
by the Creator or divine creatures and in that sense privileged to assist God in His creation of the world. Even if a picture of a group's ancestors does not appear positive (for example, the forefathers did not pay their respects to bread), their alleged contact with the divine proves significant enough to be worth remembering and recalling.

(2) the space of mythology, that is, the space of the origin of things, signified with the opening temporal formulaic expression kiedyś, za bardzo dawnych czasów ('once upon a time'): Pod Opolem kiedyś, jeszcze za bardzo dawnych czasów, to ponoć i lwy żyły. Tak starsi mieszkańcy tu opowiadali (SimKum, 14; 'Once upon a time lions lived near Opole, old people said'). This space is untamed, hostile, inhabited by wild lions, its hostility being emphasised by the distance in time between 'once upon a time' and the present.

(3) the origin of a place and/or its names;

In this case, space happens to be thematised, becoming the theme of the whole text while recalling events of a very remote past are believed to have given rise to the space itself or contributed to its name: Niedaleko Łubowic w pow. raciborskim jest pagórek, na który wszyscy w okolicy mówia Bucze. A bierze się to stad: Dawniej - jak nasi starka rozprawiali, a im to padali ich starka - stał tam bardzo piękny zamek, a koło zamku miasto. Ludzie, co tam mieszkali, byli jednak bardzo niedobrzy, wzbogacali się cudzym kosztem (SimKum, 141; 'Near Łubowice there is a hill which everyone calls Bucze. Our fathers tell us and they themselves were told by their fathers, that there was once a very beautiful castle on its top, with a town all around it. However, the people were bad as they wanted to grow rich at the expense of others').

The space of the beginning often emerges from chaos, the latter being nothing but wild, dark, and fathomless: Dawno to temu, już bardzo dawno, bo praojcowie nasi styszeli tylko od swoich praojców, był kraj nasz caly wzdtuż $i$ wszerz zarosty lasami. A lasy byty ogromne, gęste, czarne (HajPod, 38; ' A long, long time ago, so long ago that it was only our forefathers that heard the story from their own forefathers, our land was covered with the forests far and wide. And these forests were immense, dense and black'). Naturally, the way the space itself is depicted has a direct bearing on that how its inhabitants are described: $W$ tych lasach żyli też nie tacy ludzie, jak my dzisiaj, nie taki drobiazg jak teraz, ale żyli wielkoludy, którzy $z$ tych drzew stawiali domy, murowali kościoły i mieszkali w owych rozlegtych, czarnych lasach (HajPod, 38; 'Giants inhabited these huge, black forests, not people like us today and used whole tree trunks to build their dwellings and churches'). As Toporow asserts, 
Although there can be numerous stands on what it is that moulds and what it is that is moulded in the relationship between the world (space) and the First Man (the body) that is, in other words, is it the First Man who is a model of the Universe, or is it the Universe who is a model of the First Man? Or what comes first: the anthropomorphic code which serves to describe the Universe, or the cosmic code that serves to describe the human body? - it seems safe today, to say that the role of a modelling source should be ascribed to the man and the human body. It is after all according to this [anthropocentric] model that the mythopoeic mind came to construe the Universe. (Toporow 2003: 38)

No matter which direction can actually be postulated, texts of folklore show parallelisms and correspondences between people and their places, between what people are like and what their places look like.

(4) the space of plot exposition, which is where the plot of a story begins; in folklore texts (e.g., ballads) is semiotic in nature.

The space of plot exposition can embrace the following: the space of the beginning of love/coming of age, the space of the inception of a crime, and the space of one preparing to commit a crime/to die.

As to the first one, which is the space of the beginning of love/coming of age, the usual place is the garden, a symbol of a girl becoming ready for love and loving relationships: Rozkwitały kwiaty i róże w ogrodzie,/kochał Janek Zosie, bo była $w$ urodzie (BartLub, IV, 66; 'The flowers and the roses were blooming in the garden,/Janek was in love with Zosia 'cause she was comely'), u्रOj, rano, rano słońce nad zachodem,/pasła Kasiunia wołki za uxogordem (BartLub, IV, 97; 'the sun was setting in the west,/Kasia was herding her cattle in the garden'). In ballads, the garden also serves as a vehicle of comparing a girl's beauty to a rose, which produces an elaborate simile: [Była] sobie Mania jak róża w ogrodzie (BartLub, IV, 67; 'Mania once lived there, like a rose in the garden'). Apart from the garden, the space of love games and source of love can also be the orchard: Pewnego wieczoru Janka się wybrała/do sadu wiśniowego, tam zabawa była./A na tej zabawie Janka tańcowała,/z bogatym bardzo Jankiem romans zawiqzała (BartLub, IV, 97; 'One evening Janka went/to a cherry orchard were there was a party./And at this party she went dancing,/and she was flirting with wealthy Janek'). As to forbidden (bad) love, the space can be the forest, as in $O j$, $w$ lesie, $w$ lesie pod sosno,/siedziat tam Janeczek ze swo Zochno (BartLub, IV, 56; 'In the forest, in the forest, under the pine tree,/Janeczek was sitting with his Zocha'), and the valley. As J. Adamowski writes, in songs, the valley constitutes the space 'whose landscape is reduced to lonely trees; localised here and there, they are symbols of love' (Adamowski 1999: 98): Hej, dolina, dolina,/przy dolinie 
dębina,/przy dolinie dębina,/oj, tam chodziła śliczna krakowianka,/drobne listki zbierała (Bart Lub, IV, 47; 'The valley, the valley,/an oak tree in the valley,/an oak tree in the valley,/this is where a pretty Cracow girl was strolling,/picking up little leaves'). The space of plot exposition may also relates to the protagonist's trials and tribulations. In folk ballads, this is usually a grove. For example, the grove is the place where the sister-protagonists are sent to, aspiring to be married: Daj jem, matuś, dzban/ji wypraw jich w gaj,/która malin więcej zbierze,/to za żone się wybierze (BartLub, IV, 19; 'Mother, give them a jug and send them to the grove,/ the one that will pick more raspberries/will get married'). In this context, the grove is a space of competition and endeavour.

The space of the inception of a crime can be found in the ballad Podolanka (lit. 'a Podole girl'):

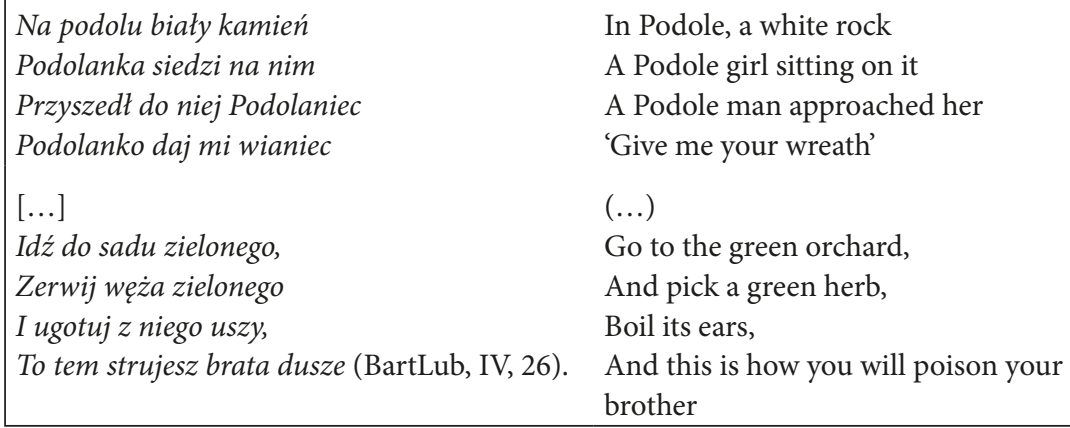

In this ballad, the inception of a crime takes place away from home, in an open, unfamiliar space. It is there that committing a crime is contemplated and initiated. Like fairy tales, in ballads this space has a clear dichotomous structure: own/ familiar (Pol. swój) versus strange/alien (Pol. obcy), safe versus dangerous, moral/ social versus immoral/antisocial, space of life versus space of death. What folk imagination places in this unfamiliar space, often identified simply with a black forest, are evil deeds or at least the contemplation of committing them. In this sense, the forest, the orchard and the grove stand for the darker side of the human soul.

More specifically, the orchard can be described as a place where one comes to realise that one is prepared to commit a crime. In Lublin-area ballads, the orchard is often zielony 'green', or wiśniowy 'cherry'. If we follow the pars pro toto claim, then these colours 'symbolise specific colour parts of the Universe and are inherent elements of the Universe' (Kowalski 2007: 223). Green connotes springtime, fertility, abundance and ripening. So, the green/cherry orchard is the space where an evil deed has its roots, from where it stems, which in specific contexts anticipates 
the reasons and circumstances of committing murder or suicide. It is also where the protagonists find the tools that will eventually aid them in the commission of a crime: Jidź do sadu zilonego,/przyniś węża ogrudnego (BartLub, IV, 21; 'Go to the green orchard,/and find a snake there'), Idź do sadu wiszniuwegu,/wykup węza zilunegu (BartLub, IV, 23; 'Go to the cherry orchard,/and get a green snake'), Idź do sadu wiśniowego,/zabij węża jadliwego (BartLub, IV, 25; 'Go to the cherry orchard,/ and kill a poisonous snake'), Idź do sadu wiśniowego,/znajdziesz gada zjadliwego (BartLub, IV, 40; 'Go to the cherry orchard,/you'll find a poisonous snake there'). People also contemplate death and talk about death in the orchard: Poszli se do sadu, $w$ sadzie spacerujo,/o śmierci gadajo i wraz sie całujo (BartLub, IV, 96; 'They went to the orchard, strolling,/talking about death but kissing each other all the same'). This relates to yet another function of the orchard - it is a place where people communicate bad news which may lead one to commit suicide: Chodź, Kasiu, na spacer do sadu zielonego,/powiem nowine od ojca swojego (BartLub, IV, 68; 'Kasia, let us go for a walk into the green orchard,/I'll let you know what my father has told me'). The source of evil may also be placed in the field, which is where evil comes from or where it 'approaches' people. In the ballad Podolanka 'a Podole girl', the female character is being talked into poisoning her brother and then, into getting rid of her wreath and in this way, breaking the ban: Na podolu bialy kamiń,/podolanka siedzi na nim (BartLub, IV, 22; 'In Podole a white rock,/a Podole girl sitting on it').

The space of the ending involves the following:

(a) the space of the end of the world, as in the following beggar's song:

Sybilla przepowiada święta:

Gdy z Antychrystem człek

Sybilla przepowiada święta:

Gdy z Antychrystem człek się zbrata, Nastapi wkrótce koniec świata -

I o tym każdy niech pamięta.

[...]

Wioski popala się i miasta, A z ziemi, z której plon wyrasta, Choć rolnik nawet ja zaorze, Już się nie będzie rodzić zboże.

$Z$ nieba deszcz krwawy padać będzie. Ciemności wnet zalegna wszędzie. Pogasna gwiazdy, słońce zgaśnie. (NyrKar, 355).
Saint Sibyl foretold this:

When a man makes friends with the Antichrist

(...)

It means the end of the world is approaching, Let everyone know that.

\section{(...)}

The villages and the towns will be burned, And the ground that provides crops for you, Though cultivated and ploughed,

Will not bring forth corn anymore.

It will rain drops of blood, Darkness will prevail all around, The stars will fall, and the sun will fade. 
(b) the space of the protagonists' death, which is where the crime (murder, suicide) is committed, the corpse is buried/hidden or acts of revenge take place as an attempt at restoring the hitherto abiding moral order.

In Lublin-area ballads, the space for committing murder is typically a dalekie pole 'remote/distant field': Odprowadziła go na dalekie pola,/na dalekie pola,/ idźże sam, Jasieńku, bo mnie boli głowa (BartLub, IV, 62; 'She took him to a distant field,/to a distant field,/Go, Jasieńku, go alone as my head is aching'). This space is far away, it is open, vast and symbolises departure (deviation) from established principles and standards of moral and social orders. It is in the field that the man kills his lover: $W$ polu ci ja zabit, $w$ lesie pochowat (BartLub, IV, 62; 'He killed her in the field, and buried her in the woods'). Another space where crime is committed in folk ballads, is the forest, often characterised as ciemny 'dark': Wyjechali $w$ ciemny las, zajechali $w$ ciemny las,/Upad jo tam złoty pas, upad jo tam złoty pas (BartLub, IV, 11; 'They went into a dark forest,/And I lost my golden belt, I lost my golden belt'). For example, in one ballad a girl is killed in the forest: uOdprowadziła go cztery mile za las,/teraz, moja miła,/zabije cie zaraz (BartLub, IV, 63; 'She walked with him four miles, through the forest,/ now, my dear,/he will kill you here'), A wy, braciszkowe, prędko powstawajcie,/ wasza siostrzenica marnie ginie w lesie (BartLub, IV, 63; 'And you, brothers, arise quickly,/your sister is in the forest being murdered gruesomely'). Another possibility is a pond or the sea, often described as głęboki 'deep', or ciemny 'dark'. Both serve as the demarcation line or the transition zone, between life and death: $E j$, siostro, siostro, chodźmy nad morze [...] młodsza usiadła na wysokiej skale,/ starsza ja pchnęła w głębokie fale (BartLub, IV, 20; 'My sister, my sister, let us go to the sea (...); as soon as the younger one sat down on a high rock, the older one pushed her into the deep waves'), Ach, wzią ci jo, wział za jej delikatne boczki,/ wrzucił ci jo $w$ staweczek głębocki (BartLub, IV, 50; 'And I grabbed her subtle hips,/and I pushed her into a deep pond'), I przywędrowali do ciemnego Dunaju,/ oj, rozpuszczaj, Kasieńku, które zginie z naju (BartLub, IV, 53; 'And they came to the dark Danube,/now, Kasieńka, guess who will drown first'). Finally, similar to all the murder sites mentioned so far, łaczki 'meadows' mark yet another far off place to commit a crime: Wyprowadził jo na łaczki,/powyrywał białe raczki (BartLub, IV, 16; 'he took her away to the meadows,/where he ripped her white hands off').

As to the space where the murdered people are hidden or buried, this could be the forest or the garden,: W polu ci ja zabit, w lesie pochowat (BartLub, IV, 62; 'He murdered her in in the field, and buried in the forest'), Pośli do gaju ciemnego,/nie znaleźli tam nikogo [...] ino Zosieńke zabite [...] i gałazkami nakryte (BartLub, IV, 
57; 'They went to the grove,/and found nobody there (...) except Zosieńka's body covered with twigs'), W ogródku go schówała,/ziela na jim nasiała (BartLub, IV, 11; 'She buried him in the garden,/and planted some herbs on him'). It is interesting that although the garden is put next to dwelling places, it is not considered to be a sacrum kind of space. For this reason, it may well serve as a space of love, or making love (mostly forbidden, premarital), a space of unnatural, premature death and a space of crime and of hiding its consequences (for example, burying one's husband's corpse).

A specific site of committing murder and simultaneously uniting lovers forever, is the river. As it has its beginning (the source) and its end (the mouth), the river reflects the idea of transience, with the end marking 'the return to the state of chaos and death, as much as the river flow at some point disappears into the immensity of an ocean, depicting the never-ending process of the rebirth of the Universe'(Kowalski 2007: 502): I poszli se oboje do pobliskiej rzeki,/by się tam mogli złączyć,/złączyć na wieki (BartLub, IV, 97; 'And they both went to a nearby river,/to stay together,/to stay together forever'), Janka ze swym Staśkiem w bystrej wodzie tonie (BartLub, IV, 99; 'Janka and her Staś are drowning in rapid waters'). In animal-based fairy tales, the river is a mirror either reflecting or even laying bare the true nature of a protagonist (as in the case of a naive wolf that turns out to be gullible enough to trust the fox's assertion that it is possible to catch fish with the tail) or deluding one into seeing what one wants to see (the hare tale): jak stot na moście, patrzy a tam w rzyce widzi psa, kery tyż trzyma w pysku taki kęs mięsa (SimGad, 165; 'As he was there on the bridge, he looked down into the river to see a dog with a good piece of meat in his teeth'); raz szot za nieskoro $i$ czekot na niego wilk przy mostku (SimGad, 172; 'He was once walking slowly, and the wolf waited for him at the bridge'). The river then, is a borderline between different worlds, or more specifically, between what we think we are and what others think we are, between the psychological space of the familiar and of the alien.

Returning to the field as a space in folklore ballads, it is also seen as both a site of taking revenge and restoring peace and order. In one text, the avengers approach the murderer's house, emerging from the field: Wyjdżże, dziwko, na polie,/czy mi jado panowie (BartLub, IV, 11; 'Come out, bitch, into the field,/ the gentlemen are coming'). The field and the house/home are here juxtaposed with each other for contrast. When the home space is defiled by the husband having been murdered, it is the field which serves as a space where moral order is restored. The same function can be performed by the forest when it is where 
a kidnapped girl is first taken to and then released: Razw pięknej, wieczorowej porze/wyszedłem na przechadzke $w$ las [...] ujrzałem prześliczno dziewczynke,/ jak zbójca prowadzit jo $w$ las (BartLub, IV, 72; 'Once on a beautiful evening/I went for a walk to the forest (...), I saw a pretty little girl,/she was led into the forest by a bandit').

In ballads, juxtaposing different spaces can be used as a metaphor of divergences between the protagonists. For example, the contrast between, on the one hand, the road and the forest and on the other hand, the house/home is in fact, meant to show how different the protagonists are: uxOn po drogach, ưon po lasach,/ưon po górach/on po lasach,/ona sama w tych pałacach/ona sama $w$ tych pałacach (BartLub, IV, 16; 'He's away on the road, in the forest,/in the mountains,/in the forest,/she's alone in the palace,/she's alone in the palace'). Taken symbolically then, space serves the purposes of an indirect crafting of protagonists. As a kind of participant-observer, space accompanies characters in their life settings and differentiates positive protagonists from negative ones: $g d y$ piersze słowo mówiła,/aż się w lesie sosna chyliła (BartLub, IV, 57; 'When she dropped her first word/some pine tree in the forest just bent forward'). Naturally, space can have other functions as well, building the dramaturgy of a narrative being one of them.

\section{Creating the world of a narrative}

A. One dimension of space is physical space. This can be measured out or more precisely, localised and identified on the map: Padaja, że utopiec mo rodzina, kobieta i dwie cery. Tu. Niedaleko Groszowic, mieszkot w Odrze taki utopek (SimKum, 123; 'People say that this utopiec ['drowned man'] has a family, a woman and two daughters. Here. Near Groszowice this utopek used to live'). This kind of space embraces place-names and geographical terms whose function amounts to presenting the spatial setting of a text as physically-real, which is especially desirable in those texts which depict unusual, mysterious or just weird events and creatures, such as drowned people haunting the living. In this latter case, a concrete, well-defined, and materially real space is set in contrast with imaginary characters and events being a background or a reality reference, for them. Physical space does not foster memory, but it has a social group reference in the sense that the group places the mythological within the bounds of the real and familiar. Since that which is real and that which is imaginary interweave in a group's collective imagination, there is no room for disbelief or doubt.

The physical dimension of space can be found in legends as much as in historical tales (where it functions as a memory aid): 


\begin{tabular}{|ll|}
\hline W nowomiejskim okręgu leża & (...) There were three villages in the \\
wsie: Domotowo, Mechowo i Starzyno. & area: Domotowo, Mechowo, and Starzyno, \\
Między tymi wsiami jest wielki las dębowy & with an immense oak and beech forest \\
i bukowy, a dęby w nim stare na tysiąc & in-between them, with oaks of a thousand \\
lat. W środku tego lasu jest jeden mol, & years old at least. In the middle of this \\
nazywa się Chlewiszcza. Na trzy tysiące & forest there is one, called Chlewiszcza. \\
kraczajów od tego mola sa wyorane zagony, & Three thousand yards away from there, \\
na których wyrosły wielkie, już zestarzałe & one can find ridge and furrow fields now \\
dęby, a między tymi dębami sa malutyńkie & covered with huge, ageing oaks, and \\
ogródki obłożone wokoło kamieniami. W & very little gardens walled off with stone \\
tym kamienistym płocie wielu ludzi znalazło & chippings. Many people have found ash \\
garnki z popiołem, a w nim pierścienie $i$ & pots in these stone walls and rings and \\
wszelkie inne rzeczy. Ojciec mi opowiadał, & other valuables inside. My father used \\
że na tym molu za dawnych czasów stała & to say that once upon a time there was \\
wies, która nazywała się Czeszkowo, $i \dot{z} e$ & a village, Czeszkowo, where there is a \\
ojca ojcowie u czeszkowskich panów za sługi & knoll now, and that our forefathers used \\
byli i stąd ta tradycja w naszym rodzie się & to work as servants for the Czeszkowo \\
zachowała (HajPod, 45). & landlords, which is why this tradition has \\
& survived in our family until this day. \\
\hline
\end{tabular}

B. The kind of space that overrides both physical space and physical time is called metaphysical. This space is archetypal in nature, indeterminate in form, and embraces timeless events. No wonder, then, that it prevails in fairy tales, as in Byt sobie roz król i królowa. Chociaż bogaci, lecz byli nieszczęśliwi, bo nie mieli żadnego potomstwa. Pewnego razu obok zamku królewskiego szła cyganka (SimKum, 33a; 'Unce upon a time there was a king and a queen. Though rich, they were unhappy because they did not have any children. One day a Gypsy woman was passing by the castle'), and in legends: Jest to opowieść naszej starki, która my zawsze radzi stuchali, bo się nam podobała. Było to jeszcze wtedy, jak Ponbóczek po ziemi chodzili i ludzi nauczali, jak maja żyć, aby się na świecie sprawiedliwie działo. (SimKum, 15; 'This is a story told by our grandma whom we always eagerly listened to because we liked her very much. So, when the Lord God was still around here on earth, teaching people how they should live for justice to abide (...)'). The metaphysical space is typical of these kind of stories no matter whether it is named (here: castle) or very general and indeterminate (here: earth), and referred to with indefinite expressions (w jednej 'in one', w pewnej 'in some'). Spatial expressions do not support memory, but serve as a mirror reflecting the memory bearer's system of values.

C. According to Edward Hall, micro-space can be distinguished as a highly characteristic kind of space in folklore texts, where crafting the reality of a narrative 
can be facilitated. The sense of micro-space is located in the subconsciousness, on the primordial level of culture. This is why micro-space is often identified with the home and contrasted with anything that extends away from home, producing one of the ultimate primeval oppositions, the own/familiar versus the strange/ alien. This dichotomy can easily be found in folk ballads and fairy tales. In these two genres, we typically have a sharp contrast between the safe, domesticated, sacrum kind of space of one's /home on the one hand and on the other hand, the wild, alien, dangerous profanum kind space which does not belong to one's home. Naturally, the characters located in the latter space are crafted with the intention of constituting a source of danger or threat, to the characters of the home zone:

Oj, w lesie, $w$ lesie pod sosno,

Oj, w lesie, $w$ lesie pod sosno,

Siedział tam Janeczek ze swo Zochno,

Siedział tam Janeczek ze swo Zochno.

Oj, Zosiu, Zosiu, chodź dali,

Niech nas tu słonko nie pali.

Pośli do lasu ciemnego,

Nie znaleźli tam nikogo.

Oj, Zosiu, Zosiu, zabije cie,

Twoje białe raczki połomie cie (BartLub,
In the forest, in the forest under a pine tree, In the forest, in the forest under a pine tree, Janeczek was sitting with his Zochna, Janeczek was sitting with his Zochna. Zosiu, Zosiu, let us go a little farther

So that the sun should not burn us. They went to the dark forest, They did not meet anybody. Zosiu, Zosiu, he will kill you now, He will break your white arms. IV, 56)

What is placed at the centre of the ballad's micro-space is the home, while that which is found outside it, are the evil deeds of bad people. In this way, the home becomes 'a universal model for depicting the Universe' (Kowalski 2007: 84), which emphasises the man-home isomorphism. 'The primary existential experience determines the order of the world, this order being mapped out first by the human body and then by the home. The focal point of the world is always home, and it is from the home that any other relationships are measured' (Kowalski 2007: 85). No wonder then, that home is considered to be imago mundi - 'one's body is one's soul's home' (p. 381), that is, the sacrum kind of space that needs to be protected and guarded from harm: Zostawił duma maleńkie pachole,/by dumu pilnowało (BartLub, IV, 12; 'He left a little boy at home,/for the boy to take care of the place'). Home is a safe and happy place: Gdy zaszedt do jej domu, Janka przy maszynie/kończy swa ślubna suknie o wesołej minie (BartLub, IV, 91; 'When he came to her home, he found Janka at a sewing machine,/finishing her wedding robe, with a grin'). Home can also be identified with one's family, with what one remembers as a place of discipline and parental guidance, which is why a home 
can turn in a hostile place to those (lovers) who do not hesitate in violating the standards of where they think they no longer belong: Mój ojciec zastrzeżenie już zrobit u księdza,/a na mnie się zagniewał, $z$ domu mnie wypędza (BartLub, IV, 97; 'My father has already had a word with the priest alone,/and is angry with me, turning me out of the home'), Ale go ojciec do domu nie wpuszczat,/córce zabronit wychodzić (BartLub, IV, 69; 'But his father did not let him in,/and forbade his daughter to go out'). As home is a protected zone, for a male character to murder his lover, he needs to take her away from home: Odprowadziła go za domek na droge,/dalej, kochaneczku, dalej iść nie moge (BartLub, IV, 63; 'She saw him off on the road behind the house,/I cannot go any further, my love').

However 'microscopic' micro-space can be, so-called mediatory points can be distinguished within it. The point that is most often exposed within ballads, is the window. Its 'mediatory' role is reflected by the fact that through the window, both the outside and inside worlds can be observed (cf. Adamowski 1999: 16), which is often how we learn the truth: Przyjeżdza on do domu, pod okno sie skrada/i widzi swoja żone w objęciach rybaka (BartLub, IV, 74; 'He comes home, looks through the window and sees his wife in the fisherman's arms'). As the place now is defiled with the wife's adultery, it must be burned down. The window can also serve as a punishment site, when it is depicted as a border between life and death, as in Lewolwer zara wydobyłem,/nabiłem siedem ostrych kul,/przez okno do ni wypaliłem,/nie zdradzaj serce zotmieza (BartLub, IV, 73; 'I reached out for the gun,/loaded seven bullets,/ and fired straight at her through the window; /you never cheat on a soldier's heart').

Another point of mediation can be the bridge, which is depicted as 'a transition, or a bringer of two different edges or worlds together, consisting of overstepping the boundary between the domesticated and familiar orbis interior and the uncertain and alien orbis exterior' (Kowalski 2007: 324). In Lublin-area ballads, the bridge like the window, represent the truth/falsehood boundary, or, more specifically, the point at which the husband discovers the truth about his unfaithful wife, and steps over the borderline between the preconception he has had so far about her and the actual truth about her: Doguniło go na lipowem moście, na lipowem moście:/Wracaj, panońku, bo u pani goście (BartLub, IV, 12; 'They caught up with him on a linden bridge, on a linden bridge:/Come back, my lord, as the lady has visitors').

Still, in some other contexts, the bridge may stand for a girl of marriageable age: U mojej Maniusi kwatera na moście,/przyjechało do Maniusi trzech kozaków w goście (BartLub, IV, 71; 'My Mania has got her quarters on the bridge,/three Kozacks have come to visit her'). One way or another, micro-space, as much as micro-time, is symbolic and archetypal in nature and sends back a system of inclusive beliefs to a social group's values. 


\section{Space in creating a protagonist}

A. One kind of space that comes to the fore while crafting a protagonist is biological space which is understood as a specific variety of the space of the beginning. Biological space is related to and determined by an individual's growth or course of life. As expected, the typical symbol of the protagonist's growing up, becoming mature and gaining life experience, is the road. The road can also mark reaching the limits of one's knowledge and of one's life. In the context of fairy tales, the road is usually depicted in terms of wayfaring and then, it becomes 'a metaphor of human fate, a never-ending search for something, of making choices, and performing tasks' (Niebrzegowska-Bartmińska 2007: 283). The journey that a fairy-tale protagonist sets out on, is meant to provide him/her with knowledge and experience.

As K. Smyk makes the point with regard to ballads, in turn,

The world of ballads is basically sideways. In my opinion, this points to a clearly anthropological dimension of the road in ballads. As I understand, it is not the road as a stretch of space, but it is the human being (homo viator), with lots of intentions, feelings and patterns of behaviour, that determines the ways and means of covering space. This makes the perspective of a man on the way [Pol. $w$ drodze], rather than of a man on the road [Pol. na drodze], come to the fore, with shifting in space being merely a symbol of life transformation, that is, the course of life leading towards love, or death. (Smyk 2012: 279)

In ballads, the road and wayfaring also denote that one is becoming prepared for the truth, searching for the truth, and discovering the truth: Wyjechat Oleś $z$ charamy na pole [...] jak sia pachole o tem dowiedziało, zaraz kuniki osiodłać kazało (BartLub, IV, 10; 'Oleś went away to the field (...); as the boy learned more about it, he ordered the horses to be saddled straightaway'). In a more metaphorical way, the road can symbolise one's search of one's soul, a journey into the dark side of the human self: Ji w piatek wieczór, gdy się już ściamniało,/ Prosit Wojtuś Kasie, by się kąpać pośli/Ona mu mówi: nie pójde ja z tobo,/Masz inno kochanke, co chodzi za Tobo (BartLub, IV, 12; 'On a Friday evening, when it was getting dark,/Wojtuś asked Kasia to go bathing in the river./She says: I'm not going with you,/'cause you have another mistress'). At the same time, 'the farther away it is from home, the closer it is to death' (Smyk 2012: 273): Odprowadziła go na rozstajne drogi,/na rozstajne drogi,/idźże sam, Jasieńku, bo mnie bola nogi (BartLub, IV, 62; 'She saw him off at the crossroads,/at the crossroads,/Go, Jasieńku, go alone, 'cause my legs are in pain'). The road or rather wayfaring, may mean losing one's way and wandering around: Idzie góro, jidzie lasem, tak bładzi do rana (BartLub, IV, 88; 'Through the mountains, through the forests, he's been wandering around since the morning'). Wayfaring in the mountains 
and the forests symbolises struggling with evil thoughts, in the text, leading to the aforementioned suicide.

A similar pattern can be noticed in animal-based fairy tales. The repeatable element of structure here is the notion of DEPARTURE, the road and the wayfaring. Some domestic animal either departs, leaves, is made to leave, escapes from the farmstead to the forest or if the protagonist-animal is a wild animal, it follows the opposite direction and comes out of the forest: Pewnego razu lis wyszedt z lasu i postanowit iść między ludzi (SimKum, 15); raz w lesie mniat skowronek gniazdko (KrzyżBaś, 37; 'One time a fox came out of the forest and decided to stay among people'). There may be various reasons why the protagonist leaves its natural and familiar space in order to enter an alien one: to sell fish, steal fish from the barrel, to see if anybody is afraid (of a hare, for example), to live among people (fox) or to see what human flesh tastes like (wolf). One way or another then, there is a transition from the world of one's own to another (foreign, strange, alien) world with the intention of getting to know something different, entering a novel interaction, getting some reward (food), or just confirming one's expected value (self-assessment, like the hare fairytale). This other world always means a danger or a threat to the protagonist-animal, as in wiloszek rad, że ma wreszcie chłopa, którego zaraz pożre, pozwolit mu iść w krzaki. Chłop wyszukat se tam taki wielgachny kij, schowat go do rękawa [...] chłop łaps za kij z rękawa, owiną se ogon wokót ręki, a tak wilka zaczął łoić, że biedak dostał nauczkę na całe życie (SimKum, 16; 'The wolf was happy to spot a man that it wanted to soon devour and it let him go into the bushes. The man found a huge stick, hid it up his sleeve (...), grabbed the wolf by its tail, and started beating it so much that the poor wolf learned a life-long lesson').

Generally, biological types of spaces serves to characterise the protagonist as well as to reveal the symbols-values cherished by a social group. In this latter function, biological space can be said to have 'a concrete relationship to a group', in J. Assmann's terminology (see Section 1 above).

B. Crafting a protagonist can also be achieved by means of depicting one's personal space of emotional states. In texts of folklore, it is fairly unusual that emotions happen to be disclosed in any explicit fashion. Personal space helps to identify emotions, because it is structured to perform semiotic and symbolic functions, which includes the safe/protected vis-à-vis alien/dangerous dichotomy. In practice, the former symbolises good, brightness, order and hierarchy, whereas the latter stands for tension, anxiety, negative emotions and socially-unacceptable deeds: Zerwała się fala, w morzu brzegi rwała,/Oj, ładna dziewczyna namówić się 
dała (BartLub, IV, 53; 'the wave started foaming, washing the sea shore away,/a pretty girl surrendered in the end').

Personal space often embraces the places that are considered to be sacred, such as crosses by the side of the road, as the one that bears witness to a girl's oath given to a lover on his way to war: Stoi $w$ polu krzyż, zbliz sie, luba, zbliz,/bo ja jade na wojenke, przysiege mi złożysz (BartLub, IV, 70; 'There is a cross in the field, come closer, my love,/'cause I'm going to war, swear an oath to me'). Like biological space, personal space reveals what a group believes in and what values it shares, which most often relates to the role nature plays in people' lives. In short, the natural world is a reflection of human psychological states, which amount to some version of animism in the sense that the way space is constructed in a narrative, denotes emotions.

\section{Reconstructivism as an objective aspect of memory}

As already stated at the end of Section 1 of this chapter, reconstructivism involves that which is (being) handed down from generation to generation, that is, reconstructed pictures of the past and the past constituting a salient value of the folklore-depicted picture of the world. As it is reconstructed in texts of folklore then, the past can be ascribed with six specific dimensions, or problem areas:

- mythological past (of the origin/beginning or of some indeterminate remote past),

- belief-reconstructing past,

- biblical past,

- historical past (also: mytho-historical),

- family and personal past,

-ritual-reconstructing past.

Each of these are here considered to be objects of reconstructivism and will be examined below according to the following analytical scheme:

- object of reconstruction (i.e. reconstructed events),

- agent/doer,

- cause of event,

- purpose of activity,

- agent's way of performing activity (purposeful vs. accidental activity, verbalisation and/or gesticulation),

-. time of event,

- space of event. 


\subsection{Mythological reconstructivism}

The mythological dimension of recostructivim touches upon the memory-myth relationship, which calls for an explanation of the notion of a myth itself. In this, Barbara Szacka's threefold typology of myths are complied with:

- objective myths, when a myth is depicted by its substance (content) or its form (structure); this category includes stories about the origin of man, the world and ways of behaviour; these stories are mythological in the sense that they pertain to supernatural beings and events or at least they explain beings and events in terms of supernatural factors and forces;

- functional myths, when a myth is depicted by the function it has to perform in/for a social group;

- subjective myths, when a myth is depicted in terms of the subject's mental activity (Szacka 2006: 72-73).

More generally, mythological mentality tends to present a global and coherent picture of the world, to set precedents as a source of evidence and/or proof and to use the pars pro toto and post hoc, ergo propter hoc principles of argumentation. The mythological mind is also judgemental in the sense that it does not perceive things in any neutral or indifferent terms, but always assesses them as either good or bad/evil. A myth can then be seen as a specific way of symbolic expression which objectifies feelings and emotions on the one hand, but on the other hand, these objectified emotions only happen to be fostered, in effect (cf. Szacka 2006: 73).

With regard to collective memory, the mythological past, according to B. Szacka, embraces some of the categories of the world of a narrative, such as time, protagonist and values and functions, the latter two being extra-textual in nature.

In the context of collective memory, time amounts, in fact, to mythological timelessness. In practice, the whole process of mythologisation of the past results in creating sacral patterns of behaviour and universal types of characters. This is possible when an individual character is disentangled from his/her actual and historical setting and transformed into an archetype. Void or deprived of their individual characteristics, protagonists become timeless types, patterns, or schemas (cf. Eliade 1998: 53). As B. Szacka implies, collective memory protagonists function more like personifications of specific values, rather than full-blooded historical figures (Szacka 2006: 93).

However, there are also other similarities in the way myths and collective memory function: both serve to identify a group and legitimise the existing social and political orders of that group. Moreover, both pertain to the sphere of feelings and emotions, which is why the truth appears to be that which is 
emotionally genuine, not rationally correct. Neither leaves room for indifference, accidental events or impartial characters - everything must be clear-cut as either good or bad. This mentality is fostered by rites, rituals, and ceremonies (Szacka 2006: 94).

The object of mythological reconstruction can be the process of creating the world (and its constitutive elements) as well as the changing world of Christ's wayfaring with the Apostles and/or Mary, Mother of God, as in legends:

A niebo to wom pawiym powstało tak: Pan

Bóg zawezwał do Siebie wszystkich kowali, ślusarzy i powiedział im, że potrzebuje takie wielgachane sklepienie niebieskie, ale takie, kiere się na noc będzie zawierać, a na dzień otwierać, bo wiecie. On se spomniał, że $w$ dzień ludziom musi być jasno, a i ptaki i bydło musza widzieć, no i słonko musi ziemia i pole rozgrzać, a roślinność cała musi przecie róść. No i nakazał im to sklepienie wykuć z najlepszego żelaza. [...] No i od tego czasu mamy sklepienie niebieskie, które na noc się zawiera, a na dzień otwiera (SimLud, 17).
Heaven, let me tell you, was created this way: the Lord God summoned all the smiths and iron-workers, and told them that He needed a huge vault in the sky, but it must close for the night and open for the day. You know, the Lord God knew that it must be bright during the day for the people, the birds and the cattle to see and for the earth to get warm, and for the plants to grow. So, $\mathrm{He}$ told them to forge this vault from the best iron available. (...) Since then we have had the firmament which opens for the day and shuts for the night.

The agent/doer of an action in a mythological reconstruction of the past is, first of all, God. It may be worth noting at this point that it is not only past events that are reconstructed, but also an image of God Himself is created. For example, this image does not have to be that of an omnipotent abstract being, but of an old and tired man:

Ponbocek był już bardzo stary i bardzo, ale to bardzo zmęczony i styrany tym tworzeniem świata, aniołów, ziemi, gadów i ptactwa wszelkiego. Chodził se Biedok po niebie, a czasem to mu się zdarzyło, że i upadł - jak to ze staruszkami bywa. Ale aniołowie go zaroz podnieśli i padali mu, że zrobia mu jaki kij, wiecie, tako kryka, co się na niej może podeprzeć, coby kaj nogi abo biodra nie złomoł. No to tyż szurgali na dół do stolarza i padaja mu, coby im piękno kryka zrobił. Ten to
The Lord God was very old and very tired of creating the world, angels, earth, animals, and all the birds. So, when the Poor One would walk across the sky, he would at times trip over and fall down, as it is so often the case with old people. But then the angels would get him up and say that they would give him a walking stick so that he did not break his leg or his hip. So they did. They stepped down to the earth and told a carpenter to make him a beautiful staff. The carpenter 


wiedzioł, jak się takie kije do podpórki
robi. Wziął taki fest sękaty kij, a na samym
dole dał pora gwoździ, coby lepiej halt ten
kij mioł. Anioły przyfurgały z tym kijem i
podarowały go Panu Bogu. Rozradował się,
bo to na nim szło się naprowda oprzeć. No
i jak tak chodził, naroz wszyscy w niebie
zmiarkowali, że na dymówce nieba porobił
pełno dziur. Bo kaj ino się oparł, tam tym
gwoździem zrobił dziura! Zafrasowali się
nie ino aniołowie, ale i sam Ponbocek.
Wtem zaś otwiera się Brama Niebieska i
jeden anioł z ziemi przyfurgoł i pado: -
Ponbócku roztomiły. Ale też wom ludziska
dziękują, aże dziękują. Naroz i w nocy pełno
światełek z nieba widać. A te światełka
sa tak miłe, że ludzie maja jasno i widza
jakie jasności bija z nieba. Wtedy Ponbocek
zrozumiał, że stworzył gwiazdy na niebie
i że wcale dymówek nieba nie popsuł, a
ludziom radości narobił (SimLud, 25).

knew well how to make the thing, so he took a gnarly stick, drove a few nails in at one end so that it had a good grip. When the angels were back with the finished stick and presented it to the Lord God, He was happy because the stick was of great support to Him. But soon everyone realised that the Lord God had made many holes in the clouds with the stick. Wherever He put the stick down, there was a hole! This made the angels concerned and the Lord God was sort of haggard, too. Yet, suddenly, the heavenly gate opened and one of the angels flying from the earth said: Lord God, people are so thankful to you because now they can see lots of lights in the night sky. These lights are so nice that people can now clearly see what brightness beams from the heaven. The Lord God understood then that he had just created the stars and that he had not spoilt any clouds, but brought joy to the world instead.

So, the lesson we learn from the analysed texts of folklore is that it is not God who created man in his own image, but it is people who create God in their image and after their likeness:

Kiedy już Pan Bóg stworzył ludzi i aniołów, to pomyślał, że dobrze by Mu było, gdyby nie musiał się cały czas przypatrywać temu, co ludzie wyprawiaja na świecie. Usiadł na stołku i rozmyślat, jak by to zrobić, żeby mieć trochę wygody, spokoju i nie patrzeć cały czas na stworzony świat. Myślał i myślat, a tu naraz taka biała chmura zasłoniła mu ziemię. Wtedy się nasz mity Stwórca rozradowat i głośno zawołał: Aniołowie i dobrzy ludzie, co już w niebie żyjecie! Przynieście mi tu największa płachtę - No i anieli $i$ święci mu przynieśli. Kazał im ja rozwinąć, tak aby
Once the Lord God had already created people and angels, he thought that it would be better for him not to see what people where scheming about down there on earth. So, he sat down on a stool and contemplated how to have some comfort and peace, without having to look at the world he had created. Then, suddenly, a big white cloud cast a shadow upon the earth. This made our Creator happy and he said: - Angels and good people, all that of you that are in the heaven already! Bring me the biggest sheet! So they did. He told them to unfold it so that the 


\begin{abstract}
przykryć i oddzielić niebo od ziemi. Przykryli ją, a on uradowany aż $w$ ręce Boże klasnął.

Siadł i już na ziemię nie musiał zawsze patrzeć, jak chciał widzieć, co się na niej dzieje, to ino płachty trochę uchyną $i$ juz widział. A i ludziom łżej się żyje, że jest ta płachta na niebie, to tak całkiem być pod obserwacja, to wam powiem, nie idzie dobrze żyć (SimLud, 16).
\end{abstract}

heaven and the earth were separated. When they did this, he simply clapped his hands with joy. He rested again and did not have to look at the earth all the time any more. Whenever he did want to see what was going on down there on the earth, he just lifted the sheet and took a little look. Now people find it easier to live as well ever since this sheet had been spread across the sky, because, to be honest, it is no good to live under constant surveillance.

Yet, the Lord God is not the only agent in folklore texts. The course of events and the present shape of the world can also be attributed to people, their desires, worries and transgressions. Yet, those that can affect reality are limited to specific professions (iron-workers, smiths, potters): Pan Bóg lepił w raju Adama i Ewę, a garncarz stał za drzewem i patrzył, i podziwiał, jak Panu Bogu to składnie idzie, jakie ładne figury potrafit zrobić. Garncarz podpatrzył to wszystko, a potem poleciał do domu, wzią kawał gliny $i$ też ulepit figurkę. I odtąd właśnie lepia garncarze figurki i naczynia (SimLud, 55; 'When the Lord God was shaping Adam and Eve in Paradise, some potter was lurking behind a tree, so he saw and appreciated how skilful the Lord God was in making those figures. Then he ran home, took a piece of clay and did the same. Ever since, the potters's job has been to make figures and pots').

As can be seen in the two examples just quoted, the picture of the beginning does not follow the biblical account either logically or chronologically. Despite clear biblical references and Christian flavouring, this is not a reflection of either, but a unique reconstruction of the past. In this past, God is so close to people that he even cooperates with some of them (craftsmen) in creating the world. Man is not God's ultimate or crowning achievement, but appears to be God's 'subcontractor', or 'outsourcer'. This gives people an active role to play, as helpers, executors, or implementers of God's ideas and plans. In specific cases, people may be unaware that they are part of the creation process, but - deliberately or not - by what they do and how they act, they affect the shape of the world that has already been created:

\footnotetext{
Działo się to wtedy, kiedy Pan Bóg z świętym This all happened when the Lord God Piotrem po ziemi chodzili i między ludźmi and Saint Peter were still around and żyli. Do nieba zaś mieli bardzo blisko, bo jak rękę wyciagli, to już nieba lived among people who, for that reason, had the sky truly at their fingertips because
} 
dotknęli. Ludzie się przyzwyczaili, że niebo maja na wyciagnięcie ręki, a Pana Boga i świętych jego aniołów na co dzień. No, tak to dawniej było. Pewnego razu matka niemowlaka wieszała na dworze mokre pieluszki na sznurze. Nie widziała, że dziecko tam coś więcej namarasiło, nie ino mocz. No i jak tak machnęła ta pieluszka, to naroz zmarasiła kasek nieba. Akurat spacerowali se Pan Bóg ze świętym Piotrem $i$ jak to ujrzeli, to tak ich to rabło, że ze złości zawołali: - Już wy ludzie nieba ręka nie dosięniecie. Nie umiecie uszanować firmamentu, to go i blisko mieć nie możecie. Jo i od tego czasu niebo jest wysoko i żaden człowiek go rękq nie dotknie (SimLud, 17). all they had to do was to stretch out their arms and they could already touch it. People got used to having the sky so close at hand and to meeting the Lord God and his holy angels day in and day out. One time a young mother was hanging up her baby's laundry. She did not notice that the baby had not only peed in the nappy, but had done something else. So, when she flicked one of the nappies, she made a piece of the sky dirty. The Lord God and Saint Peter were walking by and this really got on their nerves: - You people are not going to touch the sky anymore. You do not respect the firmament and you must not have it close at hand. Ever since then the sky has been high above our heads and no man can reach it with his hand.

Next to the human factor, the creation process is also assisted by the devil, his lust and greed, presented in terms of Goethe's disastrous force that always does good by always attempting evil or at least, that becomes the driving force of changes:

Kiedy Pan Bóg tworzył niebo, ziemię $i$ słońce, aby przyświecało ludziom, diabeł to wszystko obserwowat, schowany w czyśćcu. Gdy tylko słońce się zmęczyło i poszło na chwilę wypocząć, diabeł wyskoczył z czyśćca i zaczą hulać po ziemi. Powalit wszystkie drzewa, wykopał mnóstwo dziur, narobił sporo błota, połacie ziemi porozdzielat przepaściami, tak aby ich ludzie nie mogli przekroczyć. Gdy ujrzał to Bóg, żal mu było, iz stworzył tylko jedno słonce, dlatego stworzył dodatkowo księżyc, aby $i$ w nocy świecił. Diabeł oczywiście nie mógł sięz tym pogodzić i poleciał walczyć z księżycem. Nadgryzał go i nadgryzał, aż została ćwiartka. Księżyc poleciat po pomoc do słońca. Słońce mu pomogło, pozwoliło się odrodzić, zaś diabet nie mogąc podjąć walki ze słońcem, gdyż nie znosi on
While the Lord God was creating heaven, the earth, and the sun to shine upon people, the devil was watching this holed up in purgatory. As soon as the tired sun went down for some rest, the devil jumped up out of purgatory and started having fun. He brought all the trees down, dug lots of holes, covered everything with mud, chopped open spaces with cliffs and bluffs to make it impossible for people to cross them. When God saw this, he felt sorry for having created only one sun, and he came up with yet another one, the moon, to provide light at night. Naturally, the devil could not possible put up with that, so he started fighting with the moon. He took one bite of the moon, then another bite, and all that remained was a quarter. The moon called the sun for help 
jasności, uznat się za pokonanego. Od tego czasu księżyc rośnie i odradza się co dwa tygodnie po walce $z$ diabłem (SimLud, 23). and the sun helped the moon, which is why the moon can restore its shape. The devil was not able to fight against the sun, as he hates light and brightness, so he surrendered. Ever since then the moon is reborn every two weeks after the fight with the devil.

As the folk worldview is based on oppositions, the mythological past, as reconstructed in folklore texts, reflects an interplay of mutually exclusive extremes: Czart chciał także zrobić słońce, ale in mógł; skradł przeto u Boga kawał słońca, z którego utworzył się księżyc (SimLud, 23; 'The devil also wanted to create a sun, but he could not, so he stole a bit of the sun from God and made the moon out of that'). Thus, good and evil not only exist and function next to each other, but also complement and supplement each other and at times they may even join together for the sake of man. The same can be said about the devil himself, that is he may sometimes act for people's advantage and benefit (cf. SimLud, 33-35 for selected creation stories).

As to the cause of events in mythology-oriented texts, it is very often an individual man's sinful evildoing, such as telling lies that brings about a given event:

Kiedy Adam i Ewa zjedli jabłko z drzewa rajskiego, ukryli się i nie chcieli się pokazać nawet samemu Panu Bogu. On ich jednak zawołał przed Swe święte oblicze i spytał: „Kto pierwszy zgrzeszyt?” A szło o to, kto to jabłko z drzewa zerwat. A oni oboje powiedzieli, że sa niewinni, bo to ten wą̇̇, ta żmija zrobiła. Pan Bóg ich jużaś pyta, a oni to samo. Za trzecim razem Adam pokazał palcem na Ewę, a Ewa na Adama. To najbardziej zgorszyło Pana Boga, bo widziat, że jeden na drugiego wina zwala. Wtedy wygonił ich $z$ raju na ziemię $i$ ogłosił uroczyście: „Aby tu tak całkiem ćma nie było, to stworze na niebie słonce. Ale pamiętajcie, ono nie tylko będzie was grzało i wam światło dawało, ale ono będzie moim okiem. Wszystko co się będzie działo złego to będę widział. I na nic wasze chowanie się za krzaki.
When Adam and Eve ate the apple of the Paradise tree, they hid themselves and did not want to be seen; even by the Lord God Himself. However, He summoned them and asked: - Which of you sinned first? The point being who first took of the fruit of the tree. They both answered they were not guilty because it was the serpent, this viper, who did it. So the Lord God asked again, and their answer was the same. The third time, Adam pointed at Eve with his finger and Eve at Adam. The Lord God was concerned because he clearly saw that they were just passing the buck. So, he expelled them from Paradise to earth and solemnly proclaimed: 'In order to avoid complete darkness, let there be sun in the sky. But remember it will not only keep you warm and provide light, but it will also be my eye on you. 
Słońce obejdzie cały świat od wschodu do zachodu i zajrzy w każdy zakątek". No $i$ naprowda słońce na niebie wisi i calutki czas obserwuje ludzi, ile zła, a ile dobra czynią (SimLud, 21); Raz Pan Bóg chciał odwiedzić rodzine Adama i Ewy i zobaczyć ich potomstwo. Oni jednak - jak tylko się dowiedzieli o chęci Pana Boga - schowali część dzieci i ukazali tylko te dorodne. Ukryte dzieci zostały przez Boga zamienione $w$ demony (SimLud, 43).
I will see all that you do wrong, so there's no point in hiding among the bushes. The sun will walk around the whole world, from the east to the west, and will take a good look into every nook and cranny. (...) // One day the Lord God wanted to visit Adam and Eve's family and see their offspring. But, once they had learned about God's visit, they hid some of the children so God would only see the best ones. God turned the hidden children into demons.

So, the sun is God's response to the first peoples' lie and serves as God's eye. The world, in turn, came into being as a punishment for transgressions, which in folklore texts is frequently stated most explicitly: $Z$ młynarza jest niedźwiedź. Bo był raz młynarz $i$ widział Chrystusa, jak szedł ze św. Piotrem. "Zastraszę ich”pomyślał, wszedł pod most i mrucząc, udawał niedźwiedzia. Bóg za karę przemienił go w niedźwiedzia i jako gwiazdę osadził wysoko na niebie (SimLud, 26; 'The bear derives from the miller, because there was once a miller who saw Christ walking with Saint Peter. - I will make their flesh creep, he thought and walked over the bridge, growling and pretending he was a bear. As a punishment, God turned him into a bear and placed him in the sky as one of the stars').

Purpose of activity. In mythological constructivism, what the world actually looks like is a reminder of the events that, when recalled, serve as a warning for generations to come. So, while a given text itself is a carrier of collective memory, the picture of the world included in that text is a remembrance of either biblical or mythological events:

Pewien chłop miał dwóch synów, tym ze śmiercią swą zostawił niewielkie gospodarstwo, które nie dzielone mogło się jakkolwiek utrzymać, lecz po rozdzieleniu znikłoby $w$ małości; bracia postanowili razem gospodarzyć i szło im dobrze; lecz młodszy zawsze myślał $w$ duchu, że gdyby starszego brata nie było, on by sam mógt posiadać cały majątek, przytem się ożenić $i$ być zamożnym; myśl ta $w$ nim się wzmogła $i$ na koniec jedna raza postanowił zabić
Some peasant had two sons to whom he left his small farm to after his demise, because when partitioned, it would be so little that it was almost non-existent. The brothers decided to run it together, and they were doing fine, before the younger brother contemplated the possibility of having the farm for himself. Then he could get married and become rich. This thought was so compelling that one day he decided to kill his brother. 
swego brata. Zamiar ten wykonał w polu,
gdy oba przyjechali po snopy, uderzył więc
widłami brata starszego i zabił go. Bóg wnet
zniszczył całe zbrodniarza gospodarstwo;
a samego wtrącił żywcem do piekła. Aby
zaś ludziom widok tej wielkiej zbrodni
ciagle się przypominał i odwodził ich od
podobnej, sam swoją ręka na księżycu obraz
pomieniony nakreślit (SimLud, 24).

This text is quite typical of mythological constructivism in that it is dichotomybased and similar to the biblical account of Cain and Abel, with the natural world (the moon) being referred to in remembrance of selected mythological past events. In short, the purpose of God's activity is here twofold: to warn people and to make them remember.

An agent's way of performing activity (purposeful vs. accidental). As mentioned above, the mythological kind of reconstruction pertains to the origin/creation of the world. However, in texts of foklore, this is pictured not as a one-off process but a well-planned, worked-out and completed activity: Kiedy Pan Bóg ulepił mężczyznę i kobietę z gliny, musiat im pozszywać piersi i brzuchy, wzią jednq nitkę i zaszył mężczyznę i jeszcze został kawałek nitki, z której utworzył się członek męski; wzią druga, zeszył kobiete, ale kawałek zabrakło. Stąd powstał członek zeński (SimLud, 54; 'When the Lord God formed man and woman from the dust of the ground [lit. of clay], he still had to stitch up their breasts and bellies. He took one thread and stitched the man up. As a little piece of thread was left over, the penis came about. He then took another thread and stitched the woman up, but the thread was not long enough, so this is how the woman's vagina came into being'). So, the process of creation is on-going, never-ending and at times, even haphazard, so the Creator must fix or sort out, various imperfections: Bóg jak stworzył Adama, to stworzył go z ogonem. Po jakimśczasie Bóg zorientował się, że kiepsko jest, jeżeli i zwierzęta, i ludzie mają ogony. I tak wzią Adama, obcią mu ogon i położył go koło niego. Potem zaś zrobił z tego ogona żonę Ewę. To kobiety pochodza z męskiego ogona (SimLud, 54; 'Originally, God created Adam with a tail. After some time God figured out that it was no good for both people and animals to have tails. So he got hold of Adam, cut his tail off, and put it next to the man. Then from that tail, He created his wife Eve. This means that women come from a man's tail').

The act of creation often involves physical work, as in the forming of man from the dust of the ground (lit. of clay): Na Białorusi opowiada sie, że diabet 
obserwowat dłuższy czas poczynania Boga. Widziat jak płynie On na łódce i co jakiś czas rzuca $w$ wode garść nasion. $Z$ jednych nasion powstawała ziemia, $z$ innych lasy, z jeszcze innych pola $i$ łąki (SimLud, 38; 'In White Russia, they say that the devil was watching how God created the world, for some time. So he saw God sail in a boat and throw handfuls of seeds into the water, from time to time. Some seeds gave rise to the earth, others to the forests, and still others to fields and meadows').

That God created the world not by his word, but through some physical effort can be seen in a narrative which speaks of God's fatigue: Pan Bóg tak się spocił tworzeniem świata, że zanim stworzyć miał człowieka, to chciał się wykąpać. Przynieśli mu anieli wielka balię, nalali mu ciepłej wody i czekali, aby go wytrzeć. Jak już był czyściutki, chciał sobie na mała chwilkę wypoczać (SimLud, 51; 'The Lord God was all sweaty because of this creating of the world that before he was about to form man, he wanted to have a bath. So, the angels brought him a huge washtub, poured warm water into it, and waited to dry him off. When he was clean and fresh, he just wanted to have a little rest').

The analysed texts of folklore do not seem to cherish the biblical idea that 'in the beginning was the Word' (John 1.1), but, instead, they present God's acts of creation in terms of physical effort and build analogies to the work of a sower and a craftsman. Simply, God created the world with his own hands, not by his word. However, if there is any mention of the agential powers of words, this is in reference to the Lord Jesus: Gdy Pan Jezus chodzit po ziemi i zaszedt do chaty włościańskiej, zapytat spotkanej kobiety, czyby Go nie przeprowadziła, bo zabłądził, lecz ta nie chciała, mówiąc, że ma dużo roboty; chłop stysząc to, rzucił cepy, którymi młócił w stodole, i pobiegt, aby wskazać Mu drogę. Rzucił Pan Jezus przekleństwo na kobietę, aby nigdy jej roboty nie zabrakło. Chłop zaś, aby zawsze znalazł czas do odpoczynku (SimLud, 57; 'When the Lord Jesus walked on this earth, he once stopped by a peasant's hut. He asked the woman to show him the way because he had got lost. She did not want to help him, saying that she had many things to do. When the man heard that, he just put his flail to one side, came out of the barn and gave the directions. The Lord Jesus cursed the woman so that she would never run out of things to do and blessed the man for him to have always time for rest').

As mentioned above, in mythologically-oriented reconstructions of the past, God is not the only demiurge, but it is also people and their words that can perform acts: 
Gdy Pan Bóg stworzył ziemię, była ona zupełnie przezroczysta i świeciła jak brylant, tyle jest $w$ niej drogich kamieni, złota $i$ srebra. Później dopiero stała się czarna $i$ nieprzezroczysta jak jest teraz, a to dlatego, bo ja przeklął Kain. Gdy Kain zabił Abla, chciał go ukryć w ziemi, lecz nie mógł tego dokazać, chociaż głęboka jamę wykopat, bo wszędzie i zawsze było widać ciało zabitego brata. Rozłoszczony Kain zawołał tedy: „Przeklęta ziemio, czemu nie jesteś czarną?" I ziemia stała się czarna, bo jest przeklęta (SimLud, 36).
When the Lord God created the earth, it was utterly transparent and shone like a diamond, as there were so many precious stones, gold, and silver in it. It was only later that the earth became black and opaque, as it is now, the reason being that Cain had cursed it. When Cain killed Abel, he tried to hide his body in the ground, but failed time after time 'because no matter how deep a hole he dug, Abel's corpse could be seen anyway. Cain angrily shouted: 'Cursed earth, why aren't you black?' And at this moment the earth turned black, as it was now cursed.

Time. Mythologically-reconstructed stories are placed in omnitemporality, which means that mythological events affect the shape and functioning of the present-day world. At its simplest, this is signalled by the formulaic temporal expression od tego czasu 'ever since that time', the implication being that the process of creating the world is dynamic and progressive in nature. As biblical chronology is violated or at least it is not closely followed, the sky can be created after man is formed, for example. What we have here is, in short, how people imagine the world being created, with God the Creator being given human characteristics, inclinations, and ways of doing things. In other words, mythologicallymotivated texts present an anthropocentric reconstruction of past events, the role of people being that of active co-authors, co-creators, or passive observers at least.

In mythologically-reconstructed stories, space is indeterminate, but it can be identified by three general areas or zones:

- the earth: Gdy Pan Jezus chodził po ziemi ('when the Lord Jesus walked on this earth');

- the heaven/the sky: Chodzit se Biedok po niebie ('the Poor One walked across the sky');

- some mythological space, neither earth nor heaven, some shared property of this world and an extra-terrestial one, where God and people can meet: Pan Bóg zawezwat do Siebie wszystkich kowali, ślusarzy i powiedział im, że potrzebuje takie wielgachane sklepienie niebieskie ('The Lord God summoned all the smiths, iron-workers, and told them that He needed a huge vault in the sky'). 
Mythological reconstructions are based on naïve, common-sense knowledge that comes from the observation of the world. In a way then, these texts provide an answer to the question why the world today looks the way it does. One part of this answer is God's deliberate activity, another part is people's assistant and participant observation (i.e. either as vicarious agents or a source of changes) and another still is the devil's influence as a driving force of changes.

Furthermore, as far as the origin/genesis myths and stories about the indeterminate remote past are concerned, texts of folklore aim at fostering the values that are of supreme importance for the social group that is a bearer of these values, one of them being Sunday as a holy day of worship:

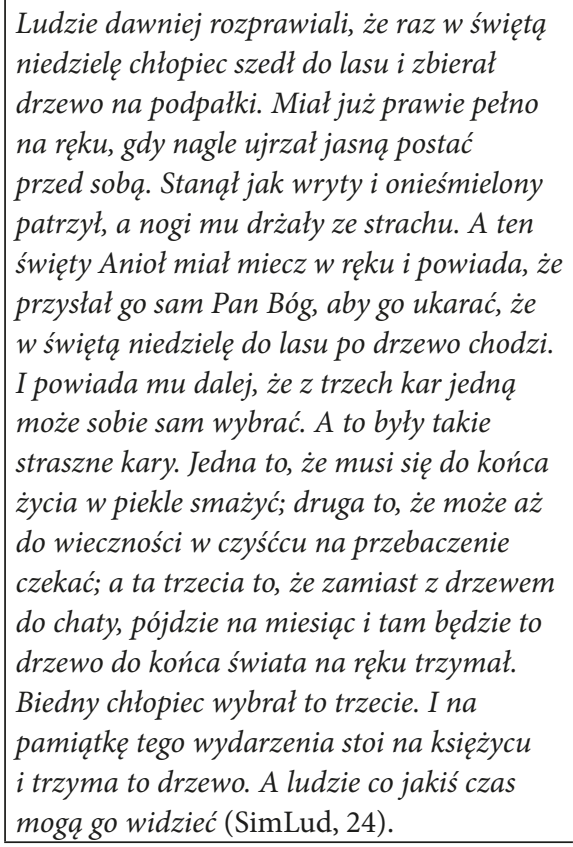

People used to tell a story about a boy who on a holy day went to the forest to pick wood chips for tinder. When he was just about had an armful of chips, he saw a bright figure. Taken aback, intimidated and shivering with terror, he saw a holy angel with a sword in his hand, saying that he had been sent by God himself to punish the boy for picking the firewood on a holy day. He also added that the boy could choose one of three punishments. One was that he would be burn in hell until the end of his life, another was that he could wait forever in purgatory for cleansing, and the third was that instead of bringing the wood chips home he had to hold them in his arms until the end of the world. The poor boy chose this third option. And as reminder of this event, he is there on the moon with the firewood in his arms. So people can see him from time to time.

In terms of genre distinctions, the mythologically-reconstructed stories firstly include folk legends, texts usually described as pertaining to Christian beliefs and Christianity-specific events. While this generalisation can be evidenced with the way the main protagonist is crafted, the other elements - the chronology of creating the world, the notion of a demiurge or ways of performing creation-related acts - cannot be said to be patterned on corresponding biblical accounts. 
Nevertheless, this mythological kind of past reconstruction can also be found in other aetiological text genres: animal-based fairy tales, belief reconstructions or urban legends. They all relate to the origin of the natural and non-natural worlds, the world of objects such as animals, plants, mountains, rivers, as well as various kinds of social anxiety disorders.

Although this mythological kind of reconstruction can generally be found in highly petrified texts, its stereotype-based variety is exemplified in fairy tales and anecdotes. In this latter case, what is depicted in texts concerns communicating stereotyped patterns of behaviour, folk images of social peace and order (good always wins, evil is always punished), an idea of animism, stereotyped characteristics of a typical peasant (cleverness and cunningness), as well as other professional and sex-related stereotypes. No wonder then, that mythological reconstruction is characteristic of archetypical genres, such as fairy tales, legends and anecdotes, which is where the object to be reconstructed belongs to unreal time or remote past.

In these texts, the agents or the doers, are chiefly physically-real figures who, with some help of magical creatures, fight various obstacles (real or unreal antagonists/adversaries). If these obstacles are put up by real characters, the agents would often try and overcome them, left to their own devises. In contrast to the prototypical version of mythological reconstructivism (see the paragraph above), the agent is not some holy or sacral figure, but people themselves. What triggers an event may be related to one's intention of setting the hero free, defeating the adversary, gaining something or mocking somebody. Most of the time, the agent is aware of his/her own acts but, as signalled above, there may as well be, in magical fairy tales that is, a fair amount of contribution from magical objects and figures. In other genres, where the agent is left exclusively to his/ her own devises, the means of performing acts include gestures and very rarely, words (e.g., when the agent attempts to cheat).

As can be noticed, the examined examples of the mythologically-reconstructed past show the characteristics which, in fact, are expected of myths. These texts narrate that which took place long ago, once or onego czasu 'one time', the time of the event being still or frozen, in the sense that it does not elapse. This is why there is no link or no correspondence between the mythological time and the time of the current events. Moreover, mythologically-reconstructed narratives depict a sacral reality which is qualitatively different from the reality of everyday hustle and bustle. Hence, what is communicated is models, patterns, and exemplars of all those rituals and pursuits which can only prove significant, such as labourand leisure-related activities. With that, mythologically-oriented texts exemplify a clear $a$-rational, if not just openly anti-rational bias - in terms of their intended impact upon the audience, they are meant to address readers/listeners' emotions 
and senses as well as their sense of judgement. Indeed, the world of mythological reconstruction is about assessing and evaluating people and objects, the framework for making judgements being based on two extremes, one of radical good and the other one of radical evil, with no room for anything (neutral, or indifferent) in-between. Anything and anybody we meet in mythological reconstruction can either be friendly or hostile (cf. Szacka 2006: 75).

\subsection{Belief-oriented reconstructivism}

This kind of reconstructivism can be found in texts depicting unbelievable elements, narrated, as if they were true, factual and of no Christian provenience, which as depicted, are a matter of belief. The category includes mainly tall (belief-related) tales (Pol. podania wierzeniowe) and urban legends. For example:

\begin{tabular}{|c|c|}
\hline $\begin{array}{l}\text { Starsi chtopaki i dziewczynki chodzili na } \\
\text { zabawy. To sobie też na zabawie dziouszki } \\
\text { znalazty dwóch takich fajnych chłopczyków. } \\
\text { To tym wszystkim tak się podobali i } \\
\text { wszystkie te dziouszki chciały tańczyć z } \\
\text { nimi. A dzioucha sobie tam przy tym żadna } \\
\text { nic nie myślała. Potem jeden chłopczyk } \\
\text { powiedziat, że ja pójdzie odprowadzić. A jak } \\
\text { już była jedenasta godzina, to już chciat } \\
\text { odchodzić. A ona padała: } \\
\text { - Ach! Być sam jeszcze! Taka fajna zabawa! } \\
\text { To on jeszcze, aże krótko byt, ale przed } \\
\text { dwunasta to już się patrzył wytracywać. [...] } \\
\text { I szła z nim. Ona rzadzi z nim, rzadzi, jak } \\
\text { już potem krótko jakoś było przed domem, } \\
\text { patrzy - chłopca nie ma. A on dycki do } \\
\text { dwunastej musiał być w domu. Utopce } \\
\text { zawsze wracały do dwunastej. Jak nie wrócit, } \\
\text { to dycki się zgubił, to już go potem nie było } \\
\text { (SimKum, 124). }\end{array}$ & $\begin{array}{l}\text { Older boys and girls would go to } \\
\text { parties. At one party two lads were so } \\
\text { exceptionally attractive that all the girls } \\
\text { wanted to dance with them, without } \\
\text { contemplating anything serious but the } \\
\text { dancing. One boy told one girl that he } \\
\text { might walk her home. As it was already } \\
11 \text { at night, he was ready to take her } \\
\text { home straightaway, but she wanted to } \\
\text { stay a bit longer, as the party was in full } \\
\text { swing. He agreed but insisted that he had } \\
\text { to leave before twelve. (...) So off they } \\
\text { went, talking and talking. As they were } \\
\text { approaching her place, she looked around } \\
\text { to see no boy at all. The thing is that he } \\
\text { had to be back at home before twelve. } \\
\text { The drowned people [Pol. utopce] would } \\
\text { always be back at home before midnight. } \\
\text { If they were not, they were doomed to lose } \\
\text { their way and they disappeared forever. }\end{array}$ \\
\hline
\end{tabular}

The object of reconstruction evolves around people meeting supernatural creatures and includes phenomena and events which go beyond rational thinking. 
There are two kinds of agents: humans and fantasy creatures, the latter being either anthropomorphised (a drowned person's daughters and sons) or animised (dog):

Jak żył mój ojciec, to były strachy. Płynęli raz barka do Rogowa. Tam jest zamek na górze. Była burza, błyskawice, grzmot, ćma, powietrze! Maszynista i ojciec zostawili barkę, a wracali do domu. Oni poszli pieszo brzegiem, nie szosa, a nad Odra. Przez cała drogę szly za nimi dwa psy, czarne, duże. Oni nie wiedzieli, co robić. Te psy wylazły nie wiadomo skąd. Oni się bali, nic do siebie nie gadali. Jak minęli cmentarz, to te psy znikły. To były złe duchy. Młodzi marynarze nie wierzyli w te opowiadania i śmiali się, ale ojciec mówili, że to prawda (SimKum, 146).
When my father was still alive, something terrifying happened. Once he we going by barge to Rogowo and a storm broke out, lightning, thunder, darkness! The driver and my father left the barge and headed for home, down by the Oder riverside, not down the road. The whole time they were followed by two big black dogs that appeared from God knows where. They did not know what to do and were so terrified that they did not exchange a word. Once they passed the graveyard, the dogs disappeared. They were evil spirits. Young sailors did not give a damn about the story and they just laughed at it, but my father used to say that it was all true.

The cause of a given event may neither be comprehensible nor explicable because the ultimate explanation of unusual phenomena is inherently bound with the nature of supernatural beings, inexplicable animal instincts or human envy:

Tę historię opowiedział mi wujek.

Dziewczyna wyszła ze znajomymi do kina. W czasie seansu poczuła lekkie ukłucie w ramie, ale zignorowała to. Gdy film się skończył $i$ włączono światła $i$ dziewczyna zainteresowała sie, co ja tak ukuło. Przyjrzała się siedzeniu i znalazła $w$ nim igłe, a do niej przyczepiona karteczke z napisem: właśnie zostałaś zarażona HIV-em. Dziewczyna uznała to za głupi dowcip i nie przejęła się tym zbytnio. Po jakimś czasie zaczęła ja jednak zadręczać myśl o tej igle i poszła zrobić testy na HIV. Wynik-zarażona. [INF 8]
This is a story that my uncle used to tell. Some girl went with her friends to the cinema and while watching the film, she felt a light prick in her arms. She did not pay any attention to it. When the film was over and lights came on, she was interested in what it was that gave her that little prick. She found a needle on her seat, with a little notice attached: 'You have just been infected with HIV. She considered it nothing but a silly joke. After some time, however, she decided to have HIV tests and the diagnosis was: HIV infection. 
What triggers the agent's activity is mainly to satisfy needs and desires:

Ten sam człowiek opowiadał mi taka historię, też tam z okolic rodzinnych spod Kraśnika, że była taka rodzina: mama, tata, dziecko. I oni mieszkali ze swoimi rodzicami, czyli z dziadkiem i babcia i mieli jakiś tam sad. I zbiory jabłek czy czegoś tam. I został sam dziadek z tym wnuczkiem i się nim opiekowat. I to wszystko, musiał wszystkiego doglądać, bo rodzice gdzieś tam wyjechali. A to dziecko było takie małe, nie wiem, czy chodziło. I on zostawit je w hamaku leżace. I... i poszedt gdzieś tam i ... A z obory wydostała się świnia, taki knur i zjadt to dziecko. No i zjadło to dziecko, on przyszedt i zobaczyt tylko jakieś tam rozszarpane kawałki jego ciała, jakaśs tam nóżę czy coś koło tego hamaka jakieś ubranko i się zorientowat, co jest grane, zobaczyl, że ta świnia tam ten. I się, nie wiem, czy się utopił, czy się powiesił $z$ rozpaczy. [INF 7]
The same man told me a story of one Kraśnik family. A mother, father, and child who lived together with the grandparents and they had an apple orchard, or something. Once, as the parents had to go away, the grandfather was left alone in order to take care of his grandson. The child was very little, I do not even know if he could already walk. So, the man left the child in a hammock, and started doing something else. At some point a pig broke out of the pigsty, a huge boar, actually, and ate the child. When the man returned, all that he could see were pieces of flesh everywhere, a piece of the child's leg here and there, some pieces of the child's clothes, so he knew what had happened. Actually, I do not know what he did, but he drowned himself, or hanged himself. In despair.

As to the way the agent performs his/her activity, most of the time specific agents are aware of what they are about to do, which makes their acts both deliberate and purposeful, as in the case of a drug addict that spreads the HIV infection to others. Even if acts are performed accidentally and unwittingly, the general reason why agents do what they do is the intention to disadvantage and handicap other people.

The time reference involves events which are either remote or current, both having to do with unusual and extraordinary phenomena, unknown to and unheard of in our everyday experience. No matter what an actual story narrates, what is at stake is always an attempt at explaining what otherwise appears to be random events or complex socio-psychological beliefs, such as diseases (HIV, AIDS), types of behaviour, attitudes etc. This stands for the mythological character of belief-oriented reconstructions except for the fact that it may well be placed in relatively recent times. 


\subsection{Apocryphal reconstructivism}

Apocryphal reconstructions feed on biblical stories, including mainly folk carols and legends, depicting the lives of Lord Jesus, the Mother of God, and saints and are set in the historical context of the birth of Christianity:

Text 4

Stała się nam nowina miła, Panna Maryja Syna powiła. Powiła go $z$ wielkim weselem, będzie on naszym Zbawicielem, Zbawicielem.

Król Herod się zafrasowat, dziatki wszystkie wycią́ kazał. Maryja się dowiedziała, do Egiptu uciekała, uciekała. I napadła chłopka w polu orzacy, swoja pszeniczkę ręką siejący. Siej, siej, chłopku, w imie moje, jutro będziesz zbierat swoje, zbierat swoje.

Nie powiadaj, chłopku, żem ja tędy szła, żem Pana Jezusa na ręku niosła, tylko powiedz, chtopku mity, żeś nie widział tu Maryji, ach, Maryji.

Żydowie się dowiedzieli, za Maryja pobieżeli,

Żydowie się dowiedzieli, za Maryją pobieżeli, pobieżeli.

I napadli chtopka w polu już żacy, swoja pszeniczkę $w$ snopy wiążacy. Szczęść ci Boże, chłopku mity, czyś nie widział tu Maryi, ach, Maryji?

$\mathrm{Oj}$, widziałem, ale łoni już Maryji nie dogoni, jeszcze się ta pszeniczka siała, jak Maryja tędy bieżata, ach, bieżata.
We have heard good tidings

That the Virgin Mary gave birth to her Son, Gave birth to Him with great joy, He will be our Saviour, our Saviour.

King Herod is troubled now, He has ordered all babies to be killed. When Mary learned about this, Off she fled to Egypt.

Where she saw a peasant ploughing his field And sowing wheat with his hands. Sow your wheat in my name And tomorrow you will get much in return.

But do not tell anybody that you have seen me

With the Lord Jesus in my arms.

Tell them only, dear friend, That you have not seen Mary.

Still, the Jews somehow found out And they started chasing Mary. Still, the Jews somehow found tout And they started chasing Mary.

When they saw the peasant ploughing his field

And bringing in sheaves of wheat:

God bless you, dear friend, Haven't you seen Mary?

Yes, I have, but you won't catch up with her As it was long ago, when I sowed my wheat, And Mary was passing by, passing by. The Jews balked at hearing that 


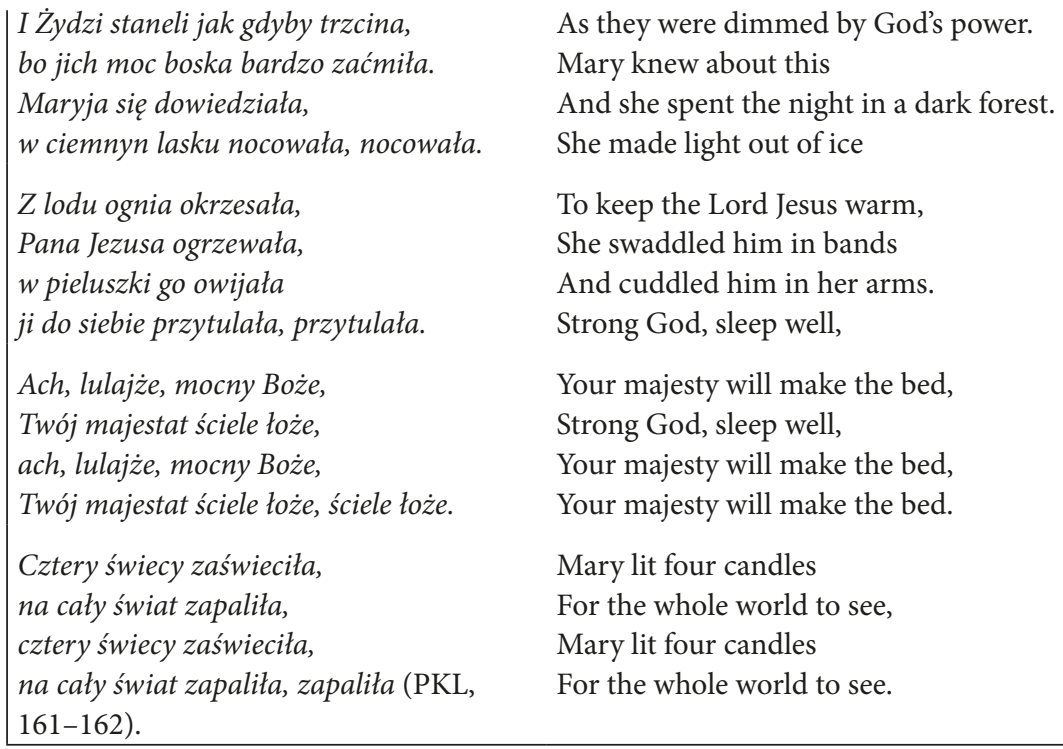

As they were dimmed by God's power.

Mary knew about this

And she spent the night in a dark forest.

She made light out of ice

To keep the Lord Jesus warm,

She swaddled him in bands

And cuddled him in her arms.

Strong God, sleep well,

Your majesty will make the bed,

Strong God, sleep well,

Your majesty will make the bed,

Your majesty will make the bed.

Mary lit four candles

For the whole world to see,

Mary lit four candles

For the whole world to see.

Object of reconstruction. The material reconstructed in apocryphal texts embraces biblical events and the origins of Christianity, the latter including the birth of Christ and his life on earth. These stories are apocryphal in the sense that they derive from and at the same time, complete corresponding biblical accounts with many details, such as additional activities, places and characters of non-biblical folk origin.

There are several types of agents that perform acts in apocryphal reconstructions. In Text 4, we have the following:

- God as an implied performer of miracles; although not a participant agent, God's presence can be deduced from the unusual circumstances of anything from the moment of Christ's birth until the flight to Egypt (e.g., the miraculously fast growth of wheat);

- a text-overt agent; mainly the Virgin Mary who features as a central figure of folk beliefs, the mother of Christ and in general, of people, the intercessor who legendarily intercedes on behalf of those that do not respect crops (e.g., wheat). In Text 4, Mother Mary awards the peasant for his loyalty which she does by means of a miracle, one that is supposed to save him from the consequences of his prospect lie;

- assistant agent: the peasant is an informer who lets the Jews know about Mary's flight. 
The cause of the event in Text 4 is the miraculous birth of Christ and the resulting persecution of Mary and Christ. Text 4 is a carol and like magical tales and legends, it is based on the good-evil opposition embracing people and their deeds. This dichotomy serves didactic and moralistic purposes by foregrounding the values and the motifs behind that which both sides, good and evil, do.

The overall purpose of activity in apocryphal reconstructions is concerned with protecting the little boy Jesus and the whole of mankind. This purpose can be examined in terms of several aspects:

- the human aspect: the purpose is short-term and focused on just one individual (Jesus);

- the transcendental aspect: the purpose is universal and timeless as long as the social group (Christians) it refers to exists: Naści, Jezu, kwiatki, boś ty moje Dzicie,/Już ty pójdziesz na śmierć straszna za niedługie życie.// A nam za to Pan Bóg da letkie skonanie,/A po śmierci żywot wieczny, w niebie królowanie ('These flowers are for you, Jesus, 'cause you're my child,/You will soon suffer painful death after a short life. // Instead God will make our death light,/And give us eternal life after we die').

On closer inspection of Text 4 , it appears that the way the agent (Mary) performs her activity is utterly purposeful because whatever she does is deliberately aimed at protecting the Lord Jesus against evil people and even his own prospective sins. This can be first seen in Mary's plea to the peasant: Siej, siej, chłopku, wimie moje,/Jutro będziesz zbierat swoje, zbierał swoje./Nie powiadaj, chłopku, żem ja tędy szła/Żem Pana Jezusa na ręku niosła,/Tylko powiedz, chłopku mity,/żeś nie widział tu Maryji, ach, Maryji ('Sow your wheat in my name/And tomorrow you will get much in return./But do not tell anybody that you have seen me/With the Lord Jesus in my arms./Tell them only, dear friend,/That you have not seen Mary'), and, later, in Mary's advice for Jesus to let people have at least as much grain as his hand can hold. Mary's way of doing things is not only words, but also performing miracles, as when the wheat produces crops overnight (her reward for the peasant).

As to the time of events, there seem to be two temporal dimensions, retrospective and prospective, the former having only an individual orientation and the latter having both individual and collective orientations:

$\mathrm{X}$ in the retrospective dimension of time of events, only the earliest stages of Christ's life on earth are reconstructed:

-annunciation: Przyliciału z nieba małe pachulatku,/przyliciału, uglundału, czy bedzie dzieciatku ('Some bairn came down from the sky,/To see if there's going to be a child'); 
-.birth: Stała się nam nowina miła,/Panna Maryja Syna powita ('We have heard good tidings/That the Virgin Mary gave birth to her Son');

-m flight to Egypt: Maryja się dowiedziała,/Do Egiptu uciekała, uciekała ('When Mary learned about this,/Off she fled to Egypt');

$\mathrm{x}$ in the prospective dimension, future developments are envisaged:

- in an individual orientation, the Lord Jesus's future is at stake: Naści, Jezu, kwiatki, boś ty moje Dziecie,/Już ty pójdziesz na śmierć straszna za niedtugie $\dot{z} y c i e$ ('These flowers are for you, Jesus, 'cause you're my child,/You will soon suffer painful death after a short life');

- in a collective orientation, the subsequent episodes from the life of Christ are narrated in order to anticipate the fate of the corresponding social group (Christians): Będzie on naszym Zbawicielem; a nam za to Pan Bóg da letkie skonanie,/A po śmierci żywot wieczny, w niebie królowanie ('Instead God will make our death light,/And give us eternal life after we die').

Space. Several specific kinds of places can be distinguished in apocryphal reconstructions:

XX heaven/sky from where good tidings (annunciation) are brought to Mother Mary: Przyliciału z nieba małe pachulatku,/przyliciału, uglundału, czy bedzie dzieciatku ('Some bairn came down from the sky,/To see if there's going to be a child');

xy earth;

XX some physically-real place which is indeterminate in its location:

-"green meadow, valley: $\mathrm{Na}$ zilonyj łacy, pszynicznyj dulinie ('On a green meadow, in a wheat valley');

-rfield: I napadła chłopka w polu orzacy ('where she saw a peasant ploughing his field');

-dark forest: $W$ ciemnym lasku nocowała, nocowała ('She spent the night in a dark forest');

XX indeterminate place: Egypt, which relates the event depicted in the text to a corresponding biblical space: Do Egiptu uciekała, uciekała ('Off she fled to Egypt');

XX the whole world: Cztery świecy zaświeciła,/Na cały świat zapaliła ('She lit four candles/For the whole world to see').

Considered jointly, all these places mark the spatial dissemination of the Good News which legitimises the existence and functioning of that social group which 
assumes and cherishes Christian values. This transmission of the Good News in space, ranges from heaven/sky (the very source of it) through to the earth (depicted symbolically in terms of a green meadow or a grazing pasture, as a token of life or alternatively, in terms of a dark forest as a token of death) to the whole world. This is supposed to be the scope of Christ's activity as well as the influence of Christian values. As the spatial extent of the reconstructed Good News stories is all-embracing, apocryphal reconstructions (legends and carols) go beyond the individual dimension to embrace the whole of the world and all the people and therefore become universal.

\subsection{Historical reconstructivism}

The historical dimension of reconstructivism pertains to real past events, historically-attested ones included.

The object of historical reconstructivism is the origin of towns, villages, rivers, lakes, mountains, and other inanimate natural objects and their names, which make the stories aetiological:

Książę Świętopełk jechał raz z Chełmna do
swego grodu w Sartowicach. Była ciemna
noc i dął silny wiatr. Przy ujściu Czarnej
Wody do Wisty prąd przewrócił łódkę i
kilku rycerzy utonęło. Sam książę był też w
niebezpieczeństwie, ale uratowało go światło,
które zabłysło w chatce nad brzegiem.
Rycerze bowiem w świetle tym zobaczyli
księcia walczacego ze wzburzonymi falami i
uratowali go. Na pamiątkę tego wydarzenia
zbudował książé Świętopełk nad ujściem
Czarnej Wody do Wisły gród i miasto,
nakazując, aby na wieży grodu palił się
dniem i noca ogień. Od światła, które
uratowało księcia nazwano tu powstałe
miasto Świeciem, a w miejscu chatki
wybudowano kościół (SimLud, 126).

Książę Świętopełk jechał raz z Chełmna do swego grodu w Sartowicach. Byla ciemna noc i dą silny wiatr. Przy ujściu Czarnej Wody do Wisty prąd przewrócit łódkę kilku rycerzy utonęło. Sam książę był też w które zabłysło $w$ chatce nad brzegiem. Rycerze bowiem $w$ świetle tym zobaczyli księcia walczacego ze wzburzonymi falami i uratowali go. Na pamiątę tego wydarzenia zbudował ksiaże Świętopetk nad ujściem Czarnej Wody do Wisty gród i miasto, nakazując, aby na wieży grodu palit sie uratowało księcia nazwano tu powstałe miasto Świeciem, a w miejscu chatki wybudowano kościół (SimLud, 126).
Prince Swiętopełk was once on his way from Chełmno to his castle in Sartowice. It was dark and windy. At the Czarna Woda [Black Water] opening to the Vistula, the current capsized the boat and several knights drowned. The prince himself was also in jeopardy, but what saved him was a light that flashed from a hut on the bank of the river. It was in this light that the knights saw their prince struggling with the billows and rushed to save him. As a reminder of this event, Prince Świętopełk had the castle and the town built at the Czarna Woda mouth of the Vistula, ordering that the light in the tower should be kept burning at all times. So, the town was named after this light which saved the prince's life - Świecie [app. 'light', rel. to świecić 'to shine' and świeca 'a candle']. In addition, a church was erected in the place where the hut was. 
In historically-driven reconstructions, the agent is some historical figure:

Niedaleko miejscowości Bardo Śląkie opowiadano, że za bardzo dawnych czasów panował tam król Bolesław Chrobry. W okolicy rosty wielkie i gęste lasy, w których pracowali biedni drwale. Jeden $z$ nich miat bardzo liczna rodzinę, bo aż dwanaścioro dzieci. [...] Sam król trzymał dziecko biednego drwala do chrztu. Przewielebny ponoć zapytał: „Kogo mam napisać jako ojca chrzestnego?” A rycerz odpowiedziat: „Króla Bolesława Chrobrego!" I od tamtego zdarzenia wieś, w której drwal żyt i mieszkat, nosi nazwę Chrobrówka (SimLud, 128).

\begin{abstract}
Not far from Bardo slaskie, it was said that Boleslaw the brave had ruled there for too long. Large, dense forests were growing in this area, where poor woodcutters worked. One of these woodcutters had a large family, as many as twelve children. The king himself dragged one of the poor children to baptism. And he asked 'who should I put down as the godfather?' And a knight answered 'King Boleslaw the brave!' And from that time onwards, the village where the woodcutter lived bears the name Chrobowka. (I lost the text in this section and had to re-translate it!)
\end{abstract}

However, the set of historical figures that can be found in reconstructions is relatively small. Most of the time, it includes the following:

.- King Bolesław Chrobry: rycerz na białym koniu. [...] A ten rycerz to byt sam król Bolesław Chrobry ze swoimi rycerzami, który polowat w tym lesie (SimLud, 127; 'A knight on a white horse. (...) And this knight was King Bolesław Chrobry himself who went hunting with his knights in this forest'),

-. King Władysław Łokietek: Król Łokietek na podziękowanie Bogu za swoje zwycięztwa postanowit ufundować piękny kościół w Wiślicy (SimLud, 132; 'As an expression of his gratitude to God for all his victories, King Łokietek founded a beautiful church in Wiślica').

-" King Henryk Brodaty (Saint Jadwiga Śląska’s husband): Podług tradycyi miat on kiedyś na polowaniu zagrząść koniem w źródlisku tu się znajdującym, a nie mając z nikąd pomocy, uczynit ślub, że jeśli się wyratuje, kościół w tym miejscu wystawi (SimLud, 129; 'According to tradition, while hunting, he once got stuck with his horse in some marshes, and having no one to help him, he made a vow that if saved, he would have a church erected in that place').

-. King Kazimierz Wielki: król polski imieniem Kazimierz rad w nich począ, spostrzegt lepiankę. W niej zastat matkę, która świeżo bliźnięta na świat wydała. Ten dobry monarcha trzymat je do chrztu. Jedno z nich nazwat on War, czyli Wara, drugie Sawa. Nie szczędził swych łask dla biednej rodziny $i$ ta szczodrobliwościa jego wkrótce dla siebie wygodniejsze mieszkanie wzniosła. (SimLud, 128; 'The Polish king Kazimierz once wanted to have a rest, and he 
spotted a mud hut. And in that hut there was a mother who had just given birth to twins. The good monarch was their godfather. He named one twin War, that is Wara, and the other one Sawa. As he was very generous to the poor family, they could soon afford a much better dwelling for themselves').

King Kazimierz Wielki also appears in historical songs:

Za króla Kazimierza to byly dobre lata, un nikogo nie krzywdził, a miał chłopa za brata.

Lud go kochał goraco i wysoko go sławit,

Zastat Polskã drewniane, a murowanu zostawiut (BartLub, III, 403).
These were good times when King

Kazimierz was around,

All people being equal, peasants were his brothers-in-arms.

The people loved him, had no reason to moan,

He found Poland hewed of wood, but he left it built of stone.

In historical songs, the hero is typically more concrete and more elaborately depicted, partly because these songs refer to well-known texts of culture. For example, the text of culture in the above quotation is the well-established traditional saying about King Kazimierz Wielki, which in its standard version reads as follows: Zastał Polske drewniana, a zostawił murowana ('He found Poland hewed of wood, but he left it built of stone').

-. Jan III Sobieski:

Wtem to widzi król Sobieski, do kościoła bieży,

upad przed Najświętszo Panno, upad, krzyżem leży.

Wtem ustyszy głos z obraza: Powstań na kolana,

A i[dź] sługo mój najmilszy, na Turka pogana!

(BartLub, III, 404).
King Sobieski saw that and he rushed to the church

To prostrate himself in front of the Virgin Mary.

Then he heard the picture say: Arise, on your knees,

And go, my dearest servant, to fight the heathen Turks.

The figure of the king is here portrayed in terms of a chosen hero, designated and supported by the Virgin Mary herself.

As can be seen in historical reconstructions, the agents are mainly recruited from princes and kings of the Piast dynasty, which takes us back to the origins of the Polish statehood. These figures are in no way insignificantly depicted. Namely, that 
they are presented as human types, rather than psychologically-real individuals and their deeds are types of acts (e.g., being a godfather, or losing one's way in the mountains/forests), rather than spontaneous activities and seem to suggest that what collective memory feeds on and makes use of is not specifically people, but (mainly) positively-assessed images and characteristics typically associated with people.

Three categories of causes of events can be distinguished, that is reasons why a given event takes place, in historical reconstructions:

- because a member of a given community is in need of someone to act on his/ her behalf, or for his/her benefit (e.g., the logger needs a godfather for his children);

- because a given historical figure (e.g., a prince or a king) is in danger;

- because a given community as a whole is in need of action, as when people are exploited by their master/landlord: Dlugo cierpiał biedny lud to znęcanie się i łakomstwo swego pana, iż toż niemogac dłużej wytrzymać, starsi uradzili zrobić czerniawę (SimLud, 128; Simple people had suffered for so long because of their landlord's greed and abuse that the elders decided to rebel in the end').

The purpose of activity in historical reconstructions is concerned with showing/ expressing one's gratitude: $Z$ wdzięczności król wybudowat im klasztor, aby nie musieli spać na ziemi, a miejsce, w którym wybudował klasztor, nazwał od wołania pustelników Wigry (SimLud, 131; 'As a token of his gratitude, the king ordered a monastery to be built for the monks not to sleep on the ground any more and he named this place Wigry, after the hermits' way of calling'). As a result of what a historical figure does, towns, villages and castles etc. come into being, their names being both reminders and memory carriers of the corresponding historical events: I tak się cieszyli, tak się cieszyli [trzej bracia], że z tej radości postanowili w tym miejscu zbudować miasto, któremu nadali nazwę Cieszyn. W mieście jest baszta $i$ studnia Trzech Braci, to na te pamiatke (SimLud, 127; 'And these three brothers were so happy that out of that joy they decided to build a town which they named Cieszyn [rel. to cieszyć się 'to be happy']. There is a tower and a well named after the three brothers in the town and this is to make people remember').

As the agent is a historical figure, the way he/she acts is deliberate and purposeful, though not quite premeditated or planned. The agent's way of doing things can best be seen as a response to current events or as a way of helping/ supporting subordinates who, in turn immortalise the agent in their stories (of the belief kind of recontructivism) which they pass on to next generation.

This brings us to a specific kind of reconstructivim - the mythologicalhistorical one - which is exemplified below with a historical song about one of the January (1863) Uprising heroes - Kazimierz Bogdanowicz (Text 5): 
Text 5

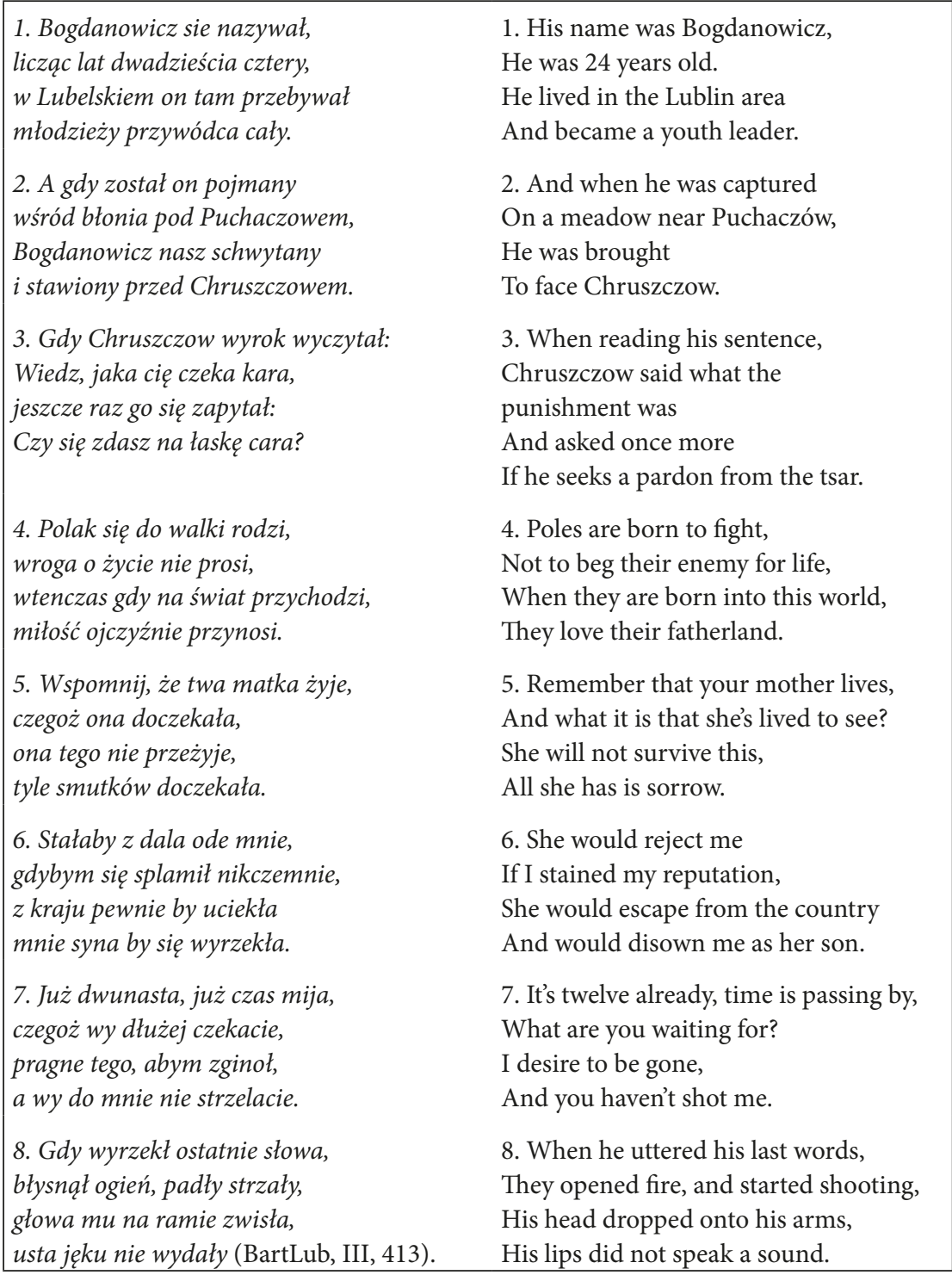

In Text 5, the object to be reconstructed involves the historical events of March 6,1863 , focusing on one of the heroes of the Polish January Uprising, Kazimierz Bogdanowicz, commander of a group of insurgents, caught, sentenced, and 
executed by Russians (for more, see Śladkowski 1993: 32-39). Text 5 is representative of the mythological-historical kind of reconstructivism in that it shows historical events through one participant's individual story. The way Text 5 recollects it from the reservoir of collective memory and narrates it, is just one single example. Yet, this example is so representative that, factually, it comes to function as a symbol of the whole event (The January Uprising), making it mythological in import.

Kazimierz Bogdanowicz is naturally, both the agent and the protagonist of the reconstruction. If we employ a faceted analysis to this text, we arrive at the following structure:

Age - lat dwadzieścia parę ('twenty four years of age'),

Place of living $-w$ Lubelskiem on tam przebywat ('in the Lublin area'),

Place of seizure - pod Puchaczowem ('near Puchaczów'),

Social position - młodzieży przywódca cały ('a youth leader'),

Values ascribed -

Polak się do walki rodzi,

wroga o życie nie prosi,

wtenczas gdy na świat przychodzi,

miłość ojczyźnie przynosi.

('Poles are born to fight,/Not to beg their enemy for life,/When they are born into

this world,/They love their fatherland'),

Death - death penalty by firing squad.

If we now put the respective facets together, we see a young hero-fighter struggling for freedom, dignity and Polish self-respect. The reconstructed Bogdanowicz is then, a patriot who will never surrender to the tsar in order to save his own life. As previously reiterated, collective memory is highly selective and Text 5 is yet another piece of evidence of that: it narrates only a small part of the protagonist's life, without any mention of his whereabouts before the Uprising. What comes to the fore instead is his young age, which builds up the tension and fuels the drama of the story, his social position (a leader) and the value that he is said to have cherished, love of his country. In short, it is plausible to generalise that Text 5 depicts a Polish patriot's attitude towards death and presents the young hero as a symbol of the fight for civil values.

However, apart from Bogdanowicz himself, the other protagonist or possible heroine of the story, seems to be his mother. She is mentioned in the context of Chruszczow's weakening of her son's resistance and the breaking of his determination. The way Bogdanowicz depicts her is reminiscent of an image of the Polish Mother (Pol. Matka Polka) - the most important value for her is her son's 
loyalty towards his fatherland and honour. Indeed, he chooses to lose his life rather than besmear his reputation by asking for a pardon from the tsar.

The cause of the event described in Text 5 is closely related to the category of time. The historical time of the story is the January Uprising of 1863 and this is marked with the names of the historical figures (Bogdanowicz, Chruszczow), whereas biological time is signalled with the main protagonist's age (24). In addition to these two, there is yet another temporal dimension which, in fact, is more of a point of reference or a transition point marking the passing from life to death. This is symbolised in the story, as much as in the whole of Polish folk culture, with the numbers 9 or 12, each being a multiple of the prime number 3 understood and conceptualised as fullness, completeness and finiteness.

The purpose of the agent activity is stated by the agent himself: Polak sie do walki rodzi,/wroga o życie nie prosi,/wtenczas gdy na świat przychodzi,/miłość ojczyźnie przynosi ('Poles are born to fight,/Not to beg their enemy for life,/When they are born into this world,/They love their fatherland').

The way the agent performs his deeds is determined by the values he shares: patriotism, honour and pride. As these are goal-oriented values, so are his acts: purposeful and deliberate. In his rejection of begging for a pardon from the tsar, or giving his life for cherished values, Bogdanowicz is fully aware of what he is doing.

In general terms, Text 5 is an example of a reconstruction where history meets memory, or external (great, global) history is seen from the perspective of internal (small, local) history. In this sense, an individual's life symbolises the dramatic history of the whole nation/country. Yet, this individual story itself is subject of symbolisation, in effect, a historical song, Text 5 does not depict the January Uprising at all, which is why there are no objective referents, such as dates, numbers, or institutions. The January Uprising is shown through the main protagonist's fate and the corresponding symbolic representations.

In other words, collective memory focuses on values not facts, with the latter merely serving to support, foster, and facilitate memory but not the reason why a text is handed down from generation to generation. The facts that play a background role in collective memory can be evidenced with the following observations: the space of events is very general and thus vague (the Lublin area, or the Lublin voivodship/province) and there is no specific data (dates and places of Bogdanowicz-led battles/skirmishes, the number and identification of his troops etc.). The impression is that the hero himself is somewhat isolated or even separated, in the sense that his activity is not shown to have anything to do with that of any other leader or to be part of some all-embracing structure. Moreover, this isolation is not only spatial, but temporal: we are told nothing 
about Bogdanowicz before the critical year of 1863 , as if his earlier life was of no importance. Most of all, we get to know about him from one single event, which is a key moment in the history of the social group he belongs to and it is this group that stores and narrates the selected space of his life (imprisonment and sentence to death). Surprisingly enough, the only socially- and physically-real reference with regard to Bogdanowicz, or rather, the attitude Bogdanowicz stands for, is his adversary Chruszczow. Through his manipulation of Bogdanowicz, Chruszczow serves to reveal the insurgent's system of values and beliefs. In fact, were it not for Chruszczow's prompting and intimidation of Bogdanowicz, we would have no grounds to perceive the latter as a Polish patriot.

The core of collective memory is constituted by elements that can be found in different variants of the song. In other words, despite differences, respective variants include or share the same elements and it is these shared elements that are the core of what is communicated/narrated. The elements that do not belong to this core, are variant-specific and can be described as implants supplementing 'memory losses', making up for what has elapsed from collective memory, or, as Kazimierz Moszyński would say, has been catapulted from it (cf. Moszyński 1939: 1362). In Text 5, the stable core includes the following: Bogdanowicz' seizure, his exchange with Chruszczow, and his death by firing squad. These three prove to be indispensable to the depiction of the insurgent's heroic and martyr-like demeanour.

As a historical song, Text 5 does not provide information about the fate of the Polish insurgents of 1863 , but it shows the Uprising as typified by one who is himself depicted as a symbol of certain values and attitudes. Both the typification of the Uprising and the depiction of Bogdanowicz are selective - though based on historical facts and they are supplemented with a number of symbolic inferences (the time of Bogdanowicz' death, the image of his mother, values). Why should the song about Bogdanowicz (Text 5) be focused on these elements, and not others? Why does it reconstruct his story the way it does, and not in any other way? The answer comes from the fact that like any other story of this kind, this song is a group-specific reconstruction, the group being the depositary of their memory and values. More specifically, the bearer of the Bogdanowicz's collective memory is a society that needs symbols and exemplars in order to legitimise the claim that the January Uprising of 1863 made sense; that freedom and dignity should go beyond living in bondage and disgrace at any cost, as values that are worth living and dying for. However in Text 5, the selected, mythologised model of demeanour is not chosen by accident or at random. As exemplars to be followed, local figures are singled out, known to the group. They are not symbols imposed by authorities, or forced from outside of the group. They are people that anyone in the group can easily identify with and follow. As Wiesław Śladkowski 
writes, Bogdanowicz 'didn't continue his fight for too long, did not gain any significant victories, but his bravery and stouthearted courage while both being interrogated and facing death made a great impression on society' (Śladkowski 1993: 39). This picture of the past stems then from the need to rationalise the Uprising and death, as well as satisfy the need to symbolise and interpret historical events. Instead of factual details, Text 5 offers a folk interpretation of historical events and figures (e.g., Chruszczow). Only those figures that communicate values (the mother) and their counter-values (Chruszczow) appear owing to our understanding of what the main protagonist's position is, what he stands for and fights for. Bogdanowicz is an insurgent-idealist exemplifying idealism as the only way of attaining freedom and independence. Although the January Uprising of 1863 was crushed and Bogdanowicz' death proved to be nothing but premature, the song seems to argue that society needs to follow noble exemplars, and focus on the positive, not the negative.

Generally speaking, the historical song about Kazimierz Bogdanowicz is a model of culture and the value system of a social group. This text reflects the mindset, the worldview, and the needs of a social group, whose collective memory the song is a part of. Yet, the robustness of the Bogdanowicz song depends on what the actual set of social values includes at any given point in time, which is to say that the song is doomed to change proportionately to the changes in the worldview and/or in how the Uprising is actually interpreted and rationalised.

\subsection{Family-personal reconstructivism}

This kind of reconstructivism can be found in recollection-like stories, as in the text below:

Text 6

Jak my za Niemca chodzili do szkoły, to nos rechtór zawsze trzcina bił, a walit tak, że my casem chodzić nie mogli, a ryncyska my mieli spuchnięte jak banie. uOjciec nasz, jak to ujrzeli, to poszli do rechtora $i$ tak sie na niego ciepali, że tyn ich podoł do sądu, że sie na rechtora dali. No i byt potym sad. uOjciec sie nie wystraszyli, ino pokozali nasze ryncyska, pedzieli, że nie maja z nos $w$ doma zodnyj pomocy, bo nic $w$ gospodarstwie $z$ takimi rękoma nie umiemy robić, no $i$ opowiedzieli, jak to zawsze
Under the German yoke, the rector [teacher] at school used to whip us so much that at times we just couldn't make it to school and our hands were all swollen like a balloon. Once when our father saw them, he went to see the rector and gave him a piece of his mind, so the rector sued him in court. Our father was not scared at all and simply let the court see our hands and said that because of the swollen hands we were of no use in the household. He also added that the 
rechtór polskie dzieci bije, jak nos zmuszo
do niemieckiej modlitwy i tak to wszystko
dokumentnie wyłożyli, że sprawa w sądzie
wygrali. No i dobrze. Ale teraz w szkole to
sie dopiero zacło. Myślicie, że nos tyn rechtór
ucył? Ani nos nigdy, a było nos pięcioro, bo
to trzech nos chopcysków i dwie siostry, no
to ưon nos nigdy ani nie pytoł, ani naszych
heftów nie uxoglądoł, ani na nasza strona
nie patrzył, no, po prostu widać było, że
chcioł z nos zrobić úosłów i może do betlejki
postawić! Ino roz nie wytrzymoł i pedzioł:

- Ihr verfluchten Polackenl - ale zaroz sie w język ugryzł. Widać jednak było, że mu na wątrobie leżymy.

No, jak powstania wybuchly, to my z bratem zaroz poszli bić się uo Polska, a po drodze spotkali my tego rechtora. Mogliście widzieć wtedy ta nasza godka na uocy! uOn spojrzol, my spojrzeli $i$ wszystko my se pedzieli. Potym w czasie walki przyprowadzili go powstańcy do Olesna. Jo ino na niego spojrzot, a kole niego sie kałuża wody zrobiła! Alech mu pedziol:

- Uciekaj, bracie, w pokoju, bo Polocy nigdy swych rechtorów niy zabijają, nawet jeśli te rechtory sa Niemcami i bija polskie dzieci! (SimKum, 155). rector always beat the Polish children and forced them to say German prayers. He presented the case nicely and won it. Good for us. But that was not the end of the story. If you think that this rector carried on teaching us, you are wrong. Never!... and there were five of us, three boys and two sisters. He would never ask us any questions, inspect our exercise books or even look at us. It was clear that he wanted us to become dumb as a bag of rocks. Only once did he get carried away:

- You fucking Polacks! But he immediately bit his tongue. Still, it was clear that for him we were a pain in the neck.

When the uprising broke out, my brother and I went to fight for Poland, and we met this rector on our way. (...) We looked at him, he looked at us, and we all went our separate ways. Later on, during the combat, the insurgents brought him to Olesno. I took a good look into his eyes and there was a puddle of water around him. All I said was this:

- Run for your life in peace, brother, because Poles never kill their rectors even if those rectors are Germans and beat Polish kids!

The object of reconstruction involves selected events from the narrator's childhood or youth, set against historical events that prove to be significant and relevant for his family, region or the whole country. However it is related to global/ national history, the story recollects either isolated events or sequences of events, each worth remembering for some local or individual reason. In Text 6 , the recalled events relate to a German teacher and are set in the context of the 
struggle for Upper Silesia as a part of Poland.

The set of agents in family-personal reconstructivism firstly includes the narrators themselves and their families. In Text 6 specifically, the narrator is depicted at two different points in time: first as a pupil persecuted by a German teacher displaying anti-Polish sentiment and then as a forgiving youth of class and dignity. It is the narrator himself that creates his own image and part of his self-creation as the hero of the story is his adversary - a spiteful and malicious German teacher. This opposition is accompanied by several more aspects: pupil-teacher, child-adult, Polish-German. In each of these oppositions we have stereotypical pictures, the narrator-related counterparts being highly idealised and the teacher-related ones being heavily downgraded. There seem to be two causes as to why events are recollected in Text 6, one being historical and the other personal. The two overlap to some extent as well as project out from each other. History has brought the pupil into confrontation with his teacher, yet the pupil seems to have broken away from history, so the moral of the story is that we are not doomed to be passive with regard to history but, instead, we need take full responsibility for our attitude even in relation to our enemies.

The purpose of the narrator's activity is not to take revenge on a German teacher for his having maltreated Polish children, but to highlight the assumed moral superiority of Poles over their persecutors. The narrator calls his enemy a brother and lets him leave in peace.

The way the agent acts in Text 6 is purposeful and deliberate and it may be argued, stems from a system of values which prove important for Polish people. The agent performs his acts both verbally (Uciekaj, bracie, w pokoju, bo Polocy nigdy swych rechtorów niy zabijaja, nawet jeśli te rechtory sq Niemcami i bija polskie dziecil; 'Run for your life in peace brother, because Poles never kill their rectors even if these rectors are Germans and beat Polish kids!') and behaviourally (that is, when he lets his personal and national enemy go). By what he says and what he does, he not only presents his national identity, but also his moral identity or superiority over his would-be lasher.

\subsection{Ritual reconstructivism}

As the name suggests, the object of ritual reconstructivism is a ritual, custom, or rite, as a whole or in its selected parts. In this case, textual reconstructions cannot be regarded as a source of reliable information on that which is narrated (e.g., rites of passage), but serves as a kind of coverage which, among other things, includes one's description of a ritual. In view of this, Edmund Leach' observation 
is espoused, that language is used to segment our visual continuum into meaningful objects and distinguishable socially-significant actors (cf. Leach 2010: 45). This is why ritual reconstructions, no matter what textual genres they actually exemplify, allow us to answer a question about the subjective characteristics of states, actions and actors that can be distinguished in the structure of a given ritual.

Canonical examples of ritual-related reconstructions include songs dedicated to either annual or interim rites. The following song exemplifies the former, one Easter custom being its focus:

Text 7

My z gaikiem wstęujemy
Józefa Kuta: Zaroz w pirsze dni po
wielkanocy chodzu dziewcynki dwie cy
trzy, z gajikam. Gajik - gałųzka z jedliny
uciänto, täm jest brano w stųzki w te
papirowe, ji uobrazek tam jest w środku ji
śpiwaju. Gajcorki żeby nazywaju.

1. My z gajikäm wstampujemy, sceścia, zdrowia wom zycämy. Gajiku zieluny, piänknieś ustrojuny, piänknie sobie chodzis, bo ci żeby tak godzi

2. My z gajikäm do gospodorza, żeby sie rodzity te wszelakie zboza. Gajiku zieluny, piänknieś ustrojuny, piänknie sobie chodzis, bo ci siä tak godzi.

3. My z gajikäm do gospodyni, zeby krowy same z pola przychodzity. Gajiku zieluny, piänknieś ustrojuny, piänknie sobie chodzis, bo ci siä tak godzi.

\section{A dajcieze num, dajcie cału kiełbasä,} niech jo se gajicek trzy razy uopasä. Gajiku zieluny, piänknieś ustrojuny, piänknie sobie chodzis, bo ci siä tak godzi.
Here we are, with our Easter Palm Józefa Kuta: Just after Easter, two or three girls went around the neighbourhood [from door to door] with the Easter Palm [Pol. gaik, rel. to gaj 'grove']. The Easter Palm is a fir branch decorated with crepe paper ribbons and a holy picture, placed on it. The girls, called gajcorki, sang this:

1. Here we are, with our Easter Palm, We wish you happiness and good health. Easter Palm, you are beautifully decorated Going around 'cause that's the proper thing to do.

2. Here we are, with our Easter Palm, Wishing the landlord abundant crops. Easter Palm, you are beautifully decorated Going around 'cause that's the proper thing to do.

3. Here we are, with our Easter Palm, Wishing the landlady her cows could come home by themselves.

Easter Palm, you are beautifully decorated Going around 'cause that's the proper thing to do.

4. Give us a whole sausage long enough For the Palm to be wrapped in it three times. Easter Palm, you are beautifully decorated Going around 'cause that's the proper thing to do. 


\begin{tabular}{|ll|} 
5. A dojcie num, dojcie chleba zolejäm, & 5. Give us bread with oil \\
zeby was synecek nie był złodziejäm. & Then your son won't become a thief. \\
Gajiku zieluny, piänknieś ustrojuny, & Easter Palm, you are beautifully decorated \\
piänknie sobie chodzis, bo ci siä tak godzi. & $\begin{array}{l}\text { Going around 'cause that's the proper thing } \\
\text { to do. }\end{array}$ \\
6. A dojcie num, dojcie kawołek placka, & 6. Give us a piece of cake \\
to wum narajamy zieńcia Jacka. & Then we will make Jacek be your \\
Gajiku zieluny, piänknieś ustrojuny, & son-in-law. \\
piänknie sobie chodzis, bo ci siä tak godzi. & Easter Palm, you are beautifully decorated \\
& Going around 'cause that's the proper thing \\
& to do. \\
7. Za kolända dziänkujämy, & 7. We thank your for your gifts [Pol. kolęda \\
Scäścia, zdrowia wom zycämy! & 'carol'] \\
Gajiku zieluny, piänknieś ustrojuny, & And wish you happiness and good health. \\
piänknie sobie chodzis, bo ci siä tak godzi & Easter Palm, you are beautifully decorated \\
(BartLub, I, 423). & Going around 'cause that's the proper thing \\
& to do. \\
\hline
\end{tabular}

On closer inspection, this song is motivated by one of the annually-celebrated Easter customs, which is why - to adopt J. Bartmiński's ideas - it reflects the structure of the ritual called chodzenie z gaikiem (lit. 'going round with the Easter Palm'):

F - welcoming (a formulaic expression)

A - introducing oneself

G - admiring the Easter Palm (what it looks like)

$\mathrm{M}$ - praising the hosts for their (1) affluence/prosperity, (2) diligence, (3) hospitality, (4) son's/daughter's beauty/looks

$\mathrm{P}$ - asking for a gift/donation: (1) degusik/dyngus (anything to avoid being drenched in water for fun), (2) jaja 'eggs', (3) słoninę/kiełbasę/kurę 'lard/ sausage/hen', (4) ciasteczko/bułeczkę/precelek/placek 'cookie/roll/pretzel/ cake', (5) kaszę 'groats', (6) ser/masło 'cottage cheese/butter', (7) chleb ( $z$ olejem) 'bread (with oil)', (8) piwo/gorzatka 'beer/booze', (9) dukaty 'coins (money)', (10) złotych jedenaście 'lit. 11 zloty'.

$\mathrm{Pd}$ - thanks for the gifts.

$\dot{\mathrm{Z}}$ - wishes of: (1) God's blessings, (2) happiness and good/great health (at New year)/a happy new year/wszelkiego dobra 'everything good'/długiego życia 'long life' (3) abundance, (4) eternal life in heaven, (5) prosperity, (6) numerous progeny. 
The same ritual-based reconstructivism can be found in the following wedding (farewell) song which is meant to be performed at the bride's departure from her family home:

1. Oj, siadaj, siadaj, kochanie moje, nic nie pomoże plakanie twoje. Nic tobie płacz nie pomoże, bo już konie stoja $w$ wozie pozakładane.

2. Oj, jak ja będe z wami siadała, jeszcze ja mamie nie dziękowała. Dziękuje ci, moja matko, żeś mnie wychowała gładko, teraz nie będziesz.

3. Oj, siadaj, siadaj, moje kochanie, nic nie pomoże twoje płakanie.

Nic tobie placz nie pomoże, bo koniki stoja w wozie pozakładane.

4. Oj, jak ja będe z wami siadała, jeszcze ja ojcu nie dziękowała.

Dziękuje ci, mity ojcze, żem chodziła u was $w$ złocie, teraz nie będe.

5. Oj, siadaj, siadaj, kochanie moje, nic nie pomoże plakanie twoje. Nic tobie płacz nie pomoże, Już koniki stoja $w$ wozie pozaprzegane

6. Oj, jak ja będe $z$ wami siadała, jeszcze ja braciom nie dziękowała. Dziękuje wam, mity bracia, Byście wy dla mnie kacia teraz nie będziesz.

7. Oj, siadaj, siadaj, kochanie moje, nic nie pomoże plakanie twoje.

Nic tobie płacz nie pomoże, już koniki stoja $w$ wozie pozakładane.
1. Sit down, my love, sit down, No point in crying tears. Tears cannot help now As the horse-driven cart is waiting outside.

2. Yes, I'm sitting down by you, But just let me thank my Mum. Thank you, Mum, That I'm brought up well, now no longer

3. Sit down, my love, sit down, No point in crying tears. Tears cannot help now As the horse-driven cart is waiting outside.

4. Yes, I'm sitting down by you, But must thank my Dad first. Thank you, my Dad, That I could walk on gold, now no longer.

5. Sit down, my love, sit down, No point in crying tears. Tears cannot help now As the horse-driven cart is waiting outside.

6. Yes, I'm sitting down by you, But must thank my brothers first. Thank you, my dear brothers, (...)

7. Sit down, my love, sit down, No point in crying tears. Tears cannot help now As the horse-driven cart is ready outside. 


\begin{tabular}{|ll} 
8. Oj, jak ja będe z wami siadała, & 8. Yes, I’m sitting down by you, \\
jeszcze ja siostrom nie dziękowała. & But must thank my sisters first. \\
Dziękuje wam, moje siostry, & Thank you, my sisters, \\
żeście były na mnie ostre, już nie będziecie. & $\begin{array}{l}\text { That you've been harsh on me, now no } \\
\text { longer. }\end{array}$ \\
$\begin{array}{ll}\text { 9. Oj, siadaj, siadaj, kochanie moje, } & \text { 9. Sit down, my love, sit down, } \\
\text { nic nie pomoże płakanie twoje. } & \text { No point in crying tears. } \\
\text { Nic tobie płacz nie pomoże, } & \text { Tears cannot help now } \\
\text { już koniki stoja w wozie pozakładane } & \text { As the horse-driven cart is waiting } \\
\text { (BartLub, II, 476). } & \text { outside. }\end{array}$ \\
\hline
\end{tabular}

What this text reconstructs is not only an element of the wedding rite (: the bride leaving her family), but it also depicts a part of the social structure so that the structure of the song as a text reflects the social hierarchy behind it. In other words, the chronology of the farewell thanks is by no means accidental. To the contrary, it mirrors the matriarchal model of the family where the central position is reserved for the mother and it is her who is mentioned first. Naturally, in some other variants of this farewell song, the father comes to the fore as the first one to be addressed by the bride which reflects the patriarchal slant of the family and/or society organisation.

On the whole, in ritual-based reconstructions (wedding/funeral/christening songs, wishes, some belief-reconstructing stories and urban legends), the very ritual in question (or its part/s) can serve the following three functions:

-. it can be the theme of the text,

- it can be the temporal frame of the text,

-. it can be the scenario of the structure of the text.

In ritual reconstructivism, the agent is the person that plays an active role and for this reason is one of the actors in a given ritual: carollers, hosts (landlord and landlady), groom, bride, or, as in belief-oriented reconstructions, extraterrestrial creatures. What human agents do, is to spread good news, laying bare some truth about how the world is constructed amounting to fully deliberate and intended activities. In the case of non-human agents, the purpose of their activity remains unclear for the narrator. For example, a belief-related reconstruction may depict one's funeral and thus touch upon the relationship between this world and the otherworld. In this account, the dying person happens to be 
found between different worlds and the narrative makes this clear when the informant says that on his/her deathbed, a dying person can be approached by mysterious zjawy 'phantoms', or zmarli 'the dead' who are in fact, messengers, or intercessors of approaching death:

Ja nie widziałam śmierci, ale to podobno, że tym osobom się przedstawia. Ja wiem, że jak tatuś mój... To było w żniwa. Myśmy poszli do żniwa, a on leżał, bo nie chodził chyba $z$ pięć lat, tylko leżał w łóżku. A mówit że, że przecież byt zamknięty $w$ dom - a mówit, że przyszedt ktoś do niego, przyszedt do niego i że byl, i rozmawial, i że pod tóżko wlazł. No gdzie? Patrzymy przecież zamknięte mieszkanie i okno zamknięte. Nie, ktoś byt. Ale czy byt, czy może on jakeś zjawę miat, to ja nie wiem i później niedlugo zmarł. [INF 9].
I haven't seen death, but they say she comes to introduce herself first. All I know is that when my dad... This was during harvest time. We went out to harvest, and he was in bed as he had not been able to walk for about 5 years by then. He told us the house had been locked and that someone had come to him, talked to him, and squeezed under the bed. How? The place was locked up, the windows closed. Well, somebody came in. But I do not know whether this really was somebody, or maybe he saw a phantom. Anyway, he died shortly after that.

Going back to the Easter Palm song (Text 7), the role of the carollers is typical of all of ritual-oriented reconstructivism. On the one hand, their function is determined by the ritual itself, which means that they serve as messengers of good news and assume the position of intercessors mediating between heaven and earth or between God and people. On the other hand however, their role exceeds that of bridging the divine and the human and embraces mutual exchanges of good words for the hosts' material gifts. This we see in the last two stanzas of Text 7, which is where the carollers call for a contribution and at the same time, express gratitude for it in advance.

The causes of events can be grouped into two categories: some events are triggered transcendentally (e.g., the birth of Christ), whereas some other events are motivated by human factors, mainly vices and weaknesses (e.g., the bride's unfaithfulness, one's urge to take revenge, friends placing a bet on something).

The way agents perform their acts in ritual-based reconstructions has a social grounding and depends on corresponding customs and principles, which explains why whatever is done is purposeful and multimodal. This multimodality, or in fact, multicoding, involves a verbal code as well as a gestural one, which is precisely what a typical ritual, be it liturgy- or family-based, such as going carolling, a wedding or funeral, consists of.

The purpose of activity stems from the structure of the underlying ritual in 
the sense that the ritual and its components are reflected in the structure of a given text and in the activity of its protagonists. In traditional ritual-based texts (wedding songs, funeral songs, Christmas carols), what the protagonists aim at is to meet the expectations denoted by their social and ritual functions. In belieforiented reconstructions (urban legends), what the protagonists do is meant either to violate the traditional structure of a rite or to restore the original social order represented/reflected in a rite.

Time. Again, the category of time on the text level corresponds closely to the temporal organisation of a ritual. One good example of this IS the following urban legend (Text 8) whose hyper-theme is death:

Text 8

Styszałem od mojej babci, a babcia od swojej znajomej, że pewna rodzina, która mieszkała $w$ Chetmie z babcia staruszka, ukrywała jej zwłoki, aby pobierać ciagle jej wysoka emeryturę. Żyli w tym oszustwie przez kilka miesięcy. Sprawa wyszła na jaw, kiedy zmienił sie listonosz roznoszacy emeryturę $w$ tej okolicy $i$ zażądat kategorycznie od rodziny, aby staruszka odebrała ja osobiście. W tym momencie rodzina musiała się przyznać, że babcia nie $\dot{z} y j$ je. Babcia trafiła wreszcie na cmentarz, a rodzina do więzienia. [INF 10]
My grandma once told me what she had heard from somebody she used to know. It was about one Chełm family who hid their grandmother's corpse after her death in order to be able to claim her pension. They managed to keep it secret for several months until a new postman demanded that the pension had to be collected personally by the granny herself. It was only then that they had to admit that the old woman had long been dead. The granny was finally buried at the cemetery and the family went to prison.

Text 8 is an example of the violation of the structure of a rite of passage (here: death/ funeral). It is safe to say that the protagonist of the story (the deceased granny) was kept by her family in a state that can be described as social timelessness. This timelessness should here be understood literally, that a deceased person is physically kept away from other people and is therefore socially isolated. What puts the family in jeopardy from their point of view, is not the dead body but the surrounding community that is completely unaware of what might possibly have happened and are insistent on seeing the granny. The expected (and lawful) order of the world is restored after the postman tried to deliver the pension. Only then can the dead person 'perform' her natural role and the rite of aggregation (inclusion) then begins.

In the margin, a special role is ascribed in rites of passage to the times of day that mark specific events. In folk tradition, specific hours are interpreted symbolically on principle. Twelve am is seen as the boundary between one day and the next so if it is used in the context of a wedding ceremony it serves as the 
demarcation line between one marital status and the other. In belief-oriented reconstructions, twelve am is a symbol of a boundary, understood as the transition of the dead to the world of the living: Jak mój dziadek konat, to poźniej mama nie dała na msze i mówi: ten dziadek wiecznie przychodził i stukał w tył szafy. Mamie nie dał spać [...] To to o tak było, a szczególnie o dwunastej w nocy. [INF 11] ('When my grandpa died, my mum did not schedule a Mass offering for him because, as she said, grandpa would keep on coming and knocking at the back of the wardrobe, preventing her from sleeping (...). This would specifically happen at $12 \mathrm{am}$ ). That the number 12 is symbolic, comes from a unique combination of 3 and 4 , in folk mentality 3 being the number of the deity and 4 being the number of the world (cf. Forstner 2001: 51), so 12 is where 3 and 4 interpenetrate each other.

Space. Following Leach' assertion that every single space has specific functions that are taboo-protected (cf. Leach 2010: 68), it can be assumed that in urban legends this taboo space is the sacrum which is subject to profanity and irreverence. Here we have one example (Text 9):

Text 9

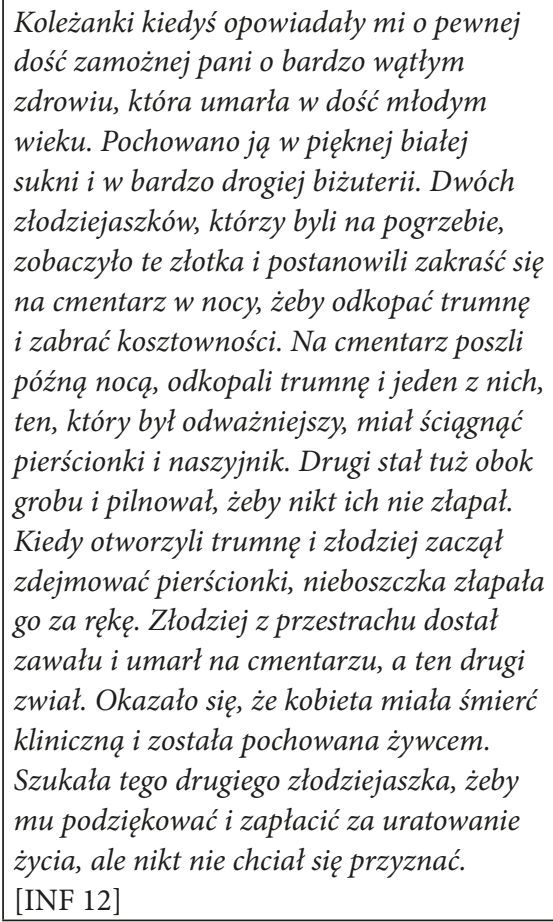

My friends once told me about a relatively affluent woman, who was in poor health, which ultimately was the reason for her premature death. She was buried in a beautiful white robe and expensive jewellery. There were two petty thieves at her funeral who saw all the glitter and decided to unearth the coffin and rob it. And this is what they did late at night. The braver one was supposed to get the rings and the necklace, while the other one was tasked with the job of lookout. So, when they got the lid off the coffin and one of them reached into get the rings, the deceased woman grabbed his hand. Scared to death, the thief had a heart attack and died right there on the spot, The other one chickened out. It turned out later that the woman was only clinically dead and had been buried alive. She tried to find the other thief to thank him for having saved her life, but nobody wanted to cop a plea. 
In Text 9, the cemetery functions as a symbolic space separating this world from the otherworld. The material/physical features of the cemetery, as a man-made space meant for performing ritual activities, constitutes a perfect reference point for a number of metaphysical oppositions, such as this world $v s$. the otherworld, sacrum vs. profanum, low status $v s$. high status, normal $v s$. abnormal, life $v s$. death, and productive $v s$. unproductive (cf. Leach 2010: 69). In general terms, the cemetery is a communication space where this world meets the otherworld, a sacred place, the last destination of the human wayfarer, a point of transformation of the dead to the living and vice versa. Moreover, the thief becomes a victim, and the victim - accidentally and unwittingly - becomes the cause of the thief's death. What happens is different from what we expect it to be, or what we may consider to be normal.

In belief-oriented reconstructions, the sacrum space that, in the course of events, happens to be profaned and corrupted may also involve the place of the protagonist's suicidal death, as in the following text (Text 10):

Text 10

Raz styszałem taka historie, że na Świcie bodajże w Lublinie była budowa domku jednorodzinnego. No i kiedyś się tak zdarzyło, że się robotnik powiesit. Bo gdzieś tam z jakiegoś powodu. No i właściciele stwierdzili, że oni nie chca tam mieszkać, prawda. Budowa, domek już zamknięty $w$ stanie surowym zostawili. No jak to zazwyczaj bywa, tam później młodzi ludzie chodzili pić i tak dalej, prawda. Te okna byly zamurowane, a drzwi byly cały czas otwarte, no nie, rozwalone. No i zawsze jak chodzili, znaczy tak styszałem, to różnie było. Czasem policja przyjechała, czasem nie. Ale zawsze jak ktoś zaczynat się śmiać z tego wszystkiego, prawda, że nie wierzy i tak dalej i z tego, że się z tego tam ktoś powiesit, to raz się drzwi zatrzasnęty. Jak nie mogli wyjść przy zamurowanych oknach, to był problem. Musieli ich wyciagać strażacy. Raz się belka stropowa zerwała, właśnie spadła obok pana, który właśnie wyśmiewał tą cała sytuację, która się wydarzyła ileś tam lat temu. Nie wiem, czy jest nawiedzony, czy nie. Nie miałbym chyba nigdy zamiaru tam iść. [INF 13]
I once heard a story that in Swit, probably in Lublin, there was a detached house being built. One of the workers hanged himself right there on the spot, for some reason. The owners decided that they didn't want to live there, So they left the house, there and then Typically, the building a drinking place for young people. The windows were sealed, but the doors were wide open, broken into, in fact. At times the police would arrive. Those that would come to drink there would normally laugh at the suicide story. But once, the door slammed shut. As the windows were all walled up, those inside were trapped. The firemen had to get them out. On another occasion one of the ceiling beams came loose and fell off just inches away from the man who had laughed at the suicide story. I really don't know whether or not the house is haunted, but I don't think I would go there. 
As can be seen in Text 10, rites of passage are often narrated in texts that are meant to cause irrational fear (Ługowska 1993), which can be found in belief narratives and some types of urban legends.

More specifically, that a given text is to narrate a rite of passage (a funeral, rather than a wedding) is already signalled in the overall structural frame of the text, mainly at its beginning. In belief-oriented reconstructions, the rite is presented in an orderly and well-structured way, whereas urban legends depict the world which - to paraphrase M. Bachtin - as placed upside down and for this reason, the order of a rite can not only be distorted, but also diverted or reversed. While the structure of a belief reconstruction seems to follow the idea of 'one death anticipates another death', the schemata exemplified in urban legends are more of 'from wedding to death', 'from death to life', or 'life for death'.

Still, ritual-based reconstructions do depict corresponding rituals and reflect their structures. In doing so, they can be regarded as carriers of memory in the sense that rites of passage themselves are texts of culture and therefore carriers of collective memory. As presented in an oral text, the picture of a given rite, custom or ceremony should, naturally be understood not in literal terms, but as a reconstruction.

\section{Subjective aspect of memory: reference to a social group}

To my mind, J. Assmann's (2011: 25-26) notion of 'a concrete relationship to a group', or 'reference to a social group', can be related to the literary and linguistic categories of the addresser, the addressee and the protagonist. In a more or less explicit way, these three point at or refer to a social group.

\subsection{The addresser of a text}

The category of the addresser (also: the subject), of a text seems to have been well researched (cf. Witosz 2009), one of the issues being the precise ontological status of the addresser: should the addresser be understood as a physically-real figure, a reading-derived constructed one (a textual figure) or a text-implied one (cf. Witosz 2009: 117)? The answer to this question is anything but simple. By analogy to religious discourse, where the speaking subject plays a twofold role, that of an addressee of God's Word and a direct addresser (Witosz 2009: 119), in folklore texts the speaking subject must also be given two functions: of a receiver of collective beliefs and traditions and of a direct sender of these beliefs and traditions. It is interesting that in folk carols the subject's function is even threefold: to receive God's Word, to receive the group's oral tradition and to communicate the intended message. One way or another, in folklore texts, the subject is 
placed in-between the group and the addressee and can be seen as a kind of an intermediary, or a depository of the past which he/she is in a position to update, modify and transform.

As B. Witosz says, 'in a structural-semiotic perspective, the literary subject (i.e. 'I' as depicted in a text) and the authorial subject (i.e. 'I' as an empirical author) are ontologically and completely independent from each other' (Witosz 2009: 121). This means that apart from the physically-real subject there is also a textual one, so that 'the author-subject is not the creator of a text because the text itself creates its addresser' (Kaniewska 2008: 93) and 'every source is marked with the irremovable subjective imprint of its creator' (Witosz 2009: 123). In other words, the internal 'I' cannot possibly be present in the structure of a text (cf. Witosz 2009: 123). As A. Pajdzińska would add, 'even the most spontaneous and private expression of one's individual experience is interpenetrated with symbolic systems of culture, with allegedly independent interpretations being navigated by narrative schemata' (Pajdzińska 2008: 228).

To sum up, the textual subject and his picture of himself and of the group he represents brings us to one of 'the three special features' of memory figures that J. Assmann distinguishes in his research, which is 'a concrete relationship to a group'.

More specifically, Bożena Witosz mentions several ways of introducing the author (as well as the group that the author represents, too) into the structure of a text:

(1) 'The first source of extra-textual references involves the author's life and typical ways of updating the author's bios on the logos level being biographical genres' (Witosz 2009: 126). With regard to texts of folklore, this includes recollections and biographical elements of belief reconstructions and urban legends:

Text 11

Duchy nie pokazują się wszystkim ludziom, ino przeważnie takim, co wiedza, jak one wyglądaja. Jak jo jeszcze był małym synkiem, toch chodzit z ojcem na polowanie. Roz my szli w ciemna noc i naroz zobaczyliśmy przed soba dwa migajace ogniki. Migały one pomiędzy drzewami. Ludzie mówili, że jest to ognisty chłop. Mój ojciec był bardzo odważny i postanowił, że musi się przekonać, co to właściwie jest. Wziąt strzelbę i pach! Strzelił do ogników. Potem czekaliśmy chwilę i ojciec poszedł sprawdzić, co to było. I wiecie, co to.
Ghosts do not appear to everyone, but usually to those that know what they look like. In my childhood, I would go hunting with my Dad. Once night we saw two lights glimmering among the trees. People used to say that this was a fiery man. My father was not afraid of anything, and he wanted to see what it really was. He grabbed his rifle and fired at the lights. We waited a little and then went up to see what it was. And guess what it was?. An owl! Whenever 


$\begin{array}{|ll|}\text { było? Sowa! Sowa, która poruszała skrzydłem. } & \text { an owl moves its wings in the dark, } \\ \text { Jak jest ciemno, to jak ona porusza skrzydłami, to } & \text { the friction causes sparks and lights. } \\ \text { tarcie powoduje ogniki i iskry. A bojący sięludzie } & \text { And lily-livered people say that this is } \\ \text { mówia, że to ogniste chłopaki (SimLud, 46) } & \text { a fiery man. }\end{array}$

Text 11 shows us that, biographical elements like those found in belief reconstructions and urban legends, serve to verify the belief in question and disclose the subject's attitude to the folk world of values as they are handed down from generation to generation. The subject is then, not only the depositary of collective memory or a continuator and carrier of established tradition, but a verifier of collective beliefs, someone who is in a position to confirm or dismiss them as mere myths projecting from human fears and anxieties. Again, we have what sociologists ascribe to collective memory: selectivity and topicality. As a bearer of tradition and a depositary of memory on the one hand, the textual subject is, on the other hand, in charge of changing and modifying beliefs in a given context.

(2) Another way of introducing the author into the overall structure of a text is known as intertextual correspondences, or text-distributed reading evidence (cf. Witosz 2009: 127). In the case of oral texts, this reading evidence does not really come with one's actual reading of texts, but it is encoded in one's auditory perception of other oral texts. Oral texts are polyphonic after all, so the author's voice is interpenetrated with somebody else's contribution (cf. Witosz 2009: 127). Intertextual correspondences in folklore texts are nothing but effects of text transmission, which is what J. Assmann captures in terms of continuity and durability. When this is the case, the means of expression in folkloric prose texts include testimonial formulaic phrases which disclose the source of a narrated story and the kind of the relationship that is gained among the group members. As it has been discussed in great detail in other publications (Wójcicka 2010), only the main findings are presented here:

XX testimonial formulaic expressions indicate the source a given story comes from and they can be found mainly in belief reconstructions and urban legends;

XX the sources of orally-transmitted texts include the following

- unspecified social groupings: people, neighbours etc.;

-" the narrator's family members: To mój rodzony ojciec opowiadał nieros nam na wieczorkach (E3, 159; 'This is what my own Dad used to tell us during evening meetings'); 
-- written sources: To chyba gdzieś czytałem. Nie wiem (CzubMity, 19; 'I think I read about that somewhere. I don't really know');

- friends and acquaintances: To sasiad mi opowiadal (CzubMity, 49; 'My neighbour told me this');

XX traditional texts (belief reconstructions) are transmitted during encounters with family members, acquaintances, neighbours;

XX present-day texts have their sources in one's interpersonal communication with the people one knows and considers close.

In the past, world knowledge used to be transmitted at the juncture of different generations, whereas nowadays it is intra-generational bonds that seem to be stronger and determine knowledge transmission. This gives us two broad categories of sources: on the one hand, it is read evidence that one derives from the press, television, Internet, and on the other hand, it is auditory perceptual evidence (family, friends, and - in the case of modern texts - acquaintances). Taking most aspects into consideration, transmission can basically be described in terms of orality, or - after W. Ong - secondary orality (as in the case of the Internet), or - in J. Goody's terminology - lectoorality (Goody 2010: 168).

Having examined metatextual references, it is safe to assume that the group behind collective memory which stores both traditional and modern texts of folklore can be characterised, respectively, as follows:

- it is traditional in the sense that it embraces a local/rural community as a whole (ludzie ze wsi mówili 'the villagers used to say') or its selected respected, mainly elderly members (starzy ludzie opowiadali 'the old ones used to say'); the community members are brought together by the location they share and cross-generational bonds; as the older ones are a depositary of the memory and knowledge that cannot be found in written sources and the younger ones look up to them and learn from them; the kind of memory that is transmitted in this interpersonal and direct transgenerational chain is oral;

- it is modern in the sense that it involves friends, colleagues and acquaintances, which are peer groups of the same age but of different places of habitation; the memory transmission is either direct and interpersonal or indirect and mass; the latter kind involves mass media and is often impersonal, that is unrelated to anybody known and specific.

The third way of introducing the author into the structure of a text is making him/her play one of the roles. 
(3) 'That the subject is part of a text also becomes evident from the ways genre patterns are activated' (Witosz 2009: 127). In other words, as B. Witosz continues, 'the way the subject manifests his/her presence extends from one single role that is chosen out of a whole array of genre-specific roles to be performed or from a mixture of selected elements of different roles brought together into one subject' (Witosz 2009: 128).

On the whole, in folkloric texts, the textual subject can perform the following roles:

- observer/spectator:

Text 12

Czasem to i czarownice jeszcze sa. Ja miałem wtedy siedem lat i pasałem krowy u mojego wujka. Na jedna kobiete $w$ Rogach u nas powiedzieli, że to jest czarownica. Pasła raz krowy. Ale to widziałem sam. Na południe doję krowę - krew! Zamiast onego było mleko, ale czerwone jak krew! Teraz mnie się pytali, kto szedt, jak pasłem krowy. A potem pada ta gospodyni:

- A ta kobieta szła?

- Szła!-padam.

Moja gospodyni wzięta i to mleko, jak wydoiła na południe, tak do ognia wylała. Ta kobieta, ani pól godziny nie przeszło, jak przyleciała. I już było pewne, że to ona (SimKum, 123).
You can still see witches all around us. When I was seven, I used to help my uncle with the grazing cattle. One woman in Rogi was believed to be a witch. She was once, when the cows were grazing, I saw it myself. At noon I started milking a cow, and all I got was blood. It was milk, but red like blood. So they asked me who was passing by when I was the cattle were grazing. The landlady asked me:

- Wasn't it that woman?

- Yes, that was her.

My landlady took the milk and poured it on the fire. No less than half an hour had passed when this woman came running. ..And it was now evident that it was her.

The role of the observer in the above belief reconstruction (Text 12) goes hand in hand with the verb of perception - widziałem 'I saw', and in this sense, it is typical of belief reconstructions in general because - similarly to urban legends - the narrator's references to the events are, in fact, his/her recollections of what he/she claims to have seen. Moreover, performing the role of the observer of extraordinary happenings, the textual subject serves to verify and legitimise the narration, which gives him/her yet another dimension, one of the guarantor. 
- intermediary who narrates the past events on behalf of the whole group:

\begin{tabular}{|c|c|}
\hline Postuchajcie, ja was prosze, o wojnie turecki, & Listen to me, you all, about the \\
\hline $\begin{array}{l}\text { Trzysta lat temu minęto jak z królem } \\
\text { Sobieskim (BartLub, III, 403). }\end{array}$ & $\begin{array}{l}\text { Turkish war } \\
\text { Three hundred years ago, about King } \\
\text { Sobieski }\end{array}$ \\
\hline $\begin{array}{l}\text { Prosze posłuchać, mili panowie, } \\
\text { Jak każdy człowiek ma kłopot na głowie. } \\
\text { Wszystkie mężczyźni, także niewiasty, } \\
\text { To rok troskliwy dziewięćset pietnasty } \\
\text { (BartLub, III, 419). }\end{array}$ & $\begin{array}{l}\text { Listen to my story, gentlemen, } \\
\text { That everyone has their problems. } \\
\text { All men, and all women, } \\
\text { Will remember the year } 1915 .\end{array}$ \\
\hline $\begin{array}{l}\text { O tęczy opowiadali tak. Było to bardzo } \\
\text { dawno temu, jak jeszcze anieli z nieba } \\
\text { schodzili i dalej świat naprawiali } \\
\text { (SimLud, 29). }\end{array}$ & $\begin{array}{l}\text { This is what they used to say about the } \\
\text { rainbow. It was so long ago that the } \\
\text { angels still kept on coming down from } \\
\text { heaven in order to make the world better }\end{array}$ \\
\hline
\end{tabular}

Again, the textual subject assumes the position of an intermediary who has got a message to pass on. This can most often be found in historical songs as well as in historical and belief reconstructions and in a text, is signalled with testimonial formulaic expressions (opowiadali 'people used to say', starka opowiadała 'my grandma used to say') which are meant to show that the narration is only a second-hand part of the (mainly oral) cross-generational transmission. In historical songs, the intermediary is often the beggar: 'singing beggars, called dziady, kept close to the Church because this was where they could perform their songs, (...) and get alms in exchange for singing basic prayers, and religious songs' (Michajłowa 2010: 63).

- participant whose mission is to pass the truth of witnessed events on to the next generations:

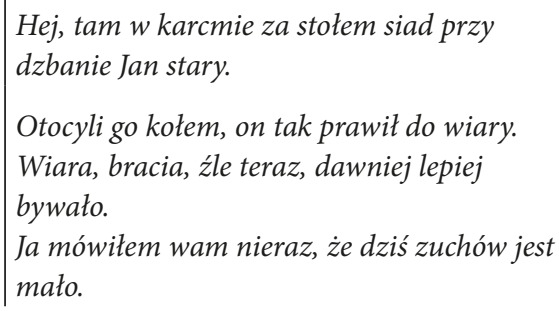

Hej, tam $w$ karcmie za stołem siad przy dzbanie Jan stary.

Otocyli go kołem, on tak prawit do wiary. Wiara, bracia, źle teraz, dawniej lepiej bywało.

Ja mówiłem wam nieraz, że dziś zuchów jest mało.

In an inn, behind a table, old John sat down for a beer.

People gathered round him, and he started his story.

The world is going to the dogs, brothers, As I've told you before, the courageous cannot be found. 


\author{
Raz pamiętam $z$ wieczora $w$ Racławicach \\ stojymy, \\ Wtem coś śmiga za borem i Moskali \\ widzimy. \\ Jak wzion machać, wywijać, my też obces \\ na wrogi, \\ Dalej ranić, zabijać, a Moskale het $w$ nogi \\ (BartLub, III, 409).
}

I remember that one evening in Racławice

We suddenly noticed the Russians in the woods.

As we turned on them, working hard with our swords,

Wounding and killing them, so they soon ran away.

In this specific historical song, the textual subject's role is a mixture of an observer and an intermediary. On the one hand then, the subject narrates what he saw and heard at the gathering in the inn but, on the other hand, he also communicates what he got to know from old John to the social group he is a member of. This means that the text exemplifies two different kinds of memory: one reflects the recollections of some participating observer, whereas the other one is reflected in the story narrated by the protagonist. We also have three distinct addressers: the protagonist, the sender of the text and the narrator/performer, which gives us a Chinese-box structure: the direct addresser communicates the text of the textual addresser who in turn, communicates the text of the protagonist (John). This arrangement is characteristic of probably all oral transmissions, as it happens to be paraphrased humorously in one Polish TV series: Tata, a Marcin powiedział, że jego tata powiedział... ('Daddy, Martin said that his father said...).

\section{- mouthpiece of a sense of community:}

Najświętsza Panno, prosim cie ze łzami: // Zlituj się, zlituj nad wdów sierotami, // Wyjednaj łaskę, niech się nie tułamy, // O Matko nasza, do ciebie wołamy (BartLub, III, 417; 'The Virgin Mary, we ask Thee all in tears // To have mercy upon us, the widows' orphans, // Ask for mercy for us so that we won't be homeless wanderers. // Our Mother, to Thee we pray').

In this text, the textual subject assumes the role of a community member, and it is on behalf of the community that the subject voices the prayer. However, the verbal forms used are the 1st person plural, which means that the subject is collective in nature. This kind of textual subject is characteristic of historical songs.

- interpreter (commentator):

[...] Jedynie ta ósma była prawdziwa kobieta, ale i ona miala $w$ sobie te cechy wszystkich sześciu razem. Dlatego Adamowe syny nie mialy lekko, bo im te żony dość nadokuczaty. A najbardziej
(...) It was only the eighth one in a row that proved to be a true woman, but even she had the traits of all the six others put together. The reason why Adams' sons did not have an easy life was because their 
zmienna była ich siostra, ta to dopiero swemu mężowi dała się we znaki. Od tamtych czasów trzeba wiedzieć, jaka kobietę kto sobie wybiera. Czy kure, czy gęś, czy kaczkę, czy owieczkę, czy kózkę, czy kotkę, czy suczkę, czy taka, co ma charakter wszystkich sześciu. Dlatego trzeba bardzo uważnie przyjrzeć się swojej przyszłej żonie, popatrzeć dobrze na jej matkę, bo każdy wie, że jaka mać - taka nać (SimLud, 58). wives kept on nagging them. The most changeable of all was their sister, she was a true pain neck for her husband. Ever since then it has made sense to know which woman one wants to choose. It is a hen, a goose, a she-duck, a sheep, a she-goat, a she-cat, a bitch, or one of all six together? This is why one needs to have a good look at one's prospect wife and her mother because one knows-like mother, like daughter.

It is safe to say that the interpreter role is most often exemplified in epic texts of folklore, which is where they function as explicit commentators on the story (being) narrated. On the whole, these texts are interpretations of what the world is like and more specifically, why people and animals behave the way they do. In other words, these texts are aetiological in character (see the closing temporal formulaic expressions, such as od tego czasu 'ever since that time') and present themselves as attempts at answering fundamental questions of why? how? where from? what for? etc. In some sense, the textual subject can be identified with the whole of the community that he/she is an offspring and a voice of.

This role is usually ascribed to the subject in traditional legends and animal fairy tales, but also, to a smaller extent in belief reconstructions and urban legends. Let us recall here that this is what we have already encountered in the Bogdanowicz historical song (see Text 5 above), and can now find in the following animal fairy tale:

Wszystkie kraje na świecie mają swego króla. Znane było to i ptakom. Myślą, jak tu wśród nas wybrać króla. [...] Naraz wrona zafurgała i powiedziała:

- Uwaga, uwaga. Kto na jeden, dwa, trzy... najwyżej wyfurgnie, ten zostanie królem. A był wśród nich taki jeden malutki, szary, mało widoczny ptaszek. Ten sobie pomyślat:

- Co ja teraz zrobię? Chciałbym być królem, ale jak tu furgać.

Myśli i naraz mu taka dobra myśl wpadła, mówi:

- Jakbym się przyczepił do skrzydła tego wielkiego orła?
There is a king in all of the countries of the world. This was known also to the birds, who started thinking about how to elect their own king. The crow had this to say:

- Attention, please! The one that flies the highest will become our king.

One little, grey and unimpressive bird said to himself:

- And what am I supposed to do now?

I'd like to be a king, but I can't fly

that high.

Then it dawned on him that he could fly hidden under this big eagle's wing. 


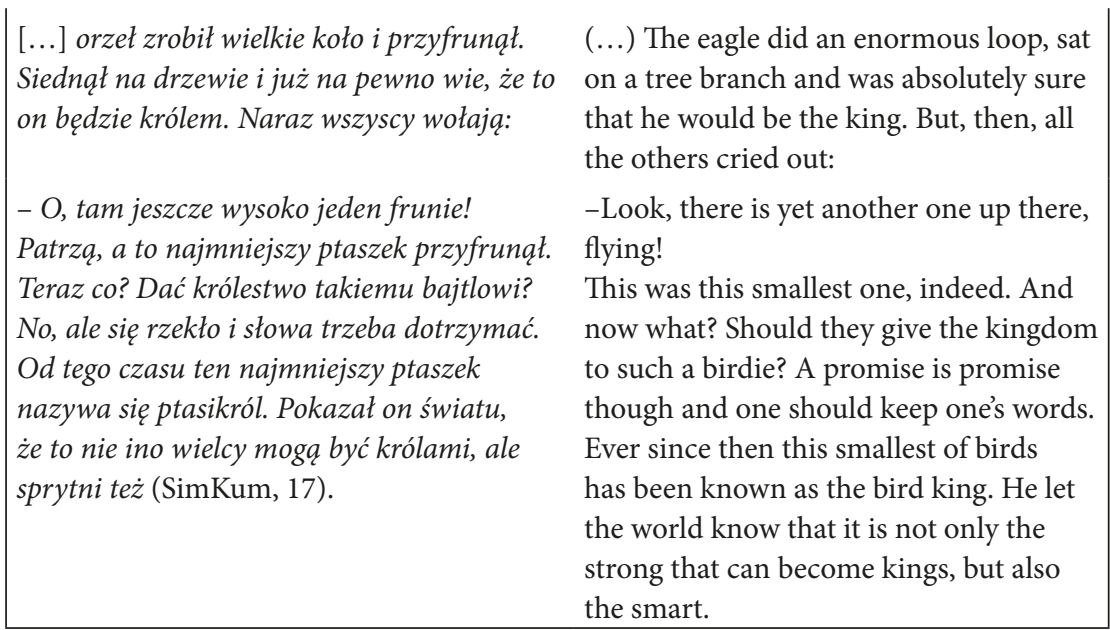

What matters in this text is not only the story that is handed down by previous generations, but also the additional explicitly-formulated authorial and generalisation-like commentary. So a personal story serves to make generalisations with regard to the Polish national character, or certain truths and all-embracing principles. This role (of an interpreter) seems to be typical of historical songs and animal fairy tales.

- reporter, as in the Rapunzel story (see Chapter VI, Text 9).

While in the previous group of texts the additional commentaries served to be generalised summaries of the narrated stories, now the textual subject does not feature explicitly at all. The role that the subject performs is that of a reporter, which is evidenced with simple and coordinated compound sentences, a lack of adjectives, and an accumulation of verbal forms. This is typically found in fairy tales of a magical slant, where the narrator does not show up in any overt way. Nor does he/she characterise any of the protagonists, or assess anything. All that they do is recall the facts and events that appear to be most important for the development of the storyline. This helps to build the stylistic characteristics of a fairy tale, which contains a high degree of abstraction and segmentation (cf. Mojkowska 2006).

- judge in a position to assess and evaluate people and things:

1. Jasio konie pojut, Kasia wode brała, oj, Jaś Kasie namawiał, żeby wędrowała.
1. Johnny was watering the horses, Katie was taking them water;

He was talking her into going away. 
2. uOj, nabierz, Kasiuniu, śrebła, złota dosyć, żeby miał wronny konik co pod nami nosić.

3. Ty myślisz, Jasiuniu, że śrebło na dworze, uoj, zamknęła mamusia $w$ tyj nowyj komorze.

4. uOpowiedz, Kasiuniu, że cie główka boli, da ci mama kliucze od nowyj komory.

\section{Mamusia myślała, że Kasiunia spała,} a Kasiunia $z$ Jasiuniem $w$ świat powędrowała.

6. Przyjechali oni do ciemnego lasu, oj, mówi Jaś do Kasi, wracaj sie zawczasu.

7. Nie po tom jechała, żebym sie wracała, oj, żebym z tobu, Jasiu, $w$ świat powędrowała.

8. Przyjechali oni pod białe brzeziny, oj, rozkładaj, Kasiuniu, poduszki, pierzyny.

9. Nie po tom jechała, żebym rozkładała, oj, żebym swojej mamie żalu dodawała.

10. Przyjechali uoni pod głębokie wisty, hoj, mówi Jaś do Kasi, co ty sobie myślisz?

11. A ja sobie myśle ji tom se myśliała, oj, żem z tobo, Jasiuniu, wświat powędrowała.

12. uOj, wziąłze Jaś Kasie, uoj, pod białe racczki, oj, rzucił jo, rzucił, w ten dunaj głęboczki.

\section{Zaczepiła Kasia fartuszkiem uo koli,} oj, ratujże mnie, ratuj, Jasiuniu sokolie.
2. Katie, you'd better take a lot of silver and gold

For our black horse to have enough to carry.

3. Don't think, Johnny, that that silver is at hand

'because my Mom keeps it locked up in a safe.

4. Why don't you, Katie, say that your head aches,

then your mum will give you the key to the safe.

5. The mother thought that Katie was asleep

But she and Johnny went away.

6. They came to a black forest, He told her to go home before it was too late.

7. I haven't come here to go back home now,

But I left my place to be with you.

8. They came to the white birches, Katie, you spread the pillows and quilts, please.

9. I haven't come here to spread anything And add to my Mom's sorrows.

10. They came to the deep waters, Katie, what do you think?

11. I think what I thought, That I left with you to go away.

12. Johnny grabbed Katie's white hands And he threw her into the deep river.

13. Katie's tunic got hooked on a branch; Save me, save me, Johnny, my love. 
14. Nie po tom cie rzucał, żebym cie ratowat, oj, musisz ty, Kasiuniu, ten dunaj

zgruntować.

15. Za nadobno Kasio wszystkie dzwony dzwonio, a za Jasiem hultajem sześć par koni gonio.

16. Nadobne Kasie już w grób wpuszczajo, a Jasiunia hultaja $w$ drobny mak siekajo (BartLub, IV, 50).
14. I haven't thrown you there to save you now,

You need to sink to the bottom. 15. All the bells are ringing after pretty Katie, dozens of horsemen are chasing wretched Johnny.

16. Pretty Katie is now being placed deep in the grave, Wretched Johnny is now being torn into pieces.

While in magical fairy tales, the role the subject performs most often is that of a reporter whereas in ballads, the subject is typically a judge. In the text above, this connects well with the structural Katie-Johnny opposition/parallel as well as with the adjectives describing the two protagonists: while Katie is nadobna 'pretty, beautiful', Johnny is hultaj 'wretched, a blaggard, and scoundrel. So, unlike magical fairy tales, in ballads the whole assessment (moral judgements) of the people and events involved has already been done by the textual subject for the listening audience to have it ready-made.

- carrier of a certain vision of the world and their corresponding values, moraliser:

[...]

Legli obok siebie wspólnie w jednym grobie, cieszcie sie, rodzice, $i \dot{z}$ artujcie sobie. Strzelecka orkiestra marsz żałobny grała, przy mogile ciemnej młodzież zaśpiewała.

Wiatr wieje tak smutno, jęk młodzieńców niesie,

którzy zmarli wspólnie przez miłość, przy lesie.

Niech sie więcej na świat nie rodzi nowina, by od kul ginęli chłopiec i dziewczyna.
They were placed next to each other in one grave,

Their parents should be happy now and couldn't stop joking.

A military band played the funeral march, Some youth sang a song at the dark tomb.

The lovers' moans blowing in the sad wind,

That they died together for their love. So, do not let the world know that at all That a girl and a boy got shot down. 
I wy tėं, rodzice, którzy dzieci macie, jak sie pokochaja, to im nie wzbraniajcie, I wy też, rodzice, którzy dzieci macie, jak sie pokochaja, to im nie wzbraniajcie (BartLub, IV, 89).

\section{Zapłacza, zapłacza moje czarne oczy,} jak ja będę odjeżdzat, jak ja będę odjeżdżał do pociagu w nocy, jak ja będę odjeżdzat, jak ja będę odjeżdżat do pociagu w nocy.

2. Do pociagu w nocy o pierwszej godzinie, wstawaj, ma Halusieńko, wstawaj, ma Halusieńko, odprowadzisz ty mnie, wstawaj, ma Halusieńko, wstawaj, ma Halusieńko, odprowadzisz ty mnie.

[...]

4. Odprowadziła go za domem na droge, dalej, mój kochaneczku, dalej, mój kochaneczku, dalej iść nie moge, dalej, mój kochaneczku, dalej, mój kochaneczku, dalej iść nie mogę.

5. Odprowadziła go za miasto trzy mile, tutaj, ma Halusieńko, tutaj, ma Halusieńko, tutaj cie zabije, tutaj, ma Halusieńko, tutaj, ma Halusieńko, tutaj cie zabije.

[...]

13. Postuchajcie, panny i młode mężatki, nie oddalajcie wy się, nie oddalajcie wy się od męża i matki, nie oddalajcie wy się, nie oddalajcie wy sie od męża i matki (BartLub, IV, 54).
And you, the parents, let your children love

Once they have fallen for each other; And you, the parents, let your children love

Once they have fallen for each other.

1. My black eyes will cry, will cry,

As I'm going away, going away,

By train this night.

As I'm going away, going away,

By train this night.

2. It is one o'clock at night,

Time to get on a train; get up, my Alice, You will see me off;

Time to get on a train; get up, my Alice, You will see me off.

(...)

4. She saw him off round the corner, I cannot, my love, go any further, I cannot, my love, go any further.

5. She saw him off three miles away, It is here, my Alice, that I will kill you; It is here, my Alice, that I will kill you.

13. Listen to me, maidens and newly-married wives, Do not stay away from your Hubbies and Mums, Do not stay away from your Hubbies and Mums. 
In the texts quoted above, the subject's role is to impose a certain worldview as well as to promote selected values and principles that correspond to that worldview (e.g., that parents should respect their children being in love or that children should be obedient to their parents). Once either of the parties has violated these familial, social values and principles, tragic things may happen (e.g. someone's death). So, the punchline in such-like ballads is usually phrased in terms of explicit admonishments or instructions, addressed equally explicitly to a specific group of addressees (here: parents, maidens, and newly-married wives).

More generally, whatever the role the textual subject is meant to perform in a text, all these roles correspond to and are determined by the genre itself, or, in other words, by the genological characteristics a given text is presented with. Here we have some of the relevant correspondences:

Finally, the question remains of what it is that available roles tell us about the social group that the textual subject is both a member and addresser of. On a closer reading of the correspondences in Tab. 5, we can see that the textual subject places his/her role either externally in relation to the group and therefore assumes a superior position with regard to the group (as its judge and moraliser) or internally within the group as its representative and mouthpiece. One way or another, as the subject performs a given role in the first person (singular or plural), the position assumed is that of a carrier and transmitter, but also of a verifier of the collective memory content.

This brings us to the picture of a social group in question, its needs, and system of values. An attempt at a brief characterisation, could be as follows: This is a group in need of getting to know the surrounding world, of asking questions not only of the group origins, but also of the beginning of the world and its constitutive elements (the Universe, plants, animals, people). This group cherishes its Christian roots and its local as well as national history. A picture of this kind prevails in information-oriented genres of folklore texts (historical songs, historical reconstructions, legends), where the textual subject performs the roles of a participant, intermediary, representative, mouthpiece, interpreter, and commentator. The selection of the available roles seems to suggest that neither the group as a whole, nor its individual members - both understood as depositaries of collective memory - remain passive in the process of memory transmission, with the memory content being actively supplemented, changed and accommodated to the group's information purposes and needs. The group described here constitutes, in fact, a kind of traditional, rural, society in search of the ontology of the natural world. It shows us that it needs clear-cut moral guidelines, principles of assessment and good-evil distinctions and we find all of 
Tab. 5: The role of the textual subject vis-a-vis genre differentiation of folklore texts (source: own representation)

\begin{tabular}{|c|c|c|c|c|}
\hline $\begin{array}{l}\text { Role of } \\
\text { textual } \\
\text { subject }\end{array}$ & $\begin{array}{l}\text { Mode of } \\
\text { representation } \\
\text { (direct vs. } \\
\text { indirect) }\end{array}$ & Verbal form & Text genre & $\begin{array}{l}\text { Text intention } \\
\text { (after J. Ługowska) }\end{array}$ \\
\hline Observer & Direct & $\begin{array}{l}\text { 1st person } \\
\text { sing. }\end{array}$ & $\begin{array}{l}\text { Belief } \\
\text { reconstructions, } \\
\text { urban legends }\end{array}$ & Fear and anxiety \\
\hline \multirow[t]{2}{*}{ Intermediary } & Direct & $\begin{array}{l}\text { 1st person } \\
\text { sing. }\end{array}$ & Historical songs, & Information \\
\hline & & & $\begin{array}{l}\text { historical } \\
\text { reconstructions, } \\
\text { belief } \\
\text { reconstructions }\end{array}$ & fear and anxiety \\
\hline Participant & Direct & $\begin{array}{l}\text { 1st person } \\
\text { sing. }\end{array}$ & $\begin{array}{l}\text { Historical songs, } \\
\text { historical } \\
\text { reconstructions }\end{array}$ & Information \\
\hline Mouthpiece & Direct & $\begin{array}{l}\text { 1st person } \\
\text { pl. }\end{array}$ & Historical songs & $\begin{array}{l}\text { Information/ } \\
\text { instruction }\end{array}$ \\
\hline \multirow[t]{3}{*}{ Interpretant } & Indirect & - & $\begin{array}{l}\text { Legends, } \\
\text { Animal fairy } \\
\text { tales, }\end{array}$ & Information \\
\hline & & & $\begin{array}{l}\text { Belief } \\
\text { reconstructions, }\end{array}$ & Fear and anxiety \\
\hline & & & $\begin{array}{l}\text { Urban legends, } \\
\text { Historical songs }\end{array}$ & $\begin{array}{l}\text { Information/ } \\
\text { instruction }\end{array}$ \\
\hline Commentator & Indirect & - & $\begin{array}{l}\text { Magical fairy } \\
\text { tales }\end{array}$ & Compensation \\
\hline Judge & Indirect & - & Ballads & Instruction \\
\hline Moralist & Indirect & - & Ballads & Instruction \\
\hline
\end{tabular}

this in morality-oriented texts (ballads, some historical songs, and animal fairy tales) as well as in compensation-targeted ones (magical fairy tales). In these texts, the subject performs the roles of a commentator, judge, moraliser, and reporter, which corresponds to J. Assmann's category of a specialised memory carrier who preserves and communicates the group's value system. The group is aware of its spiritual, irrational and magical needs, which are satisfied in belief reconstructions and urban legends, where the subject assumes the position of an observer, intermediary and interpreter. 
B. Witosz distinguishes yet another way of introducing the subject into a text and this has links to the so-called subjective worldview, or the subjective attitude to the world.

(4) In a nutshell, the subjective worldview provides an answer to the question of which of the world phenomena are considered by the subject to be assessing judgements, or how it happens that language can serve to express evaluative judgements at all. (cf. Witosz 2009: 128).

Values are a fuelling force of memory in both its individual and collective dimensions, simply because it is values that determine what is to prove permanent or unstable in collective memory resources. This poses the question of the role values play in oral texts, oral texts being one of the carriers of collective memory. As much as language, "text is a tool and a carrier of values as well as value information storage" (Bartmiński 1996: 53).

We thus proceed to the problem of memory-value correspondences and relationships which, in general, must be regarded as bidirectional in character:

- memory provides a functional basis for values because, as was quoted by Szpociński in Chapter II, collective memory 'constitutes one of the basic constituents of a social group's identification and it legitimises value orders recognised by the group's members' (Szpociński 2006: 28);

- at the same time, values constitute a functional basis for memory in the sense that 'collective memory changes proportionately to the changes in a group's system of values' (Szpociński 2006: 28).

In other words, if a text is a carrier of both memory and values, it is memory and values that bring the text together. S. Niebrzegowska-Bartmińska on the relationship between values and text genres says:

By means of paraphrasing Krzeszowski and Bartmiński, one could say that, indeed, „values lay the foundations of genre distinctions". However, we should also assume that values may be correlated with different levels of genre specification, that is, not only with those which seem to be self-evident here, which are levels of the presented world (events, characters, objects) and ways of their depiction, but also with the communicative (interactive) level that includes the addresser, addressee, intention and communicative situation. (Niebrzegowska-Bartmińska 2012: 36)

One research context that seems to have favoured the memory-values examination embraces definitional attempts at identifying memory and its functions. Thus far, in memory research, values are examined in terms of the subjective memory of events and the subjective discourse of the memory of events. To clarify the difference, the subjective memory of events discloses which and 
what values are remembered, whereas the subjective discourse of the memory of events provides answers to the questions about which and what values determine that which is remembered or forgotten and this specifically relates to the communicative level of language use (cf. Chlebda 2012: 115).

In collective memory research, the first aspect (i.e. memory of events) is related to the categories of, respectively, making judgements and the truth: 'In collective memory, (...) knowledge is considered to be true if it complies with a given group's actual feelings, systems of values and the worldview' (Szacka 2006: 29). The other aspect (speaking about memory of events) poses a question about those values which benefit from memory discourse and this, in fact, consists of the functions memory can play: 'It is for practical reasons that collective memory addresses the past. This serves the purposes of making certain (cultural, political, social) orders legitimate, and provides the building material for structuring collective identity' (Szpociński 2006: 19).

However elaborate, such-like memory definitions do not point at values in any explicit way. One notable exception can perhaps be A. Assmann's category of uninhabited (functional) memory, which is responsible for transmitting values that serve to create one's identity and patterns of behaviour (cf. A. Assmann 2009a: 127).

This calls for several points to be made with regard to the memory-values relationship:

(1) As depicted in memory, the picture of the past is subject to evaluative judgements. As routinely mentioned before, memory is a carrier of values, the lexeme carrier being understood here specifically as something that expresses and disseminates content and values important and characteristic of something else. Memory is a carrier then, in the sense that it expresses and disseminates the values that are typical, if not unique, of a given social group and that prove to be distinguishing or discriminating, for that group. One of the special features ascribed to memory figures by Halbwachs and J. Assmann is a reference to a social group which, by extension, embraces the values cherished by the group. This feature of the memory-values relationship foregrounds the very object of memory, that is, the values encoded and recalled in texts. In terms of analogies, the level of the memory of events can therefore be referred to as the level of the presented world as a text genology factor.

(2) It is values that determine whether the communicated depiction is subjected to further transmission or is rather found to be out-dated and therefore, deleted as incompatible with the group's actual norms and values: 'collective 
memory changes proportionately to the changes in a group's system of values' (Szpociński 2006: 28). In other words, that which qualifies to be handed down as collective memory must be found intriguing and worth reflecting upon.

(3) The subject cherishes the values that determine the transmission of a text. This level corresponds to the subjective discourse of the memory of events, or at its simplest, to the values communicated in the genological description of a text.

In the account developed here, there are two dimensions of memory: one is object-oriented (and results in a value-driven picture of the world), and the other one is subject-oriented (and consists of values that are implemented by the subject/observer). These two dimensions are connected to the functional aspect of memory (that is, how memory is transmitted). Nevertheless, once we think of these two dimensions in terms of their mutual interdependence, the question arises as to whether or not the values projected on the level of the presented world are still the same values projected on the level of communication. If not, how could a text possibly function in collective memory? Does this mean that the text cannot be assimilated, or accommodated, but, instead must be lost or at least remain latent?

In all these considerations, it is worth noting that memory itself is a value (see Pajdzińska 2007 for a thorough discussion). Moreover, as understood on the grounds of linguistics (Puzynina 1991) and folklorism (NiebrzegowskaBartmińska 2012), values that happen to be reflected in texts of folklore embrace that which is good for people and can then correspond to folklore genres and communication-implemented values. This is attempted in Tab. 6 .

(4). Another way of disclosing the author's presence in a text consists of identifying the subject's point of view. In other words, the author can be introduced into the text structure by specifying his social status/position as well as cognitive, psychological, somatic, historical and situational grounding. Naturally, the variety of roles that the subject can perform in a text (see Point 4 above) has a direct bearing on the variety of points of view (cf. Bartmiński and Niebrzegowska-Bartmińska 2004: 345). The latter is defined by J. Bartmińskiego as

the subjective and cultural factor determining the way the object is narrated, which includes its categorisation, onomasiological basis of its name and selection of its 
characteristics that are communicated about the corresponding object in actual utterances and in entrenched senses. (Bartmiński 1999: 111)

To put it simply, the picture of the world and its profiles in text and discourse depend rather heavily on the assumed point of view (Bartmiński and Niebrzegowska-Bartmińska 2004: 323). The reason is that the point of view is mental in nature and that binds it prototypically with the subject-person who not only passively observes the object but also actively conceptualises it (in terms of identification, categorisation, interpretation, which is everything that eventually finds its expression in the name selected) by means of processing the sensory data into the linguo-cultural picture of the object (Bartmiński and Niebrzegowska-Bartmińska 2004: 338).

The point of view is always somebody's and is inextricably connected with the conceptualising subject. This proves relevant especially when we examine collective memory and the relationship it contracts with texts of folklore. Simply, analysed in the context of a social group, the point of view tells us much about what this group is like. As the group is a bearer of tradition, be it rural or urban (which is evidenced with the genre a given text belongs to), the point of view discloses its resources of collective memory. To give an example, the rural community used to have its own model of conceptualisation which reflected the point of view of the so-called simple kind of man, that is, one born and brought up in the country and perceiving and naming the surrounding world through his 'existential needs and predispositions' (Kurek 2004: 211).

However, this does not seem to be that simple and straightforward. The following legend attempts to answer the question of why the earth is not transparent:

Gdy Pan Bóg stworzył ziemię, była ona zupetnie przezroczysta i świeciła jak brylant, tyle jest w niej drogich kamieni, złota $i$ srebra. Później dopiero stała się czarna $i$ nieprzezroczysta jak jest teraz, a to dlatego, bo ja przeklą Kain. Gdy Kain zabił Abla, chciał go ukryć w ziemi, lecz nie mógł tego dokazać, chociaż głęboka jamę wykopat, bo wszędzie i zawsze było widać ciało zabitego brata. Rozłoszczony Kain zawołał tedy: „Przeklęta ziemio, czemu nie jesteś czarną?" I ziemia stała się czarna, bo jest przeklęta (SimLud, 36).
When the Lord God created the earth, it was utterly transparent and it shone like a diamond and there were so many precious stones, gold, and silver on it. It was only later that the earth became black and opaque, as it is now, with the reason being that Cain cursed it. When Cain killed Abel, he tried to hide his body in the ground, but he failed time after time because no matter how deep a hole he dug, Abel's corpse could be seen anyway. Cain angrily shouted: 'Cursed earth, why aren't you black?' And at this moment the earth turned black, as it was now cursed. 
As reflected in this text, the point of view is complex and multifaceted: the subject respects the earth and conceptualises it in terms of the container metaphor ('precious stones, gold, and silver on it'), yet, the subject also looks down upon the earth as black and opaque. So, on the one hand, this is the point of view that is expected of a Christian believer who is aware of his Cain-Abel heritage, but on the other hand, this is the point of view of a black magic worshipper who takes Cain's words to be as creative and powerful as God's. One way or another, we can clearly see the conceptualiser's system of values and this is signalled firstly with the transparent/shining-opaque/black opposition and transparency standing for the sacred and opacity of the cursed. On top of this, a constitutive part of the point of view here also comes with the conceptualiser's sense of existential needs and priorities, the earth being right at the centre of these priorities. After all, as traditionally assumed, this point of view is that of 'a simple kind of man'.

This complexity and multidimensionality of folklore texts, as evidenced above, can be grasped in terms of polyphony. According to J. Bartmiński and S. Niebrzegowska-Bartmińska, one needs to research the possibility of the coexistence of several points of view in one text and discourse, their overlapping and mutual inclusion as well as exclusion (Bartmiński and NiebrzegowskaBartmińska 2004: 344). In this respect, they distinguish the following specific cases:

- an identical subject changes his/her original point of view and thus creates a novel picture of the object in question by setting up its new profile; if it repeats itself, we are able to discuss the multidimensional picture of the object;

- different subjects conceptualise a compatible/identical object, each conceptualisation revealing its different aspects and thus contributing, on a higher level of description, to a fuller and more complex picture of the object;

- two different subjects develop their respective points of view that either overlap and include each other;

- two different subjects assume different points of view and create incompatible, conflicting, or irreconcilable depictions of the object (Bartmiński and Niebrzegowska-Bartmińska 2004: 345).

It seems that it is only the first two options that can be found in folklore texts.

A. The subject changes his/her original point of view, be it physical or mental in nature (cf. Bartmiński and Niebrzegowska-Bartmińska 2004: 345): 
Wiecie, downiej to wszyscy ludzie wierzyli, że ziemia jest plaskato i okragło. Ona musi być plaskato, przekonywali ludzie. Przecież można nią chodzić aż do skraju, czyli tam, kaj niebo spotyka się z ziemiq. A skoro wierzono, że istnieje piekło pod ziemiq, to wszyscy też wierzyli, że ziemia musi być jakoś umocowano i musi się mocno na czymś opierać, gdyż inaczej wszystko by się zawalito i zaś byłby nieporządek. Ziemia mo swój środek. Jest to taki som kołek jak na karasolu [karuzeli]. Ziemia się wkoło kręci, a on się zepsuć nie może, boby to byt koniec świata, a my by wszyscy powpadali do piekła. [Tu informator sam się śmieje]. Mie tam $w$ szkole inakszyj uczyli, ale co tam jest prowda, to ino sam Pan Bóg wie! Babka moja, czyli starka wierzyła święcie, że środek ziemi jest w samym Opolu, ale od dziadka (starzyka) jo styszoł, że jednak w Częstochowie. Ale to i tak nie jest daleko. Czyli sam środek ziemi jest koło Opola (SimLud, 36).
Well, in the past people used to believe that the earth was round and flat. It has to be flat, they would argue, because you can walk on it up to the very edge, which is where the earth meets the sky. As it was also believed that hell is placed under the earth, the earth must be somehow fastened or fixed, because otherwise everything on it would fall off. The earth has its middle. This is precisely the same pole as in a merry-go-round. The earth keeps on spinning, but the pole must always be there, because if it collapses, it would be the end of the world, and we would all fall into hell. [The informant bursts into laughter.] I was taught a different thing at school, but God knows what the truth is. My Grandma was absolutely sure that the middle of the earth was right in Opole, but my Grandpa used to say that it is in Częstochowa. One way or another, it is not that far anyway. That is, that the middle of the earth is near Opole.

The subject assumes several different points of view, one after another and in their nature they are respectively, collective, institutional, official (I was taught (...) at school), Grandma-specific, Grandpa-specific. This allows for 'an unlimited number of different ways of presenting and interpreting an identical event' (Bartmiński and Niebrzegowska-Bartmińska 2004: 346).

B. Different subjects perceive identical events, but they narrate it in divergent terms, highlighting different aspects, which create an effect of multidimensionality and complexity (Bartmiński and Niebrzegowska-Bartmińska 2004: 347). Let us now compare the legend quoted above (why the earth was originally transparent) with the following text:

Było to tak dawno, że ludzie nie moga tego pamiętać. Na samym poczatku stworzenia świata nasza ziemia była przezroczysta i Pan Bóg mógł widzieć,
This was so long ago that people just cannot remember it. At the beginning of creation our earth was transparent so that the Lord God could see what was going on, on it. But 


\author{
co się na niej dzieje. Ale kiedy doszło \\ do pierwszej zbrodni i Kain zabił Abla, \\ wtedy wszystko się zmieniło. Kain chciał \\ ukryć ciało zamordowanego brata $i$ \\ szukał, gdzie by go pogrzebać. Co znalazł \\ jakiś dót, to wszystko było widać. \\ Spotkat czarta i powiada mu: - Skoroś \\ mnie namówił do złego, to mi teraz udziel \\ twej pomocy. Gdzie mam ukryć zwłoki \\ brata? No i szatan wziąt, coś pomruczat \\ i naraz ziemia stała się czarna. Kain \\ wykopał dót, pogrzebał brata i dotąd nikt \\ nie wie gdzie, bo on już nie żyje, a szatan \\ zła nie wyjawi. Od tego czasu ziemia jest \\ czarna (SimLud, 36).
}

when the first crime took place and Cain killed Abel, everything changed. Cain wanted to hide his murdered brother's body and searched for a suitable place to bury him. But no matter how deep a hole he found, Abel's body would stick out of it anyway. Then he met the devil and said: As you talked me into doing an evil thing, help me now. Where can I hide my brother's corpse? The devil muttered something under his breath and the earth turned black. Cain dug a hole, buried the brother, and no one knows where it is because he himself is no longer alive, and the devil would never disclose his evil deeds. Ever since then, the earth has been black.

Both texts offer accounts of how it happened that the transparent earth turned black. In the first one, the agent is Cain, the human being that curses the earth, so we understand that it is his words and deeds that prove to have creative powers. His deeds are accompanied with his emotions and these are overtly named (rozzłoszczony 'angry'). In the other text, Cain has a partner, the devil, who firstly talks him into murdering his brother and secondly, helps to hide the corpse in the black earth. In terms of responsibility, in the first text Cain takes the blame he is the source of the evil that he follows or that brings him to killing his brother. In the other text, the man's deed is justified as it is the devil who turns to be responsible for what has happened. The agent is the devil, and it is the devil's deeds and words that make a difference in the world. There is also a difference in the explanation given for why the earth should be transparent: because the Lord God ornamented it with diamonds (the first text), and because the Lord God wanted to see what was happening in it (the other text).

Apparently, these two texts deal with the same topic. Yet, because each of the two develops it in its own way of speaking or discourse, we obtain different interpretations of the topic itself and more importantly, different pictures of the carrier of folkloric texts. The first legend presents the earth as enriched by God the Giver. Although humans appear in opposition to God, they have free will and creative causative powers. The other legend depicts God the Observer, God that keeps on watching/observing His own creation. At the other end of the opposition there is the devil who succeeds in leading man astray. In addition, the two texts give different answers to the question of the sources of evil: is evil the work 
of man (internal sources), or does evil come with the devil's prompts (external sources)? The two texts may well reflect a Christian point of view, yet the first one foregrounds the dogma of human free will, whereas the other one focuses on the devil as the source of evil.

(5) Yet another way of introducing the subject comes with a reconstruction of the subjective vision of the world, which are answers to the questions of what? how? and why? in relation to the subject's perception of the world (cf. Witosz 2009: 129). (It is not the intention to develop this in any greater detail here because it has already been discussed in reconstructivism as one of the three special features of memory figures, for which see above.)

Let me repeat that it is through the analysis of folklore texts or in other words, through reconstructing the picture of the people as encoded in texts, that one can arrive at the group that appears to be the depositary of the collective memory reflected in these texts. This is important because the group itself is very seldom a topic, theme or subject matter of the communicated text. Still, assuming that the reconstructed linguistic picture of the world discloses someone's vision (point of view) and that this vision constitutes someone's subjective picture, we can identify the very social group that represents this picture, as well as creates it.

(6) The subjectification of the past finds its reflections in the structure of a text, that is in the framing operational formulae and formulaic expressions, which precisely indicate the topic of the text and mark the end of the narrated story. This subjectification of the past can be found explicitly in recollections and at times, in belief-oriented reconstructions. The reason it cannot be found in fairy tales, anecdotes, ballads, historical songs or carols, seems to be that in all these genres there is an overwhelming drive at universalism and communicating universal values, which excludes subjectifying the past events.

The theme of a given story may be signalled in metatextual commentaries (cf. Wójcicka 2010) which may also include an assessment of the past and the present, both framed in terms of a dichotomy:

Dawni to pelno było najrozmaitszych godek uo tym utopku. Tam go co chwila ludzie spotykali. To se z nim fajfka zamiynili, to zaś ryba capnęli, co była utopkiem; albo ujrzeli klocek drzewa, a jakby sie po niego schylili, toby ich do wody wciagnąt. Pierwej tam petno tego było. Teraz mniej, bo ludzie
In days of yore people would tell you stories about this utopek ['drowned man']. He would simply be encountered often People would smoke a cigarette with him, or would catch a fish that was a drowned man, or would reach out for a log floating on the river, that they had wanted to get out and he would have drawn them into the 
mądrzejsi, a młodsi sie z tego śmieja i
wierzyć nie chcą. Tóż to co wom teraz
powiem, zdarzyło sie tu niedaleko,
możecie wierzyć abo nie, co mie tam do
tego. Chcecie stuchać, to wom powiem.
Mieszkoł tu utopiec... (SimGad, 61). water. There were lots of stories like that in the past. Now, there are not many because people are wiser, and the young just laugh and do not believe a word of it. So, what I'm going to tell you now took place near here. Whether you believe it or not, it does not matter to me. If you want to listen, here is my story. Some drowned man used to live here...

The opening formula includes the temporal expression dawniej in days of yore; formely' which takes us back to the times when people used to believe in the supernatural. This is contrasted with the expression teraz 'now' which - according to the teller at least - marks the times of disbelief and doubts. In short, dawniej stands for the times of magic, whereas teraz refers to the times of the reason.

This kind of comparative assessment and evaluation stems from an access to cognitive and intellectual knowledge-basis which, as the informants argue, was much more limited 'in days of yore' than it is now. The assessment may involve an economic aspect as well (see Text 5 in Chapter V):

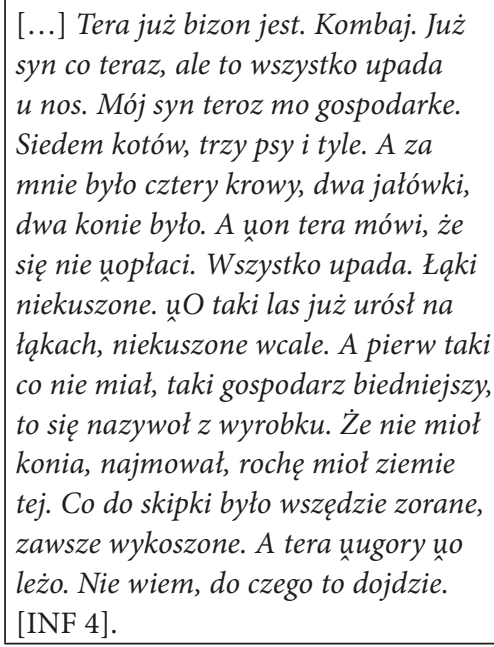

\section{(...) Now we have a combine harvester. My} son uses it, but it's all going to the dogs. My son now runs the farm. Seven cats, three dogs, and nothing else. Whereas in the past I had four cows, two heifers and two horses. And now he tells me that this all does not pay. Everything is going downhill. The meadows are not mowed, not cut at all. In the past the husbandman who was poor and did not have much land was called [app.] an aspiring one [Pol. $z$ wyrobku]. And as he did not have any horse, he would hire one and would plough every single patch of his land. He would also cut the grass. And all that you could around you were fallow fields. I honestly do not where this all is going.

This text exemplifies a more frequently-attested pattern of assessment, which is dawned 'formerly' means 'good/positive' and dziś 'today' connotes 'bad/negative.' This is simply because the informants remember their childhood and youth 
in positive terms for emotional reasons, that is, what they recall - flavours and scents - are identified with emotionally positive values (see Text 6 in Chapter V):

[...] Ale jaki ten chleb był pyszny, to aż $m i$ sie nieraz śni w nocy, że ah... no mówie Państwu, że no teroz nie ma takiego chleba. Nie dodawałam drożdży nigdy, tylko na zakwasie. [...] Fajnie. I caly tydzien, i nie był czerstwy. Naprawde. Ten chleb taki byt pyszny. Jeszcze dzisiaj bym zjadła, ale żyta już nie siejemy $i$ kto by tam piekł na dwoje ludzi. Ile by to trzeba było. [INF 5].
(...) How delicious this bread was! So good that I sometimes dream about it at night. Let me tell you this, what a pity that this bread is no longer available. I never added any yeast. Only sourdough. (...) This bread was so delicious. Even today I would like to have it straightaway, but we no longer plant rye, and who would bother to bake bread just for two people. It would be so much of an effort.

(7) Finally, what remains to be discussed is the category of modality. More specifically, the addresser's subjective attitude to the communicated message finds its expression in characteristics that in their nature are, respectively, tentative, volitional, intellectual-evaluative and emotional-assessing.

In texts of folklore, the category of modality becomes most often evident in those opening and closing formulae which show the true-false import (see Wójcicka 2010) and are persuasive in character (Labocha 1990: 92). Two broad sets of such-like formulae and formulaic expressions can be distinguished:

XX of assertive modality (Wilkoń 2002: 48, Wójcicka 2010: 95), which is when the addresser expresses his/her conviction as to the true import of the narrated story and

XX of epistemic modality (Wilkoń 2002: 48, Wójcicka 2010: 95), which is when the addresser expresses doubts as to the true import of the narrated story; what the addresser shows here is

- intellectual-assessing attitude to the world (e.g., by means of the expression nie wiem 'I don't know', cf. Jędrzejko 2001: 86) or

-hypothetical modality (cf. Grzegorczykowa 2001: 126), as in the case of podobno 'probably' and chyba 'maybe, perhaps'.

Expressed in framing formulae, these two types of modality (i.e. assertive and epistemic) can most often be found in belief reconstructions and in urban legends, where the addresser highlights his own attitude towards the phenomena which are extraordinary and unbelievable, if not supernatural. 


\subsection{The addressee}

The category of the virtual addressee, which is the addressee that is written into or ascribed to the text, is closely correlated with the category of the textual addresser, for which; see the section above. This gives us two possible relationships between the addresser and the addressee:

- a symmetrical relationship,

- an asymmetrical relationship.

That it is the asymmetrical kind of relationship that dominates in addresseraddressee correspondences is related to the fact that the (textual) addresser assumes a superior position with regard to the addressee. For example, he/she may address the audience with mili panowie, wszystkie mężczyźni, także niewiasty ('dear gentlemen, all the men as well as women') which has a patronising effect and is meant to impose one's story/song upon the audience for them to follow the addresser's advice and admonitions. This concerns the situation when the subject performs the role of a mediator and moraliser.

Let us note that the addressee, who happens to be reflected in texts of folklore explicitly, is collective in nature. It is a social group, not an individual, that the addresser informs, teaches, or guides. (See Tab. 7 for possible correspondences.) So whenever the subject becomes aloof from the group, he does not identify himself with the group and does not represent the group's values and worldview. However, once the subject performs the role of a group's representative and uses 1st person plural forms, we understand that the subject sympathises with the social group and is then, the group's mouthpiece. Naturally, in this latter case we have a symmetrical relationship.

Assuming different textual roles, the subject signals the social role as well. Specific text analyses show that the subject may be a specialised carrier of tradition, a memory depositary who explores memory resources in order to offer moral and social wisdom; to teach, to admonish and more generally, to pass on the cross-generational heritage. These specialised roles can be found in historical songs, ballads and animal fairy tales. However, the subject may well not expose his/her role, but be a regular member of the group and therefore become a nonspecialised tradition bearer.

There is yet another function that forms of address can serve - namely, they point to the performative dimension of folklore texts or in other words, they 


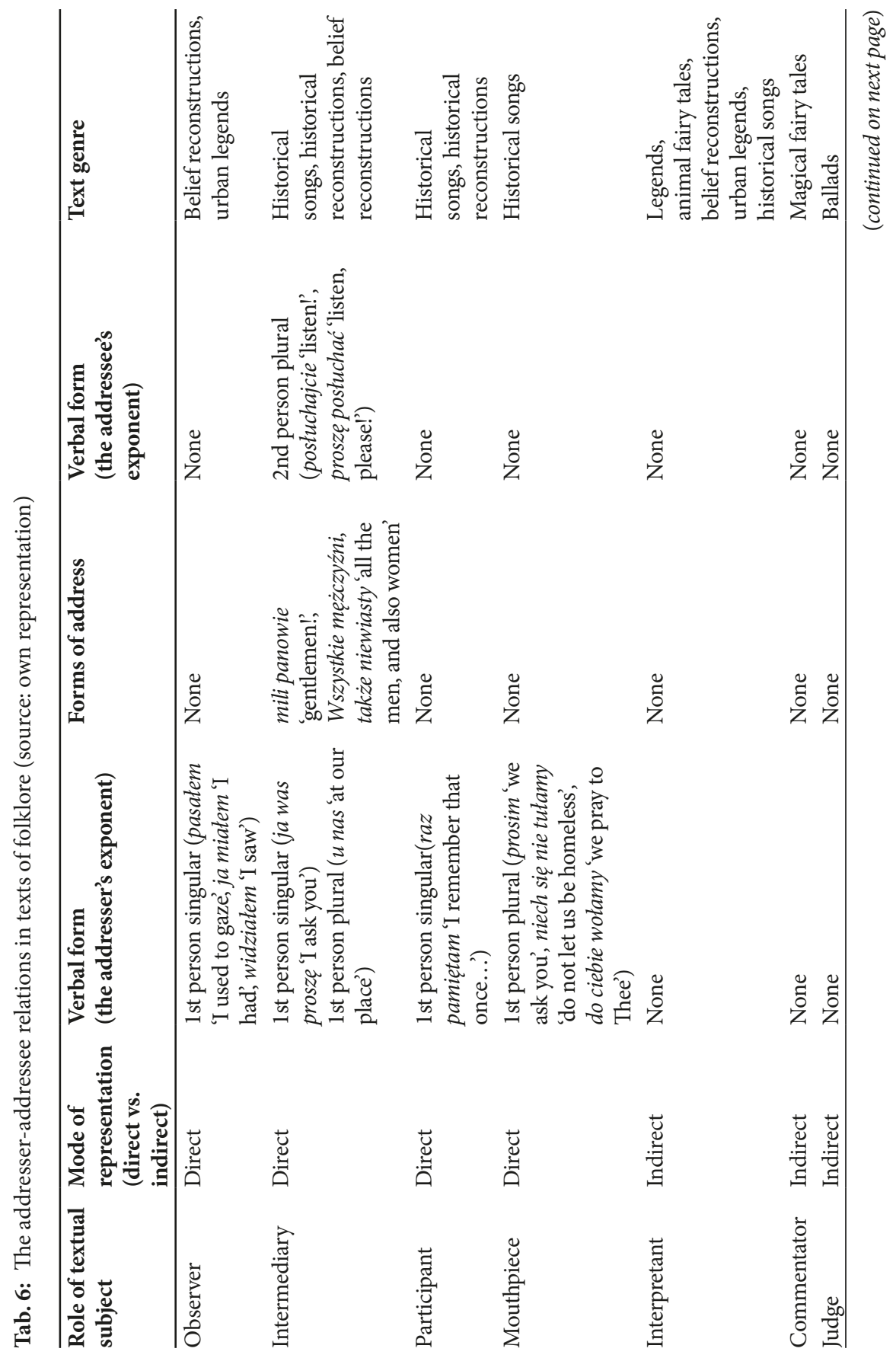




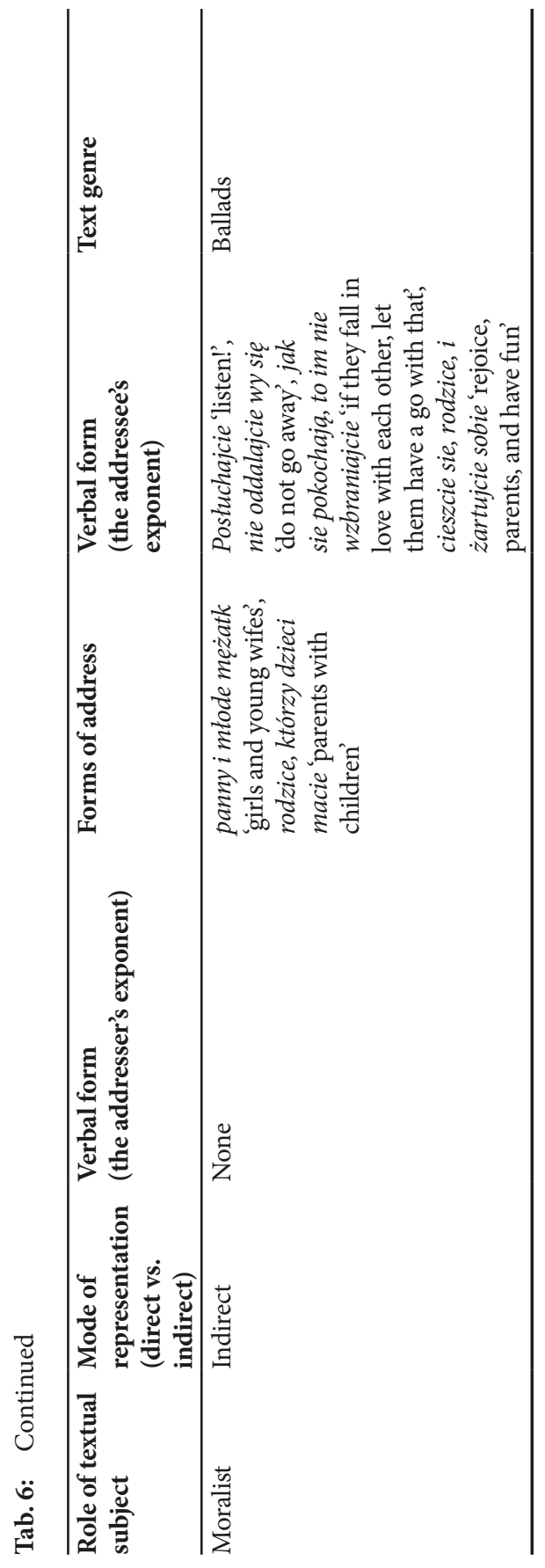


mark the circulation and reception of texts. In this respect, we can distinguish two specific cases:

-" primary (natural) circulation is possible when - during a recording session the informant allows for and enters into a more informal relationship with the enquirer/explorer. Take this example from Text 8 in Chapter VI: Styszałem, $\dot{z}$ e został znaleziony $w$ lesie $z$ rozciętym ciałem i wypatroszony na organy. Co wiem, że jej bezsensem, ale tak slyszałem od mojej mamy własnej rodzicielki ('I have heard that his body was found in the woods, eviscerated and disembowelled, for his vitals. I know this makes no sense, but that is what I have heard straight from my Mum');

-r secondary (unnatural) circulation can be found in formal/official forms of address, such as panie profesorze 'dear professor', or prosze pana 'excuse me, sir', as in Text 1 in Chapter V:

\begin{abstract}
Proszę pań. Jak Pan Bóg stwarzat świat i stworzył człowieka, osła, psa i małpe i wszystkim dał równo po trzydzieści lat. Więc człowiek przeżywszy te trzydzieści lat, to sa najpiękniejsze lata. Popatrzyl, że świat jest taki piękny, a on już będzie musiał umierać, poszedł do Pana Boga z prośbą, żeby mu przedłużył [...] No wie Pani, tych różnych morałów, to się wiedziało, ale wie Pani teraz na zawołanie, to te szufladki zaczynaja się zamykać. Czasem się tak zatrzaśnie, że się cały dzień chodzi i nie można sobie przypomnieć, co to było. Znam jeszcze takich, co ostatnio właśnie styszałam, jak $w$ jednej parafii $\dot{z} y \nmid$ ksiądz $i$ taki pijaczek, ale on jeździł autobusem [...] (WojPod, 67).
\end{abstract}

Dear Ladies. When God was creating the world, He created the man, the donkey, the dog and the monkey and gave each of them 30 years of life. So, the man would lived for 30 years, and these were the most beautiful years. And he would look around to see that the world was so beautiful, but he would soon have to die, and he went to God to ask God for a favour and let him live longer (...) You know, Ma'am, I used to know many different morals, but, you know, Ma'am, now when one needs to recall any of them, they are like shut drawers, Sometimes they are stuck for good and one cannot recall what it was at all. I have also recently heard that in one parish there was a priest, a little boozer, but also a bus driver. He would drive people around.

As to the information about the text circulation,

- it can expand from the genre convention a given text exemplifies, so it may not be included in highly petrified texts (e.g., magical fairy tales), but can appear in those genres that have less rigid forms, such as urban legends;

- it can reflect the actual addresser-addressee situation as well as the explorerinformant relationship, the informant here being the depositary of collective memory; 
- it can be correlated with a kind of communication act; collective forms of address (chcecie stuchać, to stuchajcie if you [plural] want to, listen [plural] to this') point to mass communication (i.e. the subject narrates a story to the group), whereas the lack of forms of address or the forms like wie pani 'you know, Ma'am' mark interpersonal communication, be it formal or informal (as in wiesz'you know');

- it may point to a kind of memory; if a text is used in primary circulation as an act of informal interpersonal communication, this points to communicative memory, whereas if a text is used in secondary circulation as an act of interpersonal or formal mass communication, this points to cultural memory.

Memory figures are encoded firstly in the so-called initial textual formulae. This is the part of the text structure that is a linking element between memory, the teller and the narrated text.

As to the information about the social group reference, it can be communicated in folklore texts in two ways:

-r explicitly (in initial textual formulae), and

- implicitly (through the values encoded in texts).

\section{Functions of memory figures}

Each of the three features of memory figures discussed above performs different textual functions as well as play different roles in construing and transmitting memory.

Time is a memory support in the sense that it places or localises events in the temporal domain (usually by means of specific dates) and mirrors a social group's values, the group being a collective memory bearer. In other words, time reflects the group's specificity in terms of the role it plays in bearing memory. Moreover, time is a carrier of text genre characteristics and thus, a bridge between the past and the present: Od tego czasu gdy człowiek umiera, jego ciało idzie do ziemi, a dusza do nieba, aby tam stanać przed Panem Bogiem (SimLud, s. 52; 'Ever since that time when a man passes away, his body goes to the ground, while his soul goes to heaven in order to appear before the Lord God').

Space, in turn, functions as a memory carrier in the sense in which a stone may bring back the memories of some past event. Space is then, a witness of events (that is, in order to commemorate a given event, a castle, a well, a monument etc. can be built or erected) and also a navigator of events (that is, it answers the question about what happened where): 
Tab. 7: Values vis-a-vis genre differentiation of folklore texts (source: own representation)

\begin{tabular}{|c|c|c|}
\hline Folklore genre & $\begin{array}{l}\text { Values in a genre-specific } \\
\text { picture of the world (the } \\
\text { representational level) }{ }^{56}\end{array}$ & $\begin{array}{l}\text { Values in relation to the } \\
\text { addresser and intentionality (the } \\
\text { communicative level) })^{57}\end{array}$ \\
\hline $\begin{array}{l}\text { Magical fairy } \\
\text { tales }\end{array}$ & $\begin{array}{l}\text { Moral (triumph of truth and } \\
\text { justice) }\end{array}$ & $\begin{array}{l}\text { Moral satisfaction derived from } \\
\text { the hearer's expected development } \\
\text { of events (Ługowska 1993: 35), } \\
\text { moralising }\end{array}$ \\
\hline $\begin{array}{l}\text { Animal fairy } \\
\text { tales }\end{array}$ & Cognitive, moral & $\begin{array}{l}\text { Informative (e.g., about why dogs } \\
\text { should chase cats), moralising }\end{array}$ \\
\hline $\begin{array}{l}\text { Novelistic fairy } \\
\text { tales }\end{array}$ & Moral & $\begin{array}{l}\text { Moralising, compensatory, } \\
\text { generating fear, laughter, or } \\
\text { information (Wróblewska 2007: 71) }\end{array}$ \\
\hline Legends & $\begin{array}{l}\text { Cognitive, transcendental } \\
\text { (sacrum), moral (e.g., } \\
\text { obedience, diligence, working } \\
\text { hard) }\end{array}$ & Informative, moralising \\
\hline Recollections & $\begin{array}{l}\text { Cognitive, life-promoting, } \\
\text { psychological and physiological } \\
\text { (as part of one's experience) }\end{array}$ & $\begin{array}{l}\text { Informative (about one's } \\
\text { experiences), social (sharing one's } \\
\text { experiences with others) }\end{array}$ \\
\hline Urban legends & Cognitive, physiological & $\begin{array}{l}\text { Fear-generating, hedonistic, } \\
\text { ludic (generating pleasure from } \\
\text { something having been narrated) }\end{array}$ \\
\hline $\begin{array}{l}\text { Belief } \\
\text { reconstructions }\end{array}$ & $\begin{array}{l}\text { Cognitive (supernatural world } \\
\text { knowledge), psychological } \\
\text { (safety, comfort) }\end{array}$ & Fear-generating, ludic, informative \\
\hline
\end{tabular}

(continued on next page)

56 In reference to the representational level, we follow Jadwiga Puzynina's typology of (positive) values into basic and instrumental ones. The former includes the transcendental and non-transcendental types (i.e. aesthetic, moral, cognitive, life-promoting, psychological, and physiological ones; cf. Puzynina 1991: 136).

57 As far as the communicative (interactive) level is concerned, S. NiebrzegowskaBartmińska argues that 'values correspond closely to the textual subject (that is, the addresser of the whole text) as well as to the intention of the text in question. It is on this level that values happen to be activated and become tangible in relation to the other who is the addresser's attempted target of information, instruction, amusement, admonition, promise, manipulation etc.' (Niebrzegowska-Bartmińska 2012: 39). If so, the intentions identified by Jolanta Ługowska as typical of the Polish folklore have been applied here: information, admonition, irrational fear, laughter, and moral satisfaction (Ługowska 1993: 35). The list of options has been extended with few more identified by Violetta Wróblewska: moralising, compensation, amusement, anxiety (Wróblewska 2007: 71). 
Tab. 7: Continued

\begin{tabular}{|c|c|c|}
\hline $\begin{array}{l}\text { Historical } \\
\text { reconstructions }\end{array}$ & $\begin{array}{l}\text { Cognitive (historical knowledge, } \\
\text { be it general or local) }\end{array}$ & Informative \\
\hline Anecdotes & Cognitive & Informative, fun-generating \\
\hline Ballads & $\begin{array}{l}\text { Moral ('respect for the elderly } \\
\text { and weak, sympathy, and } \\
\text { generosity' (Niebrzegowska- } \\
\text { Bartmińska 2012: 37) }\end{array}$ & $\begin{array}{l}\text { Admonition against breaching } \\
\text { generally-accepted social norms and } \\
\text { system of values, moralising }\end{array}$ \\
\hline Historical songs & $\begin{array}{l}\text { Cognitive, moral (fight for a } \\
\text { nation's political independence) }\end{array}$ & $\begin{array}{l}\text { Informative, patriotism-fostering, } \\
\text { identity-fostering, supportive, spirit- } \\
\text { fostering, heroism-commemorating }\end{array}$ \\
\hline Carols (wishes) & $\begin{array}{l}\text { Life-promoting (health, } \\
\text { happiness, properity) }\end{array}$ & $\begin{array}{l}\text { Informative (sharing good news), } \\
\text { ludic (courtship) }\end{array}$ \\
\hline Christmas carols & Life-promoting (life) & Sacrum sense of belonging \\
\hline
\end{tabular}

Pod Krakowem, pomiędzy wioskami Łagiewnikami a Wolą Duchacką, byt dawniej staw przy drodze, dzisiaj już zupełnie zarośnięty. W tym stawie głębokim mieszkał topielec ze swoją żona, i kto tylko nieostrożny kapat się w stawie, tego wciagat topielec na głębinę (SimLud, 44).

\begin{abstract}
Near Cracow, between the villages of Łagiewniki and Wola Duchacka, there was a pond by the road, completely overgrown today. It was in this pond that a drowned man used to live with his wife and whoever was not on their guard while bathing, would be drawn down $\mathrm{d}$ into the deep water by him.
\end{abstract}

Like time, space is a carrier of the world of values expressed in texts. In this sense, space builds a reference to the social group which ascribes or allocates the values it shares to specific kinds of space. For example, the house/home (Pol. dom) constitutes the centre, the sacrum the space that is familiar and safe, whereas the forest (Pol. las) is relegated to the periphery and marks the space that is profanum, alien and dangerous.

To sum up, time and space (understood jointly as the chronotope) serve to localise the event and at the same time, to anchor, legitimise, and activate memory. This is what we find in urban legends behind their formulaic temporal and spatial expressions: W Katowicach żyje pewna pani nadzwyczaj bogata. Ona skończyła uniwersytet, zna kilka języków. Przyjmuje panów bardzo rzadko, bo się szanuje. Ona należy do arystokracji między prostytutkami (Czub Mity, 63; 'An exceptionally rich woman, lives in Katowice. She is a university graduate and speaks several languages. She seldom hosts men because of her sense of dignity. 
Honestly, she belongs to the aristocracy among prostitutes').

By means of doing reconstructions, we can arrive at folk/naive images of the remote past, including, among other things, interpersonal relations and origins of things in the world of animals and/or humans. For example, in animal fairy tales, the kind of reconstructivism employed has a forward slant, which is marked by temporal formulaic expressions of aetiological character: Od tego czasu wilk ma krótki ogon i cięgiem nad tym rozmyśla, jakby się lisowi odpłacić (SimKum, 15; 'Ever since that time the wolf has had a short tail and cannot stop thinking how to pay the fox back'). Naturally, the reconstructed picture of the past involves many different perspectives. In their focus, these can be historical (which builds national identity), mythical, belief-oriented (which fosters local identity), biblical (which shapes religious identity), family-oriented and personal (which contributes to one's individual/private identity) and ritualistic (which creates a sense of cultural identity).

The feature of memory figures that are described here in terms of reference to a social group can be understood as a way of characterising the subject of collective memory or more specifically, as the values which the subject cherishes. This is the reason why this feature helps to identify the addresser's social functions, text circulation within a group included, as well as the collective memory depositary's general characteristics (that is, whether the depositary embraces specialised individuals, or whether the depositary can be any member of the group). Moreover, by means of identifying the reference to a social group, one can also reveal the attitudes the memory depositaries show with regard to, firstly, inherited resources and secondly, the addresser-addressee relationships.

As can be seen in the analyses presented above, respective memory figures happen to be implemented to varying degrees in different text genres. This is of specific concern in the following chapter. 

Memory and text genre - genre memory and genre non-memory 



\section{Memory types versus genre differentiation in folklore texts}

\section{Genres of collective memory and non-memory}

There can be no memory without forgetting, without blanking or blotting memories out. 'Without memory there are no concepts (whose integral part is a prototype understood as an idealised mental picture; neither is there language nor communication).' (Kajfosz 2012: 21). Memory is selective; while only some memory sectors are singled out to be remembered, all others are doomed to oblivion. This is to say that memory and non-memory are inseparable, and that 'non-memory is just one of the forms of memory' (Chlebda 2007: 75). As to collective non-memory, it is assumed that it embraces natural and unnatural memory gaps in what otherwise presents itself as collective memory (Wójcicka 2018b: 33).

Let it be repeated that collective memory involves four phases, or stages: memorising (encoding), remembering (storing), forgetting, and recalling/ recollecting (retrieval), 'forgetting being an important shared commonality of both memory and non-memory' (Wójcicka 2018b: 36). That which is forgotten today may be recalled later, either deliberately or accidentally or it may become collective non-memory, that is, 'a space inhabited by characters, events and facts, completely repressed or blocked, which itself alone is a socially relevant variable' (Chlebda 2007: 74).

Memory can then, be compared to the spotlight which illuminates the selected parts of the stage, leaving other sectors in half-light or darkness and with the lighting arrangement being completely different in different situations.

In non-memory research, various metaphorical expressions can be used: suppression, repression and blackout with two major causes of non-memory usually being given - natural and manipulated or (unnatural). If that is the case, we have two kinds of collective non-memory: natural and institutional non-memories (Wójcicka 2018b). While the former relates to what W. Chlebda describes as the subjective memory of events (Chlebda 2012: 115), the latter stands for the objective memory of events or in other words, memory discourse (Wójcicka 2018b: 36). As mentioned above, memory and non-memory are inseparable, dynamic and dependent on a number of factors. One of these factors is connected to the process of shaping both memory and non-memory as a text genre, on the grounds that research is called a memory genre, that is a pattern of speaking 
about something, a set of speaking conventions which serve to be the reference point for oncoming utterances: 'Memories form genres that unfold over time by referring not only to their contexts and to the 'original' event, but to their own histories and memories as texts' (Olick and Robbins 1998: 130; cf. Olick 2007). This gives us a broad idea of a genre:

I extend (...) "genre" concept to identify historically accrued "types" of utterances (...): patterns of speaking structured as a set of conventions against which or within which those utterances are produced and read. (Olick 1999: 384)

A similar position is expressed by A. Erll:

A rhetoric of collective memory can be found in all literary genres which represent the past, from romance to gothic novels, to crime thrillers, as well as in other media such as feature films. Conversely, modes of remembering need not necessarily be established by verbal, literary and narrative forms. Non-fictional media such as historiography and journalism (...) and visual media such as painting and photography (...) have developed their own "rhetorics of collective memory". (Erll 2008: 392; cf. Erll 2011: chs. 4 and 5)

So, a memory genre can be regarded as both a medium and a creation of collective memory as well as a constituent of cultural-communicative competence (cf. Witosz 2005a: 115), an element which is transmitted by and functions in collective memory. In this sense, it is a collective memory code that creates images of the past and triggers responses to these images. Memory genres then, are carriers of a group's values, norms, and worldviews (Wójcicka, in print). It is in memory genres that memory and non-memory models are reflected. In other words, that which happens to be remembered or forgotten is determined by genre conventions. 'As a text matrix, memory genre serves the purposes of memorising (encoding) and remembering (transmitting) an image of the past, so that the memory genre reproduces that image or in fact, these images as they are numerous and vary from genre convention to genre convention' (Wójcicka, in print).

\section{Folklore genre as a factor of collective memory and non-memory}

The question of what builds the content of textual memory and non-memory can only be answered in terms of Halbwachs' and Assmann's memory figures or more specifically, one of the features memory figures can be ascribed to, which is reconstructivism (subjective dimension of memory). As this is a specific research concern in Chapter VII, only brief references to the concept will now be made and set in the context of text genre distinctions. 
What comes to be remembered in historical tales and historical songs are outstanding characters and their deeds, set against the background of major historical events. In these two genres, specific details, such as the number of troops, victims, kinds of weapon used etc. are typically omitted. It is merely the exemplum that matters as an imagination trigger and it is the exemplum that is stored in memory. Naturally, part of a group's collective memory are traumatic events relating to wars, battles or selected historical figures that are usually connected with the origin of the Polish statehood and nationhood. In historical tales and songs these events have been subjected to the process of mythologisation, with the protagonists having been idealised into the exemplary Poles-patriots who adore their country. More specifically, the heroes are depicted as social and temporal isolates who come to the fore at one specific and absolutely vital moment in Polish history, the so-called great history. In summary, Polish historical songs and recollections store the mythologised memory of selected events of Poland's political history. At the same time, we find in these two genres what Kazimierz Moszyński calls catapult (Pol. wyrzutnia). That which is 'catapulted' in this case embraces 'blank spaces' in historical discourse and collective memory and can be anything that proves to be uneasy and undesirable for a given social group and its own image of itself.

The process of mythologisation can also be identified in recollections, though here it does not include any historical events or characters. That which is committed to memory involves key moments in one's life, the moments that are liminal in nature and mostly family-related (birth, childhood, wedding, death, funeral). As narrated in recollections, the images of the past are gender-specific and vary greatly from text to text. Still, mythologisation typically involves one's childhood and youth, both idealised in the past and set in opposition to the present, which provides a sentimental perspective, especially while depicting interpersonal relationships. However, when it comes to economy and living standards, it is the present that is positively assessed. In recollections then, there are two processes that mould remembering and forgetting: for comparative purposes, the past is referred to the present and then, either mythologised or rationalised and demythologised.

As evidenced in Chapter VI, folk ballads also preserve individual memories, yet instead of mythologisation we have generalisation, the object being social values and truths. Specific events, detailed accounts of peoples' past lives and appearance or behaviour are 'catapulted'. Ballads communicate only that which contributes to the values being cherished. So, for example, if a given ballad is meant to make the point that love is superior to any social and financial 
considerations, this alone will be emphasised in the characters' young lives. This explains why ballads depict character types and set them in reiterated critical social contexts and situations. Anything that escapes typicality and does not relate to a group's pending problems is relegated to non-memory. In this sense, folk ballads can be compared to reportage: it is through individual cases that global, social issues are foregrounded.

Generalisation and a kind of depersonalisation are found in proverbs where truths and wisdom are abstract from specific situational contexts. This generalisation is more typical in all kinds of fairy tales, be they magical, animal, novelistic or anecdotal.

In apocryphal carols and legends, the mechanism that moulds the memory processes consists of a kind of circumstantial (trace-by-trace) reconstruction. These two genres communicate knowledge about the origin of the world or the beginnings of Christianity, yet they also allow for imagined interpolations, biblical in nature. As with reconstruction material, 'traces' are provided, on the one hand by canonical texts and on the other hand, by God's works of Creation, the latter taken as evidence, if not proof, of the acts and activities narrated in texts.

A similar kind of circumstantial reconstruction can be found in historical recollections. The traces here are identified in real space and may involve the ruins of castles, wells and stones etc. As the past in this genre cover events that are by nature, mysterious, extraordinary, unusual and irrational, the mechanism shaping memory is that of hyperbolisation. As long as the shaping mechanism consists of exaggerating the past, it can also be found in urban legends and belieforiented reconstructions. Whatever happens and whoever does anything, be it a human or demonological agent, it is subject to hyperbolisation, frequently with the intention of being mocked and ridiculed.

In general, genre memory depends on genre conventions that feed collective memory and are communicated in a cross-generational (cultural) transmission.

Tab. 8 presents memory and non-memory mechanisms/processes in relation to selected folklore genres. As can be seen, the relationship created between collective memory and specific textual genres is bidirectional: on the one hand, genre conventions (e.g., opening and closing formulae in fairy tales or text patterns) extend from collective memory. Yet, on the other hand, any specific genre moulds a picture of the past that it communicates and as such, it shapes the memory (i.e. textual memory) that is recalled in the text, which is why textual memory can be regarded as yet another criterion of typologsing folklore genres. This will be examined in the following section. 
Tab. 8: Memory and non-memory processes in a genological perspective (source: own representation)

\begin{tabular}{|c|c|c|}
\hline Text genre & $\begin{array}{l}\text { Processes of collective } \\
\text { memory and } \\
\text { non-memory }\end{array}$ & Object of the process \\
\hline \multirow[t]{2}{*}{ Historical reconstructions } & Mythologisation & Positive historical figures \\
\hline & Reconstruction & $\begin{array}{l}\text { Events reconstructed from } \\
\text { tangible (ruins of a castle) } \\
\text { or intangible (place-names) } \\
\text { evidence }\end{array}$ \\
\hline \multirow[t]{2}{*}{ Recollections } & Mythologisation & $\begin{array}{l}\text { The past (childhood and } \\
\text { youth) }\end{array}$ \\
\hline & $\begin{array}{l}\text { Demythologisation and } \\
\text { rationalisation }\end{array}$ & $\begin{array}{l}\text { The past presented from the } \\
\text { perspective of economy and } \\
\text { business }\end{array}$ \\
\hline Legends & Reconstruction & Acts of holy figures \\
\hline Urban legends & Hyperbole & People's unusual acts and deeds \\
\hline Belief reconstruction & Hyperbole & Acts of demonic figures \\
\hline $\begin{array}{l}\text { Fairy tales (magical, animal, } \\
\text { novelistic) }\end{array}$ & Typisation & Characters' acts and activities \\
\hline Anecdotes & Typisation & Characters' acts and activities \\
\hline Ballads & $\begin{array}{l}\text { Generalisation and } \\
\text { typisation }\end{array}$ & $\begin{array}{l}\text { An individual's traumatic } \\
\text { experiences }\end{array}$ \\
\hline $\begin{array}{l}\text { Historical songs, heroic } \\
\text { ones included }\end{array}$ & Mythologisation & $\begin{array}{l}\text { Positive historical figures } \\
\text { (mainly local heroes) }\end{array}$ \\
\hline Apocryphal carols & Reconstruction & Acts of holy figures \\
\hline
\end{tabular}

\section{Memory as a criterion of typologising folklore genres: mnemonic typology of texts of folklore}

\subsection{The criteria of folklore genre differentiation}

There are about a dozen typologies of oral texts and texts of folklore, offered by linguists, folklorists, and textologists. They vary in their choice of differentiating criteria, complexity and purpose.

The basics of folklore genre typology can be traced back to the insights of Wiktor Gusiew and Władimir Propp. Gusiew assumed that when differentiating prose genres one should consider a whole set of criteria: the reality domain, the perception characteristic of that domain and the corresponding form of 
expression, in addition to social function (Gusiew 1974: 151). Propp, in turn, suggested that the classification should be based on types of storyline and plot, which in practice are implemented by the protagonists present in the story, and point to the possibility of classifying genres according to character types (cf. Propp 1977: 52). Propp would also consider the pragmatic function of texts as yet another criterion of genre typology. He based this on the observation that some folklore genres have a clear practical and life application (p. 53). Propp's third criterion is the form of performance that texts are presented in, including musical forms of performance.

In addition to the considerations already mentioned, some researchers have suggested functional-thematic (Wiktor Gusiew, Jan Stanisław Bystroń) or purely thematic criteria (Antti Aarne i Stith Thompson, Oldřich Sirovátka). Typologising and epic texts, Jeleazar M. Mieletinski considered to be 'the structure of an image of the man' (after Adamowski and Bartmiński 1988: 67). Psychological parameters were assumed by Antonio Poviña who, distinguished folklore as respectively, intellect, feeling and volition (after Adamowski and Bartmiński 1988: 67). Vilmos Voigt opted for a social-communicative approach to genre typology, to which he ascribed a set of factors such as the addressee, the addresser, the message communicated, functions, means of communication and ways of reception (after Adamowski and Bartmiński 1988: 68).

Furthermore, Roch Sulima's pragmatically-oriented typology of modern oral texts was in fact, semiotic and communicative in character as, to quote Sulima himself, 'what is taken into consideration in this approach embraces both the "memory" that is written into a given text of its earlier applications and contexts (which amounts to the identification of the "traces" of the objectivised structure of the text attested in its hitherto available variants) as well as the present application of the text, that is, the social functions it shows in actual usage' (Sulima 1977: 113). Moreover, as Sulima would continue, oral communication falls into three semiotically-independent groups of texts: texts-signals, texts that allow for their reproduction in another space but within the same time interval and texts-signs.

In her proposal, Jolanta Ługowska assumes the parameter of text intentionality as the main criterion and tool of typologising texts of folklore. For her, this consists of 'an immanent analysis - in contrast to functional approach which would require a different line of argumentation and remain transcendental with regard to the text itself' (Eugowska 1993: 9).

Let us not forget that classifications of folklore texts have also been attempted in a contrastive perspective in relation to several genres simultaneously. Fairy tales then, are compared with myths, legends, fables and tales in W. N. Toporov's 
classification. As Jakuboze (2007: 31) sees it, 'Toporov posited the elements of marvel and sacrum as well as - additionally - temporal aspects of the storyline as the distinguishing criteria of these genres'. If that is the case, myths are characterised with the sacral, the marvellous, and the foretime, fables are void of sacrum but exemplify elements of marvel and timelessness, legends lack the marvellous but show the sacral and reflect historical contexts, while in tales, only historical settings can be identified (with no sacrum or marvel).

Another suggestion of classifying folklore prose genres comes with W. Bascoma's scheme which is based on the following parameters: content - reality (myth, legend) vs. fiction (fable), time - remote past (myth) vs. recent past (legend) vs. unspecified time (fable), place - various remote and faraway worlds (myth) vs. the modern world (legend) vs. unspecified locations (fable), the worldview - religious (myth, legend) vs. the secular (fable), and dominant character - non-human (myth) vs. human (legend) vs. human and/or non-human (fable) (after Jakuboze 2007: 33).

Generally, classifications of folklore prose texts are most often attempted by theme and/or by protagonist. For example, the distinction can be made between magical, animal, and novelistic fairy tales by virtue of the kind of protagonists they exemplify, that is, respectively, unreal, animal-like and real. (On similar grounds, historical and belief reconstructions can be differentiated.)

One of the most comprehensive typologies of folklore texts has been offered by J. Bartmiński. The scheme is built on as many as ten criteria: (1) text autonomy with regard to the situation of use (customary, ritualistic, circumstantial/occasional), (2) qualitative assessment of situation (work, harvest, wedding, funeral, dance, prayer, festivity); (3) status of the storyline (obligatory, facultative, not available); (4) medium of communication (singing or speaking); (5) somatic code (present or absent); (6) form (prose or verse); (7) communicative intentions; (8) content (true or fictious); (9) poetics; (10) theme (Bartmiński 1990: 169-178).

J. Bartmiński and S. Niebrzegowska-Bartmińska, in turn, postulated an 8 point characterisation of genres, including: (1) addresser, (2) addressee, (3) communicative situation (time, space, circumstances), (4) communicative intent (internal purpose), (5) theme (object), (6) represented world ontology (fictionality), (7) form (oral or written), (8) way of depiction (poetics) (Bartmiński and Niebrzegowska-Bartmińska 2009: 146). More recently, S. NiebrzegowskaBartmińska (2012) has added one more parameter to the list, the category of value. J. Adamowski (2002) also opted for the parameter of the informant's naïve world-knowledge.

Referring to other proposals, Simonides (1961) considered the category of purpose/goal ('fables serve purposes of entertainment, while fairy-tales teach, 
mock and educate'; ibid., p. 5), and the categories of time and space (fairy tales would most often present a specific fact which had a direct bearing on other related events; neither fables nor fairy tales specify the time and the place of the course of the events that they depict; ibid., p. 6), Wróblewska (2002: 115-116) to discuss the way reality is depicted and the attitude the text showed towards the depicted reality (which explains why conflicts are resolved in different ways in, respectively, magical and novelistic fairy tales). Two of the categories that seem to have been of some interest recently with regard to fairy tales is the worldview and the construction pattern (cf. Niebrzegowska-Bartmińska 2002 and 2007; also Wójcicka 2010: 15-35).

Finally, if another criterion was to be added to the aforementioned list of differentiating factors, it would be formulae, see Wójcicka (2010: 188-189) on the differentiation of prose genres according to the type of formulae.

\subsection{The memorates-fabulates distinction versus mnemonic typology of folklore genres}

As signalled above, classifications of folklore genres can be based on the category of memory, which brings us to the possibility of postulating a mnemonic typology of texts of folklore. It seems worth mentioning here that this possibility can be traced back to Karl von Sydow and his (1934) distinction between memorates and fabulates in groups of folk texts. In a nutshell, memorates embrace 'an experiential narrative, a description of supranormal experiences undergone by the narrator, or a person close to him or her' (Green 1997: 553), while fabulates 'may have some elements based on experience, yet they do not immediately come from these, but from a mental image that has originated from elements of this type in which they are crystallized' (Green 1997: 274). Some of the memorates, that is, those that are of special significance for the group, may become part of the group's tradition. If this happens, they are typically subject to changes and modifications proportionately to the intentions of those who retell them later on. 'In this way, the memorate is turned into a recollection, with the boundary between the two being far from clear-cut' (Simonides 1969: 46).

Memorates are then, intended to reflect one's individual and personal recollection that form the basis of the resulting folk tale. As noticed by D. Simonides,

A memorate may give rise to a tale, but not every memorate is a tale. As long as one's account of his or her personal experiences is of some interest to the group, it may become a common property that later on acquires a more objective character and loses some of the original personal characteristics for the sake of (...) reflecting transcendental situations, which is why even the most prosaic and every-day life functions present themselves as 
supernatural and extraordinary. The net effect of this fabularisation is called a fabulate, by Sydow. This is to say that every memorate, that is, one's specific and actual experience, is potentially a fabulate. (Simonides 1969: 46)

This differentiation, however, is not clear enough as memorates relate to an individual's memory, whereas fabulates function as texts in collective memory. Moreover, Sydow sees both memorates and fabulates as only connected with tales, with no mention of other genres, such as modern urban legends which contain as many fabulates as memorates. Nor does Sydow consider the parameter of a text situation which has a Chinese-box structure: it is a memorate (as one's recollection of the grandma's telling of an animal fairy tale) evoking a fabulate (the actual animal fairy tale). One way or another, what we have extends from sociologically- and culturally-oriented memory research: there is no individual memory without community and communication, therefore every memorate can only exist only in and through communication which makes it part of a more general (e.g., family) circulation.

Nevertheless, the memorates-fabulates distinction does not help to identify any relationships between collective memory and folklore texts. It seems to be limited merely to thematic considerations of/in a text, that is, whether or not the narrator's experiences feed the storyline. In other words, this distinction neither embraces the way the past is depicted in the text (i.e. how memory functions texts) nor relates to the way the text functions in collective memory (i.e. how inhabited memory turns into uninhabited memory, to use A. Assmann's terminology).

\subsection{Features of memory figures versus genre differentiation of folklore texts}

To repeat, the typology attempted in this subchapter is connected with the assumed close relationship between texts of folklore and kinds of memory, with the three 'special features' of memory figures in selected folklore genres being the starting point. As discussed at the beginning of Chapter VII, M. Halbwachs and J. Assmann point at the following three considerations: time and space, reconstructivism and social group reference, all encoded in, among other things, framing formulae.

More specifically, time and space are reflected mainly in initial (temporal, locative, and chronotopic) formulaic expressions and serve the purposes of localising and legitimising the course of events as well as activating memory.

There are two ways of examining reference to a social group. One consists of a close reading of the content of a folklore text. For example, having found that a given legend reflects Christian religious beliefs, we can safely assume that 
the bearers of the text, that is, the rural community, cherish a similar Christian worldview and value system. The other way of identifying a social group is an analysis of testimonial formulaic expressions because they reveal the source of the narrated story as well as the kind of relationships that are gained among group members. The following is an instance a personal belief reconstruction: Moja matka rozprawiała raz, jak oni byli mała dziewczynka, dwanaście lat, to sizzle nad Odra, tutaj kasek, i widzieli jak się dzieci kapały (SimKum, 126; 'My Mom used to tell us that when she was a little girl, 12 years of age, she was once walking along the Oder and saw children bathing in the river'). Other things that help to identify the relevant characteristics of a social group include the categories of textual subject and addressee as well as the values that can be found in the text.

Finally, reconstructivism aims at disclosing folk images of the remote past, interpersonal relationships and origins of things, animals or people as we know them today. So the kind of reconstructivism that we find in animal fairy tales has a forward orientation, that is, the available, temporal formulaic expressions of an aetiological natural point to the oncoming development of events: Od tego czasu wilk ma krótki ogon i cięgiem nad tym rozmyśla, jakby się lisowi odpłacić (SimKum, 15; 'Ever since that time the wolf has had a short tail and cannot stop thinking how to pay the fox back'.

Genre differentiation of the three features of memory figures is attempted in Tab. 9.

\subsection{Traditional and modern folklore genres in a memory theory perspective}

The main criterion of Polish genre differentiation used to be time considerations, with the year 1945 being the demarcation line. As D. Simonides explains,

Those narratives that happened to be collected, recorded or otherwise attested after 1945 were regarded as modern (...). On the other hand however, so-called „modern stories" can also be understood as the antithesis of earlier narratives that appear old or traditional. If we take this into consideration, the differentiating parameter is the subject-matter and by modern narratives we mean those that feed on current events. (Simonides 1969: 199)

D. Simonides herself considers fairy tales, tales and anecdotes to be traditional folklore genres. 'There are no specifically novel genres or forms among modern narratives. These are new stories in old forms' (Simonides 1969: 199), and by this she means personal life stories and realistic stories about extraordinary, happy or tragic events. Generally, as she continues, 'this fantasy seems to be dominant in traditional narratives and realism in modern stories can provide an additional criterion of differentiation' (Simonides 1969: 200). 


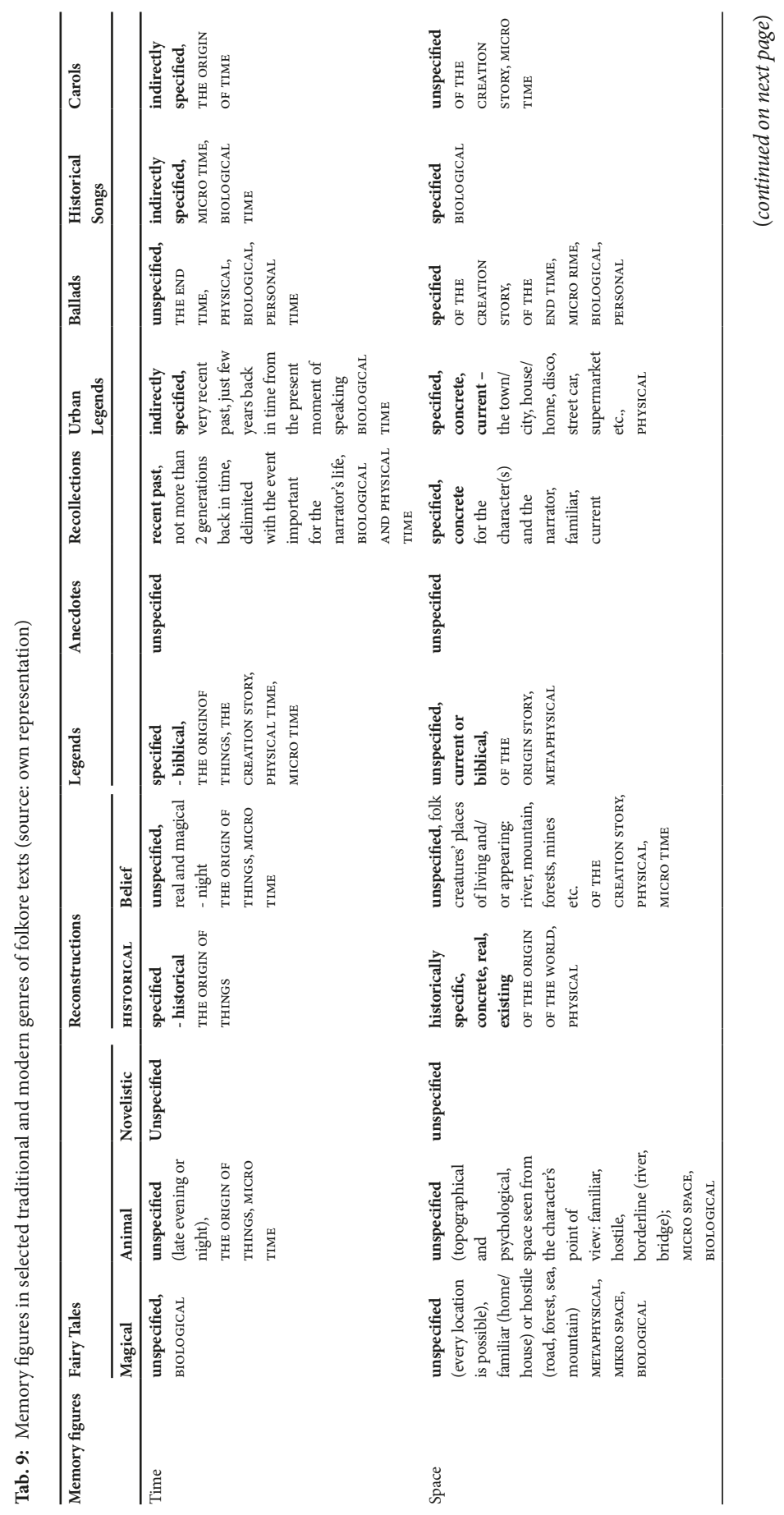




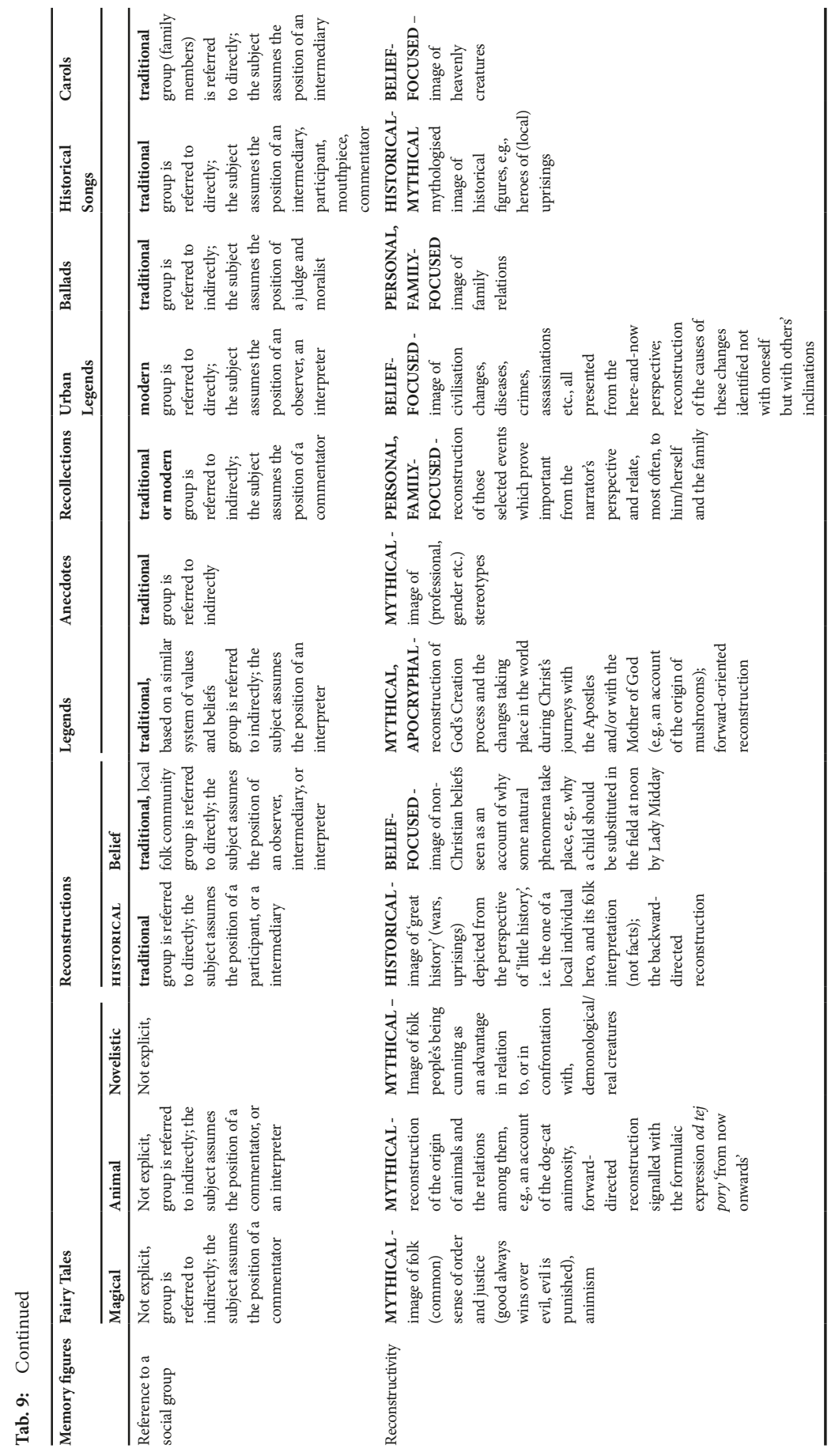


A different proposal of folklore genre differentiation comes from Dionizjusz Czubala. For him, 'historical [traditional] folklore embraces anything that is no longer part of our current living circulation, has merely become potential repertoire and is not therefore continued by the new generation' (Czubala 1985: 18). This includes, according to D. Czubala, fables, ballads, topical songs, riddles and magical formulae. By contrast, modern folklore genres are jokes, anecdotes, sensations (bombshells), personal life narratives, current paremiological expressions and songs.

It is not difficult to notice that all such topologies prove to be insufficient in all likelihood. For example, while songs may well be part of modern folklore, some of them are no longer performed though this does not mean that they cannot be reintroduced into current circulation and become part of living collective memory again.

Memory theory seems to offer ways of making up for these deficiencies by positing a new classification of traditional and modern folklore genres. Text genres are then assumed to be memory carriers, be they communicative or cultural, as are collective memory expressions, be they communicative or cultural. These are the correspondences that are absolutely plausible in the light of J. Assmann's distinction between communicative and cultural kinds of memory (see Diagram 7). If this is the case, traditional genres include those texts that are both carriers of cultural memory and function in cultural memory, such as fairy tales in their three types (magical, animal and novelistic), legends, historical songs and carols. They are all cultural memory carriers in the sense that they depict some mythical prehistory by means of either unreal characters (e.g., witches in magical fairy tales and personified animals in animal fairy tales) or saints (Jesus Christ, the Apostles) that are evoked in existential formulaic expressions. This mythical prehistory is also signalled in these genres in terms of time and space (e.g., temporal and locative formulaic expressions of unspecified character).

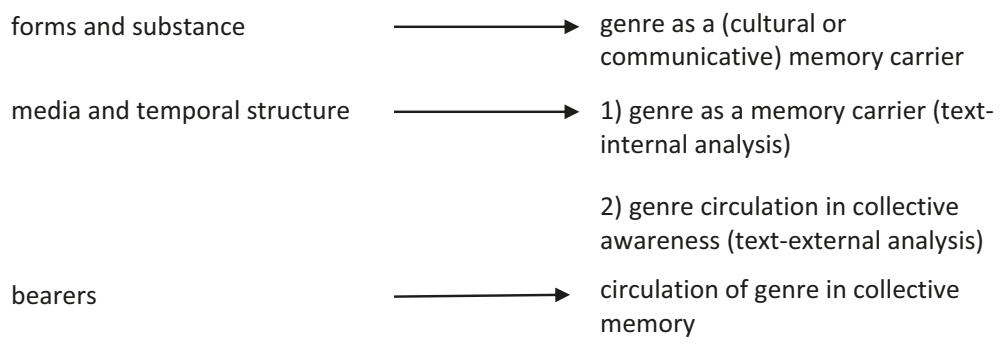

Diagram 7: Criteria of collective memory typology vis-a-vis text genre (source: own representation). 
Both fairy tales and legends are said to have a refined (J. Assmann) and petrified (folklorists) form of a clear-cut two- or even threefold construction. This structure extends from a traditional and symbolic system of encoding the good-evil opposition which, next to its obvious didactic function, also serves to structure the whole text. As these genres, most notably legends and folk carols function in cultural memory and are transmitted by specialised bearers of tradition, it appears that when attempting to record them in fieldwork research it is almost impossible now to find a first-hand recording of some fairy tales or legends.

In contrast to traditional genres, modern genres embrace texts that express and operate in communicative memory, such as recollection tales and urban legends. Their non-petrified, informal and loose form, bears witness to their communicative character. J. Assmann observes that it is also their content that builds their communicative import - they are living recollections based on and oscillating around one's personal life and as such, they function in the kind of memory which is subject to current, on-going circulation. Urban legends seem to be better examples of communicative memory than recollections, as their motifs, on principle are often reiterated in a relatively large population. Even recollections, though evoke stories that remain related to the actual and the local. In this respect, the one that narrates/tells recollections bears witness to collective memory.

Naturally, J. Assmann's types of memory reflect the two extremes of the memory spectrum, as divergent as say, a weekday and a holiday or literary and colloquial varieties of language. However, J. Assmann makes it clear that these two extremes mark the two poles of equal cline with gradual transitions moving from one to the other. The accumulation of changes and therefore a transition, will vary from case to case. Undoubtedly, there are cultures in which cultural and communicative kinds of memory are so sharply differentiated that biculturality can be considered. This is the case of Ancient Egypt. Other societies exemplify a gradation model of the communicative-cultural memory distinction, or as J. Assmann puts it, 'the model of the sliding scale' (cf. J. Assmann 2011: 40-41).

If we apply this 'sliding scale' to folk culture as a whole, not merely to its extreme expressions, then we should be able to distinguish transitional cases as well. Indeed, the two folklore genres that can be described in terms of communicative-cultural memory are (historical and belief) reconstructions and anecdotes.

As noted by D. Simonides and J. Hajduk-Nijakowska (1989), reconstructions of the historical kind narrate part of the so-called (external) great history as it is reflected in an outstanding local hero's personal life. As non-petrified texts, 
reconstructions of this kind can be handed down by both witnesses of collective memory as well as specialised tradition bearers, this depending on the subject matter and the times of the narrated events. Through their forms, historical reconstructions belong to communicative memory genres, but through their content they exemplify cultural memory genres.

In a somewhat similar fashion, belief reconstructions reflect, on the one hand, the form (undeveloped, loose, non-petrified) and the substance (personal life stories narrating one's dreams or encounters with ghosts) characteristic of communicative memory genres. However, on the other hand, belief reconstructions belong to cultural memory genres because they relate to absolute mythical foretime and contain aetiological temporal formulae. They communicate one's belief in, or conviction about the existence of demonological creatures, which we learn about from truth-based formulaic expressions, the traditional and symbolic way of depicting images of these creatures and more generally, from the otherworld. Again, belief-reconstructing texts function in communicative memory (and are communicated by memory witnesses) as well as in cultural memory (and are disseminated by specialised tradition bearers), with a proportion of the two dependent on the actual subject matter and the type of reconstructed beliefs.

Finally, as non-petrified texts exemplifying the traditional system of depicting the world by means of stereotypical judgements, anecdotes constitute one of the communicative memory genres. Yet, as they can be disseminated by specialised bearers of tradition, anecdotes also belong to the set of cultural memory genres. So, similarly to historical reconstructions, anecdotes, for their form and content, fall into the set of communicative memory genres, but because of the way they are communicated, they also belong to cultural memory genres.

Memory and its textual expression (here: framing formulae) can be treated as an important marker of traditional and modern folklore genres. Cultural memory genres (that is traditional ones,) function in collective cultural memory and can only rarely be found in the current circulation of folklore texts, whereas communicative memory genres correspond mostly to modern forms of folklore prose narratives.

Concomitantly, memory factors serve the purpose of disclosing the worldview latent in the genre and also of revealing other characteristics that the genre embodies and realises on the levels of both narration and communication. This is attempted in Tab. 10: the kind of values that prevail in cultural memory genres are firstly, moral in character and secondly, cognitive and revitalising. It seems that the relatively high degree of durability and robustness of the text forms of cultural memory genres stem from the fact that they reflect the value system stability that, for a group embraces that which is most basic and fundamental and therefore unlikely to change. 
Tab. 10: Values vis-a-vis a mnemonic typology of folklore genres (source: own representation)

\begin{tabular}{|c|c|c|c|}
\hline Folklore genres & $\begin{array}{l}\text { Values in a genre- } \\
\text { specific picture } \\
\text { of the world (the } \\
\text { representational } \\
\text { level) }\end{array}$ & $\begin{array}{l}\text { Values in relation } \\
\text { to the addresser } \\
\text { and intentionality } \\
\text { (the communicative } \\
\text { level) }\end{array}$ & Memory types \\
\hline $\begin{array}{l}\text { Magical fairy } \\
\text { tales }\end{array}$ & $\begin{array}{l}\text { Moral (triumph of } \\
\text { truth and justice) }\end{array}$ & $\begin{array}{l}\text { Moral satisfaction } \\
\text { derived from the } \\
\text { hearer's expected } \\
\text { development of } \\
\text { events (Ługowska } \\
\text { 1993: 35), moralising }\end{array}$ & \\
\hline $\begin{array}{l}\text { Animal fairy } \\
\text { tales }\end{array}$ & Cognitive, moral & $\begin{array}{l}\text { Informative (e.g., } \\
\text { about why dogs } \\
\text { should chase cats), } \\
\text { moralising }\end{array}$ & \\
\hline $\begin{array}{l}\text { Novelistic fairy } \\
\text { tales }\end{array}$ & Moral & $\begin{array}{l}\text { Moralising, } \\
\text { compensatory, } \\
\text { generating fear, } \\
\text { laughter, or } \\
\text { information } \\
\text { (Wróblewska } \\
2007: 71 \text { ) }\end{array}$ & \\
\hline Legends & $\begin{array}{l}\text { Cognitive, } \\
\text { transcendental } \\
\text { (sacrum), moral } \\
\text { (e.g., obedience, } \\
\text { diligence, working } \\
\text { hard) }\end{array}$ & $\begin{array}{l}\text { Informative, } \\
\text { moralising }\end{array}$ & $\begin{array}{l}\text { CULTURAL } \\
\text { MEMORY }\end{array}$ \\
\hline Ballads & $\begin{array}{l}\text { Moral ('respect } \\
\text { for the elderly and } \\
\text { weak, sympathy, } \\
\text { and generosity' } \\
\text { (Niebrzegowska- } \\
\text { Bartmińska } \\
\text { 2012: } 37 \text { ) }\end{array}$ & $\begin{array}{l}\text { Admonition against } \\
\text { breaching generally- } \\
\text { accepted social } \\
\text { norms and system of } \\
\text { values, moralising }\end{array}$ & \\
\hline Historical songs & $\begin{array}{l}\text { Cognitive } \\
\text { (historical } \\
\text { knowledge, be it } \\
\text { general or local) }\end{array}$ & $\begin{array}{l}\text { Informative, } \\
\text { patriotism-fostering, } \\
\text { identity-fostering, } \\
\text { supportive, spirit- } \\
\text { fostering, heroism- } \\
\text { commemorating }\end{array}$ & \\
\hline
\end{tabular}


Tab. 10: Continued

\begin{tabular}{|c|c|c|c|}
\hline Folklore genres & $\begin{array}{l}\text { Values in a genre- } \\
\text { specific picture } \\
\text { of the world (the } \\
\text { representational } \\
\text { level) }\end{array}$ & $\begin{array}{l}\text { Values in relation } \\
\text { to the addresser } \\
\text { and intentionality } \\
\text { (the communicative } \\
\text { level) }\end{array}$ & Memory types \\
\hline Carolls (wishes) & $\begin{array}{l}\text { Life-promoting } \\
\text { (health, happiness, } \\
\text { properity) }\end{array}$ & $\begin{array}{l}\text { Informative (sharing } \\
\text { good news), ludic } \\
\text { (courtship) }\end{array}$ & \\
\hline Christmas carols & $\begin{array}{l}\text { Life-promoting } \\
\text { (life) }\end{array}$ & $\begin{array}{l}\text { Sacrum sense of } \\
\text { belonging }\end{array}$ & \\
\hline Recollections & $\begin{array}{l}\text { Cognitive, life- } \\
\text { promoting, } \\
\text { psychological } \\
\text { and physiological } \\
\text { (as part of one's } \\
\text { experience) }\end{array}$ & $\begin{array}{l}\text { Informative (about } \\
\text { one's experiences), } \\
\text { social (sharing one's } \\
\text { experiences with } \\
\text { others) }\end{array}$ & $\begin{array}{l}\text { COMMUNICATIVE } \\
\text { MEMORY }\end{array}$ \\
\hline Urban legends & $\begin{array}{l}\text { Cognitive, } \\
\text { physiological }\end{array}$ & $\begin{array}{l}\text { Fear-generating, } \\
\text { hedonistic, ludic } \\
\text { (generating pleasure } \\
\text { from something } \\
\text { having been narrated) }\end{array}$ & \\
\hline $\begin{array}{l}\text { Belief } \\
\text { reconstructions }\end{array}$ & $\begin{array}{l}\text { Cognitive } \\
\text { (supernatural } \\
\text { world knowledge), } \\
\text { psychological } \\
\text { (safety, comfort) }\end{array}$ & $\begin{array}{l}\text { Fear-generating, } \\
\text { ludic, informative }\end{array}$ & $\begin{array}{l}\text { COMMUNICATIVE- } \\
\text { CULTURAL } \\
\text { MEMORY }\end{array}$ \\
\hline $\begin{array}{l}\text { Historical } \\
\text { reconstructions }\end{array}$ & $\begin{array}{l}\text { Cognitive } \\
\text { (historical } \\
\text { knowledge, be it } \\
\text { general or local) }\end{array}$ & Informative & \\
\hline Anecdotes & Cognitive & $\begin{array}{l}\text { Informative, } \\
\text { fun-generating }\end{array}$ & \\
\hline
\end{tabular}

By contrast, the values that can be identified in communicative memory genres are related to cognition and physiology; they inform us about human anxieties and attempt to explain their sources and consequences. Clearly, both in their form and content they reflect civilizational transformations and changes in the apprehension of the world. Texts in this category are less stable because the values they express are prone to change.

In the mixed (communicative-cultural) type, cognitive values are most frequent. 


\section{Transformations of folklore text genres: from communicative to cultural memories}

The process of genre transformation seems to be unidirectional and involves shifts from communicative to cultural memories. One good example of this is the transition that can be observed in recollections (a non-petrified genre) becoming folk ballads (a well-defined genre in form and content). This situation is illustrated in Grzegorz Michalec' s film Ballada o Janku ('The ballad of Johnny'), where the text of the ballad (of Johnny) is confronted with the actual people's memories (of Johnny). In practice, the film is a kind of an interwoven quilt built of blocks of communicative memory (i.e. the polyphony of the people's recollections, remembering Jane and Johnny) and blocks of cultural memory (i.e. the ballad narrating the story of Jane and Johnny). What we obtain in effect is the fossilisation process of the memory object from the change of the original prosaic form into the target lyric-epic-dramatic form, with all the three basic forms of literature in one genre (and one text). This also provides a lesson on how folklore texts may circulate, as the film is an attempt at crossing the boundaries of a local community (people who remember the love and death of Jane and Johnny), or at breaking away from the 'here-and-now', in order to create a completely novel addresser-addressee situation.

In distinguishing two kinds of memory, J. Assmann was focused on memory bearers: communicative memory is disseminated by non-specialised witnesses of events, whereas cultural memory is communicated by specialised ones. However, it seems worth completing the addresser category ( $\mathrm{J}$. Assmann's main concern) with the addressee category. This is to allow for the fact that communicative memory may also be disseminated by witnesses of events, so the addresser-addressee distinction is not clear-cut, but dynamic, which is completely natural as long as it is remembered that memory lives and functions in communication. In essence, communicative memory is local in its circulation precisely because the addresser and the addressee may be part of the same group. Nevertheless, it does happen that non-specialised memory bearer-witnesses communicate their stories beyond group boundaries, with the stories having larger and larger audiences. The memory scope and circulation is accompanied by a change of the bearer-addresser - the one now responsible for communicating narratives is specialised in the sense that he/she must be a good teller/singer/reciter. In the case of cultural memory, this scope is supralocal, with the addresser-addressee distinction becoming 
more and more visible. In the end, the communicative roles become fixed and fossilised.

We can complete J. Assmann's table with three more factors, or categories: addresser, communication situation, and memory scope (range).

In general, the three added categories pertain to the way(s) in which the text functions in collective memory, be it communicative or cultural. In the context of text genre transformation, the question is which elements of content happen to be shifted from communicative memory to cultural memory, which is, in fact, a question of why the object of memory should at all change.

The ballad of Johnny (see above) seems to indicate that content that is vulnerable to change is related to that which is shocking and unusual, such as the suicidal death of the two lovers (Jane and Johnny) brought about by their parents' interdiction. So, some parts of the original story are 'catapulted', which causes changes in the form and fosters new pieces of information. This can be evidenced with a simple comparison between the witnesses' recollections and the text of the ballad, both quoted in the film. The elements that the ballad (as a cultural memory text) lacks are socially-sensitive, communicativelyundesirable and too specific (financial status, appearance etc.) to be included in the generalised and universal story that we have narrated in the ballad. The whole idea of genre transformation consists ion shifting events from the individual and personal level to a kind of universum laden with moral values and judgements.

Naturally, what changes is also the intent/purpose of the text. The general intention behind sharing recollections is merely fostering past event by calling them to mind, whereas ballads, although based on recollected memories, treat individual cases only as the starting point, the exemplum, for eliciting generalised and universal (supraindividual) values and truths. In other words, communicatively-oriented texts attempt to reflect the greatest possible number of details or to map/represent actual and concrete stories. The kind of communication that facilitates memory here is interpersonal in nature and as such, it attracts disseminating, accumulating and variously detailed pieces of information. Culturally-oriented texts in turn, communicate images that are fixed and petrified in their form as well as generalised in their message.

Another example of text transformation is the as stupid as tall saying (Pol.jaki długi - taki głupi) which Julian Krzyżanowski quotes in relation to the following anecdote: 
Tab. 11: Attributes of communicative and cultural memory according to J. Assmann and M. Wójcicka’s own representation.

\begin{tabular}{|c|c|c|}
\hline & Communicative memory & Cultural memory \\
\hline Substance & $\begin{array}{l}\text { Historical experience within an } \\
\text { individual's lifetime }\end{array}$ & $\begin{array}{l}\text { Mythical prehistory, events } \\
\text { from absolute history }\end{array}$ \\
\hline Form & $\begin{array}{l}\text { Informal, natural, undeveloped, } \\
\text { resulting from everyday interactions }\end{array}$ & $\begin{array}{l}\text { Organised, refined, ceremonial } \\
\text { communication, festivity }\end{array}$ \\
\hline Media & $\begin{array}{l}\text { Living recollections in an individual's } \\
\text { memory, experience, and } \\
\text { transmission }\end{array}$ & $\begin{array}{l}\text { Traditional and symbolic } \\
\text { coding/staged performances } \\
\text { (literature, visual art, dance etc.) }\end{array}$ \\
\hline $\begin{array}{l}\text { Temporal } \\
\text { structure }\end{array}$ & $\begin{array}{l}80-100 \text { years, } 3-4 \text { generation span } \\
\text { evolving together with the sense of } \\
\text { the present }\end{array}$ & $\begin{array}{l}\text { Absolute past of the mythical } \\
\text { foretime }\end{array}$ \\
\hline Bearers & $\begin{array}{l}\text { Unspecialised witnesses of memory } \\
\text { community }\end{array}$ & Specialised bearers of tradition \\
\hline Addressees & Active witnesses of events & Passive, unspecified \\
\hline $\begin{array}{l}\text { Communicative } \\
\text { situation }\end{array}$ & $\begin{array}{l}\text { Dynamic and changeable roles of the } \\
\text { addresser and the addressee }\end{array}$ & $\begin{array}{l}\text { The roles of the addresser } \\
\text { and the addressee specifically } \\
\text { ascribed to well-defined types } \\
\text { of characters }\end{array}$ \\
\hline Scope/range & Local & Supralocal \\
\hline
\end{tabular}

Przysłowie to u Adalberga zanotowane [...] Noted by Adalberg (...), this saying przed laty cieszyło się niemała popularnościa was quite popular in the university $w$ środowiskach uniwersyteckich, krakowskim i lwowskim. Na jego temat krążyly anegdoty wiązane $z$ rozmaitymi znakomitościami lokalnymi, słynacymi z kostycznego dowcipu. W Krakowie tedy, circles of Cracow and Lvov, and refers to various eminent local figures known for their scathing sense of humour. In Cracow, one of these figures was Bolesław Ulanowski, an outstanding gdzie osobistością taka był wybitny prawnik, lawyer, a limbless, handicapped man, Bolesław Ulanowski, beznogi kaleka, wróg wszelkiej blagi, opowiadano o nim taka historyjkę. Zjawit się u niego na egzamin student U., znany mówca wiecowy, z biegiem lat minister-pułkownik. Odznaczał się on niezwykła pewnościa siebie, na egzamin zaś przyszedł nieprzygotowany liczac na to, $\dot{z} e$ jakoś and enemy of all that is sham. As the story goes, student U. once turned up for an exam. He was well-known for his rally speeches, extraordinary self-confidence, and was soon to become a ministercolonel. However, he came unprepared, hoping to lie his way out of the exam somehow. Professor Ulanowski asked him about 


\begin{tabular}{|ll} 
się wyłga. Profesor zapytał go o kodeks & Rules of Ulpian, and the student kept on \\
Ulpiana, na co student począ w kółko & repeating the same meaningless clichés \\
powtarzać kilka frazesów bez treści. & over and over again. The examiner \\
Egzaminator słuchał go cierpliwie przez & listened patiently for several minutes, \\
kilka minut, wreszcie przerwał mu: - Panie & then interrupted him: \\
U., jakbyś pan był tak długi, jak jesteś & - Mister U., if you were as tall as you are \\
pan głupi, mógłbyś pan klęcząc księżyc... & stupid, you could kiss the moon, while \\
pocałować. Do widzenia! - We Lwowie & kneeling down. Goodbye! \\
znowuż to samo mówiło się o kompozytorze & In Lvov, the same is said about Jan \\
Janie Gallu, z tą tylko różnica, że przedmiot & Gall, a composer, but the difference \\
jego złośliwej uwagi mógłby piwo na księżyc & is that the object of this scorching \\
podawać (KrzyżPrzysł, 1: 260) & remark is that someone could serve \\
& beer on the moon.
\end{tabular}

Here again (see Balllada o Janku above) we have an example of a projection of communicative memory into cultural memory. The changes in form, content and bearers are accompanied by changes in other categories as well: witnesses, addresser-addressee relationships and scope. Most generally, the anecdote, i.e. the narrative form that is typical of communicative memory, has now been shortened to a slogan-like saying or proverb. Indeed all that has survived is the punchline; the gist of the original anecdote. This is why the original social context cannot be identified any more. Nor is the resulting proverb of any humorous effect. Independent from context and situation, the saying lives its own life now, as a generalisation. As much as in the transformation of a personal recollection in to a ballad, transforming an anecdote into a proverb results in losing the specific for the sake of the general. The saying can now be applied to many different communicative situations as it functions as a universal linguistic cliché of supralocal scope. In repetition, folklorisation consists of shifting events and characters from the individual plane to the universal plane, from the dimension of personal characteristics to the dimension of global (moral) values. The intent of the text changes as well: from amusement and entertainment to didacticism and moralisation.

To sum up this chapter, text genre transformation involves a status-changing process; whereby texts (or their content, to be precise) proceed from communicative communication to cultural communication, with the concomitant formal changes in the addresser-addressee relationship, scope and intention. 
Tab. 12: Communicative and cultural memory in recollections and ballads (source: own representation)

\begin{tabular}{|c|c|c|}
\hline & $\begin{array}{l}\text { Recollections - carriers of } \\
\text { communicative memory }\end{array}$ & $\begin{array}{l}\text { Ballads - carriers of cultural } \\
\text { memory }^{58}\end{array}$ \\
\hline $\begin{array}{l}\text { Communicative } \\
\text { context }\end{array}$ & $\begin{array}{l}\text { Chodzity takie dziady proszalne } \\
\text { po wsi i oni roznosili różne takie } \\
\text { wiadomości 'old beggars would } \\
\text { go round the village and let } \\
\text { people know this and that' }\end{array}$ & None \\
\hline \multirow[t]{4}{*}{$\begin{array}{l}\text { Description of } \\
\text { characters }\end{array}$} & $\begin{array}{l}\text { Detailed, direct - for the sake of } \\
\text { highlighting the characteristics } \\
\text { that prove vital for the story } \\
\text { narrated: } \\
\text { Siegieda - rich: dorobkiewicz byt, } \\
\text { cośt tam zdobyt jak na tamte czasy } \\
\text { 'he was an upstart, really, that } \\
\text { which he gained did matter then'; }\end{array}$ & $\begin{array}{l}\text { Short, abridged: } \\
\text { Jest tam i kolonia Zezulin nazwana, } \\
\text { W niej mieszkat Siegieda, co miat } \\
\text { syna Jana 'There is a small village } \\
\text { Zezulin, Siegieda used to live there, } \\
\text { he had a son John' }\end{array}$ \\
\hline & $\begin{array}{l}\text { Janka 'Jane' - nieduża, blondynka, } \\
\text { petna na buzi, dlugie włosy, } \\
\text { tadnie się ubierała, dobra i } \\
\text { madra dziewczyna, mojej siostry } \\
\text { koleżanka 'small, blond, chubby- } \\
\text { cheeked, long hair, well-dressed, } \\
\text { good and wise girl, my sister's } \\
\text { friend'; }\end{array}$ & $\begin{array}{l}\text { A w Wólce Bednarek miat córke } \\
\text { Janine 'Bednarek lived in Wólka } \\
\text { and he had a daughter Jane' } \\
\text { Osiemnaście latek miał młodziutki } \\
\text { Janek 'John was very young, he was } \\
\text { just } 18 \text { years old' }\end{array}$ \\
\hline & $\begin{array}{l}\text { Janek 'John(ny)' - wysoki } \\
\text { blondyn, chodzit sobie z broniq } \\
\text { 'tall, blond, he would carry a gun } \\
\text { (on him)' }\end{array}$ & $\begin{array}{l}\text { Matka jak lucyper w sercu kamien' } \\
\text { miała 'The mother was as cold as } \\
\text { stone, like Lucifer himself' }\end{array}$ \\
\hline & & $\begin{array}{l}\text { Bez żadnej litości ten chciwy } \\
\text { Siegieda 'this greedy Siegieda was } \\
\text { of no sympathy' }\end{array}$ \\
\hline Social context & $\begin{array}{l}\text { jak się kto żenit, to zaraz ile to na } \\
\text { niego, na niq jest albo żeby z tej } \\
\text { samej wsi 'when one was about } \\
\text { to get married, he or she would } \\
\text { immediately be gossiped about } \\
\text { and expected to be of the same } \\
\text { village' }\end{array}$ & None \\
\hline
\end{tabular}

58 After Adamowski, Jan (2003) Ludowe pieśni i oracje z repertuaru Krystyny Poczek, Lublin, 75-78. See also (2011) Polska pieśn i muzyka ludowa. Źródła i materiały vol. 4, Lubelskie, edited by Jerzy Bartmiński, part IV, Pieśni powszechne, Lublin. 
Tab. 12: Continued

\begin{tabular}{|c|c|c|}
\hline & $\begin{array}{l}\text { Recollections - carriers of } \\
\text { communicative memory }\end{array}$ & $\begin{array}{l}\text { Ballads - carriers of cultural } \\
\text { memory }^{58}\end{array}$ \\
\hline Financial status & $\begin{array}{l}\text { dziesięć morgi na niego było, a } \\
\text { ona bidna podług niego, to miała } \\
\text { trzy morgi 'he had as much as } \\
10 \text { acres, whereas, according to } \\
\text { him, she was poor having only } \\
3 \text { acres' }\end{array}$ & $\begin{array}{l}\text { General information about the } \\
\text { financial mismatch between John } \\
\text { and Jane: } \\
\text { Janeczek ziemi, złota ma } w \\
\text { dostatku, A Janka otrzyma trzy } \\
\text { mordzyny w spadku 'Johnny would } \\
\text { have much land and gold, whereas } \\
\text { all that Jane inherited was these } 3 \\
\text { acres' }\end{array}$ \\
\hline $\begin{array}{l}\text { Siegieda's } \\
\text { disinclination to } \\
\text { Jane }\end{array}$ & $\begin{array}{l}\text { One's words directly quoted: ten } \\
\text { stary Siegieda powiedział, że } \\
\text { una jest dziadowska córka 'this } \\
\text { old Siegieda said that she was a } \\
\text { beggar's daughter' }\end{array}$ & None \\
\hline $\begin{array}{l}\text { Information } \\
\text { about the } \\
\text { locations of } \\
\text { events }\end{array}$ & $\begin{array}{l}\text { został kawałek dołka po piwnicy, } \\
\text { pozostałości 'just debris, a hole in } \\
\text { the ground - that is all that has } \\
\text { survived of the cellar' }\end{array}$ & None \\
\hline $\begin{array}{l}\text { Information } \\
\text { about the corpses }\end{array}$ & $\begin{array}{l}\text { całe te piersi (Janki) byli } \\
\text { objedzone (przez wrony) '[Jane's] } \\
\text { breasts were all bitten [by the } \\
\text { crows]' }\end{array}$ & $\begin{array}{l}\text { Leża młodzi w polu, wrony ich } \\
\text { targaja, Oczy, twarz i piersi rwa } i \\
\text { pożeraja 'The young ones are dead } \\
\text { out there in the field, with the } \\
\text { crows biting their eyes, faces, and } \\
\text { breasts' }\end{array}$ \\
\hline $\begin{array}{l}\text { Information } \\
\text { about the person } \\
\text { that found the } \\
\text { corpse(s) }\end{array}$ & Cygan taki '[he was] just a Gipsy' & General \\
\hline $\begin{array}{l}\text { Information } \\
\text { about the burrial }\end{array}$ & $\begin{array}{l}\text { ksiądz wtedy byt taki wredny, } \\
\text { że nie chciat pochówku, nawet } \\
\text { pokropku nie... 'the priest was } \\
\text { so mean that he did not want to } \\
\text { bury the man, he even refused } \\
\text { to sprinkle the corpse' }\end{array}$ & $\begin{array}{l}\text { Lecz ksiądz proboszcz także staje im } \\
\text { w przeszkodzicie, } \\
\text { Trzyma ciała dwa dni w kościelnym } \\
\text { obwodzie. } \\
\text { Młodzi się na księdza strasznie } \\
\text { rozgniewali } \\
\text { I gdzie chcieli Jankę z Jankiem } \\
\text { pochowali. } \\
\text { 'But the priest is a problem as he } \\
\text { keeps the corpses two days in the } \\
\text { church. The young ones got angry } \\
\text { with the priest and buried John } \\
\text { and Jane as they wished' }\end{array}$ \\
\hline
\end{tabular}


Tab. 12: Continued

\begin{tabular}{|c|c|c|}
\hline & $\begin{array}{l}\text { Recollections - carriers of } \\
\text { communicative memory }\end{array}$ & $\begin{array}{l}\text { Ballads - carriers of cultural } \\
\text { memory }^{58}\end{array}$ \\
\hline $\begin{array}{l}\text { Symbolic } \\
\text { elements }\end{array}$ & None & $\begin{array}{l}\text { i przynióst ze soba dwa cierniowe } \\
\text { wianki 'and he brought along two } \\
\text { crowns of thorns' }\end{array}$ \\
\hline \multirow{3}{*}{$\begin{array}{l}\text { Parents warned } \\
\text { not to interfere } \\
\text { with their } \\
\text { children's love } \\
\text { and marriage }\end{array}$} & None & $\begin{array}{l}\text { Niech się więcej na świat nie rodzi } \\
\text { nowina, By od kul ginęli chłopiec } i \\
\text { dziewczyna. }\end{array}$ \\
\hline & & $\begin{array}{l}1 \text { wy też rodzice, którzy dzieci } \\
\text { macie, Jak się pokochajo, to im nie } \\
\text { wzbraniajcie. }\end{array}$ \\
\hline & & $\begin{array}{l}\text { 'Let that never happen again, that } \\
\text { boys and girls are shot down; and } \\
\text { you, parents, who have children, } \\
\text { do not forbid them to love' }\end{array}$ \\
\hline
\end{tabular}


Memory and linguistic style - style memory 



\section{Memory as a distinguishing value of folk artistic style}

As mentioned in Chapter I, memory has been the focus of research of many Polish historians, sociologists (e.g., Szacka 2006; Szpociński 2005, 2006, [ed.] 2009; Kwiatkowski 2008) and psychologists for years. (Maruszewski 2005). Linguists, textologists and folklorists might have noted that oral texts, especially cliché-like folklore texts, are both stored in and recalled from collective memory though they have not developed these issues in any greater detail. The first linguistic research pieces on memory can be dated back to the year 2005 (cf. Dobrzyńska 2005, Witosz 2005b, 2007; later: Pajdzińska 2007, Chlebda 2007, Grzegorczykowa 2008). The true growth of interest in the notion of collective memory took place from 2012 onwards (cf. Pajdzińska 2012, Chlebda 2011, 2012, 2018, Dobrzyńska 2018, Czerwiński 2014, 2015, Czachur 2016, 2017, 2018, Szczęsna 2018, Kajfosz 2015, 2018, Wójcicka 2012b, 2013d, 2014).

These and other analyses point to, among other things, memory as an indispensable identity-building value (Pajdzińska 2007: 256) and in both personal and collective dimensions - as much as individual, whole societies build their identities and distinctiveness on and in reference to what and how they remember their own past. What is attempted below is connected to yet another aspect of collective memory, which is memory that serves as a distinguishing value of a given social group's linguistic style, the group being identified here as so-called folk culture bearers.

\section{Collective memory style}

However close and intimate, correspondences between linguistic styles and collective memory do not seem to be self-evident.

As understood in the context of communication, style is a medium of memory because as noted by A. Erll, memory media, along with the values and norms encoded in them constitute images of the past. It is in style then, that we find reflections of how the past is assessed, its creations evaluated and its images constructed (cf. Wójcicka 2017: 31, Wójcicka in print).

In other words, style is evidence of how one sees the past and the means of creating images of the past. The latter naturally depends on the values and current needs of their collective bearers, which is the corresponding social group. Style is also how the group manifests its presence in ' $I$ ', or how collective 
memory evidences itself in individual messages. For this reason, as a type of linguistic behaviour, style could be presented as a way of practising collective memory (cf. Wójcicka 2017: 39).

\section{Folk artistic style in a folklorist perspective}

The starting point for reflections is J. Bartmiński's semiotic-anthropologicalaxiological conception of style which is understood as stemming from the Warsaw school of linguistics (Maria Renata Mayenowa, later also Irena Dobrzyńska):

Style is a supratextual and supragenre semiotic structure in which the signified involve values ordered in some way, whereas the signifying, that is, textual exponents of these values, involve linguistic elements that belong to various levels of language organisation, that are, respectively, phonetic, morphological, syntactic, lexical-semantic and textual. (Bartmiński 1981: 33)

Furthermore, according to J. Bartmiński, style values constitute 'a set of worldview contents each of which is relative to the language user's assumed point of view' (Bartmiński 1981: 38). The following 'values of style' are mentioned: ontological assumptions about the world and man, type of rationality (i.e. how the means serve the purpose), the subject's attitude towards the reality being communicated (i.e. which/what point of view it is that generates a given image of the world), intentionality of communication (i.e. how the utterance relates to the reality) (Bartmiński 1991: 13).

It is the colloquial style that J. Bartmiński places at the centre of the stylistic differentiation of current Polish. From this, other styles can be derived: formal, scientific, artistic as well as folk artistic. The latter has been given a number of different labels by linguists: a regional artistic style (Z. Klemensiewicz), folk artistic language (A. Furdal), language of folklore, artistic language (T. Skubalanka), artistic language of folklore (A. Wilkoń), and folk artistic style (J. Bartmiński). (Interestingly enough, this kind of style does not feature at all in either S. Urbańczyk's or W. Pisarek's elaborate classifications of the styles of the Polish language.)

As to the characteristic traits of this particular style of Polish, linguists and folklorists specify the following:

- a high degree of schematisation (i.e. limited choice) of linguistic-stylistic means of expression;

- a relatively extensive repertoire of text-generating facilitating means, mnemonic devices included (recurrence of segments, expressions or single words, e.g., chain repetitions and anaphoric references); 
- a fixed syntagmatic order, structural parallelisms, a lack of enjambments;

-r frequent ellipses;

- no titles;

- typisation of themes and schematisation of motifs;

- poor lexical resources and poetic tropes;

-" a melic character of poetic texts (Wilkoń 2000: 84).

These characteristic, linguistic exponents of folk artistic style can be supplemented with several more in J. Bartmiński's suggestion: formulaic character, poeticism, rhythm, diminutives, repetitions, parallelisms, symbols and textual patterns (Bartmiński 2001). As can be noted, most of these characteristic features (repetitions, typisation, formulaic character, rhythm, textual patterns) serve to store texts in collective memory and to facilitate their retrieval and reproduction in oral communication. As they are evidently subordinate with regard to memory, it is memory that must be regarded as the principal oral text-organising value.

\section{Memory as a worldview category}

As J. Bartmiński puts it, 'in contrast to colloquial texts, folklore texts are reproduced from memory and are not created on-line during the act of communication. This is because texts of folklore result from collective creative activity and therefore, belong to so-called linguistic clichés' (Bartmiński 2001:225). Folklore fosters folk knowledge of the world, which is what J. Bartmiński reflects in his definition of folklore: 'a constituent of spiritual folk culture, its core being the living language', a constituent 'whose functioning is grounded in socially-negotiated knowledge of the world and in a system of collectively-cherished values' (Bartmiński 1990: 5). Memory turns out to be a source, warehouse and unique catalyst of both of these, knowledge and values. This can be confirmed with many Polish conceptual metaphors of memory: przechowywać w pamięci 'to store in memory', wydobywać z pamięci 'to retrieve from memory', zatrzymać w pamięci 'to keep in memory'. In her analysis of relevant collocations, A. Pajdzińska has come to conclude that 'the most numerous set of phraseological correspondences includes linguistic expressions of the ontological metaphor MEMORY IS CONTAINER' (Pajdzińska 2012: 101). Memory is then, a reservoir of collective memory in its social, cultural and communicative aspects. As encoded in words, the traditional (common and collective) image of the world is possible due to memory and in memory. The whole idea of orality is not merely information dissemination, but also bringing face-to-face generated values to widespread public awareness. If 
this is the case, orality helps to foster social relationships, to reproduce knowledge systems, judgements, and socially-negotiated moral standards, to stabilise that which is typical, repetitive, communal, stored in collective memory and recurrent as 'an echo of dialogue'. If the question is posed as to whether or not oral texts are merely processual in their nature (after all, they clearly consist of an online activity, are synchronic, linear, develop in time, and are linguistic and phonic in character), we also risk the claim that because oral texts are stored in collective memory and can be repeatedly reproduced in a ready-made and readily-available integrated whole, they can as be treated as creations exhibiting well-defined characteristics on the levels of intention, content, and 'text-making means' (Niebrzegowska-Bartmińska 2007: 48).

This all amounts to saying that memory loses its static character. It becomes dynamic by analogy to the oral text itself and the social reality with which it is correlated. We learn this from W. Chlebda:

The metaphor that best captures the memory image that extends from current discourse texts is one of matter. More precisely, it is not matter as such, or the notion of matter being fluid and abstract, but material, a building material that can be moulded, shaped, broken into pieces only for it to be brought together anew, a material that can be used to create images of that which is gone. (Chlebda 2011: 91)

From this perspective, memory is the building material of folklore, because, as a category it can be given various forms, be verbalised in different ways in different genres, and can safely serve the purposes of genre differentiation.

The characteristics of folklore (orality, traditionalism, communality, durability) which have already been mentioned by J. Bartmiński can also be found in American memory research. Were it not for memory, folklore would not exist. There is an inclination to assume that in general terms, memory is the constitutive value of the folk artistic style, the source or derivation base for the remaining values of the folk picture of the world.

It is collectivity that is usually considered to be the most important characteristic of the folk artistic style. 'As a creation, folklore functions in a group and expresses that group's collective world-view' (Bartmiński 1990: 8). Orality should be emphasised too and understood not merely as a way of transmission or how a story is actually communicated, but as an anthropological mode of existence/living which 'determines the way the world is moulded' or in other words, the way the image of the world is created (ordered). According to Joanna Tokarska-Bakir, orality is both a way of being as well as a way of understanding the world but first of all, orality is an ontological category of some cognitioncum-living sense (Tokarska-Bakir 2000: 165; cf. Hajduk-Nijakowska 2011: 13). 
In conclusion, the sources of orality and collectivity must, then, be sought among memory resources, which is proceed to in the following sections.

\subsection{Memory as a source of collectivity}

Some notion of collectivity can be found in practically most memory definitons, a further specification being either social (Pol. społeczna) or collective (Pol. zbiorowa). For A. Szpociński, social memory stands for a colloquial (everyday) image of the past (Szpociński 2006: 18). Still, however sound it is, 'social memory finds its expression in poetic, metaphorical language' (ibid.). So if applied to texts of folklore, it could be said that the language of folk poetry feeds on and is built on collective memory.

As mentioned in Chapter I, B. Szacka understands the term pamięć zbiorowa ('collective memory') as

(...) a set of a social group members' depictions of their past, which embraces ways of imagining past actions and events, as well as ways of remembering them and knowing about them, as is expected of an average member of this social group. This includes all the images present in the social imagination that a given social group may share about their past and their deliberate references to these images. (Szacka 2012: 16)

In other words,

collective images are understood, selected, and modified according to the group's own cultural standards and ideological outlooks; these standards are social products and are thus, shared by all of the members of the group, which facilitates the process of making images of the group's past uniform and legitimises the notion of the group's collective memory of the past. (Szacka 2006: 45)

In a similar fashion, J. Kajfosz believes that the essence of folklore consists of 'committing to memory and then recalling one's own experiences as well as transmitting them to others in every-day communication situations, when that which is more universal (archetypical) and systemic may absorb that which is individual and haphazard' (Kajfosz 2009: 136; also 141). We again should state that memory is a catalyst that 'cleans' the cross-generational oral message from its individual imports and eliminates the values that do not comply with the group's collective and currently abiding image of the world. Past events are first selected and, then imbued with sense from the perspective of the current present, providing that they are still part of the group's living collective memory. In this way, the past presents itself as a text to be read in the context of the present (cf. Uspienski 1998: 27). This explains why many motifs are now disappearing from aetiological stories. For example, the question of where mushrooms come from makes little sense today, in the world of science and media. 
There are as many collective memories as there are social groups which make use of their past for the sake of building their identities. Those elements of the past which linger on in collective recollections constitute a part of the group's image of oneself. Collective memory evolves proportionately to the changes in the value system cherished in a given group (Szpociński 2006: 28).

There is yet another way of showing how memory performs its catalyst function in the folk artistic style, and this is related to the folklorists' frequent analogy between folklore and language. Indeed, while defining folklore, Bogatyriew's and Jakobson's insights are often quoted (cf. Bartmiński, Kowalski, Kajfosz) that language resembles folklore in terms of its systemic organisation. To be specific, any text of folklore belongs to the category of langue: it is supraindividual, potential, collective and functions as an invariant matrix. Other than langue, it is the category of parole which embraces that which is individual, specific and can be realised in text variants. It is at the juncture of langue and parole that linguists place linguistic norms, a kind of filter, monitor, or check-and-balance of what is systemically possible and what is individually desirable. 'That which constitutes a given norm only includes a set of common features as they are entrenched in every-day language use' (Miodek 2001: 74). If these findings were to be used on the grounds of memory-folklore research, it could be said that the folklore norm is collective memory because it is collective memory that stores only that which is shared, common, and entrenched in the worldview of the corresponding group. In other words, collective memory has a direct bearing on

the process of categorisation transforming that which is unordered (heterogeneous) and variable concretes into that which is ordered (homogeneous) and invariable abstracts or in other words, transforming experience-driven chaos into memory-projected cosmos. If we allow for the fact that categorisation consists of backgrounding, if not relegating, some elements of reality and foregrounding, including bringing to life others, one can only conclude that folklore is a form of both remembering and forgetting the past. (Kajfosz 2009: 147)

Similar to linguistic norms, memory eliminates everything that is not part of the group's living circulation, does not function in the group's folklore and appears archaic and useless for the task of categorising the surrounding world.

Coming back to the initial claim, memory is a category serving to differentiate folklore texts. This is why R. Sulima defends the notion of the memory of previous applications of a folklore text and J. Bartmiński speaks about a genre formula. These and other attempts have brought folklore researchers to grasp the relationship between memory and text genres in terms of genre memory. This notion is akin to text pattern which is understood as a conceptual schema of a 
text or the matrix that is oriented towards both the addresser (in the process of encoding) and the addressee (in the process of reception). This double orientation makes the text pattern a norm for the two parties involved in the communication process (i.e. speakers and listeners) and helps them both to navigate their social communication (Niebrzegowska-Bartmińska 2007: 104). Text patterns (see below) externalise memory then, whereas text genres shape memory and interpret past events (cf. Chlebda 2012: $115 \mathrm{ff}$.).

Memory (as the folklore norm, to be remembered) can also be found operating in the process of genre transformation in the folk artistic style. This remark comes from J. Kajfosz:

The hitherto memorate has changed imperceptibly into a fabulate, preserving its subjective status of a memorate that is, being a narrative about a real and authentic event. Paradoxically, then, it is now more credible [as a fabulate than when it was a memorate] in the sense that it narrates the truth about something that took place long ago [Pol. dawno temu], whereas the true story has proved to be a mere lie. (Kajfosz 2009: 149)

As J. Kajfosz continues, 'collective awareness accommodates various imperceptible aspects of life to relatively universal patterns or in other words, it places that which is temporal in nature, hence changeable beyond time, in the sphere of durability (permanence)' (Kajfosz 2009: 147).

\subsection{Memory as support of orality}

Like orality, memory can be regarded as a constitutive category of folk culture (Sulima 1995b: 57). From this reading, the characteristic features of orality can also be ascribed to memory. As an axiological category, orality (after R. Sulima) has a clear moral-ethic slant, serves as an index of the worldview entrenched in respective cultures and expresses its aesthetic and axiological norms. Specifically, orality is marked with the following: (a) subjectivity anchored in communality, (b) spontaneity, (c) situatedness, (d) ethology (Sulima 1995b: 65).

If we were now to combine these characteristics with each other, we could say that memory makes an oral text part of communality, or it grounds the subjective in the collective. In this sense, it naturally supports and fosters orality. Moreover, memory extends from situatedness, as it is situation that triggers memory.

If I insist on claiming that memory - in itself that is, as a psychological content - remains inaccessible to our cognition, this is to say that memory research is possible as far as it consists of examining the language that is used to externalise memory content and successful insofar as we allow for the fact that verbalisation may (as it certainly does) result in abbreviations, conventionalisation, stereotypification and other deformations of the input content. (Chlebda 2012: 115) 
Inasmuch as memory remains inaccessible without language (mainly without oral texts,), oral texts (and, firstly, texts of folklore) cannot function without memory. If we follow W. Chlebda closely, we need to conclude that memory is language-entrenched, if not linguistic and text-grounded, if not simply textual, as well. Oral texts are by definition mnemonic, that is they are stored in memory and are meant for circulation through individual memory (i.e. through the agency of SUBJECT) and collective memory (i.e. through the agency of OBSERVER or rather, OBSERVERS who are prepared to accept and disseminate memory CONTENT that the group finds relevant and/or attractive).

If we take ethnolinguistics to be a study of identity (cf. Bartmiński and Chlebda 2008), the category of memory presents itself as an ethnolinguistic research topic because memory lies at the root of identity (Chlebda 2011, 2012). To call for the sociologically-oriented notion of 'community of memory', the group's identity is moulded through, precisely that which its members remember about the group's origins and what is encoded in myths. According to B. Szacka, it is myths understood as symbolic stories that play a vital role, especially in folk narratives about the origin of the world and the beginnings of social groupings. In this sense, myths constitute an important element in building the identity of a given community of memory and the language of that community's folklore. In short, it is in collective memory that the past is subject to mythologization: people's actions and events from the past happen to be transformed into 'timeless exemplars and personifications of virtues sanctioning the behaviour and attitudes important to the community' (Szacka 2006: 24).

\section{Formula as a main exponent of memory}

If 'memory exists in language and through language' (Chlebda 2012: 110), memory must have its linguistic exponents. Indeed, as W. Chlebda makes the point, "what could be understood by the linguistic entrenchment of memory [Pol. ujęzykowienie pamięci] is related, approximately, to the fact that memory constituting components do have (...) their verbal expressions (linguistic exponents)' (Chlebda 2012: 110).

One of the main linguistic exponents of memory understood as a parameter of the folk artistic style is, in my opinion, the notion of formula which J. Bartmiński described once as 'a child of tradition, collectivity, and orality' (Bartmiński 1990: 209). Formulae are not simply expressions of a given individual story teller's narrating skills, but the voice of the whole community and the exponent of the corresponding tradition:

What the formulaic character of a linguistic style connotes is always well-defined supraindividual values which constitute the ideological base of the given style. "The 
world-view" encoded in the formula is anti-individualistic. It is the group's voice addressed to everybody or the voice of the individuals who speak for the group. In this way, the formula is a tool of typicality or schematicity, which is the dominating principle of folklore on all possible levels of its organisation. (Bartmiński 1990: 213)

In other words, in its mnemotechnical function, formulae foster and support memory (cf. Lord 2010), but on the other hand, they serve as a means of expressing or exposing memory, be it individual or collective.

If we now take the formulae of the folk artistic style as carriers of the values encoded in it, they include the following:

- a folk conception of time and space (evident in temporal, locative, and chronotopic formulaic expressions), which firstly embraces the past occupying the central position and being depicted in terms of the formely-now opposition and secondly, the notions of continuity and omnitemporality (evident in such closing formulaic expressions as od tego czasu 'ever since that time', dotad 'until now', do dziś 'until today');

- the teller's attitude to what is being narrated (in testimonial and true-false formulaic expressions).

The role memory plays in retrieving a text can be illustrated with opening formulae which, apart from their mnemonic function, also structure the whole text pattern (cf. Niebrzegowska-Bartmińska 2007). So-called existential formulaic expressions are a typical example - not only do they introduce characters, but also the number of text segments to follow is anticipated. So, an opening formula retrieves a text from memory and at the same time reveals the digital concept that the text pattern is going to be built upon. Naturally, retrieving the text from memory may be accompanied with errors and slips. For example, note how an inappropriate formula may cause problems in reproducing Józefa Pidek's story, with the text frame being evidently incompatible when we compare the opening and closing sentences:

Był ojciec. Miał dwie córki. Ale do jednej dziewczyny bardzo się zjizdżaly kawaliry. A ta młodszo nic a nic, nikt nie przychodzit. Dwie... a trzy ich byto, prawda. A no raz poszly do lasu na jagody. Ta starsza bardzo była zazdrosna, bo do tyj młodszej bardzo przyjeżdżaly kawaliry, a średnia to jej nie zazdrościła. Bo ich było trzy, a nie dwie (WojDaw: 169).
There was a father who had two daughters. Many suitors would often come and visit one of them. But no one would ever visit the younger one. There were only two or three of them. One day they went to the woods to pick blueberries. The older one was very jealous because boys would be interested in the younger one, whereas the middle daughter was not jealous at all. Because there were three of them, not two. 
In a similar way memory can be fostered with text patterns, such as the consolidating chain pattern (Bartmińskiego and Niebrzegowska-Bartmińska 2007) or chronology-based pattern (Niebrzegowska- Bartmińska 2007).

\section{Memory as a treasure of folklore, folklore as a narrative about memory}

As argued in Chapter III, in numerous metaphors, memory is depicted as a container and a mechanism (cf. Pajdzińska 2007). In metatextual expressions that correspond to the memory-container metaphor, memory is specified as a kind of warehouse, a wardrobe packed with morals, or a treasure chest loaded with stories:

No wie Pani, tych rożnych morałów, to sie wiedziało, ale wie Pani teraz na zawołanie, to te szufladki zaczynaja sie zamykać. Czasem sie tak zatrzaśnie, że caly dzień sie chodzi i nie można sobie przypomnieć, co to było. Znam jeszcze takich, co ostatnio właśnie słyszałam, jak w jednej parafi $\dot{z} y \nmid$ ksiądz i taki pijaczek, ale on jeździt autobusem. Woził ludzi (WojPod, 66).
You know, Ma'am, I used to be aware of many different morals, but, you know, Ma'am, when one now needs to recall any of them, they are like locked drawers. Sometimes they are so stuck that one cannot recall what it was at all. I have also recently heard that in one parish there was a priest, a little boozer, but he would also drive the bus. He would drive people around.

Memory is then, a huge wardrobe containing many drawers in each of which various personal, generational and collective experiences are hidden and locked away, everything has been collected from early childhood. Triggered with an appropriate stimulus, such as theme, motif and association, any drawer could be opened and release stories known and communicated in a cross-generational transmission.

If we take folklore in its etymological meaning, as the wisdom of common people, then it is only natural to assume that what people know is localised in memory. At the same time, as noted by W. Chlebda, we need to make a fundamental distinction between 'memory in itself', or 'memory in se', and 'speaking about memory', or 'narration about memory content': not everything accumulate in memory by people can be translated into words, in addition to the fact that we may want to externalise everything that we remember (Chlebda 2012: 112).

In this context, we can state that on the one hand, texts of folklore - through their petrified and cliché character - are the result, product, or effect of memory. 
Yet, on the other hand, they are also narratives about memory, be it individual (as in recollection stories) or collective (as in legends and historical reconstructions). It is in texts of folklore that we have the situation which W. Chlebda analyses as an example of one person's narrating the memory content of another person; which can be done by means of so-called testimonial formulaic expressions, as in jest to opowieść naszej starki, której my zawsze radzi stuchali, bo się nam podobała (SimLud, 86; 'This was a story told by our grandma which we always eagerly listened to because we liked it very much').

Having mentioned testimonial expressions, we need to account for the relation ship between memory and truth, as remarked upon by B. Szacka,

collective memory relies on its own unique criterion of truth, quite different from the one employed in history. For history, the knowledge that is considered to be true has been obtained by means of rigorous research and has proved scientifically falsifiable. In collective memory, in turn, knowledge is considered to be true if it complies with a given group's actual feelings, systems of values and the worldview. (Szacka 2006: 29)

The category of truth which is extremely important for the bearers of folk culture, becomes evident in frames of folk texts or more precisely, in the so-called true-false formulae. Both testimonial and true-false formulae serve as differentiating features of folklore genres, which in turn, prove indispensable for depicting genre-specific images of the world (memory included) that folk culture bearers project in their texts.

In Summary, memory-generated features/values of the folk artistic style include the following:

(1) The ontology of the world presented in texts of folklore (that is, how the world is shown to exist) results in depicting reality from the perspective of a remote or recent past that is narrated by the subject or observer and recalled from memory being the communal reservoir of tradition and values. This reality is neither real nor reflected because the past is an interpretation conditioned by the norms and values present in the group's collective memory and, furthermore, is subject to a unique tug-of-war of remembering and forgetting, which varies in different genres of folklore texts.

(2) The type of rationality is common-sense as it stems from the observation of the surrounding world and attempts to explain the origin of experiential phenomena [which is why texts of folklore are frequently aetiological in nature, for example, onomastic formulaic expressions: Cała wieś na pamiątke tego zdarzenia nazwano na cześć dobrego króla Chrobrówką (HajPod, 91; 'To commemorate the good king, the whole village was named Chrobrówka, 
after him.')].

(3) The point of view and the corresponding picture/image of the world, is, in fact, the point of view assumed by the subject or observer and this is reflected in various kinds of textual formulae, such as operational, testimonial, and true-false. Recalled from memory and then narrated, the picture of the world changes proportionately to the choice of the subject/observer and/or shifts in their position.

(4). Intentionality depends on the genre of a folklore text and is revealed in its frame, in so-called operational formulae and formulaic expressions, such as Jeden kawat będe wam opowiadat (SimKum, 119 'Let me tell you this joke'). Intentionality is usually expressed with appropriate stylistic devices and exponents such as linguistic means, chiefly frame-like expressions and also medial expressions and textual formulae. They all are regarded as style exponents by J. Bartmiński and S. Niebrzegowska-Bartmińska - as they are linguistic in nature and 'serve to implement "stylistic categories", which are principles assumed in/for a given style' (Bartmiński and NiebrzegowskaBartmińska 2009: 112). 


\section{Bibliography}

Adamowski, Jan (1999) Kategoria przestrzeni w folklorze. Studium etnolingwistyczne [The category of space in folklore. An ethnolinguistic study], Lublin.

Adamowski, Jan (2002) Wiedza potoczna informatorów jako podstawa systematyki tekstów folkloru [Informants' common-sense knowledge as a basis of folkore texts classification], [in:] Adrian Mianecki and Violetta Wróblewska (eds.) Genologia literatury ludowej [A genology of folk literature], 37-46, Toruń.

Adamowski, Jan (2003) Ludowe pieśni i oracje z repertuaru Krystyny Poczek [Krystyna Poczek's selected folk songs and poems], Lublin.

Adamowski, Jan, Bartmiński, Jerzy (1988) Z problemów systematyki polskiej pieśni ludowej [Selected issues in Polish folk songs classification], [in:] Tadeusz Kłak (ed.) Z problemów badania kultury ludowej [Issues in folklore culture], 49-75, Katowice.

Adamowski, Jan, Wójcicka, Marta (eds.) (2008) Krzyże i kapliczki przydrożne jako znaki społecznej, kulturowej i religijnej pamięci [Crosses and wayside shrines as tokens of social, cultural, and religious memory], Lublin.

Assmann, Aleida (2008) Canon and Archive, [in:] Astrid Erll and Ansgar Nünning (eds.) Cultural Memory Studies. An International and Interdisciplinary Handbook, 97-108, Berlin.

Assmann, Aleida (2009a) Przestrzenie pamięci. Formy i przemiany pamięci kulturowej [Memory spaces. Forms and transformations of cultural memory], [in:] Magdalena Saryusz-Wolska (ed.) Pamiećc zbiorowa i kulturowa. Wspótczesna perspektywa niemiecka [Collective and cultural memory in a current German perspective], 101-142, Kraków.

Assmann, Aleida (2009b) 1998 - Między historia a pamięcia [1998: in-between history and memory], [in:] Magdalena Saryusz-Wolska (ed.) Pamięć zbiorowa i kulturowa. Współczesna perspektywa niemiecka [Collective and cultural memory in a current German perspective], 143-174, Kraków.

Assmann, Aleida (2009c) Pięć strategii wypierania ze świadomości [Five strategies of awareness suppression], [in:] Magdalena Saryusz-Wolska (ed.) Pamięć zbiorowa i kulturowa. Wspótczesna perspektywa niemiecka [Collective and cultural memory in a current German perspective], 333-350, Kraków.

Assmann, Aleida (2013) Między historia a pamięcią. Antologia [In-between history and memory], edited by Magdalena Saryusz-Wolska, Warszawa. Assmann, Aleida (2015) Wprowadzenie do kulturoznawstwa. Podstawowe 
terminy, problemy, pytania [An introduction to cultural studies. Basic terms, issues, and inquiries], Translated by Anna Artwińska and Katarzyna Różańska, Poznań.

Assmann, Jan (2008b) Communicative and Cultural Memory, [in:] Astrid Erll and Ansgar Nünning (eds.) Cultural Memory Studies. An International and Interdisciplinary Handbook, 109-118, Berlin.

Assmann, Jan (2009) Kultura pamięci [Culture of memory], [in:] Magdalena Saryusz-Wolska (ed.) Pamięć zbiorowa i kulturowa. Wspótczesna perspektywa niemiecka [Collective and cultural memory in a current German perspective], 59-100, Kraków.

Assmann, Jan (2011) Cultural Memory and Early Civilization. Writing, Remembrance, and Political Imagination, Cambridge.

Atkinson, Richard C, Atkinson, Rita L., Hilgard Ernest R. (1975) Introduction to Psychology. Sixth edition, New York.

Baran-Łaszkiewicz, Monika, Niebrzegowska-Bartmińska, Stanisława, Wasiuta, Sebastian (eds.) (2010) Plotka i kłamstwo w jezyku i w kulturze [Gossip and lies in language and culture], Lublin.

Bartmiński, Jerzy (1981) Derywacja stylu [Style derivation], [in:] Jerzy Bartmiński (ed.) Pojęcie derywacji w lingwistyce [Derivation in linguistics], 31-54, Lublin.

Bartmiński, Jerzy (1990) Folklor - język - poetyka [Folklore - language poetics], Lublin.

Bartmiński, Jerzy (1991) Styl potoczny jako centrum systemu stylowego języka [The colloquial as the center of the stylistic system of language], [in:] Stanisław Gajda (ed.) Synteza w stylistyce słowiańskiej [Synthesis in Slavic stylistics], 33-47, Opole.

Bartmiński, Jerzy (1992) Tekst folkloru jako przedmiot folklorystyki [Folklore text as an object of folklore research], [in:] Henryk Markiewicz and Janusz Sławiński (eds.) Nowe problemy metodologiczne literaturoznawstwa [New methodological issues in literary theory], 246-271, Kraków.

Bartmiński, Jerzy (1996) Język nośnikiem tożsamości narodowej i przejawem otwartości [Language as a carrier of national identity and an expression of openness], [in:] Leon Dyczewski (ed.) Tożsamość polska i otwartość na inne społeczeństwa [Polish identity and openness to other societies], 39-59, Lublin.

Bartmiński, Jerzy (1998) Tekst jako przedmiot tekstologii lingwistycznej [Text as an object of linguistic textology], [in:] Jerzy Bartmiński and Barbara Boniecka (eds.) Tekst. Problemy teoretyczne [Text. Selected theoretical issues], 9-25, Lublin. 
Bartmiński, Jerzy (1999) Punkt widzenia, perspektywa, językowy obraz świata [Point of view, perspective, linguistic picture of the world], [in:] Jerzy Bartmiński (ed.) Językowy obraz świata [Linguistic picture of the world], 103-120, Lublin.

Bartmiński, Jerzy (2001) Ludowy styl artystyczny [Folk artistic style], [in:] Jerzy Bartmiński (ed.) Współczesny język polski [Contemporary Polish], 223-233, Lublin.

Bartmiński, Jerzy (2004) Opozycja ustności i literackości [The orality-literacy opposition], [in:] Grzegorz Godlewski, Andrzej Mencwel, and Roch Sulima (eds.) Antropologia słowa. Zagadnienia i wybór tekstów [An anthropology of the word. Selected issues and texts], 430-434, Warszawa.

Bartmiński, Jerzy (2007) Językowe podstawy obrazu świata [Linguistic foundations of the picture of the world], Lublin.

Bartmiński, Jerzy (2008) Polifoniczność tekstu czy podmiotu? Podmiot w dialogu $z$ samym soba [A polyphonic text or a polyphonic subject? The subject's dialogue with oneself], [in:] Jerzy Bartmiński and Anna Pajdzińska (eds.) Podmiot $w$ języku $i$ kulturze [The subject in language and culture], 161-184, Lublin.

Bartmiński, Jerzy (2013) The Cognitive Definition as a Text of Culture, [in:] Adam Głaz, David S. Danaher, and Przemysław Łozowski (eds.) The Linguistic Worldview. Ethnolinguistics, Cognition, and Culture, 161-180, London.

Bartmiński, Jerzy, Chlebda, Wojciech (2008) Jak badać językowo-kulturowy obraz Stowian $i$ ich sasiadów? [How should one go about investigating the linguistic word view of Slavs and their neighbours?], „Etnolingwistyka”, 20, 11-27.

Bartmiński, Jerzy, Niebrzegowska-Bartmińska, Stanisława (2004) Dynamika kategorii punktu widzenia w języku, tekście i dyskursie [The dynamics of point of view in language, text and discourse], [in:] Jerzy Bartmiński, Stanisława Niebrzegowska-Bartmińska, and Ryszard Nycz (eds.) Punkt widzenia $w$ języku $i$ w kulturze [Point of view in language and culture], 321-358, Lublin.

Bartmiński, Jerzy, Niebrzegowska-Bartmińska, Stanisława (2009) Tekstologia [Textology], Warszawa.

Bednarek, Stefan (2010) Jeśli nie miejsca pamięci, to co? O badaniach pamięci [If not remembrance sites, then what? On memory research], „Kultura Współczesna”, 1, 100-109.

Bednarek, Stefan (2012) Mnemotopika polska [Polish mnemotopics], [in:] Jan Adamowski and Marta Wójcicka (eds.) Tradycja dla wspótczesności, t. 6: Pamięć jako kategoria rzeczywistości kulturowej [Tradition for the 
present time. Continuity and change, vol. 6: Memory as a category of the cultural reality], 33-43, Lublin.

Biskupska, Kamilla (2011) Pamięć społeczna w zwierciadle języka: analiza dyskursu pokolenia przełomu [Social memory reflected in language: discourse of the transformation generation], Opole.

Błachowicz, Ewa (2010) Plotka w świetle teorii aktów mowy i zasad etyki komunikacji międzyludzkiej [Gossip in speech act theory and interpersonal communication ethics], Rzeszów.

Bogatyriew, Piotr, Jakobson, Roman (1973) Folklor jako specyficzna forma twórczości [Folklore as a specific form of creation], „Literatura Ludowa”, 3, 28-41.

Bogocz, Irena (1996) O finale bajki zwierzęcej [On the climax in fairy tales], „Literatura Ludowa”, 1, 25-33.

Boniecka, Barbara (1999) Lingwistyka tekstu. Teoria i praktyka [Text linguistics: theory and practice], Lublin.

Bragina, Natalia G. (2007), Pamiat w jazyku i kulturie [Memory in language and culture], Moskwa.

Brocki, Marcin (2013) Antropologia społeczna i kulturowa w przestrzeni publicznej. Problemy, dylematy, kontrowersje [Social and cultural anthropology in public spaces: issues, dilemmas, controversies], Kraków.

Burszta, Józef (1974) Kultura ludowa - kultura narodowa. Szkice i rozprawy [Folk culture - national culture. Notes and essays], Warszawa.

Butzer, Günter (2009) Metaforyka pamięci [Memory metaphors], [in:] Magdalena Saryusz-Wolska (ed.) Pamięć zbiorowa i kulturowa. Współczesna perspektywa niemiecka [Collective and cultural memory in a current German perspective], 185-210, Kraków.

Chandler, Daniel (2011) Wprowadzenie do semiotyki [Semiotics. The basics], Translated by Katarzyna Hallett, Warszawa.

Chanel, Alvaro Pascual, Simarro, Alfonso Serrano (2008) Stownik symboli [Dictionary of symbols], Warszawa.

Chlebda, Wojciech (2007) Tezy o niepamięci zbiorowej [Theses on collective oblivion], „Prace Filologiczne”, LIII, s. 71-78.

Chlebda, Wojciech (2011) Szkice do językowego obrazu pamięci. Pamięć jako wartość [Towards the linguistic picture of memory. Memory as a value], „Etnolingwistyka” 23, 83-98.

Chlebda, Wojciech (2012) Pamięć ujęzykowiona [Language embedded in memory], [in:] Jan Adamowski, Marta Wójcicka (eds.) Tradycja dla wspótczesności, t. 6: Pamięć jako kategoria rzeczywistości kulturowej 
[Tradition for the present time. Continuity and change, vol. 6: Memory as a category of the cultural reality], 109-119, Lublin.

Chlebda, Wojciech (2018) Pamięć a język. Zarys relacji [Memory and language. An outline of relations], [in:] Waldemar Czachur (ed.) Pamięć w ujęciu lingwistycznym. Zagadnienia teoretyczne i metodyczne [Memory in a linguistic perspective: theory and methodology], 56-67, Warszawa.

Ciołkiewicz, Paweł (2012) Pamięć zbiorowa $w$ dyskursie publicznym. Analiza polskiej debaty na temat wypędzeń Niemców po drugiej wojnie światowej [Collective memory in public discourse. An analysis of the debate on the expulsion of Germans after World War II], Warszawa.

Confino, Alon (2008) Memory and the History of Mentalities, [in:] Astrid Erll and Ansgar Nünning (eds.) Cultural Memory Studies. An International and Interdisciplinary Handbook, 77-84, Berlin.

Connerton, Paul (1989) How Societies Remember. Cambridge.

Czachur, Waldemar (2016) Dlaczego pamięć społeczna może być obiektem badań lingwistycznych? [Why should collective memory be an object of linguistic research?], [in:] Joanna Godlewicz-Adamiec, Piotr Kociumbas, and Ewelina Michta (eds.) Karty na ramionach olbrzymów? Kultura niemieckiego obszaru językowego $w$ dialogu $z$ tradycja [Dwarfs standing on the shoulders of giants. German culture in dialogue with tradition], vol. 2, 252-260, Warszawa.

Czachur, Waldemar (2017) Pamięć zbiorowa a formuly językowe. O gramatyce niemieckiego dyskursu pamięci o II wojnie światowej [Collective memory and linguistic patterns. A contribution to the grammar of the German memory discourse on World War II], [in:] Marta Wójcicka and Małgorzata Dziekanowska (eds.) Tradycja dla współczesności, t. 11, Tożsamości $w$ procesach społeczno-kulturowych [Tradition for the present time, vol. 11: Identities in socio-cultural processes], 53-67, Lublin.

Czachur, Waldemar (2018) Lingwistyka pamięci. Założenia, zakres badań $i$ metody analizy [Linguistics of memory. Principles, questions and methods], [in:] Waldemar Czachur (ed.) Pamięć w ujęciu lingwistycznym. Zagadnienia teoretyczne i metodyczne [Memory in a linguistic perspective: theory and methodology], 7-55, Warszawa.

Czerwiński, Maciej (2014) Archiwum znaków - semiotyka pamięci kulturowej [Archive of signs: the semiotics of cultural memory], „Text and Discourse”, 7, 31-48.

Czerwiński, Maciej (2015) Kultura. Dyskurs. Znak [Culture. Discourse. Sign], Kraków.

Czubala, Dionizjusz (1985) Opowieści z życia. Z badań nad folklorem wspótczesnym [Everyday life stories. Studies in modern folklore], Katowice. 
Daneš, Frantisek (1970) Functional Sentence Perspective and the Organisation of the Text, [in:] F. Daneš (ed.) Papers on Functional Sentence Perspective, 106-128, Prague.

Dobrzyńska, Teresa (2005) Tekst i dyskurs we współpracy z pamięcia [Text and discourse in collaboration with memory], [in:] Małgorzata Kita and Bożena Witosz (eds.) Spotkania. Księga jubileuszowa dla Profesora Aleksadnra Wilkonia [Encounters. Festschrift in honour of Professor Aleksander Wilkoń], 59-71, Katowice.

Dobrzyńska, Teresa (2018) Pamięć - z perspektywy badań tekstu i dyskursu [Memory - from the perspective of text and discourse studies], [in:] Waldemar Czachur (ed.) Pamięć w ujęciu lingwistycznym. Zagadnienia teoretyczne i metodyczne [Memory in a linguistic perspective: theory and methodology], 94-113, Warszawa.

Draaisma, Douwe (2000) Metaphors of Memory. A History of Ideas about the Mind, Translated by Paul Vincent, Cambridge.

Draaisma, Douwe (2009) Machina metafor. Historia pamięci [Metaphor machinery. A history of memory], Translated by Robert Pucek, Warszawa.

Draaisma, Douwe (2012) Księga zapominania [The book of forgetting], Translated by Robert Pucek, Warszawa.

Duszak, Anna (1998) Tekst, dyskurs, komunikacja międzykulturowa [Text, discourse, intercultural communication], Warszawa.

Dziekanowska, Małgorzata (2012) Pamięć a tożsamość zbiorowa [Memory and collective identity], [in:] Małgorzata Dziekanowska and Józef Styk (eds.) Tradycja dla współczesności, t. 5: Pamięć jako kategoria rzeczywistości społecznej [Tradition for the present time. Continuity and change, vol. 5: Memory as a category of the cultural reality], 25-38, Lublin.

Echterhoff, Gerald (2008) Language and Memory: Social and Cognitive Processes, [in:] Astrid Erll and Ansgar Nünning (eds.) Cultural Memory Studies. An International and Interdisciplinary Handbook, 263-274, Berlin.

Eliade, Mircea (1998) Mit wiecznego powrotu [The myth of the eternal return], Translated by Krzysztof Kocjan, Warszawa.

Erll, Astrid (2008) Cultural Memory Studies: An Introduction, [in:] Astrid Erll and Ansgar Nünning (eds.) Cultural Memory Studies. An International and Interdisciplinary Handbook, 1-15, Berlin.

Erll, Astrid (2009) Literatura jako medium pamięci zbiorowej [Literature as a medium of collective memory], [in:] Magdalena Saryusz-Wolska (ed.) Pamięć zbiorowa i kulturowa. Współczesna perspektywa niemiecka [Collective and cultural memory in a current German perspective], 211-248, Kraków.

Erll, Astrid (2011) Memory in Culture, London. 
Filar, Dorota (2013) Narracyjne aspekty językowego obrazu świata. Interpretacja marzenia we współczesnej polszcyźnie [Narrative aspects of the linguistic worldview. The interpretation of dream in contemporary Polish], Lublin.

Forstner, Dorothea (2001) Świat symboliki chrześcijańskiej. Leksykon [The world of Christian symbols. A lexicon], Warszawa.

Fortunati, Vita, Lamberti, Elena (2008) Cultural Memory: A European Perspective, [in:] Astrid Erll and Ansgar Nünning (eds.) Cultural Memory Studies. An International and Interdisciplinary Handbook, 127-140, Berlin.

Genette, Gerald (1992) The Architect: An Introduction, Translated by Jane E. Lewin, Berkeley, CA.

Genette, Gerald (1997) Palimpsests: Literature in the Second Degree, Translated by Channa Newman and Claude Doubinsky, Lincoln.

Głażewska, Ewa, Kusio, Urszula (2012) Komunikacja niewerbalna. Płeć i kultura [Nonverbal communication. Gender and culture], Lublin.

Głowiński Michał (2004) Wokół narratologii [On narratology], [in:] Michał Głowiński (ed.) Narratologia [Narratology], Gdańsk.

Golka, Marian (2009) Pamięć społeczna i jej implanty [Social memory and its implants], Warszawa.

Golka, Marian (2010) Imiona wielokulturowości [The names of multiculturality], Warszawa.

Gomóła, Anna (2012) Kulturowa rola pamięci i jej historia utrwalona w polszczyźnie [The cultural role of memory and its history preserved in the Polish language], [in:] Jan Adamowski and Marta Wójcicka (eds.) Tradycja dla współczesności, t. 6, Pamięć jako kategoria rzeczywistości kulturowej [Tradition for the present time. Continuity and change, vol. 6: Memory as a category of the cultural reality], 61-74, Lublin.

Gomóła, Anna, Rygielska, Małgorzata (2014) Tekst kultury jako narzędzie badawcze [Text of culture as a research tool], [in:] Bożena Płonka-Syroka, Mateusz Dąsal (eds.) Źródło historyczne jako tekst kultury [Historical sources as texts of culture], 231-244, Warszawa.

Goody, Jack (2010) Myth, Ritual and the Oral, Cambridge.

Gorczyca, Wojciech (ed.) (2010) Tekst literacki i tekst kultury w glottodydaktyce [Text of literature and text of culture in glottodidactics], Bielsko-Biała.

Green, Thomas A. (1997) Folklore: An Encyclopedia of Beliefs, Customs, Tales, Music, and Art, Santa Barbara.

Griffin, Em (2003) Podstawy komunikacji społecznej [A first look at communication theory], Translated by Ola i Wojciech Kubińscy and Magdalena Kacmajor, Gdańsk. 
Grzegorczykowa, Renata (2001) Wprowadzenie do semantyki językoznawczej [An introduction to linguistic semantics], Warszawa.

Grzegorczykowa, Renata (2007) Wstęp do językoznawstwa [An introduction to linguistics], Warszawa.

Grzegorczykowa, Renata (2008) 'Pamiętanie' i 'przypominanie sobie' wśród innych aktów mentalnych (na podstawie danych języka polskiego) ['Remembering' and 'recollecting' among other mental acts (on the basis of the Polish language data)], [in:] Renata Grzegorczykowa and Krystyna Waszakowa (eds.) Pojęcie - słowo - tekst [Concept - word - text], 193-206, Warszawa.

Gusiew, Wiktor (1974) Estetyka folkloru [The aesthetics of folklore], Wrocław.

Hajduk-Nijakowska, Janina (2011) Druga młodość folklorystyki - wprowadzenie do dyskusji [The second youth of folkloristic studies - an introduction to discussion], [in:] Janina Hajduk-Nijakowska and Teresa Smolińska (eds.) Nowe konteksty badań folklorystycznych [New contexts in folklore research], 9-28, Opole.

Hałas, Elżbieta (2012) Przeszłość i przyszła teraźniejszość: refleksyjna pamięć kulturowa [The past and the future present: reflexive cultural memory], [in:] Elżbieta Hałas (ed.) Kultura jako pamięć. Posttradycjonalne znaczenie przeszłości [Culture as memory. The post-traditional meaning of the past], 153-176, Kraków.

Hałas, Elżbieta (2017) "The future orientation of culture and the memory of the past in the making of history", Sign Systems Studies, 45(3/4), 361-379.

Halbwachs, Maurice (1992) The Social Frameworks of Memory, [in:] On Collective Memory, Edited, Translated, and with an Introduction by Lewis A. Coser, 37-192, Chicago.

Hall, Edward Twitchell (2009) Ukryty wymiar [The hidden dimension], Translated by Teresa Hołówka, Warszawa.

Herzyk, Anna (1980) Zależność zapamiętywania od struktury tekstu.

Rozprawa doktorska wykonana pod kierunkiem Marcela Klimkowskiego [The dependence of remembering on text structure. An unpublished $\mathrm{PhD}$ dissertation written under the supervision of Marcel Klimkowski], Lublin.

Hirsch, Marianne (2008) „The generation of postmemory”, Poetics Today, 29(1), 103-128.

Iwańczyk, Patryk (2010) Plotka, pogłoska, pomówienie w języku polskim [Gossip, allegation, and slander in the Polish language], [in:] Monika BaranŁaszkiewicz, Stanisława Niebrzegowska-Bartmińska, and Sebastian Wasiuta (eds.) Plotka i kłamstwo w jezzyku i w kulturze [Gossip and lie in language and culture], 11-22, Lublin. 
Jagodzińska, Maria (2008) Psychologia pamięci. Badania, teorie, zastosowania [The psychology of memory: studies, theories, application], Gliwice.

Jakóbczyk-Gola, Aleksandra (2014) Akt pamięci. Tradycja akatystowa w konkteście form pamięci [Acts of memory. The Akathist tradition in the context of forms of memory], Warszawa.

Jakobson, Roman (1960) Poetyka w świetle językoznawstwa [Linguistics and poetics], Translated by Krystyna Pomorska, Warszawa.

Jakuboze, Adrian (2007) Metodologia badań baśni. Problemy i propozycje rozwiązań [Methodology of fable research: problems and applications], [in:] Adrian Jakuboze, Maria E. Pobieżyńska, and Michał Zaczek (eds.) Baśń oralność - zagadka. Studia [Fable - orality - riddle. Selected papers], edited by Jakub Z. Lichański, 7-70, Warszawa.

Jędrzejko, Ewa (2001) Jeszcze o modalności z perspektywy badań języka i stylu tekstów artystycznych [More on modality: modality in the perspective of studies in language and style of artistic text], [in:] Bożena Witosz (ed.) Stylistyka a pragmatyka [Stylistics and pragmatics], 82-95, Katowice.

Kajfosz, Jan (2009) Magia w potocznej narracji [Magic in colloquial narration], Katowice.

Kajfosz, Jan (2011) Folklor jako tekst w obiegu i jego potencjał konstruowania rzeczywistości [Folklore as a text in circulation and its potential to construct the reality], [in:] Janina Hajduk-Nijakowska and Teresa Smolińska (eds.) Nowe konteksty badan folklorystycznych [New contexts in folklore research], 53-77, Opole.

Kajfosz, Jan (2012) O kognitywnych i społecznych uwarunkowaniach pamięci [Towards cognitive and social conditions of memory], [in:] Jan Adamowski and Marta Wójcicka (eds.) Tradycja dla współczesności, t. 6: Pamięć jako kategoria rzeczywistości kulturowej [Tradition for the present time. Continuity and change, vol. 6: Memory as a category of the cultural reality], 21-31, Lublin.

Kajfosz, Jan (2015) Obraz przeszłości w percepcji magiczno-mitycznej, czyli pamięć $w$ działaniu [The image of the past in magical and mythical perception: memory in action], „Politeja”, 3(35), 27-40.

Kajfosz, Jan (2018) Presupozycje w analizie potocznych dyskursów pamięciowych [Presuppositions within the analysis of popular memory discourses], [in:] Waldemar Czachur (ed.) Pamięć w ujęciu lingwistycznym. Zagadnienia teoretyczne i metodyczne [Memory in a linguistic perspective: theory and methodology], 114-133, Warszawa.

Kaniewska, Bogumiła (2008) „I tak taki jest się, jaki jest” - wokół kategorii podmiotu literackiego ["One is what one is anyway” - The category of subject 
in Polish literary studies], [in:] Jerzy Bartmiński and Anna Pajdzińska (eds.) Podmiot w języku i kulturze [The subject in language and culture], 87-108, Lublin.

Kaniowska, Katarzyna (2004) „Memoria” i „postpamięc" a antropologiczne badanie wspólnoty ["Memoria” and „post-memory” versus an anthropological examination of a community], [in:] Codzienne i niecodzienne. O wspólnotowości $w$ realiach dzisiejszej Łodzi [The ordinary and the extraordinary. On the sense of community in the present-day Łódź], „Łódzkie Studia Etnograficzne”, vol. 43, 9-28, Łódź.

Kaźmierska, Kaja (2012) Współczesna pamięć komunikacyjna i kulturowa. Refleksja inspirowana koncepcja Jana Assmanna [Contemporary communicative and cultural memory: a reflection inspired by Jan Assmann's concept], [in:] Elżbieta Hałas (ed.) Kultura jako pamięć. Posttradycjonalne znaczenie przeszłości [Culture as memory. The post-traditional meaning of the past], 43-62, Kraków.

Kolbuszewski, Jacek (1995) Cmentarz jako tekst kultury [Cemetery as a text of culture], [in:] Olgierd Czerner (ed.) Sztuka cmentarna - Dokumenty [Cemetery arts - Documents], 17-40, Wrocław.

Kopczyńska, Żaneta, Kopczyński, Jakub (2008) „Świat karmi się plotką”. O poszukiwaniu folkloru $w$ Internecie [„The world preys on gossip”. In search of folklore in the Internet], [in:] Hubert Czachowski and Adrian Mianecki (eds.) Do Torunia kupić kunia. W 60. rocznicę założenia oddziału toruńskiego Polskiego Towarzystwa Ludoznawczego [Off we go to Toruń to buy a horse. The 60th anniversary of the Torun section of the Polish Folklore Association], 265-275, Toruń.

Kosowska, Ewa (2012) Pamięć jako zjawisko kulturowe [Memory as a cultural phenomen], [in:] Jan Adamowski and Marta Wójcicka (eds.) Tradycja dla współczesności, t. 6, Pamięć jako kategoria rzeczywistości kulturowej [Tradition for the present time. Continuity and change, vol. 6: Memory as a category of the cultural reality], 47-60, Lublin.

Kosyl, Czesław (2001a) Chrematonimy [Chrematonyms], [in:] Jerzy Bartmiński (ed.) Współczesny język polski [Contemporary Polish], 447-452, Lublin.

Kosyl, Czesław (2001b) Nazwy osobowe [Personal names], [in:] Jerzy Bartmiński (ed.) Współczesny język polski [Contemporary Polish], 431-446, Lublin.

Kowalski, Piotr (2007) Kultura magiczna. Omen, przesą, znaczenie [Magical culture: omen, superstition, meaning], Warszawa.

Krawczyk-Wasilewska, Violetta (1986) Współczesna wiedza o folklorze [Current state of folklore research], Warszawa. 
Krzeszowski, Tomasz P. (2010) Wstęp do wydania polskiego [An introduction to the Polish edition], [in:] Lakoff George and Johnson Mark (eds.), Metaphors We Live By, Warszawa.

Krzyżanowski, Julian (ed.) (1965) Słownik folkloru polskiego [A dictionary of the Polish folklore], Warszawa.

Kula Marcin (2002) Nośniki pamięci historycznej [Carriers of historical memory], Warszawa

Kurcz, Ida (1992) Pamięć, uczenie się, język [Memory, learning, language], Warszawa.

Kurek, Halina (2004) Punkt widzenia w językowym obrazie świata społeczności wiejskiej [Viewpoint in the linguistic worldview of a village community], [in:] Jerzy Bartmiński, Stanisława Niebrzegowska-Bartmińska, and Ryszard Nycz (eds.) Punkt widzenia w języku i w kulturze [Point of view in language and culture], 209-224, Lublin.

Kwiatkowski, Piotr Tadeusz (2008) Pamięć zbiorowa społeczeństwa polskiego $w$ okresie transformacji [Collective memory of the Polish society in the transformation period], Warszawa.

Labocha, Janina (1990) Opowiadania ludowe ze Śląska Cieszyńskiego w Czechosłowacji w świetle pragmalingwistyki tekstu [Folk stories from Cieszyn Silesia in Czechoslovakia: a pragmalinguistic textual perspective], Kraków.

Labocha, Janina (1996) Gramatyka polska. Cz. 3, Składnia. Podstawy analizy wypowiedzi [A grammar of Polish. Part 3. Syntax: the rudiments of utterance analysis], Kraków.

Labocha, Janina (2000) Tekst autobiograficzny jako pewna wizja świata [Autobiographical text as a specific image of the world], „)ęzyk a kultura”,13, Anna Dąbrowska and Janusz Anusiewicz (eds.) Językowy obraz świata $i$ kultura [The linguistic picture of the world versus culture], 89-96, Wrocław.

Lachmann, Renate (2009) Mnemotechnika i symulakrum [Mnemotechnics and simulacrum], [in:] Magdalena Saryusz-Wolska (ed.) Pamięć zbiorowa $i$ kulturowa. Wspótczesna perspektywa niemiecka [Collective and cultural memory in a current German perspective], 285-322, Kraków.

Lakoff, George, Johnson, Mark (2010) Metafory w naszym życiu [Metaphors we live by], Translated by Tomasz P. Krzeszowski, Warszawa.

Lakoff, George, Johnson, Mark (1980) Metaphors we live by, Chicago.

Le Goff, Jacques (1996) History and memory, Revised edition, Translated by Steven Rendall and Elizabeth Claman, (European Perspectives: A Series in Social Thought and Cultural Criticism), New York.

Leach, Edmund (2010), Kultura i komunikowanie. Logika powiązań symbolicznych, wprowadzenie do analizy strukturalnej w antropologii 
społecznej [Culture and Communication. The Logic by which Symbols Are Connected. An Introduction to the Use of Structuralist Analysis in Social Anthropology], Warszawa.

Leach, Edmund (2012) Culture and Communication. The Logic by which Symbols Are Connected. An Introduction to the Use of Structuralist Analysis in Social Anthropology, Cambridge.

Leary, Mark R. (1996) Self-presentation: Impression Management and Interpersonal Behavior (Social Psychology Series), Boulder, Colorado.

Łeńska-Bąk, Katarzyna (2010) O pokarmach, smakach i utraconych znaczeniach. Historia kultury sub speciae culinaria [About foods, tastes and lost meanings. The history of culture sub speciae culinarian], Opole.

Lévi-Strauss, Claude (1969) Myśl nieoswojona [The savage mind], Translated by Andrzej Zajączkowski, Warszawa.

Levi-Strauss Claude (1972) Trójkąt kulinarny [Culinary triangle], „Twórczość” [„,Literary creativity”], No 2.

Lévi-Strauss, Claude (2008) Trójkąt kulinarny [Culinary triangle], [in:]

Małgorzata Szpakowska (ed.) Antropologia ciała. Zagadnienia i wybór tekstów [An anthropology of the body. Selected issues and texts], 57-63, Warszawa.

Lord, Albert B. (2010) Pieśniarz i jego opowieść [The singer of tales], Translated by Paweł Majewski, Warszawa.

Łotman, Jurij (1977) O modelujacym znaczeniu „końca” $i$ „początku” $w$ przekazach artystycznych (Tezy) [On a modeling meaning of "the beginning” and „the end"], [in:] Elżbieta Janus and Maria Renata Mayenowa (eds.) Semiotyka kultury [Semiotics of culture], 344-349, Warszawa.

Łotman, Jurij (1984) Struktura tekstu artystycznego [The structure of the artistic text], Warszawa.

Łotman, Jurij (2002) Semiotyka sceny [Semiotics of the scene], [in:] Bogusław Żyłko (ed.) Sztuka w świecie znaków [Art in the world of signs], 95-124, Gdańsk.

Łotman, Jurij, Uspienski, Borys (1977) O semiotycznym mechanizmie kultury [On a semiotic mechanism of culture], [in:] Elżbieta Janus and Maria Renata Mayenowa (eds.) Semiotyka kultury [Semioics of culture], 147-170, Warszawa.

Łozowski, Przemysław (2012) Co pamięta język: krzyk jednostki czy echo zbiorowości? [What does language remember: a cry of an individual or an echo of a people?], [in:] Jan Adamowski and Marta Wójcicka (eds.) Tradycja dla współczesności, t. 6, Pamięć jako kategoria rzeczywistości kulturowej [Tradition for the present time. Continuity and change, vol. 6: Memory as a category of the cultural reality], 121-127, Lublin. 
Ługowska, Jolanta (1981) Ludowa bajka magiczna jako tworzywo literatury [Magical folk fable as a literary material], Wrocław.

Ługowska, Jolanta (1993) W świecie ludowych opowiadań. Teksty, gatunki, intencje narracyjne [In the world of folk narratives: texts, genres, narrative intentions], Wrocław.

Ługowska, Jolanta (2002) Tekst a gatunek [Text and genre], [in:] Adrian Mianecki and Violetta Wróblewska (eds.) Genologia literatury ludowej. Studia folklorystyczne [A genology of folk literature. Folklorist studies], 11-20, Torun.

Maćkiewicz, Jolanta (1999) Słowo o słowie. Potoczna wiedza o języku [A word about the word. A naive knowledge of language], Gdańsk.

Malicki, Krzysztof (2012) Polacy i ich pamięć przeszłości [Poles and their memory of the past], Kraków.

Manier, David, Hirst, William (2008) A Cognitive Taxonomy of Collective Memories, [in:] Astrid Erll and Ansgar Nünning (eds.) Cultural Memory Studies. An International and Interdisciplinary Handbook, 253-262, Berlin.

Maruszewski, Tomasz (2005) Pamięć autobiograficzna [Autobiographical memory], Gdańsk.

Mazur, Jan, Rzeszutko-Iwan, Małgorzata (eds.) (2006) Teksty kultury. Oblicza komunikacji XXI wieku [Texts of culture. Images of the 21st century communication], vols. 1-2, Lublin.

Michajłowa, Katia (2010) Dziad wędrowny w kulturze ludowej Słowian [The travelling beggar in the Slavic folk culture], Translated by Hanna Karpińska, Warszawa.

Mikułowski-Pomorski, Jerzy (2003) Komunikacja międzykulturowa. Wprowadzenie [Intercultural communication. An introduction], Kraków.

Milewski, Tadeusz (2004) Językoznawstwo [Linguistics], Warszawa.

Miodek, Jan (2001) O normie językowej [Linguistic norm], [in:] Jerzy Bartmiński (ed.) Współczesny język polski [Contemporary Polish], 73-83, Lublin.

Mojkowska, Aleksandra (2006) Max Lüthi jako bajkoznawca [Max Lüthi as a fairy tale scholar], Wrocław.

Moszyński, Kazimierz (1939) Kultura ludowa Słowian [Folk culture of the Slavs], Part II, Kultura duchowa [Spiritual culture], vol. 2, Kraków.

Myrdzik, Barbara, Tymiakin, Leszek (eds.) (2008) Teksty kultury w szkole [Texts of culture in school education], Lublin.

Napiórkowski, Marcin (2012) „Jak społeczeństwa pamiętają Paula Connertona na tle wspótczesnych badań nad pamięcia zbiorowa [Paul Connerton's How societies remember in the context of the current research on collective memory], [in:] Paul Connerton (ed.) Jak społeczeństwa 
pamiętaja [How societes remember], Translated by Marcin Napiórkowski, Warszawa.

Nedo, Paweł (1965) Folklorystyka. Ogólne wprowadzenie [Folklore studies. A general introduction], Poznań.

Neumann, Birgit (2009) Literatura, pamięć, tożsamość [Literature, memory, identity], [in:] Magdalena Saryusz-Wolska (ed.) Pamięć zbiorowa $i$ kulturowa. Współczesna perspektywa niemiecka [Collective and cultural memory in a current German perspective], 249-284, Kraków.

Niebrzegowska-Bartmińska, Stanisława (2002) Porzadek tekstu bajki jako odwzorowanie porzadku świata [The order of a fairy tale text as a reflection of the order of the world], [in:] Adrian Mianecki and Violetta Wróblewska (eds.) Genologia literatury ludowej. Studia folklorystyczne [A genology of folk literature. Foklore studies], 77-98, Toruń.

Niebrzegowska-Bartmińska, Stanisława (2003) Jechał Jezus na osiołeczku... Analiza morfologiczna tekstu zamówienia [Away rode Lord Jesus on a donkey... A morphological analysis of spells], [in:] Maria Jakitowicz and Violetta Wróblewska (eds.) W kręgu folkloru, literatury i języka. Prace ofiarowane prof. Janowi Mirosławowi Kasjanowi w 70. rocznice urodzin [Amidst folklore, literature, and language. Festschrift in honour of Professor Jan Mirosław Kasjan on his 70th birthday], 91-107, Toruń.

Niebrzegowska-Bartmińska, Stanisława (2007) Wzorce tekstów ustnych w perspektywie etnolingwistycznej [Patterns of oral texts: an ethnolinguistic approach], Lublin.

Niebrzegowska-Bartmińska, Stanisława (2012) Miejsce wartości w opisie gatunków mowy [Values in the description of speech genres], „Język a kultura”, 23, Anna Burzyńska-Kamieniecka (ed.) Akty i gatunki mowy w perspektywie kulturowej [Speech acts and genres in a cultural perspective], 33-41, Wrocław.

Nieckula, Franciszek (2001) Język ustny a język pisany [Spoken language and written language], [in:] Bartmiński Jerzy (ed.) Wspótczesny język polski [Contemporary Polish], 99-113, Lublin.

Nijakowski, Lech M. (2008) Polska polityka pamięci. Esej socjologiczny [Polish politics of memory. A sociological essay], Warszawa.

Nora, Pierre (2001) Czas pamięci [Remembrance time], „Res Publica Nowa”, 7, 37-43.

Nowak, Jacek (2011) Społeczne reguly pamiętania. Antropologia pamięci zbiorowej [Social rules of remembrance: the anthropology of collective memory], Kraków.

Nowak, Paweł, Siwiec, Adam (2008) Pamięć i jej konceptualizacje w języku $i w$ tekstach kultury [Memory and its conceptualisations in language and 
texts of culture], [in:] Dominika Staszczyk and Anna Szymańska (eds.) Pamięć i miejsce. Doświadczenie przeszłości na pograniczu [Space and memory: experiencing the past on the borderland], 63-73, Chełm.

Nowożenowa, Zoja (ed.) (2011) Tekst jako kultura, kultura jako tekst [Text as culture, culture as text], Gdańsk.

Nycz, Ryszard (2000) Tekstowy świat. Poststrukturalizm a wiedza o literaturze [The textual world: poststructuralism versus literary theory], Kraków.

Obirek, Stanisław (2010) Uskrzydlony umyst. Antropologia słowa Waltera Onga [The mind winged by the words. Walter Ong's anthropology of the word], Warszawa.

Olick, Jeffrey (2007) „Collective memory: the two cultures?”, Sociological Theory, 17(3) (Nov., 1999), 333-348.

Olick, Jeffrey K. (1999) "Genre memories and memory genres: A dialogical analysis of May 8, 1945 commemorations in the Federal Republic of Germany", American Sociological Review, 64(3), 381-402.

Olick, Jeffrey K. (2008) From Collective Memory to the Sociology of Mnemonic Practices and Products, [in:] Astrid Erll and Ansgar Nünning (eds.) Cultural Memory Studies an International and Interdisciplinary Handbook, 151-162, Berlin.

Olick, Jeffrey K. (2018) Pamięć gatunkowa i gatunki pamięci [Genre memory and memory genres], [in:] Paweł Majewski and Marcin Napiórkowski (eds.) Antropologia pamięci. Zagadnienia i wybór tekstów [An anthropology of memory: selected issues and texts], Translated by Marcin Napiórkowski, 458-470, Warszawa.

Olick, Jeffrey, Robbins, Joyce (1998) "Social memory studies: from 'collective memory' to the historical sociology of mnemonic practices", Annual Review of Sociology, 24, 105-140.

Ong, Walter J. (2002) Orality and Literacy. The Technologizing of the Word, 2nd edition, London and New York.

Ong, Walter Jackson (2009) Osoba - świadomość - komunikacja. Antologia [Person - awareness - communication. An anthology], edited by Józef Japola, Warszawa.

Ożóg, Kazimierz (2001) Ustna odmiana języka ogólnego [The spoken variety of general language], [in:] Bartmiński Jerzy (ed.) Współczesny język polski [Contemporary Polish], 85-98, Lublin.

Pajdzińska, Anna (2004) Niepamięć - córka niedbalstwa? [Non-memory: the daughter of negligence?], [in:] Jarosław Liberek (ed.) Studia nad polszczyzna wspótczesna $i$ historyczna [Studies in historical and contemporary Polish], 229-236, Poznań. 
Pajdzińska, Anna (2007) Pamięć jako wartość [Memory as value], [in:] Jan Mazur, Agata Małyska, and Katarzyna Sobstyl (eds.) Człowiek wobec wyzwań współczesności. Upadek wartości czy walka o wartość? [Man versus the challenges of the present: values in decline or a quest for values?], 253-261, Lublin.

Pajdzińska, Anna (2008) Sposoby uobecniania się podmiotu w tekście [Manifestations of subject in text], [in:] Jerzy Bartmiński and Anna Pajdzińska (eds.) Podmiot w języku i kulturze [The subject in language and culture], 225-239, Lublin.

Pajdzińska, Anna (2012) Polszczyzna o pamięci [Polish Language about Memory], [in:] Jan Adamowski and Marta Wójcicka (eds.) Tradycja dla wspótczesności, t. 6, Pamięć jako kategoria rzeczywistości kulturowej, [Tradition for the Present Time. Continuity and Change, vol. 6: Memory as a Category of the Cultural Reality], 97-108, Lublin.

Pelcowa, Halina (2007) Przeszłość jako wartość (na przykładzie wypowiedzi gwarowych) [The past as value (dialectal varieties in focus)], [in:] Jan Mazur, Agata Małyska, and Katarzyna Sobstyl (eds.) Człowiek wobec wyzwań wspótczesności. Upadek wartości czy walka o wartość? [Man versus the challenges of the present: values in decline or a quest for values?], 116-127, Lublin.

Piekarczyk, Dorota (2013) Metafory metatekstowe [Metatextual metaphors], Lublin.

Pisarek, Walery (2008) Wstęp do nauki o komunikowaniu [An introduction to communication], Warszawa.

Polska pieśń i muzyka ludowa. Źródła i materiały [The Polish folk song and music. Sources and materials] vol. 4, Lubelskie [The Lublin Voivodship], edited by Jerzy Bartmiński, part IV, Pieśni powszechne [Popular songs], Lublin.

Pomian, Krzysztof (2006) Historia. Nauka wobec pamięci [History. Science visa-vis memory], Lublin.

Prejs, Marek (2009) Oralność i mnemonika: późny barok w kulturze polskiej [Orality and mnemotechnics: late Baroque in Polish culture], Warszawa.

Propp, Władimir (1977) Podstawy klasyfikacji gatunków folkloru [Rudiments of folklore genre classification], „Literatura Ludowa”, 2, 50-57.

Propp, Władimir (1976) Nie tylko bajka [Not only a fairy tale], Warszawa.

Puzynina, Jadwiga (1991) Jak pracować nad językiem wartości [How to research language of values], „Język a kultura”, 2, [in:] Jadwiga Puzynina and Jerzy Bartmiński (eds.) Zagadnienia leksykalne i aksjologiczne [Lexical and axiological issues], 129-138, Wrocław. 
Rejter, Artur (2016) Nazwa własna wobec gatunku i dyskursu [Nom propre face genre et discours], Katowice.

Ricoeur, Paul (2004) Memory, History, Forgetting, Translated by Kathleen Blamey and David Pellauer, Chicago and London.

Riesman, David (2004) Tradycja oralna a stowo pisane [The oral tradition, the written word, and the screen image], [in:] Grzegorz Godlewski, Andrzej Mencwel, and Roch Sulima (eds.) Antropologia słowa. Zagadnienia i wybór tekstów [An anthropology of the word. Selected issues and texts], 395-401, Warszawa.

Rokosz, Tomasz (2009) Od folkloru do folku. Metamorfozy pieśni tradycyjnych we wspótczesnej kulturze [From folklore to folk. Metamorphoses of traditional songs in modern culture], Siedlce.

Rosińska, Zofia (2012) Praca pamięci [Workings of memory], [in:] Elżbieta Hałas (ed.) Kultura jako pamięć. Posttradycjonalne znaczenie przeszłości [Culture as memory. The post-traditional meaning of the past], 107-126, Kraków.

Rosnov, Ralph L. (1976) O pogłosce [On rumours], „Literatura Ludowa”, 2, 33-43.

Rzetelska-Feleszko, Ewa (2001) Nazwy własne [Proper names], [in:] Jerzy Bartmiński (ed.) Wspótczesny język polski [Contemporary Polish], 405-410, Lublin.

Saryusz-Wolska, Magdalena (2009) Wprowadzenie [Introduction], [in:] Magdalena Saryusz-Wolska (ed.) Pamięć zbiorowa i kulturowa. Współczesna perspektywa niemiecka [Collective and cultural memory in a current German perspective], 7-38, Kraków.

Saryusz-Wolska, Magdalena (2010) Zapomnieć się w pamięci. Pytania o badanie pamięci kulturowej [Getting carried away with memory. Questions of cultural memory research], „Kultura Współczesna”, 1, 76-86.

Saryusz-Wolska, Magdalena (2011) Spotkania czasu z miejscem: studia o pamięci $i$ miastach [At the juncture of time and space: memory and cities], Warszawa.

Schmidt, Siegfried J. (2008) Memory and Remembrance: A Constructivist Approach, [in:] Astrid Erll and Ansgar Nünning (eds.) Cultural Memory Studies. An International and Interdisciplinary Handbook, 191-202, Berlin.

Simonides, Dorota (1961) Baśń i podanie górnoślaskie [Upper Silesian fables and stories], Katowice.

Simonides, Dorota (1969) Wspótczesna śląska proza ludowa [Modern Silesian folk prose], Opole.

Simonides, Dorota, Hajduk-Nijakowska, Janina (1989) Opowiadania ludowe [Folk tales], [in:] Dorota Simonides (ed.), Folklor Górnego Śląska [The folklore of Upper Silesia], 333-416, Katowice. 
Simonides, Dorota (2010) Dlaczego drzewa przestały mówić? Ludowa wizja świata [Why should the trees stop talking? A folk picture of the world], Opole.

Śladkowski, Wiesław (1993) Miejsce straceń powstańców 1863 roku w Lublinie: Leon Frankowski, Kazimierz Bogdanowicz i inni [Lublin execution sites of the 1863 Uprising: Leon Frankowski, Kazimierz Bogdanowicz, and others], Lublin.

Smółkowa, Teresa (2001) Nowe słownictwo polskie [New Polish vocabulary], [in:] Jerzy Bartmiński (ed.) Współczesny język polski [Contemporary Polish], 397-404, Lublin.

Smyk, Katarzyna (2009) Choinka w kulturze polskiej. Symbolika drzewka i ozdób [The Christmas tree in Polish culture: the symbolism of the tree and its decorations], Kraków.

Smyk, Katarzyna (2012) Na drodze miłości i na drodze śmierci. Motywy podróżne w polskiej balladzie ludowej [On the way to love, on the way to death. Road motifs in Polish folk ballads], [in:] Wojciech Olszewski and Violetta Wróblewska (eds.) Za miedzę, za morze, w zaświaty... Kulturowe wymiary podróżowania [Away from home, away overseas, away to the Underworld... Cultural dimensions of travelling], 267-281, Wrocław.

Stolična, Rastislava, Drożdż, Anna (eds.) (2010) Historie kuchenne. Rola $i$ znaczenie pożywienia w kulturze [Kitchen stories. On the cultural role and significance of cooking], Cieszyn-Katowice-Brno.

Straub, Jürgen (2008) Psychology, Narrative, and Cultural Memory: Past and Present, [in:] Astrid Erll and Ansgar Nünning (eds.) Cultural Memory Studies. An International and Interdisciplinary Handbook, 215-228, Berlin.

Sulima, Roch (1992) Stowo i etos. Szkice o kulturze [Word and ethos. Essays on culture], Kraków.

Sulima, Roch (1995a) Folklor, Folkloryzm [Folklore and folklorism], [in:] Dariusz Kalisiewicz (ed.), Nowa encyklopedia powszechna PWN [New PWN encyclopedia], 391-392, Warszawa.

Sulima, Roch (1995b) Rekonstrukcje i interpretacje. Od folklorystyki do antropologii codzienności [Reconstructions and interpretations. From folklore studies to the anthropology of everyday reality], [in:] Dorota Simonides (ed.) Folklorystyka. Dylematy i perspektywy [Folklore studies: dilemmas and prospects], 55-72, Opole.

Sulima, Roch (1977) Współczesne przekazy ustne (wybrane zagadnienia) [Modern oral communication (selected issues)], [in:] Czesław Hernas, Jerzy Bartmiński, Alina Aleksandrowicz (eds.), Literatura ludowa i literatura 
chłopska. Materiały z ogólnopolskiej konferencji naukowej sesji folklorystycznej 16-18 II 1973 [Folk literature and peasants' literature], 111-128, Lublin.

Szacka, Barbara (2006) Czas przeszły, pamięć, mit [The past, memory, myths], Warszawa.

Szacka, Barbara (2012) Historia, pamięć zbiorowa i connertonowska pamięć kulturowa [History, collective memory and cultural memory of Paul Connerton], [in:] Jan Adamowski and Marta Wójcicka (eds.) Tradycja dla wspótczesności, t. 6, Pamięć jako kategoria rzeczywistości kulturowej [Tradition for the present time. Continuity and change, vol. 6: Memory as a category of the cultural reality], 13-20, Lublin.

Szacki, Jerzy (1971) Tradycja [Tradition], Warszawa.

Szczęsna, Ewa (ed.) (2002) Słownik pojęć i tekstów kultury [A dictionary of cultural concepts and texts], Warszawa.

Szczęsna, Ewa (2018) Reprezentacje pamięci w narracji cyfrowej

[Representations of memory in the digital narration], [in:] Joanna

Godlewicz-Adamiec and Dominika Wyrzykiewicz (eds.) Pamięć - dyskurs tożsamość. Rozważania interdyscyplinarne [Memory - discourse - identity. Interdisciplinary reflections], 87-103, Warszawa.

Szpociński, Andrzej (2005) Wobec przeszłości: pamięć przeszłości jako element kultury wspótczesnej [With regard to memory: the memory of the past as an element of modern culture], Warszawa.

Szpociński, Andrzej (2006) Formy przeszłości a komunikacja społeczna [Forms of the past vis-a-vis social communication], [in:] Andrzej Szpociński and Piotr Tadeusz Kwiatkowski (eds.) Przeszłość jako przedmiot przekazu [The past as an object of communication], 7-66, Warszawa.

Szpociński, Andrzej (ed.) (2009) Pamięć zbiorowa jako czynnik integracji i źródło konfliktów [Collective memory as an integration factor and a source of conflicts], Warszawa.

Tarkowska, Elżbieta (2012) Pamięć w kulturze teraźniejszości [Memory in the culture of the present], [in:] Elżbieta Hałas (ed.) Kultura jako pamięć. Posttradycjonalne znaczenie przeszłości [Culture as memory. The posttraditional meaning of the past], 17-42, Kraków.

Taylor, John (1995) Linguistic Categorization. Prototypes in Linguistic Theory, 2nd edition, Oxford.

Thiele-Dohrmann, Klaus (1980) Psychologia plotki [The psychology of gossip], Translated by A. Krzemiński, Warszawa.

Todorov, Tzvetan (1981) Introduction to Poetics, Translation from the French by Richard Howard, Introduction by Peter Brooks, (Theory and History of Literature, vol. 1), Minneapolis. 
Todorov, Tzvetan (1984) Poetyka [Poetics], Warszawa.

Tokarska-Bakir, Joanna (2000) Obraz osobliwy. Hermeneutyczna lektura źródeł etnograficznych. Wielkie opowieści [A peculiar image. Reading ethnographic sources in a hermeneutical perspective. Grand narratives], Kraków.

Tokarska-Bakir, Joanna (2004) Rzeczy mgliste: eseje i studia [Things fuzzy: esseys and studies], Sejny.

Tokarski, Ryszard (2001) Słownictwo jako interpretacja świata [Vocabulary as an interpretation of the world], [in:] Jerzy Bartmiński (ed.) Wspótczesny jezzyk polski [Contemporary Polish], 343-370, Lublin.

Tołstaja, Swietłana (1989) Tekst ustny w języku i kulturze [Oral text in language and culture], [in:] Maciej Abramowicz and Jerzy Bartmiński (eds.) Tekst ustny - texte oral. Struktura i pragmatyka - problemy semantyki - ustność w literaturze [Oral text - texte oral. Structure and pragmatics - semantics orality in literature], 9-14, Wrocław.

Tołstaja, Swietłana (2007) Władimir Toporow i jego teksty [Vladimir Toporov and his texts], „Etnolingwistyka”, 19, 11-30.

Toporow, Władimir N. (2003) Przestrzeń i rzecz [Space and thing], Translated by Bogusław Żyłko, Kraków.

Traba, Robert (2008) Pamięć kulturowa - pamięć komunikatywna. Teoria i praktyka badawcza Jana Assmanna [Cultural memory - communicative memory. Jan Assmann's theory and research practice], [in:] Jan Assmann (ed.) Pamięć kulturowa. Pismo, zapamiętywanie i polityczna tożsamość w cywilizacjach starożytnych [Cultural memory and early vivilization. Writing, remembrance, and political imagination], 11-25, Warszawa.

Uniłowski, Krzysztof, Kędra, Cezary K. (1994) Plotka. Wybór materiałów $z$ VI Konferencji Pracowników Naukowych i Studentów Instytutu Nauk o Literaturze Polskiej UŚ [Gossip. Proceedings of the 6th conference of scholars and students of the Department of Polish Literature, Silesia University] Katowice.

Uspienski, Borys (1998) Historia i semiotyka [History and semiotics], Translated by Bogusław Żyłko, Gdańsk.

van Dijk, Teun (2001a) Badania nad dyskursem [Discourse studies], [in:] Discourse as Structure and Process, Translated by Grzegorz Grochowski, 9-44, Warszawa.

van Dijk, Teun (ed.) (2001b) Discourse as Structure and Process, Translated by Grzegorz Grochowski, Warszawa.

Wallis, Mieczysław (1974) O tytułach dziet sztuki [On titles of work of arts], „Rocznik Historii Sztuki”, 10, 7-26. 
Welzer, Harald (2008) Communicative Memory, [in:] Astrid Erll and Ansgar Nünning (eds.) Cultural Memory Studies. An International and Interdisciplinary Handbook, 285-300, Berlin.

Wilkoń, Aleksander (2000) Typologia odmian językowych współczesnej polszczyzny [A typology of language varieties in contemporary Polish], Katowice.

Wilkoń, Aleksander (2002) Spójność i struktura tekstu. Wstęp do lingwistyki tekstu [Coherence and structure of a text. An introduction to text linguistics], Kraków.

Witosz, Bożena (2005a) Genologia lingwistyczna. Zarys problematyki [The linguistic genology. General issues], Katowice.

Witosz, Bożena (2005b) Видено „глазами памяти”. (Проблемы констру кции текста) [Looking through the eyes of memory (problems of text construction)], [in:] Teresa Dobrzyńska and Raya Kuncheva (eds.) Память и текст. Когнитивные и культурологические аспекты [Mетоry and text. Cognitive and cultural-logical aspects], 241-255, Sofia.

Witosz, Bożena (2007) Widzenie - pamięć - wyobraźnia. (O konstrukcji jednej $z$ odmian tekstu opisu) [Seeing - memory - imagination. On a construction of one of the varieties of descriptive texts], „Język Artystyczny”, 13, Bożena Witosz (ed.) Interakcyjny wymiar dyskursu artystycznego [An interactive dimension of artistic discourse], 140-157, Katowice.

Witosz, Bożena (2009) Dyskurs i stylistyka [Discourse and stylistics], Katowice.

Wójcicka, Marta (2010) Dawno to temu, już bardzo dawno... Formuly ramowe $w$ tekstach polskiej prozy ludowej [Long, long time ago...The framework formulas in the texts of Polish folk prose], Lublin.

Wójcicka, Marta (2011) Obraz religijności w legendach ludowych $z$ potudniowego Podlasia [The picture of religiosity in folk legends of southern Podlasie], [in:] Jan Adamowski and Marta Wójcicka (eds.) Tam na Podlasiu, III, Wierzenia i religijność [Over there in Podlasie, III, beliefs and religiosity], 65-72, Lublin.

Wójcicka, Marta (2012a) Plotka wyleci wróblem, a wraca wołem. Analiza morfologiczna legendy miejskiej o zaginionym Marku W. [„And all who told it added something new, and all who heard it, made enlargements, too". A morphologival analysis of an urban legend about lost Marek W.], „Język a kultura”, 23, Anna Burzyńska-Kamieniecka (ed.) Akty i gatunki mowy w perspektywie kulturowej [Speech acts and genres in a cultural perspective], 435-449, Wrocław.

Wójcicka, Marta (2012b) Pamięć jako wartość ludowego stylu artystycznego [Memory as a value of the folk artistic style], [in:] Jan Adamowski and 
Marta Wójcicka (eds.) Tradycja dla współczesności, t. 6, Pamięć jako kategoria rzeczywistości kulturowej [Tradition for the present time. Continuity and change, vol. 6: Memory as a category of the cultural reality], 169-181, Lublin.

Wójcicka, Marta (2013a) Tekst kultury jako struktura i process [Text of culture as a structure and a process], [in:] Olga Kielak, Anna Kowalska, and Joanna Szadura (eds.) Tekst - kontekst - intertekst [Text-context-intertext], 49-66, Lublin.

Wójcicka, Marta (2013b) Oral Textual Patterns in Modern Advertising, [in:] Liisi Laineste, Dorota Brzozowska, and Władyslaw Chłopicki (eds.) Estonia and Poland: Creativity and Tradition in Cultural Communication, vol. 2: Perspectives on National and Regional Identity, 121-136, Tartu.

Wójcicka, Marta (2013c) Urban Legends in Poland, [in:] Liisi Laineste, Dorota Brzozowska, and Władyslaw Chłopicki (eds.) Estonia and Poland: Creativity and Tradition in Cultural Communication, vol. 2: Perspectives on National and Regional Identity, 43-58, Tartu.

Wójcicka, Marta (2013d) Pamięć jako nośnik dziedzictwa kulturowego [Memory as a carrier of the cultural heritage], [in:] Jan Adamowski and Katarzyna Smyk (eds.) Niematerialne dziedzictwo kulturowe: źródła - wartości ochrona [Non-material cultural heritage: Sources - values - protection], 137-148, Lublin-Warszawa.

Wójcicka, Marta (2014) Pamięć zbiorowa a tekst ustny [Collective memory and oral text], Lublin.

Wójcicka, Marta (2014a) Pokarmy południowego Podlasia w świetle analizy onomastycznej [Foods from southern Podlasie in the light of onomastic analysis], [in:] Jan Adamowski and Marta Wójcicka (eds.) Tam na Podlasiu, IV, Pożywienie - czyli o czymś dla ciała i ducha [Over there in Podlasie, IV, foods, or something not only for your body], 27-37, Lublin.

Wójcicka, Marta (2014b) Pamięć zbiorowa a tekst folkloru (pamięć o Kazimierzu Bogdanowiczu w pieśni historycznej) [Collective memory and a text of culture (remembering Kazimierz Bogdanowicz in historical songs)], [in:] Agnieszka Drewniak and Artur Sępoch (eds.) Kultura pamięci czynnikiem rozwoju społeczności lokalnej [Culture of memory as a factor of local community development], 218-236, Lublin.

Wójcicka, Marta (2014c) Rola obrzędów przejścia w podaniu wierzeniowym $i$ legendzie miejskiej [The role of the transgression ceremonies in mythical tales and Urban legends (on selected examples)] [in:] Janina Hajduk-Nijakowska (ed.) Tradycyjna obrzędowość w kulturze współczesnej [Practicing traditions in post-traditional societies], 331-344, Opole. 
Wójcicka, Marta (2014d) Struktura tekstu ustnego jako odwzorowanie struktury pamięci [Structure of oral text as the reflection of the structure of memory], [in:] Bożena Taras (ed.) Język nasz ojczysty - historia i wspótczesność polszczyzny [Our native tongue - History and the present time of the Polish language], 36-50, Rzeszów.

Wójcicka, Marta (2014e) Pamięć zbiorowa w ujęciu kognitywnym $i$ komunikacyjnym [Collective memory in a cognitive and communicative approach], [in:] Natalia Korina and Jana Sokolova (eds.) Jazyk a kultura $z$ kognitivneho aspektu [Language vis-à-vis culture in a cognitive perspective], 200-209, Nitra.

Wójcicka, Marta (2015a) Parafraza tekstu folkloru w świetle teorii pamięci zbiorowej - od pamięci komunikatywnej do międzykulturowej [Paraphrase of folklore text in the context of the theory of collective memory: from communicative to intercultural memory], [in:] Stanisława NiebrzegowskaBartmińska, Marta Nowosad-Bakalarczyk, and Tomasz Piekot (eds.) Działania na tekście. Przekład - redagowanie - ilustrowanie [Elaborating on a text. Translation - editing - exemplification], 183-196, Lublin.

Wójcicka, Marta (2015b) Rola pamięci zbiorowej w komunikacji międzyludzkiej [The role of collective memory in interpersonal communication], [in:] Małgorzata Karwatowska, Robert Litwiński, and Adam Siwiec (eds.) Człowiek, zjawiska i teksty kultury w komunikacji społecznej [People, phenomena and texts of culture in social communication], 45-56, Lublin.

Wójcicka, Marta (2015c) Wartości a pamięć zbiorowa [Values vs. collective memory], [in:] Jan Adamowski and Marta Wójcicka (eds.) Tradycja dla wspótczesności [Tradition for modernity], vol. 8: Wartości w języku i kulturze [Values in language and culture], 65-72, Lublin.

Wójcicka, Marta (2017) Styl jako praktyka i forma pamięci zbiorowej [Style as a practice and a form of collective memory], „Terium. Półrocznik językoznawczy", 2, 29-42. https://journal.tertium.edu.pl/index.php/JaK/ article/view/2/58 [28.12.2019].

Wójcicka, Marta (2018) Język pamięci zbiorowej (w kontekście kultury oralności, piśmienności i eletralności). Prolegomena [Language of collective memory (In the context of the culture of orality, writing and electracy). Prolegomena], [in:] Waldemar Czachur (ed.) Pamięć w ujęciu lingwistycznym. Zagadnienia teoretyczne i metodyczne [Memory in a linguistic perspective: theory and methodology], 68-93, Warszawa.

Wójcicka, Marta (2018b) Niepamięć jako negacja wartości? [Non-memory as a negation of values], [in:] Ewa Szudlarek-Śmiechowicz and Bartłomiej Cieśla (eds.) Negacja w języku, tekście, dyskursie [Negation in language, text, discourse], 31-40, Łódź. 
Wójcicka, Marta (in print) Gatunek pamięci zbiorowej. Rekonesans [Collective memory genre. Reconnaissance], "Stylistyka", 2019, nr XXVIII, 81-92.

Woźniak, Marek (2008) Pamięć a historia. Pamięć miejsca - miejsce pamięci [Memory and history. Memory of a site - rememberance sites], [in:] Dominika Staszczyk and Anna Szymańska (eds.) Pamięć i miejsce. Doświadczenie przeszłości na pograniczu [Space and memory. Experiencing the past on the borderland], 51-62, Chełm.

Woźniak, Marek (2010) Przeszłość jako przedmiot konstrukcji. O roli wyobraźni $w$ badaniach historycznych [The past as an object of reconstruction. On the role of imagination in historical studies], Lublin.

Wróblewska, Violetta (2002) Bajka nowelowa w perspektywie genologicznej [Novelistic fairy tales in a genological perspective], [in:] Adrian Mianecki and Violetta Wróblewska (eds.) Genologia literatury ludowej [A genology of folk literature], 109-118, Toruń.

Wróblewska, Violetta (2007) Ludowa bajka nowelistyczna (źródła - wątki - konwencje) [Folk novelistic fairy tales (sources - motifs - conventions)], Torun.

Żółkiewski, Stefan (1988) Tekst kultury: studia [Text of culture: selected papers], Warszawa.

Zumthor, Paul (2004) Właściwości tekstu oralnego [Properties of oral texts], [in:] Grzegorz Godlewski, Andrzej Mencwel, and Roch Sulima (eds.) Antropologia słowa. Zagadnienia i wybór tekstów [An anthropology of the word: selected issues and texts], 210-218, Warszawa.

Zumthor, Paul (2010) Pamięć i wspólnota [Memory and society], [in:] Przemysław Czapliński (ed.) Literatura ustna [Oral literature], 151-179, Gdańsk.

Zumthor, Paul, McGarry, Jean (1984) “The impossible closure of the oral text", Yale French Studies, 67, 25-42.

Żyłko, Bogusław (2002) Słowo wstępne [Introduction], [in:] Bogusław Żyłko (ed.) Sztuka w świecie znaków [Art in the world of signs], 5-16, Gdańsk.

Żyłko, Bogusław (2009) Semiotyka kultury. Szkoła tartusko-moskiewska [Semiotics of culture in the Moscow-Tartu school], Gdańsk.

Żyłko, Bogusław (2011) Kultura i znaki. Semiotyka stosowana w szkole tartuskomoskiewskiej [Culture and signs. Semiotics in the Moscow-Tartu school], Gdańsk. 


\section{Sources}

BartLub - Polish Songs and Folk Music. Sources and Materials, vol. 4, The Lublin County, edited by Jerzy Bartmiński, Lublin 2011: Part 1, Songs and Annual Festivals, Part 2, Songs and Family Ceremonies, Part 3, Songs and Situational Texts, Part 4, Common Songs.

CzubMity - Dionizjusz Czubala, Myths of our Times, Katowice 1996.

E 3 - „Ethnolinguistics. Problems of Language and Culture”, Jerzy Bartmiński (editor), vol. 3, Lublin 1990.

HajPod - Not Everything is a Fairy Tale. Polish Historical Folk Stories, edited by Janina Hajduk-Nijakowska, Warszawa 1983.

KnL - Going Carolling in the Lublin County, edited by Jerzy Bartmiński and Czesław Hernas, Lublin 1986.

KrzyżBaś - Helena Kapełuś and Julian Krzyżanowski, One Hundred Folk Fables, Warszawa 1957.

KrzyżPrzysł - Julian Krzyżanowski, Great Minds Think Alike, vol. 2, Warszawa 1975.

NyrKar - Beggars' Carnival. Songs of Travelling Singers (19th to 20th centuries), edited by Stanisław Nyrkowski, Warszawa 1977.

PKL - Polish Folk Carols. An Anthology, edited by Jerzy Bartmiński, Kraków 2002.

SimGad - Chat after Chat. Three hundred Fables, Fairy Tales, and Anecdotes from Upper Silesia, edited by Dorota Simonides and Józef Ligęza, Katowice 1973.

SimKum - The Devil's Knot. Folk Stories from the Opole Silesia Region, edited by Dorota Simonides, Warszawa 1977.

SimLud - Dorota Simonides, Why Should the Trees Stop Talking? A Folk Picture of the World, Opole 2010.

WojDaw - Marta Wójcicka, Long Long Time Ago... Framing Formuli in Polish Folk Prose Texts, Lublin 2010.

WojPoc - I Should Be Gone now, but I'll Leave you my Song. Proceedings of the 35th Jan Pocek Literature Competition, selection, commentaries, and edition by Donat Niewiadomski and Marta Wójcicka, Lublin 2006.

WójPod - Far away in the Podlachia Region, Part 3, Beliefs and Religiosity, edited by Jan Adamowski and Marta Wójcicka, Lublin 2011. 



\section{List of Diagrams}

Diagram 1: Kinds of collective memory according to their scope of influence: a proposal.

Diagram 2: Prototypical versus peripheral texts of culture (source: own representation).

Diagram 3: (Tangible and intangible) cultural heritage vis-a-vis memory vis-a-vis texts of culture (source: own representation).

Diagram 4: Cultural heritage vis-à-vis memory vis-à-vis texts of culture relations in a research perspective (source: own representation).

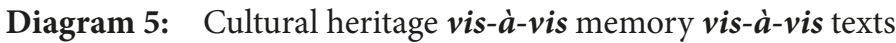
of culture relations in a metaphorical perspective (source: own representation). 79

Diagram 6: Four stages of memory (source: own representation). 98

Diagram 7: Criteria of collective memory typology vis-a-vis text genre (source: own representation). 



\section{List of Tables}

Tab. 1: Inhabited vis-a-vis uninhabited memory (after A. Assmann 2009a: 127)

Tab. 2: Communicative versus cultural memory according to Assmann (2011:41, similarly 2008b:117)

Tab. 3: Memory in Polish metaphorical expressions (source: own representation)

Tab. 4: Memory: communicative, cultural, and intercultural (source: J. Assmann and own representation)

Tab. 5: The role of the textual subject vis-a-vis genre differentiation of folklore texts (source: own representation)

Tab. 6: The addresser-addressee relations in texts of folklore (source: own representation)

Tab. 7: Values vis-a-vis genre differentiation of folklore texts (source: own representation)

Tab: 8: Memory and non-memory processes in a genological perspective (source: own representation)

Tab. 9: Memory figures in selected traditional and modern genres of folkore texts (source: own representation)

Tab. 10: Values vis-a-vis a mnemonic typology of folklore genres (source: own representation)

Tab. 11: Attributes of communicative and cultural memory according to J. Assmann and M. Wójcicka

Tab. 12: Communicative and cultural memory in recollections and ballads (source: own representation) 



\section{Sounds - Meaning - Communication}

Landmarks in Phonetics, Phonology and Cognitive Linguistics

Edited by Jolanta Szpyra-Kozłowska

Vol. 1 Hubert Kowalewski: Motivating the Symbolic. Towards a Cognitive Theory of the Linguistic Sign. 2016.

Vol. 2 Jolanta Szpyra-Kozłowska / Eugeniusz Cyran (eds.): Phonology, its Faces and Interfaces. 2016.

Vol. 3 Angelina Żyśko: English 'Joyful' Vocabulary - Semantic Developments. 2016.

Vol. 4 Anna Bloch-Rozmej / Anna Bondaruk (eds.): Constraints on Structure and Derivation in Syntax, Phonology and Morphology. 2017.

Vol. 5 Małgorzata Krzemińska-Adamek: Receptive and Productive L2 Vocabularies. Acquisition, Growth and Assessment. 2018.

Vol. 6 Anna Bloch-Rozmej / Anna Bondaruk (eds.): Studies in Formal Linguistics Universal Patterns and Language Specific Parameters. 2018.

Vol. 7 Marek Radomski: Polish consonant clusters in the British mouth. A study in online loanword adaptation. 2019.

Vol. 8 Maria Bloch-Trojnar / Mark Ó Fionnáin (eds.): Centres and Peripheries in Celtic Linguistics. 2019.

Vol. 9 Anna Malicka-Kleparska / Maria Bloch-Trojnar (eds.): Valency in Verbs and Verb-Related Structures. 2019.

Vol. 10 Jolanta Szpyra-Kozłowska / Marek Radomski (eds.): Phonetics and Phonology in Action. 2019.

Vol. 11 Izabela Jarosz: In Search of the Cultural Motivation in Language. Girl and Woman in James Joyce's “Dubliners". 2020.

Vol. 12 Marta Wójcicka: Collective Memory and Oral Text. 2020.

www.peterlang.com 
